ALFREDO GAY NETO

ESTABILIDADE ESTRUTURAL DA CONFIGURAÇÃO ESTÁTICA DE RISERS EM CATENÁRIA 



\section{ESTABILIDADE ESTRUTURAL DA CONFIGURAÇÃO ESTÁTICA DE RISERS EM CATENÁRIA}

Tese apresentada à Escola Politécnica da Universidade de São Paulo para obtenção do título de Doutor em Engenharia 



\title{
ESTABILIDADE ESTRUTURAL DA CONFIGURAÇÃO ESTÁTICA DE RISERS EM CATENÁRIA
}

\author{
Tese apresentada à Escola Politécnica da \\ Universidade de São Paulo para obtenção do \\ título de Doutor em Engenharia \\ Área de Concentração: Eng. de Controle \\ e Automação \\ Mecânica \\ Orientador: Prof. Dr. Clóvis de Arruda \\ Martins
}


FICHA CATALOGRÁFICA

\section{Gay Neto, Alfredo}

Estabilidade estrutural da configuração estática de risers em catenária / A. Gay Neto. -- São Paulo, 2012. $389 \mathrm{p}$.

Tese (Doutorado) - Escola Politécnica da Universidade de São Paulo. Departamento de Engenharia Mecânica.

1. Estruturas offshore 2. Estabilidade de sistemas 3. Método dos elementos finitos 4. Tubos flexíveis I. Universidade de São Paulo. Escola Politécnica. Departamento de Engenharia Mecânica II. t. 
Dedico este trabalho ao meu pai Alfredo, à minha mãe Mara e à minha esposa Juliana. 



\section{AGRADECIMENTOS}

À Deus por ter me possibilitado a oportunidade para realizar esse trabalho.

Ao Prof. Dr. Clóvis de Arruda Martins pela orientação nesse trabalho e por seus conselhos profissionais e pessoais durante todos esses anos que trabalhamos juntos.

Ao Prof. Dr. Celso Pupo Pesce pelos conselhos e ideias e pelas oportunidades de trabalhar em projetos correlatos que ajudaram muito em minha formação.

Ao Prof. Dr. Paulo de Mattos Pimenta pela grande ajuda no entendimento da formulação do modelo de vigas, estando sempre disposto a explicar-me os detalhes da matemática e da física envolvidas nos modelos bem como dando boas ideias para o trabalho.

Ao Prof. Dr. Eduardo Campello pela ajuda no início do trabalho, inclusive me auxiliando a encontrar erros em implementações computacionais das teorias.

Ao Prof. Dr. Carlos Eduardo Nigro Mazzilli pela colaboração na parte conceitual de teoria de estabilidade.

A todos os outros professores que me ajudaram de alguma forma no trabalho.

Aos meus colegas de trabalho do NDF (Núcleo de Dinâmica e Fluidos): Provasi, Nemoto, Fabiano, Franzini, César, Reinaldo (Chaves), Fernanda, Eduardo (Bradock), Christiano, Gioria, Ivan, Iago, Alessandro (Roque), Pedro, Stergios, Adson, Amin, Amir, Bruno, Gustavo e outros que durante esses anos tornaram o convívio e o trabalho uma alegria diária.

À FAPESP (Fundação de Amparo à Pesquisa do Estado de São Paulo) pelo apoio financeiro durante o trabalho com a bolsa de Doutorado Direto (processo 2006/06277-0). 

"O trabalho é um bem do homem - é um bem da sua humanidade - porque, mediante o trabalho, o homem não somente transforma a natureza, adaptando-a às suas próprias necessidades, mas também se realiza a si mesmo como homem e até, num certo sentido, « se torna mais homem »."

JOT̃O PAULO II 



\section{RESUMO}

Risers em configuração de catenária podem apresentar nível de tração muito baixo próximos ao fundo do mar. Isso pode ocorrer em algumas condições de lançamento, em que sua estrutura pode se configurar de forma quase vertical. Quando se trata de tubos flexíveis ou cabos umbilicais, a composição interna do riser contém armaduras helicoidais de tração. Essas podem induzir a ocorrência de giro axial quando o tubo é solicitado à tração. Se esse movimento não for permitido, surgirá um momento de torção na estrutura. O baixo nível de tração da configuração de catenária combinado com o momento de torção surgido durante o lançamento do riser pode levar a uma forma de instabilidade estrutural que culmina na formação de um laço. Isso é indesejável uma vez que, se existe o laço, dependendo dos esforços submetidos à linha, é possível que o laço se transforme em uma dobra, danificando a estrutura. O presente trabalho analisa as condições de formação de laços em configurações de catenária. Para isso, foram utilizados critérios de estabilidade aplicados a um modelo de elementos finitos, que leva em conta as não linearidades geométrica e de contato entre o riser e o solo. Foi utilizada uma formulação cinematicamente exata de elemento de viga através de uma descrição lagrangiana atualizada, que pode tratar de forma correta as grandes rotações que são impostas ao riser para induzir o surgimento do momento de torção. É mostrado que uma expressão analítica baseada na Fórmula de Greenhill pode prever o fenômeno com boa concordância com os resultados numéricos, mesmo considerando-se fenômenos como contato unilateral com atrito e correntezas marítimas. Além disso foi feita uma análise paramétrica para prever a formação do laço para diversas geometrias de catenária, procurando generalizar as conclusões obtidas.

Palavras-chave: Estruturas offshore. Estabilidade de sistemas. Método dos Elementos Finitos. Tubos flexíveis. 



\section{ABSTRACT}

Catenary risers can show a very low tension level close to the seabed. This can occur in some launching conditions, in which the structure can be almost vertical. When dealing with flexible pipes or umbilical cables, their internal composition includes the helical tension armors. These can induce an axial rotation to the riser when it is tensioned. If this movement is constrained, a torsion moment will act upon the structure. The low tension level present in the catenary configuration combined with the torsion moment that occurs during the riser launching can lead to a structural instability, resulting in a loop formation. This is undesirable since, if the loop is present, depending on the loads applied to the riser it is possible that it turns into a kink, causing damage. The present work analyzes the loop formation conditions in catenary riser. For that, stability criteria were applied to a finite element model that takes into account the geometric nonlinearities and also the contact between the riser and the seabed. A kinematically-exact beam formulation was adopted, dealing correctly with the large rotations that are imposed to the riser, in order to induce the torsion moment. It is showed that an analytical expression based on Greenhill's formula can predict the phenomenon with a good agreement with numerical results, even including phenomena as frictional unilateral contact and sea currents. Furthermore, a parametric analysis was done to predict the loop formation to some catenary geometries, in order to generalize the obtained conclusions.

Keywords: Offshore structures. Stability of systems. Finite Element Method. Flexible pipes. 



\section{LISTA DE FIGURAS}

Figura - 1.1 Plataforma do tipo jaqueta. Imagem disponível em (TWI TECHNOLOGY AND ENGINEERING, 2011).

Figura - 1.2 Plataforma do tipo semi-submersível. Imagem disponível em (MARINE LOG, 2010).

Figura - 1.3 Plataforma do tipo TLP. Imagem disponível em (GLOBAL SECURITY, 2010b).

Figura - 1.4 Plataforma do tipo FPSO. Imagem disponível em (PETROBRAS, 2010).

Figura - 1.5 Plataforma do tipo SPAR. Imagem disponível em (GLOBAL SECURITY, 2010a).

Figura - 1.6 Diferentes concepções de configurações de risers. (a) Vertical (b) Catenária (c) Steep-wave (d) Lazy-wave

Figura - 1.7 Exemplo de concepção de tubo flexível. Fonte: Tanque de provas numérico da USP.

Figura - 1.8 Camadas de um exemplo de tubo flexível. Extraído de (API, 2002) . 51

Figura - 1.9 Exemplo de concepções de cabos umbilicais. Disponível em (PRYSMIAN CABLES AND SYSTEMS, 2010)

Figura - 1.10 Esquema de instalação de um riser em catenária. Extraído de API (2002)

Figura - 1.11 Formação de dobra em um cabo. Extraído de (LIU, 1975) . ....... 54

Figura - 1.12 Estágios da formação de dobra em um cabo. Extraído de (LIU, 1975) 55

Figura - 2.1 Curva adimensional de critério de formação de dobra para alguns modelos de cabos eletromecânicos. Extraído de Liu (1975)

Figura - 2.2 Evolução da elastica de uma viga com $\phi_{m}=0$. Extraído de Miyazaki e Kondo (1997)

Figura - 2.3 Evolução da elastica de uma viga com $\phi_{m}=2 \pi$. Extraído de Miyazaki e Kondo (1997) 
Figura - 2.4 Evolução da elastica de uma viga com $\phi_{m}=3 \pi$. Extraído de Miyazaki

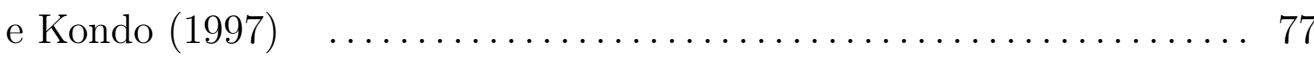

Figura - 2.5 Tração aplicada à viga versus $\xi$. Extraído de Miyazaki e Kondo (1997) 77

Figura - 2.6 Evolução da elastica de uma viga no problema do tipo Encurtamentotorção. Extraído de Miyazaki e Kondo (1997) .............. 78

Figura - 2.7 Mapeamento das regiões de instabilidade do problema de uma viga com aplicação de uma folga axial e ângulo de torção. Extraído de Miyazaki e Kondo $(1997)$...................................... 78

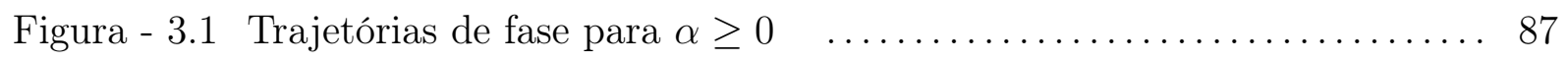

Figura -3.2 Trajetórias de fase para $\alpha \leq 0 \quad \ldots \ldots \ldots \ldots \ldots \ldots \ldots \ldots \ldots \ldots \ldots \ldots \ldots \ldots \ldots$

Figura - 3.3 Trajetórias de equilíbrio ilustrando uma bifurcação do tipo pitchfork 88

Figura - 3.4 Diagramas de carregamento $P$ versus deslocamento no grau de liberdade $q_{j}$ ilustrando exemplos de: (a) ponto limite (b) bifurcação assimétrica (c) bifurcação simétrica estável e (d) bifurcação simétrica instável. Adaptado de Thompson e Hunt (1973). ..................... 89

Figura - 3.5 Diferentes formas de equilíbrio. Extraído de Alfutov (2000) ….. 92

Figura - 3.6 Exemplo de treliças de von Mises com dois graus de liberdade (a) Ilustração da estrutura (b) Comportamento do sistema com controle de força (c) Comportamento do sistema com controle de deslocamento. Adaptado de Bazant e Cedolin (2003). . . ...................... 101

Figura - 3.7 Classificação de tipos de sistemas quanto à estabilidade. Figura extraída de Ziegler (1968). .................................... 104

Figura - 3.8 Vínculo do contato unilateral presente em alguns tipo de configurações de risers ................................................110

Figura - 3.9 Esquema que representa o modelo de uma catenária submetida às condições de contorno (bi-engastamento), vínculo do contato com o solo e

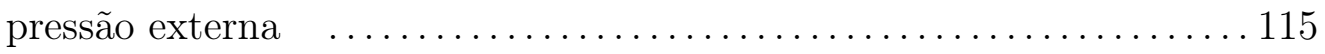

Figura - 3.10 Plano complexo mostrando regiões de estabilidade ou instabilidade do sistema dinâmico analisado. Figura extraída de Bazant e Cedolin (2003).

Figura - 4.1 Relação entre momento fletor e curvatura para um exemplo de tubo compósito. Extraído de Witz e Tan (1992) .................... 129 
Figura - 4.2 Configurações de referência e deformada para um riser em catenária

Figura - 4.3 Exemplo de um campo de velocidades de um corpo rígido (visualizando o eixo helicoidal instantâneo) - vista isométrica $\ldots \ldots \ldots \ldots \ldots 137$

Figura - 4.4 Exemplo de um campo de velocidades de um corpo rígido - vista supe-

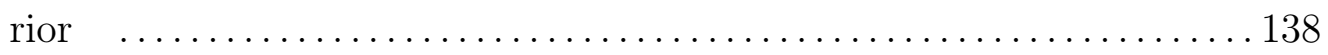

Figura - 4.5 Vetores utilizados na obtenção do tensor rotação na forma de Euler 139

Figura - 4.6 Vetores utilizados na obtenção do tensor rotação na forma de Rodrigues 141

Figura - 4.7 Sistemas de coordenadas e vetores utilizados na Formulação Cinematicamente Exata com descrição lagrangiana atualizada ............ 149

Figura - 4.8 Exemplo de perfil 2D de correnteza marítima. $\quad \ldots \ldots \ldots \ldots \ldots \ldots \ldots \ldots$

Figura - 4.9 Sistema de coordenadas naturais para uma barra com 3 nós com espa-

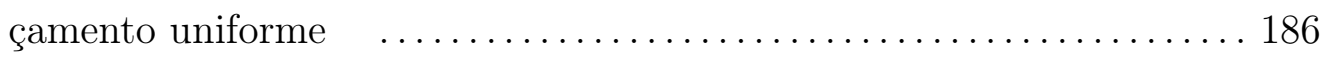

Figura - 4.10 Exemplo de uma montagem com elementos de viga, conectados por nós.

(a) Numeração global (b) Numeração local ................... 192

Figura - 4.11 Método de Newton-Raphson (interpretação geométrica) ......... 193

Figura - 4.12 Configurações de riser nas formas de catenária e de lazy-wave ilustrando

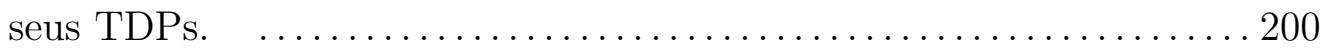

Figura - 4.13 Descrição das superfícies master e slave para definir o par de contato 201 Figura - 4.14 Leis constitutivas para o comportamento do contato na direção normal. (a) Idealização da restrição normal (b) Utilização de uma Compliance law (c) Utilização do Método das Penalidades ................... 204

Figura - 4.15 Leis constitutivas para o comportamento do contato na direção tangencial. (a) Lei de Coulomb (b) Lei de Coulomb modificada por um parâmetro de penalidade tangencial

Figura - 4.16 Campo de forças de atrito entre o riser e o solo na região de deslizamento para o modelo estático

Figura - 4.17 Elemento de contato com um nó slave e uma região plana definida como master

Figura - 5.1 Perspectiva do riser em catenária simulado através do software ANSYS 218

Figura - 5.2 Elastica do riser em catenária - vista do plano XZ (Caso 1) .......218

Figura - 5.3 Tração no riser em função da abscissa curvilínea indeformada $s$ (Caso 
1)

Figura - 5.4 Curvatura no riser em função da abscissa curvilínea indeformada $s$ (Caso

1)

Figura - 5.5 Elastica do riser em catenária - vista do plano XZ (Caso 2) …....221

Figura - 5.6 Tração efetiva no riser em função da abscissa curvilínea indeformada $s$

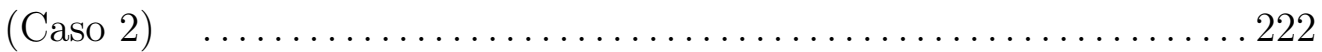

Figura - 5.7 Curvatura no riser em função da abscissa curvilínea indeformada $s$ (Caso

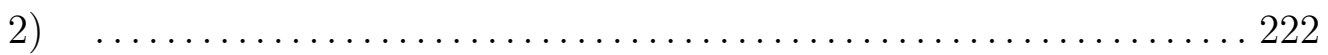

Figura - 5.8 Elastica do riser em catenária - vista do plano XZ (Caso 3) .......225

Figura - 5.9 Elastica do riser em catenária - vista do plano XY (Caso 3) ..... 225

Figura - 5.10 Tração efetiva no riser em função da abscissa curvilínea indeformada $s$

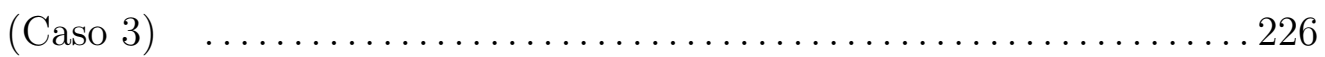

Figura - 5.11 Curvatura no riser em função da abscissa curvilínea indeformada $s$ (Caso

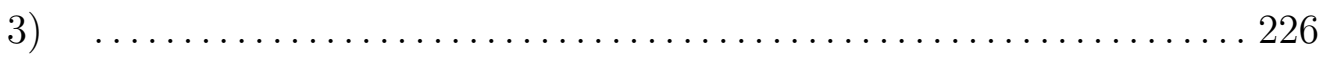

Figura - 5.12 Elastica do riser em catenária - vista do plano XZ (Caso 4) .......229

Figura - 5.13 Elastica do riser em catenária - vista do plano XY (Caso 4) ...... 229

Figura - 5.14 Tração efetiva no riser em função da abscissa curvilínea indeformada $s$

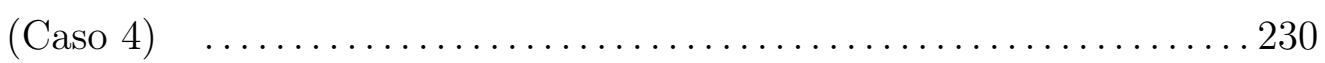

Figura - 5.15 Curvatura no riser em função da abscissa curvilínea indeformada $s$ (Caso

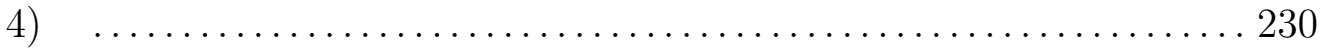

Figura - 5.16 Elastica do riser em catenária - vista do plano XZ (Caso 5) ....... 232

Figura - 5.17 Elastica do riser em catenária - vista do plano XY (Caso 5) ..... 232

Figura - 5.18 Tração efetiva no riser em função da abscissa curvilínea indeformada $s$

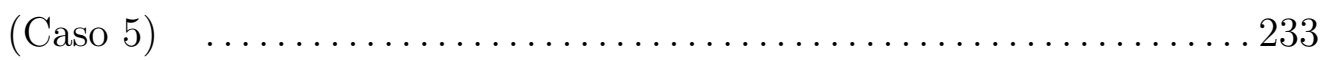

Figura - 5.19 Curvatura no riser em função da abscissa curvilínea indeformada $s$ (Caso

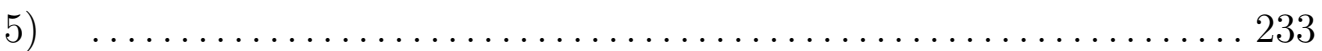

Figura - 5.20 Evolução da configuração da viga vista lateralmente (figuras à esquerda) e superiormente (figuras à direita) (a) Logo após o início da compressão (b) Um pouco de tridimensionalização começa a aparecer (c) Antes da formação do laço (d) Logo após a formação do laço (e) Configuração final, quando os pontos extremos da viga atingem a mesma posição 236

Figura - 5.21 Força compressiva aplicada pelo engaste móvel à extremidade da viga, 
em função do deslocamento axial desse ponto de aplicação

Figura - 5.22 Momentos que causam flexão aplicados pelo engaste móvel à extremidade da viga, em função do deslocamento axial desse ponto de aplicação . 237

Figura - 5.23 Soma vetorial dos momentos que causam flexão aplicados pelo engaste móvel à extremidade da viga, em função do deslocamento axial desse ponto de aplicação

Figura - 5.24 Momento que causa torção aplicado pelo engaste móvel à extremidade da viga, em função do deslocamento axial desse ponto de aplicação .238

Figura - 5.25 Referência para orientação da correnteza marítima (vista superior) . 240

Figura - 5.26 Ângulo de inclinação $(\theta)$ de um riser em catenária em relação a um

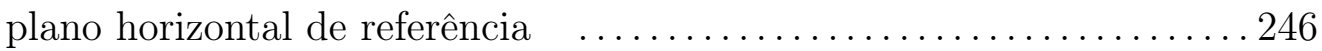

Figura - 5.27 Momento de torção crítico versus ângulo do topo da configuração de catenária. Modelo analítico de Greenhill

Figura - 5.28 Comparação entre a imposição de momento de torção e imposição de rotação axial no estudo de estabilidade.

Figura - 5.29 Trajetória de equilíbrio $M_{t}$ versus $\alpha$ e evolução do menor autovalor da matriz de rigidez tangente do sistema para o caso $\mathrm{L}=1001 \mathrm{~m}$ $\left(\theta_{\text {topo }}=89,93^{\circ}\right)$. TDP engastado.

Figura - 5.30 Trajetória de equilíbrio $M_{t}$ versus $\alpha$ e evolução do menor autovalor da matriz de rigidez tangente do sistema para o caso $\mathrm{L}=1002 \mathrm{~m}$ $\left(\theta_{\text {topo }}=89,88^{\circ}\right)$. TDP engastado.

Figura - 5.31 Trajetória de equilíbrio $M_{t}$ versus $\alpha$ e evolução do menor autovalor da matriz de rigidez tangente do sistema para o caso $\mathrm{L}=1003 \mathrm{~m}$ $\left(\theta_{\text {topo }}=89,82^{\circ}\right)$. TDP engastado.

Figura - 5.32 Trajetória de equilíbrio $M_{t}$ versus $\alpha$ e evolução do menor autovalor da matriz de rigidez tangente do sistema para o caso $\mathrm{L}=1005 \mathrm{~m}$ $\left(\theta_{\text {topo }}=89,71^{\circ}\right)$. TDP engastado.

Figura - 5.33 Trajetória de equilíbrio $M_{t}$ versus $\alpha$ e evolução do menor autovalor da matriz de rigidez tangente do sistema para o caso $\mathrm{L}=1007 \mathrm{~m}$ $\left(\theta_{\text {topo }}=89,60^{\circ}\right)$. TDP engastado.

Figura - 5.34 Trajetória de equilíbrio $M_{t}$ versus $\alpha$ e evolução do menor autovalor da matriz de rigidez tangente do sistema para o caso $\mathrm{L}=1010 \mathrm{~m}$ $\left(\theta_{\text {topo }}=89,43^{\circ}\right)$. TDP engastado. 
Figura - 5.35 Trajetória de equilíbrio $M_{t}$ versus $\alpha$ e evolução do menor autovalor da matriz de rigidez tangente do sistema para o caso $\mathrm{L}=1020 \mathrm{~m}$ $\left(\theta_{\text {topo }}=88,86^{\circ}\right)$. TDP engastado.

Figura - 5.36 Trajetória de equilíbrio $M_{t}$ versus $\alpha$ e evolução do menor autovalor da matriz de rigidez tangente do sistema para o caso $\mathrm{L}=1030 \mathrm{~m}$ $\left(\theta_{\text {topo }}=88,29^{\circ}\right)$. TDP engastado.

Figura - 5.37 Trajetória de equilíbrio $M_{t}$ versus $\alpha$ e evolução do menor autovalor da matriz de rigidez tangente do sistema para o caso $\mathrm{L}=1040 \mathrm{~m}$ $\left(\theta_{\text {topo }}=87,74^{\circ}\right)$. TDP engastado.

Figura - 5.38 Trajetória de equilíbrio $M_{t}$ versus $\alpha$ e evolução do menor autovalor da matriz de rigidez tangente do sistema para o caso $\mathrm{L}=1050 \mathrm{~m}$ $\left(\theta_{\text {topo }}=87,18^{\circ}\right)$. TDP engastado.

Figura - 5.39 Trajetória de equilíbrio $M_{t}$ versus $\alpha$ e evolução do menor autovalor da matriz de rigidez tangente do sistema para o caso $\mathrm{L}=1100 \mathrm{~m}$ $\left(\theta_{\text {topo }}=84,50^{\circ}\right)$. TDP engastado.

Figura - 5.40 Trajetória de equilíbrio $M_{t}$ versus $\alpha$ e evolução do menor autovalor da matriz de rigidez tangente do sistema para o caso $\mathrm{L}=1150 \mathrm{~m}$ $\left(\theta_{\text {topo }}=81,95^{\circ}\right)$. TDP engastado.

Figura - 5.41 Momento de torção crítico versus ângulo do topo da configuração de catenária. Modelo com o TDP engastado comparado com Greenhill. 260

Figura - 5.42 Configuração final da simulação realizada utilizando-se as propriedades descritas nas Tabelas 5.7 e 5.8. Visualização da formação do laço para o caso com TDP engastado com $1001 \mathrm{~m}$ de comprimento de umbilical. 262

Figura - 5.43 Configuração final da simulação realizada utilizando-se as propriedades descritas nas Tabelas 5.7 e 5.8. Visualização da formação do laço para o caso com TDP engastado com $1050 \mathrm{~m}$ de comprimento de umbilical. 262

Figura - 5.44 Trajetória de equilíbrio $M_{t}$ versus $\alpha$ para o caso $\mathrm{L}=1001 \mathrm{~m}\left(\theta_{\text {topo }}=\right.$ $\left.89,93^{\circ}\right)$. Sem atrito.

Figura - 5.45 Trajetória de equilíbrio $M_{t}$ versus $\alpha$ para o caso $\mathrm{L}=1002 \mathrm{~m}\left(\theta_{\text {topo }}=\right.$ $\left.89,88^{\circ}\right)$. Sem atrito.

Figura - 5.46 Trajetória de equilíbrio $M_{t}$ versus $\alpha$ para o caso $\mathrm{L}=1003 \mathrm{~m}\left(\theta_{\text {topo }}=\right.$ $\left.89,82^{\circ}\right)$. Sem atrito. 
Figura - 5.47 Trajetória de equilíbrio $M_{t}$ versus $\alpha$ para o caso $\mathrm{L}=1005 \mathrm{~m}\left(\theta_{\text {topo }}=\right.$ $\left.89,71^{\circ}\right)$. Sem atrito.

Figura - 5.48 Trajetória de equilíbrio $M_{t}$ versus $\alpha$ para o caso $\mathrm{L}=1007 \mathrm{~m}\left(\theta_{\text {topo }}=\right.$ $\left.89,60^{\circ}\right)$. Sem atrito. 266

Figura - 5.49 Trajetória de equilíbrio $M_{t}$ versus $\alpha$ para o caso $\mathrm{L}=1010 \mathrm{~m}\left(\theta_{\text {topo }}=\right.$ $\left.89,43^{\circ}\right)$. Sem atrito. 266

Figura - 5.50 Trajetória de equilíbrio $M_{t}$ versus $\alpha$ para o caso $\mathrm{L}=1020 \mathrm{~m}\left(\theta_{\text {topo }}=\right.$ $\left.88,86^{\circ}\right)$. Sem atrito. 267

Figura - 5.51 Trajetória de equilíbrio $M_{t}$ versus $\alpha$ para o caso $\mathrm{L}=1030 \mathrm{~m}\left(\theta_{\text {topo }}=\right.$ $\left.88,29^{\circ}\right)$. Sem atrito.

Figura - 5.52 Trajetória de equilíbrio $M_{t}$ versus $\alpha$ para o caso $\mathrm{L}=1040 \mathrm{~m}\left(\theta_{\text {topo }}=\right.$ $\left.87,74^{\circ}\right)$. Sem atrito. 268

Figura - 5.53 Trajetória de equilíbrio $M_{t}$ versus $\alpha$ para o caso $\mathrm{L}=1050 \mathrm{~m}\left(\theta_{\text {topo }}=\right.$ $\left.87,18^{\circ}\right)$. Sem atrito. 268

Figura - 5.54 Trajetória de equilíbrio $M_{t}$ versus $\alpha$ para o caso $\mathrm{L}=1100 \mathrm{~m}\left(\theta_{\text {topo }}=\right.$ $\left.84,50^{\circ}\right)$. Sem atrito. 269

Figura - 5.55 Trajetória de equilíbrio $M_{t}$ versus $\alpha$ para o caso $\mathrm{L}=1150 \mathrm{~m}\left(\theta_{\text {topo }}=\right.$ $\left.81,95^{\circ}\right)$. Sem atrito. 269

Figura - 5.56 Momento de torção crítico versus ângulo do topo da configuração de catenária. Modelo com contato unilateral sem atrito comparado com Modelo com TDP engastado. 270

Figura - 5.57 Torção total e rotação imposta por unidade de comprimento $\left(\frac{\alpha}{L}\right)$ no ponto-limite versus ângulo do topo da configuração de catenária. . .2272

Figura - 5.58 Torção total no ponto limite versus ângulo do topo da configuração de catenária. Comparação entre o modelo com contato sem atrito e Greenhill.

Figura - 5.59 Trajetória de equilíbrio $M_{t}$ versus $\alpha$ para o caso $\mathrm{L}=1001 \mathrm{~m}\left(\theta_{\text {topo }}=\right.$ $\left.89,93^{\circ}\right)$. Com atrito $\mu=0,4$ 274

Figura - 5.60 Trajetória de equilíbrio $M_{t}$ versus $\alpha$ para o caso $\mathrm{L}=1002 \mathrm{~m}\left(\theta_{\text {topo }}=\right.$

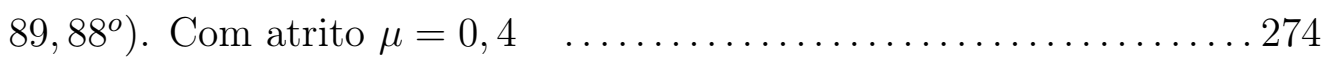

Figura - 5.61 Trajetória de equilíbrio $M_{t}$ versus $\alpha$ para o caso $\mathrm{L}=1003 \mathrm{~m}\left(\theta_{\text {topo }}=\right.$ 
$\left.89,82^{\circ}\right)$. Com atrito $\mu=0,4$

Figura - 5.62 Trajetória de equilíbrio $M_{t}$ versus $\alpha$ para o caso $\mathrm{L}=1005 \mathrm{~m}\left(\theta_{\text {topo }}=\right.$ $\left.89,71^{\circ}\right)$. Com atrito $\mu=0,4$

Figura - 5.63 Trajetória de equilíbrio $M_{t}$ versus $\alpha$ para o caso L $=1007 \mathrm{~m}\left(\theta_{\text {topo }}=\right.$

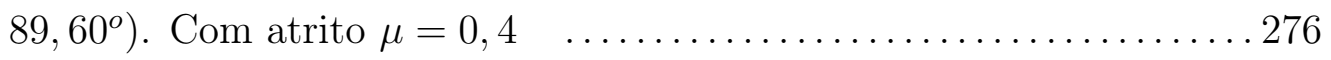

Figura - 5.64 Trajetória de equilíbrio $M_{t}$ versus $\alpha$ para o caso $\mathrm{L}=1010 \mathrm{~m}\left(\theta_{\text {topo }}=\right.$

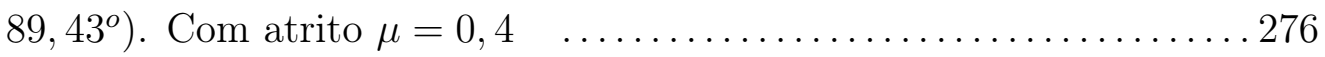

Figura - 5.65 Trajetória de equilíbrio $M_{t}$ versus $\alpha$ para o caso L $=1020 \mathrm{~m}\left(\theta_{\text {topo }}=\right.$

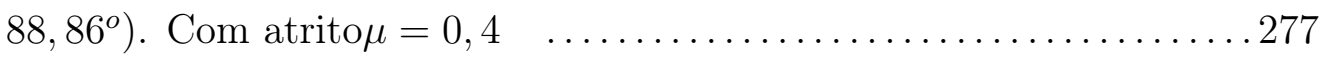

Figura - 5.66 Trajetória de equilíbrio $M_{t}$ versus $\alpha$ para o caso $\mathrm{L}=1030 \mathrm{~m}\left(\theta_{\text {topo }}=\right.$

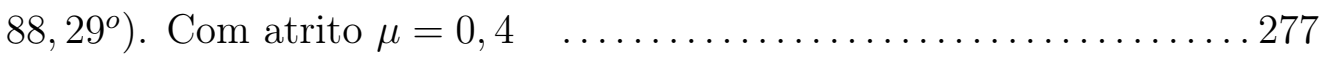

Figura - 5.67 Trajetória de equilíbrio $M_{t}$ versus $\alpha$ para o caso $\mathrm{L}=1040 \mathrm{~m}\left(\theta_{\text {topo }}=\right.$

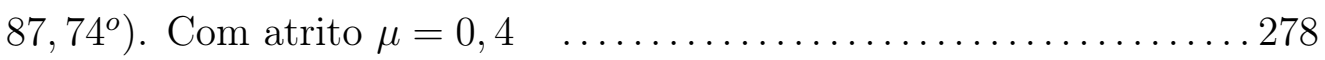

Figura - 5.68 Trajetória de equilíbrio $M_{t}$ versus $\alpha$ para o caso L $=1050 \mathrm{~m}\left(\theta_{\text {topo }}=\right.$

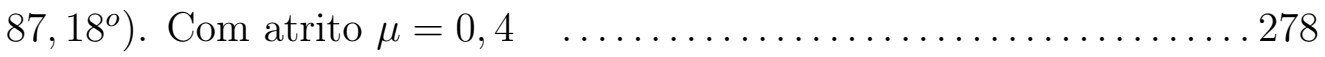

Figura - 5.69 Trajetória de equilíbrio $M_{t}$ versus $\alpha$ para o caso $\mathrm{L}=1100 \mathrm{~m}\left(\theta_{\text {topo }}=\right.$

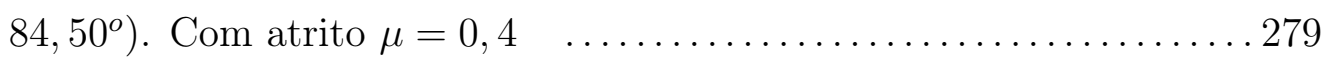

Figura - 5.70 Trajetória de equilíbrio $M_{t}$ versus $\alpha$ para o caso $\mathrm{L}=1150 \mathrm{~m}\left(\theta_{\text {topo }}=\right.$

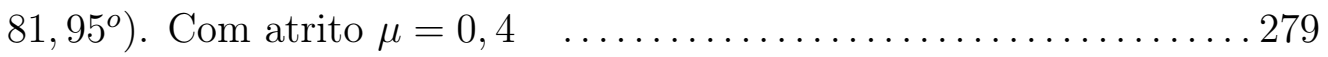

Figura - 5.71 Trajetória de equilíbrio $M_{t}$ versus $\alpha$ para o caso $\mathrm{L}=1001 \mathrm{~m}\left(\theta_{\text {topo }}=\right.$

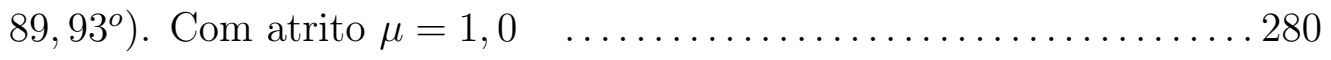

Figura - 5.72 Trajetória de equilíbrio $M_{t}$ versus $\alpha$ para o caso $\mathrm{L}=1002 \mathrm{~m}\left(\theta_{\text {topo }}=\right.$

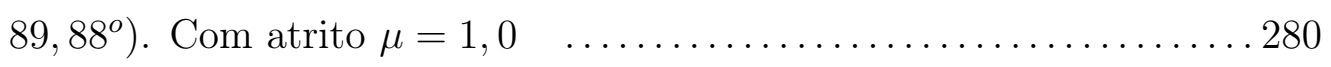

Figura - 5.73 Trajetória de equilíbrio $M_{t}$ versus $\alpha$ para o caso $\mathrm{L}=1003 \mathrm{~m}\left(\theta_{\text {topo }}=\right.$ $\left.89,82^{\circ}\right)$. Com atrito $\mu=1,0 \quad \ldots \ldots \ldots \ldots \ldots \ldots \ldots \ldots \ldots \ldots \ldots \ldots \ldots \ldots \ldots \ldots \ldots$

Figura - 5.74 Trajetória de equilíbrio $M_{t}$ versus $\alpha$ para o caso $\mathrm{L}=1005 \mathrm{~m}\left(\theta_{\text {topo }}=\right.$

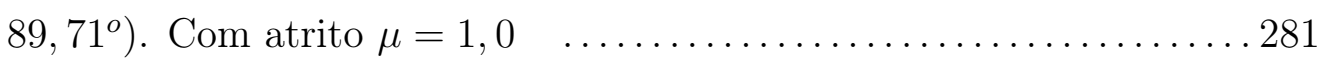

Figura - 5.75 Trajetória de equilíbrio $M_{t}$ versus $\alpha$ para o caso $\mathrm{L}=1007 \mathrm{~m}\left(\theta_{\text {topo }}=\right.$ $\left.89,60^{\circ}\right)$. Com atrito $\mu=1,0$ 282

Figura - 5.76 Trajetória de equilíbrio $M_{t}$ versus $\alpha$ para o caso $\mathrm{L}=1010 \mathrm{~m}\left(\theta_{\text {topo }}=\right.$ $\left.89,43^{\circ}\right)$. Com atrito $\mu=1,0$ 282

Figura - 5.77 Trajetória de equilíbrio $M_{t}$ versus $\alpha$ para o caso $\mathrm{L}=1020 \mathrm{~m}\left(\theta_{\text {topo }}=\right.$ 
$\left.88,86^{\circ}\right)$. Com atrito $\mu=1,0$

Figura - 5.78 Trajetória de equilíbrio $M_{t}$ versus $\alpha$ para o caso $\mathrm{L}=1030 \mathrm{~m}\left(\theta_{\text {topo }}=\right.$

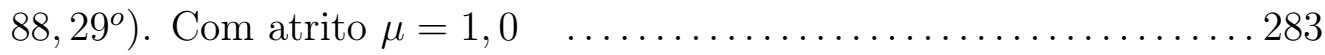

Figura - 5.79 Trajetória de equilíbrio $M_{t}$ versus $\alpha$ para o caso $\mathrm{L}=1040 \mathrm{~m}\left(\theta_{\text {topo }}=\right.$

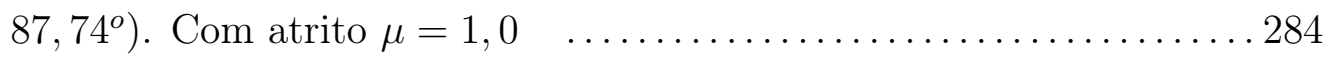

Figura - 5.80 Trajetória de equilíbrio $M_{t}$ versus $\alpha$ para o caso $\mathrm{L}=1050 \mathrm{~m}\left(\theta_{\text {topo }}=\right.$

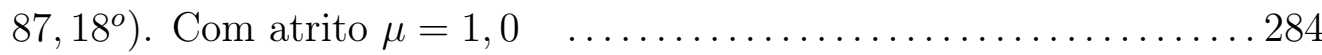

Figura - 5.81 Trajetória de equilíbrio $M_{t}$ versus $\alpha$ para o caso $\mathrm{L}=1100 \mathrm{~m}\left(\theta_{\text {topo }}=\right.$

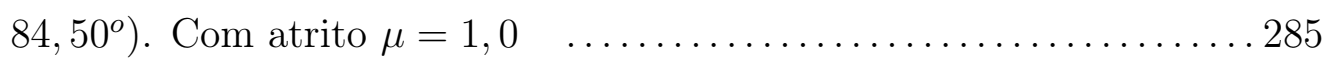

Figura - 5.82 Trajetória de equilíbrio $M_{t}$ versus $\alpha$ para o caso $\mathrm{L}=1150 \mathrm{~m}\left(\theta_{\text {topo }}=\right.$

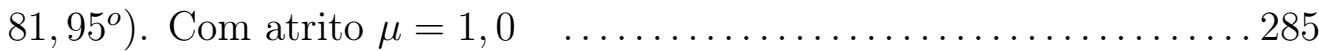

Figura - 5.83 Momento de torção crítico versus ângulo do topo da configuração de catenária. Modelo com contato unilateral com atrito.

Figura - 5.84 Momento de torção crítico versus ângulo do topo da configuração de catenária. Comparação entre os modelos. ................. 288

Figura - 5.85 Momento fletor na configuração associada ao ponto-limite para o caso $\mathrm{L}=1001 \mathrm{~m}$ em função da abscissa curvilínea $s$. Comparação entre os modelos com e sem atrito.

Figura - 5.86 Trajetória de equilíbrio $M_{t}$ versus $\alpha$ para o caso $\mathrm{L}=1030 \mathrm{~m}-2$. Com atrito e correnteza marítima.

Figura - 5.87 Trajetória de equilíbrio $M_{t}$ versus $\alpha$ para o caso $\mathrm{L}=1030 \mathrm{~m}-3$. Com atrito e correnteza marítima.

Figura - 5.88 Trajetória de equilíbrio $M_{t}$ versus $\alpha$ para o caso $\mathrm{L}=1030 \mathrm{~m}-4$. Com atrito e correnteza marítima.

Figura - 5.89 Trajetória de equilíbrio $M_{t}$ versus $\alpha$ para o caso $\mathrm{L}=1030 \mathrm{~m}-5$. Com atrito e correnteza marítima.

Figura - 5.90 Trajetória de equilíbrio $M_{t}$ versus $\alpha$ para o caso $\mathrm{L}=1030 \mathrm{~m}-6$. Com atrito e correnteza marítima.

Figura - 5.91 Trajetória de equilíbrio $M_{t}$ versus $\alpha$ para o caso $\mathrm{L}=1030 \mathrm{~m}-7$. Com atrito e correnteza marítima.

Figura - 5.92 Momento de torção crítico versus ângulo do topo da configuração de catenária. Comparação entre os modelos sem atrito, com atrito e pu- 
ramente analítico

Figura - 5.93 Configuração final da simulação realizada utilizando-se as propriedades descritas nas Tabelas 5.7 e 5.8. Visualização da formação do laço para o caso sem atrito com $1001 \mathrm{~m}$ de comprimento de umbilical.

Figura - 5.94 Configuração final da simulação realizada utilizando-se as propriedades descritas nas Tabelas 5.7 e 5.8. Visualização da formação do laço para o caso sem atrito com $1040 \mathrm{~m}$ de comprimento de umbilical.

Figura - 5.95 Configuração final da simulação realizada utilizando-se as propriedades descritas nas Tabelas 5.7 e 5.8. Visualização da formação do laço para o caso com atrito com $1001 \mathrm{~m}$ de comprimento de umbilical.

Figura - 5.96 Configuração final da simulação realizada utilizando-se as propriedades descritas nas Tabelas 5.7 e 5.8. Visualização da formação do laço para o caso com atrito com $1040 \mathrm{~m}$ de comprimento de umbilical.

Figura - 5.97 Elasticas antes da imposição de rotação que causa torção no riser para

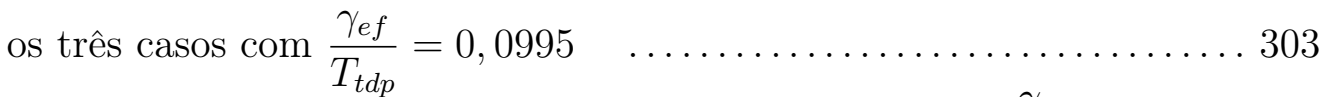

Figura - 5.98 Evolução dos momentos de torção para os três casos com $\frac{\gamma_{e f}}{T_{t d p}}=0,0995$ ilustrando essencialmente o mesmo valor de carga crítica ......... 304

Figura - 5.99 Relação entre os adimensionais $\alpha_{l}$ e $\beta_{l}$ para os casos das Tabelas 5.20 a 5.24 e para os casos das seções 5.3 .3 (extras) e 5.3 .6 (extras 2) ... 314

Figura - A.1 Exemplo de ovalização da carcaça intertravada de um tubo flexível. . 330 Figura - A.2 Riser vertical perfeitamente retilíneo com pressurização interna e imerso

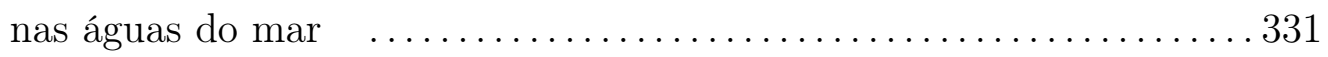

Figura - A.3 Carregamentos axi-simétricos das pressões interna e externa aplicadas a uma seção transversal de um riser retilíneo $\quad \ldots \ldots \ldots \ldots \ldots . \ldots . \ldots . \ldots 31$

Figura - A.4 Influência da pressão interna como um carregamento lateral quando ocorre flexão no tubo. (a) Tubo com pressão interna (b) Forças atuantes em um corte do fluido interno ao tubo $\ldots \ldots \ldots \ldots \ldots \ldots \ldots \ldots \ldots \ldots \ldots$

Figura - A.5 Ponto $P$ localizado em uma coluna de fluido $\ldots \ldots \ldots \ldots \ldots \ldots \ldots 34$

Figura - A.6 Pressão externa distribuída em um corte de riser submerso ....... 335

Figura - A.7 Representação da parede externa de um riser reto $\ldots \ldots \ldots \ldots \ldots . . . . . .336$

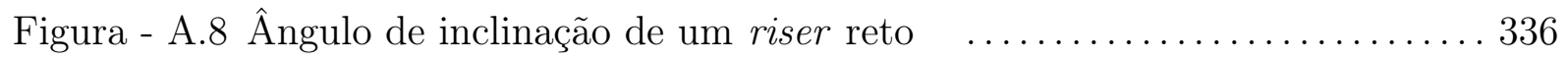

Figura - A.9 Exemplo de um torus utilizado como base para a determinação do ele- 
mento infinitesimal no comprimento de um riser curvo

Figura - A.10Corte na direção da abscissa curvilínea (s) de um riser curvo com raio de curvatura $R$

Figura - A.11Triedro de Frenet utilizado na descrição vetorial dos esforços em um elemento infinitesimal de riser $\ldots \ldots \ldots \ldots . \ldots . \ldots . \ldots . \ldots . \ldots . \ldots 39$

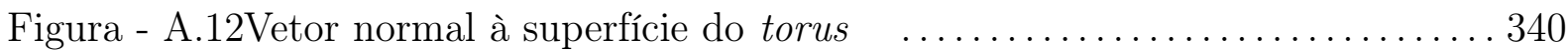

Figura - A.13Pressão hidrostática externa e peso próprio da estrutura do riser $\quad$... 347

Figura - A.14Exemplo de um cilindro vertical para discussão sobre o conceito de tração efetiva

Figura - A.15Exemplo de um cilindro vertical para discussão sobre o conceito de tração efetiva. Inclusão de uma bóia no problema anterior.

Figura - A.16Tubo sob pressão interna $p_{i}$ e fixo dos dois lados, de forma a surgirem tensões axiais devidas ao efeito de Poisson

Figura - A.17Tubo sob pressão interna $p_{i}$ e fixo apenas de um lado de forma a surgirem tensões de axiais de tração

Figura - A.18Esquema de um tubo em catenária com sua ancoragem no solo e unidade flutuante (tubo fora de escala)

Figura - A.19Exemplo 1 - semi-torus submerso em uma posição $\quad \ldots \ldots \ldots \ldots \ldots \ldots . \ldots . \ldots$

Figura - A.20Exemplo 1 - semi-torus submerso em uma segunda posição ........ 361

Figura - A.21Exemplo 2 - Tubo com pressurização interna e com junta que permite

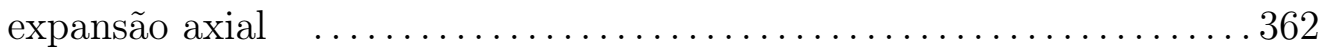

Figura - A.22Resultado das simulações para o exemplo 2 - flambagem de Euler para

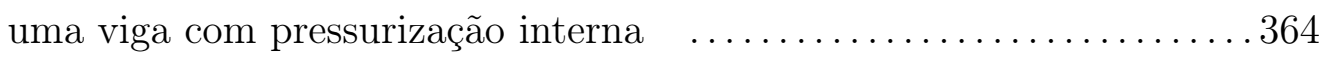

Figura - A.23Exemplo 3. Configuração do cabo umbilical $\ldots \ldots \ldots \ldots \ldots \ldots \ldots \ldots \ldots \ldots \ldots \ldots \ldots$

Figura - A.24Exemplo 3. Distribuição de tração ao longo do cabo umbilical ..... 368

Figura - B.1 Elastica e rotações das seções transversais de uma viga curva tridimensional, sendo visualizados dois sistemas de coordenadas em cada seção transversal: o formado pelas direções do triedro de Frenet e o formado pelas direções principais de flexo-torção $\ldots \ldots \ldots \ldots \ldots \ldots \ldots \ldots \ldots \ldots$

Figura - B.2 Elemento infinitesimal de viga curva no espaço $\ldots \ldots \ldots \ldots \ldots \ldots \ldots . \ldots 375$

Figura - C.1 (a)Problema de uma viga bi-apoiada (b)Elemento diferencial .......380

Figura - C.2 Trajetórias de equilíbrio para o problema da viga de Euler sob compressão 
(problema linear)

Figura - C.3 Fatores de flambagem de Euler para diferentes condições de contorno.

Extraído de Ziegler (1968) 383

Figura - C.4 Viga bi-apoiada sob compressão e sob torção 384

Figura - C.5 Fatores de flambagem para serem utilizados para obtenção do momento de torção crítico através da equação C.27. Extraído de Ziegler (1968) 389 


\section{LISTA DE TABELAS}

Tabela 4.1 Tabela de conectividade ilustrando a relação entre os graus de liberdade

(GL) locais e globais para cada elemento ................... 192

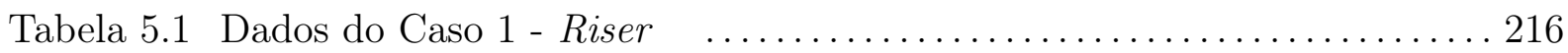

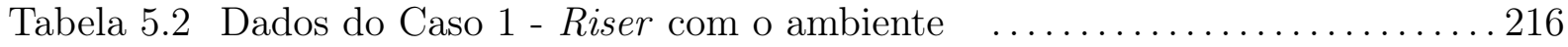

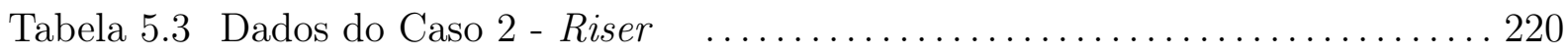

Tabela 5.4 Dados do Caso 2 - Riser com o ambiente $\quad \ldots \ldots \ldots \ldots \ldots \ldots \ldots \ldots \ldots \ldots \ldots . \ldots . \ldots . \ldots 220$

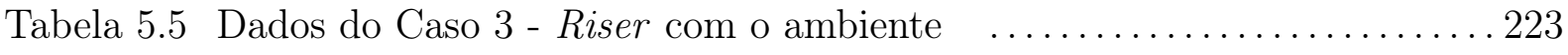

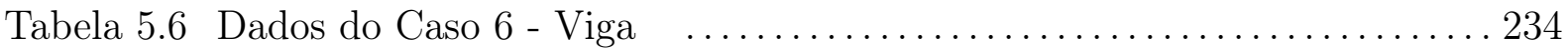

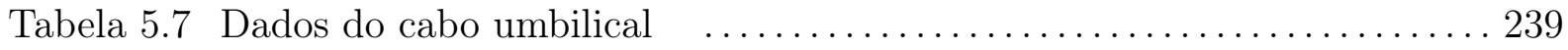

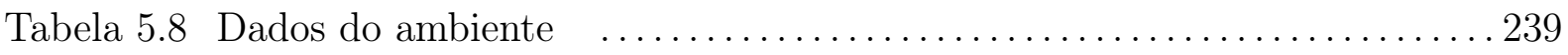

Tabela 5.9 Frequências naturais - sem correnteza e sem atrito $\ldots \ldots \ldots \ldots \ldots \ldots . . .241$

Tabela 5.10 Frequências naturais - sem correnteza e com atrito $\mu=0,4 \quad \ldots \ldots \ldots 242$

Tabela 5.11 Frequências naturais - com correnteza de orientação $\psi=30^{\circ}$ e sem atrito 243

Tabela 5.12 Frequências naturais - com correnteza de orientação $\psi=30^{\circ}$ e com atrito

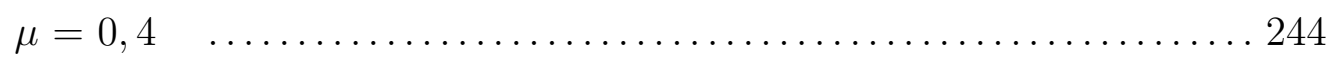

Tabela 5.13 Frequências naturais - com correnteza de orientação $\psi=90^{\circ}$ e sem atrito 245

Tabela 5.14 Configurações analisadas de um cabo umbilical e suas predições analíticas

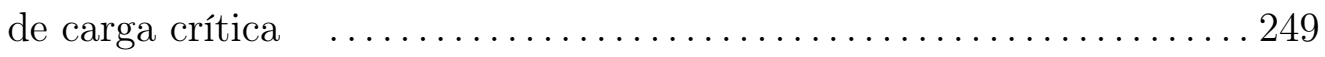

Tabela 5.15 Momentos de torção críticos. Comparação entre os valores numéricos sem atrito e com atrito.

Tabela 5.16 Informações dos casos com correnteza $\quad \ldots \ldots \ldots \ldots \ldots \ldots \ldots \ldots \ldots \ldots . \ldots . \ldots . \ldots . \ldots 1$

Tabela 5.17 Cargas-limite para casos com correnteza marítima $\ldots \ldots \ldots \ldots \ldots \ldots . \ldots 296$

Tabela 5.18 Tração no TDP e momento de torção crítico calculados pelo Modelo puramente analítico, através da equação $5.5 \quad \ldots \ldots \ldots \ldots \ldots \ldots \ldots \ldots . \ldots . \ldots 298$

Tabela 5.19 Curvaturas no TDP consideradas nos casos de generalização . . . .... 307 
Tabela 5.20 Dados e resultados para os casos do conjunto L1 309

Tabela 5.21 Dados e resultados para os casos do conjunto L2 310

Tabela 5.22 Dados e resultados para os casos do conjunto L3 311

Tabela 5.23 Dados e resultados para os casos do conjunto L4 312

Tabela 5.24 Dados e resultados para os casos do conjunto L5 313

Tabela A.1 Dados do Exemplo 3 - Cabo umbilical 365

Tabela A.2 Dados do Exemplo 3 - Cabo umbilical com o ambiente 365 


\section{LISTA DE SÍMBOLOS}

\section{Alfabeto Grego}

$\alpha \quad$ Parâmetro de rotação de Rodrigues (Capítulo 4), Ângulo que mede a rotação imposta no riser (recalque angular) (Capítulo 5)

$\boldsymbol{\alpha} \quad$ Vetor rotação de Rodrigues

$\alpha_{l} \quad$ Adimensional de carregamento

$\beta \quad$ Ângulo para medir a inclinação de um riser

$\beta_{l} \quad$ Adimensional de geometria da catenária

$\gamma \quad$ Peso por unidade de comprimento do riser

$\gamma_{a r} \quad$ Peso por unidade de comprimento de um riser no ar

$\gamma_{e f} \quad$ Peso efetivo por unidade de comprimento do riser

$\boldsymbol{\Gamma} \quad$ Tensor que relaciona a derivada temporal do vetor rotação de Euler com o vetor velocidade angular

$\Gamma_{C} \quad$ Região de contato entre o riser e o solo

$\boldsymbol{\Gamma}(\boldsymbol{t}) \quad$ Curva parametrizada em relação a $t$

$\boldsymbol{\delta}^{\boldsymbol{\Delta}} \quad$ Deslocamento de um ponto genérico da seção transversal da viga em certo subpasso da análise

$\Delta \quad$ Como índice, relaciona as configurações $i$ e $i+1$ do modelo de viga. Nas equações, como operador diferencial

$\boldsymbol{\epsilon}^{\boldsymbol{i}} \quad$ Vetor deformação generalizada em uma dada seção transversal na configuração $i$

$\epsilon_{N} \quad$ Parâmetro de penalidade na direção normal do contato

$\epsilon_{T} \quad$ Parâmetro de penalidade na direção tangencial do contato 
$\epsilon_{z} \quad$ Deformação axial de um vaso de pressão cilíndrico

$\epsilon_{z}^{\prime} \quad$ Deformação axial aproximada de um vaso de pressão cilíndrico

$\zeta \quad$ Variável escalar que descreve a direção axial de uma viga na configuração de referência

$\boldsymbol{\zeta} \quad$ Vetor posição do ponto $\boldsymbol{A}$ definido pela intersecção entre o eixo da viga e a seção transversal que está sendo analisada (em sua configuração de referência)

$\boldsymbol{\eta}^{\boldsymbol{i}} \quad$ Vetor deformação translacional associado à configuração $i$

$\theta$ Parâmetro de rotação de Euler (Capítulo 4), Ângulo de inclinação de um riser (Capítulo 5), Ângulo para localizar os pontos ao longo do perímetro de uma seção transversal do riser (Apêndice A)

$\boldsymbol{\theta} \quad$ Vetor rotação de Euler

$\Theta \quad$ Forma skew do vetor rotação de Euler

$\kappa \quad$ Curvatura em uma das direções principais de flexo-torção

$\kappa^{\prime} \quad$ Curvatura em uma das direções principais de flexo-torção

$\kappa_{t d p} \quad$ Curvatura do riser no TDP

$\boldsymbol{\kappa}^{i} \quad$ Vetor rotação específica associado à configuração $i$

$\lambda \quad$ Comprimento de flexão

$\lambda_{k} \quad$ Autovalor $k$ da matriz de evolução de estados de um sistema dinâmico

$\Lambda^{i} \quad$ Operador contendo os tensores rotação

$\mu \quad$ Momento de torção adimensionalizado (Capítulo 2), Coeficiente de atrito (Capítulo 4 e Capítulo 5)

$\boldsymbol{\mu}^{\boldsymbol{\theta}} \quad$ Pseudo-momento associado ao vetor rotação de Euler

$\boldsymbol{\mu}^{\boldsymbol{\alpha}} \quad$ Pseudo-momento associado ao vetor rotação de Rodrigues

$\nu \quad$ Coeficiente de Poisson

$\xi \quad$ Deformação axial imposta na viga 
$\boldsymbol{\xi}$ Vetor posição de um ponto genérico da seção transversal considerada da viga em sua configuração de referência

$\boldsymbol{\Xi}$ Tensor que relaciona a derivada temporal do vetor rotação de Rodrigues com o vetor velocidade angular

$\rho \quad$ Massa específica da viga

$\rho_{e} \quad$ Massa específica do fluido externo ao riser

$\rho_{f} \quad$ Massa específica do fluido externo ao riser

$\rho_{i} \quad$ Massa específica do fluido interno ao riser

$\bar{\rho} \quad$ Massa por unidade de comprimento da viga

$\sigma^{i} \quad$ Componente do vetor $\boldsymbol{\tau}_{\boldsymbol{i}}$ na direção $\boldsymbol{e}_{\mathbf{3}}^{\boldsymbol{i}}$

$\boldsymbol{\sigma}^{\boldsymbol{i}} \quad$ Esforço solicitante generalizado (ou tensão generalizada) em uma dada seção transversal na configuração $i$

$\sigma_{\theta} \quad$ Tensão circunferencial em um vaso de pressão cilíndrico

$\sigma_{r} \quad$ Tensão radial em um vaso de pressão cilíndrico

$\tau \quad$ Tração adimensionalizada

$\tau_{c} \quad$ Tortuosidade de uma viga

$\tau^{i} \quad$ Vetor tensão associado à configuração $i$ no plano cuja normal da configuração de referência é $\boldsymbol{e}_{3}^{r}$

$\tau_{1}^{i} \quad$ Componente do vetor $\boldsymbol{\tau}_{\boldsymbol{i}}$ na direção $\boldsymbol{e}_{1}^{i}$

$\tau_{2}^{i} \quad$ Componente do vetor $\boldsymbol{\tau}_{\boldsymbol{i}}$ na direção $\boldsymbol{e}_{\mathbf{2}}^{\boldsymbol{i}}$

$\tau_{p} \quad$ Torção própria de uma viga

$\tau_{t} \quad$ Torção total do riser

$\Upsilon^{\boldsymbol{i}} \quad$ Operador que multiplica as acelerações generalizadas na variação virtual da energia cinética

$\phi_{m} \quad$ Imposição de rotação axial na viga

$\Phi \quad$ Função de Lyapunov 
$\boldsymbol{\Phi}^{\boldsymbol{i}} \quad$ Operador contendo $\boldsymbol{Z}^{\boldsymbol{i}}$ e outros tensores

$\chi \quad$ Curvatura de uma curva no espaço

$\psi \quad$ Função energia de deformação por unidade de volume de referência (Capítulo 4), Ângulo azimutal para referência da orientação da correnteza marítima (Capítulo 5)

$\Psi^{i} \quad$ Operador que multiplica as velocidades generalizadas na variação virtual da energia cinética

$\boldsymbol{\omega} \quad$ Vetor velocidade angular

$\omega_{k} \quad$ Frequência natural $k$ de um sistema dinâmico

$\boldsymbol{\Omega} \quad$ Tensor velocidade angular

\section{Alfabeto Latino}

$\boldsymbol{a}^{\boldsymbol{i}} \quad$ Diferença entre os vetores $\boldsymbol{x}$ e $\boldsymbol{z}$ em uma configuração $i$

$\boldsymbol{a}^{\boldsymbol{r}} \quad$ Diferença entre os vetores $\boldsymbol{\xi}$ e $\boldsymbol{\zeta}$

$\boldsymbol{a}_{1} \quad$ Vetor tangencial à superfície master do elemento de contato

$\boldsymbol{a}_{2} \quad$ Vetor tangencial à superfície master do elemento de contato

A Área da seção transversal da viga

$\boldsymbol{A} \quad$ Forma skew do vetor rotação de Rodrigues

$A_{i} \quad$ Área de influência de cada nó slave (Capítulo 4), Área da seção transversal interna de um riser (Apêndice A)

$\boldsymbol{A}_{\boldsymbol{i}} \quad$ Matriz da evolução de estados no ponto de linearização "i” de um sistema dinâmico

$A_{\text {int }} \quad$ Área da seção transversal interna de um riser

$\boldsymbol{b} \quad$ Vetor binormal à elastica

$\bar{b} \quad$ Esforços distribuídos no volume da viga, por unidade de volume da configuração de referência 
$C_{a t} \quad$ Coeficiente de massa adicional na direção tangencial do riser

$C_{a n} \quad$ Coeficiente de massa adicional na direção transversal do riser

$C_{d} \quad$ Coeficiente de arrasto do riser

$C_{d t} \quad$ Coeficiente de arrasto na direção tangencial do riser

$C_{d n} \quad$ Coeficiente de arrasto na direção transversal do riser

$\boldsymbol{d}^{\boldsymbol{\Delta}} \quad$ Vetor deslocamento generalizado de uma dada seção transversal entre as configurações $i$ e $i+1$

D Diâmetro externo do riser

$\boldsymbol{D}^{r} \quad$ Operador constitutivo da viga (na configuração de referência)

$\boldsymbol{e} \quad$ Versor que representa a direção do eixo de rotação em parametrizações vetoriais

E $\quad$ Módulo de Young

$E A \quad$ Rigidez axial de uma viga ou riser

EI Rigidez flexional de uma viga ou riser

$E I_{1} \quad$ Rigidez flexional da viga na direção $e_{1}^{r}$

$E I_{2} \quad$ Rigidez flexional da viga na direção $\boldsymbol{e}_{2}^{r}$

$\boldsymbol{E} \quad$ Vetor força de empuxo

$\boldsymbol{f}$ Vetor força resultante da integração da ação da pressão nas paredes de um riser (Apêndice A), Força distribuída (por unidade de comprimento da viga) (Apêndice B)

$\boldsymbol{f}_{\boldsymbol{i}} \quad$ Vetor de carregamentos no ponto de linearização "i" de um sistema dinâmico

$f_{N} \quad$ Norma da componente normal da força de contato

$f_{T} \quad$ Norma da componente tangencial da força de contato (atrito)

$\boldsymbol{f}_{\boldsymbol{T}} \quad$ Vetor componente tangencial da força de contato (atrito)

$\boldsymbol{f}_{d s} \quad$ Resultante do campo de pressão externa integrado nas paredes de um tubo curvo de comprimento $d s$ 
$F_{c} \quad$ Tração crítica

$\boldsymbol{F}^{\boldsymbol{i}} \quad$ Gradiente de transformação associado à configuração $i$

$\boldsymbol{F}_{\boldsymbol{n}}^{\boldsymbol{i}} \quad$ Vetor esforço hidrodinâmico transversal ao riser na configuração $i$

$\boldsymbol{F}_{\boldsymbol{t}}^{\boldsymbol{i}} \quad$ Vetor esforço hidrodinâmico tangencial ao riser na configuração $i$

$\boldsymbol{g}$ Aceleração da gravidade local, função gap (contato)

$\boldsymbol{g}_{f} \quad$ Função vetorial esforço desbalanceado

$g_{N} \quad$ Função gap normal

$\boldsymbol{g}_{\boldsymbol{T}} \quad$ Função gap tangencial

$\boldsymbol{G}^{\boldsymbol{i}} \quad$ Operador matricial presente na parte geométrica do operador tangente

$G A \quad$ Rigidez ao cisalhamento da viga

GJ Rigidez à torção de uma viga ou riser

$h \quad$ Altura de lâmina d'água

$i \quad$ Ponto de linearização de um sistema dinâmico (Capítulo 3), Índice de um ponto na descrição do vínculo do contato unilateral (Capítulo 3), Índice de uma configuração do modelo de viga (Capítulo 4)

I $\quad$ Momento de inércia

$I_{p} \quad$ Momento polar de inércia

$I_{11} \quad$ Momento de inércia da seção transversal da viga em relação à $\boldsymbol{e}_{\mathbf{1}}^{r}$

$I_{22} \quad$ Momento de inércia da seção transversal da viga em relação à $\boldsymbol{e}_{2}^{\boldsymbol{r}}$

$I_{12} \quad$ Produto de inércia da seção transversal da viga

$J \quad$ Jacobiano que relaciona as coordenadas naturais com as coordenadas reais de um elemento

$\overline{\boldsymbol{J}} \quad$ Tensor de inércia por unidade de comprimento da viga

$k \quad$ Índice de uma coordenada generalizada ou variável de estado

$\boldsymbol{K}_{\boldsymbol{C} i}^{\boldsymbol{N}} \quad$ Matriz de rigidez tangente do elemento de contato (influência da direção normal) 
$\boldsymbol{K}_{\boldsymbol{C} i}^{\boldsymbol{T}} \quad$ Matriz de rigidez tangente do elemento de contato (influência da direção tangencial)

$\boldsymbol{K}_{\boldsymbol{i}} \quad$ Matriz de rigidez tangente no ponto de linearização "i" de um sistema dinâmico

$\boldsymbol{K}^{\boldsymbol{i}} \quad$ Tensor rotação específica associado à configuração $i$

$\boldsymbol{K}_{\boldsymbol{T}} \quad$ Matriz de rigidez tangente

$\boldsymbol{L}^{\boldsymbol{i}} \quad$ Operador matricial presente na parte dos carregamentos do operador tangente

$\boldsymbol{m} \quad$ Momento distribuído (por unidade de comprimento da viga)

$\boldsymbol{m}^{\boldsymbol{i}} \quad$ Momento solicitante em uma dada seção transversal na configuração $i$

$\overline{\boldsymbol{m}} \quad$ Momento externo aplicado em cada uma das seções transversais da viga (por unidade de comprimento de referência)

$\boldsymbol{M}_{\boldsymbol{i}} \quad$ Matriz de massa tangente no ponto de linearização "i" de um sistema dinâmico

$M_{c} \quad$ Momento de torção crítico

$M_{c r}^{0} \quad$ Momento de torção crítico na ausência de cargas compressivas

$M_{t} \quad$ Momento de torção aplicado ao riser ou viga

$M_{x} \quad$ Momento fletor na direção $x$

$M_{y} \quad$ Momento fletor na direção $y$

$M_{z} \quad$ Momento de torção na direção $z$

$M_{1} \quad$ Momento fletor na direção $\boldsymbol{e}_{1}^{i}$

$M_{2} \quad$ Momento fletor na direção $\boldsymbol{e}_{2}^{i}$

$M_{3} \quad$ Momento de torção na direção $\boldsymbol{e}_{3}^{i}$, energia cinética

$\overline{\boldsymbol{M}} \quad$ Tensor de massa por unidade de comprimento da viga

$\boldsymbol{M}^{\boldsymbol{i}}$ Tensor anti-simétrico associado ao vetor $\boldsymbol{m}^{\boldsymbol{i}}$

$M_{T} \quad$ Matriz de massa tangente

$M(x) \quad$ Momento fletor

$n \quad$ Número de graus de liberdade de um sistema dinâmico (Capítulo 3) 
$\boldsymbol{n} \quad$ Vetor normal à superfície master do elemento de contato (Capítulo 4), Vetor normal à elastica (Apêndice A e Apêndice B)

$\boldsymbol{n}_{\mathbf{1}} \quad$ Vetor normal à superfície master

$\boldsymbol{n}_{\boldsymbol{p}} \quad$ Vetor normal à superfície do riser em um ponto $\boldsymbol{P}$

$\boldsymbol{n}_{\boldsymbol{T}} \quad$ Vetor direção do deslizamento

$\bar{n} \quad$ Força externa aplicada em cada uma das seções transversais da viga (por unidade de comprimento de referência)

$\boldsymbol{n}^{\boldsymbol{i}} \quad$ Força solicitante em uma dada seção transversal na configuração $i$

$N \quad$ Força normal na direção $\boldsymbol{e}_{\mathbf{3}}^{\boldsymbol{i}}$ (Capítulo 4), Força normal em uma viga (Apêndice B)

$\mathbf{N} \quad$ Matriz das funções de forma

$N_{a} \quad$ Função de forma de um nó cuja coordenada é $a$

$\boldsymbol{N}^{\boldsymbol{i}} \quad$ Tensor anti-simétrico associado ao vetor $\boldsymbol{n}^{\boldsymbol{i}}$

$p_{\text {crit }} \quad$ Pressão interna crítica de flambagem de uma viga

$p_{e} \quad$ Pressão externa em um riser

$p_{h} \quad$ Pressão hidrostática

$p_{i} \quad$ Pressão interna em um riser

$p_{N} \quad$ Pressão de contato

$p_{o} \quad$ Pressurização adicional à hidrostática em um riser

$p(z) \quad$ Função pressão em um riser em função da cota $z$

$P \quad$ Parâmetro escalar que rege o carregamento em um sistema dinâmico (Capítulo 3), Força compressiva na viga (Apêndice C)

$P_{\text {crit }} \quad$ Carga compressiva crítica de flambagem de uma viga

$P_{c r}^{0} \quad$ Carga crítica compressiva na ausência de momentos de torção

$P_{\text {ext }} \quad$ Potência dos esforços externos 
$\boldsymbol{P}^{\boldsymbol{i}} \quad$ Primeiro Tensor de Piola-Kirchhoff associado à configuração $i$

Pint Potência dos esforços internos

$P_{n} \quad$ n-ésima carga crítica de flambagem

$\boldsymbol{q} \quad$ Vetor de coordenadas generalizadas de um sistema dinâmico

$\overline{\boldsymbol{q}} \quad$ Vetor de esforços externos generalizados

$q_{k} \quad$ Coordenadas generalizada $k$ de um sistema dinâmico

$Q_{x} \quad$ Força cortante na direção $x$

$Q_{y} \quad$ Força cortante na direção $y$

$r \quad$ Direção radial de um vaso de pressão cilíndrico

$\boldsymbol{r} \quad$ Função vetorial que monitora as posições dos infinitos pontos de um corpo rígido

$r_{e} \quad$ Raio externo em um riser

$r_{i} \quad$ Raio interno em um riser

$R \quad$ Raio de curvatura do riser

$\boldsymbol{R} \quad$ Tensor rotação

$s \quad$ Abscissa curvilínea da elastica do riser

$\boldsymbol{t} \quad$ Versor que indica direção tangente à uma curva

$\overline{\boldsymbol{t}} \quad$ Esforços aplicados na superfície externa da viga $C$, por unidade de área dessa superfície na configuração de referência

$\boldsymbol{t}_{\boldsymbol{T}} \quad$ Vetor tensão de cisalhamento na interface de contato

$T_{c} \quad$ Torque crítico

$T_{\text {ef }} \quad$ Tração efetiva de um riser

$T_{s} \quad$ Tração solicitante de um riser

$T_{t d p} \quad$ Tração do riser no TDP

$\boldsymbol{u}^{\boldsymbol{\Delta}} \quad$ Vetor deslocamento que vai do ponto $\boldsymbol{B}^{\boldsymbol{i}}$ até o ponto $\boldsymbol{B}^{\boldsymbol{i + 1}}$ 
$\boldsymbol{u}^{\boldsymbol{i}} \quad$ Vetor deslocamento que vai do ponto $\boldsymbol{A}$ até o ponto $\boldsymbol{B}^{\boldsymbol{i}}$

$\dot{u} \quad$ Norma da velocidade absoluta do riser em relação a um referencial fixo

$\ddot{u} \quad$ Norma da aceleração absoluta do riser em relação a um referencial fixo

U Funcional da energia potencial de um sistema dinâmico

$U_{\text {ext }}$ Energia potencial dos esforços externos conservativos de um sistema dinâmico

$U_{\text {int }}$ Energia potencial dos esforços internos de um sistema dinâmico (Capítulo 3), Energia interna da viga (Capítulo 4)

$\bar{U} \quad$ Função dos graus de liberdade de um sistema dinâmico

$\dot{U} \quad$ Norma da velocidade do escoamento externo ao longe do riser

$\ddot{U} \quad$ Norma da aceleração do escoamento externo ao longe do riser

$\dot{\boldsymbol{U}} \quad$ Vetor velocidade da correnteza ao longe do riser

$\dot{\boldsymbol{U}}_{\boldsymbol{t}}^{\boldsymbol{i}} \quad$ Vetor velocidade da correnteza ao longe do riser na direção tangencial ao mesmo na configuração $i$

$\dot{\boldsymbol{U}}_{\boldsymbol{n}}^{\boldsymbol{i}} \quad$ Vetor velocidade da correnteza ao longe do riser na direção transversal ao mesmo na configuração $i$

$\boldsymbol{v} \quad$ Vetor de velocidades generalizadas de um sistema dinâmico (Capítulo 3), Função vetorial que monitora as velocidades dos infinitos pontos de um corpo rígido (Capítulo 4)

$v(x) \quad$ Carregamento transversal distribuído na viga, Função que descreve a elastica da viga

$\boldsymbol{V}$ Operador associado à uma derivada de um vetor em relação ao vetor rotação de Rodrigues

$V_{1} \quad$ Força cortante na direção $\boldsymbol{e}_{1}^{i}$

$V_{2} \quad$ Força cortante na direção $\boldsymbol{e}_{2}^{i}$

$V(x) \quad$ Força cortante

$w(x) \quad$ Função que descreve a elastica da viga 
$w_{v}(x)$ Função que descreve a solução particular da elastica da viga com carregamento $v(x)$

$\boldsymbol{W}$ Operador associado à uma derivada de um vetor em relação ao vetor rotação de Euler

$W_{C} \quad$ Trabalho dos esforços de contato

$W_{\text {ext }}$ Trabalho dos esforços externos conservativos de um sistema dinâmico (Capítulo 3), Trabalho dos esforços externos (Capítulo 4)

$W_{\text {int }} \quad$ Trabalho dos esforços internos

$W_{r} \quad$ Trabalho residual

$\boldsymbol{x} \quad$ Vetor de variáveis de estado de um sistema dinâmico (Capítulo 3), Posição no espaço associada a um ponto de um corpo rígido (Capítulo 4)

$\boldsymbol{x}^{\boldsymbol{i}} \quad$ Posição no espaço associada a um ponto de um corpo rígido na configuração $i$

$x_{k} \quad$ Estado $k$ de um sistema dinâmico

$\boldsymbol{x}_{1} \quad$ Vetor posição de um nó master

$\boldsymbol{x}_{2} \quad$ Vetor posição de um nó slave

$\boldsymbol{Y}^{\boldsymbol{\Delta}} \quad$ Operador contendo os tensores $\boldsymbol{\Xi}^{\boldsymbol{\Delta}}$

$\boldsymbol{z}^{\boldsymbol{i}} \quad$ Vetor posição do ponto $\boldsymbol{B}^{\boldsymbol{i}}$ definido pela intersecção entre o eixo da viga e a seção transversal que está sendo analisada

$\boldsymbol{Z}^{\boldsymbol{i}} \quad$ Tensor anti-simétrico associado ao vetor $\boldsymbol{z}^{\boldsymbol{i}}$

\section{Operadores}

- $\quad$ Produto escalar entre dois vetores

: $\quad$ Produto escalar entre dois tensores

$\otimes \quad$ Produto tensorial

$\times \quad$ Produto vetorial

skew Retorna o tensor anti-simétrico associado a um vetor

axial Retorna o vetor associado a um tensor anti-simétrico 



\section{SUMÁRIO}

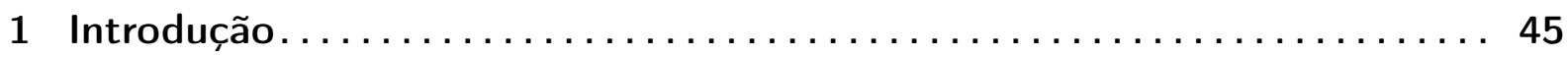

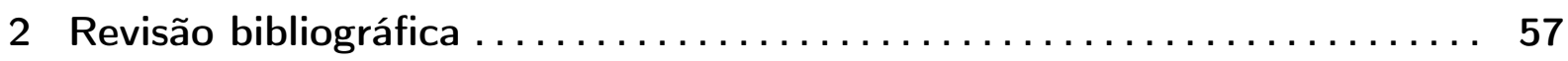

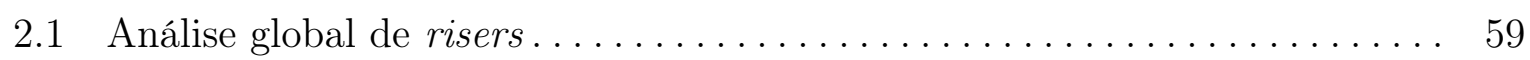

$2.1 .1 \quad$ Abordagem diferencial $\ldots \ldots \ldots \ldots \ldots \ldots \ldots \ldots \ldots \ldots \ldots \ldots \ldots$

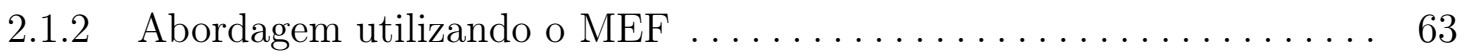

2.2 Estabilidade de cabos e risers sob torção, compressão e tração . . . . . . . 68

3 Estabilidade estrutural da configuração estática de risers em catenária ... 81

3.1 Fundamentos sobre sistemas dinâmicos $\ldots \ldots \ldots \ldots \ldots \ldots \ldots \ldots \ldots \ldots$

3.1 .1 Descrição de um sistema dinâmico $\ldots \ldots \ldots \ldots \ldots \ldots \ldots \ldots \ldots$

3.1.2 Estabilidade de um sistema dinâmico ................ 83

3.1.3 Pontos de bifurcação e pontos limite $\ldots \ldots \ldots \ldots \ldots \ldots \ldots \ldots \ldots$

3.1.4 Metodologias para análise de estabilidade em estruturas . . . . . . . . 91

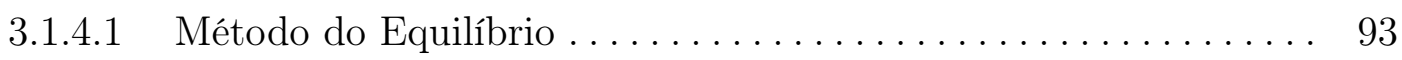

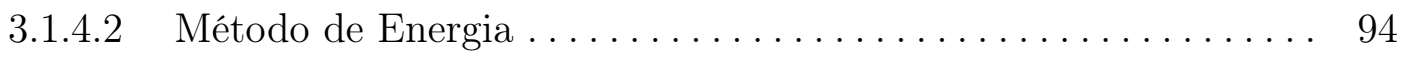

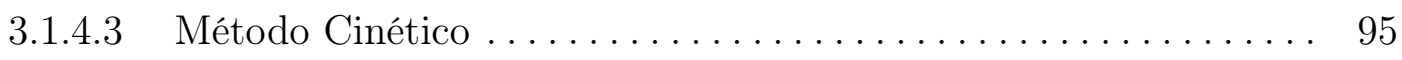

3.1.4.4 Primeiro Método de Lyapunov . . . . . . . . . . . . . . . . 95

3.1.4.5 Segundo Método de Lyapunov . . . . . . . . . . . . . . 97

3.1.5 Discussão sobre a metodologia de análise e critérios de estabilidade . . 97

3.1 .6 Classificação de forças e sistemas . . . . . . . . . . . . . . . . . . . 99

3.1.7 Teoremas e observações sobre estabilidade de estruturas . . . . . . . . . 103

3.2 A configuração estática de risers em catenária .................. 108 


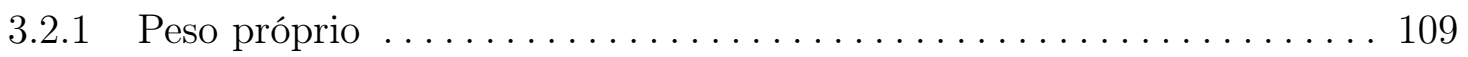

3.2.2 Contato unilateral entre o riser e o fundo do mar . . . . . . . . . . . 109

3.2.3 Esforços hidrostáticos atuantes externa e internamente à estrutura do

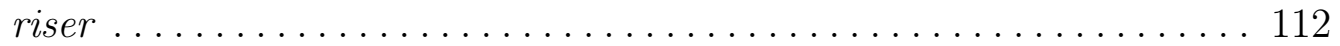

3.2.4 Esforços hidrodinâmicos de correnteza marítima ............. 116

3.2.5 Imposições de rotações na extremidade do riser . . . . . . . . . . . . . 118

3.2.6 Discussão e critérios de estabilidade . . . . . . . . . . . . . . . . . . . . 118

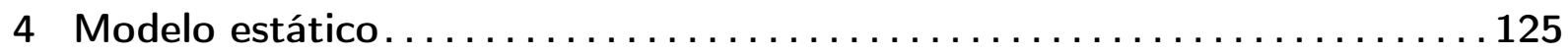

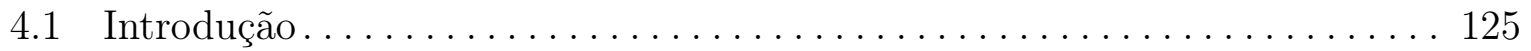

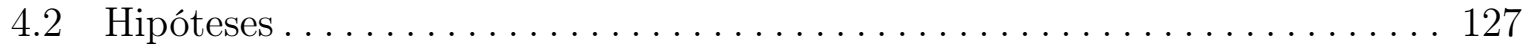

4.2 .1 Formulação Co-rotacional . . . . . . . . . . . . . . . . . . . . . . 130

4.2 .2 Formulação Cinematicamente Exata . . . . . . . . . . . . . . . . . . . . . . . 132

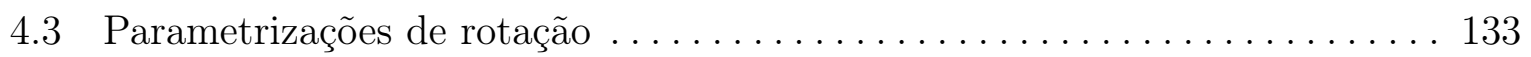

4.3.1 Estudo do movimento geral de um corpo rígido . . . . . . . . . . 134

4.3 .2 Descrição das rotações . . . . . . . . . . . . . . . . . . . . . . . . 138

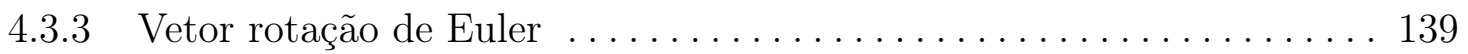

4.3.4 Vetor rotação de Rodrigues . . . . . . . . . . . . . . . . . . . . . . . . 141

4.3.5 Relações entre a derivada temporal do vetor rotação e os vetores velocidade e aceleração angular . . . . . . . . . . . . . . . . . . . . . . . . . 142

4.3.6 Potência das forças aplicadas a um corpo rígido . . . . . . . . . . . . 146

4.3.7 Não comutatividade das rotações . . . . . . . . . . . . . . . . . . . 147

4.3.8 Escolha dos parâmetros de rotação . . . . . . . . . . . . . . . . . 148

4.4 Formulação do modelo estrutural de viga $\ldots \ldots \ldots \ldots \ldots \ldots \ldots \ldots \ldots \ldots$

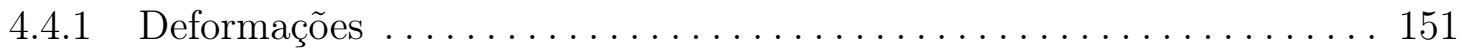

4.4.2 Relações entre as diferentes configurações . . . . . . . . . . . . . . . 153

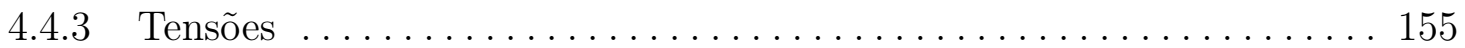




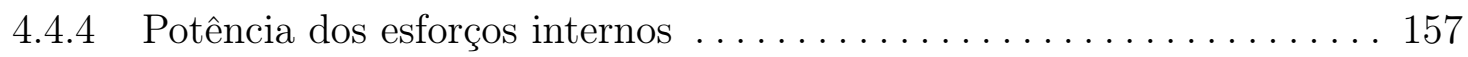

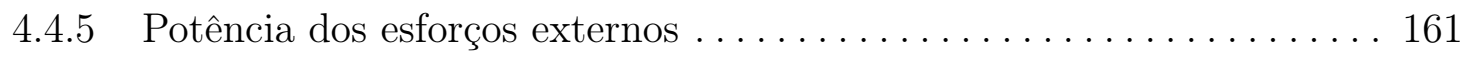

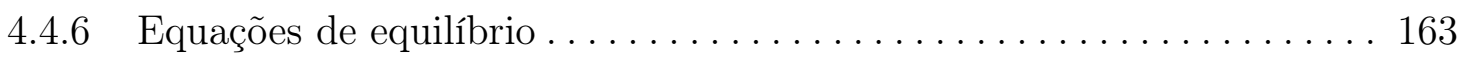

4.4.6.1 Variação virtual da energia cinética . . . . . . . . . . . . . 165

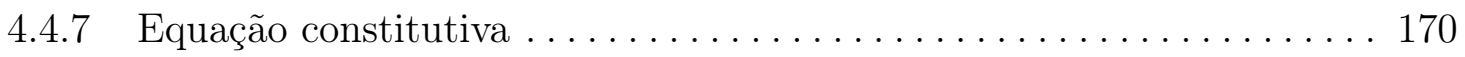

4.4 .8 Operador tangente $\ldots \ldots \ldots \ldots \ldots \ldots \ldots \ldots \ldots \ldots \ldots \ldots \ldots \ldots$

4.4.9 Carregamentos em problemas de risers ............... 176

4.4.9.1 Carregamento do peso próprio $\ldots \ldots \ldots \ldots \ldots \ldots \ldots \ldots \ldots$

4.4.9.2 Carregamento de pressão interna e externa $\ldots \ldots \ldots \ldots \ldots \ldots$

4.4.9.3 Carregamento de correntezas marítimas em risers . . . . . . . . 179

4.5 Solução aproximada utilizando o Método dos Elementos Finitos (MEF) . . 185

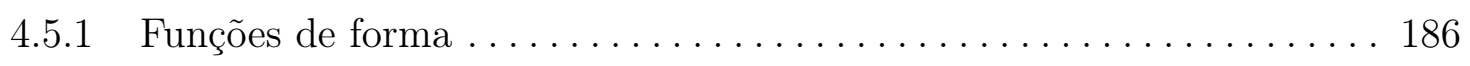

4.5.2 Equação de equilíbrio e operador tangente discretizados . . . . . . . . . 188

4.5.3 Integração numérica por Quadratura-Gaussiana . . . . . . . . . . . . 190

4.5.4 Montagem da matriz de rigidez global da estrutura ............ 191

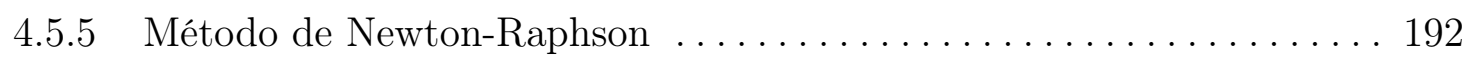

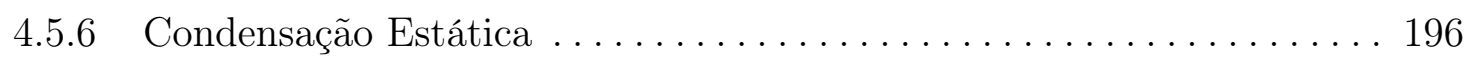

4.5.7 Divisões de carregamentos $\ldots \ldots \ldots \ldots \ldots \ldots \ldots \ldots \ldots \ldots \ldots \ldots \ldots$

4.5.8 Preditor e corretor de incrementos de carga . . . . . . . . . . . . 198

4.6 Contato em problemas de risers e elementos de contato . . . . . . . . . . 199

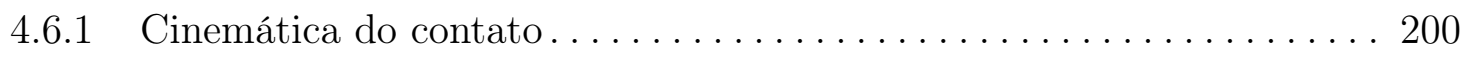

4.6.2 Leis constitutivas de contato na direção normal . . . . . . . . . . . . 203

4.6.3 Lei constitutiva de contato na direção tangencial (atrito) . . . . . . . . 204

4.6.4 Linha de lançamento e atrito entre riser e o solo . . . . . . . . . 206

4.6.5 Elemento de contato entre o riser e o solo ............... 207 
5.2 Análises estáticas de risers - verificação dos modelos . . . . . . . . . . . 216

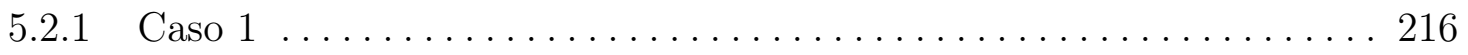

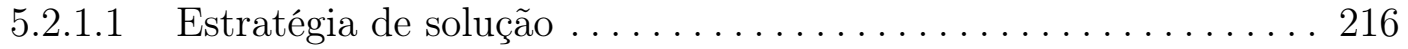

5.2 .1 .2 Resultados . . . . . . . . . . . . . . . . . . . 217

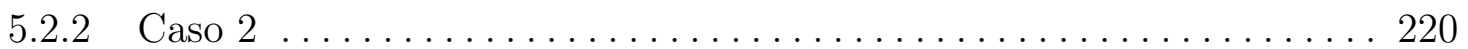

$5.2 .2 .1 \quad$ Estratégia de solução . . . . . . . . . . . . . . . . . . 220

$5.2 .2 .2 \quad$ Resultados . . . . . . . . . . . . . . . . . . . . . . 221

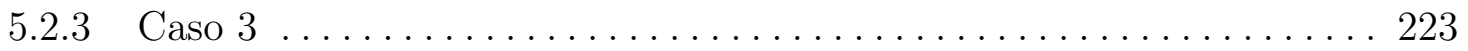

$5.2 .3 .1 \quad$ Estratégia de solução . . . . . . . . . . . . . . . . . 223

$5.2 .3 .2 \quad$ Resultados .............................. 224

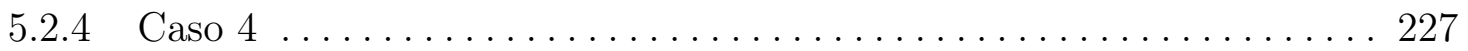

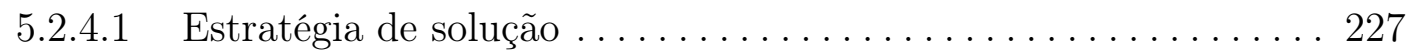

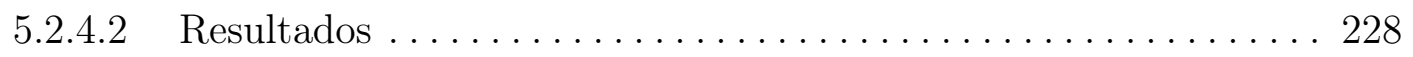

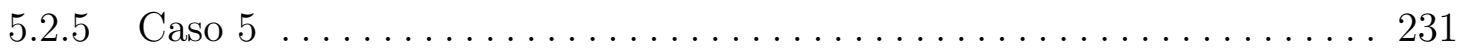

$5.2 .5 .1 \quad$ Estratégia de solução . . . . . . . . . . . . . . . . . 231

$5.2 .5 .2 \quad$ Resultados . . . . . . . . . . . . . . . . . . . 231

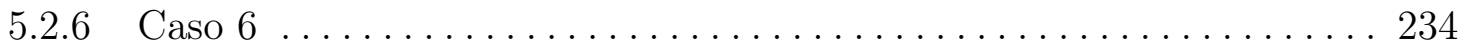

5.2.6.1 Estratégia de solução . . . . . . . . . . . . . . . . . . . 234

$5.2 .6 .2 \quad$ Resultados . . . . . . . . . . . . . . . . . . . . 235

5.2 .7 Análise Modal . . . . . . . . . . . . . . . . . . . . . . . . . 239

5.2 .7 .1 Sem correnteza e sem atrito $\ldots \ldots \ldots \ldots \ldots \ldots \ldots \ldots \ldots \ldots \ldots$

5.2.7.2 Sem correnteza e com atrito $\mu=0,4 \ldots \ldots \ldots \ldots \ldots \ldots \ldots 242$

5.2.7.3 Com correnteza de orientação $\psi=30^{\circ}$ e sem atrito $\ldots \ldots \ldots 243$

5.2.7.4 Com correnteza de orientação $\psi=30^{\circ}$ e com atrito $\mu=0,4 \ldots 244$

5.2.7.5 Com correnteza de orientação $\psi=90^{\circ}$ e sem atrito . . . . . . 245 
5.3 Estudo da estabilidade de configurações de risers instalados em catenária . 245

5.3.1 Comparação entre a imposição do momento e da rotação . . . . . . . . . 250

5.3 .2 Modelo com o TDP engastado .................... 252

5.3.3 Modelo considerando o contato unilateral sem atrito . . . . . . . . 263

5.3.4 Modelo considerando o contato unilateral com atrito . . . . . . . . . 273

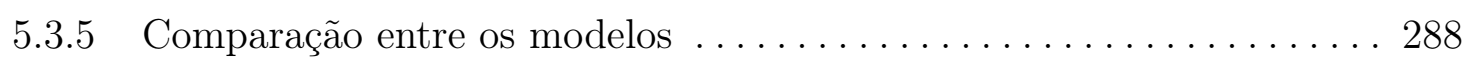

5.3 .6 Casos com correnteza marítima . . . . . . . . . . . . . . . . 290

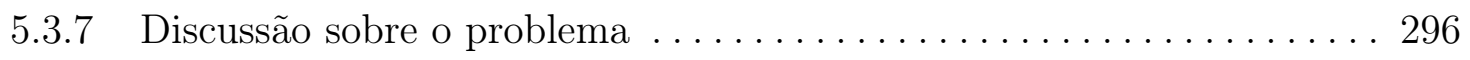

5.3 .8 Generalização . . . . . . . . . . . . . . . . . . . . . . . 304

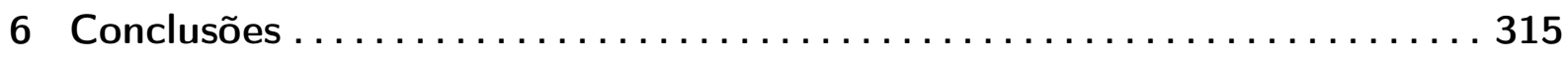

Referências . . . . . . . . . . . . .

\section{Apêndice A - Efeito das pressões interna e externa na estabilidade estrutural}

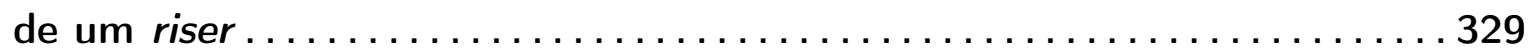

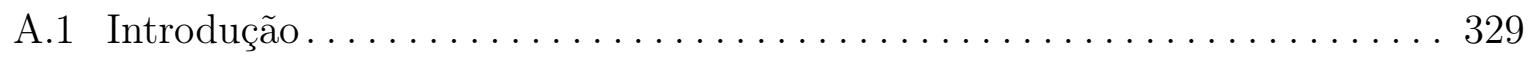

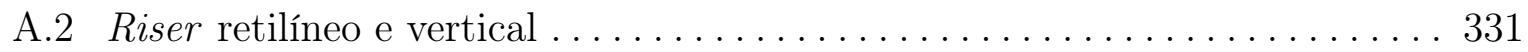

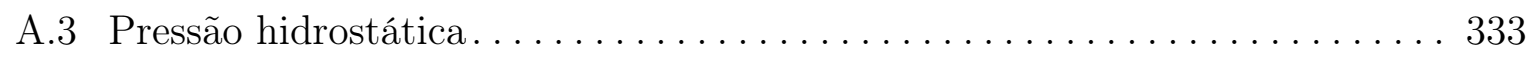

A.4 Carregamento da pressão externa sobre um riser . . . . . . . . . . 335

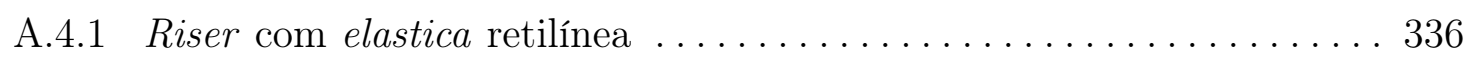

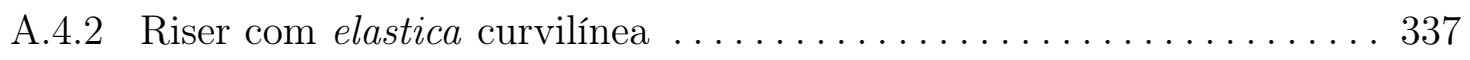

A.5 Carregamento da pressão interna sobre um riser . . . . . . . . . . . 344

A.6 Expressões para carregamentos de pressão interna e externa combinadas . . 345

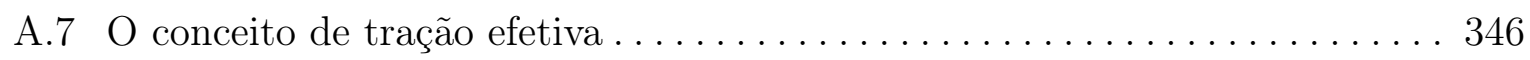

A.8 Tração efetiva e estabilidade estrutural $\ldots \ldots \ldots \ldots \ldots \ldots \ldots \ldots \ldots \ldots \ldots 4$

A.9 Condições de contorno e efeitos de fechamento do tubo (end cap) . . . . . 357

A.10 Exemplos de aplicações . . . . . . . . . . . . . . . . . . . . . . 359 
A.10.1 Exemplo 1 - semi-torus submerso

A.10.2 Exemplo 2 - flambagem de Euler para uma viga com pressurização

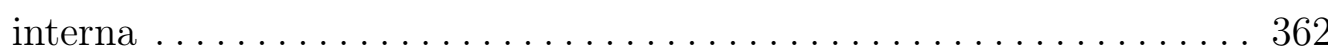

A.10.3 Exemplo 3 - cabo umbilical imerso em água do mar . . . . . . . . . 364

Apêndice B - Teoria de vigas curvas de Love.................... 369

B.1 Triedro de Frenet . . . . . . . . . . . . . . . . . . . . . . . . 370

B.2 Equações diferenciais de equilíbrio $\ldots \ldots \ldots \ldots \ldots \ldots \ldots \ldots \ldots \ldots \ldots \ldots \ldots \ldots$

Apêndice C - Flambagem de Euler e Fórmula de Greenhill . . . . . . . . . . 379

C.1 Flambagem de Euler . . . . . . . . . . . . . . . . . . . . 379

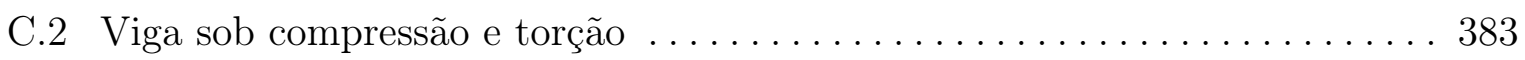




\section{INTRODUÇÃO}

A importância do petróleo na sociedade atual é indiscutível. Automóveis, aviões e navios se utilizam de derivados de petróleo para sua propulsão. De fato, os hidrocarbonetos presentes no petróleo são matérias-primas para muitos produtos como, por exemplo, plásticos, combustíveis e tecidos sintéticos.

No Brasil há um histórico bastante relevante quanto à extração de petróleo de bacias localizadas no subsolo oceânico (offshore). A tecnologia para perfuração de poços de extração de petróleo no fundo dos mares vem se desenvolvendo há algumas décadas e vários recordes de profundidade foram seguidamente batidos pela Petrobras. Em 1977 o recorde de produção offshore era de 124 m de profundidade (THOMAS, 2001). Já em 1998, foi alcançada a marca de 1853 m, estabelecendo um novo recorde mundial na época. Hoje se fala em produção em águas ultra-profundas, o que pode significar uma medida em torno de 2000 m a 3000 m de lâmina de d'água. Essas profundidades propõem novos desafios, que demandam um desenvolvimento tecnológico cada vez maior para tornar possível a exploração comercial dos campos petrolíferos. Com o descobrimento de reservas de petróleo no pré-sal anunciado nos últimos anos, os problemas se tornam ainda mais desafiadores. No desenvolvimento da tecnologia para resolver tais problemas se enquadram diversos estudos relacionados a sistemas de exploração de petróleo.

Uma unidade de produção de petróleo apresenta, basicamente, uma plataforma na superfície do mar, que pode ser fixa no solo ou flutuante, um sistema de tubos para transporte de fluidos da plataforma ao fundo do mar e também no sentido oposto, cabos de comando hidráulico e elétrico, além de um conjunto de válvulas localizado no fundo mar que conectam os tubos de transporte de fluido. Esse conjunto de válvulas é denominado "árvore de natal".

As plataformas de petróleo, nas quais os tubos de transporte de fluidos e os cabos de comando são fixados, podem se apresentar de formas bastante distintas. Dependendo das condições de mar e lâmina d'água em que a unidade será instalada podem se tornar 
viáveis diferentes concepções de plataforma, flutuantes ou fixas, tais como:

- Jaqueta (Figura 1.1): esse tipo de plataforma é fixa no fundo do mar. Possui uma estrutura metálica semelhante a uma torre. É utilizada em situações de profundidade baixa, de até poucas centenas de metros. É o tipo mais simples de plataforma, porém possui baixa aplicabilidade para águas profundas.

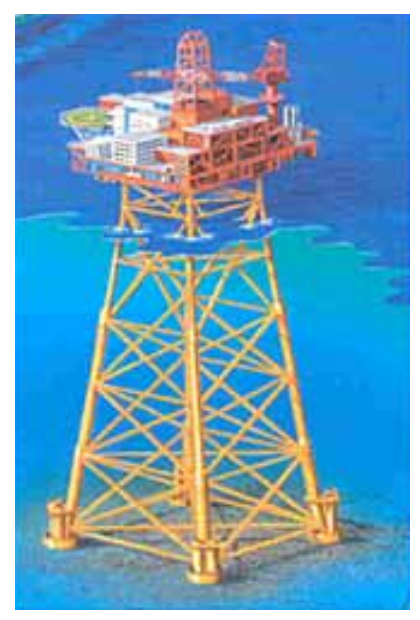

Figura 1.1: Plataforma do tipo jaqueta. Imagem disponível em (TWI TECHNOLOGY AND ENGINEERING, 2011).

- Semi-submersível (Figura 1.2): possui colunas apoiadas em flutuadores submersos e sua posição é mantida por um sistema de ancoragem (com cabos e correntes). Pode possuir também um sistema de controle, com propulsores localizados no casco. Apresenta bom grau de mobilidade, o que é bastante interessante para quesitos de perfuração, também podendo ser utilizada nessa função.

- Tension leg platform - TLP (Figura 1.3): plataforma muito semelhante à semisubmersível, porém seus movimentos verticais são restritos pela ação de tendões prétensionados instalados, com objetivo de fixar a plataforma ao fundo do mar. Esses tendões também contribuem para a restauração da plataforma em seu movimento horizontal. O custo inicial é elevadíssimo quando comparado a outros modelos. É utilizada em regiões como o Golfo do México.

- Floating production storage and offloading - FPSO (Figura 1.4): inicialmente surgiu como uma solução de adaptação de navios para operarem como plataformas. A principal vantagem desse sistema é a alta capacidade de armazenamento de óleo. A principal desvantagem é o movimento induzido às tubulações que transportam óleo e gás do fundo do mar para a superfície que, em geral, atinge amplitudes mais 


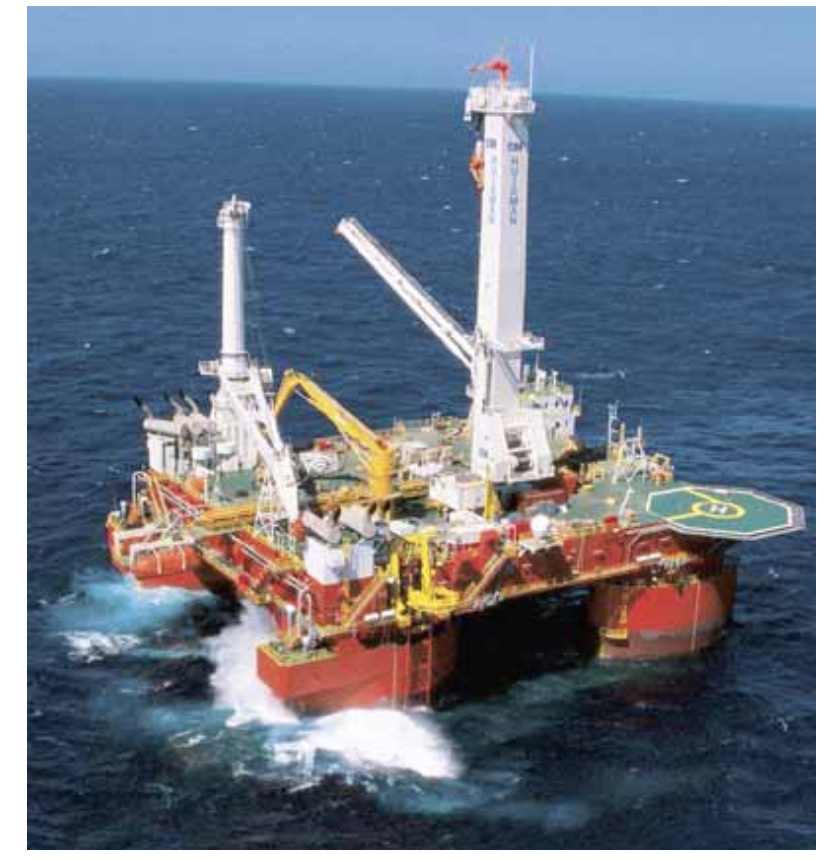

Figura 1.2: Plataforma do tipo semi-submersível. Imagem disponível em (MARINE LOG, 2010).

elevadas do que outros tipos de plataforma. Isso ocorre pois o movimento é regido pelo comportamento hidrodinâmico do navio, que pode ter movimentos de maior amplitude do que os outros tipos de plataforma. Podem ser utilizadas bolinas para atenuar alguns desses movimentos.

- SPAR (Figura 1.5): plataforma formada por um grande cilindro vertical imerso no mar, mantendo sua estrutura presa por linhas de amarração. Essa estrutura procura reduzir movimentos verticais, minimizando os esforços hidrodinâmicos provenientes das ondas de superfície. No entanto, devido à sua geometria, apresenta problemas de vibração induzida por vórtices (VIV). Por isso, são colocados supressores de vórtices em sua superfícies externa. A Figura 1.5 ilustra uma plataforma SPAR com um exemplo de supressor utilizado, denominado strake.

Em uma unidade de produção de petróleo existem vários elementos que podem ser vistos como cabos submersos. Quando essas estruturas são utilizadas para transporte de fluidos, são denominados tubos (rígidos ou flexíveis). Quando forem estruturas para acionamento eletro-hidráulico ou por fibra óptica de mecanismos ou válvulas submersas, bem como transmissão de sinais ou potência, são denominadas cabos umbilicais. Existem, ainda, outros tipos de estruturas como mangueiras e linhas de ancoragem, que também podem ser categorizadas como "cabos submersos". 

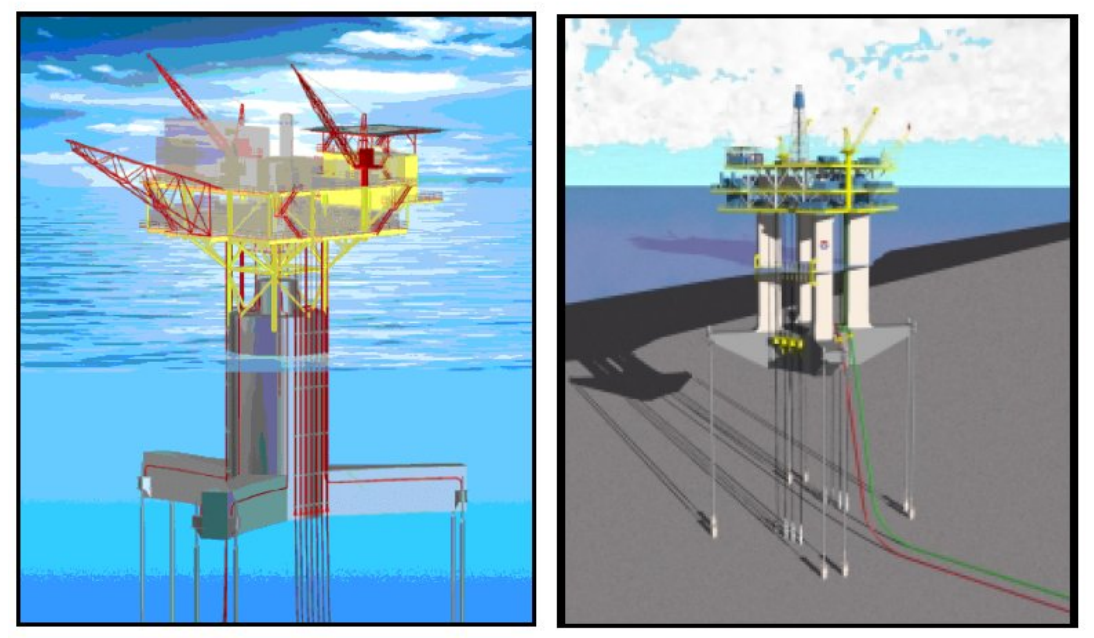

Figura 1.3: Plataforma do tipo TLP. Imagem disponível em (GLOBAL SECURITY, 2010b).

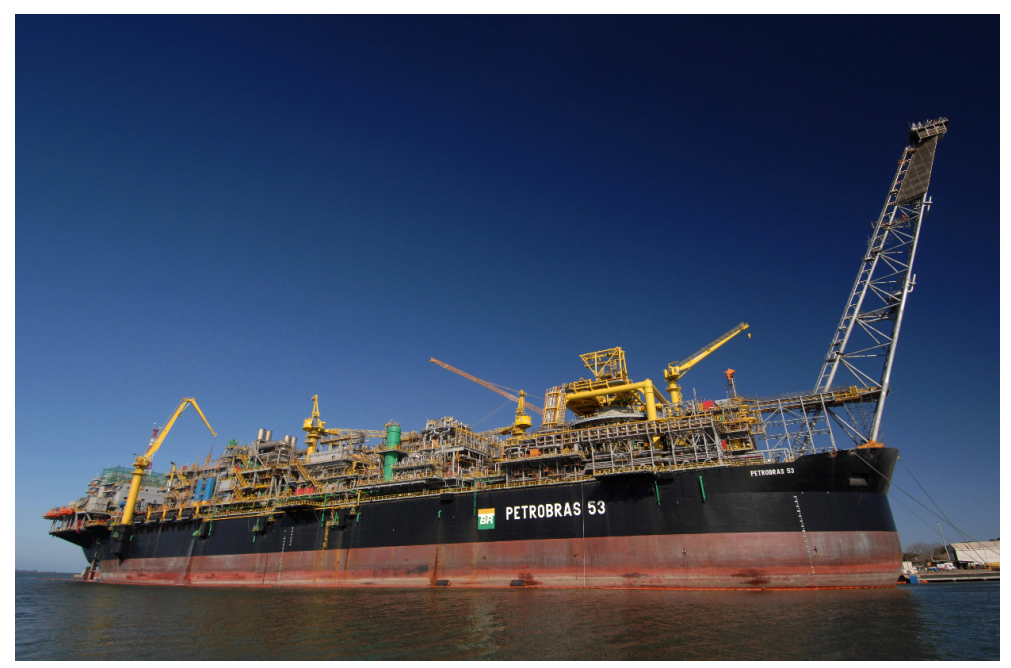

Figura 1.4: Plataforma do tipo FPSO. Imagem disponível em (PETROBRAS, 2010).

As tubulações que se destinam ao transporte de fluidos como petróleo bruto ou gás natural bem como os cabos umbilicais podem se localizar assentados no fundo do mar (flowlines) ou suspensas entre o fundo do mar e a unidade flutuante (risers). Nesse trabalho, em muitos momentos será feita referência a uma classe geral incluindo tanto tubos como cabos umbilicais, tanto sua parte assentada no solo do fundo do mar como a parte suspensa. A nomenclatura utilizada em todo o texto para se referir a esse tipo de estrutura será, simplesmente: risers.

Risers podem se apresentar em diversos tipos de configurações geométricas, como mostram Patel e Seyed (1995). Em algumas delas, aparecem flutuadores que buscam reduzir os esforços de tração e, tirantes, para limitar movimentos. Uma configuração de riser muito utilizada no Brasil é a catenária (free hanging). Nessa, o riser é mantido tracionado, estando submetido ao seu peso próprio e fixo no topo. No entanto essa 


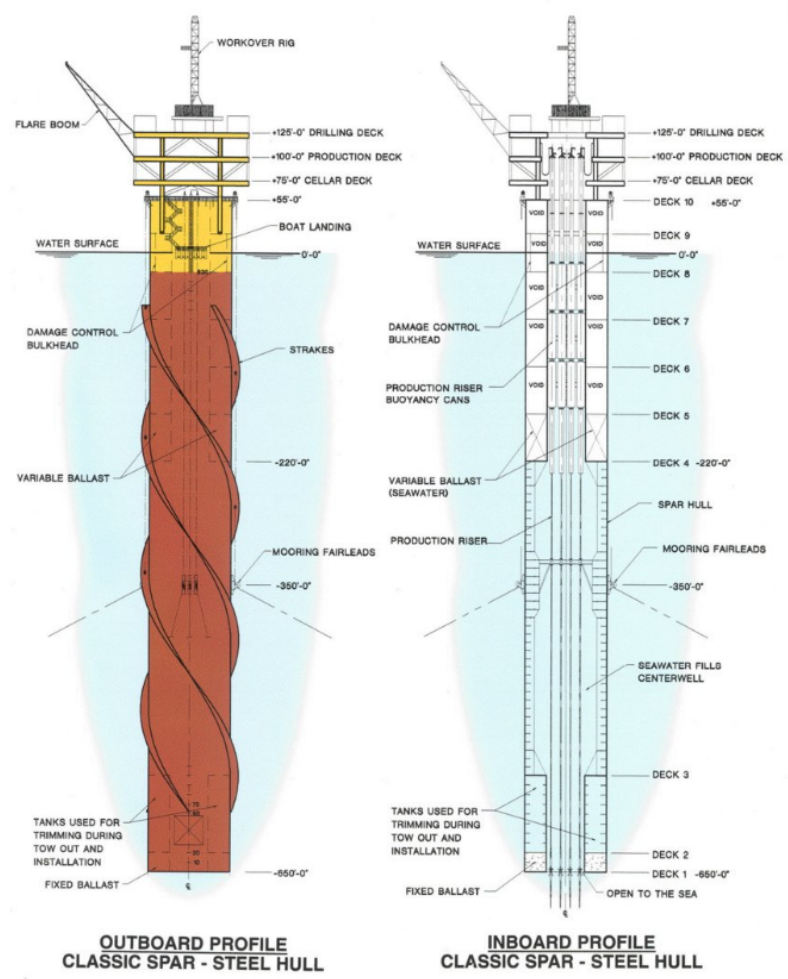

Figura 1.5: Plataforma do tipo SPAR. Imagem disponível em (GLOBAL SECURITY, 2010a). configuração pode se tornar inviável para águas ultra-profundas, quando existem grandes movimentos da plataforma de produção. Nesse caso, devem ser consideradas configurações alternativas, como a lazy-wave, na qual existem flutuadores distribuídos ao longo da porção intermediária do riser. A Figura 1.6 traz alguns exemplos dessas configurações.

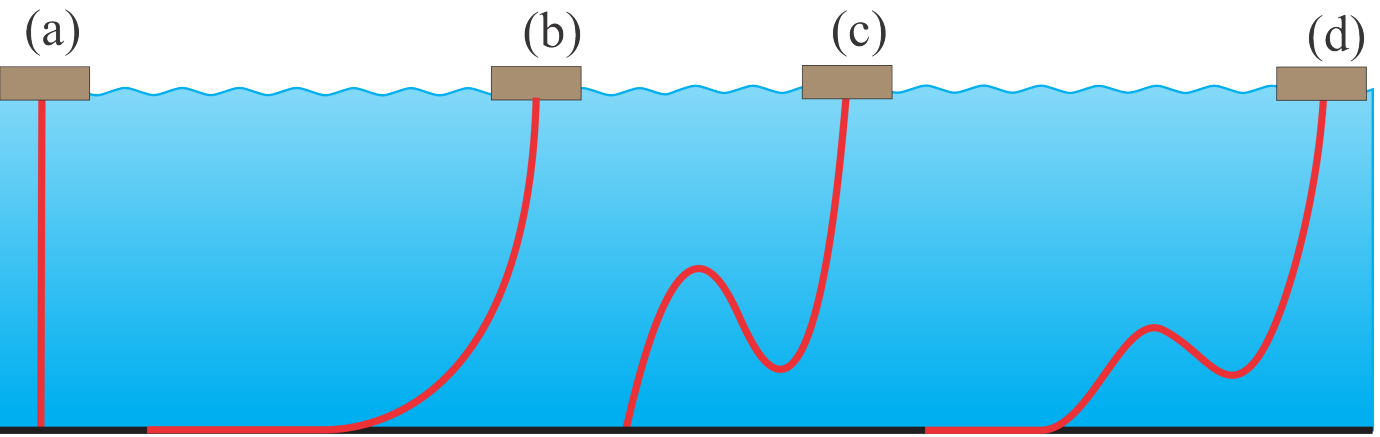

Figura 1.6: Diferentes concepções de configurações de risers. (a) Vertical (b) Catenária (c) Steep-wave (d) Lazy-wave

Os tipos de risers mais comuns são os seguintes:

- Tubos rígidos: são tubos de aço utilizados para transporte de petróleo. O nome "rígido" é dado uma vez que são muito mais rígidos do que outra concepção de tubos 
que será apresentada a seguir:

- Tubos flexíveis: tubos compósitos, formados por diversas camadas, cada qual responsável por funções específicas. Possuem detalhamento geométrico muito mais complexo do que o dos tubos rígidos. Algumas de suas camadas são enroladas de forma helicoidal e, outras, são extrudadas em sua direção axial. Possuem rigidez flexional muito mais baixa do que os tubos rígidos, uma vez que muitas de suas camadas são intertravadas. A Figura 1.7 ilustra um exemplo de tubo flexível.

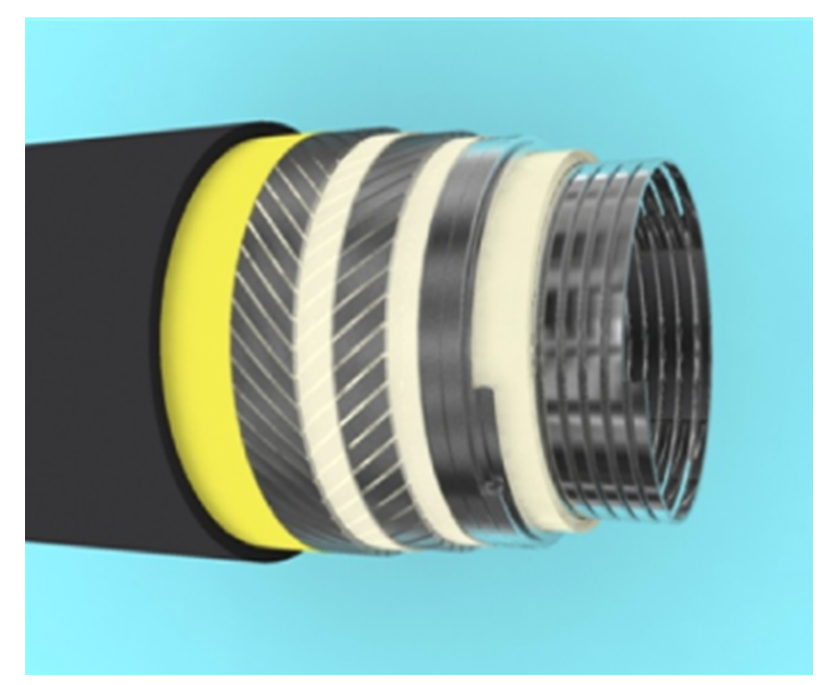

Figura 1.7: Exemplo de concepção de tubo flexível. Fonte: Tanque de provas numérico da USP.

Algumas camadas que compõem tal tubo estão mais detalhadas na Figura 1.8. De dentro para fora do tubo tem-se: a carcaça intertravada, que tem a função de servir de caminho para o escoamento interno, e deve resistir à pressão externa sem colapsar no caso de falha da barreira externa. Em seguida, encontra-se a barreira de pressão interna, que garante a estanqueidade do tubo sendo uma camada plástica. Temse também as armaduras de pressão que suportam pressões interna e externa ao tubo, bem como carregamentos de esmagamento durante sua instalação. Mais para fora, encontram-se as armaduras de tração, que garantem a rigidez axial, bem como algumas fitas anti-desgaste entre essas armaduras. Por último, encontra-se uma camada polimérica mais externa, servindo de proteção a todo o sistema.

- Cabos umbilicais: são conexões existentes entre a plataforma e o fundo do mar, contendo mangueiras para injeção de fluido e controle hidráulico, bem como cabos elétricos para transmitir comandos para mecanismos localizados no fundo do mar. Existem diversas concepções diferentes de cabo umbilical, dependendo do requisito do número de funções desejadas. Alguns exemplos estão ilustrados na Figura 1.9. 


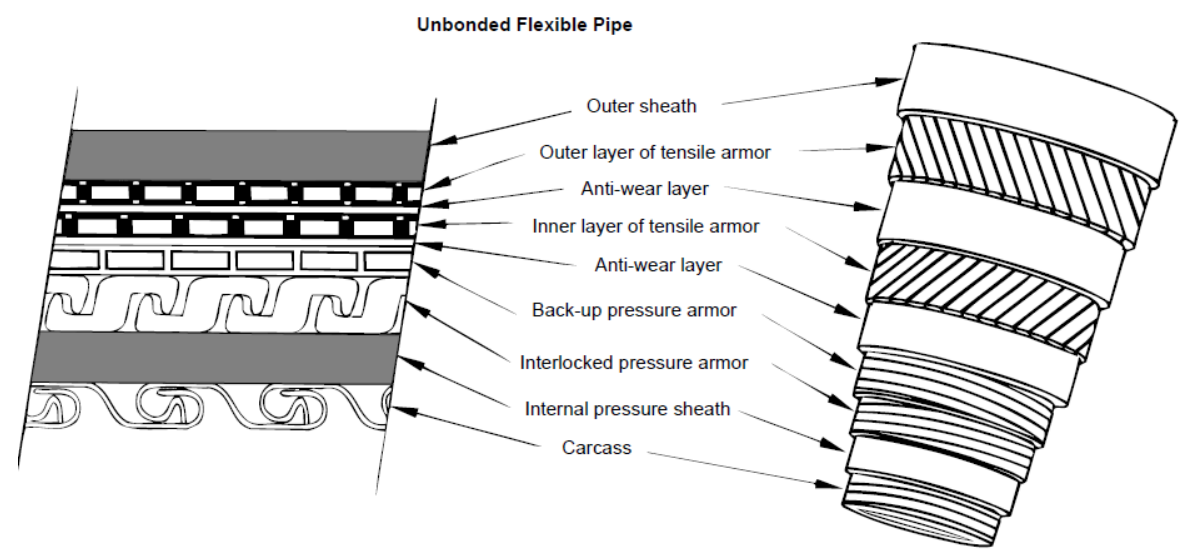

Figura 1.8: Camadas de um exemplo de tubo flexível. Extraído de (API, 2002)

Durante a instalação, risers em catenária ficam pendurados em um navio instalador, podendo atingir ângulos de topo bastante próximos de $90^{\circ}$ em relação ao plano horizontal (ver Figura 1.10).

O nível de tração nesse tipo de situação se torna bastante reduzido em algumas regiões do riser, principalmente nas proximidades do início de sua região de contato com o solo, denominada touchdown zone (TDZ). Algumas situações de baixa tração, ou até mesmo compressão, combinadas com torção no riser, podem ocasionar a formação de laços (loops). Esse fenômeno é conhecido na literatura como hockling. Segundo Rosenthal (1976), o fenômeno hockling ocorre quando a tração em um cabo se torna insuficiente para sustentar uma reação vincular de torque aplicada nas suas extremidades. Nessa situação, pode haver folga axial e a formação de um laço. Em uma situação de retomada da tração no cabo o laço pode ter seu nível de curvatura aumentado, possivelmente causando uma dobra (kink), ocasionando uma falha estrutural. Segundo Liu (1975), é necessário que haja torque nos cabos para que se forme a dobra. Ele enfatiza a pergunta: de onde vem o torque para causar esse tipo de falha estrutural?

Tubos flexíveis e cabos umbilicais apresentam armaduras de tração externa, responsável por prover rigidez axial à estrutura. Essas armaduras geralmente são construídas aos pares, com ângulos de enrolamentos opostos a fim de estabelecer o completo balanceamento, isto é, a não tendência de giro axial quando se aplica um esforço de tração no riser (ver Figura 1.8). Apesar dessa preocupação estar presente no projeto desse tipo de estrutura, todo riser sempre apresenta certo grau de desbalanceamento por imperfeições de manufatura. Ao sofrer esforços de tração, portanto, o mesmo tende a girar em torno de seu próprio eixo. Se o riser estiver livre para girar, não haverá acúmulo de torque em sua estrutura. No entanto, caso não apresente liberdade de giro, haverá acúmulo de momento 


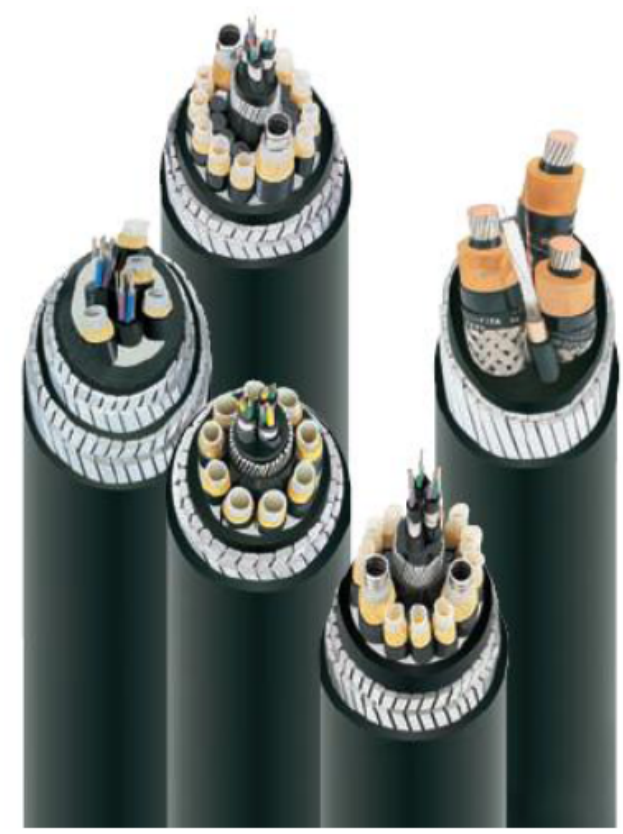

Figura 1.9: Exemplo de concepções de cabos umbilicais. Disponível em (PRYSMIAN CABLES AND SYSTEMS, 2010)

de torção ao longo de seu comprimento. Esse tipo de situação pode ocorrer durante sua instalação principalmente quando há restrição às rotações nas extremidades do riser que está sendo instalado. Nessas condições, o giro da estrutura em torno de seu próprio eixo axial que aliviaria o torque não é permitido.

Além disso, movimentos de rotação (yaw) da plataforma ou do navio instalador podem ocorrer durante a instalação do riser, provocando em algumas situações um acréscimo de momento de torção ao longo do riser. Assim, o desbalanceamento devido à própria concepção de tubos flexíveis e cabos umbilicais, bem como movimentos das unidades flutuantes podem causar uma distribuição de momento de torção nessas estruturas, facilitando a ocorrência de laços e abrindo a possibilidade da formação de uma dobra quando o laço procura se desfazer. O mesmo tipo de fenômeno pode ocorrer em linhas de amarração, bem como em cabos de aço utilizados para içar estruturas da superfície ao fundo do mar, durante instalações. As Figuras 1.11 e 1.12 mostram a formação das dobras que podem surgir nesses cabos, em experimentos realizados.

Ermolaeva, Regelink e Krutzen (2008) afirmam que a formação de um laço não necessariamente implica a formação de uma dobra, especialmente se as condições permitirem a re-abertura do laço, situação em que em geral não há danos permanentes à estrutura, uma vez que não ocorrem raios de curvatura muito pequenos. No presente trabalho optou-se por seguir a mesma linha de Ermolaeva, Regelink e Krutzen (2008): 


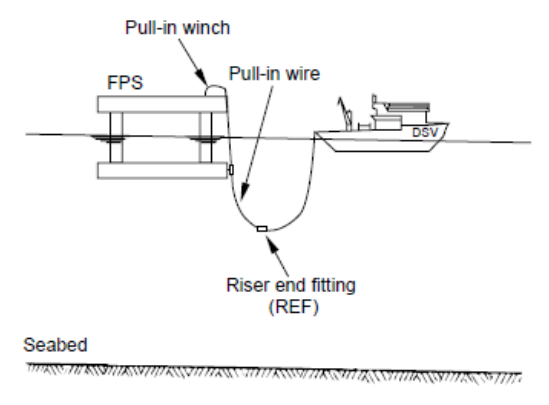

1. Pull-in riser end fitting (REF)

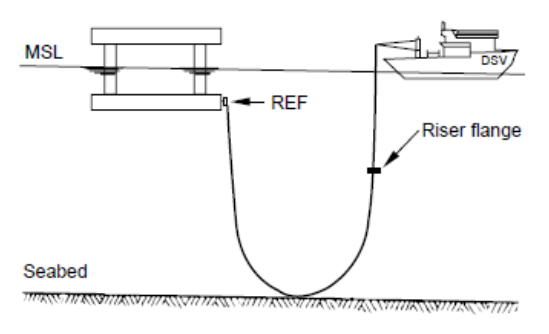

3. Overboard riser lower end flange

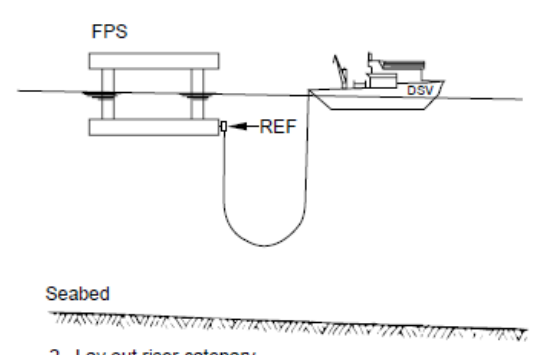

2. Lay out riser catenary

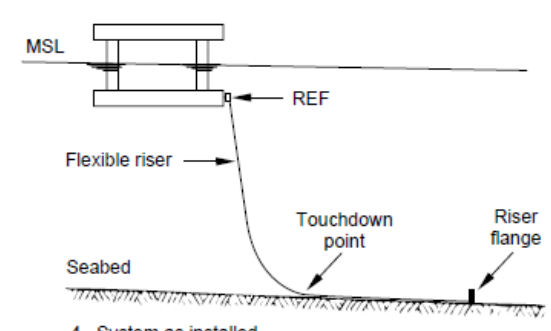

4. System as installed

Figura 1.10: Esquema de instalação de um riser em catenária. Extraído de API (2002)

por razões de segurança, a formação do laço não é desejada e pode ser estabelecida como um critério de falha, uma vez que nessa situação se abre a possibilidade da ocorrência de uma posterior dobra. Assim, procura-se prever as condições de formação de um laço, a fim de evitá-las durante a instalação e operação de risers, garantindo que a formação de dobras também não ocorra.

A maior parte dos trabalhos encontrados na área de estabilidade de cabos sob condições de tração, compressão e torção se referem ao cabo inicialmente retilíneo. No trabalho de Rosenthal (1976) o estudo da estabilidade de cabos inicialmente curvos é apontado como um tópico de interesse para trabalhos futuros. Ainda, mais recentemente, Ermolaeva, Regelink e Krutzen (2008) fazem a hipótese de que o critério para a formação do laço em um cabo inicialmente retilíneo é válido para prever a mesma formação em um cabo curvado na forma de catenária.

É exatamente nesse contexto que surge o tema do presente trabalho: existe a necessidade de se entender melhor o mecanismo de formação de laços em risers inicialmente curvos. A situação real de instalação de uma configuração de catenária apresenta sempre curvatura e, de modo geral, curvaturas bastante elevadas próximas do ponto de início de contato com o solo - touchdown point (TDP). Procura-se esclarecer até que ponto é válida 


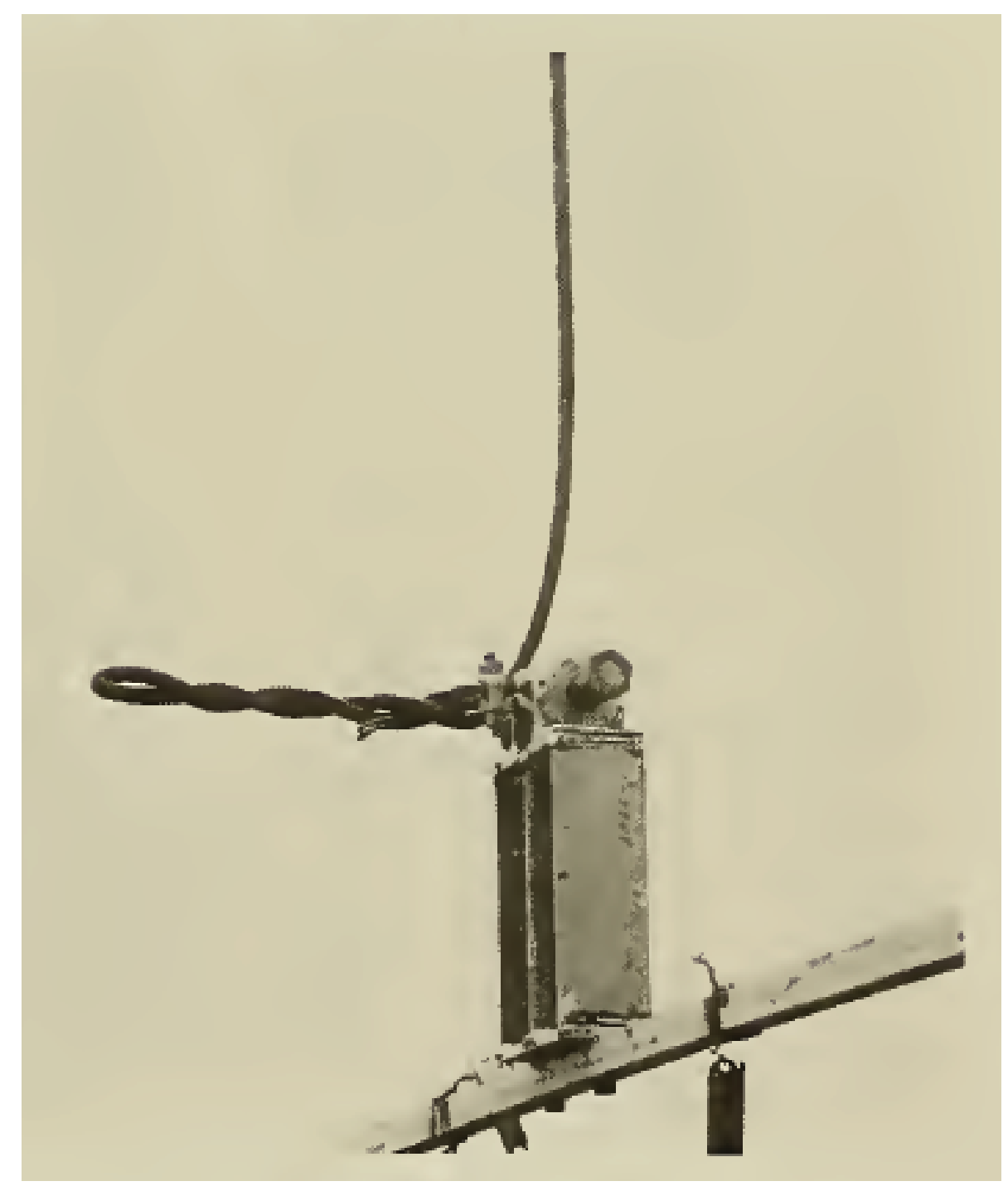

Figura 1.11: Formação de dobra em um cabo. Extraído de (LIU, 1975)

a hipótese de que a previsão de formação de um laço em um riser em catenária pode ser feita como se a estrutura fosse retilínea. Para tal, o presente trabalho apresenta um estudo da influência de diversos fatores na previsão da formação de um laço em configurações de catenária, como o ângulo do topo do riser, o contato unilateral e o atrito com o solo, o efeito da pressão hidrostática externa causada pela coluna d'água presente no problema, bem como a existência de correntezas marítimas durante a instalação.

Para poder fazer esse estudo, foi necessário avaliar os possíveis critérios de estabilidade estrutural segundo a ocorrência das diversas influências citadas anteriormente. Para de fato modelar o problema, utilizou-se uma teoria estrutural de pórticos espaciais que considera a cinemática exata do ponto de vista de grandes rotações e translações no espaço. Essa teoria foi escolhida para tratar de forma correta o movimento das subsequentes seções transversais do riser em situações que poderiam propiciar a formação de 


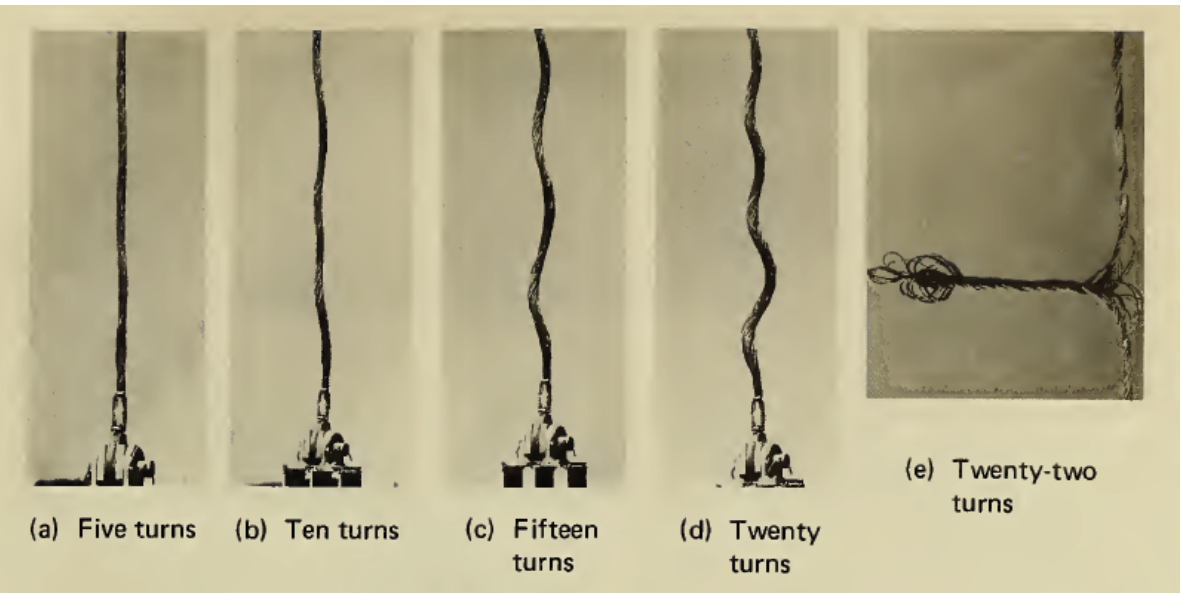

Figura 1.12: Estágios da formação de dobra em um cabo. Extraído de (LIU, 1975)

laços, sem aproximações geométricas na magnitude das grandezas cinemáticas envolvidas. Com isso, pôde-se estudar o problema e compará-lo com outras abordagens simplificadas, a fim de extrair a essência da causa da formação de laços em configurações de risers em catenária.

O texto está organizado em capítulos, da seguinte forma:

Introdução : É apresentada uma introdução sobre o assunto, o que são risers, tipos de plataformas de petróleo, o contexto e a motivação do presente trabalho.

Revisão bibliográfica : É feita uma revisão bibliográfica sobre análise global de risers, bem como sobre o estudo de estabilidade de vigas sob tração/compressão e torção. Embora esse capítulo seja intitulado "Revisão bibliográfica", não é o único do texto que contém revisões de trabalhos anteriores. Em outros pontos, quando conveniente, faz-se uso de breves revisões bibliográficas específicas para as áreas de discussão locais do texto.

Estabilidade estrutural da configuração estática de risers em catenária : Um estudo teórico de problemas de estabilidade estrutural é apresentado, enfatizando as diferentes formas de abordar um problema de estabilidade, dependendo do tipo de carregamentos e vínculos presentes. Uma discussão mais direcionada é feita em relação aos esforços presentes no problema da configuração estática de uma catenária.

Modelo estático : É apresentado o modelo estático desenvolvido para a aplicação em estabilidade de risers. Apresentam-se as hipóteses do modelo, bem como sua formu- 
lação completa, tanto a teoria estrutural como a aproximação da solução utilizandose o Método dos Elementos Finitos (MEF).

Resultados e análises : São apresentados os resultados das diversas simulações feitas no trabalho, bem como comparações com outras abordagens analíticas/numéricas.

Conclusões : São apresentadas as conclusões do trabalho.

O texto inclui, também, alguns apêndices com os seguintes temas:

Efeito das pressões interna e externa na estabilidade estrutural de um riser : É feita uma dedução de expressões para o cálculo do carregamento devido às pressões interna e externa aos risers. Comparam-se essas expressões com a clássica abordagem de tração efetiva, focando no contexto de análise de estabilidade estrutural.

Teoria de vigas curvas de Love : É mostrada uma dedução simplificada das equações de Love (LOVE, 1944) que servem de base teórica para entendimento do comportamento de vigas curvas.

Flambagem de Euler e Fórmula de Greenhill : São deduzidas algumas expressões clássicas para flambagem de vigas retas, tanto sob compressão como torção. 


\section{REVISÃO BIBLIOGRÁFICA}

Na literatura referente à modelagem de risers é possível identificar duas escalas distintas de análise estrutural:

- Escala global: a modelagem nessa escala visa a descobrir qual a posição e quais os movimentos do riser, bem como os esforços solicitantes que ocorrem em cada seção transversal. É empregado um cenário de carregamentos externos relevantes para a análise. A distribuição de tensões em cada seção transversal não é detalhada, porém são identificados os valores dos esforços solicitantes ao longo da elastica. A determinação de uma ou mais seções transversais críticas, bem como suas solicitações, podem servir de dados de entrada para uma análise em escala local. Uma análise em escala global será denominada nesse texto simplesmente como "análise global".

- Escala local: visa a descobrir a distribuição de esforços em uma dada seção transversal do riser. Essa escala privilegia o detalhamento da seção transversal, porém, perde o detalhamento global, uma vez que é necessária a escolha de um conjunto de esforços solicitantes para realizar uma análise local. Quando se trata de tubos flexíveis, ainda é possível realizar o estudo de modos de falha de camadas específicas, como colapso da carcaça intertravada, explosão da armadura de pressão, esmagamento do núcleo estrutural do riser, dentre outros, caracterizando diversos tipos de análise local. Alguns tipos de análise local ainda são capazes de prever valores de rigidez axial, flexional e à torção para risers de seção transversal complexa. Uma análise em escala local será denominada nesse texto simplesmente como "análise local".

Ambas as escalas se complementam, uma vez que para realizar uma análise local, é necessário saber quais são os esforços solicitantes que atuam na seção transversal de interesse, obtendo-os através de uma análise global. Entretanto, para realizar uma análise global são necessários os dados de rigidez do riser, obtidos através da análise local. 
A análise de uma configuração de riser envolve não somente o cálculo das solicitações estruturais mas também o estudo dos escoamentos interno e externo atuantes. Para o estudo do efeito do escoamento do fluido externo sobre o riser geralmente as variáveis de interesse são coeficientes de arrasto, coeficientes de sustentação, bem como o desprendimento de vórtices no escoamento. Já no escoamento interno, o interesse seria no estudo do escoamento das frações multifásicas presentes no fluido, bem como as perdas de carga que ocorrem no transporte do óleo e gás no interior de tubos rígidos ou flexíveis.

A análise estrutural está acoplada com a análise de fluidos para o problema de risers, uma vez que ocorre interação entre o fluido e a estrutura. Um típico exemplo de acoplamento entre o escoamento externo e a estrutura é a vibração induzida por vórtices (VIV - vortex-induced vibration). Nesse tipo de fenômeno o desprendimento de vórtices no escoamento externo induz um movimento no riser. O desprendimento de vórtices pode ocorrer de maneira alternada promovendo na estrutura um carregamento periódico. Essa forçante possui um período característico e pode induzir um movimento vibratório na estrutura.

A interação entre o riser e o escoamento interno também pode ser relevante. Um fenômeno conhecido como "golfada" diz respeito a variações no escoamento interno multifásico. As diferentes massas específicas dos fluidos envolvidos no escoamento causam variações da massa específica do sistema tubo + fluido no decorrer do tempo. Esse fenômeno pode causar um esforço alternado na estrutura do riser.

Com base nos diferentes esforços e efeitos envolvidos em uma configuração de riser, é possível separar sua análise estrutural em uma parte estática e outra dinâmica.

A análise estática considera os carregamentos estáticos existentes em um riser, como o arrasto hidrodinâmico devido às correntezas marítimas, modelado como uma força constante no tempo em cada seção transversal do riser, o peso próprio submerso da estrutura, a imposição de ângulos de topo devido à existência de enrijecedores de flexão em posições especificadas e a imposição de vínculos cinemáticos, como o solo do fundo do mar. Não são considerados na análise estática carregamentos que variam no tempo, como por exemplo o movimento induzido pela unidade flutuante no topo do riser. Assume-se que todos os carregamentos são inseridos de uma forma quase estática, ou seja, efeitos inerciais não são relevantes. Assim sendo, todos os carregamentos e restrições impostas são considerados como independentes da variável temporal. Segundo Cook (1995), no caso de carregamentos cíclicos, essa hipótese é provavelmente válida quando a frequência da aplicação do carregamento é menor do que cerca de um terço da menor frequência 
natural da estrutura. Quando essa condição não é obedecida é necessário realizar uma análise dinâmica.

Na análise dinâmica é possível incorporar todos os carregamentos presentes na análise estática e, adicionalmente, inserir carregamentos que dependam do tempo, como por exemplo:

- Imposições de movimento do topo do riser, podendo ser modelados como harmônicos ou aleatórios. Surgem devido ao movimentos transmitido pela unidade flutuante, submetida a efeitos hidrodinâmicos lineares e não lineares

- Efeitos inerciais na estrutura do riser

- Efeitos de amortecimento hidrodinâmico do riser

Mourelle (1993) afirma que linhas de ancoragem e risers frequentemente possuem períodos naturais na mesma faixa das ondas do mar. Isso torna o estudo dinâmico algo estritamente necessário no projeto de um riser. No entanto, o modelo estático pode ser utilizado como um ponto de linearização do modelo dinâmico, como feito em vários trabalhos, como por exemplo em Martins (2000).

O presente trabalho tem seu foco na estabilidade estrutural da configuração estática de um riser em catenária. Trata-se de uma abordagem que envolve a análise global do riser e a verificação de sua estabilidade. Por isso, a seguir serão apresentadas duas seções de revisão bibliográfica: a primeira voltada à análise global de risers do ponto de vista de como modelar o problema e, a segunda, em relação à estabilidade de risers, vigas ou cabos sob condição de tração, compressão e torção.

\subsection{Análise global de risers}

A modelagem global de risers pode ser feita através da abordagem diferencial, na qual se escrevem equações diferenciais utilizando uma série de hipóteses e, posteriormente, integra-se o sistema de equações obtido. Essa integração pode levar a soluções analíticas ou numéricas e, no caso de sistemas mais complexos, pode ser feita através do MEF. Por se tratar de formas bastante distintas de modelar o problema, uma revisão bibliográfica separada será apresentada para cada uma dessas frentes. 


\subsubsection{Abordagem diferencial}

A obtenção de soluções analíticas para o problema de um riser, primeiramente sob hipótese de cabo (que considera rigidez flexional nula) pode ser vista em diversas referências clássicas que contêm a solução da catenária. O modelo de cabo pode ser escrito em uma equação diferencial, cuja solução depende da componente horizontal da tração no cabo, de sua massa por unidade de comprimento e das condições de contorno. Essa solução representa uma primeira aproximação para um problema de risers em catenária. As limitações existentes são que o riser deve ser tratado como perfeitamente inextensível (rigidez axial infinita), com rigidez flexional e à torção nulas e com carregamento uniformemente distribuído, devido a seu peso próprio. Estando esse riser fixado em suas extremidades, a solução para a elastica é uma curva denominada catenária, do latim, catena, que significa "corrente".

No entanto, a rigidez flexional, axial e à torção são bastante importantes em alguns tipos de problemas, como para o estudo de estabilidade estrutural da configuração de catenária, quando há possibilidade de formação de laços. Assim, a solução analítica com as hipóteses anteriormente mencionadas não é suficiente para todos os propósitos de uma análise de uma configuração de riser. Existem outras possibilidades de soluções analíticas, por exemplo, abordadas por Pesce (1997), através da inclusão de termos de rigidez flexional e, em alguns casos, a correnteza marítima. No entanto a solução analítica se torna cada vez mais complexa e difícil de ser obtida quando são inseridos mais efeitos na modelagem.

Em risers na forma de catenária o efeito da rigidez flexional é relevante somente nas vizinhanças de algumas regiões que apresentam altas curvaturas, como o TDP. O topo do risers também geralmente é uma região de grande interesse prático, pois o nível de tração é bastante elevado. Geralmente um enrijecedor de flexão é instalado no topo dos risers para limitar a curvatura nessa região em que são conectados com a unidade flutuante. Em configurações do tipo lazy-wave o efeito da rigidez flexional se pronuncia bastante também nas regiões de transição de segmentos diferentes do riser, ou seja, de trechos que possuem diferentes pesos efetivos por unidade de comprimento ${ }^{1}$.

Uma vez que a solução de cabo não inclui o efeito da rigidez flexional, ainda que esse seja importante somente em regiões limitadas, essas são de grande interesse prático, dada a magnitude de curvatura ou tração que ocorre em seu entorno. Assim sendo, é

\footnotetext{
A.

${ }^{1} \mathrm{O}$ conceito de peso efetivo e uma discussão mais ampla sobre o tema são apresentados no Apêndice
} 
importante que se estabeleça de alguma forma um cálculo da influência da rigidez flexional na solução do modelo de riser. Isso pode ser feito de duas formas:

- através de uma correção na solução de cabo, através da técnica da camada limite, com um procedimento analítico/numérico;

- através da integração numérica da equação diferencial, incluindo o termo da flexão.

A correção da solução de cabo pode ser vista em Aranha, Martins e Pesce (1997), quando os autores apresentam a solução para a região em que a flexão é importante em risers, através da técnica da camada limite. Nessa publicação, mostra-se que o fenômeno da flexão é bastante importante em uma escala limitada que depende essencialmente do valor da rigidez flexional e da força de tração no riser. Nas regiões em que a tração é muito baixa, a escala de influência da rigidez flexional é maior. Isso é típico na região do TDP de um riser em catenária. Os autores obtêm a solução da equação para a região de influência da rigidez flexional através de métodos assintóticos. Ainda é obtida uma expressão matemática que permite prever a curvatura dinâmica do TDP, quando aplicada ao riser uma tração oscilatória, levando em conta efeitos não lineares provenientes da interação de contato entre o riser e o solo. No artigo de Pesce, Aranha e Martins (1997) além da expressão analítica para a correção da rigidez flexional, também é mostrado o resultado comparativo desse modelo com ensaios experimentais, a fim de validá-lo.

A solução estática para o modelo de risers é apresentada de forma muito interessante em Pesce (1997), em que o autor parte das equações de Love e relações constitutivas lineares elásticas e simplifica-as para diversos casos de interesse conceitual, a fim de interpretar os efeitos físicos dominantes no problema. São apresentados a solução de catenária, a solução assintótica de um riser no plano, com ação de correnteza, bem como um estudo do efeito da rigidez do solo no valor da curvatura estática dos risers. Ainda a solução de camada limite estática é obtida a partir das equações de Love.

Quando se lida diretamente com a equação diferencial do problema completo, sem trabalhar com soluções assintóticas, se for incluído o efeito da rigidez flexional, a solução analítica não pode mais ser obtida para a maioria dos casos. É necessário recorrer a integrações numéricas da equação diferencial.

Um exemplo de modelo estático 2D de risers tratado na forma diferencial é proposta por Martins (2000). O autor apresenta um conjunto de equações diferenciais que regem o comportamento de um riser bidimensional com rigidez flexional não nula. Assim sendo, fica proposto um problema de condição de contorno a ser resolvido integrando-se 
o sistema de equações. É utilizado o Método de Runge-Kutta com passo adaptativo em função da curvatura do riser, uma vez que um passo de integração menor é requerido em regiões em que ocorrem grandes variações na curvatura do riser. A solução da integração da equação diferencial foi apresentada por Silveira e Martins (2004) e comparada com a solução dada pela técnica da camada limite.

Em Silveira e Martins (2004) é apresentada uma técnica para integração numérica do sistema de equações diferenciais que rege o problema de um cabo, incluindo o efeito da rigidez flexional. O sistema de equações se torna numericamente difícil de resolver em problemas práticos em que o valor da rigidez flexional é pequeno, uma vez que o termo cuja derivada é mais elevada na equação diferencial se torna pequeno, podendo ocasionar problemas numéricos na integração. Silveira e Martins (2004) comentam que esses erros numéricos dificultam muito a integração do sistema de equações diferenciais do modelo estático. A dificuldade numérica reside no fato de que, se resolvido algebricamente, o problema de contorno em que a flexão é dominante (através do método da camada limite) resulta em uma soma de funções exponenciais com expoentes positivo e negativo. Impondo-se as condições de contorno, a exponencial com termo positivo não ganha influência na solução final do problema. No entanto, ao integrar-se o problema de contorno numericamente, pode haver coeficientes muito pequenos multiplicando uma exponencial positiva, ocasionando em divergência de solução, uma vez que a função cresce muito rápido. Para solucionar essa dificuldade numérica, os autores propõem uma abordagem de solução em que a integração é feita por trechos do riser, minimizando o efeito de erros numéricos a domínios mais restritos. Basicamente, tudo é feito como se fossem resolvidos diversos problemas de contorno sequenciais no domínio do comprimento do riser, limitando o erro numérico de cada trecho a seu próprio domínio. A técnica se mostrou eficaz para integração de modelos de catenária e lazy-wave, tendo boa correlação com as soluções de camada limite, utilizando as expressões desenvolvidas em Aranha, Martins e Pesce (1997).

Não apenas problemas estáticos e dinâmicos de risers já instalados devem ser analisados. Durante a instalação também cabem questionamentos sobre a posição e os esforços solicitantes presentes no riser. Deseja-se, adicionalmente, predizer a posição do TDP, trações na linha, distribuição de curvatura, etc. Um interessante trabalho que contempla análise 3D de cabos durante sua instalação é o de Vaz e Patel (2000). Cabos marítimos são analisados quando sujeitos a correntezas arbitrárias. Através de uma formulação que envolve dois ângulos para descrição da posição do cabo, que são os ângulos azimutal e inclinação, o método abordado envolve a integração direta da equação diferen- 
cial do problema, utilizando-se para tal do método de Runge-Kutta, de ordens 4 e 5. São incluídos nas equações do problema os efeitos do peso próprio, arrasto normal e tangencial, arrasto binormal, forças de inércia, bem como efeitos de inércia adicional hidrodinâmica. A formulação desenvolvida não inclui efeitos de rigidez flexional ou à torção do riser. $\mathrm{O}$ modelo construído é bastante rápido em termos de processamento e os autores até mesmo comentam sobre sua possibilidade de uso em tempo real, em campo, durante a instalação dos risers.

Outra contribuição para o estudo do problema sob a ótica da integração direta da equação diferencial é o trabalho de Santos (2003), em que os modelos de Martins (2000) são generalizados para o caso 3D, porém sem inclusão do efeito da rigidez flexional. Para incluir esses efeitos, Santos (2003) realiza a correção da solução do modelo estático e dinâmico através da técnica da camada limite, porém enfatiza a dificuldade do método quando aplicado ao modelo 3D. A solução da camada limite 3D deve ser feita numericamente e, segundo o autor, o sistema de equações diferenciais apresenta elevada dificuldade de convergência numérica. Santos (2003) apresenta também um modelo de atrito baseado no modelo de Coulomb, para solos infinitamente rígidos.

A extensão do trabalho de Santos (2003) foi feita por Takafuji (2010), em que a autora procurou desenvolver um modelo dinâmico com a mesma abordagem diferencial, porém, concluiu ser algo bastante laborioso, uma vez que as equações se tornaram extensas, pois várias parcelas deixaram de se cancelar. Assim sendo, optou por realizar o modelo utilizando-se do MEF. O modelo desenvolvido apresentou muito boa correlação com o software ORCAFLEX ${ }^{\mathrm{TM}} 2$. Além disso, implementou-se no código próprio desenvolvido um modelo de contato com o solo que incluiu os efeitos de sucção e trincheiras, com análises interessantes qualitativas sobre esses fenômenos.

\subsubsection{Abordagem utilizando o MEF}

Uma publicação interessante da década de 1980-1990 é a de Patel, Sarohia e Ng (1984). Os autores comentam características de simulações de risers marítimos através do MEF. O trabalho aborda apenas problemas bidimensionais e inclui nas análises efeitos de peso próprio da estrutura, empuxo e pressões interna e externa ao riser. Efeitos de carregamentos hidrodinâmicos como correnteza marítima e ondas também são incluídos nos modelos.

\footnotetext{
${ }^{2} \mathrm{O}$ ORCAFLEX ${ }^{\mathrm{TM}}$ é um programa de computador especializado em análise de risers, havendo a possibilidade da inclusão de diversos efeitos estáticos e dinâmicos na análise. Detalhes sobre algoritmos, bem como métodos de solução desse programa podem ser vistos em seu manual do usuário (ORCINA, 2009)
} 
Os autores apresentam modelos tanto estáticos como dinâmicos e, quanto à resolução dos modelos dinâmicos, tanto no domínio do tempo como no domínio da frequência. Na época dessa publicação não era prática a simulação de muitos casos tridimensionais de problemas desse tipo. O objetivo final das análises e modelos montados é análise de fadiga de risers. Por isso, fala-se de algumas possíveis configurações de risers para minimizar o nível de tração no topo, como é o caso das configurações lazy-wave e lazy-S. No modelo de elementos finitos são utilizados elementos de viga 2D com 3 graus de liberdade por nó, sendo dois de translação e um de rotação. Quanto aos esforços hidrodinâmicos, é utilizada a Fórmula de Morison (ver ítem 4.4.9.3).

Como a expressão da força de arrasto é proporcional à velocidade ao quadrado, é utilizada uma técnica de linearização igualando-se o trabalho realizado pelo esforço de arrasto linearizado e pelo esforço não linearizado, obtendo dessa forma um coeficiente de arrasto equivalente, para ser utilizado no modelo linearizado. Essa abordagem é feita no domínio da frequência para o trabalho de Patel et al. Conclui-se no trabalho sobre algumas limitações do método do domínio da frequência empregado, que perde a informação da fase da sequência de ondas aplicada, ocasionando numa descrição inexata da ciclagem de tensões que ocorrem no riser, dificultando um bom resultado de uma posterior análise de fadiga. Outra diferença citada é sobre a diferença nos picos de tensão que surgem nas análises no domínio do tempo e da frequência. Os autores atribuem as diferenças ao erro cometido na linearização do amortecimento hidrodinâmico.

Um detalhamento maior sobre o problema do amortecimento hidrodinâmico pode ser encontrado em Takafuji e Martins (2007). Em primeiro lugar é apresentada uma forma semelhante à do trabalho de Patel, Sarohia e Ng (1984), igualando-se a energia dissipada por ciclo no modelo linear e no modelo não-linear. A seguir, propõem um procedimento iterativo para o cálculo da velocidade relativa utilizada para o cálculo do amortecimento. Essa forma iterativa é feita através da equação de equilíbrio dinâmico do problema. Takafuji e Martins (2007) detalham, por fim, diferentes abordagens para obtenção da amplitude de movimento relativo, sendo que esse pode ser para cada nó da malha montada, um único valor por segmento do riser (segmentos de diferentes materiais ou com flutuadores), ou um único valor de velocidade relativa para todo o riser. Quanto à comparação dos resultados com as diferentes abordagens, a que melhor representa a física do problema e apresenta melhores resultados é a primeira. No entanto, é a mais demorada para convergir numericamente.

A busca de uma forma eficaz de linearizar o problema do amortecimento é algo 
que pode interessar muito em termos de projeto de risers, principalmente para as análises realizadas na primeira volta da espiral de projeto. A análise no domínio da frequência é linear, a menos de iterações para a linearização do amortecimento. Esse procedimento é, de modo geral, muito mais rápido do que uma análise no domínio do tempo.

Mais comentários sobre técnicas de linearização do amortecimento hidrodinâmico podem ser encontradas em Patel e Seyed (1995). Os autores apresentam uma retrospectiva até a data de sua publicação dos métodos desenvolvidos para análise de cabos submersos no domínio da frequência. É citado o método de Langley, que basicamente consiste em realizar uma linearização estatística da força de arrasto para mares multi-direcionais ou unidirecionais. O método impõe a minimização do erro utilizando-se de uma média quadrática na representação de uma força não linear, através de uma linear.

O’Brien e Mcnamara (1989) apresentam as principais características físicas relevantes nos modelos de risers em catenária. A abordagem para resolução do modelo físico é através do método dos elementos finitos, utilizando-se elementos de viga tridimensionais, com efeito de rigidez axial inclusa. São apontadas as principais dificuldades que surgem no tratamento numérico do problema, como:

- As diferentes ordens de magnitude entre os valores de rigidez axial e flexional, ambas importantes no problema, podendo resultar em sistemas de equação mal condicionados

- Grandes rotações de corpo rígido presentes, sendo necessária a utilização de diversos sistemas de referência para localizar no espaço cada elemento. Conceitos como sistema de coordenadas global, do elemento, e dos nós surgem para a descrição do problema

- A estrutura apresenta diversas faixas de frequências naturais e, portanto, um largo espectro. Por isso, pode ser necessário um procedimento de passo de integração temporal variável, a fim de não estender desnecessariamente o tempo computacional de uma simulação

- O contato entre o riser e o solo do fundo do mar que influencia muito a configuração geométrica do riser, tanto em aspectos estáticos como dinâmicos, principalmente em casos de correntes marítimas transversais ao plano original do cabo e quando ocorre grande movimento da unidade flutuante

O’Brien realiza análises no domínio do tempo, com o programa FLEXCOM- 
$3 \mathrm{D}^{\mathrm{TM}}$, que se utiliza dos modelos citados no artigo. Citando o modelo do solo utilizado por esse software, o mesmo funciona através de imposição de deslocamentos (condições de contorno). Para tratar o atrito, são incluídos dois tipos de modelo, sendo um para a componente transversal e, outro para a componente axial do riser. Quanto ao algoritmo de marcha temporal para integração do problema, é utilizado o método HHT.

Um artigo relevante que traz uma vasta revisão bibliográfica sobre modelagem de risers flexíveis e técnicas de análise é o de Patel e Seyed (1995). É feita uma revisão sobre diversos trabalhos na área de análise estática, explicando as ideias e algoritmos de solução dos problemas que foram surgindo no decorrer do tempo. Uma especial atenção, na parte estática, é dada ao caráter não linear presente nas equações do problema, principalmente pelos grandes deslocamentos existentes como pela restrição de contato com o solo. É apresentado o método incremental de solução de problemas não lineares que, basicamente, consiste em aplicar carregamentos passo a passo e, a cada iteração, atualizar a rigidez do modelo. Em uma abordagem de MEF, esse método representaria a atualização da matriz de rigidez e a inserção de novos incrementos de carregamento, até que o total desejado seja atingido. Também são comentados alguns trabalhos nos quais são desenvolvidas algumas soluções estáticas analíticas para modelos de cabos. O artigo também aborda a parte de análise dinâmica, relatando as práticas mais comuns para modelagem dinâmica de risers, tanto no domínio da frequência, como no domínio do tempo.

Mais recentemente, Low e Langley (2006) apresentam um artigo em que desenvolvem um código próprio para resolver a dinâmica de risers flexíveis em catenária, tanto em abordagem no domínio do tempo como no domínio da frequência. É utilizado o MEF não-linear para modelagem do domínio espacial do problema. A consideração da rigidez flexional é feita através de molas rotacionais equivalentes, localizadas nos nós. O modelo não inclui efeitos de correnteza marítima, torção, interação do riser com o solo, vibração induzida por vórtices e efeitos de pressão interna da tubulação. É utilizado o algoritmo de integração Wilson- $\theta$ para a resolução do problema no domínio do tempo. São apresentados diversos resultados de estudos de caso, e é feita uma comparação com o programa comercial ORCAFLEX ${ }^{\mathrm{TM}}$. Os autores concluem que o método de integração temporal Wilson- $\theta$ é bastante robusto e preciso para aplicações típicas de engenharia offshore, incluindo efeitos de ondas marítimas. Ainda se conclui que efeitos de interação riser-solo que não foram inseridos no modelo devem ser tratados posteriormente.

Esse tratamento foi feito por Takafuji (2010), que apresenta modelos dinâmicos para interação entre riser e solo, incluindo efeitos de sucção e trincheiras, além do vínculo 
de contato unilateral e da força de atrito. Elementos de viga 3D são utilizados para a representação do riser. O solo é considerado como flexível, e são dadas faixas típicas de rigidez de solo, sendo esse arenoso ou argiloso.

Um outro trabalho que se mostra bastante interessante é o de Kordkheili e Bahai (2007). Esse envolve simulações tridimensionais de cabos submersos utilizando o MEF não linear, porém não com elementos de viga, como classicamente os risers são representados, mas com elementos de tubo com 24 graus de liberdade cada. Ainda é inserido um modelo de interação entre o tubo e o solo. Esse é baseado em resultados experimentais e impõe esforços de sucção no tubo, quando esse se move para cima, tentando se afastar do solo. Também são considerados efeitos de empuxo, peso próprio da estrutura e carregamento da correnteza marítima.

Muitos trabalhos apresentam o método de resolução de problemas no domínio temporal como o mais exato, pois permite a captura de transientes, e mares aleatórios de maneira bastante satisfatória. Porém, um grande problema que surge ao resolver um modelo global de riser, sujeito a esforços de natureza aleatória é o tempo computacional excessivo para realização das análises. Uma abordagem diferente para procurar otimizar a resolução de problemas de risers pode ser encontrada em Guarize et al. (2008). Os autores falam sobre uma técnica híbrida para resolução de problemas no domínio do tempo, que inclui a utilização de um procedimento acoplado do MEF e de redes neurais. Basicamente a técnica é demonstrada como uma alternativa para reduzir muito o tempo computacional de uma análise no domínio do tempo quando estão envolvidos efeitos aleatórios nos carregamentos. Consiste em resolver, primeiramente, para um dado modelo de riser, uma análise utilizando-se o MEF não linear, com carregamentos de uma imposição de movimento no topo. Com o resultado dessa análise, alimenta-se uma rede neural que, busca parâmetros para montar um modelo equivalente e que seja mais eficiente, para resolver o mesmo problema. Uma vez estabelecidos os parâmetros da rede neural, são inseridos os carregamentos aleatórios, e a resolução a partir de então é feita não mais com o modelo de MEF, mas com o gerado pela rede neural.

O artigo apresenta um estudo comparativo entre dois casos práticos - uma catenária e uma configuração lazy-wave. Ambos foram simulados no programa ANFLEX e também foram simulados através da técnica proposta de redes neurais. Os resultados são excelentes, e com uma redução bastante significativa de tempo computacional. Porém, o método possui limitações. Como o comportamento de cada riser instalado pode apresentar diferentes não linearidades, é necessário que cada caso seja analisado primeiro uma 
vez pelo MEF e, somente depois utilizado o novo modelo gerado pela rede neural.

\subsection{Estabilidade de cabos e risers sob torção, com- pressão e tração}

O problema de estabilidade de vigas em situações de compressão e torção é um assunto que começou a ser estudado formalmente no século XIX. A teoria de vigas de Love permitiu o estudo de situações combinadas de carregamentos de forças e momentos. As conhecidas equações de Kirchhoff-Clebsh-Love, ou simplesmente equações de Love permitem o estudo de configurações de vigas espaciais, apresentando uma analogia com as equações do movimento de um pião, de tal forma que é possível estudar o comportamento de uma viga no espaço através da analogia direta com um sistema dinâmico. No século XIX, o matemático Love trabalhou com o assunto de torção, definindo a denominada torção de Love. Em sua obra é citado o trabalho de Greenhill (ver Apêndice C). A obra de Love (1944) é uma referência clássica para o estudo de vigas curvas. O Apêndice B apresenta um resumo da teoria de vigas curvas de Love, bem como a sua definição de torção.

Muitos dos trabalhos que serão citados a seguir possuem sua base nessa teoria de vigas curvas, apresentando modelos bastante interessantes envolvendo a tridimensionalização da elastica de vigas sob compressão ou tração e, também, submetidas à torção.

Procura-se, a seguir, descrever alguns trabalhos tanto teóricos como experimentais sobre a estabilidade de cabos e risers sob condições de formação de laços.

Liu (1975) apresenta um estudo analítico e experimental sobre a formação de laços em cabos eletromecânicos com múltiplos arames. O autor motiva seu estudo no torque residual que surge em cabos quando tracionados sem a liberdade de eliminação do torque. Nessas situações pode ocorrer a formação de laços, ocasionando posteriormente a formação de dobras (kinking). Um modelo analítico é apresentado para a estimativa do limiar da formação do laço, o qual é baseado na Fórmula de Greenhill. O autor apresenta uma explicação sobre o mecanismo da formação de laços em cabos tracionados, resumido por: o processo da formação do laço é mais complexo do que a flambagem de uma viga com comprimento curto. Para a viga, tanto a compressão axial como o torque tendem a acelerar a falha. Uma vez que existe uma excentricidade inicial criada pelo torque, a compressão pode ocasionar por si só a flambagem. Isso não ocorre para cabos sob tração. Nesses casos, a tração atua como moderador do efeito de excentricidade inicial causado pelo torque no cabo. Assim, momentos de torção maiores são necessários para causar a 
formação de laço, ou hélice. Conforme o torque aumenta, vai-se exigindo mais do momento da força de tração, que busca equilibrar e manter o sistema em sua configuração antes de flambar. Existe um valor máximo para tal equilíbrio. Ao ser atingindo e ultrapassado, haverá uma formação de um ou mais laços. Uma hipótese feita pelo autor para realizar a comparação entre os resultados experimentais e analíticos é acerca do valor da rigidez à torção $(G J)$ e da rigidez flexional $(E I)$ do cabo. O valor de $G J$ é calculado com base em suas medições experimentais e, o valor de EI é estimado através da relação entre o momento de inércia $I$ e o momento polar de inércia $I_{p}$ (segundo a notação do autor), supondo que $I=I_{p} / 2$. Um resultado relevante de Liu (1975) e citado em vários outros trabalhos é a curva mostrada na Figura 2.1, com as comparações de seus experimentos com o modelo analítico.

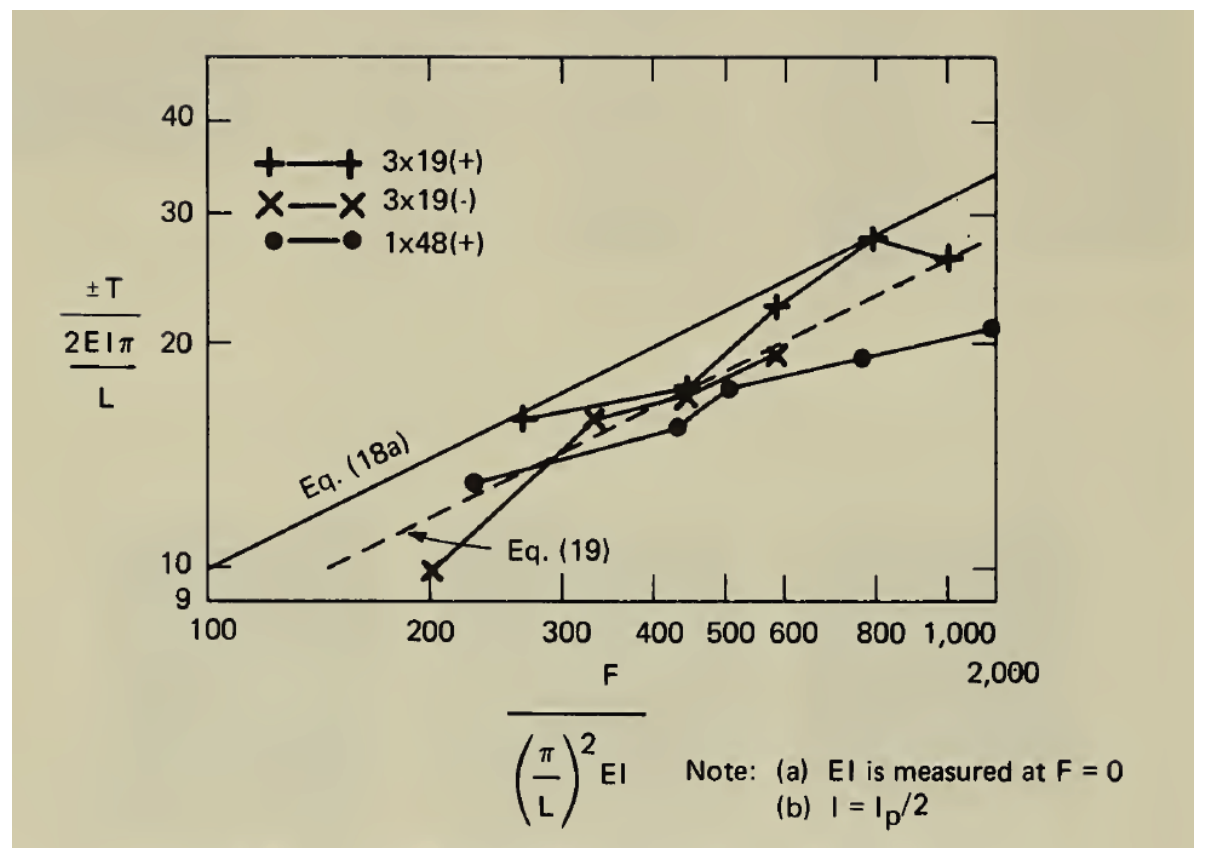

Figura 2.1: Curva adimensional de critério de formação de dobra para alguns modelos de cabos eletromecânicos. Extraído de Liu (1975)

A equação referida na Figura 2.1 como (18a), que se refere à condição crítica de formação do laço, relaciona o torque crítico $T_{c}$ com a tração crítica $F_{c}$ e é dada por:

$$
F_{c}=\frac{T_{c}^{2}}{4 E I}
$$

A fórmula empírica mostrada por Liu (1975) para ser utilizada como critério de formação de dobra, referida como equação (19) na Figura 2.1, é dada por: 


$$
F_{c}=\frac{3 T_{c}^{2}}{8 E I}
$$

Rosenthal (1976) apresenta um estudo envolvendo a solução das equações de Love (ver Apêndice B) para diversas condições de carregamentos combinados por forças axiais e momentos de torção aplicados nas extremidades de uma viga. Com as diferentes soluções, constrói um plano relacionando a tração adimensionalizada $\left(\tau=\frac{T L^{2}}{E I}\right)$ e o momento de torção adimensionalizado $\left(\mu=\frac{M L}{E I}\right)$. Nesse plano, são identificadas as parábolas de Greenhill para compressão e tração ${ }^{3}$. Uma das discussões mais importantes da publicação é referente à fórmula de Greenhill, interpretada da seguinte forma: a condição de instabilidade de Greenhill não é apenas um ponto em que inicia a migração de uma solução de pura torção para outra natureza de solução (com flexão). Representa o máximo torque que pode ser aplicado a uma viga, para uma dada tração ou, a mínima tração necessária para suportar um dado torque. Se o torque for aumentado, haverá instabilidade. Em problemas de cabos essa instabilidade deve ser particularmente violenta, uma vez que na situação antes da flambagem toda a energia é armazenada na forma de torção. Com a ocorrência de curvatura na viga, parte dessa energia será transferida para a forma de flexão. Sendo geralmente a rigidez flexional um valor relativamente baixo para cabos é esperado um deslocamento muito maior do que em vigas. No plano $\tau$ vs. $\mu$ ilustram-se três diferentes regiões com comportamentos diferentes em relação à estabilidade. São citados ensaios, como o já discutido de Liu (1975) para investigar a formação de laços em cabos. A conclusão é que cabos longos e inicialmente retilíneos submetidos à tração e torção, de fato se tornam instáveis na situação prevista pela equação 2.1.

Rosenthal (1976) ainda aponta que em aplicações de cabos que sejam inicialmente curvos, nos quais as influências da gravidade e de arrastos são elevadas, a situação é menos clara. Tal estudo é apontado como uma necessidade para um trabalho futuro.

Ross (1977) apresenta uma formulação analítica para a formação de laços em cabos oceânicos. Através de uma abordagem de energia, o autor iguala o trabalho do momento de torção e da força axial em um cabo com a energia de deformação de um laço perfeito, suposto na forma de uma circunferência. Com isso, determina uma equação que caracteriza uma relação entre a tração e o torque para a formação do laço. O autor aponta esse critério como sendo um limite inferior da previsão da formação de um laço, ou seja,

\footnotetext{
${ }^{3}$ As parábolas de Greenhill nada mais são do que a interpretação gráfica da Fórmula de Greenhill, nesse artigo sendo visualizadas de forma adimensionalizada. A dedução da fórmula de Greenhill se encontra no Apêndice C
} 
se essa condição não for atingida, com certeza não se formará um laço. A abordagem é comparada com a de Liu (1975) e Rosenthal (1976), que são descritas por Ross (1977) como limites superiores do problema. O autor ainda compara seus resultados analíticos com os experimentos de Liu (1975).

Yabuta (1984) apresenta uma análise de dobramento e de abertura de dobras em cabos. O autor analisa a formação do laço utilizando-se de uma abordagem de energia de deformação, no entanto, não faz somente a análise do equilíbrio, mas também da estabilidade estrutural, através da definição de um potencial. Quando ocorre a restauração da tração, ou seja, quando se elimina a folga no cabo, o laço pode se desfazer ou pode surgir uma dobra, o que é um problema sério à sua integridade estrutural. O autor faz uma análise de estabilidade de configurações possíveis para o cabo, em situações de recuperação de tração e folga, e chega à conclusão de que são três os parâmetros que regem o fenômeno: a torção inicial no cabo, a razão entre a rigidez flexional e à torção, e o diâmetro do cabo. É apontado que para evitar o surgimento de dobras recomenda-se manter controle sobre a folga do cabo, bem como a razão entre a rigidez flexional e à torção. Os resultados do modelo são comparados com experimentos, embora não se dêem detalhes sobre o aparato utilizado.

Coyne (1990), ao comentar o trabalho de Rosenthal (1976) diz: "Por causa do contorno das vigas serem tratados por Rosenthal como articulações, seus resultados não são diretamente aplicáveis ao caso usual de um cabo no qual atua uma força na direção de sua própria linha ao longe da região de formação do laço." Motivado por essa e outras simplificações feitas em trabalhos anteriores, Coyne constrói uma formulação analítica para análise da formação de laços em cabos devido à folga (slack) existente entre os pontos extremos, bem como a condição de pop-out (abertura do laço) no caso da diminuição da folga. O modelo utiliza-se de ângulos de Euler para descrever a orientação das seções transversais e considera as extremidades do cabo com restrição ao movimento rotativo. O cabo é considerado como sendo inicialmente retilíneo e bastante longo em relação ao tamanho do laço formado. O autor constrói um gráfico relacionando a folga entre os extremos do cabo e a força de tração aplicada em suas extremidades, apresentando um comportamento de mudança de rigidez associada à formação do laço. Ainda é determinada a elastica na condição de pop-out e sua curvatura. O artigo propõe uma expressão analítica para determinação da máxima folga admissível para que não haja formação de um laço no cabo. As expressões encontradas são comparadas com experimentos e boa correlação foi encontrada na predição da formação do laço. No caso da predição da abertura do laço, o número de dados experimentais era reduzido e a correlação com a teoria não foi boa. A 
previsão teórica de abertura do laço se mostrou precoce à abertura observada na prática.

Stump (2000) dá continuidade ao trabalho de Coyne, quando desenvolve um modelo matemático para o tratamento da formação de laços e também da abertura dos mesmos quando há recuperação da elastica original (pop-out). Stump (2000) inclui no modelo as deformações axiais e por cisalhamento, não inclusas no modelo de Coyne. Seus resultados recuperam os de Coyne quando se realiza o limite da rigidez axial e cisalhante muito altas. O autor identifica que os efeitos da extensibilidade e das deformações cisalhantes não se apresentam como importantes para a predição da formação do laço. No entanto, no estudo da abertura do laço, bem como na possibilidade da formação de uma dobra, os efeitos podem diferir cerca de $15 \%$ em relação a modelos que não consideram tais deformações.

Uma contribuição importante referente à formação de laços em cabos, tanto em aspectos teóricos como experimentais é o artigo de Thompson e Champneys (1996). Os autores apresentam um estudo experimental da concorrência entre modos de hélice previstos por Love (1944) (denominados $H_{3}$ ) e modos localizados, previsto por Coyne (1990) (denominados $L_{3}$ ) na flambagem de vigas sob flexo-torção. Um experimento foi feito fixando-se ambas as extremidades de uma viga e, posteriormente, impondo-se deslocamentos e rotações, ou forças e momentos nessa extremidades. Utilizaram-se vigas de borracha, bastante flexíveis, e arames de aço. Trata-se de um aparato capaz de impor deslocamentos ou rotações, havendo condições para a ocorrência de instabilidade estrutural. Os resultados obtidos foram qualitativamente semelhantes para ambos os tipos de materiais ensaiados. Observou-se nos experimentos que os modos de flambagem na forma de hélice $\left(H_{3}\right)$ não foram reproduzidos, enquanto que aqueles localizados $\left(L_{3}\right)$ puderam ser visualizados. Na realidade, o que ocorreu foi a formação de uma hélice prévia e logo depois o surgimento de um modo localizado superposto à hélice. A hélice observada, no entanto, não fora prevista através da teoria de vigas de Love, utilizada na formulação analítica apresentada. Justificou-se essa não previsão por algumas hipóteses, como: algum fenômeno não contemplado pela teoria de vigas utilizada, algo relacionado às condições de contorno e ao comprimento finito da viga, ou ainda algo relacionado à curvatura inicial pelo carregamento do peso próprio, presente nos ensaios. É apontado que o modo de hélice que apareceu não é um modo de flambagem, mas uma solução fundamental perturbada por carregamentos gravitacionais ou curvatura inicial da viga. Os autores, após uma ampla e interessante discussão teórica atrelada aos resultados experimentais, concluem que o modo localizado é energeticamente mais favorável do que o em hélice e, por isso, em nenhum experimento a hélice prevista na teoria foi observada. No experimento 
os carregamentos foram aplicados de forma quase-estática. As variáveis fundamentais de controle foram o deslocamento axial imposto, a rotação imposta na forma de pré-torção da viga, o momento de torção na extremidade da viga e a força axial nesse mesmo ponto. Ainda são discutidas condições de carregamentos para o experimento, uma vez que deve ser utilizado algum parâmetro de controle: o deslocamento imposto (rigid loading) ou a força imposta (dead loading). Dentre os diversos resultados mostrados uma observação é feita: que os comportamentos local, global e quanto à estabilidade de vigas são muito sensíveis a aparentes pequenas mudanças de condições de contorno.

Na mesma linha do artigo discutido anteriormente, Champneys e Thompson (1996) apresentam um estudo matemático sobre a solução localizada obtida por Coyne. É explorada a analogia de Kirchhoff-Love para a equação de vigas curvas e um sistema dinâmico (especificamente, o movimento de um pião). As soluções localizadas de Coyne correspondem a órbitas homoclínicas do sistema dinâmico análogo às equações da viga (nessa analogia, a abscissa $s$ da viga corresponde ao tempo $t$ do sistema dinâmico equivalente). Os autores recuperam através da análise de um problema de Bifurcação de Hopf o resultado da carga crítica já discutido no trabalho de Thompson e Champneys (1996). Ainda é feito um teste acerca da influência da não linearidade do material da viga no comportamento de instabilidade estrutural localizada e é concluído que não existem mudanças qualitativas relevantes devidas às variações das propriedades do material. Sendo o teste feito com um material do tipo softening, o único efeito é uma maior flexibilidade da estrutura no tocante à rotação, mas não há mudanças no comportamento do deslocamento dos extremos da viga em relação à equação constitutiva linear. Ainda, por fim, os autores consideram um caso em que não existe simetria na seção transversal considerada. Esse caso apresenta comportamento muito mais complexo, havendo evidências inclusive de situações caóticas. A analogia com o sistema dinâmico ainda seria explorada em outros trabalhos futuros do mesmo grupo, sendo um assunto de grande interesse para a compreensão do tipo de comportamento mecânico presente na solução localizada (laço).

A investigação acerca das dúvidas geradas no artigo de Thompson e Champneys (1996) sobre a configuração de hélice de 1 giro de torção por passo $\left(H_{1}\right)$, surgida antes da flambagem localizada, foram estudadas no trabalho de Champneys, Heijden e Thompson (1997). Os autores retomam a discussão sobre o tipo de configuração não trivial surgida na forma de hélice, até então não prevista analiticamente através das equações de Love. Para investigar de forma mais profunda o assunto foram desenvolvidos modelos de viga segundo a teoria de Cosserat, possibilitando a inclusão de efeitos cisalhantes não contemplados na teoria de Love. Os autores apontam que, anteriormente, os efeitos não levados em conta 
seriam o peso próprio da estrutura (uma vez que a maioria dos experimentos foram feitos com a estrutura submetida a esse carregamento, sem uma forma de neutralizá-lo através de empuxo, por exemplo), deformações cisalhantes e curvaturas inicialmente existentes na configuração não tensionada da viga (sempre presentes devido à forma de armazenamento das mesmas na forma enrolada em bobinas). As integrações numéricas das equações diferenciais obtidas pelos autores levaram a notáveis conclusões, por exemplo: o efeito do cisalhamento não muda qualitativamente o resultado do parâmetro de carga crítica. Ainda a inclusão de curvaturas iniciais na formulação permitiu interessantes conclusões, por exemplo, a da possibilidade de uma configuração de equilíbrio estável de uma hélice com um passo por giro de torção (o mesmo tipo de configuração obtida nos experimentos publicados em Thompson e Champneys (1996)). Ainda os autores mostram, através da linearização do problema, como varia o parâmetro de carga crítica segundo a variação da curvatura inicial da viga. É notado que, para pequenas curvaturas iniciais, não existe grande influência no valor do parâmetro de carga crítica. No entanto, com o aumento da curvatura inicial existe uma importante diminuição no valor da carga crítica (ver Champneys, Heijden e Thompson (1997), Figura 5). Assim, a ocorrência do fenômeno de instabilidade de vigas com curvatura inicial ocorre com uma configuração em hélice seguida pela formação de um laço localizado.

Ainda seguindo a mesma linha de pesquisa, van der Heijden e Thompson (2000) formalizam uma teoria fundamentada no artigo de Thompson e Champneys (1996). Os autores apresentam a teoria de vigas de Cosserat, bem como sua analogia com um sistema dinâmico. Realiza-se um aprofundamento teórico nos conceitos de torção de uma viga, através dos conceitos de Link, Twist e Writhe. É apresentado o equacionamento para o modo de flambagem de hélice, bem como para o modo localizado, discutido inicialmente por Coyne (1990). Ilustra-se adicionalmente, um resultado experimental de uma viga sofrendo flambagem localizada, porém, com efeito do peso próprio desprezível, pois a mesma fora ensaiada imersa. O resultado foi o direto aparecimento do modo $L_{3}$ (introduzido por Thompson e Champneys (1996)). Não foi observada a formação de uma hélice com um passo por giro de torção $\left(H_{1}\right)$, como nos resultados mostrados em Thompson e Champneys (1996). Assim, os autores concluem que, de fato, esse modo surgiu pela curvatura inicial das amostras ensaiadas por Thompson e Champneys (1996).

Certamente um dos trabalhos de maior relevância sobre o estudo de instabilidades de vigas sob torção e compressão/tração é o de Miyazaki e Kondo (1997). É desenvolvida uma formulação analítica para o problema da elastica espacial, porém indo além das hipóteses das equações de Love. Considera-se, adicionalmente, a influência do cisalhamento no 
modelo de viga, bem como a extensibilidade axial da estrutura. Além disso, é considerada uma formulação de auto-contato para ser levada em conta em situações em que a formação de um laço pode ocasionar um contato da viga com ela mesma. Os autores abordam dois problemas típicos para aplicação de sua formulação: problema de torção-encurtamento (aplicação da torção e posterior imposição de folga em uma viga, com a aproximação de suas extremidades) e o problema de encurtamento-torção (imposição de uma folga na viga através da aproximação de seus extremos e, posteriormente, a prescrição de um ângulo de torção em uma das extremidades). Ambos consideram uma viga inicialmente retilínea, engastada em um extremo e com uma imposição de rotação axial $\phi_{m}$ e de deslocamento axial $\xi L$ na outra extremidade. As rotações nas direções ortogonais à configuração inicial da viga são impedidas nas suas extremidades e o comprimento inicial da mesma é $L$.

- Problema de torção-encurtamento:

Primeiramente se considera o caso com $\phi_{m}=0$. Ao impor um deslocamento axial causando uma folga na viga ocorre flambagem no plano. Trata-se de uma primeira bifurcação. Posteriormente pode ocorrer uma bifurcação secundária, ocasionando a formação de um laço e o surgimento de uma distribuição não nula de momento de torção ao longo da viga. A possibilidade de ocorrência do laço depende da razão entre a rigidez flexional e à torção da viga, sendo que se essa razão for um valor maior do que 0,5 a formação do laço poderá ocorrer. A Figura 2.2 mostra a evolução da elastica de uma viga nesse cenário proposto.

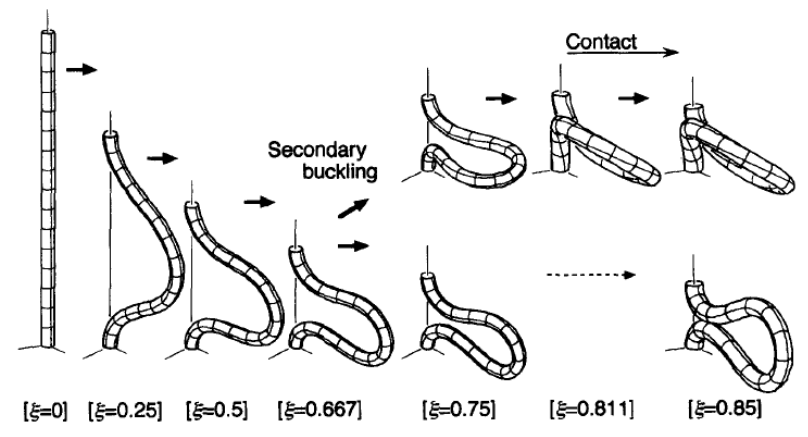

Figura 2.2: Evolução da elastica de uma viga $\operatorname{com} \phi_{m}=0$. Extraído de Miyazaki e Kondo (1997)

Ao considerar $\phi_{m}=2 \pi$ (Figura 2.3), o comportamento será diferente. Em primeiro lugar, a flambagem que irá ocorrer ao impor a folga na viga já será inicialmente 3D. Aumentando a folga imposta, o laço sempre poderá se formar, independente da razão entre os valores de rigidez flexional e à torção. No entanto, essa razão determinará a folga $\xi L$ associada à formação do laço que tornará plano o problema após sua formação (plano 
de formação do laço). Ao procurar retirar a folga axial da viga, é possível a ocorrência de uma solução denominada semi-kinking, que prevê a formação de uma dobra na viga, porém não considera a possibilidade de contato da viga com ela mesma.

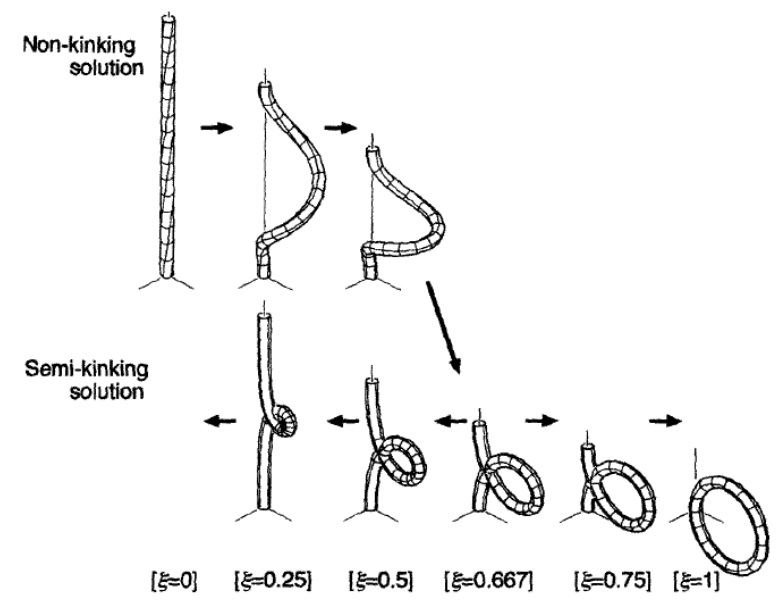

Figura 2.3: Evolução da elastica de uma viga com $\phi_{m}=2 \pi$. Extraído de Miyazaki e Kondo (1997)

Ao considerar um caso com $\phi_{m}=3 \pi$ (Figura 2.4), tem-se um comportamento bastante interessante. Antes da formação do laço, o problema se comporta de forma semelhante ao anterior. Após a formação do laço, ao procurar retomar a viga a sua configuração inicial através da diminuição da folga imposta ocorrerá o contato da viga com ela mesma. A solução do problema considerando essa força de contato é denominada kinking. De fato, nesse tipo de problema ocorrerá uma dobra na viga durante certa faixa do alívio da folga imposta. Quando a dobra se desfaz, a solução com menores valores de curvatura é retomada. Durante o fenômeno, a dobra pode chegar a curvaturas bastante elevadas, antes de se desmanchar, podendo danificar a viga (em situações realistas considerando plasticidade e re-acomodações internas na seção transversal de um riser sofrendo esse tipo de esforço, a dobra pode se acentuar e formar um vinco, inutilizando o trecho da linha envolvido).

A Figura 2.5 mostra a relação entre a tração aplicada nesse último caso, versus $\xi$. Note que inicialmente a solução non-kinking surge, ao iniciar a imposição da folga na viga. Ao atingir certo valor de $\xi$, ocorre a formação do laço. Com isso, pode-se analisar duas soluções possíveis para o problema: a semi-kinking e a kinking. Devido à existência do contato da viga com ela mesma, a solução que surge no problema é a última. Assim, ao incrementar a folga, o laço persiste e, ao procurar retirar a folga, para certo valor de $\xi$ a solução semi-kinking e a kinking coincidem. Esse ponto está associado ao limiar da perda do contato. Se tentar se reduzir ainda mais a folga, voltar-se-á à solução non-kinking. 


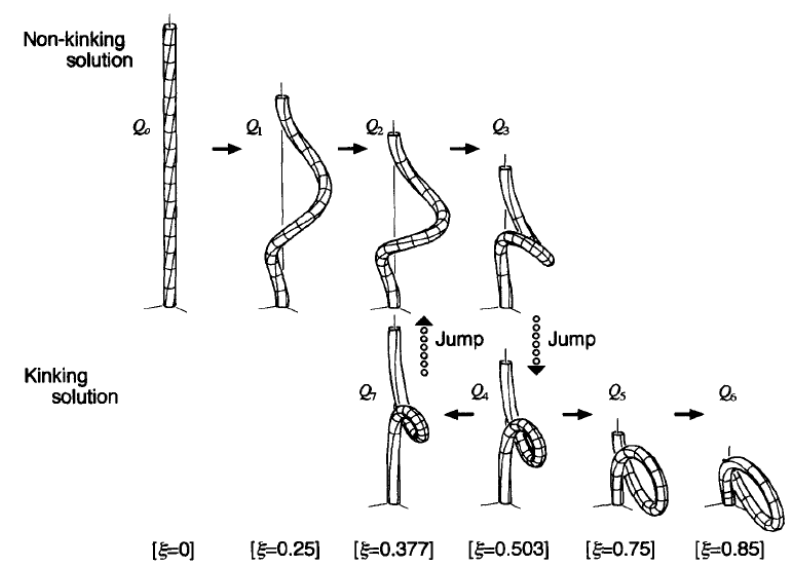

Figura 2.4: Evolução da elastica de uma viga com $\phi_{m}=3 \pi$. Extraído de Miyazaki e Kondo (1997)

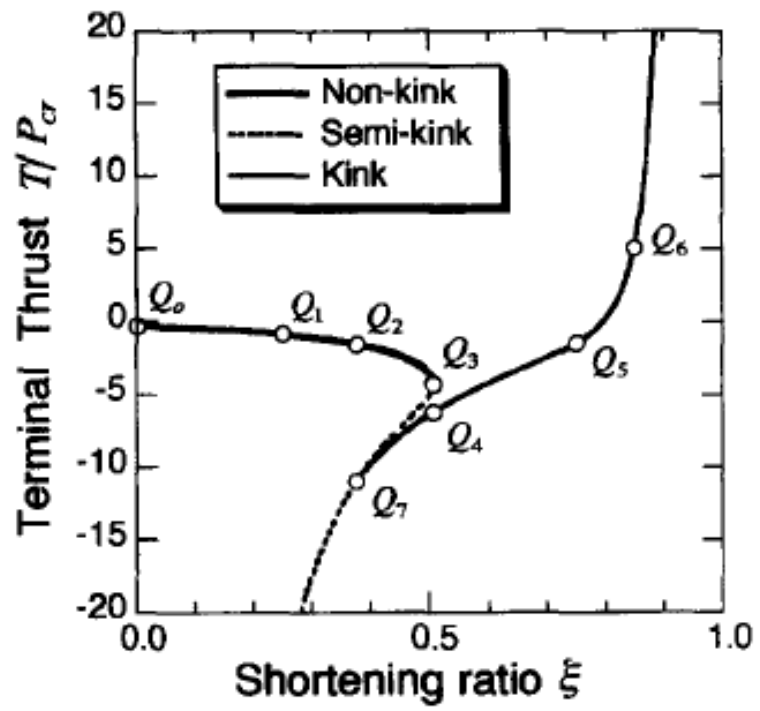

Figura 2.5: Tração aplicada à viga versus $\xi$. Extraído de Miyazaki e Kondo (1997)

- Problema de encurtamento-torção:

A importância da sequência de aplicação dos carregamentos em um problema não linear se evidencia através do estudo do problema em que primeiro se aplica a folga axial da viga e, posteriormente, se aplica um ângulo de rotação $\phi_{m}$. A Figura 2.6 mostra a evolução da elastica nesse problema. Primeiramente, ao impor a folga axial na viga, surge uma primeira bifurcação (flambagem de Euler). Posteriormente, assim como o caso analisado na Figura 2.2, surge uma segunda bifurcação, através da formação de um laço. Ao aplicar uma rotação $\phi_{m}$ em uma extremidade da viga, surge um comportamento do tipo snapdown, dado pelo gráfico exibido na Figura 2.6. Basicamente o laço dá um giro ao atingir os pontos S2 ou $S_{4}$ exibidos no gráfico. O salto que ocorre é dinâmico, e a configuração pós-salto muda bastante em relação à inicial. 


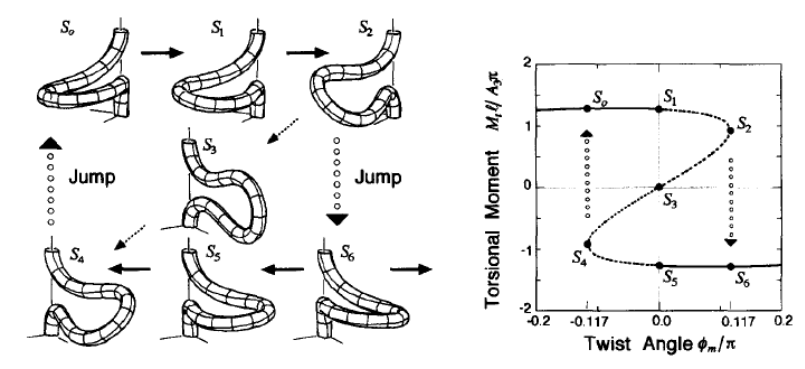

Figura 2.6: Evolução da elastica de uma viga no problema do tipo Encurtamento-torção. Extraído de Miyazaki e Kondo (1997)

Posteriormente, Miyazaki e Kondo (1997) apresentam uma importante contribuição para a literatura sobre esse problema, dada por um completo mapeamento através de uma superfície de soluções do problema de estabilidade, envolvendo as soluções das duas sequências de carregamentos analisadas em um único gráfico. Trata-se da Figura 2.7.

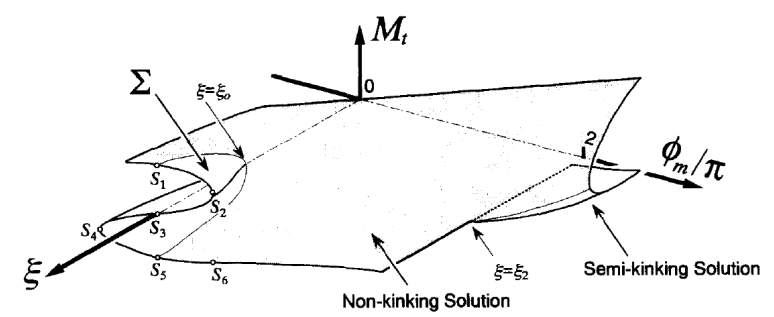

Figura 2.7: Mapeamento das regiões de instabilidade do problema de uma viga com aplicação de uma folga axial e ângulo de torção. Extraído de Miyazaki e Kondo (1997)

Posteriormente Goss (2003) retomou em sua tese o mapa de soluções do problema da viga, através de uma análise das duas diferentes regiões de flambagem apontadas por Miyazaki e Kondo (1997). Goss (2003) apresenta uma rica análise através de modelos analíticos integrados numericamente (Teoria de vigas de Cosserat) e ainda desenvolve importantes experimentos sobre a formação de laços. A análise feita também culminou no artigo Goss et al. (2005). Os experimentos são feitos com barras de uma liga de Níquel e Titânio (Nitinol) com um aparato capaz de aplicar deslocamentos, ou rotações de forma controlada, bem como medir esforços axiais e momentos de torção que surgem na barra. Isso propiciou diferentes tipos de controle de ensaio, como impor deslocamento axial e posteriormente monitorar o momento de torção, segundo um ângulo de torção imposto ou, impor o ângulo de torção e posteriormente impor um deslocamento axial, monitorando a tração na extremidade fixa da barra. Essa versatilidade do aparato utilizado permite recuperar comportamentos apresentados na Figura 2.7. Boa correlação qualitativa e quantitativa é mostrada na maioria dos resultados obtidos, com algumas exceções, relacionadas à carga crítica para ocorrência da flambagem primária nos casos de aplica- 
ção de torção e posterior aplicação de folga axial. O valor estimado analiticamente difere do experimental, na medida que antecipa a ocorrência da flambagem. A discrepância é atribuída pelos autores como sendo devida ao efeito do peso próprio da estrutura, não considerado no modelo analítico, e que poderia postergar o valor da flambagem, uma vez que tende a tracionar a barra. No entanto, a inclusão desse efeito no modelo analítico não foi suficiente para justificar a discrepância. O trabalho deixa em aberto tal questão.

Goss (2003) ainda apresenta um capítulo em sua tese dedicado ao estudo do efeito de movimento do tipo yaw imposto ao topo de configurações de catenária. O objetivo do estudo é uma aplicação da teoria desenvolvida em sua tese, porém, com modificações no modelo matemático, para que possa ser levada em conta corretamente a geometria de uma catenária. O autor, através de simplificações em seu modelo chega na equação da catenária (considerando a rigidez flexional nula) e da elastica pesada (considerando efeitos da rigidez flexional, inclusive com alusões ao efeito localizado nas camadas-limite próximas do topo e do TDP). O trabalho, no entanto, limitou-se à monitoração da tridimensionalidade atingida pela configuração através da monitoração do deslocamento máximo que ocorre para fora do plano em situações de imposição de rotação yaw no topo. Comparações com deslocamentos medidos em experimentos são feitas e boa correlação é atingida. No entanto, a formação de laços e uma análise de estabilidade não foi feita nem através dos experimentos nem do modelo matemático.

Goyal, Perkins e Lee (2008) apresentam uma análise dinâmica sobre a formação de laços em cabos quando submetidos a um momento de torção. Considera-se um modelo de viga de Love, porém, o equilíbrio considera além dos esforços internos e externos, os esforços de inércia. Além disso, é considerado também o contato entre as vigas, que pode ocorrer durante a formação de um laço (self-contact). É mostrado um estudo de caso, de uma viga engastada com a aplicação de um momento em sua extremidade livre, alinhado com sua direção axial inicial. Inicialmente o carregamento causa apenas momento de torção em toda a barra. Após certo nível de carga inicia-se a tridimensionalização da viga e, posteriormente, o surgimento de um laço. Nesse ponto, parte da energia de deformação que era de torção, passa a ser de flexão. Posteriormente, aumentando ainda mais o momento aplicado, ocorre contato da viga com ela mesma e surge uma nova mudança na configuração, uma vez que novas voltas surgem no laço já formado, inclusive aumentando as regiões de contato.

Ermolaeva, Regelink e Krutzen (2008) discutem o comportamento de formação de dobras em cabos formados por arames. O estudo é motivado pelos danos que a dobra pode 
causar, impossibilitando o uso do cabo após sofrer tal avaria. Os autores classificam os danos em cabos em duas categorias: a formação de laços, que podem ocasionar a formação de dobras e, o dano individual dos arames que formam os cabos através do fenômeno de birdcage. Dependendo da tração a que os cabos são submetidos e de suas condições de contorno, eles podem apresentar o surgimento de um torque devido ao desbalanceamento da tração que carrega os arames. Os autores comentam sobre o problema de formação de laços em operações de instalação de componentes offshore, como tubulações. O sistema de instalação transporta para o fundo do mar as peças a serem montadas através de um ou mais cabos. Quando possui um único cabo, o sistema permite eliminar a torção através do giro livre. No entanto, para novos sistemas que são formados por múltiplos cabos fixados em um conector, isso não é possível pela própria concepção do projeto. Em situações de águas profundas, trabalhando-se com níveis de tração mais elevados no topo podem surgir situações com níveis ainda maiores de momento de torção no cabo. Assim, um certo nível de torção fica armazenado nos cabos quando o sistema é tracionado. São apontadas duas situações típicas de falha: com tração nula (devido à folga do cabo) e com tração não nula (segundo a Fórmula de Greenhill). Um possível critério, para evitar a dobra dos cabos, é que não ocorra a formação do laço. O laço já formado, num caso de retomada da tração ou retirada da folga poderia voltar à sua configuração original (cabo retilíneo) ou apertar o laço, formando uma dobra. A fim de evitar a segunda possibilidade, um bom critério é evitar a formação do laço. Ermolaeva, Regelink e Krutzen (2008) fazem uma hipótese bastante forte em seu trabalho: o critério para formação de laços em cabos inicialmente retilíneos é válido para um cabo inicialmente na forma de uma catenária. São feitos experimentos em cabos inicialmente retilíneos, bem como em cabos inicialmente curvilíneos. A maior parte dos experimentos refere-se à imposição de uma folga no cabo e monitoração da formação do laço. Já o ensaio com imposição de tração foi o critério baseado na Fórmula de Greenhill, e não apresentou boa correlação. No entanto, para esse ensaio é possível extrair apenas um único ponto, o que é bastante questionável, uma vez que não é mostrada a repetibilidade do resultado. 


\section{ESTABILIDADE ESTRUTURAL DA CONFIGURAÇÃO ESTÁTICA DE RISERS EM CATENÁRIA}

Nesse capítulo será abordado o estudo de estabilidade de risers em configuração de catenária. O objetivo é estudar as situações em que podem ocorrer instabilidades localizadas, isto é, a formação de um laço em algum ponto do riser. Essa situação deve ser evitada pois, uma vez existente um laço, surge a possibilidade da formação de dobras (kinks) que podem danificar a estrutura. O capítulo inicia-se com uma revisão conceitual sobre a caracterização de sistemas dinâmicos e critérios de estabilidade. Posteriormente são discutidos aspectos particulares para o problema da configuração de um riser em catenária, bem como os critérios para a análise de estabilidade estrutural desse tipo de configuração.

\subsection{Fundamentos sobre sistemas dinâmicos}

Essa seção apresenta alguns conceitos de sistemas dinâmicos, de forma bastante sucinta, com o foco na utilização dos fundamentos no presente trabalho. Para maior aprofundamento, recomenda-se a leitura das referências originais citadas bem como outras referências, dentre a vasta gama que existe sobre o assunto.

\subsubsection{Descrição de um sistema dinâmico}

A presente discussão será focada em um sistema dinâmico discreto autônomo com $n$ graus de liberdade. No presente momento nada será discutido sobre possíveis vínculos presentes no sistema, pois isso será feito somente com base no problema específico da estabilidade da configuração de catenária, apresentado posteriormente no tópico 3.2. Após deduzir o sistema de equações diferenciais que regem a dinâmica do sistema, é possível escrevêlas em função de um vetor que contém as coordenadas generalizadas $\boldsymbol{q}$ e suas derivadas temporais $\dot{\boldsymbol{q}}$ : 


$$
\ddot{\boldsymbol{q}}=\boldsymbol{g}(\boldsymbol{q}, \dot{\boldsymbol{q}})
$$

Definem-se as variáveis de estado: $q_{1}, q_{2}, \ldots, q_{n}, \dot{q}_{1}, \dot{q}_{2}, \ldots, \dot{q_{n}}$. Define-se um vetor $\boldsymbol{x}$ com $2 n$ posições contendo as variáveis de estado do sistema. As equações diferenciais podem ser escritas em função do vetor $\boldsymbol{x}$ da forma:

$$
\dot{\boldsymbol{x}}=\boldsymbol{h}(\boldsymbol{x})
$$

Alguns conceitos são bastante importantes para o estudo da estabilidade de sistemas dinâmicos. A seguir, alguns desses conceitos serão apresentados, pois serão utilizados no desenvolvimento desse trabalho.

Espaço de fase é o espaço gerado pelas variáveis de estado. É bastante comum analisar a característica de sistemas dinâmicos autônomos de uma grau de liberdade (e portanto com espaço de fase de dimensão dois) através de trajetórias no denominado plano de fase. A forma com que se relacionam as variáveis de estado contém muitas informações sobre as características do sistema e mostra a topologia da solução das equações diferenciais. Mesmo para sistemas com mais graus de liberdade a visualização do espaço de fase pode ser feita elegendo-se com o devido cuidado certo grau de liberdade que represente algum fenômeno de interesse. Essa escolha, no entanto, pode ser não imediata.

Um conceito importante para a determinação das trajetórias de fase de um sistema dinâmico é o equilíbrio. A condição para o equilíbrio de um sistema autônomo é:

$$
\dot{\boldsymbol{x}}=\mathbf{0}
$$

Fisicamente o equilíbrio representa uma condição na qual não ocorre variação temporal nas variáveis de estado. Para um sistema mecânico, por exemplo, com as variáveis de estado sendo os deslocamentos e as velocidades, o equilíbrio representa a condição em que as velocidades e as acelerações são nulas.

Outro conceito bastante importante e de caráter mais matemático é a topologia do sistema dinâmico. Nesse texto não se tem o propósito de definir formalmente o que é to- 
pologia do ponto de vista matemático. No entanto, de maneira informal, a topologia pode ser entendida como a forma com que as trajetórias de fase se apresentam, caracterizando o

sistema. É possível associar mudanças na topologia com modificações de comportamento físico, ou mudanças no comportamento das trajetórias de fase, podendo estar associadas a certa variação nos parâmetros do sistema, contidos nas equações diferenciais que regem seu comportamento.

\subsubsection{Estabilidade de um sistema dinâmico}

A palavra "estabilidade" está associada ao comportamento de um sistema e pode ser utilizada em diversos contextos. Por exemplo, é bastante comum dizer que uma pessoa atinge sua estabilidade profissional quando consegue um tipo de trabalho que seja muito pouco suscetível a grandes mudanças devidas a efeitos diversos, como crises econômicas ou mudanças nos costumes e pretensões da sociedade. A estabilidade está associada à relação entre causa e efeito.

Essa ideia pode ser aplicada no estudo de um sistema dinâmico, modelado utilizando equações diferenciais. Variações paramétricas de massa, amortecimento ou rigidez do sistema podem modificar a solução de seu modelo matemático, levando a conclusões absolutamente distintas em relação à evolução temporal do estado. A mudança de um tipo de solução do modelo matemático para outra forma de solução está associada a distintos comportamentos do sistema, estando portanto associada à estabilidade do mesmo. No contexto de aplicações em mecânica das estruturas, por exemplo, o comportamento de uma estrutura carregada ou descarregada pode ser bastante distinto, dependendo do nível atingido pelo carregamento. Uma coluna, por exemplo, submetida a esforços compressivos inferiores à sua carga crítica, apresenta certo campo de deslocamentos e tensões. Já quando a carga compressiva se torna crítica, a solução se modifica e pode assumir formas bastante distintas, possibilitando a existência de campos de deslocamentos e de tensões completamente diferentes do original. Diz-se, nesse caso, que a estrutura se tornou instável para tal nível de carregamento que, nesse caso é o parâmetro que sensibiliza o sistema.

A estabilidade do movimento também é algo bastante estudado como, por exemplo, no estudo da órbita de um satélite. Nesse caso, deseja-se responder a perguntas como: por quanto tempo o satélite poderá orbitar dentro de certa região do espaço, ou ainda, como varia sua órbita ao longo do tempo.

A estabilidade de um sistema dinâmico está associada à tendência do sistema em 
permanecer em certo estado, ainda que haja perturbações que procurem tirá-lo de tal situação. Para tal, é necessário analisar algum estado específico, ou seja, de um conjunto de variáveis de estado dadas pelo vetor $\boldsymbol{x}_{\boldsymbol{i}}$. Tal estado, é denominado estado básico. Mazzilli (2009) afirma que: “... um estado básico satisfazendo as equações 3.2, e correspondendo a especificadas condições iniciais, será considerado estável ante perturbações nas condições iniciais se as novas soluções das equações 3.2 permanecerem suficientemente próximas da correspondente ao estado básico." As perturbações introduzidas no sistema podem ser representadas pela variável $\delta \boldsymbol{x}$.

Para realizar uma análise de estabilidade é conveniente seguir o caminho descrito em Mazzilli (1982). O primeiro passo é a escolha do estado básico de estudo, que pode ser um movimento ou o equilíbrio. É necessário decidir, posteriormente, qual a escala de tempo de interesse, se é de um tempo finito ou infinito. A seguir é necessário pensar no tipo de perturbação que o sistema irá sofrer. Poderão ser perturbações em parâmetros estruturais, levando a problemas de estabilidade paramétrica ou, condições iniciais, levando a problemas de estabilidade cinética. O tamanho da perturbação deve ser levado em conta.

Nesse ponto é necessário definir se o interesse é o estudo em relação a pequenas ou grandes perturbações. No presente trabalho o estudo de estabilidade não objetiva contemplar grandes perturbações, mas somente pequenas, a fim de analisar a vizinhança do estado básico de interesse. Segundo Mazzilli (2009) as definições usuais em mecânica das estruturas consideram pequenas perturbações. O estado básico pode ser, de forma particular, um ponto de equilíbrio. Esse tipo de estado é bastante importante para o estudo de estruturas quando, muitas vezes, deseja-se estudar a estabilidade do equilíbrio. Enfatiza-se que o estudo de grandes perturbações pode ser essencial em sistemas de controle, por exemplo, quando o o objetivo é garantir que perturbações físicas não consigam desestabilizar o sistema. Assim é necessário pensar não somente em âmbito local, mas na chamada estabilidade global. Nesse ponto entram metodologias fora do escopo do presente trabalho. Assim, quando se utilizar a terminologia "estável", subentende-se que se está se referindo a pequenas perturbações e, adicionalmente, segundo a definição de Lyapunov, conforme explicado a seguir.

Assumindo-se que o estado básico seja dado por $\boldsymbol{x}_{\boldsymbol{i}}$, é possível escrever um estado do sistema como sendo o estado básico acrescido de uma perturbação $\delta \boldsymbol{x}$ : 


$$
\boldsymbol{x}=\boldsymbol{x}_{\boldsymbol{i}}+\delta \boldsymbol{x}
$$

É possível escrever a equação 3.2 para o estado descrito na equação 3.4:

$$
\dot{\boldsymbol{x}}_{\boldsymbol{i}}+\dot{\delta} \boldsymbol{x}=\boldsymbol{h}\left(\boldsymbol{x}_{\boldsymbol{i}}+\delta \boldsymbol{x}\right)
$$

Para um dado estado básico conhecido, re-arranjando a equação 3.5 é possível determinar as seguintes equações (forma perturbada das equações do sistema):

$$
\dot{\delta \boldsymbol{x}}=\boldsymbol{f}(\delta \boldsymbol{x})
$$

Nesse trabalho é utilizada a definição de estabilidade de Lyapunov, bastante geral e aplicável a diversas áreas. Com base no apresentado em Mazzilli (2009), tem-se:

"Seja o estado básico trivial caracterizado por $\delta \boldsymbol{x}=0$. Tal estado será dito Lyapunov-estável se e somente se, para cada número $\epsilon$ positivo e arbitrariamente pequeno, for possível encontrar um segundo número $\delta(\epsilon)$ de tal forma que estados perturbados satisfazendo em $t=0$ a $\left\|\delta x_{j}(0)\right\| \leq \delta$, satisfaçam também para qualquer outro $t$ positivo a $\left\|\delta x_{j}\right\| \leq \epsilon$, para $1 \leq j \leq 2 n "$

Ao introduzir uma perturbação $\delta \boldsymbol{x}$ a um estado básico $\boldsymbol{x}_{\boldsymbol{i}}$ pode ocorrer que o sistema apresente uma tendência assintótica para o estado básico. Caso isso ocorra, pode-se afirmar que existe estabilidade assintótica.

A definição de estabilidade de Lyapunov pode ser modificada, em termos de norma da medição do desvio do estado em relação ao estado básico. Baseando-se em Ziegler (1968), a seguir é apresentado um critério bastante simples, que modifica o critério de Lyapunov:

Seja um sistema dinâmico autônomo com $n$ graus de liberdade, portanto definido no espaço de estados $2 n$. Deseja-se estudar o estado básico de equilíbrio dado por $\boldsymbol{x}_{\boldsymbol{i}}$. Sendo $1 \leq j \leq 2 n$, é possível escrever tal estado básico utilizando-se um sistema de coordenadas, tal que $x_{0 j}=0$. O sistema será dito cineticamente estável se e somente se o estado do sistema se limitar ao interior de uma hiperesfera de raio $\eta$, dado que as condições iniciais do sistema se encontram limitadas a uma certa região suficientemente 
pequena do espaço de fase. A equação da hiperesfera é dada por:

$$
x_{1}^{2}+x_{2}^{2}+\ldots+x_{2 n}^{2}=\eta^{2}
$$

No critério de Lyapunov, as regiões de delimitação para que o sistema seja estável são individuais para cada variável de estado. Nesse critério apresentado por Ziegler (1968), não se verifica individualmente cada variável de estado, mas essa varredura é substituída por uma norma no espaço de fase.

\subsubsection{Pontos de bifurcação e pontos limite}

As variações de parâmetros do sistema podem alterar as posições e formas das trajetórias de fase. No entanto, essas mudanças podem ou não acarretar grandes mudanças de comportamento, ou seja, na topologia. Uma grande mudança pode estar associada, por exemplo, ao surgimento de pontos de equilíbrio onde não os havia, ou à instabilização de pontos de equilíbrio que outrora eram estáveis. Quando esse tipo de mudança de comportamento ocorre se diz que houve mudança topológica no sistema. Dessa forma, cabe aqui definir: o aparecimento de diagramas de fase topologicamente não equivalentes segundo a variação de parâmetros de um sistema dinâmico é denominado bifurcação (KUZNETSOV, 2004). A expressão "topologicamente não equivalente" pode ser entendida como o que ocorre quando há grandes mudanças topológicas nas trajetórias de fase do sistema dinâmico.

Para ilustrar esse conceito, será utilizado um clássico exemplo de equação diferencial, bastante simples, mas que mostra a existência de uma bifurcação:

$$
\dot{x}=\alpha x-x^{3}
$$

O sistema em questão é sensível ao parâmetro $\alpha$. É possível definir duas diferentes topologias para as trajetórias de fase quando se varia $\alpha$. As Figuras 3.1 e 3.2 ilustram essas trajetórias de fase para $\alpha \geq 0$ e $\alpha \leq 0$, respectivamente. Note que para $\alpha \leq 0$ existe um único ponto de equilíbrio no sistema, dado por $x=0$, e esse equilíbrio é estável (as trajetórias de fase convergem para esse ponto). No entanto, quando $\alpha>0$, surgem outros pontos de equilíbrio, para $x= \pm \sqrt{\alpha}$, além do $x=0$. No entanto, para essa faixa de $\alpha$, 
o equilíbrio na origem se torna instável, enquanto que os outros pontos de equilíbrio são estáveis.

Portanto, essa mudança de comportamento topológica ocorre para o valor de $\alpha=0$. Ambas as Figuras 3.1 e 3.2 ilustram o valor da trajetória de fase também para $\alpha=0$, que se mostra como um valor de parâmetro que causa bifurcação para as soluções da equação diferencial.

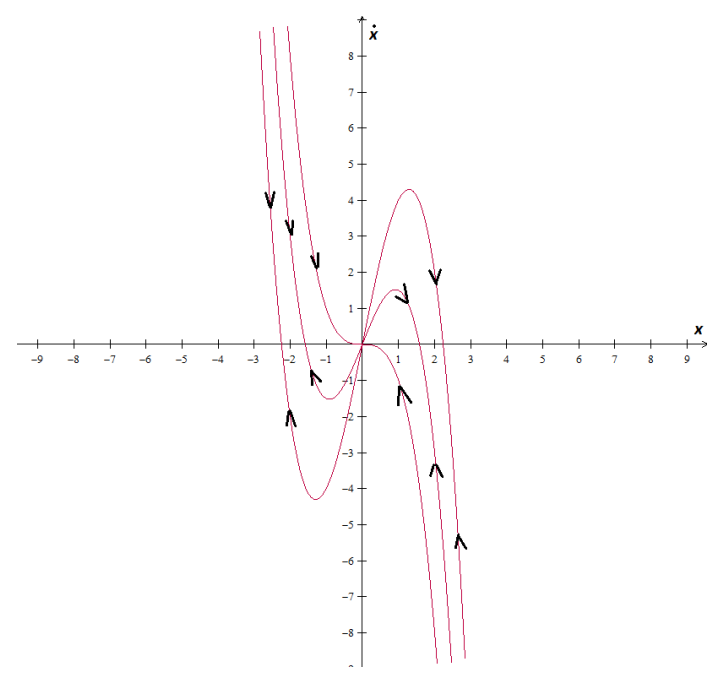

Figura 3.1: Trajetórias de fase para $\alpha \geq 0$

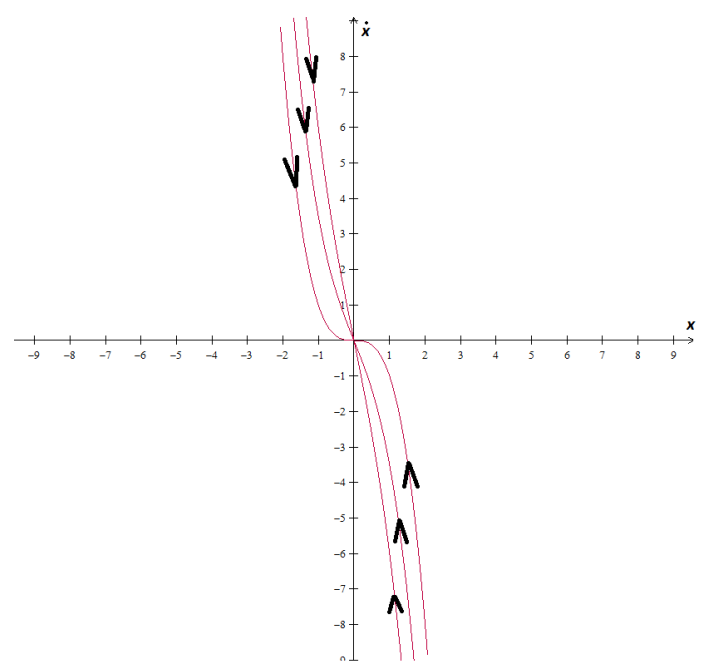

Figura 3.2: Trajetórias de fase para $\alpha \leq 0$

É possível construir, adicionalmente, o diagrama das trajetórias de equilíbrio. Trata-se da exibição dos infinitos pontos de equilíbrio que ocorrem em função do valor de $\alpha$. Esses pontos podem ser visualizados na Figura 3.3. Note que esse diagrama ilustra de forma bastante concisa muitas informações sobre o comportamento paramétrico das soluções da equação diferencial, sendo portanto uma ferramenta muito utilizada para 
analisar sistemas dinâmicos. Nesse exemplo, o nome da bifurcação em questão é pitchfork devido à sua forma, que pode ser visualizada no diagrama das trajetórias de equilíbrio (Figura 3.3). Enfatiza-se que a forma das trajetórias de equilíbrio por si só de modo geral não dá a informação da estabilidade do sistema. Conclusões sobre a estabilidade podem ser obtidas utilizando-se das metodologias e teoremas discutidos na seção 3.1.4.

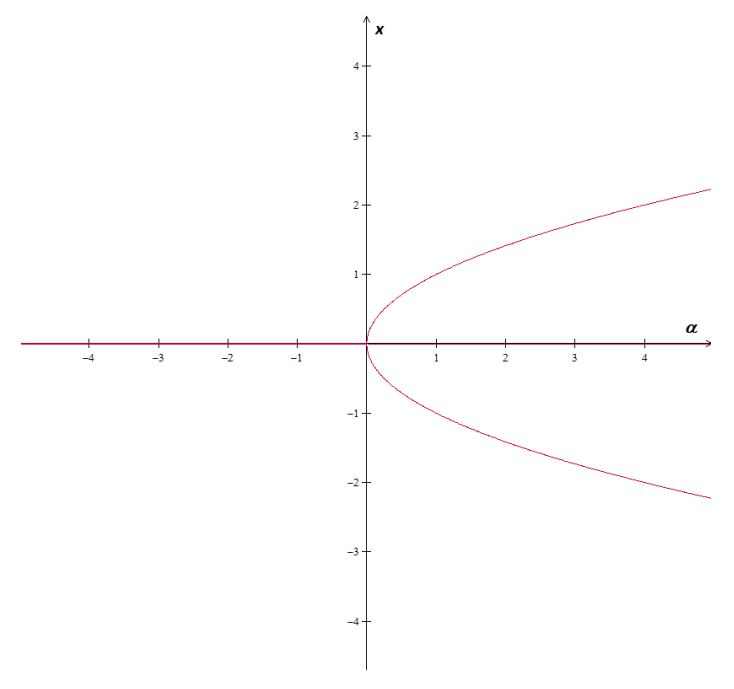

Figura 3.3: Trajetórias de equilíbrio ilustrando uma bifurcação do tipo pitchfork

No contexto de análise de estabilidade da configuração de equilíbrio estático de estruturas, Thompson e Hunt (1973) apresentam o conceito de ponto de bifurcação como um dos casos que pode ocorrer de "pontos críticos". Através de uma apresentação bastante didática os autores apontam além da bifurcação, um outro tipo de ocorrência de ponto crítico, denominada "ponto limite". Supondo um sistema perfeito ${ }^{1}$ de $n$ graus de liberdade com um parâmetro $P$ que rege o carregamento, Thompson e Hunt (1973) apresentam os seguintes conceitos:

- Ponto limite: A Figura 3.4 (a) ilustra a ocorrência de um ponto limite. Para parâmetros de carregamento $P$ de valor pequeno o sistema apresenta-se estável. No entanto, quando $P$ atinge um valor crítico associado a um ponto de máximo da trajetória de equilíbrio, a estrutura se torna instável. Como não existe estado de equilíbrio possível para valor acima do ponto limite, a estrutura experimenta o fenômeno denominado snap-through, que é uma busca dinâmica por uma nova configuração de equilíbrio. Por se tratar de um sistema com $n$ graus de liberdade, a escolha da variável $q_{j}$ deve ser feita com cuidado. No caso de uma escolha ruim, o

\footnotetext{
${ }^{1}$ A nomenclatura "sistema perfeito" diz respeito a um sistema que não contém nenhum tipo de imperfeição geométrica ou na aplicação do carregamento. Trata-se de uma idealização teórica que serve de base ao estudo da estabilidade. Um sistema real, no entanto, sempre apresentará imperfeições que alteram as predições de carga crítica determinadas de maneira teórica para sistemas perfeitos.
} 

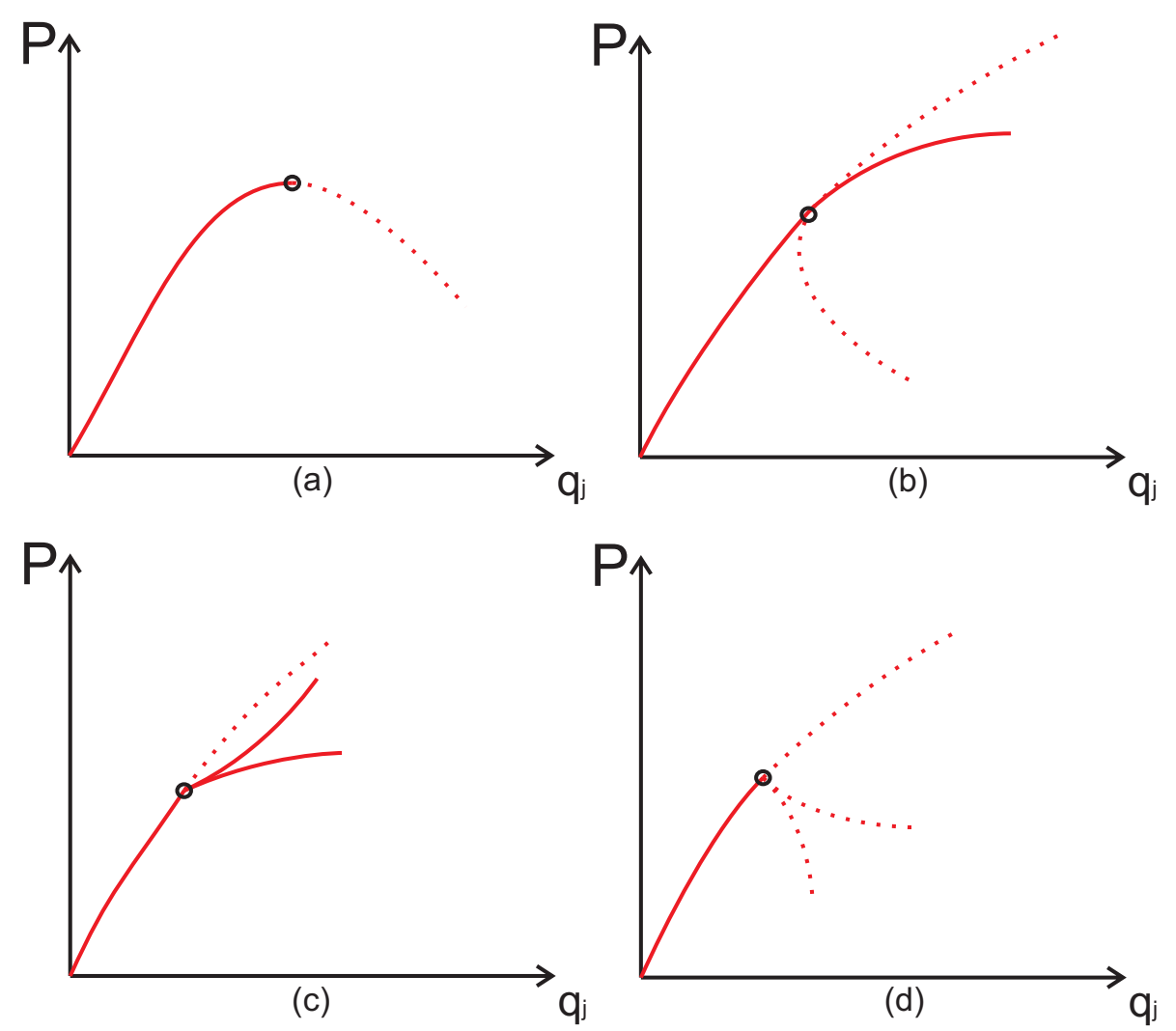

Figura 3.4: Diagramas de carregamento $P$ versus deslocamento no grau de liberdade $q_{j}$ ilustrando exemplos de: (a) ponto limite (b) bifurcação assimétrica (c) bifurcação simétrica estável e (d) bifurcação simétrica instável. Adaptado de Thompson e Hunt (1973).

comportamento suave ilustrado na Figura 3.4 (a) pode não ser identificado mas, ao contrário, algo como uma cúspide bastante aguda. Assim, no caso de estudar um sistema que apresente um ponto limite, a escolha do grau de liberdade $q_{j}$ adequado para a construção da trajetória de equilíbrio se faz fundamental.

- Ponto de bifurcação assimétrica: A Figura 3.4 (b) ilustra a ocorrência de um ponto de bifurcação assimétrica. Para valores pequenos de $P$ o equilíbrio é estável. Atingindo-se o ponto crítico, a estrutura pode recair sobre diferentes caminhos: o aumento da carga $P$ através de um caminho de equilíbrio estável ou de um equilíbrio instável, ou um caminho de decréscimo de carregamento e instável.

- Ponto de bifurcação simétrica estável: A Figura 3.4 (c) ilustra trajetórias de equilíbrio que caracterizam um sistema com um ponto de bifurcação simétrica estável. Aumentando-se monotonicamente o parâmetro $P$, o sistema atinge um ponto de bifurcação caracterizado por duas trajetórias de equilíbrio estáveis partindo desse ponto. Também co-existe uma trajetória instável que é a continuação da trajetória inicial. O sistema não apresenta no regime pós-crítico um salto dinâmico 
em busca de uma nova configuração de equilíbrio.

- Ponto de bifurcação simétrica instável: A Figura 3.4 (d) mostra a existência desse tipo de ponto crítico. Trata-se de um sistema que exibe um comportamento estável até o ponto crítico. Uma vez atingido tal ponto, a estrutura se torna instável e escolhe um dos caminhos caracterizados por uma busca instável do equilíbrio através de um salto dinâmico.

O sistema real, com suas imperfeições, não apresenta pontos de bifurcação. De acordo com a imperfeição existente, os pontos de bifurcação dos casos das Figuras 3.4 (b) e (c) se tornam pontos limite. Imperfeições podem diminuir substancialmente as cargas críticas determinadas para um sistema perfeito. A natureza das imperfeições pode ser geométrica, do material da estrutura, ou na forma de aplicação do carregamento. Thompson e Hunt (1973) apresentam um parâmetro de imperfeição a partir do qual podese estudar o comportamento do sistema. De acordo com a variação do ponto crítico em função desse parâmetro é possível concluir sobre a sensibilidade do sistema às imperfeições.

Sistemas perfeitos caracterizados por um ponto limite apresentam resposta não muito severa à imperfeição, pois a variação da carga crítica em relação ao parâmetro de perturbação não modifica significativamente a trajetória de equilíbrio. Em sistemas perfeitos caracterizados por uma bifurcação simétrica estável não há sensibilidade à imperfeição, uma vez que essa causa simplesmente a "escolha" do sistema para um dos caminhos pós-críticos existentes no sistema perfeito desde o início da aplicação da carga $P$. Assim, não há mais cargas críticas, mas somente um comportamento não-linear nas trajetórias de equilíbrio. Já os sistemas perfeitos com bifurcação simétrica instável ou assimétrica podem apresentar grande sensibilidade à imperfeição, de tal forma que passam a ser caracterizados por pontos limite com significativa redução na carga crítica em relação à do sistema perfeito. Falhas catastróficas podem ocorrer, por exemplo, em estruturas de cascas que podem apresentar redução de cerca de 30\% em relação ao predito para o sistema perfeito.

O tema "sensibilidade à imperfeição" é bastante vasto e não se tem a pretensão de apresentar algo completo nesse texto. Maiores informações podem ser encontradas por exemplo em Thompson e Hunt (1973) e Bazant e Cedolin (2003). 


\subsubsection{Metodologias para análise de estabilidade em estruturas}

Uma abordagem estática para a avaliação da estabilidade estrutural é muito comum em problemas clássicos, como o desenvolvido por Euler para uma coluna sob compressão (ver Apêndice C). Essa forma de tratar o problema consiste em escrever, em primeiro lugar, as equações de equilíbrio estático da estrutura. Posteriormente, buscam-se soluções para essas equações e, portanto, que representam soluções para o equilíbrio. Algumas equações diferenciais possuem soluções triviais ou não triviais. A técnica reside em determinar quais são as soluções não triviais, e quando podem ocorrer. A conclusão seria que, quando podem ocorrer soluções não triviais, a estrutura poderia buscar formas de equilíbrio alternativas em relação ao estado básico considerado em uma nova configuração que envolve instabilidade.

No entanto, é de se imaginar que essa abordagem possa não se mostrar adequada para qualquer problema, uma vez que existem situações em que um problema de instabilidade estrutural não está associado à busca de uma nova configuração de equilíbrio estática. Para um estudo mais criterioso de estabilidade, não se pode fazer a hipótese de que haverá de fato uma configuração estática após a estrutura sair de seu estado básico. Deve-se pensar em um critério como o de Lyapunov que é essencialmente cinético, não estando atrelado necessariamente à estática do problema analisado.

Existem problemas em que, após a estrutura sair de seu estado básico (nesse contexto, a solução trivial de equilíbrio), a mesma experimenta oscilações com amplitude crescente. Esse tipo de instabilidade não assume uma nova solução de equilíbrio estático e leva à falência alguma técnica que envolva a busca de uma nova configuração de equilíbrio. Portanto é necessário realizar uma discussão mais profunda acerca de quando é possível se analisar uma estrutura quanto à sua estabilidade com a abordagem estática e, quando é necessário utilizar uma abordagem cinética. Essa discussão será feita posteriormente nesse capítulo.

Quando se constrói um modelo de uma estrutura, geralmente são feitas algumas idealizações quanto à geometria e à forma de aplicação de carregamentos. No caso de uma viga, por exemplo, pode-se assumir que sua configuração descarregada é perfeitamente retilínea. No entanto, tal situação é impossível de ser atingida na fabricação de uma viga real, uma vez que, por menor que seja, sempre há algum tipo de imperfeição geométrica. Quanto à forma de aplicação de carregamentos, é impossível aplicar uma carga compressiva em uma viga sem induzir momento fletor algum, por menor que seja. Isso, pois sempre há uma imperfeição na aplicação do carregamento. 
Essas e outras imperfeições podem levar a estrutura a buscar novas configurações de equilíbrio quando atingido certo nível de carregamento. Sem essas imperfeições, o equilíbrio em configurações triviais poderia continuar a existir, mesmo que instável. Por exemplo, uma coluna de Euler perfeitamente retilínea com carregamento compressivo aplicado de forma a não causar momento fletor algum e sem nenhum tipo adicional de imperfeição não flambaria nunca, por maior que fosse o nível do carregamento. Note, portanto, que a busca de novas configurações de equilíbrio ocorre devido à existência de imperfeições, sejam essas geométricas ou na aplicação do carregamento, na medida em que o equilíbrio trivial se torna instável.

Essa ideia pode ser discutida através do exemplo de uma esfera sob ação de seu peso próprio, que pode ser visto em Alfutov (2000). A Figura 3.5 mostra diferentes condições de equilíbrio.

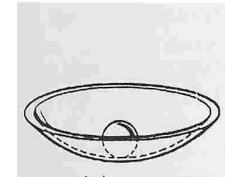

(a)

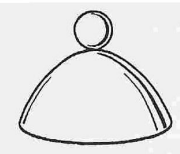

(b)

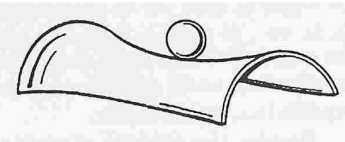

(c)

Figura 3.5: Diferentes formas de equilíbrio. Extraído de Alfutov (2000)

Note que a ilustração (a) representa uma posição estável da esfera, e as ilustrações (b) e (c) representam posições instáveis. O conceito de estabilidade de uma configuração de equilíbrio necessariamente está associado à perturbação do sistema. Se ocorrer uma perturbação na posição de equilíbrio e o sistema procurar voltar para sua posição inicial ou, segundo Lyapunov, ao menos ficar contido em um subconjunto limitado de estados, o equilíbrio é chamado de estável. Caso o sistema busque outro ponto de equilíbrio ou mesmo se desgoverne, sem mais encontrar um ponto de equilíbrio, o equilíbrio inicial e que fora perturbado será denominado instável.

Portanto, para o estudo de instabilidade estrutural, é necessário que se assuma uma mudança de configuração (seja estática ou dinâmica) que surja em função de perturbações que atuem na configuração inicial da estrutura. Ziegler (1968) apresenta três diferentes métodos que assumem que o sistema busque configurações de equilíbrio estático, em situações de instabilidade. Trata-se do Método da Imperfeição, do Método do Equilíbrio, e do Método de Energia. O mesmo autor também apresenta uma técnica para a análise dinâmica de estabilidade, o denominado Método Cinético. Mazzilli (2009) apresenta o Primeiro Método de Lyapunov, também para análise estabilidade cinética de estruturas. A seguir serão detalhadas as ideias básicas de alguns um desses métodos, 
relevantes para o trabalho em questão.

\subsubsection{Método do Equilíbrio}

A ideia do Método do Equilíbrio é prever a perda de estabilidade da solução trivial de equilíbrio através do aparecimento de possibilidades de soluções não triviais. Esse fato é ilustrado no Apêndice C quando na equação C.9 e no sistema de equações C.15 impõe-se a possibilidade de ocorrência de soluções não triviais. Dessa imposição decorrem as cargas críticas que nada mais são do que parâmetros do sistema que possibilitam as soluções não triviais. Essa classe de problemas é denominada de "autovalores e autovetores". As cargas críticas representam os autovalores e, os modos de flambagem, os autovetores ${ }^{2}$. Para o caso particular do problema da viga de Euler, por se tratar de um problema de infinitos graus de liberdade, uma vez que a solução é uma função, o autovetor é denominado "autofunção".

Segundo Ziegler (1968), a solução do método do equilíbrio consiste em responder a seguinte pergunta: "Quais os valores de carregamento para os quais o sistema perfeito admite configurações de equilíbrio não triviais?"

Pode-se interpretar o Método do Equilíbrio como o estudo matemático das possíveis soluções de uma equação diferencial segundo a variação de algum parâmetro. Esse parâmetro seria a carga compressiva e, a mudança de comportamento na solução da equação do sistema perfeito é feita em função dessa carga. O surgimento de soluções não triviais é a indicação de que o parâmetro sensibilizou o sistema, tal que matematicamente essas soluções se tornam possíveis. No entanto, como de fato não foi introduzida uma imperfeição no equacionamento físico do problema, o único resultado quantitativo válido para esse tipo de análise é o valor teórico da carga crítica para o sistema perfeito.

A solução (ou soluções) não triviais representam formas que a estrutura tende a assumir quando sofre flambagem (são denominados modos de flambagem). Trata-se de resultados qualitativos, uma vez que valores de amplitude de deslocamentos na configuração pós-flambagem não são identificados através dessa metodologia.

\footnotetext{
${ }^{2}$ A palavra flambagem tem nesse contexto a conotação de bifurcação do equilíbrio. O Método do Equilíbrio, no entanto, não se restringe a problemas associados a pontos de bifurcação mas, também, a situações que envolvem pontos limite.
} 


\subsubsection{Método de Energia}

O Método da Energia procura explorar a equivalência entre a mecânica vetorial e a mecânica analítica para resolver um problema mecânico. Para discutir esse método, é necessário antes algumas definições e hipóteses.

Seja um sistema conservativo, é possível definir um funcional $U$ que representa a energia potencial desse sistema:

$$
U=U_{i n t}+U_{e x t}
$$

Em que:

- $U_{\text {int }}$ é a energia potencial dos esforços internos (energia potencial elástica no sistema conservativo)

- $U_{\text {ext }}$ é a energia potencial dos esforços externos conservativos

A energia potencial dos esforços externos $U_{\text {ext }}$ é igual ao oposto do trabalho realizado por esses esforços, ou seja:

$$
U_{e x t}=-W_{e x t}
$$

A primeira variação do funcional $U$ é dada por:

$$
\delta U=\delta U_{i n t}-\delta W_{e x t}
$$

O Teorema da Energia Potencial diz que um ponto de estacionariedade do funcional $U$ equivale a um ponto de equilíbrio estático do sistema. Assim sendo, pode-se afirmar que no equilíbrio vale:

$$
\delta U_{\text {int }}-\delta W_{\text {ext }}=0
$$

A ideia do Método de Energia é estudar o sinal do funcional $U$, utilizando o princípio de que em situações estáveis o funcional $U$ será positivo-definido. Assim sendo, a ocorrência de cargas críticas seria caracterizada por uma situação em que o funcional deixa de ser positivo definido. Existe total equivalência entre o resultado do Teorema da Energia Potencial apresentado na equação 3.12 e a imposição do equilíbrio no sistema. É possível verificar essa equivalência para o exemplo do problema da viga de Euler em Ziegler (1968), que se trata de um problema conservativo e não giroscópico. O autor mostra, inclusive, que a ocorrência de soluções não triviais de equilíbrio é que fazem com que o funcional não 
mais seja positivo-definido. Essa ocorrência se dá, como previsto, para valores superiores à carga de Euler.

Assim, Ziegler (1968) define o Método da Energia para análise de estabilidade estrutural através da seguinte pergunta: "Qual é o valor do carregamento para o qual a energia potencial do sistema perfeito deixa de ser positivo-definida?"

As bases teóricas para a utilização desse método estão fundamentadas no Teorema de Lagrange-Dirichlet, descrito na seção 3.1.7.

\subsubsection{Método Cinético}

Diferente dos dois métodos apresentados até então, o Método Cinético considera efeitos inerciais na qual não existe a hipótese de que o sistema estará em equilíbrio estático. É possível, portanto, prever comportamentos de instabilidade dinâmica, sem a ocorrência de equilíbrio na configuração pós-crítica. Para tal, a ideia é escrever o Princípio Fundamental da Dinâmica para o problema em questão, chegando em equações diferenciais que envolvem além das variáveis espaciais, a variável temporal. A solução dessas equações resultam na conclusão acerca do comportamento do sistema, segundo a variação de algum parâmetro de interesse.

Por exemplo, para a viga de Euler, Ziegler (1968) mostra que a ocorrência da carga crítica levaria a solução da equação diferencial do sistema a um movimento não limitado e, portanto, instável. Esse tipo de situação seria instável segundo o critério de Lyapunov.

Por fim, coloca-se a pergunta à qual se deve procurar responder para determinar a estabilidade de um sistema utilizando o Método Cinético, ou também chamado de Método de Vibrações. Traduzindo-se as palavras de Ziegler (1968): "Qual o valor do carregamento para o qual o mais genérico movimento livre do sistema perfeito, nas vizinhanças da posição de equilíbrio, deixa de ser limitado?"

\subsubsection{Primeiro Método de Lyapunov}

O primeiro método de Lyapunov se propõe a avaliar a estabilidade cinética de uma estrutura. A ideia é estudar a evolução temporal da perturbação introduzida. Se a mesma tender a se amplificar de forma descontrolada, o sistema será instável. Caso ela se mantenha limitada ou tenda a desaparecer, o sistema será estável. Alguns teoremas surgem para auxiliar o estudo da estabilidade. Para utilizá-los, é necessário linearizar a equação 
3.6, de tal forma que a mesma possa ser escrita da forma matricial:

$$
\dot{\delta \boldsymbol{x}}=\boldsymbol{A}_{\boldsymbol{i}} \delta \boldsymbol{x}
$$

em que a matriz $\boldsymbol{A}_{\boldsymbol{i}}$ pode ser calculada por:

$$
\boldsymbol{A}_{\boldsymbol{i}}=\left[\frac{\partial \boldsymbol{f}}{\partial \delta \boldsymbol{x}}\right]_{\delta \boldsymbol{x}=\mathbf{0}}=\left[\frac{\partial \boldsymbol{h}}{\partial \boldsymbol{x}}\right]_{\boldsymbol{x}=\boldsymbol{x}_{\boldsymbol{i}}}
$$

A solução da equação 3.13 é bastante simples e se apresenta de forma exponencial, com expoentes $\lambda_{j}$ com $1 \leq j \leq 2 n$. A solução desses expoentes recai em um problema de autovalor (ver, por exemplo Kuznetsov (2004)), de tal forma que cada autovalor possui uma parte real e outra imaginária. Tem-se os seguintes teoremas de Lyapunov relacionando as partes reais dos autovalores com o comportamento do sistema:

- Se todos os autovalores tiverem parte real negativa, o estado básico de 3.13 será de equilíbrio estável.

- Se pelo menos um autovalor tiver parte real positiva, o estado básico de 3.13 será instável.

Se nenhum desse dois teoremas se aplicar, o sistema possui comportamento crítico e sua estabilidade só pode ser verificada através de outros teoremas. O interessante é que, se o sistema se enquadrar em algum dos teoremas de Lyapunov, existe outro teorema que diz:

- Se o sistema 3.13 não possuir comportamento crítico, então suas características topológicas de estabilidade serão idênticas às do sistema das equações de perturbação 3.6, mesmo que o sistema seja não linear.

Dessa forma, a linearização realizada para o estudo da estabilidade não representa uma perda de generalidade da conclusão, que também será válida para o problema não linearizado. 


\subsubsection{Segundo Método de Lyapunov}

O Segundo Método de Lyapunov não será utilizado diretamente nesse trabalho. No entanto, será brevemente apresentado por sua grande importância para análise da estabilidade de um sistema dinâmico e como base para alguns teoremas de estabilidade.

Define-se em primeiro lugar uma função escalar, denominada Função de Lyapunov $(\Phi)$. Essa função deve ser escrita em função dos componentes do vetor que descreve o estado perturbado do sistema, dado por $\delta \boldsymbol{x}$. A construção de tal função não é única para um dado sistema. De fato, a obtenção da Função de Lyapunov pode ser uma tarefa complexa. No entanto, uma vez determinada tal função, o problema de estabilidade estará resolvido. Os teoremas que permitem o estudo de estabilidade garantem que:

Seja uma função $\Phi$ que satisfaça:

- $\Phi\left(\delta x_{1}, \delta x_{2}, \ldots, \delta x_{2 n}\right) \geq 0$

- $\Phi\left(\delta x_{1}, \delta x_{2}, \ldots, \delta x_{2 n}\right)=0 \Leftrightarrow\left(\delta x_{1}, \delta x_{2}, \ldots, \delta x_{2 n}\right)=(0,0, \ldots, 0)$

- $\dot{\Phi} \leq 0$

então o estado básico será estável.

Ao restringir mais a última condição e, portanto, se $\dot{\Phi}<0$, então a estabilidade do estado básico será assintótica.

No entanto, se $\dot{\Phi}>0$ em algum ponto de uma vizinhança da origem, então o estado de equilíbrio será instável.

\subsubsection{Discussão sobre a metodologia de análise e critérios de es- tabilidade}

A aplicação das diferentes formas apresentadas no problema de estabilidade de uma viga de Euler leva exatamente à mesma conclusão: ocorre instabilidade da estrutura para uma força compressiva superior à carga de Euler. No entanto, surge a dúvida acerca da possibilidade de generalizar tal equivalência de métodos para qualquer tipo de sistema mecânico. Em Ziegler (1968) e em Leipholz (1975) mostra-se que não existe essa equivalência mas, dependendo das características do sistema, algumas abordagens conseguem prever corretamente a instabilidade e outras não. 
Surge naturalmente outro questionamento, acerca de qual é a relação entre o Método do Equilíbrio e da Energia com os conceitos de estabilidade dinâmica apresentados anteriormente segundo a ótica de Lyapunov.

A real necessidade do estudo de estabilidade de uma estrutura é a previsão da ocorrência de grandes deslocamentos medidos a partir de uma configuração não deformada, podendo colocar o sistema em risco. Independente do critério que se utiliza, a análise a ser feita deve ser sempre baseada na dinâmica, uma vez que, mesmo que se estude a mudança de configurações de equilíbrio estáticas, tal migração será um processo dinâmico. Ou seja, mesmo que se adote um equacionamento que não envolva termos inerciais e uma análise que envolva o tempo, a preocupação física é essencialmente relacionada aos deslocamentos e velocidades, determinados à partir das equações da dinâmica do sistema.

Serão referidos nesse texto como "métodos estáticos", os dois primeiros apresentados, por possuírem como hipótese básica a imposição de equilíbrio estático e, como "métodos dinâmicos" os últimos apresentados. Um estudo cuidadoso acerca das condições para as quais os métodos estáticos são válidos deve ser feito.

Em Leipholz (1975) é apresentado um histórico interessante sobre abordagens de problemas de estabilidade, comentando justamente sobre os clássicos problemas de Euler e de Greenhill (mostrados no Apêndice C), para os quais a abordagem estática de estabilidade se mostra condizente com a dinâmica. É apontada a falha dos métodos estáticos em certas situações, como alguns problemas não conservativos. Leipholz (1975) faz alusão aos trabalhos de Ziegler que mostrou que alguns problemas de torção de eixos não poderiam ser resolvidos por abordagens estáticas, sendo necessário um método cinético. Outra questão importante é avaliar se o sistema possui forças seguidoras, ou seja, dependentes dos deslocamentos da estrutura. Um problema clássico que surgiu na década de 1950 é o de uma viga submetida a uma força seguidora, mais tarde denominado por: "Coluna de Beck". Nesse problema, a força seguidora é um carregamento que sempre se encontra na direção tangencial à viga em seu ponto de aplicação, por mais que haja rotações nesse ponto. O problema relacionado com esse tipo de carregamento, muitas vezes com aplicações para mísseis e foguetes, pode ser não conservativo, não podendo ser resolvido por métodos estáticos de estabilidade. Carregamentos seguidores podem estar presentes de maneira mais comum do que se possa imaginar à primeira instância. Por exemplo, qualquer tipo de pressão aplicada em uma estrutura é um esforço seguidor, pois sempre atua ortogonalmente à superfície em questão. 
O assunto "forças seguidoras" certamente possui ainda hoje discussões em aberto na literatura, uma vez que ainda há controvérsias quanto à real aplicabilidade prática desse tipo de esforço, ou se isso não seria apenas uma forma de modelar problemas que complica sua matemática e estudo e que na verdade, muitas vezes, rouba a cena da essência a ser estudada. Elishakoff (2005) em um artigo muito bem escrito faz uma revisão colocando em pauta as diversas discussões sobre as forças seguidoras, critérios de estabilidade estáticos ou dinâmicos, experimentos sobre o assunto, bem como os clássicos problemas, como o da coluna de Beck e da coluna de Leipholz. O autor foi inspirado a escrever tal trabalho, dada a leitura que fizera de dois outros artigos com certas divergências sobre o assunto.

No que diz respeito à discussão entre critérios estáticos e cinéticos, Elishakoff (2005) mostra diversos trechos de obras de outros autores que comentam o assunto, chegando à conclusão de que, de modo geral, problemas não conservativos não podem ser resolvidos de forma estática em termos de estabilidade estrutural. Nessas situações seria necessário recorrer à dinâmica. No entanto, nem todos os problemas que apresentam forças seguidoras são não conservativos. Por exemplo, a pressão hidrostática que é uma força seguidora, em algumas situações é conservativa. Isso será discutido posteriormente nesse texto.

A seguir será feita uma classificação sobre os tipos de forças, e também sobre os tipos de sistemas dinâmicos, quanto à natureza de suas forças atuantes. O objetivo de tal classificação é mostrar em quais situações é possível utilizar métodos estáticos e, quando será necessário adotar-se um método cinético para o estudo de estabilidade estrutural.

\subsubsection{Classificação de forças e sistemas}

É possível classificar um esforço atuante em uma estrutura segundo diversos critérios. No contexto de mecânica, uma força é considerada sempre como um vetor com um ponto de aplicação. Esse ponto de aplicação pode mudar de posição com o tempo ou pode ser fixo. Além disso, o vetor que indica a norma, direção e sentido da força também pode se alterar com o tempo. Para aplicações que envolvam carregamentos distribuídos no volume ou na superfície da estrutura em questão, o raciocínio é semelhante, com a diferença de que não se trata diretamente de uma força mas, de um campo vetorial que deve ser integrado no volume ou na área em questão. Essa é a primeira classificação de esforços que será aqui mencionada: esforços que variam no tempo são denominados não estacionários e, aqueles que são invariantes no tempo, são estacionários. Essa variação pode ocorrer tanto em norma, alterando a magnitude do esforço, como em direção e sentido. 
Outra forma de classificação de um esforço é relacionada ao trabalho realizado. Segundo Ziegler (1968), algumas forças são usualmente referidas como conservativas pois são compatíveis com a noção de conservação de energia em um sentido puramente mecânico. Nesse caso, o trabalho realizado pela força deve ser independente da trajetória realizada pelo seu ponto de aplicação. Outra forma de definir o que são forças conservativas é apresentada tanto por Ziegler (1968) como por Leipholz (1975): uma força é conservativa se o trabalho realizado ao longo de um deslocamento de seu ponto de aplicação depender somente das posições inicial e final desse ponto. Uma força que não satisfizer essa condição deve ser classificada como não conservativa. Além disso, um sistema de forças será considerado conservativo, se todas as suas forças forem conservativas. Ziegler (1968) mostra que, para sistemas escleronômicos e holônomos um esforço conservativo pode ser obtido através da derivação de um potencial escalar, em relação às coordenadas generalizadas do sistema. O autor ainda comenta que, de modo geral, somente esforços que dependam exclusivamente da configuração do sistema podem ser classificados como conservativos.

Outra forma de classificação é a de um esforço poder ser ativo ou reativo. Um esforço ativo é aquele que, de modo geral, depende das variáveis de estado $q_{k}, \dot{q}_{k}$ e do tempo. Já uma força reativa é aquela que não é conhecida a priori, e decorrerá da integração temporal das equações diferenciais do problema. Surgem quando ocorrem vínculos na estrutura. Em sistemas escleronômicos, os vínculos não são variantes no tempo. Essa situação resultaria em reações vinculares que não realizam trabalho positivo. Ou as reações não realizam trabalho (pressão e atrito seco estático, por exemplo) ou são puramente dissipativas realizando trabalho negativo, como atrito seco cinético (ZIEGLER, 1968). Já em situações de vínculos reonômicos, pode haver trabalho realizado pela reação vincular, uma vez que o vínculo se move no tempo, podendo haver deslocamentos não nulos na direção da reação. Nessa situação é necessário que se tenha bastante cuidado ao analisar se o esforço vincular é ou não conservativo. Por exemplo, o problema da flambagem de Euler pode ser formulado de forma alternativa à apresentada em C.1. Em vez de se impor um carregamento compressivo no topo da viga, pode-se imaginar que exista um vínculo que impõe deslocamento compressivo no topo da viga. Assim sendo, a força vincular realizaria trabalho.

Do ponto de vista de análise de estabilidade podem existir diferenças conceituais entre o problema em que se impõe força ou deslocamento ${ }^{3}$.

\footnotetext{
${ }^{3} \mathrm{~A}$ nomenclatura para forças impostas é denominada load control, ou controle nas forças. Para se referir a situações de imposição de deslocamentos, usa-se a expressão displacement control.
} 
Bazant e Cedolin (2003) ilustram um exemplo de treliças de von Mises. Esse problema é caracterizado por instabilidade do tipo ponto limite. Obviamente, para o sistema com um grau de liberdade com deslocamento imposto, nunca ocorrerá instabilidade. No entanto, quando se consideram as treliças de von Mises com uma mola adicional (Figura 3.6 (a)) o sistema se apresenta com dois graus de liberdade e diferentes comportamentos podem ocorrer quando se impõe força ou deslocamento segundo o grau de liberdade $q_{2}$. Dependendo do coeficiente de rigidez $C$ da mola o comportamento do sistema pode apresentar não somente um ponto limite mas, adicionalmente, um comportamento denominado snapback, ilustrado na Figura 3.6 (b) e (c). Partindo do ponto limite e seguindo pela trajetória de equilíbrio, uma tangente vertical ao gráfico pode ser identificada e a trajetória volta a ter uma inclinação positiva. Esse comportamento é denominado snap$b a c k$, fazendo alusão ao decremento do deslocamento segundo o grau de liberdade $q_{2}$ que é necessário para construir a trajetória de equilíbrio. No caso de se tentar impor um deslocamento infinitesimalmente maior ao ponto de snapback, ocorre um salto dinâmico da estrutura para o ramo inferior da trajetória de equilíbrio. Essa busca por uma nova configuração de equilíbrio é denominada snapdown ${ }^{4}$.

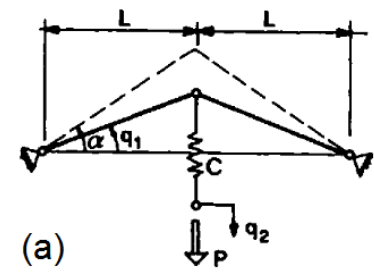

(b)

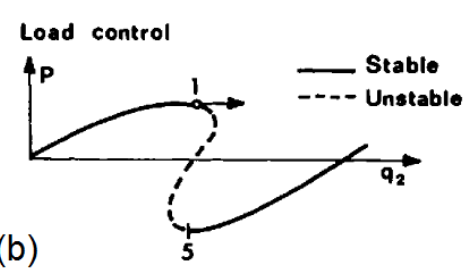

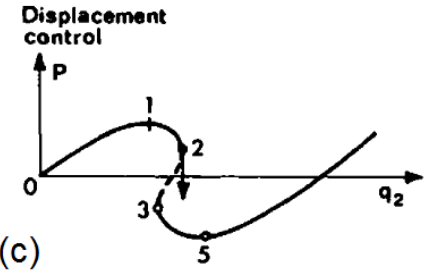

(c)

Figura 3.6: Exemplo de treliças de von Mises com dois graus de liberdade (a) Ilustração da estrutura (b) Comportamento do sistema com controle de força (c) Comportamento do sistema com controle de deslocamento. Adaptado de Bazant e Cedolin (2003).

Realizando-se a análise de estabilidade das trajetórias de equilíbrio para ambos os casos, é possível concluir que o ponto limite é o relacionado à perda de estabilidade apenas no caso de controle de força. Quando o controle é feito no deslocamento, o sistema se torna instável somente após a ocorrência do snapback. Esse comportamento está ilustrado na Figura 3.6 (b) e (c). Essa é uma conclusão muito importante pois o mesmo problema resolvido com duas estratégias diferentes leva a distintas conclusões sobre o ponto de perda de estabilidade.

Ainda quanto à questão de imposições de deslocamentos versus forças, cabe um comentário acerca de aplicações em simulações estáticas que envolvam passos de aplicação

\footnotetext{
${ }^{4}$ Nota-se que o comportamento do tipo snapback pode ser claramente visto na Figura 2.6, referente ao problema da formação de laços em vigas inicialmente retilíneas para o problema encurtamento-torção apresentado de forma bastante completa por Miyazaki e Kondo (1997).
} 
de carregamentos utilizando-se o MEF. Muitas vezes é mais conveniente trabalhar com a imposição de um deslocamento, em vez da imposição de uma força. Quando o controle é feito em função do deslocamento imposto, a força vincular decorre para cada incremento de deslocamento. Assim sendo, é possível simular com facilidade situações em que há perda de rigidez da estrutura, muitas vezes refletindo em um decréscimo de reação vincular para alguns passos de carregamento. Problemas que apresentam instabilidade do tipo ponto limite são típicos exemplos desses cenários em que, dentro da hipótese de problema estático, pode haver grande dificuldade numérica para se trabalhar com com imposição de forças, uma vez que a rigidez do sistema se torna negativa após o ponto limite. Isso obriga o algoritmo a realizar um decréscimo na força para um aumento nos deslocamentos. Nessas situações, ao trabalhar com imposição de forças é necessário utilizar-se de métodos do tipo Arc-length, a fim de possibilitar esse decréscimo na força. Já com a imposição de deslocamentos, não existe essa necessidade (a não ser em situações em que seria necessário realizar decrementos de deslocamentos impostos, como o caso de snapback) e normalmente existe muito maior facilidade de convergência numérica.

Por fim, a escolha entre trabalhar com forças ou deslocamentos impostos não deve fazer alusão somente à conveniência numérica para o problema em questão. O questionamento mais importante deve ser relacionado a qual seria o que melhor modela o problema que se deseja resolver. No entanto, uma vez feita a escolha é importante ter em mente as diferenças esperadas nas predições de instabilidade. Em muitas situações que ocorrem nesse trabalho os pontos limite e de snapback são tão próximos que a predição de instabilidade se torna praticamente equivalente com imposição de deslocamentos ou de forças. Esse tema será retomado no Capítulo 5 no contexto dos resultados.

Uma outra classificação de forças seria quanto à sua dependência com a velocidade. Esforços dependentes das velocidades $\dot{q}_{k}$ dos graus de liberdade do sistema podem ou não realizar trabalho. São classificados como esforços giroscópicos quando são dependentes da velocidade, mas não realizam trabalho, sendo inerentes ao movimento do próprio sistema. Ex. forças de Coriolis. Já quando são dependentes da velocidade e realizam trabalho, possuem grande importância os esforços que realizam trabalho negativo. Esses são denominados dissipativos, pois dissipam energia do sistema. Ex: forças de arrasto hidrodinâmico.

Ainda, para as forças que são independentes das velocidades dos graus de liberdade do sistema, é possível fazer uma outra classificação. Esforços independentes da velocidade e que são conservativos, são denominados não circulatórios. Aqueles que são 
independentes da velocidade e não são conservativos são denominados circulatórios.

Esforços circulatórios são bastante comuns, pois realizam trabalho em ciclos de movimento que passam pela mesma posição, por exemplo em eixos, polias, etc. Uma força seguidora, de modo geral é um carregamento circulatório, pois seu trabalho realizado em um movimento depende da trajetória do sistema. Existem, no entanto, situações peculiares em que esforços seguidores de pressão aplicada em sistemas estruturais são conservativos.

Um outro exemplo é o de um momento aplicado a um corpo rígido. O trabalho realizado pelo momento ocorrerá somente se houver alguma componente de rotação na direção do momento. No entanto, diferentes sequências de rotação passando através de diferentes eixos podem levar um sistema de uma certa posição inicial para outra final. Assim sendo, como o trabalho realizado pelo momento depende do histórico de rotações realizadas, ou seja, de qual o caminho que o sistema percorreu no espaço, esse esforço é classificado como circulatório, pois não é conservativo. Situações em que há restrição de rotação em mais de uma direção tornam o momento um carregamento conservativo, pois dessa forma se impossibilitam as diferentes sequências de rotação para ir de estado inicial a outro final, tornando o caminho único. Isso permite calcular o trabalho realizado pelo momento segundo a rotação realizada por um único possível caminho. Essa discussão é aprofundada no Apêndice C, onde são discutidas as influências das condições de contorno na carga crítica do problema de Greenhill.

Com base nos tipos de forças definidas, é possível classificar alguns problemas típicos para análise de estabilidade estrutural. A Figura 3.7 é apresentada em Ziegler (1968), pois cada um desses tipos de problema apresenta uma específica forma de ser abordado para análise de estabilidade estrutural.

A seguir serão apresentados alguns teoremas e observações sobre estabilidade de estruturas. O objetivo é fundamentar os tipos de problemas que podem ser analisados com as diversas técnicas de estudo de estabilidade.

\subsubsection{Teoremas e observações sobre estabilidade de estruturas}

Os teoremas serão apresentados sem demonstração. Tais detalhes estão presentes em Ziegler (1968), Mazzilli (2009) e Thompson e Hunt (1973). Supõe-se a existência de um sistema dinâmico, por exemplo uma estrutura, com $n$ graus de liberdade, cujas coordenadas generalizadas por construção possuam valor nulo no equilíbrio, sendo esse o estado 


\begin{tabular}{|c|c|c|c|c|}
\hline \multicolumn{2}{|c|}{ Conservative systems } & \multicolumn{3}{c|}{ Nonconservative systems } \\
\hline Nongyroscopic & Gyroscopic & $\begin{array}{c}\text { Purely } \\
\text { dissipative }\end{array}$ & $\begin{array}{c}\text { Purely } \\
\text { circulatory }\end{array}$ & $\begin{array}{c}\text { Purely } \\
\text { instationary }\end{array}$ \\
\hline $\begin{array}{c}\text { Euler } \\
\text { buckling }\end{array}$ & $\begin{array}{c}\text { Critical } \\
\text { speeds }\end{array}$ & $\begin{array}{c}\text { Buckling with } \\
\text { damping }\end{array}$ & $\begin{array}{c}\text { Buckling by } \\
\text { tangential load }\end{array}$ & $\begin{array}{c}\text { Buckling by } \\
\text { pulsating load }\end{array}$ \\
\hline
\end{tabular}

Figura 3.7: Classificação de tipos de sistemas quanto à estabilidade. Figura extraída de Ziegler (1968).

básico, isto é, $q_{k}=0$ com $k=1, \ldots, n$. O objetivo é o estudo da estabilidade desse ponto de equilíbrio, a fim de prever quais são suas condições de estabilidade/instabilidade utilizando-se de métodos estáticos ou cinéticos, de acordo com a natureza dos esforços atuantes, segundo a Figura 3.7.

Teorema 1 (Lagrange-Dirichlet): "Supondo-se que a energia total de um sistema é contínua, o equilíbrio desse sistema contendo apenas esforços conservativos e dissipativos é estável sempre que a energia potencial for positivo-definida." (ZIEGLER, 1968)

Outra forma de enunciar o teorema também pode ser vista: "Quando a energia potencial tiver um mínimo associado a uma posição de equilíbrio, a posição de equilíbrio é estável." (LEIPHOLZ, 1987)

É importante notar que esse teorema afirma que a energia potencial ser positivodefinida (ou apresentar um ponto de mínimo associado) é condição suficiente, porém não necessária para garantir a estabilidade. Para sistemas giroscópicos, por exemplo, pode ocorrer a estabilidade mesmo que a energia potencial não seja positivo-definida. Existe grande generalidade em aplicações desse teorema, uma vez que nenhuma ressalva é feita sobre o sistema ser linear ou não linear.

Dirichlet demonstrou esse teorema para sistemas conservativos discretos. Segundo Mazzilli (1979), ainda para esse tipo de sistema não se pode afirmar formalmente que é válida a recíproca do teorema. Mazzilli ainda afirma que Koiter (1966) mencionou que aparentemente Chetayev teria feito uma demonstração de caráter geral da recíproca do teorema de Lagrange-Dirichlet, mas essa prova acabou não sendo publicada nem mesmo 
no trabalho de Chetayev por sua complexidade matemática. Koiter ainda afirma que, ao considerar pequenas forças dissipativas em um sistema, algo que sempre está presente na realidade, seria possível garantir a recíproca do Teorema de Lagrange-Dirichlet e, ainda, que a estabilidade (no caso de sua ocorrência) seria assintótica. Divergências entre Koiter e Truesdell surgiram, na medida que o primeiro procurou sempre demonstrar para diversos casos particulares, bem como fundamentado por evidências experimentais que, desde que tomados alguns cuidados, a inversão do Teorema de Lagrange-Dirichlet é válida. No entanto, Truesdell apresentava-se com uma postura mais radical do ponto de vista teórico, sempre questionando os argumentos de Koiter. Nessa discussão identificam-se diferentes pontos de vista filosóficos de ambos.

Por fim, pela ausência de contra-exemplos e por todo o histórico do tema, acabase hoje por aceitar a recíproca do teorema para sistemas discretos, conservativos e nãogiroscópicos.

Muitos autores, por exemplo Leipholz (1987) e Mazzilli (1982), apresentam o Teorema de Lagrange-Dirichlet como uma decorrência do Segundo Método de Lyapunov aplicado a sistemas conservativos. Para tal, toma-se como função de Lyapunov a energia mecânica total do sistema, que é constante. Uma vez que a energia mecânica é dada pela soma da energia cinética (positivo-definida) com a energia potencial (pode ser positiva ou negativa), ao analisar um ponto de equilíbrio utilizando-se do Segundo Método de Lyapunov, decorre a tese do Teorema de Lagrange-Dirichlet.

O próximo teorema que será apresentado utiliza-se de um conceito denominado "sistema simples":

Um sistema linear é classificado como "simples" se for possível escrever sua energia potencial da seguinte forma:

$$
U=U_{i n t}+U_{e x t}=U_{i n t}-P \bar{U}
$$

Nessa expressão, $U_{i n t}$ é uma função dos deslocamentos nos graus de liberdade do sistema, mas é independente dos carregamentos atuantes por ser a parcela referente à energia de deformação. $P$ é um parâmetro escalar de carregamento para quantificar a intensidade da carga, e $\bar{U}$ é uma função dos graus de liberdade do sistema. Quando o sistema é "simples" é possível escrever a energia potencial da seguinte forma: 


$$
U=\frac{1}{2} \sum_{i, k=1}^{n}\left(a_{i k}-P b_{i k}\right) q_{i} q_{k}
$$

A matriz $a_{i k}$ é sempre positivo-definida e a matriz $b_{i k}$ poderá ser positivo-semidefinida. Se o valor do parâmetro de carregamento $P$ for aumentado, para um certo valor $P_{1}$ a energia potencial deixará de ser positivo-definida, indicando ocorrência de instabilidade no sistema.

Ziegler (1968) afirma que com poucas exceções, sempre um sistema será "simples". As exceções estariam por conta de alguns problemas caracterizados por grandes deslocamentos. Assim, agora pode-se apresentar o:

Teorema 2: "Em problemas de estabilidade linear de sistemas conservativos não giroscópicos, todos os carregamentos críticos são dados não somente pelo Método Cinético, mas também pelo Método da Energia. Uma vez que o problema é "simples", o sistema é estável para qualquer carregamento $P<P_{1}$ e instável para $P \geq P_{1}$, em que $P_{1}$ é o menor valor de carregamento para o qual a energia potencial é não positivo-definida. O Método do Equilíbrio também determina $P_{1}$ e as cargas críticas superiores que, entretanto, não são significantes." (ZIEGLER, 1968)

Esse teorema justifica o funcionamento do Método do Equilíbrio para sistemas conservativos e não giroscópicos, como é o caso da viga de Euler, e do problema de Greenhill (desde que o momento de torção seja aplicado de forma conservativa) apresentados no Apêndice C. O Método do Equilíbrio é largamente utilizado, com sucesso, em muitos outros problemas clássicos da mecânica dos sólidos.

Uma análise de estabilidade através da hipótese estática não considera efeitos inerciais. Assim, existe mais um teorema que mostra que para alguns tipos de sistemas a distribuição de massa não afeta as cargas críticas.

Teorema 3: "Em um sistema conservativo não giroscópico, linear ou linearizado, as cargas críticas são independentes da distribuição de massa." (ZIEGLER, 1968)

Esse teorema deve ser observado com o cuidado que se refere à contribuição da massa nas forças de inércia. No entanto, a massa pode ter um papel importante no que tange a carregamentos de campo. Por exemplo, o problema de flambagem de uma estrutura pelo seu peso próprio é absolutamente dependente da massa da estrutura.

Havendo o interesse em estudar também sistemas dissipativos, apresenta-se mais 
um teorema, dessa vez não para sistemas conservativos, mas sujeitos a esforços de amortecimento, ou atritos de deslizamento, que drenam energia do sistema.

Define-se um sistema puramente dissipativo como sendo aquele no qual além das forças conservativas (que estão praticamente sempre presentes), somente forças dissipativas atuam. Assim, não atuam forças circulatórias ou não estacionárias.

Teorema 4: "O teorema 2 permanece válido para sistemas puramente dissipativos." (ZIEGLER, 1968)

Assim sendo, também é possível calcular a instabilidade de sistemas puramente dissipativos através de abordagens estáticas. No entanto, nas situações em que ocorrem esforços circulatórios ou não estacionários será necessário um cuidado muito maior, uma vez que:

Teorema 5: "Sistemas conservativos podem ser estabilizados ou instabilizados por meio de esforços circulatórios." (ZIEGLER, 1968)

Teorema 6: "Em geral, problemas de estabilidade do tipo circulatório não podem ser resolvidos por abordagens estáticas" (ZIEGLER, 1968)

Teorema 7: "Problemas de estabilidade do tipo não estacionário não podem ser resolvidos por abordagens estáticas." (ZIEGLER, 1968)

A seguir apresentam-se dois importantes teoremas, creditados a Thompson. Devem ser especificamente aplicáveis à utilização do Método do Equilíbrio, ou seja, válidos para quando se lida com problemas conservativos não giroscópicos, ou ainda puramente dissipativos segundo os teoremas apresentados por Ziegler. A demonstração dos Teoremas 8 e 9 é feita somente para problemas de um grau de liberdade, mas os próprios Thompson e Hunt (1973) afirmam que: "Como se poderia supor a partir de seu caráter não-linear, os teoremas não estão prontamente provados, e somente provas limitadas estão disponíveis no presente. A evidência de muitos exemplos estruturais específicos e a experiência na teoria geral da estabilidade elástica realmente no entanto oferecem suporte à total validade dos teoremas: mais uma prova é dada pela significante falta de contra-exemplos, os quais foram intensamente procurados."

Teorema 8: "Uma trajetória de equilíbrio inicialmente estável, dita trajetória primária, crescendo monotonicamente com o parâmetro de carregamento, não pode tornar-se instável sem interceptar uma outra trajetória de equilíbrio, dita trajetória secundária."(THOMPSON; HUNT, 1973) 
Teorema 9: "Uma trajetória de equilíbrio inicialmente estável, crescendo com o parâmetro de carregamento, não pode alcançar um estado instável, a partir do qual o sistema exiba o fenômeno de snap-through (deslocamentos dinâmicos, na busca de novos estados equilibrados), sem que se aproxime de uma trajetória de equilíbrio - que pode ou não ser uma extensão da trajetória original - definida para valores do parâmetro de carregamento inferiores àquele do estado instável."(THOMPSON; HUNT, 1973)

Em resumo, dos teoremas 8 e 9 pode-se afirmar que quando se tem uma trajetória de equilíbrio inicialmente estável, para que ela passe a ser instável é condição necessária que passe por um ponto de bifurcação ou por um ponto limite.

A seguir será discutido o problema central desse trabalho, bem como qual a metodologia utilizada para o seu estudo de estabilidade, com base nos teoremas apresentados.

\subsection{A configuração estática de risers em catenária}

O problema específico que se analisa nesse trabalho é o de um riser em configuração estática de catenária. Estudam-se situações em que ocorre instabilidade estrutural nesse tipo de configuração. Para tal, segundo o que foi discutido anteriormente, vários tipos de abordagens existem para a solução de um problema de estabilidade estrutural, dependendo da classificação do sistema, ou seja, dos tipos de forças e vínculos que atuam. Com base nos teoremas enunciados na seção 3.1.7, pode-se estabelecer uma série de hipóteses para a utilização de critérios estáticos (por exemplo o Método do Equilíbrio) ou cinéticos (por exemplo o Primeiro Método de Lyapunov).

Será feita agora uma discussão de alguns possíveis efeitos a serem levados em conta na modelagem de um riser em configuração de catenária. Serão discutidos os tipos de esforços externos atuantes, bem como sua implicação quanto à abordagem de metodologia para avaliação da estabilidade estrutural. Serão discutidos os seguintes aspectos: peso próprio da estrutura, contato unilateral entre o riser e o fundo do mar, esforços hidrostáticos atuantes externa e internamente à estrutura do riser, esforços hidrodinâmicos de correnteza marítima e imposições de movimentos de rotação nas extremidades do riser. Considera-se que a análise será feita em uma configuração de catenária, com suas extremidades fixas na âncora no fundo do mar e na posição da unidade flutuante, no topo.

Enfatiza-se que o objetivo do trabalho é identificar instabilidades de laços no riser que possam surgir por conta do momento de torção acumulado na mesma. Assim, o carregamento que desencadeia a instabilidade é o momento de torção aplicado ou a rotação 
imposta que cause o surgimento desse momento. No entanto, durante essa aplicação, os outros carregamentos e vínculos podem influenciar nas características do sistema. Por isso essa discussão se faz necessária.

\subsubsection{Peso próprio}

O carregamento do peso próprio presente em risers é dependente de um campo no espaço e, só existe, devido ao fato de o riser estar nas proximidades da Terra. Trata-se de um carregamento conservativo, uma vez que o trabalho realizado por tal esforço não depende da trajetória feita pelo riser que sofre ação do seu peso próprio, mas somente das suas posições final e inicial. Conclui-se que o sistema mecânico formado pelo riser fixado em suas extremidades e submetido somente ao seu peso próprio é conservativo.

\subsubsection{Contato unilateral entre o riser e o fundo do mar}

Em configurações de riser em catenária e também em alguns outros tipos como lazy-wave, existe uma porção do riser que se encontra apoiada sobre o solo. Os esforços presentes nessa região de interação entre superfícies do riser e do solo podem ser simplificados para duas componentes atuantes: normal e tangencial, para cada ponto de interação de contato entre as partes.

A componente normal não realiza trabalho se o solo for considerado como rígido, uma vez que a força atua somente quando há sua solicitação e, nessa situação, o deslocamento de seu ponto de aplicação é nulo na direção normal. Dessa forma, quando a força atua e existe deslocamento, esse será ortogonal à mesma, não havendo trabalho realizado. No caso de se considerar a flexibilidade do solo, seu efeito pode ser simplificado ao de uma base elástica conservativa que acomoda o sistema. De modo mais geral, pode ocorrer algum efeito de amortecimento na direção normal das regiões de contato para movimentos cíclicos que envolvam alternância das forças de contato. Nesse caso, o esforço poderia ser considerado como não conservativo, mas possuiria um papel dissipativo, uma vez que haveria energia drenada do sistema.

Já o efeito tangencial dos esforços de contato, denominado "força de atrito" não realiza trabalho no caso de não haver deslizamento, uma vez que o ponto de aplicação da força não se move nessa situação. Quando há deslizamento, o trabalho do atrito é dissipativo, uma vez que a "força de atrito" se oporá ao movimento que induziu seu surgimento. 
Assim, o efeito do carregamento de contato unilateral entre o riser em catenária e o solo do fundo do mar não acrescenta energia ao sistema e, de forma mais realista, pode-se considerar que essa interação pode drenar energia. Trata-se de um vínculo não linear, uma vez que os outros esforços presentes no riser podem alterar sua elastica e, consequentemente, sua região de contato, bem como os esforços que atuam nessa interação.

O vínculo do contato unilateral pode ser escrito na forma de uma inequação que restringe o movimento dos pontos da estrutura a certa região do espaço. Seja um conjunto de pontos $\boldsymbol{P}_{\boldsymbol{i}}$ cujas coordenadas são dadas por $\boldsymbol{x}_{\boldsymbol{P} \boldsymbol{i}}$ forçados a permanecer em certa região do espaço delimitada por uma superfície plana cuja normal é $\boldsymbol{k}$ e que passa pela origem do sistema de coordenadas (Figura 3.8). Se os pontos devem permanecer acima dessa superfície, cotas negativas da coordenada z não são permitidas. Assim, o vínculo é dado por:

\section{$\boldsymbol{X P i}_{\mathrm{Pi}}$}

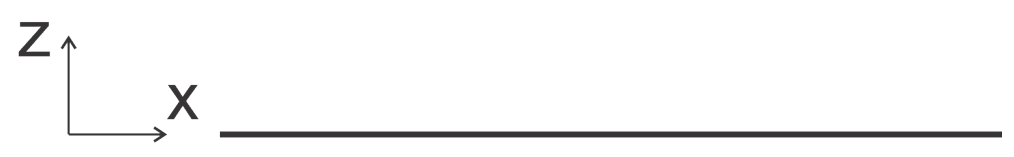

Figura 3.8: Vínculo do contato unilateral presente em alguns tipo de configurações de risers

$$
\boldsymbol{x}_{\boldsymbol{P i}} \cdot \boldsymbol{k} \geq 0
$$

Goldstein (1980) discute os tipos de vínculos que podem ocorrer em problemas mecânicos. O caso do vínculo descrito pela inequação 3.17 é classificado como nãoholônomo. Além disso, trata-se de um vínculo não dependente explicitamente do tempo. Obviamente as posições dos pontos $\boldsymbol{x}_{\boldsymbol{P} \boldsymbol{i}}$ podem variar ao longo do tempo, ou mesmo que se pense em um problema quase-estático, cada ponto do riser pode se mover e iniciar/finalizar o contato com o solo conforme a estrutura se assenta sobre o solo ou sofre outros carregamentos, como correntezas marítimas. No entanto, como o solo é considerado fixo ao longo do tempo, o mesmo não realiza excitação de suporte no riser, o que poderia representar uma injeção de energia no sistema. Assim, suas reações vinculares podem ser classificadas como "não realizadoras de trabalho" (por exemplo, a pressão normal e o atrito seco estático) ou "dissipativas" (realizam trabalho negativo, por exemplo o atrito seco cinético). Logo os esforços que atuam no contato unilateral não podem realizar trabalho positivo, mas são carregamentos puramente dissipativos (um sistema conservativo com a adição de forças dissipativas). 
No entanto, o vínculo unilateral que representa o contato torna a solução do sistema mecânico não-suave. Esse tipo de situação ocorre quando se introduz um tipo de vínculo no sistema que pode levar à não-suavidade das funções que descrevem os deslocamentos e velocidades (non-smooth mechanics). O questionamento que surge é quanto à validade dos teoremas de Lyapunov, bem como do Teorema de Lagrange-Dirichlet nesse tipo de situação. O desenvolvimento desse assunto é muito bem explorado por Leine e van de Wouw (2008). Os autores apontam esse tipo de estudo como uma área de pesquisa iniciada duas décadas antes da publicação de seu livro e, portanto, algo muito mais novo do que datam os teoremas originais de estabilidade que foram citados anteriormente, desenvolvidos cerca de 100 anos antes. Para abordar tal assunto, é necessário uma base matemática que envolve análise convexa e relações que apontam para conjuntos (set-valued relations) compiladas nos Capítulos 2 e 3 de Leine e van de Wouw (2008).

Chareyron e Wieber (2004) afirmam que a teoria de estabilidade de Lyapunov é usualmente apresentada para sistemas dinâmicos cujos estados variam de forma contínua ao longo do tempo. Por isso, procuram propor uma extensão do teorema de estabilidade de Lyapunov para esse tipo de sistema. Os autores comentam que sua extensão é bastante próxima à forma que é apresentada para o caso contínuo. A única diferença seria na primeira condição do teorema que, no caso contínuo, exigiria que a Função de Lyapunov fosse positivo-definida somente na vizinhança do estado básico. No caso que considera sistemas dinâmicos não suaves, é exigido que a Função de Lyapunov seja positivo-definida em todo o espaço de estados, uma vez que as descontinuidades poderiam fazer o estado dar um salto brusco a qualquer momento para uma região muito longe do estado básico. Chareyron e Wieber (2004) ainda afirmam que é possível estender o Teorema de LagrangeDirichlet para sistemas dinâmicos não-suaves. O mesmo foi anteriormente apresentado por Brogliato (2004), que estendeu o teorema de Lagrange-Dirichlet para situações que envolvem não-linearidades do tipo contato unilateral sem atrito.

Leine e van de Wouw (2008) generalizam o Método Direto de Lyapunov (Segundo Método de Lyapunov), dentre outras técnicas e teoremas para problemas que envolvem restrições de contato unilateral. Apontam, inclusive, que a escolha natural de funções de Lyapunov para tratar tais problemas seria a energia mecânica total do sistema incluindo a função-suporte da restrição unilateral. Inclusive algumas aplicações são feitas para problemas que envolvem contato com atrito. 


\subsubsection{Esforços hidrostáticos atuantes externa e internamente à estrutura do riser}

Carregamentos de pressão hidrostática atuantes na superfície externa do riser ou, no caso de tubos, também na superfície interna, são seguidores. Isso, pois sempre estão alinhados com a direção normal à superfície na qual estão sendo aplicados. No item 3.1.6 foi dito que esforços seguidores podem ou não ser circulatórios. No caso da pressão hidrostática, apesar de ser uma carga seguidora, para algumas situações de condição de contorno da superfície na qual a pressão está sendo aplicada tal esforço pode ser classificado como não circulatório, uma vez que poderá ser escrito na forma de um potencial escalar. Essa questão será discutida a seguir.

Bolotin (1963) apresenta uma discussão acerca das situações em que um carregamento de pressão pode ser considerado como não circulatório. O autor mostra que forças seguidoras, de modo geral, não possuem um potencial escalar associado. Bolotin enfatiza o problema de um carregamento uniformemente distribuído em uma região da superfície externa de um corpo, e sempre permanecendo normal a essa superfície. Nessa situação, o carregamento é denominado hidrostático e se, de fato, for causado por um líquido em repouso, será uma força conservativa. Bolotin ainda vai além e mostra que, em uma superfície espacial que forma uma casca não necessariamente plana, se todo o seu contorno estiver vinculado na direção normal à casca, ou nas direções tangenciais à mesma, o carregamento de uma pressão uniforme aplicado nesse casca, mesmo que seguidor, pode ser escrito na forma de um potencial escalar. Conclui-se que dependendo das condições de contorno, um campo de pressão uniforme atuante em uma estrutura pode ou não ser conservativo.

Discussões acerca da generalização da possibilidade de escrever uma distribuição de pressão qualquer na forma de um potencial escalar foram feitas posteriormente à obra de Bolotin. Cohen (1966) apresenta uma curta coluna publicada no AIAA Journal com informações bastante relevantes sobre o assunto. O autor mostra que a expressão obtida por Bolotin para o potencial da pressão é válida somente para cascas planas (placas) e, além disso, generaliza o resultado para um campo de pressões não uniforme contínuo atuante em uma casca arbitrária. As possibilidades de condições apontadas por Cohen (1966) para garantir que o campo de pressão é conservativo são as seguintes:

- A pressão é nula no contorno da casca ou,

- O deslocamento na direção normal à casca em seu contorno é nulo ou, 
- O deslocamento nas direções tangenciais à casca em seu contorno é nulo ou,

- O deslocamento em uma direção intermediária entre a normal e a tangencial da casca é nulo em suas extremidades. Nesse caso o potencial é alterado por um termo adicional que depende de uma integral no contorno do problema.

Ainda pode-se apontar o trabalho de Schweizerhof e Ramm (1984) em que é feita uma discussão acerca de tipos de carregamentos de pressão e condições para serem ou não conservativos. Os autores comentam que os potenciais apontados para a pressão por Bolotin (1963) e Cohen (1966) são válidos somente para problemas de estabilidade linear, portanto para a hipótese de pequenos deslocamentos.

Para situações de grandes deslocamentos alguns trabalhos como o de Romano (1972) mostram a possibilidade de a pressão ser um carregamento conservativo, desde que algumas condições de contorno sejam satisfeitas. O autor apresenta uma demonstração matemática sobre as condições para que uma pressão hidrostática possa ser um carregamento conservativo e, aponta as condições dadas por Bolotin como um caso particular das condições suficientes para tal conclusão. Schweizerhof e Ramm (1984) afirmam ainda que as condições dadas por Romano podem ser generalizadas para um caso de pressão não uniforme. Em meio a uma rica discussão acerca das condições para o fato de os esforços serem ou não conservativos, Schweizerhof e Ramm (1984) apresentam uma classificação para esforços de pressão que sejam dependentes da posição do sistema:

- Esforços vinculados ao espaço: aqueles nos quais a direção e magnitude do carregamento são dependentes dos deslocamentos da estrutura, a qual se deforma em meio ao campo de pressão vinculado ao espaço.

- Esforços vinculados ao corpo: aqueles nos quais somente a direção do carregamento é dependente dos deslocamentos da estrutura. O campo de pressão, nesse caso, é definido na configuração inicial da estrutura e sua distribuição não se modifica em termos de magnitude.

Os resultados de Romano (1972) e Schweizerhof e Ramm (1984) são de que a condição para que o carregamento seja conservativo é que a matriz de rigidez do carregamento em questão seja simétrica ${ }^{5}$. No entanto, muitas vezes a hipótese do tipo de

\footnotetext{
${ }^{5} \mathrm{O}$ termo matriz de rigidez do carregamento se refere à contribuição de rigidez obtida derivando-se os carregamentos aplicados em relação aos deslocamentos que ocorrem na estrutura. Trata-se de uma contribuição não nula somente em situações em que os carregamentos não são constantes, como é o caso de forças seguidoras.
} 
carregamento ser vinculado ao espaço ou ao corpo pode causar a simetria ou assimetria dessa matriz. Assim, é desenvolvido um equacionamento completo no qual se mostra em detalhes a fonte das não simetrias para os dois tipos de esforços classificados.

No caso de esforços vinculados ao espaço, de fato, as condições necessárias para garantir a simetria da matriz de rigidez do carregamento e, portanto, que tal esforço seja conservativo, são as seguintes:

- A pressão é nula no contorno da superfície de aplicação do esforço ou,

- Pelo menos duas componentes de deslocamentos no contorno são prescritas.

O contorno do problema está associado ao bordo da superfície na qual é aplicado o carregamento de pressão. No caso de um riser, o contorno está nas extremidades da superfície externa/interna da linha. Schweizerhof e Ramm (1984) apresentam ainda uma terceira condição que anularia alguns termos de rigidez assimétricas no operador tangente do esforço de pressão. Trata-se da imposição de que o contorno da superfície de aplicação da pressão esteja sempre restrito em sua direção normal, ainda que se deforme durante a aplicação da pressão.

No caso de esforços vinculados ao corpo, a condição de simetria se torna muito mais restrita. Para carregamentos de pressão não constante, sempre aparecerá uma parte do operador tangente que será não simétrica, tornando o esforço não conservativo. Já quando a pressão for constante, a vinculação ao corpo se torna equivalente à vinculação ao espaço, uma vez que a magnitude do carregamento não se modifica. Nessas condições a pressão não será nula no contorno (pois se assim o fosse, seria nula em toda superfície de aplicação, tornando o problema sem sentido) e, portanto, as condições de contorno relacionadas ao deslocamento no contorno da superfície de aplicação da pressão podem garantir que o carregamento é conservativo ou não de acordo com as condições discutidas anteriormente.

Schweizerhof e Ramm (1984) ainda apontam que a maioria dos campos de pressão na realidade podem ser identificados como sendo vinculados ao espaço, e não ao corpo. Ainda dizem que se deve ter cuidado ao analisar a estabilidade em estruturas quando se faz a vinculação ao corpo, uma vez que falsas não simetrias podem ocorrer, comprometendo as conclusões acerca da estabilidade do problema.

Para a aplicação no problema de risers em catenária, é possível idealizar o modelo da Figura 3.9. 


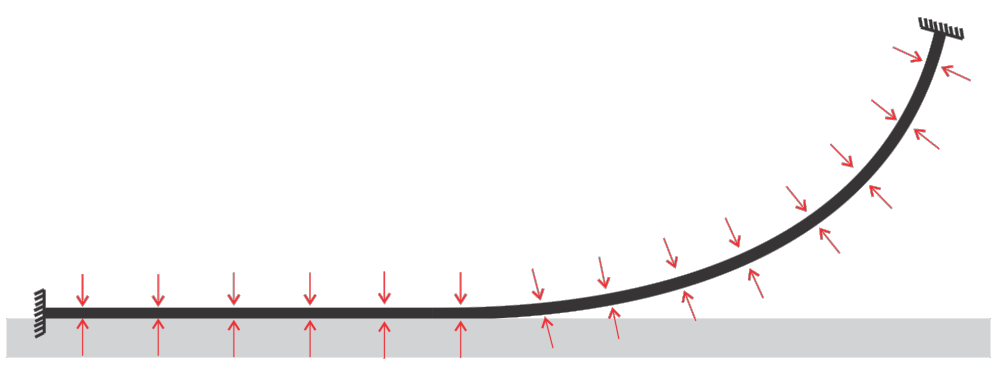

Figura 3.9: Esquema que representa o modelo de uma catenária submetida às condições de contorno (bi-engastamento), vínculo do contato com o solo e pressão externa

Nesse modelo existe o contato unilateral entre o riser e solo. Essa interação pode ser modelada através de vínculos de contato, conforme será ilustrado no Capítulo 4. A presença do atrito entre o riser e o solo na região em que há contato pode fazer com que haja total ancoragem do mesmo, tornando os esforços de tração nulos quando se está próximo de sua extremidade inferior. Ainda, dependendo da história do movimento do riser durante seu lançamento, é possível que haja esforços não nulos, mas acumulados em trechos de flowline (região do cabo umbilical ou tubo flexível que se encontra no solo). De qualquer forma, o modelo global do riser deve considerar um trecho suspenso e um trecho de flowline que seja suficiente para representar os possíveis movimentos e acomodações que possam surgir na parte suspensa. O ponto extremo inferior do riser que é representado na análise global é denominado âncora. Essa é considerada como engastada. Já o ponto extremo superior que representa a conexão entre o riser e a unidade flutuante, também pode ser considerado como engastado, mas geralmente com um ângulo de topo que anule momentos fletores nessa posição para a configuração de catenária em questão.

As condições de contorno adotadas consideram o bordo da superfície de aplicação das pressões interna e externa ao riser como estando engastadas. Logo, nessas condições, carregamentos de pressão uniforme ou não, tanto na superfície interna como externa do riser podem ser classificados como conservativos, pois a matriz de rigidez possui seus termos de contorno nulos, segundo as discussões desenvolvidas por Schweizerhof e Ramm (1984).

Sendo o tratamento numérico do contato com o solo independente do termo de contorno de rigidez, seu papel resultará na alteração da rigidez de certos graus de liberdade do domínio do modelo. O Princípio dos Trabalhos Virtuais aplicado ao conjunto de todos os esforços presentes e aos vínculos de contato acabará por determinar diversas parcelas da matriz de rigidez que devem ser superpostas. Logo, a parcela da matriz de rigidez proveniente do carregamento de pressão hidrostática que resulta no modelo da Figura 3.9 é simétrica, ainda que possa se modificar devido às não linearidades. A parcela do 
contato, como já foi explorado, poderá ser simétrica ou não, dependendo do atrito.

No Apêndice A é mostrado um estudo da integração da pressão nas paredes externas e internas de um riser. É concluído que nas condições mostradas na Figura 3.9 é possível utilizar-se do peso efetivo para realizar uma análise global. Nessa abordagem, a tração que surge na estrutura é denominada tração efetiva, e é quem governa o problema em termos de estabilidade estrutural. Logo, o efeito da pressão hidrostática (tanto externa como interna ao riser) pode ser modelado através do peso efetivo da estrutura. Essa forma de encarar o problema facilita bastante a interpretação do papel da pressão hidrostática em uma configuração global. Tudo pode ser corretamente tratado como se a estrutura tivesse um peso efetivo diferente do peso em ar e que já considera os efeitos da pressão hidrostática.

Ao trabalhar simplesmente com o peso efetivo, por ser um carregamento constante em norma, direção e sentido, é imediato que se trata de uma força conservativa, tal como o peso próprio da estrutura. Assim, sua contribuição para a matriz de rigidez do sistema será nula, estando presente somente no vetor de carregamentos.

\subsubsection{Esforços hidrodinâmicos de correnteza marítima}

A correnteza marítima possui papel importante na obtenção da elastica de um riser em catenária. Seu principal efeito na configuração estática é a força de arrasto. A modelagem desse tipo de esforço pode ser feita utilizando-se a Fórmula de Morison (MORISON et al., 1950). A aplicação dessa formulação no modelo desenvolvido nesse trabalho está detalhada no ítem 4.4.9.3, do Capítulo 4. Nessa formulação são utilizados dois coeficientes de arrasto: normal e tangencial ao riser. A parcela normal do arrasto possui uma ordem de grandeza mais elevada do que a tangencial. Por isso não é incomum desprezar o efeito do arrasto tangencial na determinação da elastica de uma catenária. Mesmo que os esforços de arrasto hidrodinâmico sejam função da velocidade da correnteza, que não é constante no tempo, é bastante razoável frente à baixa frequência de variação dessa velocidade que se considere tal esforço como quase-estático dentro da hipótese de coeficientes de arrasto médios constantes nas direções tangencial e normal. Mesmo com velocidade de correnteza constante, isso pode não ser razoável no caso de ocorrência de regime de VIV, em que o coeficiente de arrasto pode oscilar em frequências que afetem modos de vibrar do riser.

O coeficiente de arrasto normal, se calculado para um cilindro fixo, possui uma variação segundo o número de Reynolds. Para as faixas de velocidade de correnteza de aplicações offshore típicas, o coeficiente de arrasto possui um valor aproximadamente 
constante na faixa de 1, 1 a 1,2. No entanto, no caso de se considerar o cilindro com possibilidade de movimento, esse coeficiente pode subir consideravelmente, dependendo da velocidade considerada no escoamento externo. Dessa forma, a utilização de certo valor de coeficiente de arrasto para a determinação do arrasto médio que sensibilizará a configuração estática de um riser pode ser uma tarefa conceitualmente complexa, envolvendo inclusive o efeito do VIV e as mudanças de coeficientes de arrasto que ocorrem devido a esse fenômeno. Essa discussão está fora do escopo do presente trabalho, no qual será adotado um valor fixo de coeficiente de arrasto assumindo-se, portanto, que o fenômeno do VIV está sendo desprezado tanto no esforço de sustentação (que é essencialmente dinâmico e com média nula) como no arrasto médio (que pode ter uma importante influência na estática).

Uma vez que o riser se encontra em sua configuração estática, se a estrutura procurar realizar algum movimento em torno dessa configuração haverá um amortecimento hidrodinâmico. Na medida que as velocidades relativas entre a água e o riser se alteram, flutuações no campo de pressão dinâmico ocorrem. É razoável imaginar que quando não há correnteza, um movimento qualquer imposto ao riser irá se dissipar devido ao amortecimento hidrodinâmico. Nessa situação, o esforço de arrasto se oporá sempre ao movimento imposto. Da mesma forma ocorre quando há correnteza. A diferença é que em vez de a força de arrasto surgir somente quando a estrutura se move, nesse caso a mesma já existe e mantém a estrutura em uma configuração alterada. Caso haja movimentos da estrutura, haverá dissipação para procurar manter a elastica da configuração estática. Portanto, para a estrutura do riser o efeito da correnteza (desprezando-se os efeitos de VIV e de variação no arrasto médio) é uma força de arrasto média, dependente da velocidade relativa entre o riser e as águas.

O movimento do riser, mesmo que tratado estaticamente, pode levar a variações no valor das forças aplicadas na estrutura. Trata-se de um carregamento que depende tanto do perfil de velocidades do mar (ver ítem 4.4.9.3), como da orientação do riser, que em cada ponto é quem definirá a direção normal e tangencial e, portanto, quais as componentes de velocidade que sensibilizarão o arrasto normal e o tangencial. Trata-se, portanto, de um carregamento que depende dos deslocamentos e rotações da estrutura e que, de acordo com o histórico de movimento pode alterar o valor de seu trabalho realizado, sendo não conservativo. 


\subsubsection{Imposições de rotações na extremidade do riser}

Uma vez que se assumiu que a configuração de catenária está fixa em suas extremidades superior e inferior, o estudo da estabilidade da configuração pode incluir um efeito de rotação imposta em uma das extremidades considerada. Esse efeito visa a introduzir a torção residual que pode surgir durante a instalação ou, ainda, que aparece devido a movimentos rotativos (yaw) da unidade flutuante. Considera-se que a rotação é imposta na extremidade superior ou inferior do riser. O ponto escolhido para a aplicação da rotação possui deslocamentos fixos e nulos e as duas rotações ortogonais à direção axial do riser também fixas e nulas. Essa representação é bastante realista, uma vez que as extremidades do riser se encontram engastadas no fundo do mar e na unidade flutuante. Assim, o único grau de liberdade prescrito através da imposição de rotação é a direção axial de um ponto na extremidade do riser. De forma alternativa, é possível não prescrever a rotação na direção axial nesse ponto mas, impor um carregamento de momento com direção axial que cause o mesmo efeito na estrutura. A distinção entre aplicar o momento ou impor a rotação é discutida no Capítulo 5 e é bastante semelhante ao controle de forças e deslocamentos já discutido no tópico 3.1.6.

Nessa situação, a imposição de rotação ou do momento será um esforço conservativo, uma vez que a torção aplicada para esse tipo de condição de contorno é conservativa, pois as outras rotações do ponto estão fixas (ver Apêndice C).

\subsubsection{Discussão e critérios de estabilidade}

Com base na caracterização dos tipos de esforços presentes no problema de um riser em catenária, é possível afirmar com base nas hipóteses aqui presentes para cada esforço e nos teoremas discutidos, que é possível tratar o problema do estudo de instabilidade de configurações de catenária através de uma abordagem estática, desde que a correnteza marítima não seja considerada, tampouco se incluam efeitos de escoamento interno. No caso de considerar a correnteza, é possível que sua dependência ao campo de deslocamentos, que a torna não conservativa, sensibilize a estrutura de tal forma que um critério cinético seja importante.

Em função do exposto, nesse trabalho foram considerados dois critérios de estabilidade: estático e cinético. Dessa forma é possível comparar as abordagens e chegar a conclusões mais fundamentadas sobre o comportamento do sistema.

Para realizar o estudo de estabilidade foi necessário utilizar-se de um modelo com 
as seguintes especificações:

- Ser não linear, considerando as grandes rotações no espaço de forma cinematicamente não aproximada, inclusive com magnitudes de rotações superiores a um giro completo da seção transversal, visando a aplicar ângulos de giro elevados em algumas seções transversais sensibilizadas por torção residual e movimentos de rotação induzidos da unidade flutuante. Essa necessidade vem do fato de que podem ocorrer grandes rotações antes que o sistema atinja sua condição crítica;

- Contemplar o contato unilateral entre o riser e o solo do fundo do mar, inclusive com efeitos de atrito estático ou de deslizamento com um tratamento não linear, não sendo a região de contato conhecida a priori. Situações em que o movimento do TDP ocorre e, portanto, a região de contato se modifica durante a aplicação de outros esforços devem ser contempladas;

- Considerar o efeito das pressões hidrostáticas atuantes no riser de forma a prever corretamente sua influência no problema de estabilidade;

- Levar em conta o esforço da correnteza marítima utilizando-se para tal da Fórmula de Morison.

- A obtenção das matrizes do modelo que caracterizam o sistema pode ser feita de forma quase-estática, uma vez que o objetivo é analisar em função da torção imposta na linha, quando irá ocorrer sua instabilidade. Assume-se que todos os esforços envolvidos na análise possam ser aplicados de forma quase-estática. Enfatiza-se que essa hipótese não invalida a utilização de um critério de estabilidade cinético uma vez que, para cada passo de carregamento considerado, tem-se as matrizes do sistema, podendo ser aplicado o critério cinético.

Para realizar o estudo de estabilidade, uma vez atendidas as hipóteses que permitem a utilização de um critério estático, pode ser utilizado o critério citado por Schweizerhof e Ramm (1984), que consiste em estudar os autovalores da matriz de rigidez tangente (já assumindo que o sistema é discreto). A existência de uma singularidade nessa matriz indicaria que o sistema está com comportamento crítico (podendo ser um ponto de bifurcação ou ou ponto limite). A matriz de rigidez deve estar montada de forma completa, ou seja, com as contribuições constitutiva, geométrica e de carregamento. O critério estático aplicado à matriz de rigidez tangente $\boldsymbol{K}_{\boldsymbol{i}}$ para cada ponto " $i$ " de linearização do modelo é o seguinte: 


$$
\boldsymbol{K}_{i} \boldsymbol{q}_{i}=\mathbf{0}
$$

A indicação da existência de um ponto crítico ocorrerá quando o sistema linear descrito em 3.18 possuir solução não-trivial para o vetor $\boldsymbol{q}_{\boldsymbol{i}}$. Nesse caso, deve-se impor que o determinante da matriz de rigidez seja nulo.

Os esforços surgidos no problema certamente causam não linearidade geométrica devido à grande magnitude de deslocamentos e rotações que estão envolvidos na análise. No entanto, é conveniente que se resolva o modelo através de passos de carregamento, a fim de determinar a matriz de rigidez a cada passo para a análise de estabilidade ao longo da aplicação das cargas. Esse procedimento, quando aplicado ao modelo estático, permite a obtenção das trajetórias de equilíbrio, possibilitando a visualização de possíveis pontos limite ou bifurcações.

Em situações que envolvam a correnteza marítima existe a necessidade de se utilizar um critério de estabilidade cinético. Para tal, pela facilidade de aplicação à concepção do modelo desenvolvido, foi escolhido para realizar esse estudo o Primeiro Método de Lyapunov.

Sendo o modelo não linear, é possível realizar a análise de estabilidade em cada ponto sucessivo de linearização. Uma forma prática de realizar esse estudo é, no decorrer do incremento de certo carregamento (por exemplo, inserindo-se um momento de torção no riser), realizar sucessivas avaliações. Cada linearização pode ser feita após a aplicação de um certo passo de carregamento no sistema. Assim, tem-se o conhecimento das matrizes de massa e de rigidez tangentes ao longo da aplicação de certo carregamento que sensibilize a estabilidade. Em cada ponto de linearização do modelo resulta uma matriz de rigidez $\boldsymbol{K}_{\boldsymbol{i}}$ e uma matriz de massa $\boldsymbol{M}_{\boldsymbol{i}}$. Para a situação em questão assume-se que o sistema está sendo forçado com um carregamento constante no tempo $\boldsymbol{f}_{\boldsymbol{i}}$, que induz um estado de equilíbrio $\boldsymbol{x}_{\boldsymbol{i}}$.

Para o problema em questão, espera-se que todo e qualquer tipo de amortecimento tenderá somente a dissipar energia do sistema, não surtindo nenhum efeito instabilizador mas, pelo contrário, tendendo a estabilizar o problema. Por isso, desprezou-se qualquer tipo de amortecimento, de forma que se o critério de estabilidade valer para o problema não amortecido, também valerá para quando houver amortecimento. Para cada ponto de linearização " $i$ " pode-se escrever: 


$$
M_{i} \ddot{q}+K_{i} q=f_{i}
$$

Escrevendo a equação 3.19 considerando o vetor de estados $\boldsymbol{x}$, contendo tanto os deslocamentos $\boldsymbol{q}$ como as velocidades $\boldsymbol{v}=\dot{\boldsymbol{q}}$, tem-se:

$$
\dot{x}=\left[\begin{array}{c}
\dot{v} \\
\dot{q}
\end{array}\right]=\left[\begin{array}{cc}
0 & -M_{i}^{-1} K_{i} \\
I & 0
\end{array}\right]\left[\begin{array}{c}
v \\
q
\end{array}\right]+\left[\begin{array}{c}
M_{i}^{-1} f_{i} \\
0
\end{array}\right]
$$

Seja o estado básico dado por $\boldsymbol{x}_{\boldsymbol{i}}$ e o estado perturbado dado por $\boldsymbol{x}=\boldsymbol{x}_{\boldsymbol{i}}+\delta \boldsymbol{x}$ e que também haja uma perturbação nas forças externas $\delta \boldsymbol{f}_{\boldsymbol{i}}$. Introduzindo o estado perturbado na equação 3.20, é possível obter:

$$
\dot{\boldsymbol{x}}+\delta \dot{\boldsymbol{x}}=\left[\begin{array}{cc}
\mathbf{0} & -\boldsymbol{M}_{\boldsymbol{i}}^{-1} \boldsymbol{K}_{\boldsymbol{i}} \\
\boldsymbol{I} & \mathbf{0}
\end{array}\right](\boldsymbol{x}+\delta \boldsymbol{x})+\left[\begin{array}{c}
\boldsymbol{M}_{\boldsymbol{i}}^{-1} \boldsymbol{f}_{\boldsymbol{i}} \\
\mathbf{0}
\end{array}\right]+\left[\begin{array}{c}
\boldsymbol{M}_{\boldsymbol{i}}^{-1} \delta \boldsymbol{f}_{\boldsymbol{i}} \\
\mathbf{0}
\end{array}\right]
$$

O cálculo de $\delta \boldsymbol{f}_{\boldsymbol{i}}$ é dado por:

$$
\delta \boldsymbol{f}_{i}=\left[\begin{array}{ll}
\frac{\partial \boldsymbol{f}_{i}}{\partial \boldsymbol{v}} & \frac{\partial \boldsymbol{f}_{i}}{\partial \boldsymbol{q}}
\end{array}\right] \delta \boldsymbol{x}
$$

Logo:

$$
\left[\begin{array}{c}
\boldsymbol{M}_{\boldsymbol{i}}^{-1} \delta \boldsymbol{f}_{\boldsymbol{i}} \\
\mathbf{0}
\end{array}\right]=\left[\begin{array}{cc}
\boldsymbol{M}_{\boldsymbol{i}}^{-1} \frac{\partial \boldsymbol{f}_{\boldsymbol{i}}}{\partial \boldsymbol{v}} & \boldsymbol{M}_{\boldsymbol{i}}^{-1} \frac{\partial \boldsymbol{f}_{\boldsymbol{i}}}{\partial \boldsymbol{q}} \\
\mathbf{0} & \mathbf{0}
\end{array}\right] \delta \boldsymbol{x}
$$

Por hipótese, assume-se que $\boldsymbol{M}_{\boldsymbol{i}}{ }^{-1} \frac{\partial \boldsymbol{f}_{\boldsymbol{i}}}{\partial \boldsymbol{v}}=\mathbf{0}$. Assim, são desprezadas as contribuições de variações de forças em relação às velocidades nos graus de liberdade do sistema. Sendo o objeto de análise o estudo de um problema quase estático, assume-se que essas velocidades são muito pequenas e desprezíveis. Com isso, é possível desenvolver a equação 3.21 para chegar em: 


$$
\delta \dot{\boldsymbol{x}}=\left[\begin{array}{cc}
\mathbf{0} & -\boldsymbol{M}_{\boldsymbol{i}}^{-1}\left(\boldsymbol{K}_{\boldsymbol{i}}-\frac{\partial \boldsymbol{f}_{i}}{\partial \boldsymbol{q}}\right) \\
\boldsymbol{I} & \mathbf{0}
\end{array}\right] \delta \boldsymbol{x}
$$

Logo, o Primeiro Método de Lyapunov recai na determinação dos autovalores da matriz $\boldsymbol{A}_{i}$ dada por:

$$
\boldsymbol{A}_{i}=\left[\begin{array}{cc}
\mathbf{0} & -\boldsymbol{M}_{i}^{-1}\left(\boldsymbol{K}_{i}-\frac{\partial \boldsymbol{f}_{i}}{\partial \boldsymbol{q}}\right) \\
\boldsymbol{I} & \mathbf{0}
\end{array}\right]
$$

O termo $\boldsymbol{K}_{\boldsymbol{i}}-\frac{\partial \boldsymbol{f}_{\boldsymbol{i}}}{\partial \boldsymbol{q}}$ é exatamente a matriz de rigidez tangente completa utilizada para a solução não linear de um modelo de elementos finitos. De acordo com o sinal da parte real dos autovalores de $\boldsymbol{A}_{i}$ será possível extrair a informação da estabilidade do sistema, de acordo com o que foi comentado no tópico 3.1.4.4.

Schweizerhof e Ramm (1984) apresentam um critério cinético para o estudo de estabilidade através do cálculo das frequências naturais $\omega$ do sistema. Escrito para a notação aqui apresentada, tal critério consiste em resolver o seguinte problema de autovalor:

$$
\left[\left(\boldsymbol{K}_{i}-\frac{\partial \boldsymbol{f}_{i}}{\partial \boldsymbol{q}}\right)-\omega^{2} \boldsymbol{M}_{\boldsymbol{i}}\right] \boldsymbol{q}=\mathbf{0}
$$

É possível verificar de maneira imediata que os autovalores $\omega_{k}^{2}$ do problema proposto na equação 3.26 estão diretamente relacionados com os da matriz 3.25. Sejam os autovalores $\lambda_{k}$ da matriz $\boldsymbol{A}_{\boldsymbol{i}}$, é possível mostrar que:

$$
\lambda_{k}= \pm i \omega_{k}
$$

Assim, para estudar a estabilidade do sistema utilizando o Primeiro Método de Lyapunov é possível simplesmente utilizar o critério cinético da forma apresentada por Schweizerhof e Ramm (1984), interpretando os autovalores $\omega_{k}$ com a equação 3.27. A observação da evolução de $\omega_{k}$ ao longo da aplicação do carregamento de interesse permite afirmar se o sistema é estável. 
Se todas as frequências naturais forem positivas e reais o sistema será estável, pois o valor de $\lambda_{k}$ será sempre puramente imaginário, representando dinamicamente uma oscilação com amplitude constante.

No caso de instabilidades estáticas ou por divergência, a evolução das frequências naturais apontam para uma queda no valor $\omega_{k}$ até o zero quando, ao se tornar imaginário, torna real o valor de $\lambda_{k}$. Essa mudança de comportamento torna a evolução do sistema regida por uma soma de exponenciais crescente e decrescente, sendo portanto instável.

Um segundo tipo de instabilidade pode ser identificado quando duas frequências naturais vizinhas se aglutinam em um valor real não nulo e posteriormente sua parte imaginária se torna não nula. Trata-se de uma instabilidade dinâmica, ou flutter e pode ser identificada através do surgimento da parte real no autovalor $\lambda_{k}$ sem a transição passando pela origem do plano complexo. A Figura 3.10 mostra como evoluem os autovalores $\lambda_{k}$ nas situações de divergência e de flutter.

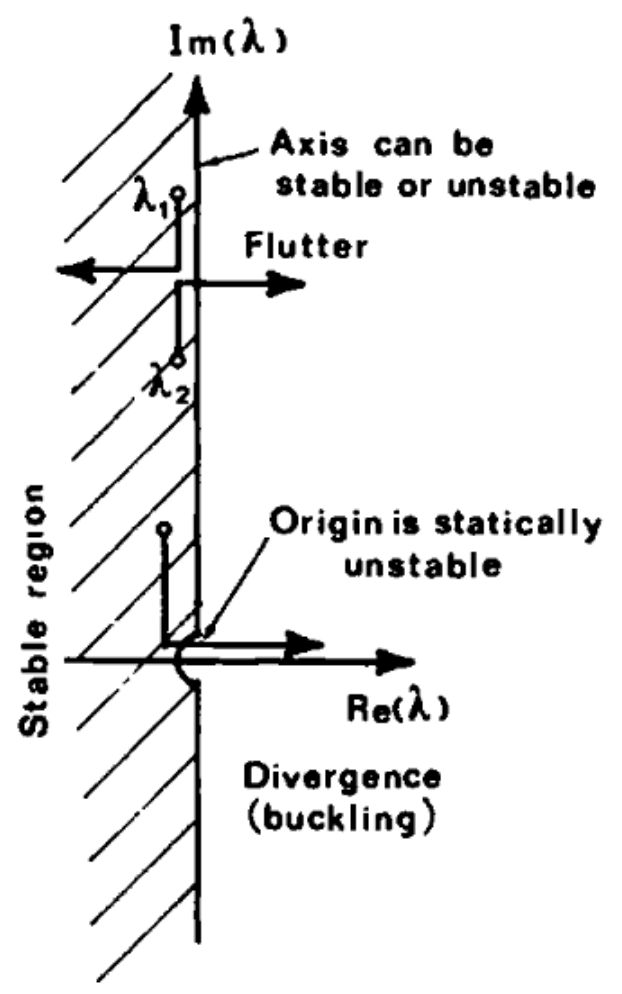

Figura 3.10: Plano complexo mostrando regiões de estabilidade ou instabilidade do sistema dinâmico analisado. Figura extraída de Bazant e Cedolin (2003). 


\section{MODELO ESTÁTICO}

\subsection{Introdução}

Nesse capítulo é desenvolvido um modelo para análise estrutural de risers. O objetivo é determinar a elastica e os esforços solicitantes de configurações de risers em catenária quando submetidos a carregamentos estáticos ou quase estáticos. Esse modelo obedece as especificações feitas no Capítulo 3 para o estudo da estabilidade da configuração de riser em catenária.

As bases teóricas utilizadas na fundamentação são citadas no decorrer do texto. É importante enfatizar quais foram as contribuições feitas pelo autor no presente capítulo. Detalharam-se interpretações e discussões na dedução do equacionamento do modelo além daquelas presentes nos trabalhos usados como referências. Isso certamente é de utilidade para uma futura referência para continuidade do trabalho. Também foram desenvolvidas expressões específicas para a inclusão dos carregamentos envolvidos em problemas de risers, como o peso próprio, a correnteza marítima e as pressões externa e interna. Além disso, a formulação e a equação constitutiva foram discutidas para o contexto da aplicação de análise global de risers, bem como foram detalhados os algoritmos numéricos específicos e estritamente necessários para sua aplicação com sucesso para essa classe de problemas. Ainda foi desenvolvida uma formulação para o tratamento do contato entre o riser e o solo (fundo do mar).

Os principais carregamentos envolvidos no problema são os seguintes:

- Peso próprio do riser: sendo um tubo flexível ou um cabo umbilical, a estrutura do riser apresenta massa e, estando submetida ao campo gravitacional terrestre, apresenta peso próprio. Pode ser considerado como um carregamento distribuído ao longo do comprimento do riser.

- Pressão interna e externa: risers são submetidos a um campo de pressão hidrostática em toda a sua superfície externa. Além disso, tubos flexíveis ou rígidos 
também podem estar submetidos à pressão interna, que é de grande importância no projeto, uma vez que pode ocasionar a explosão do tubo. Uma discussão mais detalhada sobre o assunto é apresentada no Apêndice A que traz o procedimento de integração da pressão nas paredes do tubo. Nesse Apêndice também é discutida a equivalência entre a integração da pressão nas paredes do tubo e a abordagem de peso e tração efetivos apresentada em diversas referências, tais como Martins (2000), Pesce (1997) e Sparks (1984).

- Correntezas marítimas: ao interagir com a estrutura do riser as correntezas marítimas submetem-no a esforços de arrasto hidrodinâmico. Além disso podem surgir esforços de sustentação (ortogonais à direção da correnteza) devido ao desprendimento de vórtices alternados, ocasionando uma excitação cíclica na estrutura. O arrasto hidrodinâmico surge tanto na direção normal como tangencial ao riser. Essa natureza de esforço é dependente do quadrado da velocidade relativa entre a correnteza e o estrutura. Se o riser estiver em repouso e se a correnteza for considerada constante, o arrasto hidrodinâmico pode ser considerado como um carregamento estático. Sendo a ordem de grandeza do período de flutuações na correnteza marítima em geral muito maior do que os maiores períodos naturais da estrutura do riser, o tratamento quase-estático do carregamento de arrasto hidrodinâmico representa uma boa forma de modelagem.

- Interação com o solo: mais bem descrito como um vínculo do que como um carregamento, a interação entre o riser e o solo do fundo do mar é um tópico bastante complexo. Em primeiro lugar, a caracterização do solo é difícil de ser feita em um modelo, dada a dificuldade de realizar uma amostragem experimental significativa do mesmo. As forças de contato trocadas entre o riser e o solo possuem grande importância na obtenção da elastica. As forças de contato podem ser decompostas em duas direções distintas: normal e tangencial. A configuração é afetada pela direção normal, na medida que o riser é impedido de penetrar no solo e, pela componente tangencial (atrito). As forças de atrito presentes no problema são dependentes da história do movimento do riser sobre o solo. A importância do atrito é estática, pois influencia na configuração em torno da qual se movimentará o riser após sua instalação e, dinâmica, na medida que também pode ser importante, quando solicitada dinamicamente durante a vida da estrutura. Assim sendo, o atrito tratado no modelo estático é apenas uma parcela de sua atuação, ou seja, a parcela que determina a configuração estática do riser, de acordo com uma hipótese acerca da história de movimento ocorrida durante a instalação. 
Efeitos de onda de superfície não são considerados no modelo estático, mas devem ser considerados em um modelo dinâmico, conforme descrito no Capítulo 2.

\subsection{Hipóteses}

Existem diversas formas de buscar a solução do problema estático de risers. Tanto se tratando dos tubos flexíveis, tubos rígidos, bem como dos cabos umbilicais, o comprimento dessas estruturas é cerca de três ordens de grandeza acima do diâmetro das mesmas. Trata-se, portanto, de estruturas que podem ser muito bem representadas globalmente se utilizando de teorias estruturais de barra para simplificações no campo de tensões. Existem diversas teorias estruturais que poderiam ser adotadas, com maior ou menor detalhamento:

- Treliças: a estrutura resiste apenas à tração e à compressão, não apresentando energia de deformação devida a efeitos de momentos fletores ou de torção, nem tampouco energia de deformação devida ao cisalhamento.

- Vigas de Euler-Bernoulli: a estrutura resiste à tração, compressão, e também a momentos fletores ou de torção, porém, existe a hipótese de que cada seção transversal deve permanecer ortogonal ao eixo da viga. Dessa forma, não se considera a energia de deformação devido a efeitos cisalhantes da força cortante, mas somente a energia de deformação referentes ao momento fletor, ou de torção e tração (ou compressão) da barra.

- Vigas de Timoshenko: a estrutura resiste à tração, compressão, momentos fletores ou de torção, e esforços cisalhantes cortantes à barra. A teoria não considera o mesmo vínculo cinemático em relação à seção transversal considerado na viga de Euler-Bernoulli.

- Teorias que envolvem empenamento da seção transversal: as teorias de barras exemplificadas anteriormente assumem a seguinte hipótese: a seção transversal possui o movimento de um corpo rígido e, portanto, não apresenta nenhum tipo de empenamento ou variação de área. Existem diversos trabalhos publicados, por exemplo Campello (2000) e Dasambiagio (2008) que tratam deformações na seção transversal de modelos de barras. Essas teorias acrescentam graus de liberdade à estrutura para representar movimentos de deformação da seção transversal de cada ponto da viga. Dessa forma podem surgir outros tipos de esforços solicitantes, não 
preditos pelas teorias de Euler-Bernoulli e Timoshenko. O empenamento da seção transversal pode se dar de forma uniforme ou não uniforme, de acordo com a hipótese adotada. Uma formulação clássica para empenamento é a chamada viga de Saint Venant, que prevê empenamento uniforme da seção transversal. Porém existem outras formas de prever esse fenômeno, de forma não uniforme. Vide, por exemplo, El Fatmi (2007).

Nesse trabalho foi utilizada a teoria de Vigas de Timoshenko. A real importância dos efeitos cisalhantes devido à força cortante no problema é questionável. No entanto, pela natureza da formulação escolhida para o tratamento cinemático de cada seção transversal, o mais natural foi considerar que não houvesse nenhum tipo de vínculo cinemático como o de Euler-Bernoulli. Assim a formulação se tornou mais genérica. Efeitos de empenamento e qualquer tipo de alteração na seção transversal foram desprezados. Essa hipótese deve ser analisada com bastante cuidado. No trabalho de El Fatmi (2007), que aborda a questão de empenamento não uniforme em vigas é dito que desprezar os efeitos de empenamentos de viga pode resultar em erros bastante significativos nos seguintes casos: vigas de perfil aberto sob torção ou flexão e cisalhamento combinados em vigas curtas. Além disso, o autor aponta o estudo de vigas compósitas como uma situação em que o empenamento pode se evidenciar de forma muito significativa.

O assunto "vigas compósitas" é abordado em muitos artigos, e em especial pode-se citar o breve artigo de Rand (2000). O autor aponta que estruturas como pás de helicóptero e asas de avião, quando feitas de forma compósita, podem apresentar efeitos bastante significativos de empenamento em sua seção transversal. O autor ainda aponta que para vigas isotrópicas as tensões axiais não dependem de deformações cisalhantes. Já para vigas compósitas essa particularidade não é verdadeira. Devido a efeitos de cisalhamento nas seções transversais, vigas compósitas podem apresentar relações entre momento e curvatura que dependem essencialmente do empenamento. Esse tipo de comportamento é verificado em tubos flexíveis. A estrutura compósita desses tubos levam a relações não lineares entre momento e curvatura. Um modelo para tratar tal fenômeno é apresentado, por exemplo, em Witz e Tan (1992). Os autores além de explorar a modelagem de tubos compósitos para aplicação offshore, apresentam um gráfico que ilustra a relação entre o momento fletor e a curvatura para tubos flexíveis - Figura 4.1.

A relação entre o momento fletor e a curvatura pode ser muito próxima de bilinear. Isso se deve à ocorrência de deslizamento entre camadas da estrutura. A primeira inclinação (mais elevada) da curva, ocorre quando o atrito seco entre camadas adjacentes 


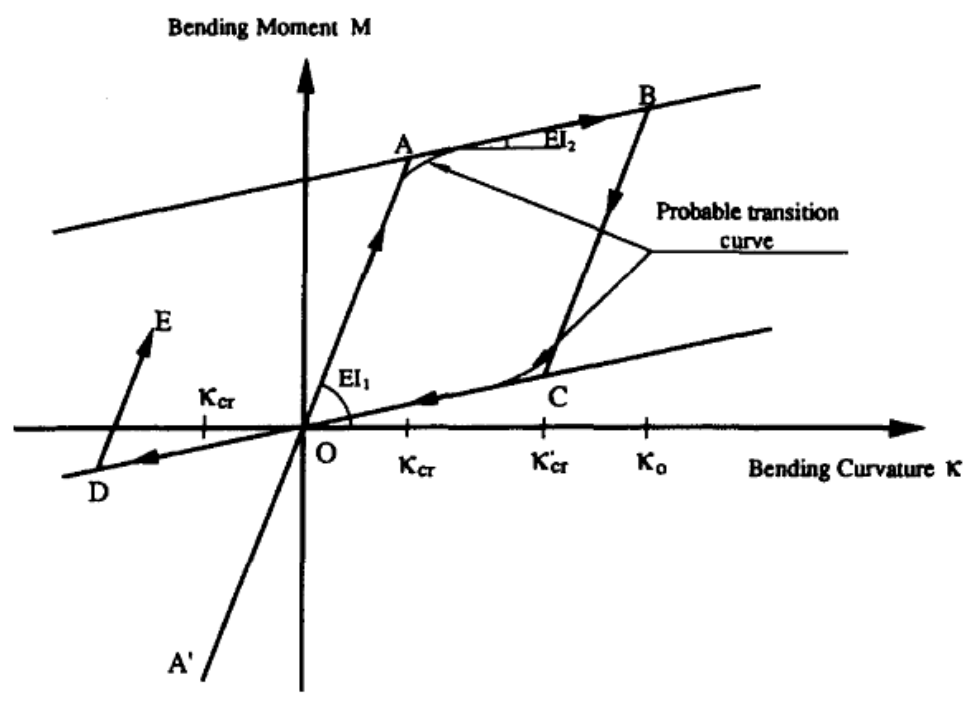

Figura 4.1: Relação entre momento fletor e curvatura para um exemplo de tubo compósito. Extraído de Witz e Tan (1992)

não permite o movimento de escorregamento entre as mesmas, fazendo a estrutura funcionar de forma uniforme, com pouco empenamento da seção. Já a partir de um certo valor de curvatura, ocorre escorregamento entre algumas camadas adjacentes, causando uma grande diminuição de rigidez flexional do tubo. Ainda, quando carregado em sentido oposto, é notado um comportamento de histerese. O fenômeno ilustrado é muito semelhante à plasticidade em aços estruturais, e à ocorrência de encruamento após tal material sofrer escoamento. Aliás, pode-se inclusive afirmar que o mecanismo de plasticidade em aços estruturais é também o escorregamento de camadas, porém, em escala da microestrutura do aço estrutural envolvido (mecanismo associado ao deslizamento de planos cristalográficos, causando deformações permanentes).

Com base nessas observações, a hipótese adotada de Vigas de Timoshenko para o modelo global de risers se mostra adequada à aplicações para risers rígidos, ou para tubos flexíveis ou cabos umbilicais, desde que não se verifique nível de esforço solicitante que cause significativo empenamento e mudanças de rigidez devido a alterações da seção transversal. Por isso, para aplicações para tubos compósitos, uma verificação posterior entre o nível de esforços solicitantes e o valor de rigidez flexional adotado para a análise global do riser, deve ser feita.

Ainda no tocante às teorias de barras e formas de modelar o problema de risers, hipóteses cinemáticas devem ser feitas acerca do movimento de cada seção transversal das vigas que formam a estrutura. O movimento pode ser considerado com pequena magnitude em termos de deslocamentos e rotações, com simplificações no equacionamento. 
Ainda, pode ser considerado com grandes deslocamentos e grandes rotações, representando de forma mais realista problemas que tenham esse tipo de comportamento. Imaginando uma configuração de referência como um riser retilíneo e sem nenhum tipo de pré-tensão, e uma configuração deformada e final para um riser em catenária (após a aplicação do carregamentos estáticos bem como das condições de contorno do problema), podem ser identificados grandes deslocamentos e grandes ângulos de rotação (ver Figura 4.2).

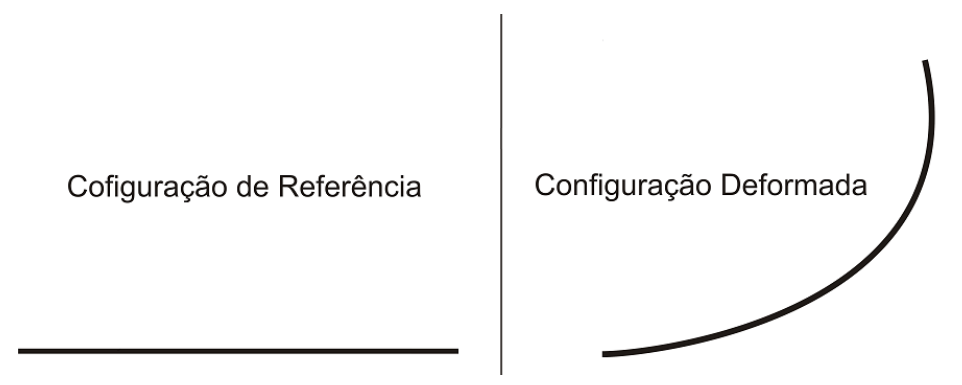

Figura 4.2: Configurações de referência e deformada para um riser em catenária

Em situações em que se deseja estudar a estabilidade de configurações de riser submetidos a grandes rotações axiais devido a momentos de torção aplicados, podem ocorrer grandes movimentos compostos por translações e rotações de cada seção transversal analisada. Para tratar corretamente esses movimentos é necessário equacionar de forma bastante cautelosa as rotações e translações envolvidas nas seções transversais das vigas, com o mínimo de simplificações cinemáticas. Uma vez que no modelo de viga de Timoshenko as seções transversais permanecem rígidas, seu tratamento deve ser aquele que é utilizado para o movimento geral de um corpo rígido, abordado no ítem 4.3.

A seguir serão comentadas duas técnicas utilizadas para desenvolver teorias estruturais de viga que possam ser submetidas a grandes movimentos de corpo rígidos (grandes deslocamentos e grandes rotações). As técnicas são: Formulação Co-rotacional e Formulação Cinematicamente Exata.

\subsubsection{Formulação Co-rotacional}

Formulações clássicas de viga que consideram pequenos deslocamentos não incluem grandes movimentos de corpo rígido que podem surgir em uma estrutura, mesmo que não haja grandes deformações. Para estudar esse tipo de situação é bastante conveniente que se construa um referencial local no elemento considerado, em sua configuração deformada, a fim de eliminar a parte do movimento de corpo rígido (vista por esse referencial) na caracterização das deformações. Constrói-se, portanto, um novo referencial que é solidário 
ao movimento de corpo rígido do elemento. A técnica pode ser aplicada não somente a elementos de viga, como em Crisfield (1990) e Battini e Pacoste (2002), mas também para elementos sólidos, como por exemplo foi feito por Crisfield e Moita (1996).

Crisfield (1990) apresenta uma formulação 3D de viga utilizando a ideia do referencial co-rotacional. O autor busca de forma bastante didática descrever o tratamento a ser dado para as grandes rotações possivelmente presentes em suas aplicações e define de maneira bastante análoga à aqui tratada, os tensores de rotação na forma de Euler e de Rodrigues, bem como os quaternions, introduzidos por Hamilton em $1844^{1}$.

Crisfield (1990) apresenta a ideia básica de como definir o referencial móvel que acompanha o movimento de corpo rígido do elemento de viga. O elemento desenvolvido possui 6 graus de liberdade por nó, sendo 3 deles de translação e 3 de rotação. O autor se utiliza do Princípio dos Trabalhos Virtuais para realizar a dedução das matrizes do elemento.

A formulação co-rotacional é uma alternativa para considerar não linearidades de grandes deslocamentos e grandes rotações, porém, apresenta dificuldade para a determinação do grau da aproximação e do erro cometido uma vez que, dentro do referencial solidário ao elemento, em geral é assumida linearidade. Além disso, não existe uma forma única de se formular um elemento co-rotacional, sendo o referencial móvel e solidário ao elemento sujeito a certa arbitrariedade. Mesmo com essas dificuldades uma formulação co-rotacional se faz capaz de resolver problemas estáticos de risers. Nesse capítulo, busca-se uma formulação que aborde a cinemática das rotações da forma mais exata possível, com o mínimo de arbitrariedades, a fim de conseguir prever o comportamento de risers não somente nas configurações mais comuns, mas também em situações de instabilidades estruturais em que pode haver importantes acoplamentos entre torção, flexão e tração e grandes ordens de grandeza de rotação. As arbitrariedades presentes na Formulação Co-rotacional poderiam dificultar a interpretação das rotações no espaço. Uma outra abordagem, portanto, pareceu ser mais conveniente para a necessidade do presente trabalho. Trata-se da:

\footnotetext{
${ }^{1}$ Os quaternions são uma generalização dos números complexos, possuindo não duas, mas quatro componentes, sendo funções do parâmetro de rotação $\theta$ de Euler, mostrado na seção 4.3.3. Existe uma álgebra desenvolvida somente para operar com essas entidades matemáticas, apresentada por exemplo em Spring (1986), utilizada em diversas áreas da física, e não somente na mecânica estrutural. A utilização de quaternions é uma alternativa ao uso do tensor de rotação, aqui apresentado, nas formas de Euler e de Rodrigues nos tópicos 4.3.3 e 4.3.4.
} 


\subsubsection{Formulação Cinematicamente Exata}

A Formulação Cinematicamente Exata pode ser utilizada para desenvolver diversos tipos de teorias estruturais, como por exemplo as vigas e as cascas. Sua forma de tratar o problema é bastante interessante, uma vez que a teoria estrutural é construída do início ao fim com uma grande consistência cinemática dentro das hipóteses feitas. Um dos maiores pesquisadores no desenvolvimento e formalização dessa teoria é Simo, J.C., que nos artigos Simo (1985), Simo (1986) e Simo (1991) apresenta a teoria cinematicamente exata para diferentes aplicações de vigas. Esses trabalhos apresentam uma formulação dinâmica, com bastante rigor matemático no tratamento das rotações no espaço. Pimenta, Campello e Wriggers (2008) apresentam também um interessante trabalho utilizando a Formulação Cinematicamente Exata. É desenvolvida a formulação para a dinâmica, e elucidadores exemplos são discutidos, inclusive entrando no mérito de uma análise sobre a energia potencial e cinética de sistemas dinâmicos e sua conservação no método numérico utilizado para realizar a marcha transiente.

Para descrever o comportamento de uma viga ou casca segundo esse tipo de formulação, é possível trabalhar com duas diferentes descrições cinemáticas:

\section{- Descrição lagrangiana total}

- Descrição lagrangiana atualizada

A descrição lagrangiana total trata as translações e rotações envolvidas no problema sempre em relação à configuração de referência e, portanto, valores muito elevados de ângulo de rotação podem ocorrer. A principal vantagem dessa técnica é a facilidade de descrever as rotações, pois não há mudanças de referencial, tampouco atualizações de ângulos acumulados de rotação entre passos subsequentes de carregamento aplicados no modelo em questão. A principal desvantagem é a falha ao lidar com rotações de magnitude muito elevada, pois nessas situações podem surgir singularidades nos tensores de rotação (seja na forma de Euler ou de Rodrigues). Isso pode ocorrer, por exemplo, para um problema que envolva torção de uma viga muito longa que sofreu várias rotações.

Já a descrição lagrangiana atualizada constrói referenciais intermediários a fim de tratar grandezas de translação e rotação não em relação a um único referencial inicial mas, em relação a outros referenciais mais próximos da configuração a ser descrita. Possui maior complexidade no tratamento das rotações, principalmente em aspectos computacionais. Pode-se trabalhar com passos de carregamento de modo a definir ao fim de cada passo uma 
nova referência para a rotação. Dessa forma, através da solução de um modelo através de pequenos passos de carregamento pode-se lidar dentro de cada passo com rotações não elevadas, não tornando singular o tensor rotação. É necessário, para tal, redefinir um referencial a cada passo de carregamento. Adicionalmente deve-se acumular os esforços internos na estrutura bem como os ângulos de rotação durante os passos de carregamento subsequentes. Não existe limite teórico para a magnitude da rotação acumulada através da descrição lagrangiana atualizada. No entanto, cada passo de carregamento deverá se restringir à faixa de não singularidade do tensor rotação.

A descrição lagrangiana atualizada foi escolhida no presente estudo para abordar o problema da estabilidade da configuração de risers em catenária, pois se desejou estudar condições de rotações muito elevadas que não seriam corretamente contempladas na descrição lagrangiana total.

Para desenvolver um modelo estrutural de vigas através da Formulação Cinematicamente Exata (seja com descrição lagrangiana total ou atualizada) é importante adotar um parâmetro para descrever as rotações das seções transversais. Para isso, procurouse no tópico 4.3 ilustrar algumas possibilidades, bem como a justificativa da escolha de parâmetro feita pelo autor.

\subsection{Parametrizações de rotação}

O deslocamento é uma grandeza vetorial. Assim, a soma de dois vetores de deslocamentos de certo ponto que ocorrem sequencialmente é algo trivial. Já quando o assunto é a rotação, a complexidade do tema é muito maior. O assunto de grandes rotações de uma seção transversal de uma viga no plano é considerado simples no atual estado da arte, uma vez que só surgem efeitos de movimentos bidimensionais de corpo rígido. Ainda que haja grandes rotações, existe comutatividade das mesmas, isto é, se faz possível a soma direta dos valores das rotações em passos subsequentes de um movimento, obtendo de maneira única a posição angular final da seção transversal.

O problema que envolve rotações no espaço certamente apresenta dificuldades adicionais em relação ao 2D. A torção de uma viga, por exemplo, surge em dois tipos de problemas: quando ocorre apenas a torção própria sem alteração da elastica da viga ou, quando ocorre junto com a flexão, tornando o problema necessariamente 3D. Conforme apresentado no Apêndice B, o conceito de torção pode se tornar bem mais complexo em problemas espaciais do que em problemas em que ocorre apenas a torção própria $\tau_{p}$ 
da viga sem alteração de sua elastica, uma vez que os efeitos da torção própria $\tau_{p}$ e da tortuosidade $\tau_{c}$ se combinam.

Quando tratadas de maneira consistente as rotações em um problema 3D podem apresentar grande dificuldade conceitual em seu entendimento. Não se trata apenas de uma generalização da rotação no plano, através da simples inserção de mais ângulos para caracterizar a orientação da seção transversal de uma viga no espaço, mas sim de uma nova teoria com uma abordagem completamente diferente daquela que se pode usar no tratamento de problemas 2D. O assunto teórico de rotações no espaço pode ser estudado através do memorável livro de Altmann (2005), com aspectos históricos e matemáticos de grande relevância no assunto. Um pouco do histórico dos modelos de viga existentes e suas diferentes abordagens para o tratamento de rotações pode ser vista, por exemplo em Campello (2000) e Campello (2005). Os primeiros modelos de vigas no plano e no espaço datam da época de Bernoulli, no século XVIII, e até os dias atuais se desenvolvem diferentes metodologias de formulações de vigas, com diferentes hipóteses e aplicações.

\subsubsection{Estudo do movimento geral de um corpo rígido}

A base teórica para estudo do movimento de um corpo rígido é um assunto clássico na mecânica e pode ser encontrado em muitas referências, por exemplo Goldstein (1980), França e Matsumura (2004) e Pimenta (1987). A fim de introduzir o tema, a seguir será apresentada uma breve dedução do equacionamento que rege um movimento qualquer de um corpo rígido.

Seja um corpo rígido $\mathcal{S}$ que pode se movimentar no espaço 3D. Seja um referencial inercial $\left(\boldsymbol{O}, \boldsymbol{e}_{1}, \boldsymbol{e}_{2}, \boldsymbol{e}_{3}\right)$ para monitorar as posições, velocidades e acelerações desse corpo rígido. A origem $\boldsymbol{O}$ pertence ao espaço considerado e $\left(\boldsymbol{e}_{1}, \boldsymbol{e}_{2}, \boldsymbol{e}_{3}\right)$ é a base adotada. As posições do corpo rígido podem ser mapeadas através de uma função $\boldsymbol{r}(t, \boldsymbol{x})$, sendo $t$ o tempo, pois o corpo pode movimentar-se livremente em função do tempo. O vetor $\boldsymbol{x}$ é a posição no espaço associada a um ponto do corpo em um certo instante de referência. A função vetorial $\boldsymbol{r}(t, \boldsymbol{x})$ monitora as posições dos infinitos pontos do corpo rígido, dadas suas posições de referência $\boldsymbol{x}$.

A propriedade fundamental de um corpo rígido é que a distância entre dois pontos genéricos de seu interior $\boldsymbol{P}$ e $\boldsymbol{Q}$ se mantém constante, independente do tipo de movimento que o corpo realize. Esse vínculo pode ser escrito de forma matemática através da equação 4.1 . 


$$
\left(\boldsymbol{r}_{P}-\boldsymbol{r}_{Q}\right)^{T}\left(\boldsymbol{r}_{P}-\boldsymbol{r}_{Q}\right)=\left(\boldsymbol{x}_{P}-\boldsymbol{x}_{Q}\right)^{T}\left(\boldsymbol{x}_{P}-\boldsymbol{x}_{Q}\right)
$$

Assume-se, por hipótese uma forma de escrever a função $\boldsymbol{r}(t, \boldsymbol{x})$, separando-se as suas dependências espacial e temporal da seguinte forma:

$$
\boldsymbol{r}(t, \boldsymbol{x})=\boldsymbol{r}_{Q}(t)+\boldsymbol{R}(t)\left(\boldsymbol{x}-\boldsymbol{x}_{Q}\right)
$$

Essa forma assume conhecidas as posições em função do tempo, para um ponto $\boldsymbol{Q}$ do corpo rígido. O valor de $\boldsymbol{r}_{Q}(t)$ representa a translação desse ponto $\boldsymbol{Q}$, em função do tempo. Já o segundo membro aplica um operador $\boldsymbol{R}(t)$ à diferença entre as posições de um ponto genérico e do ponto $\boldsymbol{Q}$. Nessa forma assumida, o segundo membro representará a rotação ocorrida no vetor que vai do ponto $\boldsymbol{Q}$ a um ponto genérico.

Utilizando-se 4.2 em 4.1, chega-se à seguinte conclusão acerca do operador $\boldsymbol{R}$ :

$$
\boldsymbol{R}^{T} \boldsymbol{R}=\boldsymbol{I}
$$

Imposta a propriedade fundamental, garante-se que o operador $\boldsymbol{R}$ não irá distorcer o sólido nem deformá-lo, mas apenas realiza uma rotação no vetor ao qual ele é aplicado. Trata-se de um operador ortogonal, que necessariamente deve possuir determinante de módulo unitário e, para evitar reflexões durante a aplicação do operador, necessariamente $\operatorname{det}(\boldsymbol{R})=+1$.

Através da equação 4.2 é possível encontrar também uma relação entre as velocidades dos pontos de um corpo rígido. Derivando-se a equação 4.2 em relação ao tempo, tem-se:

$$
\boldsymbol{v}(t, \boldsymbol{x})=\boldsymbol{v}_{Q}(t)+\dot{\boldsymbol{R}}(t)\left(\boldsymbol{x}-\boldsymbol{x}_{Q}\right)
$$

A expressão 4.4 permite monitorar a velocidade $\boldsymbol{v}(t, \boldsymbol{x})$ em um ponto genérico através da diferença entre as posições desse ponto ao ponto $Q$ na configuração associada ao instante de referência. Isolando-se o termo $\left(\boldsymbol{x}-\boldsymbol{x}_{Q}\right)$ na equação 4.2 , tem-se: 


$$
\left(\boldsymbol{x}-\boldsymbol{x}_{Q}\right)=\boldsymbol{R}^{T}(t)\left[\boldsymbol{r}(t, \boldsymbol{x})-\boldsymbol{r}_{Q}(t)\right]
$$

Substituindo na equação 4.4, tem-se:

$$
\boldsymbol{v}(t, \boldsymbol{x})=\boldsymbol{v}_{Q}(t)+\dot{\boldsymbol{R}}(t) \boldsymbol{R}^{T}(t)\left[\boldsymbol{r}(t, \boldsymbol{x})-\boldsymbol{r}_{Q}(t)\right]
$$

Nomeando o operador $\boldsymbol{\Omega}(t)=\dot{\boldsymbol{R}}(t) \boldsymbol{R}^{T}(t)$, a equação 4.6 fica da forma:

$$
\boldsymbol{v}(t, \boldsymbol{x})=\boldsymbol{v}_{Q}(t)+\boldsymbol{\Omega}(t)\left[\boldsymbol{r}(t, \boldsymbol{x})-\boldsymbol{r}_{Q}(t)\right]
$$

O operador $\boldsymbol{\Omega}(t)$ é anti-simétrico ${ }^{2}$. É possível escrever um único vetor $\boldsymbol{\omega}(t)$ tal que $\boldsymbol{\omega}(t)=$ axial $[\boldsymbol{\Omega}(t)]^{3}$. Dessa forma, a expressão 4.7 se torna:

$$
\boldsymbol{v}(t, \boldsymbol{x})=\boldsymbol{v}_{Q}(t)+\boldsymbol{\omega}(t) \times\left[\boldsymbol{r}(t, \boldsymbol{x})-\boldsymbol{r}_{Q}(t)\right]
$$

O que se mostrou através desse procedimento é o caráter tensorial associado ao operador $\Omega(t)$ que, por ser anti-simétrico, pode ser utilizado como um vetor extraído do tensor skew correspondente.

Se o vetor $\boldsymbol{\omega}$ for escrito da forma $\boldsymbol{\omega}=\left(\omega_{1}, \omega_{2}, \omega_{3}\right)$, é possível escrever o operador $\Omega$ da seguinte forma:

\footnotetext{
${ }^{2} \mathrm{~A}$ anti-simetria pode ser facilmente verificada derivando-se em relação ao tempo a expressão 4.3

${ }^{3}$ Seja o tensor anti-simétrico $\Omega$ definido na equação 4.9. O resultado da operação de $\boldsymbol{\Omega}$ por um vetor $\boldsymbol{a}$ pode ser escrito na forma de um produto vetorial, utilizando-se o vetor $\boldsymbol{\omega}=\left[\begin{array}{lll}\omega_{1} & \omega_{2} & \omega_{3}\end{array}\right]^{T}$, tal que:

$$
\Omega a=\omega \times a
$$

Os operadores axial e e skew são bastante convenientes para trabalhar com tensores anti-simétricos, estabelecendo uma relação entre o tensor $\boldsymbol{\Omega}$ e o vetor $\boldsymbol{\omega}$, tal que:

$$
\begin{aligned}
& \boldsymbol{\Omega}=\operatorname{skew}(\boldsymbol{\omega}) \\
& \boldsymbol{\omega}=\operatorname{axial}(\boldsymbol{\Omega})
\end{aligned}
$$
}




$$
\Omega=\left[\begin{array}{ccc}
0 & -\omega_{3} & \omega_{2} \\
\omega_{3} & 0 & -\omega_{1} \\
-\omega_{2} & \omega_{1} & 0
\end{array}\right]
$$

Analisando-se a equação 4.7 é possível demonstrar que existe um lugar geométrico denominado eixo helicoidal instantâneo associado às velocidades mínimas no campo de velocidades de um corpo rígido. Os pontos localizados nesse eixo podem ser associados ao eixo de rotação instantâneo do corpo. O único movimento dos pontos do corpo que se encontram sobre o eixo para o instante considerado é uma translação pura paralela ao eixo. Vide Figuras 4.3 e 4.4 .

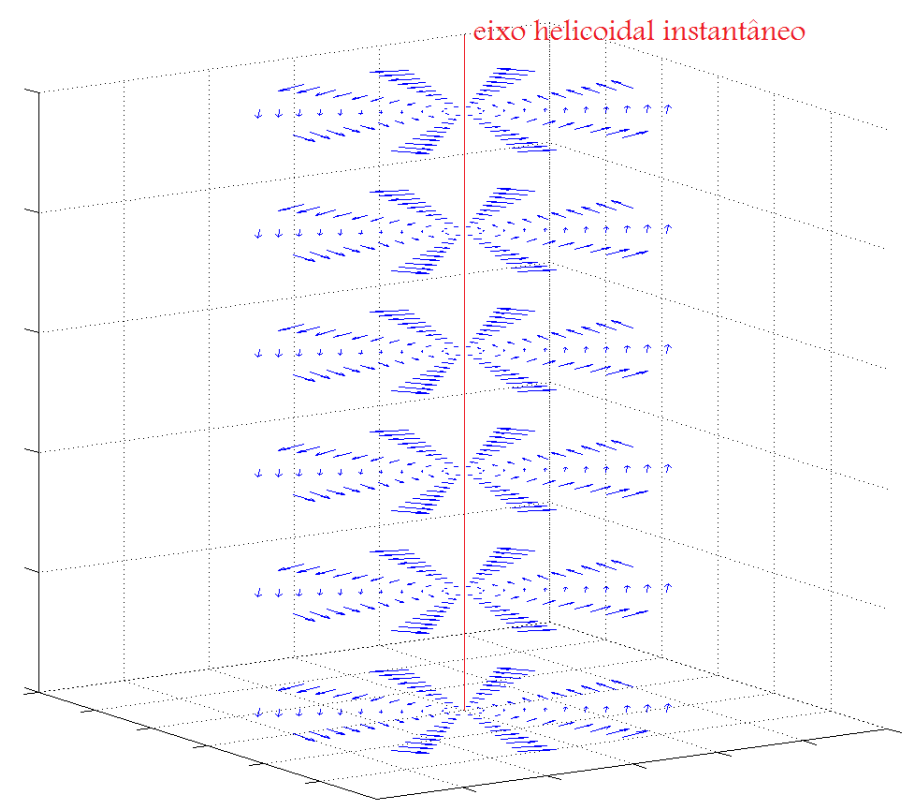

Figura 4.3: Exemplo de um campo de velocidades de um corpo rígido (visualizando o eixo helicoidal instantâneo) - vista isométrica

É possível, adicionalmente, derivar a equação 4.7 em relação ao tempo para obter o campo de acelerações do corpo rígido. Através dessa descrição é possível estudar de maneira cinematicamente exata todo e qualquer movimento de um corpo rígido, com qualquer magnitude e direção de rotação sofrida. 


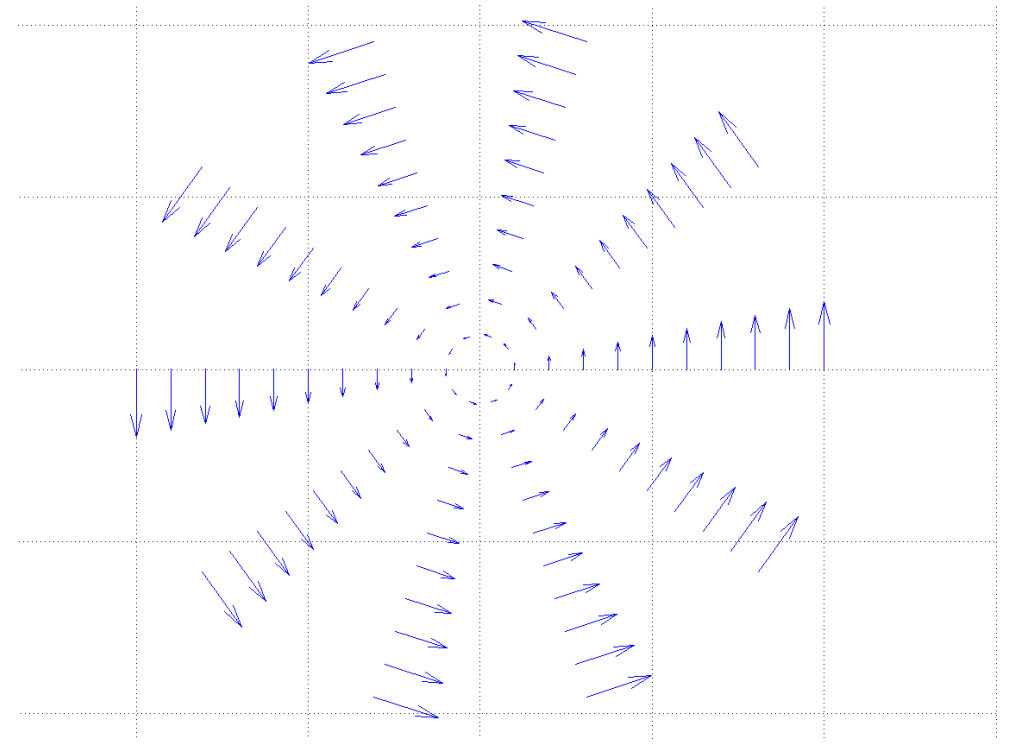

Figura 4.4: Exemplo de um campo de velocidades de um corpo rígido - vista superior

\subsubsection{Descrição das rotações}

A forma de escrever o tensor de rotação $\boldsymbol{R}(t)$ não é única, existindo diversas formas possíveis para sua parametrização. De acordo com a escolha feita, surgem diferentes dificuldades de como calcular e descrever a direção e o ângulo (ou ângulos) de rotação.

Deve-se, no entanto, enfatizar que o tensor rotação $\boldsymbol{R}(t)$ não é a única maneira de descrever a rotação de corpos rígidos. Spring (1986) apresenta diversos métodos existentes para realizar o estudo de rotação. São citadas três formas de escrever as rotações de corpos rígidos: matrizes de rotação, spinors e quaternions, sendo todas essas formas baseadas no importante teorema de Euler, de que a atitude de um corpo após sofrer uma sequência de rotações é equivalente a uma única rotação do corpo, de um valor $\theta$ através de um eixo de direção $\boldsymbol{e}$. O autor comenta sobre as diversas formas de parametrizar as rotações:

- Transformação de coordenadas entre dois referenciais distintos (matriz de rotação), podendo ser obtida, por exemplo, através dos cossenos diretores entre as direções dos eixos de cada um dos sistemas;

- Parâmetros de Euler através de quaternions

- Parâmetros Lineares, através de quaternions

- Parâmetro de Rodrigues, através do vetor rotação 
- Parâmetros de Euler, através de um vetor rotação, semelhante à abordagem de Rodrigues $^{4}$

- Ângulos de Euler, descrevendo três rotações $(\psi, \theta, \phi)$ através de eixos que acompanham o movimento do corpo rígido

- Ângulos de Bryant ou Cardan

Dentre as tantas abordagens possíveis, Spring (1986) enfatiza a importância e facilidade que trazem os quaternions à descrição dos movimentos, mostrando duas aplicações voltadas à robótica e sistemas da indústria aeroespacial. Moreira (2009) também compara diversas formas de parametrizar rotações, apresentando algumas formas vetoriais, como a parametrização de Euler e de Rodrigues. Também comenta sobre algumas formas não vetoriais, como os ângulos de Euler, cossenos diretores, dentre outras.

No contexto de aplicação para teoria estrutural de vigas segundo a abordagem apresentada nesse capítulo, a parametrização utilizada é do tipo vetorial. Assim, serão apresentados de forma concisa o vetor rotação de Euler e de Rodrigues.

\subsubsection{Vetor rotação de Euler}

A ideia básica da representação do vetor rotação de Euler é facilmente interpretada através da Figura 4.5.
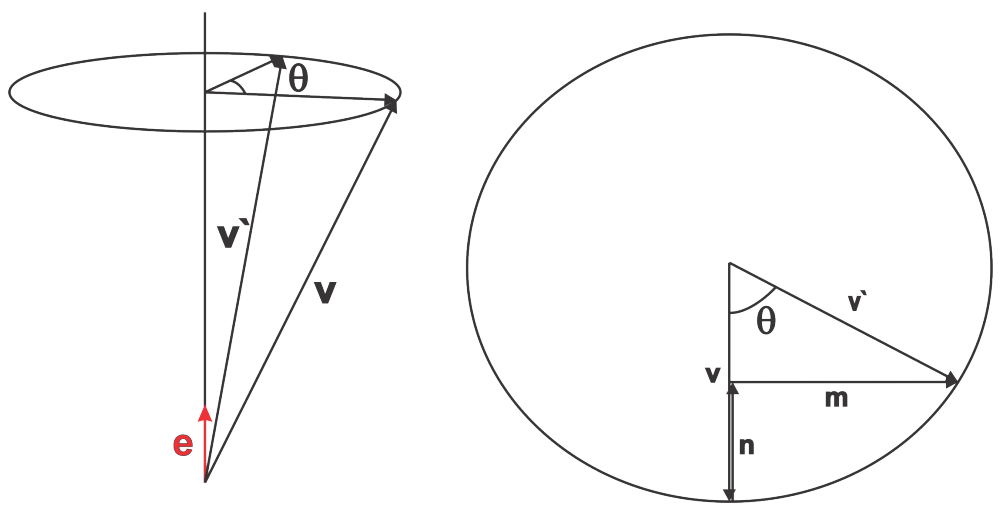

Figura 4.5: Vetores utilizados na obtenção do tensor rotação na forma de Euler

Sendo uma parametrização vetorial, um versor $\boldsymbol{e}$ representa a direção do eixo de rotação. O ângulo $\theta$ indica o valor do ângulo de rotação, na vista de topo, ou seja, para

\footnotetext{
${ }^{4}$ A nomenclatura "vetor rotação" é mais precisada por alguns autores pelo nome "pseudo-vetor rotação". Isso, pois tal vetor não goza das propriedades dos vetores, como a propriedade comutativa, por se tratar de uma descrição de rotações no espaço. Nesse trabalho em todos os momentos que for usada a nomenclatura "vetor rotação", a mesma deve ser interpretada de acordo com essa ressalva.
} 
um observador visualizando o versor $\boldsymbol{e}$ de topo. É possível rotacionar um vetor $\boldsymbol{v}$ de um ângulo $\theta$, resultando em um vetor $\boldsymbol{v}^{\prime}$. Escreve-se a seguinte relação vetorial entre $\boldsymbol{v}$ e $\boldsymbol{v}^{\prime}$ :

$$
\boldsymbol{v}^{\prime}=\boldsymbol{v}+\boldsymbol{m}+\boldsymbol{n}
$$

Sendo os vetores $\boldsymbol{m}=\operatorname{sen}(\theta)(\boldsymbol{e} \times \boldsymbol{v})$ e $\boldsymbol{n}=(1-\cos (\theta)) \boldsymbol{e} \times(\boldsymbol{e} \times \boldsymbol{v})$, é possível escrever o vetor $\boldsymbol{v}^{\prime}$ da seguinte forma:

$$
\boldsymbol{v}^{\prime}=\boldsymbol{v}+\operatorname{sen}(\theta)(\boldsymbol{e} \times \boldsymbol{v})+(1-\cos (\theta)) \boldsymbol{e} \times(\boldsymbol{e} \times \boldsymbol{v})
$$

Que por sua vez pode ser escrita na forma tensorial:

$$
\boldsymbol{v}^{\prime}=\left[\boldsymbol{I}+\operatorname{sen}(\theta) \boldsymbol{E}+(1-\cos (\theta)) \boldsymbol{E}^{2}\right] \boldsymbol{v}
$$

Na expressão anterior utilizou-se o tensor anti-simétrico: $\boldsymbol{E}=\operatorname{skew}(\boldsymbol{e})$. Note que o operador que relaciona o vetor $\boldsymbol{v}^{\prime}$ com o vetor $\boldsymbol{v}$ é o operador linear procurado (tensor rotação). Logo, na forma de Euler, o tensor de rotação $\boldsymbol{R}$ é dado por:

$$
\boldsymbol{R}=\left[\boldsymbol{I}+\operatorname{sen}(\theta) \boldsymbol{E}+(1-\cos (\theta)) \boldsymbol{E}^{2}\right]
$$

Define-se o vetor rotação de Euler $\boldsymbol{\theta}$, que possui a mesma direção do versor $\boldsymbol{e}$, e a norma igual ao valor do ângulo de rotação visto de topo $\theta$.

$$
\boldsymbol{\theta}=\theta \boldsymbol{e}
$$

É possível escrever a expressão 4.13 em função do vetor rotação de Euler, em sua forma skew, ou seja, sendo $\boldsymbol{\Theta}=\operatorname{skew}(\boldsymbol{\theta})$.

$$
\boldsymbol{R}=\left[\boldsymbol{I}+\frac{\operatorname{sen}(\theta)}{\theta} \boldsymbol{\Theta}+\frac{1-\cos (\theta)}{\theta^{2}} \Theta^{2}\right]
$$




\subsubsection{Vetor rotação de Rodrigues}

De maneira análoga à apresentada anteriormente, pode-se adotar outra forma para determinar o tensor de rotação, através dos vetores mostrados na Figura 4.6:
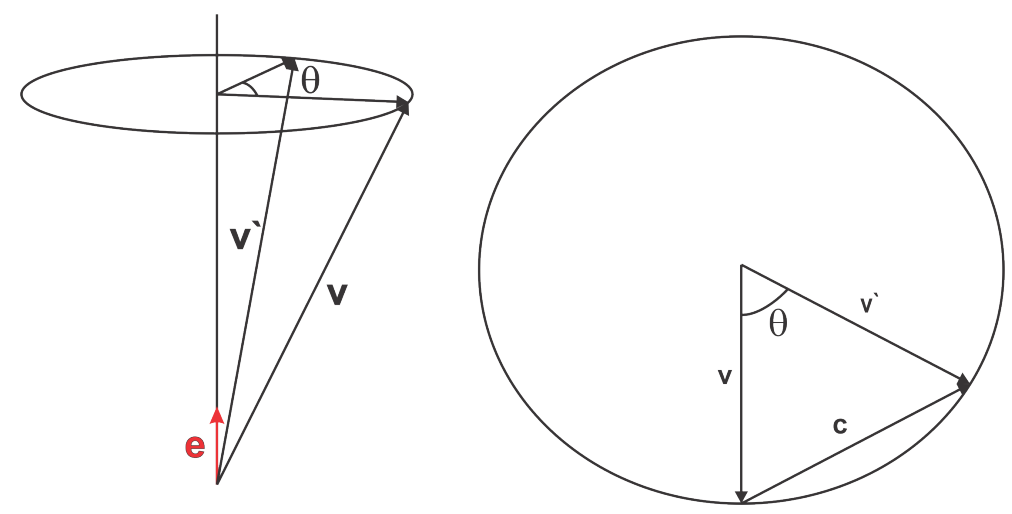

Figura 4.6: Vetores utilizados na obtenção do tensor rotação na forma de Rodrigues

Pode-se escrever:

$$
c=v^{\prime}-v
$$

Pode-se definir o vetor $\boldsymbol{m}$ como:

$$
\boldsymbol{m}=\frac{1}{2}\left(\boldsymbol{v}^{\prime}+\boldsymbol{v}\right)
$$

Define-se o vetor rotação de Rodrigues $\boldsymbol{\alpha}$, como sendo:

$$
\boldsymbol{\alpha}=\alpha \boldsymbol{e}
$$

Em que $\alpha=2 \tan \frac{\theta}{2}$. Pode-se escrever a seguinte relação geométrica:

$$
\boldsymbol{c}=\alpha(\boldsymbol{e} \times \boldsymbol{m})
$$

Após manipulações algébricas, inserindo as relações 4.19 em 4.17, é possível obter 
a seguinte relação:

$$
\boldsymbol{v}^{\prime}=\left(\boldsymbol{I}-\frac{1}{2} \boldsymbol{A}\right)^{-1}\left(\boldsymbol{I}+\frac{1}{2} \boldsymbol{A}\right) \boldsymbol{v}
$$

Nessa equação $\boldsymbol{A}=\operatorname{skew}(\boldsymbol{\alpha})$. O tensor rotação, portanto pode ser escrito da seguinte forma:

$$
\boldsymbol{R}=\left(\boldsymbol{I}-\frac{1}{2} \boldsymbol{A}\right)^{-1}\left(\boldsymbol{I}+\frac{1}{2} \boldsymbol{A}\right)
$$

Ainda, após manipulações algébricas, pode-se chegar em:

$$
\boldsymbol{R}=\boldsymbol{I}+\frac{4}{4+\alpha^{2}}\left(\boldsymbol{A}+\frac{1}{2} \boldsymbol{A}^{2}\right)
$$

Em algumas referências, denomina-se a função $r_{0}(\alpha)$, que aparece em vários operadores tensoriais.

$$
r_{0}(\alpha)=\frac{4}{4+\alpha^{2}}
$$

Portanto, a forma de Rodrigues representa uma alternativa à forma de Euler, uma vez que dado um ângulo de rotação $\theta$ e o eixo de rotação, é possível calcular o parâmetro $\alpha$ de Rodrigues, e com esse parâmetro calcular de forma alternativa o tensor rotação $\boldsymbol{R}$. No entanto, os parâmetros de Rodrigues que caracterizam o vetor $\boldsymbol{\alpha}$ não apresentam significado físico imediato como o vetor $\boldsymbol{\theta}$ dos parâmetros de Euler, mas apresentam vantagens no caso de composição de rotações, havendo uma fórmula direta para compor rotações sucessivas. A parametrização de Euler não goza de tal fórmula, sendo muito mais trabalhoso realizar essa tarefa. Essa expressão é apresentada na equação 4.64.

\subsubsection{Relações entre a derivada temporal do vetor rotação e os vetores velocidade e aceleração angular}

Nas parametrizações de Euler e de Rodrigues foram definidos vetores rotação $(\boldsymbol{\theta}$ e $\boldsymbol{\alpha})$ com referência ao versor $\boldsymbol{e}$, que indica a direção do eixo de rotação entre dois instantes 
sucessivos de um corpo rígido. Para estudar a evolução dinâmica desse movimento é natural que se observe os vetores $\dot{\boldsymbol{\theta}}$ e o vetor velocidade angular $\boldsymbol{\omega}$. Ambos podem à primeira instância parecer semelhantes, uma vez que se referem à variação temporal de grandezas associadas à rotação de um corpo rígido. No entanto, possuem interpretações bastante diferentes.

O tensor rotação está relacionado a uma transformação que ocorre em certo intervalo de tempo, ou seja, à mudança de orientação entre dois vetores em instantes consecutivos. Esses vetores podem estar associados à posição de certo ponto de referência em um corpo rígido (equação 4.2) estando definidos em duas configurações consecutivas, sendo a primeira a configuração de referência e a segunda, uma configuração posterior.

Em relação ao vetor velocidade angular, sua interpretação é também a de um operador, porém trata-se de um conceito instantâneo utilizado para relacionar as velocidades de pontos de um corpo rígido com as posições dos mesmos. A equação 4.8 ilustra essa relação. Trata-se, portanto, de uma grandeza completamente distinta da derivada temporal do vetor rotação (seja na forma de Euler, ou de Rodrigues).

É possível obter, no entanto, uma relação entre os vetores $\dot{\boldsymbol{\theta}}$ (ou $\dot{\boldsymbol{\alpha}}$ ) e $\boldsymbol{\omega}$. Essa relação se dá através de um operador tensorial. A equação 4.24 define dois operadores, tanto para a forma de Euler, como para a forma de Rodrigues:

$$
\begin{aligned}
& \boldsymbol{\omega}=\boldsymbol{\Gamma} \dot{\boldsymbol{\theta}} \\
& \boldsymbol{\omega}=\boldsymbol{\Xi} \dot{\boldsymbol{\alpha}}
\end{aligned}
$$

Para os parâmetros de Euler a dedução do cálculo desses operadores pode ser encontrada em Dasambiagio (2008). Em uma abordagem mais genérica para diversos parâmetros de rotação, Moreira (2009) apresenta também esses operadores. As expressões que estão detalhadas a seguir se utilizam das seguintes funções para o parâmetros de Euler: 


$$
\begin{aligned}
& e_{0}=1 \\
& e_{1}=\frac{\operatorname{sen}(\theta)}{\theta} \\
& e_{2}=\frac{1-\cos (\theta)}{\theta^{2}} \\
& e_{3}=\frac{1-\frac{\operatorname{sen}(\theta)}{\theta}}{\theta^{2}} \\
& e_{4}=\frac{1}{\theta^{2}}\left(e_{1}-2 e_{2}\right) \\
& e_{5}=\frac{1}{\theta^{2}}\left(e_{2}-3 e_{3}\right) \\
& e_{6}=\frac{1}{\theta^{2}}\left(e_{3}-e_{2}-4 e_{4}\right) \\
& e_{7}=\frac{1}{\theta^{2}}\left(e_{4}-5 e_{5}\right)
\end{aligned}
$$

E para a parametrização de Rodrigues:

$$
\begin{aligned}
& r_{0}=\frac{4}{4+\alpha^{2}} \\
& r_{1}=r_{0} \\
& r_{2}=\frac{1}{2} r_{0} \\
& r_{4}=-\frac{1}{4} r_{0}^{2} \\
& r_{6}=\frac{1}{4} r_{0}^{3} \\
& r_{8}=-\frac{1}{2} r_{0}^{2} \\
& r_{9}=\frac{1}{2} r_{0}^{3}
\end{aligned}
$$

Tem-se:

$$
\begin{aligned}
& \boldsymbol{\Gamma}=e_{0} \boldsymbol{I}+e_{2} \boldsymbol{\Theta}+e_{3} \boldsymbol{\Theta}^{2} \\
& \boldsymbol{\Xi}=r_{0} \boldsymbol{I}+r_{2} \boldsymbol{A}
\end{aligned}
$$

É possível derivar em relação ao tempo as expressões 4.24 a fim de obter expres- 
sões para o cálculo das acelerações angulares:

$$
\begin{aligned}
& \dot{\omega}=\dot{\Gamma} \dot{\boldsymbol{\theta}}+\Gamma \ddot{\boldsymbol{\theta}} \\
& \dot{\boldsymbol{\omega}}=\dot{\boldsymbol{\Xi}} \dot{\alpha}+\Xi \ddot{\alpha}
\end{aligned}
$$

Note que para o cálculo da aceleração angular surgem derivadas temporais tanto do vetor rotação, como dos operadores $\boldsymbol{\Gamma}$ e $\boldsymbol{\Xi}$ definidos anteriormente. Derivando-se em relação à variável temporal as expressões 4.27 , obtém-se:

$$
\begin{aligned}
& \dot{\boldsymbol{\Gamma}}=e_{2} \dot{\boldsymbol{\Theta}}+e_{3}(\boldsymbol{\Theta} \dot{\boldsymbol{\Theta}}+\dot{\boldsymbol{\Theta} \Theta})+e_{4}(\boldsymbol{\theta} \cdot \dot{\boldsymbol{\theta}}) \boldsymbol{\Theta}+e_{5}(\boldsymbol{\theta} \cdot \dot{\boldsymbol{\theta}}) \boldsymbol{\Theta}^{\mathbf{2}} \\
& \dot{\Xi}=r_{2} \dot{\boldsymbol{A}}+r_{4}(\boldsymbol{\alpha} \cdot \dot{\boldsymbol{\alpha}}) \boldsymbol{A}+r_{8}(\boldsymbol{\alpha} \cdot \dot{\boldsymbol{\alpha}}) \boldsymbol{I}
\end{aligned}
$$

A seguir são definidos outros dois operadores, com o objetivo de compactar a notação da formulação de teoria estrutural de viga apresentada no presente capítulo. Seja um tensor anti-simétrico $\boldsymbol{T}$ genérico cujo vetor axial é $\boldsymbol{t}$. É possível definir os tensores $\boldsymbol{W}(\boldsymbol{\theta}, \boldsymbol{t})$ e $\boldsymbol{V}(\boldsymbol{\alpha}, \boldsymbol{t})$ :

$$
\begin{aligned}
& \boldsymbol{W}(\boldsymbol{\theta}, \boldsymbol{t})=\frac{\partial\left(\boldsymbol{\Gamma}^{T} \boldsymbol{t}\right)}{\partial \boldsymbol{\theta}}=\left(-e_{4} \boldsymbol{\Theta} \boldsymbol{t}+e_{5} \boldsymbol{\Theta}^{2} \boldsymbol{t}\right) \otimes \boldsymbol{\theta}+e_{2} \boldsymbol{T}-e_{3}(2 \boldsymbol{\Theta} \boldsymbol{T}-\boldsymbol{T} \boldsymbol{\Theta}) \\
& \boldsymbol{V}(\boldsymbol{\alpha}, \boldsymbol{t})=\frac{\partial\left(\boldsymbol{\Xi}^{T} \boldsymbol{t}\right)}{\partial \boldsymbol{\alpha}}=\left(r_{8} \boldsymbol{t}-r_{4} \boldsymbol{A} \boldsymbol{t}+\right) \otimes \boldsymbol{\alpha}+r_{2} \boldsymbol{T}
\end{aligned}
$$

As derivadas temporais de 4.30 são dadas por:

$$
\begin{aligned}
\dot{\boldsymbol{W}}(\boldsymbol{\theta}, \dot{\boldsymbol{\theta}}, \boldsymbol{t})= & (\boldsymbol{\theta} \cdot \dot{\boldsymbol{\theta}})\left(-e_{6} \boldsymbol{\Theta} \boldsymbol{t}+e_{7} \Theta^{2} \boldsymbol{t}\right) \otimes \boldsymbol{\theta}+ \\
& +\left(-e_{4} \Theta \boldsymbol{\boldsymbol { t }}+e_{5} \Theta^{2} \boldsymbol{t}\right) \otimes \dot{\boldsymbol{\theta}}+ \\
& +\left(e_{5}(\boldsymbol{\Theta} \dot{\boldsymbol{\Theta}}+\dot{\boldsymbol{\Theta} \Theta}) \boldsymbol{t}-e_{4} \dot{\boldsymbol{\Theta}} \boldsymbol{t}\right) \otimes \boldsymbol{\theta}+ \\
& +e_{4}(\boldsymbol{\theta} \cdot \dot{\boldsymbol{\theta}}) \boldsymbol{T}-e_{5}(\boldsymbol{\theta} \cdot \dot{\boldsymbol{\theta}})(2 \boldsymbol{\Theta} \boldsymbol{T}-\boldsymbol{T} \boldsymbol{\Theta})+ \\
& -e_{3}(2 \dot{\boldsymbol{\Theta}} \boldsymbol{T}-\boldsymbol{T} \dot{\boldsymbol{\Theta}})
\end{aligned}
$$




$$
\begin{aligned}
\dot{\boldsymbol{V}}(\boldsymbol{\alpha}, \dot{\boldsymbol{\alpha}}, \boldsymbol{t})= & (\boldsymbol{\alpha} \cdot \dot{\boldsymbol{\alpha}})\left(r_{9} \boldsymbol{t}-r_{6} \boldsymbol{A} \boldsymbol{t}\right) \otimes \boldsymbol{\alpha}+ \\
& +\left(r_{8} \boldsymbol{t}-r_{4} \boldsymbol{A} \boldsymbol{t}\right) \otimes \dot{\boldsymbol{\alpha}}+ \\
& -\left(r_{4} \dot{\boldsymbol{A}} \boldsymbol{t}\right) \otimes \boldsymbol{\alpha}+ \\
& +r_{4}(\boldsymbol{\alpha} \cdot \dot{\boldsymbol{\alpha}}) \boldsymbol{T}
\end{aligned}
$$

\subsubsection{Potência das forças aplicadas a um corpo rígido}

É possível escrever uma expressão para o cálculo da potência das forças externas que agem em um corpo rígido de uma forma bastante conveniente, tal que se possa enxergar a conjugação energética das forças e momentos em relação a grandezas cinemáticas. A potência de uma força sobre uma partícula é uma grandeza primitiva da física e pode ser escrita como: $P_{i}=\boldsymbol{f}_{i} \cdot \boldsymbol{v}_{i}$, sendo $\boldsymbol{f}_{i}$ a força atuante na partícula $i$ e $\boldsymbol{v}_{i}$ a velocidade da mesma. Sendo uma grandeza escalar, pode-se escrever que a potência das forças em um sistema de forças $P_{S}$ é simplesmente o somatório das potências sobre cada uma das partículas do sistema: $P_{S}=\sum_{i} \boldsymbol{f}_{i} \cdot \boldsymbol{v}_{i}$.

A velocidade de um ponto genérico de um corpo rígido pode ser escrita através da equação 4.8. Utilizando-a é possível obter a seguinte equação para o cálculo da potência:

$$
P_{S}=\sum_{i} \boldsymbol{f}_{i} \cdot\left[\boldsymbol{v}_{O}+\boldsymbol{\omega} \times\left(\boldsymbol{P}_{i}-\boldsymbol{O}\right)\right]
$$

Sendo o momento em relação a um pólo $\boldsymbol{O}$ de uma força $\boldsymbol{f}_{i}$ aplicada em um ponto $\boldsymbol{P}_{i}$ dado por $\boldsymbol{M}_{O}^{i}=\left(\boldsymbol{P}_{i}-\boldsymbol{O}\right) \times \boldsymbol{f}_{i}$ e a resultante de um sistema de forças $\boldsymbol{f}_{i}$ dado por $\boldsymbol{f}=\sum_{i} \boldsymbol{f}_{i}$, tem-se que:

$$
P_{S}=\boldsymbol{f} \cdot \boldsymbol{v}_{O}+\boldsymbol{M}_{O} \cdot \boldsymbol{\omega}
$$

O vetor $\boldsymbol{M}_{O}$ representa o momento de todas as forças atuantes no sistema, em relação ao pólo $\boldsymbol{O}$. A expressão 4.34 mostra as grandezas energeticamente conjugadas para o cálculo da potência. Nota-se que a força é energeticamente conjugada à velocidade e que o momento de uma força é energeticamente conjugado à velocidade angular. É 
possível realizar uma conversão do momento de um sistema de forças, a fim de torná-lo energeticamente conjugado a $\dot{\boldsymbol{\theta}}$ ou $\dot{\boldsymbol{\alpha}}$. Pode-se escrever que:

$$
P_{S}=\boldsymbol{f} \cdot \boldsymbol{v}_{O}+\boldsymbol{M}_{O} \cdot \boldsymbol{\omega}=\boldsymbol{f} \cdot \boldsymbol{v}_{O}+\boldsymbol{M}_{O} \cdot \boldsymbol{\Gamma} \dot{\boldsymbol{\theta}}=\boldsymbol{f} \cdot \boldsymbol{v}_{O}+\boldsymbol{M}_{O} \cdot \boldsymbol{\Xi} \dot{\boldsymbol{\alpha}}
$$

Assim, definem-se duas novas grandezas, energeticamente conjugadas com as derivadas temporais dos parâmetros utilizados nos vetores rotação. Essas grandezas são denominadas pseudo-momentos $\boldsymbol{\mu}$, e são dadas de formas diferentes dependendo da forma que se parametriza o vetor rotação (Euler e Rodrigues):

$$
\begin{aligned}
& \boldsymbol{\mu}^{\boldsymbol{\theta}}=\boldsymbol{\Gamma}^{T} \boldsymbol{M}_{O} \\
& \boldsymbol{\mu}^{\boldsymbol{\alpha}}=\boldsymbol{\Xi}^{T} \boldsymbol{M}_{O}
\end{aligned}
$$

De modo geral, $\boldsymbol{\mu}^{\boldsymbol{\theta}} \neq \boldsymbol{\mu}^{\boldsymbol{\alpha}}$. Note que, ao aplicar o Princípio dos Trabalhos Virtuais para formular alguma teoria estrutural, deve-se tomar o cuidado de escrever a energia de deformação da viga devido a suas rotações de forma correta, utilizando-se os pseudomomentos, e não os momentos. Por exemplo, o trabalho de um momento $\boldsymbol{M}_{O}$, associado a um vetor rotação na forma de Euler $\boldsymbol{\theta}$ é dado por: $\boldsymbol{\Gamma}^{T} \boldsymbol{M}_{O} \boldsymbol{\theta}=\boldsymbol{\mu}^{\boldsymbol{\theta}} \boldsymbol{\theta}$.

\subsubsection{Não comutatividade das rotações}

Grandes rotações de um corpo rígido podem ser entendidas como uma transformação linear $\boldsymbol{R}(t)$, entre um vetor associado a um instante de referência, até um instante posterior. A equação 4.2 mostra claramente essa relação.

Sendo $\boldsymbol{R}_{1}$ e $\boldsymbol{R}_{2}$ transformações lineares associadas a uma rotação, pode-se aplicar duas diferentes rotações a um vetor $\boldsymbol{y}$ em duas diferentes ordens, da seguinte forma:

$$
\begin{aligned}
& \boldsymbol{z}_{1}=\boldsymbol{R}_{1} \boldsymbol{y} \\
& \boldsymbol{z}_{2}=\boldsymbol{R}_{2} \boldsymbol{z}_{1}
\end{aligned}
$$

Logo:

$$
\boldsymbol{z}_{2}=\boldsymbol{R}_{2} \boldsymbol{R}_{1} \boldsymbol{y}
$$

Se a aplicação for feita de maneira inversa, ou seja, primeiro a rotação 2 e depois a rotação 
1, o resultado seria:

$$
\boldsymbol{z}_{2}=\boldsymbol{R}_{1} \boldsymbol{R}_{2} \boldsymbol{y}
$$

De modo geral, tem-se $\boldsymbol{R}_{1} \boldsymbol{R}_{2} \neq \boldsymbol{R}_{2} \boldsymbol{R}_{1}$, o que leva a crer que duas rotações seguidas, no caso geral que independa de sua ordem de magnitude, não comutam. Portanto, todo e qualquer problema que possua grandes rotações necessariamente deve ser tratado como não-linear, pelo simples fato de que diferentes sequências de rotações podem chegar a resultados diferentes. O princípio da superposição, não se aplica às rotações, uma vez que elas não podem ser representadas por vetores, mas sim por tensores de segunda ordem.

\subsubsection{Escolha dos parâmetros de rotação}

Para o problema estático resolvido com descrição lagrangiana total, tanto as parametrizações de Euler como de Rodrigues possuem um comportamento bastante semelhante. No entanto, em uma abordagem dinâmica ou mesmo estática através de uma descrição lagrangiana atualizada, a formulação de Rodrigues torna-se mais vantajosa, tanto pela simplicidade das expressões envolvidas no cálculo das rotações, que não possuem funções trigonométricas, bem como a composição de rotações sucessivas se torna muito mais simples, pois existe uma equação desenvolvida por Rodrigues para a composição do parâmetro de rotação. Essa equação é mostrada na seção 4.4 .2 e é utilizada em trabalhos como Pimenta, Campello e Wriggers (2008) e em Moreira (2009), bases teóricas para a formulação desenvolvida a seguir. Os parâmetros de Euler poderiam também ser escolhidos. No entanto, essa equação de composição de rotações não está disponível e, portanto, a composição de rotações no contexto da descrição lagrangiana atualizada seria muito mais trabalhosa. Por isso foi utilizada a parametrização de Rodrigues.

\subsection{Formulação do modelo estrutural de viga}

A Figura 4.7 ilustra as configurações da estrutura de uma viga analisada com a descrição lagrangiana atualizada. A ideia é subdividir os carregamentos do modelo em sub-passos, associados a soluções parciais que resultem em novas configurações, que gerem novos referenciais sucessivos. Para descrever tais eventos define-se um índice " $i$ ", tal que em " $i$ " são conhecidos os deslocamentos, tensões e deformações e, em " $i+1$ " se está buscando a solução dessas incógnitas. Grandezas relacionando os referenciais " $i$ " e " $i+1$ " são referenciadas com o índice " $\Delta$ ". 


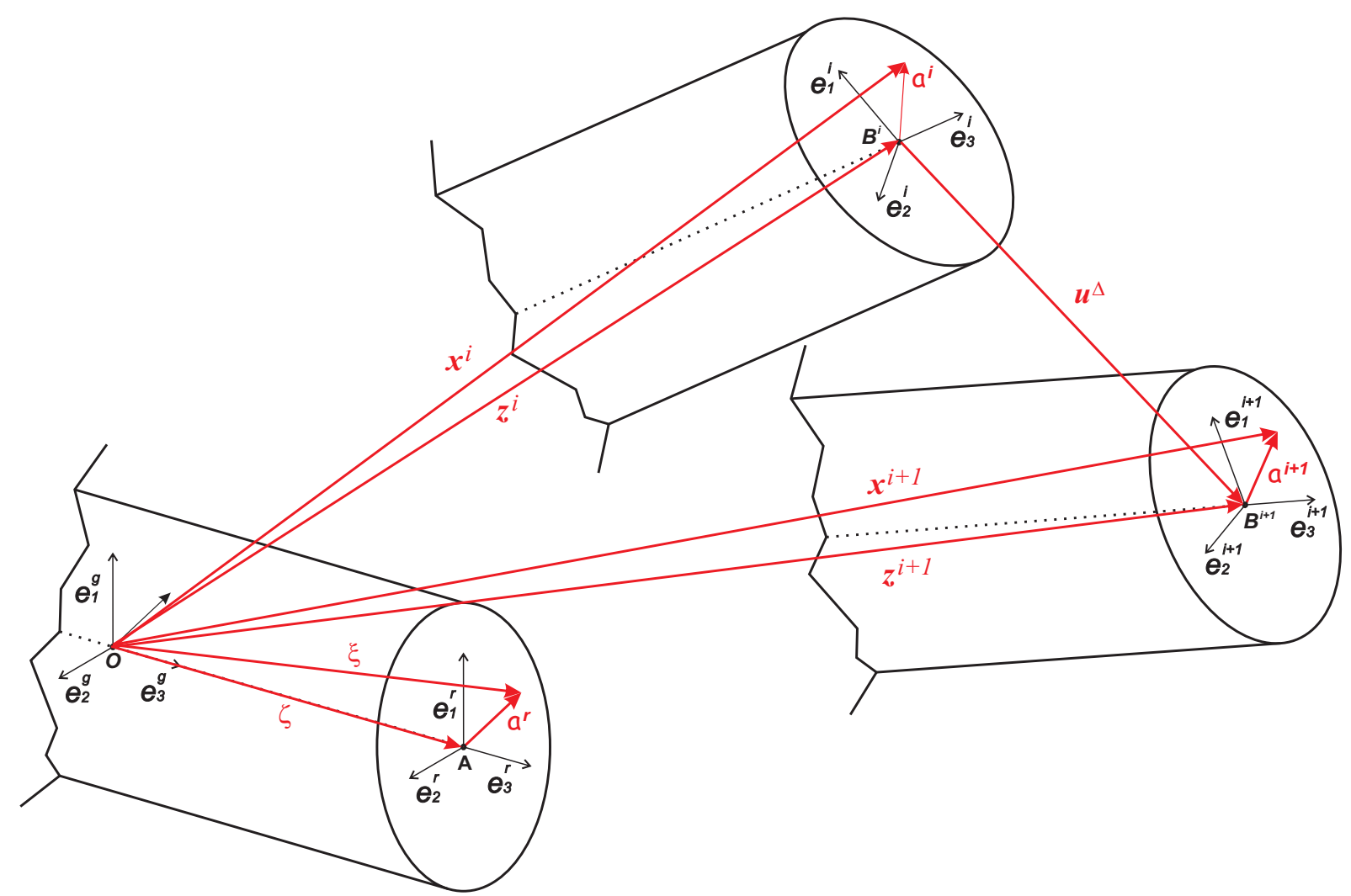

Figura 4.7: Sistemas de coordenadas e vetores utilizados na Formulação Cinematicamente Exata com descrição lagrangiana atualizada

Define-se um referencial global fixo $\left(\boldsymbol{O}, \boldsymbol{e}_{1}^{g}, \boldsymbol{e}_{2}^{g}, \boldsymbol{e}_{3}^{g}\right)$ que é utilizado para escrever todos os vetores e tensores aqui apresentados. Escolhida uma seção transversal genérica de uma viga reta, nomeiam-se as seguintes variáveis:

- $\boldsymbol{\zeta}$ é o vetor posição do ponto $\boldsymbol{A}$, definido pela interseç̧ão entre o eixo da viga e a seção transversal que está sendo analisada (em sua configuração de referência);

- $\xi$ é o vetor posição de um ponto genérico da seção transversal considerada da viga em sua configuração de referência;

- $\boldsymbol{a}^{\boldsymbol{r}}$ é a diferença entre os vetores $\boldsymbol{\xi}$ e $\boldsymbol{\zeta}$. Após o movimento da estrutura se transforma em $\boldsymbol{a}^{i}$ na configuração " $i$ " e $\boldsymbol{a}^{i+1}$ na configuração " $i+1$ ";

- $\boldsymbol{z}^{\boldsymbol{i}}$ e $\boldsymbol{z}^{\boldsymbol{i + 1}}$ são os vetores posição dos pontos $\boldsymbol{B}^{\boldsymbol{i}}$ e $\boldsymbol{B}^{\boldsymbol{i + 1}}$, definidos pela intersecção entre o eixo da viga e a seção transversal que está sendo analisada, respectivamente nas configurações " $i$ " e " $i+1$ ";

- $\boldsymbol{x}^{i}$ e $\boldsymbol{x}^{i+1}$ são os vetores posição de um ponto genérico da seção transversal considerada da viga, respectivamente nas configurações " $i$ " e " $i+1$ "; 
- $\boldsymbol{u}^{\boldsymbol{\Delta}}$ é o vetor deslocamento que vai do ponto $\boldsymbol{B}^{\boldsymbol{i}}$ até o ponto $\boldsymbol{B}^{\boldsymbol{i + 1}}$, origens dos referenciais locais " $i$ " " $i+1$ ", respectivamente.

Sendo $\boldsymbol{\delta}^{\boldsymbol{\Delta}}$ o deslocamento de um ponto genérico da seção transversal da viga em certo sub-passo da análise, é possível escrever algumas relações vetoriais:

$$
\begin{aligned}
& x^{i+1}=z^{i+1}+a^{i+1} \\
& z^{i+1}=z^{i}+u^{\Delta} \\
& \delta^{\Delta}=x^{i+1}-x^{i}
\end{aligned}
$$

Definindo a variável escalar $\zeta$, tal que $\boldsymbol{\zeta}=\zeta \boldsymbol{e}_{3}^{r}$, um ponto genérico da configuração de referência pode ser escrito da seguinte forma:

$$
\boldsymbol{\xi}=x_{1} \boldsymbol{e}_{1}^{r}+x_{2} \boldsymbol{e}_{2}^{r}+\zeta \boldsymbol{e}_{3}^{r}
$$

Utilizando-se das mesmas coordenadas, tem-se:

$$
\boldsymbol{a}^{r}=x_{1} \boldsymbol{e}_{1}^{r}+x_{2} \boldsymbol{e}_{2}^{r}
$$

Os momentos e produtos de inércia da seção transversal podem ser calculados da seguinte forma:

$$
\begin{aligned}
I_{11} & =\int_{A} x_{2}^{2} d A \\
I_{22} & =\int_{A} x_{1}^{2} d A \\
I_{12} & =\int_{A} x_{1} x_{2} d A
\end{aligned}
$$

No modelo estático de uma viga cuja configuração de referência é retilínea, cada seção transversal pode ser referenciada unicamente pela variável escalar $\zeta$, apresentando um tensor rotação $\boldsymbol{R}=\boldsymbol{R}(\zeta)$. A fim de descrever os movimentos de uma dada seção transversal genérica da viga, utiliza-se do tensor rotação apresentado em 4.3.3 ou 4.3.4. O tensor rotação relaciona vetores entre a configuração de referência e a configuração " $i$ ", 
tal que: $\boldsymbol{a}^{\boldsymbol{i}}=\boldsymbol{R}^{\boldsymbol{i}} \boldsymbol{a}^{\boldsymbol{r}}$. A rotação entre $\boldsymbol{a}^{\boldsymbol{i}}$ e $\boldsymbol{a}^{\boldsymbol{i + 1}}$ é dada por: $\boldsymbol{a}^{\boldsymbol{i + 1}}=\boldsymbol{R}^{\boldsymbol{\Delta}} \boldsymbol{a}^{\boldsymbol{i}}$. Assim, para compor as rotações entre a configuração de referência e a configuração " $i+1$ " é possível escrever:

$$
\boldsymbol{R}^{i+1}=\boldsymbol{R}^{\Delta} \boldsymbol{R}^{i}
$$

Define-se também o vetor $\boldsymbol{u}^{i}=\left(\boldsymbol{B}^{i}-\boldsymbol{A}\right)$, de modo que:

$$
\boldsymbol{x}^{i}=\zeta \boldsymbol{e}_{3}^{r}+\boldsymbol{u}^{i}+\boldsymbol{R}^{i} \boldsymbol{a}^{r}
$$

Por conveniência de notação, derivadas em relação à variável escalar $\zeta$ são denotadas pelo símbolo ( $)^{\prime}$ em toda a formulação.

\subsubsection{Deformações}

O gradiente de transformação associado à configuração " $i$ " é dado por:

$$
\boldsymbol{F}^{\boldsymbol{i}}=\frac{\partial \boldsymbol{x}^{i}}{\partial \boldsymbol{\xi}}=\frac{\partial \boldsymbol{x}^{i}}{\partial x_{1}} \otimes \boldsymbol{e}_{1}^{r}+\frac{\partial \boldsymbol{x}^{i}}{\partial x_{2}} \otimes \boldsymbol{e}_{2}^{r}+\boldsymbol{x}^{i^{\prime}} \otimes \boldsymbol{e}_{3}^{r}
$$

Para o desenvolvimento da equação 4.46, utiliza-se: $\boldsymbol{x}^{\boldsymbol{i}}=\zeta \boldsymbol{e}_{3}^{r}+\boldsymbol{u}^{\boldsymbol{i}}+\boldsymbol{a}^{\boldsymbol{i}}$. O cálculo de $\boldsymbol{a}^{\boldsymbol{i}}$ pode ser feito com: $\boldsymbol{a}^{\boldsymbol{i}}=x_{1} \boldsymbol{e}_{\mathbf{1}}^{\boldsymbol{i}}+x_{2} \boldsymbol{e}_{\mathbf{2}}^{\boldsymbol{i}}$, levando à expressão:

$$
\boldsymbol{a}^{i}=\boldsymbol{R}^{i}\left(x_{1} \boldsymbol{e}_{1}^{r}+x_{2} \boldsymbol{e}_{2}^{r}\right)
$$

Logo, os dois primeiros termos da expressão 4.46 resultam em:

$$
\begin{aligned}
& \frac{\partial \boldsymbol{x}^{i}}{\partial x_{1}} \otimes \boldsymbol{e}_{1}^{r}=\boldsymbol{R}^{i}\left(\boldsymbol{e}_{1}^{r} \otimes \boldsymbol{e}_{1}^{r}\right) \\
& \frac{\partial \boldsymbol{x}^{i}}{\partial x_{2}} \otimes \boldsymbol{e}_{2}^{r}=\boldsymbol{R}^{i}\left(\boldsymbol{e}_{2}^{r} \otimes \boldsymbol{e}_{2}^{r}\right)
\end{aligned}
$$

O terceiro termo da expressão 4.46 é desenvolvido da seguinte forma: 


$$
\begin{aligned}
& x^{i^{\prime}} \otimes e_{3}^{r}=\left(e_{3}^{r}+u^{i^{\prime}}+R^{i^{\prime}} a^{r}\right) \otimes e_{3}^{r}= \\
& =\left(e_{3}^{r}+u^{i^{\prime}}+R^{i^{\prime}} R^{i^{T}} a^{i}\right) \otimes e_{3}^{r}
\end{aligned}
$$

Define-se o tensor anti-simétrico $\boldsymbol{K}^{\boldsymbol{i}}=\boldsymbol{R}^{\boldsymbol{i}^{\prime}} \boldsymbol{R}^{\boldsymbol{i}^{T}}$ que é matematicamente similar à velocidade angular, definida na equação 4.7. A velocidade angular é um tensor que define a rotação de pontos de um corpo rígido ao longo do tempo. O tensor $\boldsymbol{K}^{\boldsymbol{i}}$ recém definido e doravante denominado "rotação específica" define a taxa de variação de rotação de pontos das seções rígidas da viga ao longo do comprimento da viga representado pela variável $\zeta^{5}$. Assim, a rotação específica está relacionada à curvatura e à rotação axial por unidade de comprimento da viga, presente em problemas de torção. Sendo um tensor anti-simétrico, pode-se definir o vetor "rotação específica" como:

$$
\boldsymbol{\kappa}^{i}=\operatorname{axial}\left(\boldsymbol{R}^{\boldsymbol{i}^{\prime}} \boldsymbol{R}^{i^{T}}\right)
$$

O gradiente de transformação é dado por:

$$
F^{i}=R^{i}\left(e_{1}^{r} \otimes e_{1}^{r}\right)+R^{i}\left(e_{2}^{r} \otimes e_{2}^{r}\right)+\left(e_{3}^{r}+u^{i^{\prime}}+R^{i^{\prime}} R^{i^{T}} a^{i}\right) \otimes e_{3}^{r}
$$

É possível definir o vetor deformação translacional $\eta^{i}=\boldsymbol{z}^{\boldsymbol{i}^{\prime}}-\boldsymbol{e}_{3}^{\boldsymbol{i}}$. Realizando algumas substituições de variáveis, é fácil chegar em:

$$
u^{i^{\prime}}=\eta^{i}-e_{3}^{r}+e_{3}^{i}
$$

Utilizando o resultado da equação 4.52 na equação 4.51 e realizando algum trabalho algébrico é possível escrever a seguinte expressão para o gradiente de transformação:

\footnotetext{
${ }^{5}$ Retirando-se o índice referente à configuração " $i$ " e utilizando-se da notação indicial (em que $i$ e $j$ se referem aos índices do tensor) é possível escrever o tensor rotação específica da seguinte forma:

$$
K_{i j}=R_{i j}^{\prime} R_{j i}
$$

A anti-simetria pode ser facilmente demonstrada derivando-se a equação 4.3 em relação à variável $\zeta$ :

$$
R_{j i}^{\prime} R_{i j}+R_{j i} R_{i j}^{\prime}=0 \Rightarrow R_{j i}^{\prime} R_{i j}=-R_{j i} R_{i j}^{\prime}
$$
}

Logo: $K_{i j}=-K_{j i}$. 


$$
F^{i}=R^{i}+\left(\eta^{i}+K^{i} a^{i}\right) \otimes e_{3}^{r}
$$

A fim de simplificar ainda mais essa expressão, pode-se definir os tensores retrorotacionados:

$$
\begin{aligned}
& \boldsymbol{\eta}^{i^{r}}=\boldsymbol{R}^{i^{T}} \boldsymbol{\eta}^{i} \\
& \boldsymbol{\kappa}^{i^{r}}=\boldsymbol{R}^{i^{T}} \boldsymbol{\kappa}^{i}
\end{aligned}
$$

Assim, chega-se à seguinte expressão para o gradiente de transformação:

$$
\boldsymbol{F}^{i}=\boldsymbol{R}^{i}\left(\boldsymbol{I}+\boldsymbol{\eta}^{i^{r}}+\boldsymbol{K}^{i^{r}} \boldsymbol{a}^{r}\right) \otimes \boldsymbol{e}_{3}^{r}
$$

\subsubsection{Relações entre as diferentes configurações}

Na configuração " $i+1$ ”, o cálculo do vetor rotação específica é dado por:

$$
\boldsymbol{\kappa}^{i+\mathbf{1}}=\operatorname{axial}\left(\boldsymbol{R}^{i+\mathbf{1}^{\prime}} \boldsymbol{R}^{i+\mathbf{1}^{T}}\right)
$$

Utilizando-se a equação 4.44, chega-se em:

$$
\boldsymbol{\kappa}^{i+\mathbf{1}}=\operatorname{axial}\left(\boldsymbol{R}^{\boldsymbol{\Delta}^{\prime}} \boldsymbol{R}^{\boldsymbol{\Delta}^{T}}\right)+\boldsymbol{R}^{\boldsymbol{\Delta}} \operatorname{axial}\left(\boldsymbol{R}^{\boldsymbol{i}^{\prime}} \boldsymbol{R}^{\boldsymbol{i}^{T}}\right)
$$

Explorando a similaridade entre os vetores velocidade angular e rotação específica, é possível se utilizar dos parâmetro de rotação de Rodrigues para calcular a rotação específica tal que:

$$
\boldsymbol{\kappa}^{\boldsymbol{\Delta}}=\operatorname{axial}\left(\boldsymbol{R}^{\boldsymbol{\Delta}^{\prime}} \boldsymbol{R}^{\boldsymbol{\Delta}^{T}}\right)=\boldsymbol{\Xi}^{\boldsymbol{\Delta}} \boldsymbol{\alpha}^{\boldsymbol{\Delta}^{\prime}}
$$

Sendo $\boldsymbol{\kappa}^{\boldsymbol{\Delta}}=$ axial $\left(\boldsymbol{R}^{\boldsymbol{\Delta}^{\prime}} \boldsymbol{R}^{\boldsymbol{\Delta}^{T}}\right)$, utilizando-se da equação 4.58 em 4.57 é possível concluir que: 


$$
\kappa^{i+1}=\kappa^{\Delta}+R^{\Delta} \kappa^{i}
$$

Multiplicando-se a equação 4.59 por $\boldsymbol{R}^{\boldsymbol{i + 1} \mathbf{1}^{T}}$ obtém-se a rotação específica retrorotacionada:

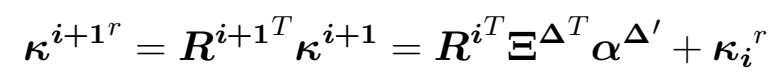

Já o vetor das deformações translacionais $\boldsymbol{\eta}^{\boldsymbol{i + 1}}$ assume a forma:

$$
\eta^{i+1}=z^{i+1^{\prime}}-e_{3}^{i+1}
$$

Realizando a retro-rotação, obtém-se:

$$
\eta^{i+1^{r}}=R^{i+1^{T}} z^{i+1^{\prime}}-e_{3}^{r}
$$

Para calcular as deformações acumuladas na viga ao longo da aplicação dos subpassos de carregamento é necessário realizar a atualização de algumas variáveis. É necessário atualizar a rotação específica calculada na configuração " $i+1$ ”, conforme a expressão 4.60. Além disso, a atualização do tensor rotação deve ser feito através da expressão 4.44.

A atualização dos deslocamentos e do vetor rotação de Rodrigues também deve ser feita. A atualização dos deslocamentos é trivial, uma vez que é possível fazer a soma direta do vetor deslocamento em " $i$ " ao incremento de deslocamento $\boldsymbol{u}^{\boldsymbol{\Delta}}$, da seguinte forma:

$$
u^{i+1}=u^{i}+u^{\Delta}
$$

Já a atualização do vetor rotação não é tão simples. Não é possível simplesmente somar os vetores $\boldsymbol{\alpha}^{\boldsymbol{i}}$ e $\boldsymbol{\alpha}^{\boldsymbol{\Delta}}$, uma vez que os mesmos não gozam de propriedades vetoriais (ver ítem 4.3.2). O procedimento de atualização do ângulo $\boldsymbol{\alpha}_{\boldsymbol{i}}$ poderia ser: atualizar primeiramente o tensor rotação com a expressão 4.44 e, posteriormente, extrair o ângulo 
desse tensor. No entanto, ao utilizar-se os parâmetros de Rodrigues é possível utilizar-se da fórmula para a atualização direta do pseudo-vetor rotação. Essa expressão pode ser encontrada, por exemplo em Moreira (2009) ou Pimenta, Campello e Wriggers (2008) e é dada por:

$$
\boldsymbol{\alpha}^{i+1}=\frac{4}{4-\boldsymbol{\alpha}^{\boldsymbol{\Delta}} \cdot \boldsymbol{\alpha}^{\boldsymbol{i}}}\left(\boldsymbol{\alpha}^{\boldsymbol{\Delta}}+\boldsymbol{\alpha}^{i}+\frac{1}{2} \boldsymbol{\alpha}^{\boldsymbol{\Delta}} \times \boldsymbol{\alpha}^{i}\right)
$$

\subsubsection{Tensões}

A descrição das tensões na seção transversal da viga é feita através do Primeiro Tensor de Piola-Kirchhoff, a fim de descrever o estado de tensões na configuração atual, em função da configuração de referência. Essa abordagem é conveniente pois o vetor de deformações é também desenvolvido na configuração de referência. Para uma configuração genérica " $i$ ", tem-se:

$$
P^{i}=t_{1}^{i} \otimes e_{1}^{r}+t_{2}^{i} \otimes e_{2}^{r}+\tau^{i} \otimes e_{3}^{r}
$$

Os vetores $\boldsymbol{t}_{\mathbf{1}}^{\boldsymbol{i}}$ e $\boldsymbol{t}_{\mathbf{2}}^{\boldsymbol{i}}$ são as tensões atuantes na configuração atual, por unidade de área da configuração de referência relacionadas aos planos cujas normais de referência são $\boldsymbol{e}_{1}^{r}$ e $\boldsymbol{e}_{2}^{r}$ respectivamente. A tensão $\boldsymbol{\tau}^{i}$ é relacionada ao plano cuja normal na configuração de referência é $\boldsymbol{e}_{\mathbf{3}}^{r}$.

O vetor $\tau^{i}$ é dado por duas componentes cisalhantes $\tau_{1}^{i}$ e $\tau_{2}^{i}$ e por uma componente normal $\sigma^{i}$ :

$$
\tau^{i}=\tau_{1}^{i} e_{1}^{i}+\tau_{2}^{i} e_{2}^{i}+\sigma^{i} e_{3}^{i}
$$

Os esforços solicitantes atuantes em cada seção transversal são dados pela integração do campo de tensões no domínio da área da seção transversal de referência, da seguinte forma: 


$$
\begin{aligned}
& \boldsymbol{n}^{i}=\int_{A} \tau^{i} d A=V_{1} \boldsymbol{e}_{1}^{i}+V_{2} \boldsymbol{e}_{2}^{i}+N \boldsymbol{e}_{3}^{i} \\
& \boldsymbol{m}^{i}=\int_{A} \boldsymbol{a}^{i} \times \boldsymbol{\tau}^{i} d A=M_{1} \boldsymbol{e}_{1}^{i}+M_{2} \boldsymbol{e}_{2}^{i}+M_{3} \boldsymbol{e}_{3}^{i}
\end{aligned}
$$

Os vetores $\boldsymbol{n}^{\boldsymbol{i}}$ e $\boldsymbol{m}^{\boldsymbol{i}}$ introduzidos representam a força e o momento atuantes em uma dada seção transversal da configuração " $i$ ". Os componentes $V_{1}$ e $V_{2}$ são as forças cortantes, $N$ é a força normal, $M_{1}$ e $M_{2}$ são os momentos fletores e $M_{3}$ é o momento de torção. Ainda é possível definir de forma mais genérica um vetor de seis dimensões denominado "esforço generalizado" (por se tratar de uma combinação de forças e momentos):

$$
\boldsymbol{\sigma}^{i}=\left[\begin{array}{c}
\boldsymbol{n}^{i} \\
\boldsymbol{m}^{\boldsymbol{i}}
\end{array}\right]=\left[\begin{array}{c}
\boldsymbol{n}^{i}=\int_{A} \boldsymbol{\tau}^{i} d A \\
\boldsymbol{m}^{i}=\int_{A} \boldsymbol{a}^{i} \times \boldsymbol{\tau}^{i} d A
\end{array}\right]=\left[\begin{array}{c}
V_{1} \boldsymbol{e}_{\mathbf{1}}^{\boldsymbol{i}}+V_{2} \boldsymbol{e}_{\mathbf{2}}^{\boldsymbol{i}}+N \boldsymbol{e}_{\mathbf{3}}^{\boldsymbol{i}} \\
M_{1} \boldsymbol{e}_{\mathbf{1}}^{\boldsymbol{i}}+M_{2} \boldsymbol{e}_{\mathbf{2}}^{\boldsymbol{i}}+M_{3} \boldsymbol{e}_{\mathbf{3}}^{\boldsymbol{i}}
\end{array}\right]
$$

Uma vez que se deseja trabalhar na configuração de referência, é necessário definir o mesmo vetor de esforços generalizados na configuração de referência através de uma retro-rotação:

$$
\boldsymbol{\sigma}^{\boldsymbol{i}^{r}}=\left[\begin{array}{c}
\boldsymbol{n}^{i^{r}} \\
\boldsymbol{m}^{i^{r}}
\end{array}\right]=\left[\begin{array}{c}
\boldsymbol{R}^{i^{T}} \boldsymbol{n}^{i} \\
\boldsymbol{R}^{i^{T}} \boldsymbol{m}^{i}
\end{array}\right]
$$

Sendo $\boldsymbol{\tau}^{\boldsymbol{i}^{r}}=\boldsymbol{R}^{\boldsymbol{i}^{T}} \boldsymbol{\tau}^{\boldsymbol{i}}$, as expressões retro-rotacionadas para os esforços solicitantes são as seguintes:

$$
\begin{aligned}
& \boldsymbol{n}^{i^{r}}=\int_{A} \boldsymbol{\tau}^{i^{r}} d A \\
& \boldsymbol{m}^{i^{r}}=\int_{A} \boldsymbol{a}^{r} \times \boldsymbol{\tau}^{i^{r}} d A
\end{aligned}
$$

Aplicando-se a retro-rotação $\boldsymbol{R}^{i^{T}}$ na expressão 4.68, obtém-se expressões para os esforços retro-rotacionados: 


$$
\begin{array}{r}
\boldsymbol{n}^{\boldsymbol{i}^{r}}=V_{1} \boldsymbol{R}^{\boldsymbol{i}^{T}} \boldsymbol{e}_{\mathbf{1}}^{\boldsymbol{i}}+V_{2} \boldsymbol{R}^{\boldsymbol{i}^{T}} \boldsymbol{e}_{\mathbf{2}}^{\boldsymbol{i}}+N \boldsymbol{R}^{\boldsymbol{i}^{T}} \boldsymbol{e}_{\mathbf{3}}^{\boldsymbol{i}}=V_{1} \boldsymbol{e}_{\mathbf{1}}^{\boldsymbol{r}}+V_{2} \boldsymbol{e}_{\mathbf{2}}^{\boldsymbol{r}}+N \boldsymbol{e}_{\mathbf{3}}^{\boldsymbol{r}} \\
\boldsymbol{m}^{\boldsymbol{i}^{r}}=M_{1} \boldsymbol{R}^{\boldsymbol{i}^{T}} \boldsymbol{e}_{\mathbf{1}}^{\boldsymbol{i}}+M_{2} \boldsymbol{R}^{\boldsymbol{i}^{T}} \boldsymbol{e}_{\mathbf{2}}^{\boldsymbol{i}}+M_{3} \boldsymbol{R}^{\boldsymbol{i}^{T}} \boldsymbol{e}_{\mathbf{3}}^{\boldsymbol{i}}=M_{1} \boldsymbol{e}_{\mathbf{1}}^{\boldsymbol{r}}+M_{2} \boldsymbol{e}_{2}^{\boldsymbol{r}}+M_{3} \boldsymbol{e}_{\mathbf{3}}^{\boldsymbol{r}}
\end{array}
$$

Note que no processo de retro-rotação os valores dos esforços solicitantes não são modificados. Somente as direções de sua ocorrência é que se modificam, e passam a ser escritas na configuração de referência. Uma vez que as tensões escritas na configuração de referência podem ser tratadas de forma objetiva e que, nessa configuração não se perde a interpretação física dos esforços solicitantes, a forma ilustrada se torna bastante conveniente.

\subsubsection{Potência dos esforços internos}

A expressão do gradiente de transformação 4.55 associada à configuração " $i+1$ " pode ser derivada em relação ao tempo, obtendo-se:

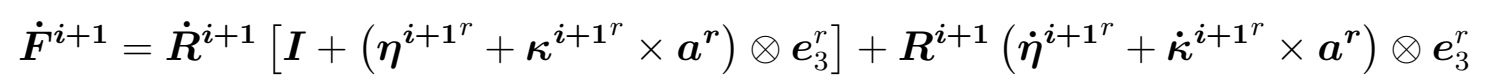

O primeiro termo da equação 4.73 pode ser desenvolvido da seguinte forma:

$$
\begin{aligned}
& \dot{\boldsymbol{R}}^{i+\mathbf{1}}\left[\boldsymbol{I}+\left(\boldsymbol{\eta}^{i+\mathbf{1}^{r}}+\boldsymbol{\kappa}^{i+\mathbf{1}^{r}} \times \boldsymbol{a}^{\boldsymbol{r}}\right) \otimes \boldsymbol{e}_{3}^{r}\right]= \\
& \dot{\boldsymbol{R}}^{i+1} \boldsymbol{R}^{i+\mathbf{1}^{T}} \boldsymbol{R}^{\boldsymbol{i}+\mathbf{1}}\left[\boldsymbol{I}+\left(\boldsymbol{\eta}^{\boldsymbol{i + 1} \mathbf{1}^{r}}+\boldsymbol{\kappa}^{i+\mathbf{1}^{r}} \times \boldsymbol{a}^{\boldsymbol{r}}\right) \otimes \boldsymbol{e}_{3}^{r}\right]=\boldsymbol{\Omega} \boldsymbol{F}^{\boldsymbol{i + 1}}
\end{aligned}
$$

Em que $\Omega$ é o tensor anti-simétrico associado ao vetor velocidade angular. A expressão para o cálculo de $\dot{\boldsymbol{\eta}}^{i+1^{r}}$ pode ser desenvolvida por:

$$
\dot{\boldsymbol{\eta}}^{i+\mathbf{1}^{r}}=\dot{\boldsymbol{R}}^{i+\mathbf{1}^{T}} \boldsymbol{z}^{i+\mathbf{1}^{\prime}}+\boldsymbol{R}^{i+\mathbf{1}^{T}} \dot{\boldsymbol{z}}^{i+\mathbf{1}^{\prime}}=\dot{\boldsymbol{R}}^{i+\mathbf{1}^{T}} \boldsymbol{z}^{i+\mathbf{1}^{\prime}}+\boldsymbol{R}^{i+1^{T}} \dot{\boldsymbol{u}}^{i+\mathbf{1}^{\prime}}
$$

É possível desenvolver ainda mais a equação 4.75 através da utilização das propriedades de tensores anti-simétricos e de algumas manipulações algébricas, levando-a à seguinte forma: 


$$
\dot{\eta}^{i+1^{r}}=\boldsymbol{R}^{i+1^{T}}\left[\dot{\boldsymbol{u}}^{i+1^{\prime}}+\boldsymbol{z}^{i+1^{\prime}} \times\left(\boldsymbol{\Xi}^{\Delta} \dot{\boldsymbol{\alpha}}^{\Delta}\right)\right]
$$

Também pode-se desenvolver uma expressão para $\dot{\boldsymbol{\kappa}}^{i+\mathbf{1}^{r}}$. Após manipulações algébricas, chega-se em:

$$
\dot{\kappa}^{i+\mathbf{1}^{r}}=\boldsymbol{R}^{i+\mathbf{1}^{T}}\left(\boldsymbol{\Xi}^{\boldsymbol{\Delta}^{\prime}} \dot{\boldsymbol{\alpha}}^{\Delta}+\boldsymbol{\Xi}^{\boldsymbol{\Delta}} \dot{\boldsymbol{\alpha}}^{\boldsymbol{\Delta}^{\prime}}\right)
$$

Na equação 4.77 o termo $\boldsymbol{\Xi}^{\boldsymbol{\Delta}^{\prime}}$ possui exatamente a mesma forma de $\dot{\boldsymbol{\Xi}}$ (expressão 4.29), porém a derivação é feita em relação a $\zeta$ e não ao tempo. Além disso, o ângulo utilizado para o cálculo do operador é $\boldsymbol{\alpha}^{\boldsymbol{\Delta}}$.

Pode-se organizar o vetor deformação translacional e a rotação específica em uma única entidade matemática de modo a definir a deformação generalizada $\boldsymbol{\epsilon}^{\boldsymbol{i + 1}}$ :

$$
\epsilon^{i+1}=\left[\begin{array}{l}
\eta^{i+1} \\
\kappa^{i+1}
\end{array}\right]
$$

Aplicando-se-a retro-rotação, também é possível definir a deformação generalizada retro-rotacionada $\boldsymbol{\epsilon}^{i+\mathbf{1}^{r}}$ :

$$
\epsilon^{i+1^{r}}=\left[\begin{array}{c}
\eta^{i+1^{r}} \\
\kappa^{i+1^{r}}
\end{array}\right]
$$

Define-se o vetor de deslocamentos generalizados contendo os incrementos de translações da seção transversal e o vetor rotação de Rodrigues que descreve a rotação da mesma seção entre as configurações " $i$ " e " $i+1$ ":

$$
d^{\Delta}=\left[\begin{array}{l}
u^{\Delta} \\
\alpha^{\Delta}
\end{array}\right]
$$

A fim de escrever de forma matricial a relação deslocamento-deformação (mais conveniente para a programação computacional da formulação), pode-se definir alguns 
operadores:

$$
\begin{aligned}
\Lambda^{i+1} & =\left[\begin{array}{cc}
R^{i+1} & O \\
O & R^{i+1}
\end{array}\right] \\
\Phi^{i+1} & =\left[\begin{array}{ccc}
I & O & Z^{i+1^{\prime}} \\
O & I & O
\end{array}\right] \\
Y^{\Delta} & =\left[\begin{array}{ccc}
I & O & O \\
O & \Xi^{\Delta} & \Xi^{\Delta^{\prime}} \\
O & O & \Xi^{\Delta}
\end{array}\right] \\
\Delta & =\left[\begin{array}{cc}
I \frac{\partial}{\partial \zeta} & O \\
O & I \frac{\partial}{\partial \zeta} \\
O & I
\end{array}\right]
\end{aligned}
$$

em que $\boldsymbol{Z}^{\boldsymbol{i + 1 ^ { \prime }}}$ é o tensor anti-simétrico associado ao vetor axial $\boldsymbol{z}^{\boldsymbol{i + \mathbf { 1 } ^ { \prime }}}$.

Com base no equacionado em 4.76 e 4.77 é possível escrever a seguinte relação entre deslocamentos generalizados e deformações generalizadas:

$$
\dot{\boldsymbol{\epsilon}}^{i+\mathbf{1}^{r}}=\left[\begin{array}{c}
\dot{\eta}^{i+1^{r}} \\
\dot{\boldsymbol{\kappa}}^{i+1^{r}}
\end{array}\right]=\Lambda^{i+1^{T}} \boldsymbol{\Phi}^{i+1} \boldsymbol{Y}^{\Delta} \Delta \dot{d}^{\Delta}
$$

Uma observação relevante acerca do vetor de deformações generalizadas que foi definido é que, apesar de não se constituir em nenhuma forma usual de medida de deformação, é sempre escrito na configuração de referência. O procedimento de retro-rotação para o tratamento das deformações é bastante conveniente pois, independentemente dos movimentos de corpo rígido que ocorram com a seção transversal analisada, o referencial utilizado para descrever as deformações é sempre o mesmo. Isso torna muito mais fácil o desenvolvimento de uma equação constitutiva que obedeça ao Princípio da Objetividade.

Seja uma viga retilínea de comprimento de referência $L$ com área de seção transversal $A$. A potência dos esforços internos $P_{\text {int }}$ para a configuração " $i+1$ " é por definição: 


$$
P_{i n t}=\int_{0}^{L} \int_{A} \boldsymbol{P}^{i+1}: \dot{\boldsymbol{F}}^{i+1} d A d \zeta
$$

Utilizando-se equação 4.73 pode-se escrever o integrando do cálculo da potência dos esforços internos como:

$$
\begin{array}{r}
P^{i+1}: \dot{\boldsymbol{F}}^{i+1}=\boldsymbol{P}^{i+1}:\left\{\Omega \boldsymbol{F}^{i+1}+\boldsymbol{R}^{i+1}\left(\dot{\eta}^{i+1^{r}}+\dot{\boldsymbol{\kappa}}^{i+1^{r}} \times \boldsymbol{a}^{r}\right) \otimes e_{3}^{r}\right\}= \\
=P^{i+1}: \Omega \boldsymbol{F}^{i+1}+\boldsymbol{P}^{i+1}:\left\{\boldsymbol{R}^{i+1}\left(\dot{\eta}^{i+1^{r}}+\dot{\boldsymbol{\kappa}}^{i+1^{r}} \times \boldsymbol{a}^{r}\right) \otimes e_{3}^{r}\right\}
\end{array}
$$

O primeiro termo da expressão 4.87 pode ser escrito como:

$$
P^{i+1}: \Omega F^{i+1}=P^{i+1} F^{i+1^{T}}: \Omega
$$

É possível demonstrar através da segunda equação local de equilíbrio de Cauchy que o tensor dado por $\boldsymbol{P}^{\boldsymbol{i + 1}} \boldsymbol{F}^{\boldsymbol{i + 1} \mathbf{1}^{T}}$ é simétrico. O produto escalar tensorial entre um tensor simétrico e outro anti-simétrico é igual a zero, anulando os efeitos desse termo na potência dos esforços internos. Já o segundo termo pode ser desenvolvido utilizando-se da expressão 4.65:

$$
\begin{gathered}
\boldsymbol{P}^{i+1}:\left\{\boldsymbol{R}^{i+1}\left(\dot{\boldsymbol{\eta}}^{i+\mathbf{1}^{r}}+\dot{\boldsymbol{\kappa}}^{i+\mathbf{1}^{r}} \times \boldsymbol{a}^{r}\right) \otimes \boldsymbol{e}_{3}^{r}\right\}= \\
\boldsymbol{R}^{i+\mathbf{1}^{T}} \boldsymbol{P}^{i+1}:\left\{\left(\dot{\boldsymbol{\eta}}^{i+\mathbf{1}^{r}}+\dot{\boldsymbol{\kappa}}^{i+\mathbf{1}^{r}} \times \boldsymbol{a}^{r}\right) \otimes \boldsymbol{e}_{3}^{r}\right\}= \\
\boldsymbol{\tau}^{i+\mathbf{1}^{r}} \cdot\left(\dot{\boldsymbol{\eta}}^{i+\mathbf{1}^{r}}+\dot{\boldsymbol{\kappa}}^{i+\mathbf{1}^{r}} \times \boldsymbol{a}^{r}\right)
\end{gathered}
$$

Substituindo-se a equação 4.90 em 4.86, utilizando-se posteriormente propriedades do produto misto entre vetores e separando as integrações, pode-se escrever a seguinte expressão para a potência dos esforços internos:

$$
\begin{gathered}
P_{\text {int }}=\int_{0}^{L}\left[\int_{A} \boldsymbol{\tau}^{i+\mathbf{1}^{r}} \cdot\left(\dot{\boldsymbol{\eta}}^{i+\mathbf{1}^{r}}+\dot{\boldsymbol{\kappa}}^{i+\mathbf{1}^{r}} \times \boldsymbol{a}^{\boldsymbol{r}}\right) d A\right] d \zeta= \\
\int_{0}^{L}\left[\dot{\boldsymbol{\eta}}^{i+\mathbf{1}^{r}} \cdot \int_{A} \boldsymbol{\tau}^{i+\mathbf{1}^{r}} d A+\dot{\boldsymbol{\kappa}}^{i+\mathbf{1}^{r}} \cdot \int_{A}\left(\boldsymbol{a}^{\boldsymbol{r}} \times \boldsymbol{\tau}^{i+\mathbf{1}^{r}}\right) d A\right] d \zeta
\end{gathered}
$$


Portanto as grandezas construídas como tensões e deformações generalizadas na configuração de referência são energeticamente conjugadas, pois:

$$
P_{i n t}=\int_{0}^{L}\left(\boldsymbol{n}^{i+1^{r}} \cdot \dot{\boldsymbol{\eta}}^{i+\mathbf{1}^{r}}+\boldsymbol{m}^{i+\mathbf{1}^{r}} \cdot \dot{\boldsymbol{\kappa}}^{i+\mathbf{1}^{r}}\right) d \zeta
$$

Utilizando os operadores definidos anteriormente, a expressão para a potência dos esforços internos pode ser escrita de forma compacta:

$$
P_{\text {int }}=\int_{0}^{L} \boldsymbol{\sigma}^{i+\mathbf{1}^{r}} \cdot \dot{\boldsymbol{\epsilon}}^{i+\mathbf{1}^{r}} d \zeta=\int_{0}^{L} \boldsymbol{\sigma}^{i+\mathbf{1}^{r}} \cdot \boldsymbol{\Lambda}^{\boldsymbol{i + \mathbf { 1 } ^ { T }}} \boldsymbol{\Phi}^{i+\mathbf{1}} \boldsymbol{Y}^{\boldsymbol{\Delta}} \boldsymbol{\Delta} \dot{\boldsymbol{d}}^{\boldsymbol{\Delta}} d \zeta
$$

\subsubsection{Potência dos esforços externos}

Pode-se definir dois tipos de esforços externos distribuídos atuantes em uma viga, de maneira bastante genérica:

- $\overline{\boldsymbol{t}}$ são os esforços aplicados na superfície externa da viga $C$, por unidade de área dessa superfície na configuração de referência;

- $\overline{\boldsymbol{b}}$ são os esforços distribuídos no volume da viga, por unidade de volume da configuração de referência;

Pode-se escrever a seguinte expressão para a potência dos esforços externos atuantes na viga:

$$
P_{e x t}=\int_{0}^{L}\left[\int_{C} \overline{\boldsymbol{t}} \cdot \dot{\boldsymbol{\delta}}^{\Delta} d C+\int_{A} \overline{\boldsymbol{b}} \cdot \dot{\boldsymbol{\delta}}^{\Delta} d A\right] d \zeta
$$

O campo de velocidades de cada seção rígida da viga é dado por: $\dot{\boldsymbol{\delta}}^{\boldsymbol{\Delta}}=\dot{\boldsymbol{u}}^{\boldsymbol{\Delta}}+$ $\boldsymbol{\Omega} \boldsymbol{a}^{\boldsymbol{i + 1}}$. Utilizando essa relação na expressão 4.94 e já adotando a parametrização de Rodrigues para a descrição das rotações, chega-se em:

$$
P_{e x t}=\int_{0}^{L}\left[\int_{C} \overline{\boldsymbol{t}} \cdot\left(\dot{\boldsymbol{u}}^{\boldsymbol{\Delta}}+\left(\boldsymbol{\Xi}^{\boldsymbol{\Delta}} \dot{\boldsymbol{\alpha}}^{\boldsymbol{\Delta}}\right) \times \boldsymbol{a}^{i+\mathbf{1}}\right) d C+\int_{A} \overline{\boldsymbol{b}} \cdot\left(\dot{\boldsymbol{u}}^{\boldsymbol{\Delta}}+\left(\boldsymbol{\Xi}^{\boldsymbol{\Delta}} \dot{\boldsymbol{\alpha}}^{\boldsymbol{\Delta}}\right) \times \boldsymbol{a}^{i+\mathbf{1}}\right) d A\right] d \zeta
$$


Separando-se as forças e os momentos e colocando-os devidamente agrupados, a potência dos esforços externos pode ser re-escrita da seguinte forma:

$$
P_{e x t}=\int_{0}^{L}\left[\overline{\boldsymbol{n}} \cdot \dot{\boldsymbol{u}}^{\boldsymbol{\Delta}}+\overline{\boldsymbol{m}} \cdot\left(\boldsymbol{\Xi}^{\boldsymbol{\Delta}} \dot{\boldsymbol{\alpha}}^{\boldsymbol{\Delta}}\right)\right] d \zeta
$$

em que $\overline{\boldsymbol{n}}$ e $\overline{\boldsymbol{m}}$ representam os esforços externos aplicados em cada uma das seções transversais da viga (por unidade de comprimento de referência). Esses esforços são dados por:

$$
\begin{aligned}
& \overline{\boldsymbol{n}}=\int_{C} \overline{\boldsymbol{t}} d C+\int_{A} \overline{\boldsymbol{b}} d A \\
& \overline{\boldsymbol{m}}=\int_{C} \boldsymbol{a}^{\boldsymbol{i}+\mathbf{1}} \times \overline{\boldsymbol{t}} d C+\int_{A} \boldsymbol{a}^{\boldsymbol{i + 1}} \times \overline{\boldsymbol{b}} d A
\end{aligned}
$$

Manipulando-se algebricamente a potência dos momentos externos, é possível mudar a posição do operador $\boldsymbol{\Xi}^{\boldsymbol{\Delta}}$, a fim de resgatar os já definidos pseudo-momentos $\boldsymbol{\mu}^{\boldsymbol{\alpha}}$ :

$$
\boldsymbol{\mu}^{\alpha}=\Xi^{\boldsymbol{\Delta}^{T}} \overline{\boldsymbol{m}}
$$

O uso do pseudo-momento em vez do momento propriamente dito para a inserção do carregamento é energeticamente conjugado com o vetor rotação de Rodrigues. Dessa forma, o vetor de esforços externos generalizados é dado por:

$$
\overline{\boldsymbol{q}}=\left[\begin{array}{c}
\overline{\boldsymbol{n}} \\
\boldsymbol{\Xi}^{\boldsymbol{\Delta}^{T}} \overline{\boldsymbol{m}}
\end{array}\right]
$$

A expressão para o cálculo da potência dos esforços externos, portanto, é dada por:

$$
P_{e x t}=\int_{0}^{L} \overline{\boldsymbol{q}} \cdot \dot{\boldsymbol{d}}^{\Delta} d \zeta
$$




\subsubsection{Equações de equilíbrio}

A solução do modelo de viga é feita através do Princípio dos Trabalhos Virtuais (PTV). Moreira (2009) mostra a formulação cinematicamente exata para elementos de viga utilizando tanto o PTV como através de uma forma alternativa: o Teorema das Potências. As equações que resultam do PTV dão origem a operadores simétricos (para problemas conservativos), enquanto que utilizando-se o Teorema das Potências os operadores são sempre não simétricos.

Sendo $\delta W_{\text {int }}$ o trabalho virtual dos esforços internos, $\delta W_{\text {ext }}$ o trabalho virtual dos esforços externos, e $\delta T$ a variação virtual da energia cinética, o PTV pode ser enunciado por:

$$
\delta W_{\text {int }}-\delta W_{\text {ext }}+\delta T=0
$$

As expressões para o trabalho virtual dos esforços internos e externos podem ser obtidas utilizando-se as potências dos esforços internos e externos. Através de uma analogia com as equações 4.76 e 4.77, as seguintes expressões são escritas: ${ }^{6}$

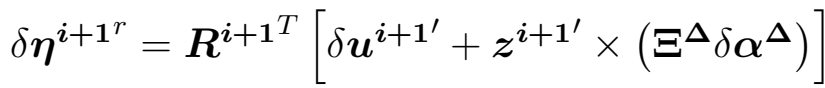

$$
\begin{aligned}
& \delta \boldsymbol{\kappa}^{i+\mathbf{1}^{r}}=\boldsymbol{R}^{i+\mathbf{1}^{T}}\left(\boldsymbol{\Xi}^{\boldsymbol{\Delta}^{\prime}} \delta \boldsymbol{\alpha}^{\boldsymbol{\Delta}}+\boldsymbol{\Xi}^{\boldsymbol{\Delta}} \delta \boldsymbol{\alpha}^{\boldsymbol{\Delta}^{\prime}}\right)
\end{aligned}
$$

O vetor das deformações virtuais generalizadas é dado por:

$$
\delta \boldsymbol{\epsilon}^{i+\mathbf{1}^{r}}=\left[\begin{array}{c}
\delta \boldsymbol{\eta}^{i+1^{r}} \\
\delta \boldsymbol{\kappa}^{i+1^{r}}
\end{array}\right]=\Lambda^{i+1^{T}} \boldsymbol{\Phi}^{i+1} \boldsymbol{Y}^{\Delta} \Delta \delta \boldsymbol{d}^{\boldsymbol{\Delta}}
$$

Para uma viga cuja configuração de referência é retilínea com comprimento $L$, o trabalho virtual dos esforços internos é dado por:

\footnotetext{
${ }^{6}$ Todas as grandezas que apresentam o prefixo $\delta($.$) são denominadas "virtuais". Tal nomenclatura não$ deve ser confundida com o símbolo $\boldsymbol{\delta}^{\boldsymbol{\Delta}}$ designado para descrever a cinemática do modelo de viga.
} 


$$
\begin{aligned}
& \delta W_{i n t}=\int_{0}^{L} \boldsymbol{\sigma}^{i+\mathbf{1}^{r}} \cdot \delta \boldsymbol{\epsilon}^{i+\mathbf{1}^{r}} d \zeta= \\
& \int_{0}^{L} \boldsymbol{\sigma}^{i+\mathbf{1}^{r}} \cdot \boldsymbol{\Lambda}^{\boldsymbol{i + 1} \mathbf{1}^{T}} \boldsymbol{\Phi}^{i+\mathbf{1}} \boldsymbol{Y}^{\boldsymbol{\Delta}} \boldsymbol{\Delta} \delta \boldsymbol{d}^{\boldsymbol{\Delta}} d \zeta= \\
& \int_{0}^{L}\left(\boldsymbol{n}^{i+\mathbf{1}^{r}} \cdot \delta \boldsymbol{\eta}^{i+\mathbf{1}^{r}}+\boldsymbol{m}^{i+\mathbf{1}^{r}} \cdot \delta \boldsymbol{\kappa}^{i+\mathbf{1}^{r}}\right) d \zeta
\end{aligned}
$$

O cálculo do trabalho virtual dos esforços externos é feito por analogia com o cálculo da potência dos esforços externos de forma que:

$$
\delta W_{e x t}=\int_{0}^{L} \overline{\boldsymbol{q}} \cdot \delta \boldsymbol{d}^{\boldsymbol{\Delta}} d \zeta=\int_{0}^{L}\left[\overline{\boldsymbol{n}} \cdot \delta \boldsymbol{u}^{\boldsymbol{\Delta}}+\overline{\boldsymbol{m}} \cdot\left(\boldsymbol{\Xi}^{\boldsymbol{\Delta}} \delta \boldsymbol{\alpha}^{\boldsymbol{\Delta}}\right)\right] d \zeta
$$

Assim, no caso da solução de um modelo estático em que $\delta T=0$, a substituição dos trabalhos virtuais $\delta W_{\text {int }}$ e $\delta W_{\text {ext }}$ na equação 4.101 leva a:

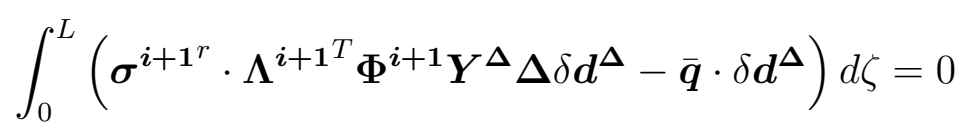

Nessa expressão o valor de $\delta \boldsymbol{d}^{\boldsymbol{\Delta}}$ é arbitrário, no entanto deve obedecer às condições de contorno essenciais do problema. A forma integral apresentada pode ser interpretada como um resíduo escalar, que idealmente deve ser nulo. Resolver um modelo de viga utilizando essa formulação pode ser entendido como: dado uma configuração de viga submetida a condições de contorno e esforços externos conhecidos, qual o campo de deslocamentos que satisfaz o PTV?

Se for utilizada alguma forma de aproximação para o campo de deslocamentos, a equação 4.106 necessariamente deve ser obedecida. Assim sendo, para algoritmos iterativos de solução para determinação do campo de deslocamentos, essa equação se torna uma verificação para a convergência.

A expressão 4.106 é equivalente à imposição do equilíbrio através das Leis de Newton. De fato, como ilustram os trabalhos de Moreira (2009) para descrições lagrangiana atualizada e Campello (2000) para a descrição lagrangiana total, a equivalência da forma integral apresentada com as equações de equilíbrio locais de uma barra pode 
ser facilmente demonstrada. O procedimento para verificar essa equivalência é realizar uma integração por partes na referida equação, chegando às equações locais de equilíbrio. Assim, resolver a equação 4.106 implica em resolver o equilíbrio da estrutura. Por estar na forma integral, a equação 4.106 representa uma forma bastante interessante de impor o equilíbrio de forma aproximada utilizando o Método dos Elementos Finitos.

\subsubsection{Variação virtual da energia cinética}

Nesse trabalho o modelo utilizado é estático. No entanto, quando se adota um critério cinético de estabilidade, é necessário calcular a variação virtual da energia cinética $\delta T$ (ver Capítulo 3). Ainda o resultado apresentado nessa seção pode ser utilizado em uma generalização do atual modelo para que considere efeitos dinâmicos.

Seja uma viga com a configuração de referência retilínea, suposta feita de material de massa específica constante de valor $\rho$. A energia cinética na configuração $i+1$ é dada por:

$$
T=\frac{1}{2} \int_{0}^{L} \int_{A}\left(\rho \dot{\boldsymbol{x}}^{i+1} \cdot \dot{\boldsymbol{x}}^{i+\mathbf{1}}\right) d A d \zeta
$$

Uma vez que as seções transversais da viga são consideradas rígidas, tomando-se o ponto $\boldsymbol{B}^{\boldsymbol{i + 1}}$ (ver Figura 4.7) como referência tem-se que: $\dot{\boldsymbol{x}}^{\boldsymbol{i + 1}}=\dot{\boldsymbol{z}}^{\boldsymbol{i + 1}}+\boldsymbol{\omega} \times \boldsymbol{a}^{\boldsymbol{i + 1}}$. Logo é possível reescrever a expressão para o cálculo da energia cinética 4.107 decomposta em três termos:

$$
T=T_{1}+T_{2}+T_{3}
$$

em que: 


$$
\begin{aligned}
& T_{1}=\frac{1}{2} \int_{0}^{L} \int_{A}\left(\rho \dot{\boldsymbol{z}}^{\boldsymbol{i + 1}} \cdot \dot{\boldsymbol{z}}^{\boldsymbol{i + 1}}\right) d A d \zeta+ \\
& T_{2}=\frac{1}{2} \int_{0}^{L} \int_{A}\left[\rho\left(\boldsymbol{\omega} \times \boldsymbol{a}^{i+\mathbf{1}}\right) \cdot\left(\boldsymbol{\omega} \times \boldsymbol{a}^{i+\mathbf{1}}\right)\right] d A d \zeta+ \\
& T_{3}=\int_{0}^{L} \int_{A}\left[\rho \dot{\boldsymbol{z}}^{i+\mathbf{1}} \cdot\left(\boldsymbol{\omega} \times \boldsymbol{a}^{i+\mathbf{1}}\right)\right] d A d \zeta
\end{aligned}
$$

Para facilitar a escrita da energia cinética para o modelo de viga é conveniente definir a massa por unidade de comprimento $\bar{\rho}$ bem como o tensor de inércia por unidade de comprimento $\overline{\boldsymbol{J}}$. Note que o sistema de coordenadas utilizado para descrever o tensor de inércia é o global cartesiano. Assim é necessário referenciar tal tensor à configuração na qual o mesmo está escrito, por exemplo, $\overline{\boldsymbol{J}}^{\boldsymbol{i}+\mathbf{1}}$ para associá-lo à configuração " $i+1$ ". É conveniente definir a inércia por unidade de comprimento na configuração de referência $\overline{\boldsymbol{J}}^{r}$ e posteriormente as seguintes relações:

$$
\overline{\boldsymbol{J}}^{i+1}=\boldsymbol{R}^{i+1} \overline{\boldsymbol{J}}^{r} \boldsymbol{R}^{i+1^{T}}=\boldsymbol{R}^{\Delta} \boldsymbol{R}^{i} \overline{\boldsymbol{J}}^{r} \boldsymbol{R}^{i^{T}} \boldsymbol{R}^{\boldsymbol{\Delta}^{T}}
$$

Ao tratar a configuração " $i+1$ ", os dados provenientes da configuração anterior " $i$ " são considerados como invariantes no tempo. Assim, $\dot{z}^{i+1}=\dot{\boldsymbol{u}}^{\boldsymbol{\Delta}}$. Logo, o termo $T_{1}$ da energia cinética pode ser reescrito como:

$$
T_{1}=\frac{1}{2} \int_{0}^{L}\left(\bar{\rho} \dot{\boldsymbol{u}}^{\boldsymbol{\Delta}} \cdot \dot{\boldsymbol{u}}^{\boldsymbol{\Delta}}\right) d \zeta
$$

O termo $T_{2}$, por sua vez após manipulações algébricas é dado por:

$$
T_{2}=\frac{1}{2} \int_{0}^{L}\left[\left(\overline{\boldsymbol{J}}^{\boldsymbol{i}+\mathbf{1}} \boldsymbol{\omega}\right) \cdot \boldsymbol{\omega}\right] d \zeta
$$

O termo $T_{3}$ pode ser desenvolvido por:

$$
T_{3}=\int_{0}^{L}\left[\dot{\boldsymbol{z}}^{i+1} \cdot\left(\boldsymbol{\omega} \times \int_{A} \rho \boldsymbol{a}^{i+1}\right) d A\right] d \zeta
$$


Assim, uma escolha conveniente para o eixo da viga é a configuração que passa pelos baricentros das seções transversais, uma vez que o termo $T_{3}$ se anula. Adota-se, portanto, essa escolha a partir desse ponto.

Ainda pode-se de forma conveniente definir um tensor para descrever a massa na estrutura de forma semelhante ao tratamento do tensor de inércia, só que aplicado à inércia de translação. Define-se o tensor $\bar{M}$ :

$$
\overline{\boldsymbol{M}}=\left[\begin{array}{lll}
\bar{\rho} & 0 & 0 \\
0 & \bar{\rho} & 0 \\
0 & 0 & \bar{\rho}
\end{array}\right]
$$

A definição dada em 4.114 é conveniente para situações em que se deseja considerar distintos valores de massa da estrutura em relação à translação em diferentes direções. À primeira instância isso seria absolutamente não físico. No entanto, em típicas situações em que se considera a massa adicional de uma estrutura imersa em um fluido a definição do tensor $\overline{\boldsymbol{M}}$ se torna interessante ${ }^{7}$. O valor da massa adicional depende do fluido no qual a estrutura está imerso, bem como da geometria do corpo considerado. Sendo a viga em análise considerada do ponto de vista de comportamento hidrodinâmico como um cilindro, pode-se utilizar na presente formulação coeficientes de massa adicional de um corpo com essa forma geométrica, já supondo que não há acoplamentos entre as direções tangencial e axial, levando a um tensor diagonal. Assim, o tensor $\overline{\boldsymbol{M}}$ pode ser construído incluindo-se os efeitos de massa adicional. Em típicas situações em que não se considera variação do diâmetro externo ao longo do comprimento da viga é razoável adotar um coeficiente nulo de massa adicional na direção tangencial e, na direção transversal, um valor não nulo. De forma mais geral denomina-se $C_{a t}$ o coeficiente de massa adicional na direção tangencial e $C_{a n}$ na direção transversal (normal à direção axial). Supondo que a viga está imersa em um fluido com massa específica $\rho_{f}$, reescreve-se o tensor $\bar{M}$ considerando a contribuição da massa adicional mas, dessa vez com base na configuração de referência, em que facilmente se faz a distinção entre as direções tangencial e transversal:

$$
\overline{\boldsymbol{M}}^{\boldsymbol{r}}=\left[\begin{array}{ccc}
\bar{\rho}+\rho_{f} C_{a n} A & 0 & 0 \\
0 & \bar{\rho}+\rho_{f} C_{a n} A & 0 \\
0 & 0 & \bar{\rho}+\rho_{f} C_{a t} A
\end{array}\right]
$$

\footnotetext{
${ }^{7} \mathrm{O}$ assunto "massa adicional" é discutido com maiores detalhes no tópico 4.4.9.3 do presente texto.
} 
Analogamente ao apresentado para o tensor de inércia à rotação, pode-se escrever para o recém definido tensor de inércia à translação:

$$
\bar{M}^{i+1}=\boldsymbol{R}^{i+1} \bar{M}^{r} \boldsymbol{R}^{i+1^{T}}=\boldsymbol{R}^{\Delta} \boldsymbol{R}^{i} \bar{M}^{r} \boldsymbol{R}^{i^{T}} \boldsymbol{R}^{\Delta^{T}}
$$

Logo, a energia cinética da estrutura na configuração " $i+1$ " vale:

$$
T=\frac{1}{2} \int_{0}^{L}\left[\left(\overline{\boldsymbol{M}}^{\boldsymbol{i}+\mathbf{1}} \dot{\boldsymbol{u}}^{\boldsymbol{\Delta}}\right) \cdot \dot{\boldsymbol{u}}^{\boldsymbol{\Delta}}+\left(\overline{\boldsymbol{J}}^{\boldsymbol{i + 1}} \boldsymbol{\omega}\right) \cdot \boldsymbol{\omega}\right] d \zeta
$$

Para calcular a variação virtual da energia cinética é necessário derivar a expressão 4.117 em relação ao tempo. Para tal, algumas relações algébricas se fazem necessárias:

$$
\begin{gathered}
\dot{\boldsymbol{R}}^{\Delta}=\Omega \boldsymbol{R}^{\boldsymbol{\Delta}} \\
\dot{\boldsymbol{R}}^{\boldsymbol{\Delta}^{T}}=-\boldsymbol{R}^{\boldsymbol{\Delta}^{T}} \Omega
\end{gathered}
$$

Partindo-se do termo $\dot{T}_{1}$, tem-se:

$$
\dot{T}_{1}=\frac{1}{2} \int_{0}^{L}\left[\left(\dot{\bar{M}}^{i+1} \dot{\boldsymbol{u}}^{\Delta}\right) \cdot \dot{\boldsymbol{u}}^{\Delta}+\left(\overline{\boldsymbol{M}}^{i+1} \ddot{\boldsymbol{u}}^{\Delta}\right) \cdot \dot{\boldsymbol{u}}^{\Delta}+\left(\overline{\boldsymbol{M}}^{i+1} \dot{\boldsymbol{u}}^{\Delta}\right) \cdot \ddot{\boldsymbol{u}}^{\Delta}\right] d \zeta
$$

Partindo-se de 4.116 e se utilizando das relações 4.118 e 4.119 é possível calcular $\dot{\bar{M}}^{i+1}$ como:

$$
\dot{\bar{M}}^{i+1}=\dot{\boldsymbol{R}}^{\Delta} \boldsymbol{R}^{i} \bar{M}^{r} \boldsymbol{R}^{i^{T}} \boldsymbol{R}^{\Delta^{T}}+\boldsymbol{R}^{\Delta} \boldsymbol{R}^{i} \bar{M}^{r} \boldsymbol{R}^{i^{T}} \dot{\boldsymbol{R}}^{\Delta^{T}}=\Omega \bar{M}^{i+1}-\bar{M}^{i+1} \Omega
$$

Assim, após algumas manipulações algébricas chega-se em:

$$
\dot{T}_{1}=\int_{0}^{L}\left[\left(\Omega \overline{\boldsymbol{M}}^{\boldsymbol{i}+\mathbf{1}} \dot{\boldsymbol{u}}^{\boldsymbol{\Delta}}\right) \cdot \dot{\boldsymbol{u}}^{\boldsymbol{\Delta}}+\left(\overline{\boldsymbol{M}}^{\boldsymbol{i}+\mathbf{1}} \ddot{\boldsymbol{u}}^{\boldsymbol{\Delta}}\right) \cdot \dot{\boldsymbol{u}}^{\boldsymbol{\Delta}}\right] d \zeta
$$


O resultado da equação 4.122 mostra duas parcelas de variação da energia cinética, sendo um termo proporcional à velocidade e outro proporcional à aceleração dos baricentros das seções transversais da viga. Enfatiza-se que o termo proporcional à velocidade só surgiu pelo valor não nulo da derivada temporal do tensor $\overline{\boldsymbol{M}}^{\boldsymbol{i + 1}}$. Caso seja possível escrever tal tensor na forma 4.114 (com todos os coeficientes de mesmo valor) sua variação temporal será nula e consequentemente o termo proporcional à velocidade se anulará.

Também é possível calcular $\dot{T}_{2}$ :

$$
\dot{T}_{2}=\frac{1}{2} \int_{0}^{L}\left[\left(\dot{\bar{J}}^{i+1} \boldsymbol{\omega}\right) \cdot \boldsymbol{\omega}+\left(\overline{\boldsymbol{J}}^{i+1} \dot{\boldsymbol{\omega}}\right) \cdot \boldsymbol{\omega}+\left(\overline{\boldsymbol{J}}^{i+1} \boldsymbol{\omega}\right) \cdot \dot{\boldsymbol{\omega}}\right] d \zeta
$$

De maneira análoga à mostrada em 4.121, tem-se:

$$
\dot{\overline{\boldsymbol{J}}}^{i+1}=\dot{\boldsymbol{R}}^{\boldsymbol{\Delta}} \boldsymbol{R}^{i} \overline{\boldsymbol{J}}^{r} \boldsymbol{R}^{\boldsymbol{i}^{T}} \boldsymbol{R}^{\boldsymbol{\Delta}^{T}}+\boldsymbol{R}^{\boldsymbol{\Delta}} \boldsymbol{R}^{i} \overline{\boldsymbol{J}}^{r} \boldsymbol{R}^{\boldsymbol{i}^{T}} \dot{\boldsymbol{R}}^{\boldsymbol{\Delta}^{T}}=\Omega \overline{\boldsymbol{J}}^{i+1}-\overline{\boldsymbol{J}}^{i+1} \Omega
$$

Realizando-se manipulações algébricas na expressão 4.123, chega-se em:

$$
\dot{T}_{2}=\frac{1}{2} \int_{0}^{L}\left[\left(\Omega \overline{\boldsymbol{J}}^{i+1}\right) \boldsymbol{\omega}\right] \cdot \boldsymbol{\omega} d \zeta+\int_{0}^{L}\left(\overline{\boldsymbol{J}}^{\boldsymbol{i}+\mathbf{1}} \boldsymbol{\omega}\right) \cdot \dot{\boldsymbol{\omega}} d \zeta
$$

A equação 4.125 ilustra dois termos, sendo o da esquerda a contribuição giroscópica e o da direita aquele causado pela aceleração angular. Com algum trabalho algébrico é possível visualizar o resultado clássico de que o termo giroscópico é conservativo e, portanto, não causa variação de energia cinética. Por isso simplifica-se ainda mais a expressão de $\dot{T}_{2}$ para:

$$
\dot{T}_{2}=\int_{0}^{L}\left(\overline{\boldsymbol{J}}^{i+1} \dot{\boldsymbol{\omega}}\right) \cdot \boldsymbol{\omega} d \zeta
$$

Utilizando-se da parametrização de Rodrigues é possível reescrever a expressão 4.126 em função do parâmetro de rotação de Rodrigues. Sendo $\boldsymbol{\omega}=\boldsymbol{\Xi}^{\boldsymbol{\Delta}} \dot{\boldsymbol{\alpha}}$, sua derivada temporal é dada por $\dot{\boldsymbol{\omega}}=\dot{\boldsymbol{\Xi}}^{\boldsymbol{\Delta}} \dot{\boldsymbol{\alpha}}+\boldsymbol{\Xi}^{\boldsymbol{\Delta}} \ddot{\boldsymbol{\alpha}}$. Assim, tem-se: 


$$
\dot{T}_{2}=\int_{0}^{L}\left(\boldsymbol{\Xi}^{\boldsymbol{\Delta}^{T}} \overline{\boldsymbol{J}}^{\boldsymbol{i + 1}} \dot{\boldsymbol{\Xi}}^{\boldsymbol{\Delta}} \dot{\boldsymbol{\alpha}}\right) \cdot \dot{\boldsymbol{\alpha}} d \zeta+\int_{0}^{L}\left(\boldsymbol{\Xi}^{\boldsymbol{\Delta}^{T}} \overline{\boldsymbol{J}}^{\boldsymbol{i}+\mathbf{1}} \boldsymbol{\Xi}^{\boldsymbol{\Delta}} \ddot{\boldsymbol{\alpha}}\right) \cdot \dot{\boldsymbol{\alpha}} d \zeta
$$

Definem-se a seguir dois operadores matriciais dados por:

$$
\Psi^{i+1}=\left[\begin{array}{cc}
\Omega \bar{M}^{i+1} & O \\
O & \Xi^{\Delta^{T}} \bar{J}^{i+1} \dot{\Xi}^{\Delta}
\end{array}\right]
$$

e

$$
\Upsilon^{i+1}=\left[\begin{array}{cc}
\bar{M}^{i+1} & O \\
O & \Xi^{\Delta^{T}} \bar{J}^{i+1} \Xi^{\Delta}
\end{array}\right]
$$

A variação temporal da energia cinética pode ser escrita de forma mais compacta por:

$$
\dot{T}=\int_{0}^{L}\left(\Psi^{i+1} \dot{d}^{\Delta}+\Upsilon^{i+1} \ddot{d}^{\Delta}\right) \cdot \dot{d}^{\Delta} d \zeta
$$

Assim, a variação virtual da energia cinética é dada por:

$$
\delta T=\int_{0}^{L}\left(\Psi^{i+1} \dot{\boldsymbol{d}}^{\Delta}+\mathbf{\Upsilon}^{i+\mathbf{1}} \ddot{\boldsymbol{d}}^{\Delta}\right) \cdot \delta \boldsymbol{d}^{\Delta} d \zeta
$$

\subsubsection{Equação constitutiva}

Assume-se que o comportamento constitutivo possa ser descrito por uma caracterização de material hiperelástico. Pata tal, define-se uma função que descreve a energia de deformação por unidade de volume de referência em uma configuração " $i "$ por $\psi\left(\boldsymbol{\epsilon}^{\boldsymbol{i}^{r}}\right)$. Assim, é possível escrever a energia interna da viga $U_{\text {int }}$ por:

$$
U_{i n t}=\int_{0}^{L} \int_{A} \psi\left(\boldsymbol{\epsilon}^{i^{r}}\right) d A d \zeta
$$


Utilizando-se da mesma notação de Pimenta, Campello e Wriggers (2008) é possível definir uma função de energia de deformação por unidade de comprimento da viga $\bar{\psi}\left(\boldsymbol{\epsilon}^{\boldsymbol{i}^{r}}\right)$, tal que:

$$
U_{i n t}=\int_{0}^{L} \bar{\psi}\left(\boldsymbol{\epsilon}^{\boldsymbol{i}^{r}}\right) d \zeta
$$

As tensões generalizadas podem ser obtidas por:

$$
\boldsymbol{\sigma}^{i^{r}}=\frac{\partial \bar{\psi}\left(\boldsymbol{\epsilon}^{i^{r}}\right)}{\partial \boldsymbol{\epsilon}^{i^{r}}}
$$

Os coeficientes que descrevem o comportamento constitutivo pode ser obtidos por:

$$
\boldsymbol{D}^{r}=\frac{\partial^{2} \bar{\psi}\left(\boldsymbol{\epsilon}^{\boldsymbol{i}^{r}}\right)}{\partial \boldsymbol{\epsilon}^{i^{2}}}
$$

A forma mais simples de função $\bar{\psi}\left(\boldsymbol{\epsilon}^{\boldsymbol{i}^{r}}\right)$ é dada por uma relação de material linear elástico, definido por um potencial quadrático:

$$
\bar{\psi}\left(\boldsymbol{\epsilon}^{\boldsymbol{i}^{r}}\right)=\frac{1}{2} \boldsymbol{\epsilon}^{\boldsymbol{i}^{r T}} \boldsymbol{D}^{r} \boldsymbol{\epsilon}^{\boldsymbol{i}^{r}}
$$

Se for assumido que $\boldsymbol{D}^{r}$ é constante, é possível escrever a seguinte equação constitutiva:

$$
\boldsymbol{\sigma}^{i^{r}}=\boldsymbol{D}^{r} \boldsymbol{\epsilon}^{i^{r}}
$$

O tensor $\boldsymbol{D}^{r}$ relaciona as tensões com as deformações generalizadas. Essa relação deve obedecer ao Princípio da Objetividade, ou seja, movimentos de corpo rígido não devem afetar a relação entre a tensão e a deformação. A estratégia adotada na definição da tensão e deformação generalizadas para essa formulação foi a de sempre fazer uma retro-rotação para a configuração de referência. Isso foi feito a fim de que todo e qualquer movimento de corpo rígido seja excluído para a correta relação entre tensão e deformação. 
Uma discussão sobre o comportamento constitutivo de vigas é feita em Campello (2000). Para a formulação de viga em questão, a forma mais simples de representar a relação constitutiva, sem acoplamentos entre a tensão e a deformação em diferentes direções, é apresentada em Pimenta, Campello e Wriggers (2008) através dos seguinte tensor:

$$
\boldsymbol{D}^{r}=\left[\begin{array}{cccccc}
G A & 0 & 0 & 0 & 0 & 0 \\
0 & G A & 0 & 0 & 0 & 0 \\
0 & 0 & E A & 0 & 0 & 0 \\
0 & 0 & 0 & E I_{1} & 0 & 0 \\
0 & 0 & 0 & 0 & E I_{2} & 0 \\
0 & 0 & 0 & 0 & 0 & G J
\end{array}\right]
$$

Note que apesar de não existir acoplamento constitutivo entre esforços solicitantes, a formulação cinematicamente exata garante o acoplamento geométrico entre os esforços. Os valores dos coeficientes presentes no operador constitutivo são os seguintes:

- $G A$ - rigidez ao cisalhamento da viga

- $E A$ - rigidez axial da viga

- $E I_{1}$ - rigidez flexional segundo a direção 1 da viga

- $E I_{2}$ - rigidez flexional segundo a direção 2 da viga

- $G J$ - rigidez à torção da viga

Como comentado anteriormente no item 4.2, para um riser flexível os valores dos coeficientes de rigidez podem variar segundo o carregamento. No presente modelo, esse efeito não é considerado. Alguma forma de variação dos coeficientes segundo valores de carregamento, inclusive associados a efeitos de histerese poderiam ser modelados através de uma analogia com a teoria da plasticidade.

Em casos de tubos flexíveis e cabos umbilicais, modelos constitutivos mais elaborados poderiam prever uma matriz constitutiva não diagonal, uma vez que pode haver acoplamentos mais complexos entre esforços solicitantes, como entre a tração e a torção, nos casos em que não há balanceamento total dos efeitos das armaduras de tração. Esse tipo de efeito poderia ser facilmente incluso nesse modelo, somente modificando a expressão 4.138. A determinação dos coeficientes do operador $\boldsymbol{D}^{r}$, no entanto, não é uma 
tarefa simples. Trabalhos como os de Witz e Tan (1992) e Ramos Jr (2001) procuram determinar esses coeficientes para tubos flexíveis ou cabos umbilicais.

\subsubsection{Operador tangente}

A solução das equações da teoria estrutural aqui apresentada pode ser feita utilizando-se métodos iterativos, como o de Newton-Rahpson. O objetivo é a determinação do campo de deslocamentos que satisfaça a expressão do PTV. Para tal, é necessário que se desenvolva um operador tangente, ou seja, aquele que faz o papel da derivada da expressão do PTV.

O problema pode ser posto matematicamente da seguinte forma: dado um funcional $\delta W_{r}$ denominado trabalho virtual residual e diversas funções candidatas $\delta \boldsymbol{d}^{\boldsymbol{\Delta}}$, qual é a função candidata que satisfaz o PTV, ou seja, que leva o valor de $\delta W_{r}$ para zero? A expressão para o funcional vem da equação de equilíbrio estático apresentada em 4.106:

$$
\delta W_{r}=\int_{0}^{L}\left(\boldsymbol{\sigma}^{i+\mathbf{1}^{r}} \cdot \boldsymbol{\Lambda}^{i+\mathbf{1}^{T}} \boldsymbol{\Phi}^{i+\mathbf{1}} \boldsymbol{Y}^{\boldsymbol{\Delta}} \boldsymbol{\Delta} \delta \boldsymbol{d}^{\boldsymbol{\Delta}}-\overline{\boldsymbol{q}} \cdot \delta \boldsymbol{d}^{\boldsymbol{\Delta}}\right) d \zeta
$$

Para realizar a derivação do funcional em relação aos deslocamentos generalizados é necessário utilizar-se da definição da derivada de Fréchet. Para tal, assim como na dedução das expressões para os trabalhos virtuais, esse procedimento pode ser feito através da analogia com a derivada em relação ao tempo, estando o tempo relacionado também às variações dos deslocamentos generalizados. A variável escalar do tempo no caso de um problema estático pode ser compreendida apenas como um artifício algébrico, a partir do qual o operador tangente $\delta\left(\delta W_{r}\right)$ pode ser obtido:

$$
\begin{aligned}
& \frac{\partial}{\partial t}\left(\delta W_{r}\right)= \\
& \int_{0}^{L}\left(\dot{\boldsymbol{\sigma}}^{i+\mathbf{1}^{r}} \cdot \boldsymbol{\Lambda}^{i+\mathbf{1}^{T}} \boldsymbol{\Phi}^{i+1} \boldsymbol{Y}^{\boldsymbol{\Delta}} \boldsymbol{\Delta} \delta \boldsymbol{d}^{\boldsymbol{\Delta}}+\boldsymbol{\sigma}^{i+\mathbf{1}^{r}} \cdot \frac{.}{\boldsymbol{\Lambda}^{i+\mathbf{1}^{T}} \boldsymbol{\Phi}^{i+1} \boldsymbol{Y}^{\boldsymbol{\Delta}}} \boldsymbol{\Delta} \delta \boldsymbol{d}^{\boldsymbol{\Delta}}\right. \\
& \left.-\dot{\overline{\boldsymbol{q}}} \cdot \delta \boldsymbol{d}^{\boldsymbol{\Delta}}\right) d \zeta
\end{aligned}
$$

Note que na expressão 4.140 existem três termos, sendo esses descritos da seguinte forma:

- $\dot{\boldsymbol{\sigma}}^{i+1^{r}} \cdot \boldsymbol{\Lambda}^{i+\mathbf{1}^{T}} \boldsymbol{\Phi}^{i+1} \boldsymbol{Y}^{\boldsymbol{\Delta}} \boldsymbol{\Delta} \delta \boldsymbol{d}^{\boldsymbol{\Delta}}$ : corresponde à contribuição constitutiva ao operador tangente, uma vez que a derivada temporal está presente somente no termo das 
tensões, estando os outros termos referentes a variações geométricas constantes;

- $\boldsymbol{\sigma}^{i+\mathbf{1}^{r}} \cdot \overline{\Lambda^{i+\mathbf{1}^{T}} \boldsymbol{\Phi}^{i+1} \boldsymbol{Y}^{\boldsymbol{\Delta}}} \boldsymbol{\Delta} \delta \boldsymbol{d}^{\boldsymbol{\Delta}}$ : corresponde à contribuição geométrica ao operador tangente, uma vez que a derivada temporal está presente somente em termos que dependem dos deslocamentos e rotações e, portanto, da geometria do problema na configuração deformada;

- $\dot{\overline{\boldsymbol{q}}} \cdot \delta \boldsymbol{d}^{\boldsymbol{\Delta}}$ : corresponde à contribuição dos carregamentos ao operador tangente, estando a derivada temporal aplicada no termo das forças externas. Esse termo possui valor não nulo somente se as forças variarem em função de mudanças geométricas no problema, como por exemplo para carregamentos seguidores (ver Capítulo 3).

A expressão para o operador tangente pode ser manipulada utilizando-se a regra da cadeia de derivação. É possível chegar a uma expressão para esse operador após extensas manipulações algébricas detalhadas, por exemplo, em Moreira (2009). Utilizando-se das definições apresentadas no tópico 4.3 .5 chega-se na seguinte expressão para o operador tangente:

$$
\begin{aligned}
\delta\left(\delta W_{r}\right)= & \int_{0}^{L}\left[\left(\boldsymbol{D}^{r} \boldsymbol{\Lambda}^{i+\mathbf{1}^{T}} \boldsymbol{\Phi}^{i+\mathbf{1}} \boldsymbol{Y}^{\boldsymbol{\Delta}} \boldsymbol{\Delta} \delta \boldsymbol{d}^{\boldsymbol{\Delta}}\right) \cdot\left(\boldsymbol{\Lambda}^{i+\mathbf{1}^{T}} \boldsymbol{\Phi}^{i+\mathbf{1}} \boldsymbol{Y}^{\boldsymbol{\Delta}} \boldsymbol{\Delta} \delta \boldsymbol{d}^{\boldsymbol{\Delta}}\right)+(4.141)\right. \\
& +\left(\boldsymbol{G}^{\boldsymbol{i + 1}} \boldsymbol{\Delta} \delta \boldsymbol{d}^{\boldsymbol{\Delta}}\right) \cdot\left(\boldsymbol{\Delta} \delta \boldsymbol{d}^{\boldsymbol{\Delta}}\right)+ \\
& \left.-\left(\boldsymbol{L}^{i+\mathbf{1}} \delta \boldsymbol{d}^{\boldsymbol{\Delta}}\right) \cdot\left(\delta \boldsymbol{d}^{\boldsymbol{\Delta}}\right)\right] d \zeta
\end{aligned}
$$

em que o operador $\boldsymbol{D}^{\boldsymbol{r}}$ representa a relação entre o vetor $\boldsymbol{\sigma}^{\boldsymbol{r}}$ e o vetor $\boldsymbol{\epsilon}^{\boldsymbol{r}}$. Trata-se, portanto, da relação constitutiva considerada, apresentada em 4.4.7:

$$
\boldsymbol{D}^{r}=\frac{\partial \boldsymbol{\sigma}^{\boldsymbol{r}}}{\partial \boldsymbol{\epsilon}^{\boldsymbol{r}}}=\left[\begin{array}{cc}
\frac{\partial \boldsymbol{n}^{r}}{\partial \boldsymbol{\eta}^{r}} & \frac{\partial \boldsymbol{n}^{r}}{\partial \boldsymbol{\kappa}^{r}} \\
\frac{\partial \boldsymbol{m}^{r}}{\partial \boldsymbol{\eta}^{r}} & \frac{\partial \boldsymbol{m}^{r}}{\partial \boldsymbol{\kappa}^{r}}
\end{array}\right]
$$

O operador $\boldsymbol{G}^{\boldsymbol{i + 1}}$ é dado por: 


$$
\boldsymbol{G}^{i+1}=\left[\begin{array}{rrr}
\boldsymbol{O} & \boldsymbol{O} & \boldsymbol{G}_{u^{\prime} \alpha} \\
\boldsymbol{O} & \boldsymbol{O} & \boldsymbol{G}_{\alpha \alpha^{\prime}} \\
\boldsymbol{G}_{u^{\prime} \alpha}^{T} & \boldsymbol{G}_{\alpha \alpha^{\prime}}^{T} & \boldsymbol{G}_{\alpha \alpha}
\end{array}\right]
$$

Sendo os tensores $\boldsymbol{N}^{\boldsymbol{i + 1}}=\operatorname{skew}\left(\boldsymbol{n}^{\boldsymbol{i + 1}}\right), \boldsymbol{M}^{\boldsymbol{i + 1}}=\operatorname{skew}\left(\boldsymbol{m}^{\boldsymbol{i + 1}}\right)$ e $\boldsymbol{Z}^{\boldsymbol{i + \mathbf { 1 } ^ { \prime }}}=\operatorname{skew}\left(\boldsymbol{z}^{\boldsymbol{i + \mathbf { 1 } ^ { \prime }}}\right)$, os tensores que aparecem no operador $\boldsymbol{G}^{\boldsymbol{i}+\boldsymbol{1}}$ são dados por:

$$
\begin{aligned}
& G_{u^{\prime} \alpha}=-N^{i+1} \Xi^{\Delta} \\
& \boldsymbol{G}_{u^{\prime} \alpha}^{T}=\boldsymbol{\Xi}^{\boldsymbol{\Delta}^{T}} \boldsymbol{N}^{\boldsymbol{i + 1}} \\
& G_{\alpha \alpha}=\Xi^{\Delta^{T}} Z^{i+1^{\prime}} N^{i+1} \Xi^{\Delta}-V\left(\alpha^{\Delta}, Z^{i+1^{\prime}} n^{i+1}\right)+V^{\prime}\left(\alpha^{\Delta}, \alpha^{\Delta^{\prime}}, m^{i+1}\right)-\Xi^{\Delta^{T^{\prime}}} M^{i+1} \Xi^{\Delta} \\
& \boldsymbol{G}_{\alpha \alpha^{\prime}}=\boldsymbol{V}\left(\boldsymbol{\alpha}^{\boldsymbol{\Delta}}, \boldsymbol{m}^{i+1}\right)-\boldsymbol{\Xi}^{\boldsymbol{\Delta}^{T}} \boldsymbol{M}^{i+1} \boldsymbol{\Xi}^{\boldsymbol{\Delta}} \\
& G_{\alpha \alpha^{\prime}}^{T}=V\left(\alpha^{\Delta}, m^{i+1}\right)
\end{aligned}
$$

Quanto ao operador $\boldsymbol{L}^{\boldsymbol{i + 1}}$ que surge no terceiro termo do operador tangente, representa a variação dos carregamentos em função dos deslocamentos generalizados. Temse:

$$
\boldsymbol{L}^{\boldsymbol{i}+\mathbf{1}}=\frac{\partial \overline{\boldsymbol{q}}}{\partial \boldsymbol{d}^{\boldsymbol{\Delta}}}=\left[\begin{array}{cc}
\boldsymbol{L}_{u u} & \boldsymbol{L}_{u \alpha} \\
\boldsymbol{L}_{\alpha u} & \boldsymbol{L}_{\alpha \alpha}
\end{array}\right]
$$

Sendo:

$$
\begin{aligned}
\boldsymbol{L}_{u u} & =\frac{\partial \overline{\boldsymbol{n}}}{\partial \boldsymbol{u}^{\boldsymbol{\Delta}}} \\
\boldsymbol{L}_{u \alpha} & =\frac{\partial \overline{\boldsymbol{n}}}{\partial \boldsymbol{\alpha}^{\boldsymbol{\Delta}}} \\
\boldsymbol{L}_{\alpha u} & =\frac{\partial \boldsymbol{\Xi}^{\boldsymbol{\Delta}^{T}} \overline{\boldsymbol{m}}}{\partial \boldsymbol{u}^{\boldsymbol{\Delta}}} \\
\boldsymbol{L}_{\alpha \alpha} & =\frac{\partial \boldsymbol{\Xi}^{\boldsymbol{\Delta}^{T}} \overline{\boldsymbol{m}}}{\partial \boldsymbol{\alpha}^{\boldsymbol{\Delta}}}
\end{aligned}
$$

É possível observar que o operador tangente pode ser simétrico ou não simétrico, dependendo da contribuição dos carregamentos, ou seja, do operador $\boldsymbol{L}^{\boldsymbol{i + 1}}$. Sendo a 
contribuição constitutiva simétrica, bem como a geométrica, no caso de haver algum tipo de carregamento dependente dos deslocamentos generalizados, não se garante a simetria do operador tangente.

Como observado por Nowinski (1983), é possível demonstrar que para um operador ser denominado "potencial", uma condição necessária e suficiente é o fato de possuir sua derivada de Fréchet simétrica.

A seguir serão discutidos os carregamentos presentes no problema típico de análise de risers, objeto fundamental desse estudo. Para cada carregamento é feita uma discussão sobre a dependência ou não em relação aos deslocamentos generalizados e sua consequência na contribuição ao operador tangente.

\subsubsection{Carregamentos em problemas de risers}

\subsubsection{Carregamento do peso próprio}

O peso próprio de risers é classificado como um esforço de campo, distribuído no volume das vigas que compõem o domínio do riser. A força peso em um corpo com massa $m$ é dada por $m \boldsymbol{g}$, sendo $\boldsymbol{g}$ a aceleração da gravidade. Assumindo uma distribuição homogênea de massa no domínio da viga, com massa específica $\rho$, o campo que descreve a força por unidade de volume $\boldsymbol{b}_{\text {peso }}$ é dado por:

$$
\boldsymbol{b}_{\text {peso }}=\rho \boldsymbol{g}
$$

Utilizando-se da equação 4.97, pode-se calcular para esse carregamento o valor de $\overline{\boldsymbol{n}}$, denominado por $\overline{\boldsymbol{n}}_{\text {peso }}$

$$
\overline{\boldsymbol{n}}_{\text {peso }}=\int_{A} \overline{\boldsymbol{b}} d A=\int_{A} \rho \boldsymbol{g} d A=\rho A \boldsymbol{g}
$$

Analogamente, é possível calcular as contribuições do peso para os momentos dos esforços externos:

$$
\overline{\boldsymbol{m}}_{\text {peso }}=\int_{A} \boldsymbol{a}^{\boldsymbol{i}} \times \overline{\boldsymbol{b}} d A=\int_{A} \boldsymbol{a}^{\boldsymbol{i}} \times \rho \boldsymbol{g} d A=\rho \int_{A} \boldsymbol{a}^{\boldsymbol{i}} \times \boldsymbol{g} d A=\mathbf{0}
$$


A equação 4.149 mostra que $\overline{\boldsymbol{m}}_{\text {peso }}$ é dado por uma integração de um sistema de forças paralelas no domínio da seção transversal do riser. Se tomado o centro de forças paralelas, nesse caso, o centro de massa, o valor dessa integração será nulo. Assim sendo, se for escolhido um eixo conveniente passando pelo baricentro das seções transversais ao longo do comprimento do riser, a contribuição dos momentos do peso próprio será nula.

Concluindo, a contribuição do peso próprio no vetor de esforços externos generalizados é dada por:

$$
\overline{\boldsymbol{q}}_{\text {peso }}=\left[\begin{array}{c}
\rho A \boldsymbol{g} \\
\mathbf{0}
\end{array}\right]=\left[\begin{array}{c}
\bar{\rho} \boldsymbol{g} \\
\mathbf{0}
\end{array}\right]
$$

Define-se o peso por unidade de comprimento da estrutura por $\gamma=\bar{\rho} g$.

\subsubsection{Carregamento de pressão interna e externa}

O Apêndice A mostra a obtenção de expressões para o carregamento das pressões externa e interna ao riser.

A expressão 4.152 mostra as componentes cartesianas do carregamento existente em função das pressões externa e interna em um riser do tipo tubo flexível ou rígido. Para inserir esse efeito como carregamento é necessário definir a força por unidade de comprimento $\frac{d \boldsymbol{f}_{\boldsymbol{p}}}{d \zeta}$, a ser integrada ao longo do comprimento da viga. O integrando de cada componente da expressão 4.152 representa exatamente as componentes do vetor força por unidade de comprimento, tal que:

$$
\frac{d \boldsymbol{f}_{\boldsymbol{p}}}{d \zeta}=\left(\frac{d f_{x}}{d \zeta}, \frac{d f_{y}}{d \zeta}, \frac{d f_{z}}{d \zeta}\right)
$$

As componentes detalhadas são dadas por (notação do Apêndice A): 


$$
\begin{aligned}
\frac{d f_{x}}{d \zeta=} & {\left[\frac{\pi}{R(\zeta)}\left(g h_{o}(\zeta) \rho_{e} r_{e}^{2}-g h_{o}(\zeta) \rho_{i} r_{i}^{2}-p_{o} r_{i}^{2}\right)+\right.} \\
& \left.+\pi g_{n}\left(-\rho_{e} r_{e}^{2}+\rho_{i} r_{i}^{2}\right)\right] n_{x}(\zeta)+\pi g_{b}\left(-\rho_{e} r_{e}^{2}+\rho_{i} r_{i}^{2}\right) b_{x}(\zeta) \\
\frac{d f_{y}}{d \zeta}= & {\left[\frac{\pi}{R(\zeta)}\left(g h_{o}(\zeta) \rho_{e} r_{e}^{2}-g h_{o}(\zeta) \rho_{i} r_{i}^{2}-p_{o} r_{i}^{2}\right)+\right.} \\
& \left.+\pi g_{n}\left(-\rho_{e} r_{e}^{2}+\rho_{i} r_{i}^{2}\right)\right] n_{y}(\zeta)+\pi g_{b}\left(-\rho_{e} r_{e}^{2}+\rho_{i} r_{i}^{2}\right) b_{y}(\zeta) \\
\frac{d f_{z}}{d \zeta=} & {\left[\frac{\pi}{R(\zeta)}\left(g h_{o}(\zeta) \rho_{e} r_{e}^{2}-g h_{o}(\zeta) \rho_{i} r_{i}^{2}-p_{o} r_{i}^{2}\right)+\right.} \\
& \left.+\pi g_{n}\left(-\rho_{e} r_{e}^{2}+\rho_{i} r_{i}^{2}\right)\right] n_{z}(\zeta)+\pi g_{b}\left(-\rho_{e} r_{e}^{2}+\rho_{i} r_{i}^{2}\right) b_{z}(\zeta)
\end{aligned}
$$

Assumindo-se que a contribuição da pressão externa e interna possa ser feita apenas através da inserção de forças e sem nenhuma contribuição de momentos, sua participação como carregamento no modelo de viga é dada por $\overline{\boldsymbol{q}}_{p}$ :

$$
\overline{\boldsymbol{q}}_{p}=\left[\begin{array}{c}
\frac{d \boldsymbol{f}_{\boldsymbol{p}}}{d \zeta} \\
\mathbf{0}
\end{array}\right]
$$

Note que as componentes de $\frac{d \boldsymbol{f}_{\boldsymbol{p}}}{d \zeta}$ envolvem as direções do triedro de Frénet, o raio de curvatura, bem como o cálculo da cota do eixo principal da viga (a fim de calcular a pressão hidrostática nesse ponto). Em uma configuração de riser genérica, pode haver variação de todas essas propriedades, uma vez que todas elas dependem da posição e das deformações ocorridas. Assim sendo, trata-se de um carregamento que depende dos deslocamentos.

Uma alternativa bastante interessante e usual para a inclusão dos efeitos da pressão externa e interna ao riser é a utilização do denominado peso efetivo, apresentado em detalhes no Apêndice A. Sendo $A$ a área da seção transversal externa do riser e $A_{\text {int }}$ a área interna (quando se trata de um tubo), se $\rho_{f}$ e $\rho_{i}$ representarem respectivamente as massas específicas da água do mar externa ao riser e do fluido interno ao mesmo, então o peso efetivo é dado por $\gamma_{e f}$ : 


$$
\gamma_{e f}=\gamma+\rho_{i} g A_{i n t}-\rho_{f} g A
$$

Assumiu-se por hipótese que a adoção de um peso efetivo por unidade de comprimento implica na obtenção de esforços de tração efetiva ao longo do riser. Isso não é geral, conforme discutido no Apêndice A. A tração efetiva é quem domina o problema do ponto de vista de estabilidade estrutural, bem como de frequências naturais. No Capítulo 3 foi discutida essa questão, pormenorizada no Apêndice A. Assim, as expressões 4.152 não foram utilizadas, a menos do exemplo de sua aplicação apresentado no Apêndice A. Com a hipótese de um peso efetivo, tudo se passa como se a estrutura possuísse um peso menor e constante, e independente dos deslocamentos sofridos pelo corpo.

\subsubsection{Carregamento de correntezas marítimas em risers}

Um carregamento que atua nos risers é aquele devido à interação entre o escoamento externo e sua estrutura, podendo aparecer forças de arrasto e de sustentação hidrodinâmicas nessa interação. Dependendo da faixa de velocidade de escoamento externo, do diâmetro externo do riser, e da viscosidade cinemática do fluido externo (água do mar) podem surgir diferentes características de força, constantes ou variáveis ao longo do tempo. O arrasto hidrodinâmico pode ser uma força constante ou variável no tempo, no entanto apresenta média não nula que pode ser considerada em um modelo estático. Esforços de sustentação de modo geral não são constantes, possuindo uma frequência típica, associada aos desprendimentos de vórtices alternados no escoamento externo (vortex shedding). Esse fenômeno é essencialmente dinâmico e não será considerado no presente modelo estrutural.

O modelo para o cálculo de forças considerado é regido pela fórmula de Morison (MORISON et al., 1950). Para utilizá-lo, é necessário descrever um perfil de velocidades associado às correntezas marítimas no local de instalação do riser. Esse perfil pode ser obtido experimentalmente. Uma vez que a escala de variação temporal dessas velocidades é bastante superior aos períodos de interesse das estruturas típicas de risers, o perfil de velocidades ao longe pode ser considerado como constante ao longo do tempo e pode ser 2D ou 3D, de acordo com o mar local da posição de instalação do riser. Sua descrição se dá geralmente através de uma tabela com diferentes cotas, em que para cada cota associa-se um vetor que descreve a norma, direção e sentido da velocidade das águas. Um exemplo de perfil de corrente bidimensional está mostrado na Figura 4.8. 


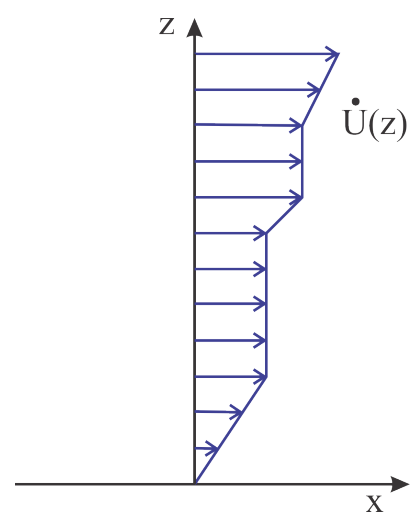

Figura 4.8: Exemplo de perfil 2D de correnteza marítima.

A fórmula de Morison é apresentada de forma didática em Blevins (2001). Basicamente a fórmula considera a superposição dos efeitos inercial e arrasto hidrodinâmico do fluido sobre a estrutura. Segundo Blevins (2001), a força inercial por unidade de comprimento (cuja norma será representada por $d F_{i}$ ), associada a acelerações do fluido, bem como acelerações relativas entre o fluido e a estrutura, pode ser interpretada como sendo a contribuição de dois efeitos:

- Gradiente de pressão que se forma nas superfícies externas do riser devido ao escoamento externo ao longe sofrer aceleração, provocando um efeito semelhante a um empuxo em um corpo imerso em um fluido, submetido a um campo gravitacional;

- Massa adicional de fluido. Esse efeito está associado ao fluido que se move junto do corpo durante uma aceleração do escoamento ao longe. Tudo se passa como se houvesse uma massa adicional no corpo, formada por fluido.

Assume-se, primeiramente, um escoamento cujo campo de velocidades seja ortogonal ao riser, considerado como fixo. Seja $\dot{U}$ a norma da velocidade do escoamento ao longe do riser, e $\ddot{U}$ a norma de sua aceleração, e $C_{a n}$ é o coeficiente de massa adicional do riser, tratado como um cilindro. Tem-se:

$$
d F_{i}=\rho_{f} A \ddot{U}+C_{a n} \rho_{f} A \ddot{U}
$$

Essa expressão ilustra os dois termos interpretados anteriormente, como as duas contribuições de efeitos inerciais. Essa equação pode ser modificada para levar em consideração o efeito do movimento do riser. Sendo $\dot{u}$ e $\ddot{u}$ as normas da velocidade e aceleração 
absolutas do riser em relação a um referencial fixo, pode-se modificar a equação 4.155 para a seguinte forma:

$$
d F_{i}=\rho_{f} A \ddot{U}+C_{a n} \rho_{f} A(\ddot{U}-\ddot{u})
$$

Note que o primeiro termo não foi modificado, uma vez que a sua contribuição tem a ver com o gradiente de pressão do fluido sobre o riser, interpretado como semelhante a um empuxo. Já o segundo termo se modifica, apresentando a aceleração relativa entre o riser e a fluido externo.

Quanto ao efeito do arrasto hidrodinâmico, pode-se escrever a seguinte expressão:

$$
d F_{d}=\frac{1}{2} \rho_{f}(\dot{U}-\dot{u})^{2} D C_{d}
$$

em que:

- $D$ é o diâmetro externo do riser;

- $C_{d}$ é o coeficiente de arrasto do riser.

A norma da força total por unidade de comprimento, dada pela fórmula de Morison, é a seguinte:

$$
d F=\rho_{f} A \ddot{U}+C_{a n} \rho_{f} A(\ddot{U}-\ddot{u})+\frac{1}{2} \rho_{f}(\dot{U}-\dot{u})^{2} D C_{d}
$$

Para o caso particular do modelo estático desenvolvido nesse capítulo, o riser se encontra em configuração estacionária e o fluido externo possui velocidade constante. A expressão da força se simplifica bastante, contendo agora somente o termo de arrasto hidrodinâmico. Todo o efeito inercial é desprezado, a menos para cálculos de frequências naturais da estrutura, quando se faz necessária a utilização da massa adicional. Isso é utilizado quando se faz uma análise de estabilidade cinética, utilizando-se do Primeiro Método de Lyapunov, conforme relatado no Capítulo 3

$$
d F=\frac{1}{2} \rho_{f} \dot{U}^{2} D C_{d}
$$


No entanto, essa expressão não é suficiente para todos os casos de análise de risers, uma vez que ela só trata condições em que o escoamento é sempre ortogonal ao riser. A forma de tratar escoamentos não ortogonais à estrutura, segundo Faltisen (1990), pode ser feita através da decomposição da velocidade e da aceleração em duas direções: direção normal e direção tangencial ao riser $^{8}$. Ambas as direções são tratadas como independentes e, posteriormente, seus efeitos são superpostos. Considerando somente o efeito do arrasto hidrodinâmico, a equação 4.159 pode ser decomposta da seguinte forma:

$$
\begin{aligned}
& d F_{t}=\frac{1}{2} \rho_{f} \dot{U}_{t}^{2} D C_{d t} \\
& d F_{n}=\frac{1}{2} \rho_{f} \dot{U}_{n}^{2} D C_{d n}
\end{aligned}
$$

Os novos coeficientes que surgem nessas equações são os coeficientes de arrasto normal $\left(C_{d n}\right)$ e tangencial $\left(C_{d t}\right)$. Para os modelos em questão é assumido que esses coeficientes são constantes no tempo.

As expressões escalares apresentadas em 4.160 podem ser reescrita de forma vetorial, dependentes somente da velocidade da correnteza $\dot{\boldsymbol{U}}$ e da direção tangencial instantânea para cada seção transversal da viga, descrita pelo vetor $\boldsymbol{e}_{\mathbf{3}}^{\boldsymbol{i}}$. As componentes das velocidades tangencial e normal à seção transversal cuja normal é $\boldsymbol{e}_{\mathbf{3}}^{\boldsymbol{i}}$ podem ser calculadas por:

$$
\begin{aligned}
\dot{U}_{t}^{i} & =\left(\dot{U} \cdot e_{3}^{i}\right) e_{3}^{i} \\
\dot{U}_{n}^{i} & =\dot{U}-\dot{U}_{t}^{i}=\dot{U}-\left(\dot{U} \cdot e_{3}^{i}\right) e_{3}^{i}
\end{aligned}
$$

As componentes tangencial $\boldsymbol{F}_{\boldsymbol{t}}^{\boldsymbol{i}}$ e normal $\boldsymbol{F}_{\boldsymbol{n}}^{\boldsymbol{i}}$ do esforço hidrodinâmico de correnteza marítima (por unidade de comprimento de riser) são dadas por:

\footnotetext{
${ }^{8}$ É necessário o cuidado de não confundir a direção normal (ortogonal ao riser) aqui definida, em relação à normal de Frénet abordada no Apêndice B. Para definir a velocidade na direção tangencial ao riser, basta projetar o vetor velocidade nessa direção. Para definir a velocidade na direção ortogonal, basta subtrair do vetor velocidade a componente tangencial recém determinada. Dessa forma, as direções tangencial e ortogonal para decomposição de velocidades e de forças hidrodinâmicas dependem do vetor velocidade do escoamento externo e da direção tangencial do riser. A direção normal de Frénet não possui relação nenhuma com a normal da correnteza, aqui definida.
} 


$$
\begin{aligned}
\boldsymbol{F}_{\boldsymbol{t}}^{\boldsymbol{i}} & =\frac{1}{2} \rho_{f} D C_{d t}\left\|\dot{\boldsymbol{U}}_{\boldsymbol{t}}^{\boldsymbol{i}}\right\| \dot{\boldsymbol{U}}_{\boldsymbol{t}}^{\boldsymbol{i}} \\
\boldsymbol{F}_{\boldsymbol{n}}^{\boldsymbol{i}} & =\frac{1}{2} \rho_{f} D C_{d n}\left\|\dot{\boldsymbol{U}}_{\boldsymbol{n}}^{\boldsymbol{i}}\right\| \dot{\boldsymbol{U}}_{\boldsymbol{n}}^{\boldsymbol{i}}
\end{aligned}
$$

Assume-se, que os esforços hidrodinâmicos estáticos não induzem momentos na estrutura do riser em relação ao eixo que passa pelo baricentro das seções transversais, mas somente as forças dadas pela Fórmula de Morison. Aplicando-se a Fórmula de Morison para a teoria estrutural de vigas, tem-se a contribuição desse carregamento dada por:

$$
\overline{\boldsymbol{q}}_{\text {hidro }}^{i}=\left[\begin{array}{c}
\boldsymbol{F}_{t}^{i}+\boldsymbol{F}_{n}^{i} \\
0
\end{array}\right]
$$

Fisicamente, a componente normal desse esforço é cerca de uma ordem de grandeza mais elevada do que a componente na direção tangencial, sendo comum desprezá-la. No entanto, a forma aqui apresentada considera as duas componentes.

A componente tangencial pode ser reescrita por:

$$
\boldsymbol{F}_{\boldsymbol{t}}^{\boldsymbol{i}}=\left\{\begin{array}{l}
+\frac{1}{2} \rho_{f} D C_{d t}\left(\dot{\boldsymbol{U}} \cdot \boldsymbol{e}_{\mathbf{3}}^{\boldsymbol{i}}\right)^{2} \boldsymbol{e}_{\mathbf{3}}^{\boldsymbol{i}} \text { se } \dot{\boldsymbol{U}} \cdot \boldsymbol{e}_{\mathbf{3}}^{\boldsymbol{i}}>0 \\
-\frac{1}{2} \rho_{f} D C_{d t}\left(\dot{\boldsymbol{U}} \cdot \boldsymbol{e}_{\mathbf{3}}^{\boldsymbol{i}}\right)^{2} \boldsymbol{e}_{\mathbf{3}}^{\boldsymbol{i}} \text { se } \dot{\boldsymbol{U}} \cdot \boldsymbol{e}_{\mathbf{3}}^{\boldsymbol{i}}<0
\end{array}\right.
$$

A componente normal pode ser reescrita por:

$$
\boldsymbol{F}_{\boldsymbol{n}}^{\boldsymbol{i}}=\frac{1}{2} \rho_{f} D C_{d n}\left[\dot{\boldsymbol{U}} \cdot \dot{\boldsymbol{U}}-\left(\dot{\boldsymbol{U}} \cdot \boldsymbol{e}_{\mathbf{3}}^{\boldsymbol{i}}\right)^{2}\right]^{1 / 2}\left[\dot{\boldsymbol{U}}-\left(\dot{\boldsymbol{U}} \cdot \boldsymbol{e}_{\mathbf{3}}^{\boldsymbol{i}}\right) \boldsymbol{e}_{\mathbf{3}}^{\boldsymbol{i}}\right]
$$

É necessário derivar as expressões 4.164 e 4.165 escritas na configuração " $i+1$ ” em relação aos vetores $\boldsymbol{u}^{\boldsymbol{\Delta}}$ e $\boldsymbol{\alpha}^{\boldsymbol{\Delta}}$ para obter os termos $\boldsymbol{L}_{u u}$ e $\boldsymbol{L}_{u \alpha}$ da expressão 4.146.

A variação da força hidrodinâmica devido a mudanças na orientação da seção transversal analisada é bem descrita pela variação do vetor $\boldsymbol{e}_{\mathbf{3}}^{\boldsymbol{i + 1}}$ em relação ao vetor rotação $\boldsymbol{\alpha}^{\boldsymbol{\Delta}}$, contemplada no termo $\boldsymbol{L}_{u \alpha}$. Já a contribuição do termo $\boldsymbol{L}_{u u}$ será nula se o perfil de velocidades da correnteza for uniforme em todo o espaço. Assim, por mais que haja translação da viga, a mesma não apresentará variações no vetor $\dot{\boldsymbol{U}}$. O vetor $\boldsymbol{e}_{\mathbf{3}}^{\boldsymbol{i + 1}}$ 
tampouco não varia com os deslocamentos, mas sim com as rotações. Assim, para obter o operador tangente o único termo não nulo será o $\boldsymbol{L}_{u \alpha}$, uma vez que já se assumiu também que os momentos causados pelo carregamento hidrodinâmico são nulos.

$$
\boldsymbol{L}_{u \boldsymbol{\alpha}}^{i+1}=\frac{\partial \boldsymbol{F}_{t}^{i+1}}{\partial \boldsymbol{\alpha}^{\boldsymbol{\Delta}}}+\frac{\partial \boldsymbol{F}_{n}^{i+1}}{\partial \boldsymbol{\alpha}^{\boldsymbol{\Delta}}}
$$

A contribuição de cada parcela do esforço hidrodinâmico ao operador tangente é descrita a seguir ${ }^{9}$ :

$$
\begin{aligned}
& \frac{\partial \boldsymbol{F}_{t}^{i+1}}{\partial \boldsymbol{\alpha}^{\boldsymbol{\Delta}}}= \pm \frac{1}{2} \rho D C_{d t}\left\{\frac{\partial \boldsymbol{e}_{\mathbf{3}}^{\boldsymbol{i + 1}}}{\partial \boldsymbol{\alpha}^{\boldsymbol{\Delta}}}\left(\dot{\boldsymbol{U}} \cdot \boldsymbol{e}_{\mathbf{3}}^{\boldsymbol{i + 1}}\right)^{2}+\boldsymbol{e}_{\mathbf{3}}^{\boldsymbol{i + 1}}\left[2\left(\dot{\boldsymbol{U}} \cdot \boldsymbol{e}_{\mathbf{3}}^{\boldsymbol{i + 1}}\right) \dot{\boldsymbol{U}}^{T} \frac{\partial \boldsymbol{e}_{\mathbf{3}}^{\boldsymbol{i + 1}}}{\partial \boldsymbol{\alpha}^{\boldsymbol{\Delta}}}\right]\right\} \\
& \frac{\partial \boldsymbol{F}_{\boldsymbol{n}}^{\boldsymbol{i}+\mathbf{1}}}{\partial \boldsymbol{\alpha}^{\boldsymbol{\Delta}}}=\frac{1}{2} \rho D C_{d n}\left\{\left[\dot{\boldsymbol{U}}-\left(\dot{\boldsymbol{U}} \cdot \boldsymbol{e}_{\mathbf{3}}^{\boldsymbol{i + 1}}\right) \boldsymbol{e}_{\mathbf{3}}^{\boldsymbol{i}+\mathbf{1}}\right]\left[-\frac{\dot{\boldsymbol{U}} \cdot \boldsymbol{e}_{\mathbf{3}}^{\boldsymbol{i + 1}}}{\left(\dot{\boldsymbol{U}} \cdot \dot{\boldsymbol{U}}-\left(\dot{\boldsymbol{U}} \cdot \boldsymbol{e}_{\mathbf{3}}^{\boldsymbol{i + 1}}\right)^{2}\right)^{1 / 2}} \dot{\boldsymbol{U}}^{T} \frac{\partial \boldsymbol{e}_{\mathbf{3}}^{\boldsymbol{i}+\mathbf{1}}}{\partial \boldsymbol{\alpha}^{\boldsymbol{\Delta}}}\right]+\right. \\
& \left.-\left(\dot{\boldsymbol{U}} \cdot \dot{\boldsymbol{U}}-\left(\dot{\boldsymbol{U}} \cdot \boldsymbol{e}_{\mathbf{3}}^{\boldsymbol{i + 1}}\right)^{2}\right)^{1 / 2}\left[\frac{\partial \boldsymbol{e}_{\mathbf{3}}^{\boldsymbol{i + 1}}}{\partial \boldsymbol{\alpha}^{\boldsymbol{\Delta}}}\left(\dot{\boldsymbol{U}} \cdot \boldsymbol{e}_{\mathbf{3}}^{\boldsymbol{i + 1}}\right)+\boldsymbol{e}_{\mathbf{3}}^{\boldsymbol{i + 1}}\left(\dot{\boldsymbol{U}}^{T} \frac{\partial \boldsymbol{e}_{\mathbf{3}}^{\boldsymbol{i + 1}}}{\partial \boldsymbol{\alpha}^{\boldsymbol{\Delta}}}\right)\right]\right\}
\end{aligned}
$$

Percebe-se nas equações 4.167 e 4.168 que é necessário calcular o termo $\frac{\partial \boldsymbol{e}_{3}^{\boldsymbol{i + 1}}}{\partial \boldsymbol{\alpha}^{\boldsymbol{\Delta}}}$. Uma vez que $\boldsymbol{e}_{\mathbf{3}}^{i+\mathbf{1}}=\boldsymbol{R}^{\boldsymbol{\Delta}} \boldsymbol{e}_{\mathbf{3}}^{i}$, escreve-se que:

$$
\frac{\partial \boldsymbol{e}_{3}^{i+1}}{\partial \boldsymbol{\alpha}^{\boldsymbol{\Delta}}}=\frac{\partial\left(\boldsymbol{R}^{\boldsymbol{\Delta}} \boldsymbol{e}_{\mathbf{3}}^{i}\right)}{\partial \boldsymbol{\alpha}^{\boldsymbol{\Delta}}}
$$

Sendo o tensor rotação escrito na forma 4.22, após um extenso trabalho algébrico

\footnotetext{
${ }^{9} \mathrm{~A}$ álgebra utilizada nessa dedução utiliza-se de algumas formas convenientes para a escrita de produtos escalares e derivadas de vetores:

O produto escalar $\dot{\boldsymbol{U}} \cdot \boldsymbol{e}_{\mathbf{3}}^{\boldsymbol{i + 1}}$ pode ser escrito por $\dot{\boldsymbol{U}}^{T} \boldsymbol{e}_{\mathbf{3}}^{\boldsymbol{i + 1}}$.

Seja uma função vetorial $\boldsymbol{v}$ escrita em relação ao vetor $\boldsymbol{a}$ tal que $\boldsymbol{v}(\boldsymbol{a})=\boldsymbol{b}(\boldsymbol{a}) m(\boldsymbol{a})$. Ao derivar a função $\boldsymbol{v}$ em relação ao vetor $\boldsymbol{a}$, pode-se escrever o resultado utilizando-se da regra da cadeia da seguinte forma:

$$
\frac{\partial \boldsymbol{v}}{\partial \boldsymbol{a}}=m \frac{\partial \boldsymbol{b}}{\partial \boldsymbol{a}}+\boldsymbol{b} \frac{\partial m}{\partial \boldsymbol{a}}
$$
}


é possível escrever a seguinte expressão:

$$
{\frac{\partial \boldsymbol{e}_{\mathbf{3}}^{\boldsymbol{i + 1}}}{\partial \boldsymbol{\alpha}^{\boldsymbol{\Delta}}}}_{i j}=\frac{1}{2} r_{0}^{2} \alpha_{j}\left[\frac{1}{2} A_{i k}^{2}+A_{i k}\right]\left(e_{3}^{i}\right)_{k}+g M_{i j}
$$

Em que:

$$
\begin{aligned}
& M_{11}=\frac{1}{2}\left(\alpha_{2}\left(e_{3}^{i}\right)_{2}+\alpha_{3}\left(e_{3}^{i}\right)_{3}\right) \\
& M_{12}=\alpha_{2}\left(e_{3}^{i}\right)_{1}+\frac{1}{2} \alpha_{1}\left(e_{3}^{i}\right)_{2}+\left(e_{3}^{i}\right)_{3} \\
& M_{13}=-\alpha_{3}\left(e_{3}^{i}\right)_{1}-\left(e_{3}^{i}\right)_{2}+\frac{1}{2} \alpha_{1}\left(e_{3}^{i}\right)_{3} \\
& M_{21}=-\alpha_{1}\left(e_{3}^{i}\right)_{2}-\left(e_{3}^{i}\right)_{3}+\frac{1}{2} \alpha_{2}\left(e_{3}^{i}\right)_{1} \\
& M_{22}=\frac{1}{2}\left(\alpha_{1}\left(e_{3}^{i}\right)_{1}+\alpha_{3}\left(e_{3}^{i}\right)_{3}\right) \\
& M_{23}=-\alpha_{3}\left(e_{3}^{i}\right)_{2}+\left(e_{3}^{i}\right)_{1}+\frac{1}{2} \alpha_{2}\left(e_{3}^{i}\right)_{3} \\
& M_{31}=-\alpha_{1}\left(e_{3}^{i}\right)_{3}+\left(e_{3}^{i}\right)_{2}+\frac{1}{2} \alpha_{3}\left(e_{3}^{i}\right)_{1} \\
& M_{32}=-\alpha_{2}\left(e_{3}^{i}\right)_{3}-\left(e_{3}^{i}\right)_{1}+\frac{1}{2} \alpha_{3}\left(e_{3}^{i}\right)_{2} \\
& M_{33}=\frac{1}{2}\left(\alpha_{1}\left(e_{3}^{i}\right)_{1}+\alpha_{2}\left(e_{3}^{i}\right)_{2}\right)
\end{aligned}
$$

Na expressão 4.170 está implícita a convenção de Einstein. Na expressão 4.171 os índices 1, 2 e 3 se referem aos componentes dos vetores $\boldsymbol{\alpha}^{\boldsymbol{\Delta}}$ e $\boldsymbol{e}_{\mathbf{3}}^{\boldsymbol{i}}$.

\subsection{Solução aproximada utilizando o Método dos Ele- mentos Finitos (MEF)}

O MEF é um método numérico para determinar uma solução aproximada de equações diferenciais parciais, com vasta aplicação para problemas de valor de contorno. É possível mostrar que a equação de equilíbrio 4.106 baseada no PTV é equivalente equação diferencial de equilíbrio local. Assim, o PTV representa uma forma integral para a equação diferencial do problema. Essa forma é bastante interessante do ponto de vista computacional para se resolver o problema utilizando o MEF. Detalhes teóricos sobre tal método podem ser amplamente encontrados na literatura do assunto, por exemplo nos livros de Bathe (1996) e Cook (1995) 


\subsubsection{Funções de forma}

O primeiro passo para a determinação de uma solução aproximada do modelo é a escolha do espaço de aproximação que será utilizado. Basicamente, uma vez escolhida a base de funções que comporão a solução do problema, a discretização está feita. O problema passa a ser a determinação de coeficientes (coordenadas generalizadas) para cada uma das funções escolhidas.

A forma de aproximação escolhida foi a de funções polinomiais, dada sua facilidade de manipulação. Cada elemento pode possuir certo número finito de nós, determinando assim a ordem de sua função de aproximação. Por exemplo, para elementos de viga com dois nós, a aproximação é linear, para três nós, a aproximação é quadrática. A construção das funções de forma é feita através de polinômios na forma de Lagrange. Sendo $\xi$ a variável do polinômio, é possível escrever um polinômio que representará a função de forma de um nó, cuja coordenada é $\xi_{a}$ :

$$
N_{a}=\frac{\left(\xi-\xi_{1}\right)\left(\xi-\xi_{2}\right) \ldots\left(\xi-\xi_{a-1}\right)\left(\xi-\xi_{a+1}\right) \ldots\left(\xi-\xi_{n}\right)}{\left(\xi_{a}-\xi_{1}\right)\left(\xi_{a}-\xi_{2}\right) \ldots\left(\xi_{a}-\xi_{a-1}\right)\left(\xi_{a}-\xi_{a+1}\right) \ldots\left(\xi_{a}-\xi_{n}\right)}
$$

Para facilitar a interpolação polinomial para a construção de funções de forma, geralmente é adotado um tamanho padrão de elemento utilizando as chamadas coordenadas naturais que assumem os seguintes valores para $\xi$ :

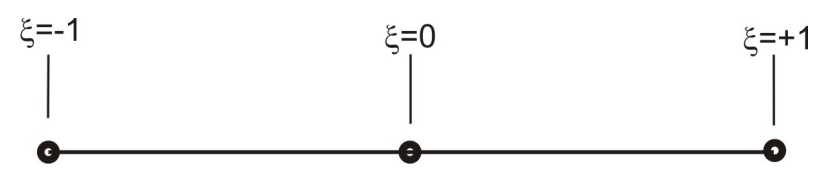

Figura 4.9: Sistema de coordenadas naturais para uma barra com 3 nós com espaçamento uniforme

Para calcular um polinômio de primeira ordem com 2 pontos localizados nos extremos $\xi=-1$ e $\xi=+1$ as funções de forma polinomiais para os pontos 1 e 2 (respectivamente $N_{1}$ e $N_{2}$ ) são as seguintes:

$$
\begin{aligned}
& N_{1}=\frac{(\xi-1)}{(-1-1)}=\frac{(1-\xi)}{2} \\
& N_{2}=\frac{(\xi+1)}{(1+1)}=\frac{(1+\xi)}{2}
\end{aligned}
$$


Essas funções de forma podem ser utilizadas para interpolar grandezas em elementos de viga de primeira ordem. Se for necessário um elemento de segunda ordem, devem ser escolhidas três posições para os nós. Por exemplo, nos pontos $\xi=-1, \xi=0$ e $\xi=+1$. Assim, as funções de forma para cada nó seriam:

$$
\begin{aligned}
& N_{1}=\frac{(\xi-0)(\xi-1)}{(-1-0)(-1-1)}=\frac{\xi(\xi-1)}{2} \\
& N_{2}=\frac{(\xi+1)(\xi-1)}{(0+1)(0-1)}=1-\xi^{2} \\
& N_{3}=\frac{(\xi+1)(\xi-0)}{(+1+1)(+1-0)}=\frac{\xi(\xi+1)}{2}
\end{aligned}
$$

As funções de forma construídas não são utilizadas somente para a interpolação da grandeza de interesse, por exemplo os deslocamentos na presente aplicação. Também podem ser utilizadas para interpolar as próprias coordenadas das barras. Essa utilização da mesma função de forma tanto para interpolação dos deslocamentos como das coordenadas é chamada de isoparamétrica. Essa ideia é utilizada a seguir para determinação do jacobiano para transformação de coordenadas entre as coordenadas físicas do elemento de viga considerado (variando de 0 a $L$ ) e as coordenadas naturais. Assim sendo, pode-se escrever para o elemento de 3 nós:

$$
\zeta=\zeta_{1} N_{1}+\zeta_{2} N_{2}+\zeta_{3} N_{3}=\frac{l}{2} N_{2}+l N_{3}=\frac{l}{2}\left(1-\xi^{2}\right)+l \frac{\xi(\xi+1)}{2}
$$

Derivando a relação 4.175 em relação a $\xi$ obtém-se o jacobiano $J$ da transformação de coordenadas:

$$
J=\frac{\partial \zeta}{\partial \xi}=-l \xi+l \frac{\xi(\xi+1)}{2}=\frac{l}{2}
$$

A forma de aproximação para o vetor deslocamento generalizado da viga $\boldsymbol{d}^{\boldsymbol{\Delta}}$ é feita utilizando-se das mesmas funções de forma desenvolvidas anteriormente. Para o elemento de 3 nós uniformemente distribuídos tem-se:

$$
d^{\Delta}=N p
$$


Em que $\boldsymbol{N}$ é a chamada matriz das funções de forma, e $\boldsymbol{p}$ é o vetor com os deslocamentos generalizados nodais. Assim sendo, assumindo que haja 6 graus de liberdade por nó, ou seja, as três componentes do vetor deslocamento e as três componentes do vetor rotação, pode-se escrever:

$$
N=\left[\begin{array}{lll}
N_{1} & N_{2} & N_{3}
\end{array}\right]
$$

Em que cada uma das matrizes $\boldsymbol{N}_{\boldsymbol{i}}$, com $i=1,2,3$ é dada por:

$$
\boldsymbol{N}_{\boldsymbol{i}}=\left[\begin{array}{cccccc}
N_{i} & 0 & 0 & 0 & 0 & 0 \\
0 & N_{i} & 0 & 0 & 0 & 0 \\
0 & 0 & N_{i} & 0 & 0 & 0 \\
0 & 0 & 0 & N_{i} & 0 & 0 \\
0 & 0 & 0 & 0 & N_{i} & 0 \\
0 & 0 & 0 & 0 & 0 & N_{i}
\end{array}\right]
$$

Em todas as aplicações e resultados mostrados nesse trabalho foi utilizada a função de forma quadrática e, portanto, um elemento de 3 nós.

\subsubsection{Equação de equilíbrio e operador tangente discretizados}

As equações de equilíbrio baseadas no PTV descritas em 4.106 podem ser escritas na forma discreta, ou seja, aproximando-se os deslocamentos $\boldsymbol{d}^{\boldsymbol{\Delta}}$ através da expressão aproximada descrita em 4.177 que se utiliza das funções de forma e dos deslocamentos nodais. Realizando esse procedimento a equação 4.106 fica da forma:

$$
\begin{aligned}
& \int_{0}^{L}\left(\boldsymbol{\sigma}^{i+\mathbf{1}^{r}} \cdot \boldsymbol{\Lambda}^{\boldsymbol{i + 1} \mathbf{1}^{T}} \boldsymbol{\Phi}^{\boldsymbol{i + 1}} \boldsymbol{Y}^{\boldsymbol{\Delta}} \boldsymbol{\Delta} \boldsymbol{N} \delta \boldsymbol{p}-\overline{\boldsymbol{q}} \cdot \boldsymbol{N} \delta \boldsymbol{p}\right) d \zeta=0 \Rightarrow \\
& \int_{0}^{L}\left((\boldsymbol{\Delta} \boldsymbol{N})^{T} \boldsymbol{Y}^{\boldsymbol{\Delta}^{T}} \boldsymbol{\Phi}^{i+\mathbf{1}^{T}} \boldsymbol{\Lambda}^{\boldsymbol{i + 1}} \boldsymbol{\sigma}^{i+\mathbf{1}^{r}}-\boldsymbol{N}^{T} \overline{\boldsymbol{q}}\right) \cdot \delta \boldsymbol{p} d \zeta=0
\end{aligned}
$$

A expressão 4.180 deve ser obedecida para um conjunto de deslocamentos nodais arbitrários $\delta \boldsymbol{p}$, e por isso: 


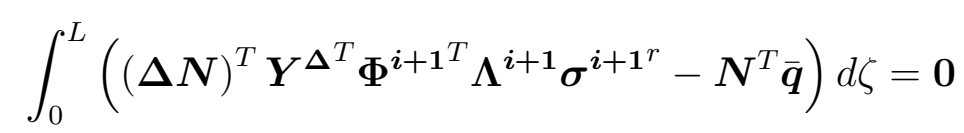

Com o objetivo de definir uma forma de estimar o erro presente ao não obedecer essa equação, é possível definir uma função denominada "função esforço desbalanceado" $\boldsymbol{g}_{\boldsymbol{f}}$. Essa função é definida por:

$$
\boldsymbol{g}_{\boldsymbol{f}}=\int_{0}^{L}\left((\boldsymbol{\Delta} \boldsymbol{N})^{T} \boldsymbol{Y}^{\boldsymbol{\Delta}^{T}} \boldsymbol{\Phi}^{\boldsymbol{i + 1} \mathbf{1}^{T}} \boldsymbol{\Lambda}^{\boldsymbol{i + 1}} \boldsymbol{\sigma}^{\boldsymbol{i + \mathbf { 1 } ^ { r }}}-\boldsymbol{N}^{T} \overline{\boldsymbol{q}}\right) d \zeta
$$

Deve-se impor que:

$$
g_{f}=0
$$

O problema que agora se propõe é determinar um campo de deslocamentos associado ao zero da função 4.183. Isso pode ser conseguido através do Método de NewtonRaphson. Para tal é necessário que se determine a discretização do operador tangente. Utilizando a equação 4.141 e aplicando a aproximação para o campo de deslocamentos feito com as funções de forma, denominando por $\boldsymbol{K}_{\boldsymbol{T}}$ o operador tangente discretizado, tem-se:

$$
\begin{aligned}
\boldsymbol{K}_{\boldsymbol{T}}= & \int_{0}^{L}\left[(\boldsymbol{\Delta} \boldsymbol{N})^{T} \boldsymbol{Y}^{\boldsymbol{\Delta}^{T}} \boldsymbol{\Phi}^{i+\mathbf{1}^{T}} \boldsymbol{\Lambda}^{\boldsymbol{i + 1}} \boldsymbol{D}^{\boldsymbol{r}} \boldsymbol{\Lambda}^{\boldsymbol{i + 1} \mathbf{1}^{T}} \boldsymbol{\Phi}^{i+\mathbf{1}} \boldsymbol{Y}^{\boldsymbol{\Delta}} \boldsymbol{\Delta} \boldsymbol{N}+\right. \\
& +(\boldsymbol{\Delta N})^{T} \boldsymbol{G}^{\boldsymbol{i + 1}}(\boldsymbol{\Delta} \boldsymbol{N})+ \\
& \left.-\boldsymbol{N}^{T} \boldsymbol{L}^{\boldsymbol{i + 1}} \boldsymbol{N}\right] d \zeta
\end{aligned}
$$

Aos três termos que surgem na discretização do operador tangente, se dão respectivamente os nomes de: contribuição constitutiva, contribuição geométrica e contribuição dos carregamentos. Todas essas contribuições são matrizes, doravante denominadas matrizes de rigidez constitutiva, geométrica e dos carregamentos. À soma dos três efeitos se dá simplesmente o nome de matriz de rigidez. 
Embora o presente modelo seja estático, conforme apresentado na equação 4.131 é possível estabelecer a variação virtual da energia cinética para utilização em critérios de estabilidade cinéticos, já discutidos no Capítulo 3. Aplicando-se a discretização de MEF a essa equação é possível obter:

$$
\delta T=\int_{0}^{L}\left(\boldsymbol{N}^{T} \boldsymbol{\Psi}^{i+1} \boldsymbol{N} \dot{\boldsymbol{p}}+\boldsymbol{N}^{T} \boldsymbol{\Upsilon}^{\boldsymbol{i + 1}} \boldsymbol{N} \ddot{\boldsymbol{p}}\right) \cdot \delta \boldsymbol{p} d \zeta
$$

Tomando-se a parcela da variação virtual da energia cinética proporcional à aceleração dos graus de liberdade, define-se a matriz de massa por:

$$
\boldsymbol{M}_{\boldsymbol{T}}=\int_{0}^{L} \boldsymbol{N}^{T} \boldsymbol{\Upsilon}^{\boldsymbol{i + 1}} \boldsymbol{N} d \zeta
$$

Note que as integrais que surgem no cálculo da matriz de rigidez e de massa são na variável $\zeta$, e não na variável $\xi$, utilizada para escrever as funções de forma em coordenadas naturais. Assim sendo, é necessário o uso do jacobiano para realizar a mudança de variável de integração corretamente.

\subsubsection{Integração numérica por Quadratura-Gaussiana}

Para realizar a integração no domínio de cada um dos elementos, a fim de obter suas matrizes de rigidez e de massa, além da função esforço desbalanceado, é necessário escolher um método numérico ou analítico. Devido ao grande número de integrações analíticas que seriam necessárias para realizar esse processo, opta-se por uma técnica de integração numérica. Dentre os diversos métodos de integração numérica, aquele que é o mais utilizado no contexto de elementos finitos é a Quadratura Gaussiana. Esse representa uma forma muito simples de realizar uma integração de um polinômio, uma vez o valor da integral é calculado como sendo um somatório de valores da função do integrando (calculada em alguns pontos específicos do domínio), ponderados por alguns pesos $p_{i}$, da seguinte forma:

$$
\int_{a}^{b} F(r) d r=p_{1} F\left(r_{1}\right)+p_{2} F\left(r_{2}\right)+\ldots+p_{n} F\left(r_{n}\right)+R_{n}
$$

Sendo $n$ o número de pontos utilizados (denominados Pontos de Gauss). O valor do resíduo $R_{n}$ é o resíduo da integração, que pode ou não ser nulo, dependendo da função 
do integrando e do número de pontos de Gauss utilizados. A escolha das posições dos pontos para integrações em coordenadas naturais pode ser vista, por exemplo, em Bathe (1996).

É possível determinar o número de pontos para realizar a integração de forma exata para polinômios de uma dada ordem, ou seja, impor que o resíduo $R_{n}$ seja nulo. No entanto, nem sempre a forma mais conveniente de se realizar a integração é com o número total de pontos. Pode ser interessante trabalhar com um número menor de pontos (integração reduzida), não obtendo a solução exata, porém muitas vezes com precisão aceitável, com significativo menor custo computacional.

Para a realização de uma integração reduzida em um domínio unidimensional em coordenadas naturais (para os elementos de viga aqui formulados), utilizando-se 2 pontos de Gauss (integração para o elemento de viga de 3 nós), pode-se escrever:

$$
\int_{-1}^{+1} F(r) d r \approx 1,0 F(-0,577350269189626)+1.0 F(+0,577350269189626)
$$

\subsubsection{Montagem da matriz de rigidez global da estrutura}

O cálculo das matrizes de rigidez e de massa apresentados anteriormente são referentes a um único elemento de viga. Para abordar um problema que seja formado por diversas vigas é necessário realizar um procedimento de montagem de uma matriz global, ou seja, da rigidez ou massa de todo o sistema a ser analisado. A composição do sistema pode ser feita com vários elementos de viga conectados entre si através dos nós. Os valores dos deslocamentos generalizados associados aos nós representam os graus de liberdade da estrutura. Para realizar a montagem das matrizes globais é necessário numerar os graus de liberdade globais e locais (de cada elemento). A relação entre a numeração global e local se dá através de uma tabela de conectividade. A Figura 4.10 ilustrada um exemplo de relação entre graus de liberdade locais e globais, bem como sua tabela de conectividade. 
(a) Esquema de numeração global

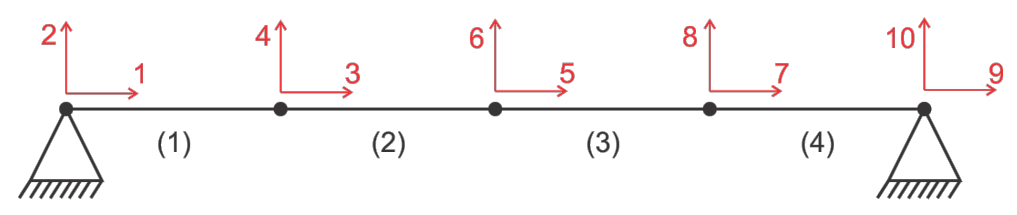

(b) Esquema de numeração local

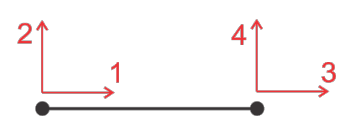

Figura 4.10: Exemplo de uma montagem com elementos de viga, conectados por nós. (a) Numeração global (b) Numeração local

Tabela 4.1: Tabela de conectividade ilustrando a relação entre os graus de liberdade (GL) locais e globais para cada elemento

\begin{tabular}{|c|c|c|c|c|}
\hline & Elemento (1) & Elemento (2) & Elemento (3) & Elemento (4) \\
\hline GL local 1 & 1 & 3 & 5 & 7 \\
\hline GL local 2 & 2 & 4 & 6 & 8 \\
\hline GL local 3 & 3 & 5 & 7 & 9 \\
\hline GL local 4 & 4 & 6 & 8 & 10 \\
\hline
\end{tabular}

Após construir essa tabela para o sistema composto pelos elementos, é necessário realizar a montagem das matrizes de rigidez e de massa e dos vetores de esforços globais. Para tal, basta agrupar as contribuições de cada um dos elementos, realizando a transcrição de numeração local para global, através da tabela de conectividade. Esse procedimento pode ser facilmente automatizado em termos computacionais, realizando uma varredura nas matrizes de cada um dos elementos, e preenchendo trechos da matriz e vetores globais com as contribuições individuais. No final, tem-se as matrizes do sistema, bem como os vetores de esforços do sistema, possibilitando a resolução do agrupamento de elementos de uma única vez, mantendo suas conexões e considerando seus acoplamentos.

\subsubsection{Método de Newton-Raphson}

Para determinação da solução dos deslocamentos nodais $\boldsymbol{p}$ pelo Método dos Elementos Finitos é necessário determinar o zero da função 4.183. Trata-se de uma função não linear em relação aos deslocamentos generalizados, uma vez que tanto os esforços externos, como internos, são funções não lineares em relação aos deslocamentos e rotações. O problema 
pode ser encarado como: dada a função $\boldsymbol{g}_{\boldsymbol{f}}$, qual o campo de deslocamentos que leva essa função ao vetor nulo, ou seja, qual o zero dessa função.

Um método numérico que pode ser utilizado para determinação de zeros de funções é o Método de Newton-Raphson. Existe uma simples interpretação geométrica sobre o método para um caso de funções de uma variável. A Figura 4.11 ilustra como ocorre a convergência, a partir de uma estimativa inicial de raiz $x_{1}$. Calcula-se o valor de $f\left(x_{1}\right)$ e posteriormente sua derivada também nesse ponto. Uma melhor aproximação para o valor do $x$ que corresponde ao zero da função pode ser determinada através da tangente (derivada da função), conforme a figura. O método, portanto, necessita do cálculo da derivada da função em todos os pontos $\left(x_{1}, x_{2}, x_{3}, \ldots\right)$ que forem aproximações da raiz, durante as iterações.

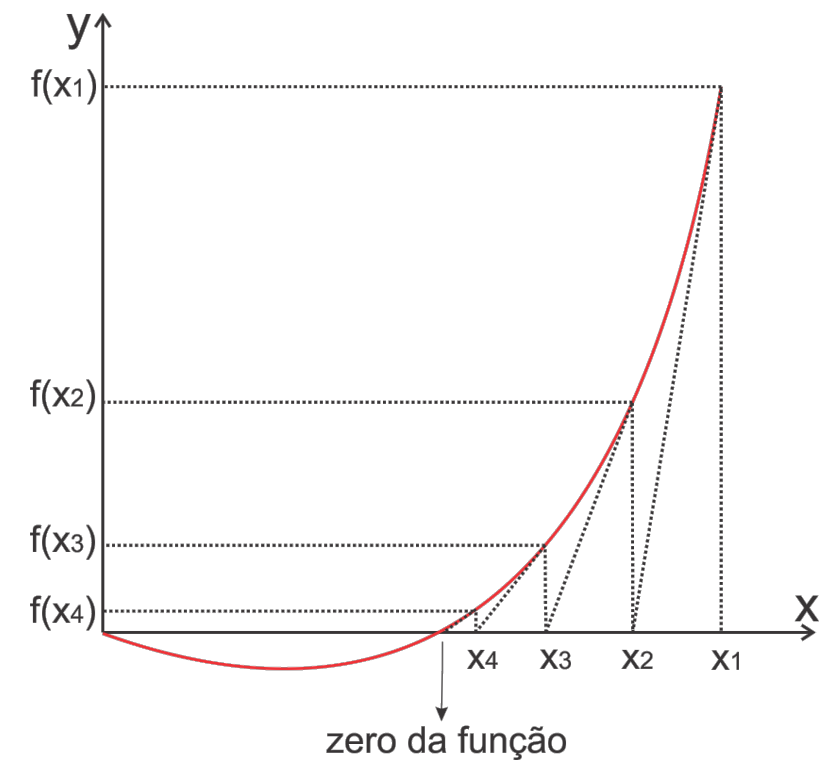

Figura 4.11: Método de Newton-Raphson (interpretação geométrica)

Como pode ser observado na Figura 4.11 o Método de Newton-Raphson utiliza-se a cada iteração de uma aproximação linear para a função. A ideia básica, portanto, é encontrar o zero de funções quaisquer por meio de aproximações lineares sucessivas.

É possível generalizar o método para funções vetoriais de ordem $N$, escritas em variáveis vetoriais, também de ordem $N$, conforme o procedimento mostrado em Gay Neto e Correia (2006). Nesse caso, continua valendo o raciocínio de aproximar uma função não linear em funções lineares a cada iteração.

Dada uma função do vetor $\boldsymbol{g}_{\boldsymbol{f}}(\boldsymbol{u})$ de $N$ variáveis, situada em um espaço de ordem $\mathrm{N}\left(\boldsymbol{g}_{\boldsymbol{f}}: \Re^{N} \rightarrow \Re^{N}\right)$, pode-se escrever a expansão de $\boldsymbol{g}_{\boldsymbol{f}}(\boldsymbol{u})$ utilizando-se a série de Taylor, 
em torno de um ponto genericamente chamado de $\boldsymbol{u}_{k}$. Essa função $\boldsymbol{g}_{\boldsymbol{f}}(\boldsymbol{u})$ para a aplicação aqui abordada é a função esforço desbalanceado.

$\boldsymbol{g}_{\boldsymbol{f}}(\boldsymbol{u})=\boldsymbol{g}_{\boldsymbol{f}}\left(\boldsymbol{u}_{\boldsymbol{k}}\right)+\left.\frac{\boldsymbol{d} \boldsymbol{g}_{\boldsymbol{f}}}{\boldsymbol{d u}}\right|_{\boldsymbol{u}_{\boldsymbol{k}}}\left(\boldsymbol{u}-\boldsymbol{u}_{\boldsymbol{k}}\right)+\left.\frac{1}{2 !} \frac{\boldsymbol{d}^{\mathbf{2}} \boldsymbol{g}_{\boldsymbol{f}}}{\boldsymbol{d} \boldsymbol{u}^{\mathbf{2}}}\right|_{\boldsymbol{u}_{\boldsymbol{k}}}\left(\boldsymbol{u}-\boldsymbol{u}_{\boldsymbol{k}}\right)^{2}+\left.\frac{1}{3 !} \frac{\boldsymbol{d}^{3} \boldsymbol{g}_{\boldsymbol{f}}}{\boldsymbol{d} \boldsymbol{u}^{\mathbf{3}}}\right|_{\boldsymbol{u}_{k}}\left(\boldsymbol{u}-\boldsymbol{u}_{\boldsymbol{k}}\right)^{3}+\boldsymbol{O}^{4}$

Seja $\overline{\boldsymbol{u}}$ o vetor que se deseja buscar, associado ao zero da função, representando um conjunto de deslocamentos nodais. Assim sendo, $\boldsymbol{g}_{\boldsymbol{f}}(\overline{\boldsymbol{u}})=\mathbf{0}$.

O Método de Newton para um espaço $N$-dimensional se propõe a apresentar uma metodologia para calcular, iterativamente, o valor do vetor $\overline{\boldsymbol{u}}$. Para conseguir uma fórmula de iteração, simplifica-se a expansão de Taylor para primeira ordem, e impõe-se que o valor de $\boldsymbol{g}_{\boldsymbol{f}}(\boldsymbol{u})$ seja identicamente nulo.

$$
\boldsymbol{g}_{f}\left(\boldsymbol{u}_{\boldsymbol{k}}\right)+\left.\frac{d \boldsymbol{g}_{f}}{d \boldsymbol{u}}\right|_{\boldsymbol{u}_{k}}\left(\boldsymbol{u}_{k+1}-\boldsymbol{u}_{\boldsymbol{k}}\right)=\mathbf{0}
$$

Na expressão 4.191 o vetor $\boldsymbol{u}_{\boldsymbol{k}+\mathbf{1}}$ representa uma aproximação de primeira ordem para o zero da função $\boldsymbol{g}_{\boldsymbol{f}}(\boldsymbol{u})$. É possível determiná-lo, desde que se conheçam os valores das componentes do vetor $\boldsymbol{u}_{k}$ em torno do qual se está expandindo a série, bem como o valor da derivada $\left.\frac{d \boldsymbol{g}_{\boldsymbol{f}}}{d \boldsymbol{u}}\right|_{\boldsymbol{u}_{\boldsymbol{k}}}$, que é uma matriz $N \times N$.

Se for tomada uma nova expansão de Taylor em torno do ponto $\boldsymbol{u}_{\boldsymbol{k}+\mathbf{1}}$ recém determinado, re-calculando-se o novo valor da derivada, desta vez em torno do ponto $\boldsymbol{u}_{\boldsymbol{k}+\mathbf{1}}$, é possível calcular uma aproximação mais precisa para o vetor $\overline{\boldsymbol{u}}$. Generalizando, pode-se escrever a fórmula iterativa para o cálculo da aproximação de $\overline{\boldsymbol{u}}$ :

$$
\boldsymbol{u}_{\boldsymbol{k}+\mathbf{1}}=\boldsymbol{u}_{\boldsymbol{k}}-\left(\left.\frac{d \boldsymbol{g}_{\boldsymbol{f}}}{d \boldsymbol{u}}\right|_{\boldsymbol{u}_{k}}\right)^{-1} \boldsymbol{g}_{\boldsymbol{f}}\left(\boldsymbol{u}_{\boldsymbol{k}}\right)
$$

Chamando o valor da derivada $\left.\frac{d \boldsymbol{g}_{\boldsymbol{f}}}{d \boldsymbol{u}}\right|_{\boldsymbol{u}_{k}}$ de $\boldsymbol{K}_{\boldsymbol{T}_{k}}$, e definindo um vetor:

$$
\Delta u_{k}=u_{k+1}-u_{k}
$$

Pode-se escrever a fórmula de recorrência de outra forma, mais prática do ponto 
de vista computacional:

$$
\begin{aligned}
& K_{T_{k}} \Delta u_{k}=-g_{f}\left(u_{k}\right) \\
& u_{k+1}=u_{k}+\Delta u_{k}
\end{aligned}
$$

Utilizando-se essa formulação, primeiro deve ser calculado o valor de $\boldsymbol{\Delta} \boldsymbol{u}_{\boldsymbol{k}}$ através da resolução de um sistema linear e depois se deve calcular o valor da nova aproximação do vetor $\overline{\boldsymbol{u}}$ da função $\boldsymbol{u}_{\boldsymbol{k}+\mathbf{1}}$, incrementando-se o valor da aproximação anterior $\boldsymbol{u}_{\boldsymbol{k}}$ com o vetor $\boldsymbol{\Delta} \boldsymbol{u}_{\boldsymbol{k}}$. Salienta-se que, apesar de trabalhar com deslocamentos e rotações como graus de liberdade do problema estrutural que se está resolvendo, no instante em que se escreve o Método de Newton-Raphson a atualização de toda e qualquer coordenada generalizada se dá simplesmente pela soma ao valor determinado na iteração anterior, independente da natureza dessa coordenada. Portanto, não é necessário modificar a atualização de diferentes naturezas de coordenadas generalizadas. O método irá convergir para a solução requerida da forma apresentada em 4.194.

O termo $\boldsymbol{K}_{\boldsymbol{T}_{\boldsymbol{k}}}$ representa a matriz de rigidez tangente, descrita de forma discretizada na equação 4.184. O vetor $\boldsymbol{\Delta} \boldsymbol{u}_{\boldsymbol{k}}$ é o vetor de deslocamentos que ocorre a cada iteração do método. É o resultado direto da resolução de um sistema linear, a cada iteração. O termo $\boldsymbol{u}_{\boldsymbol{k}}$ é o vetor que descreve o total de deslocamentos em cada grau de liberdade ocorrido até a iteração $k$. Esse vetor descreve os deslocamentos de todo o sistema, a partir das coordenada dos nós da configuração anteriormente convergida na descrição lagrangiana atualizada.

O Método de Newton-Raphson é computacionalmente bastante eficiente uma vez que, nas vizinhanças da solução, apresenta convergência quadrática (é possível realizar matematicamente essa demonstração, porém está fora do escopo desse texto). A grande maioria dos programas comerciais de elementos finitos utilizam-se do Método de NewtonRaphson para resolver o zero da função esforço desbalanceado, dada sua eficiência. Existem algumas restrições para a localização da estimativa inicial $\boldsymbol{u}_{\mathbf{1}}$, a fim de garantir a convergência. Essas restrições são definidas segundo o comportamento da função $\boldsymbol{g}_{\boldsymbol{f}}(\boldsymbol{u})$. Porém, para o problema de MEF não linear que está sendo resolvido, a função $\boldsymbol{g}_{\boldsymbol{f}}(\boldsymbol{u})$ não é conhecida a priori mas, somente sua derivada, em cada ponto de cálculo (matriz de rigidez tangente). Assim sendo, não há forma de se determinar a priori se haverá ou não convergência, dada uma estimativa inicial de deslocamentos. O raio de convergência do método seria uma região indicativa do quão longe pode estar o chute inicial da solu- 
ção requerida porém, de modo geral, não se pode determinar esse raio de convergência a priori. Portanto, o método de tentativa e erro acaba sendo inevitável para esse tipo de procedimento, embora possa ser automatizado e otimizado através de algumas técnicas discutidas no tópico 4.5.7.

\subsubsection{Condensação Estática}

Um problema de valor de contorno de mecânica estrutural pode ser dividido em duas regiões distintas do domínio:

A regiões onde os carregamentos são impostos, e decorrem os deslocamentos e rotações

B regiões onde os deslocamentos e rotações são impostos, e decorrem as reações vinculares

Os graus de liberdade de uma estrutura representam as possibilidades de movimento da mesma, ou seja, estão associados aos deslocamentos nodais. Restrições de movimento colaboram com a diminuição do número de graus de liberdade de uma estrutura. A fim de realizar um procedimento organizado para a montagem da matriz de rigidez do sistema, é possível que se realize a numeração dos graus de liberdade ignorando a existência de condições de contorno, como se todos os nós pudessem se mover em todas as direções. Assim sendo, pode-se utilizar a seguinte nomenclatura:

- grau de liberdade livre: aquele que possui de fato a liberdade de movimento na estrutura

- grau de liberdade fixo: aquele que não possui liberdade de movimento, mas foi considerado como um grau de liberdade pois ignoraram-se até o momento as condições de contorno do problema

Admite-se a ordem de numeração dos graus de liberdade tal que, primeiramente estejam os graus de liberdade livres e, posteriormente, os graus de liberdade fixos, ou seja, a região A seguida da região B. Dessa forma, é possível escrever, para cada iteração do Método de Newton-Raphson, a expressão 4.194 da seguinte forma:

$$
\left[\begin{array}{ll}
K_{T_{k A A}} & K_{T_{k A B}} \\
K_{T_{k B A}} & K_{T_{k B B}}
\end{array}\right]\left[\begin{array}{c}
\Delta u_{k A} \\
\Delta u_{k B}
\end{array}\right]=\left[\begin{array}{c}
-g_{f}\left(u_{k}\right)_{A} \\
-g_{f}\left(u_{k}\right)_{B}
\end{array}\right]
$$


A equação matricial 4.195 pode ser particionada em duas outras equações, da seguinte forma:

$$
\begin{aligned}
& K_{T_{k A A}} \Delta u_{k A}+K_{T_{k A B}} \Delta u_{k_{B}}=-g_{f}\left(u_{k}\right)_{A} \\
& K_{T_{k B A}} \Delta u_{k A}+K_{T_{k B B}} \Delta u_{k B}=-g_{f}\left(u_{k}\right)_{B}
\end{aligned}
$$

A primeira delas pode ser utilizada para a determinação do campo de deslocamentos $\boldsymbol{\Delta} \boldsymbol{u}_{\boldsymbol{k} \boldsymbol{A}}$, dada a função esforço desbalanceado nos graus de liberdade livres $\boldsymbol{g}_{\boldsymbol{f}}\left(\boldsymbol{u}_{\boldsymbol{k}}\right)_{\boldsymbol{A}}$. Uma vez resolvida essa equação, pode-se determinar o esforço desbalanceado nos graus de liberdade fixos $\boldsymbol{g}_{\boldsymbol{f}}\left(\boldsymbol{u}_{\boldsymbol{k}}\right)_{\boldsymbol{B}}$ através da segunda equação. Além da imposição de carregamentos, também é possível impor deslocamentos (ou rotações) nos graus de liberdade fixos da estrutura. Basta impor o vetor $\boldsymbol{\Delta} \boldsymbol{u}_{\boldsymbol{k} \boldsymbol{B}}$ não nulo.

Uma observação deve ser feita acerca da prescrição de deslocamentos ou rotações em um problema não linear: tal ação deve ser feita somente na primeira iteração do Método de Newton-Raphson. Após a prescrição do deslocamento, o sistema adquire esforços internos que nas iterações subsequentes procurarão se balancear com as reações vinculares surgidas nos pontos de imposição de deslocamentos. Isso não ocorre com a imposição de forças, as quais devem ser mantidas em todas as iterações até que haja convergência.

\subsubsection{Divisões de carregamentos}

Uma vez que o raio de convergência do Método de Newton-Raphson não pode ser determinado a priori para os casos práticos de análise estrutural, não se sabe se um certo valor de estimativa inicial de deslocamentos nodais irá convergir para a solução requerida. Porém, é possível trabalhar de formas mais convenientes para a convergência através da divisão do carregamento em passos. Por exemplo, a aplicação de uma carga pode ser feita de $10 \%$ em $10 \%$ de seu valor total. Dessa forma, tudo se passa como se 10 problemas fossem resolvidos sequencialmente, sendo que a estimativa inicial de cada problema é o resultado final do anterior. Essa abordagem de divisões de carregamentos pode ser utilizada na descrição lagrangiana atualizada, em que ao final de cada incremento é definida uma nova configuração " $i$ ". Essa técnica representa além de uma estratégia para facilitar a convergência, um ponto no qual serão armazenados os deslocamentos e rotações e serão salvos os esforços acumulados até a estrutura chegar no configuração " $i$ ". Dessa forma, para tirar proveito da descrição lagrangiana atualizada em situações de grandes rotações, 
é necessário que se utilizem divisões de carregamentos.

Essa ideia pode ser utilizada tanto para aplicação de carregamentos como para imposição de deslocamentos. Às divisões de um certo carregamento, dá-se o nome de sub-passos.

Além disso, é possível que em certos problemas se deseja impor alguns carregamentos ou deslocamentos em uma sequência pré-determinada. Por exemplo, primeiro impor um certo deslocamento para, posteriormente, aplicar uma força. Para realizar tal sequencia a abordagem de sub-passos não é suficiente. É necessário uma nova ideia, denominado passo. Assim, pode-se construir uma história de carregamentos para um dado problema, com diversos passos resolvidos sequencialmente. Cada passo pode ser dividido em alguns sub-passos para facilitar a sua convergência, dependendo do grau de não-linearidade encontrado na solução, ou da magnitude das rotações em cada um desses passos.

\subsubsection{Preditor e corretor de incrementos de carga}

A ideia de sub-passos exige certa experiência no problema a ser processado, uma vez que um número excessivo de sub-passos leva a tempos computacionais bastante elevados. No entanto, um número muito pequeno de sub-passos pode não ser suficiente para o alcance da convergência. Dessa forma, procurou-se desenvolver um método para predizer ou corrigir o número de sub-passos a serem aplicados em um dado passo. Para formalizar o procedimento, pode-se definir uma função tempo que representa o percentual do carregamento aplicado em um dado passo. Assim sendo, quando essa função atinge 100\% significa que o total do carregamento (ou deslocamento) foi aplicado. O incremento de carga é baseado no número de sub-passos escolhido. Porém, nem sempre em todo o decorrer da solução de um problema são encontradas as mesmas dificuldades de convergência. Assim, em algumas etapas é necessário utilizar-se de incrementos menores, para conseguir garantir convergência e, em outras, incrementos maiores, a fim de não desperdiçar tempo computacional.

Visando a construir um procedimento que prediz facilidade ou dificuldade de convergência, podem ser definidos alguns parâmetros, a fim de guiar o algoritmo para que realize os ajustes de incrementos de forma automática, dependendo da dificuldade de convergência encontrada. Para identificar dificuldade de convergência, os seguintes parâmetros são bastante úteis: 
- Número máximo de iterações: indica um certo número de iterações máximo que, quando atingido, indica que o método não está convergindo com facilidade

- Valor máximo de resíduo: indica um valor máximo para a norma da função esforço desbalanceado que, quando atingido, indica que o problema está com dificuldade de convergência

Quando alguma dessas condições é atingida durante a solução do problema, é necessário tomar-se uma mudança de incremento de carga. Isso pode ser dado por uma bissecção (dividir o incremento ao meio) ou, através de um outro fator de redução, diferente de 0,5 .

Já para analisar a facilidade de convergência, o seguinte parâmetro é bastante útil:

- Número mínimo de iterações: indica um certo número de iterações mínimo que, quando não atingido, indica que o método está convergindo com muita facilidade, possibilitando um aumento no incremento de carregamento ou deslocamento imposto

Quando isso ocorre, é interessante aumentar o incremento de carga de um certo fator, por exemplo 1,3 ou, de forma mais severa, 2,0.

Esse procedimento é muito importante para problemas práticos de configuração de riser, possibilitando a solução desses que, sem essas técnicas, seriam bastante demorados. Uma típica aplicação muito útil para tais estratégias é em problemas que apresentam contato, que representa uma não linearidade bastante importante em problemas práticos de risers em configuração de catenária ou lazy-wave, e será discutido a seguir.

\subsection{Contato em problemas de risers e elementos de contato}

Alguns tipos de configurações típicas de risers, como catenária e lazy-wave apresentam o problema de contato unilateral com o solo. Essas configurações apresentam uma porção do riser acomodado sobre o fundo do mar, estando sujeito, portanto, a esforços normais e tangenciais a essa superfície. A Figura 4.12 ilustra essas configurações, bem como um ponto de notável importância: o TDP. Esse ponto representa, para essas configurações 
típicas, a divisão entre a região do riser em contato com o solo, e a que não está em contato. Fisicamente o TDP possui grande importância na análise de risers pois representa uma transição entre curvaturas muito pequenas (parte que está sobre o solo - superfície tratada como plana) e curvaturas muito elevadas (parte que está suspensa próxima ao solo).

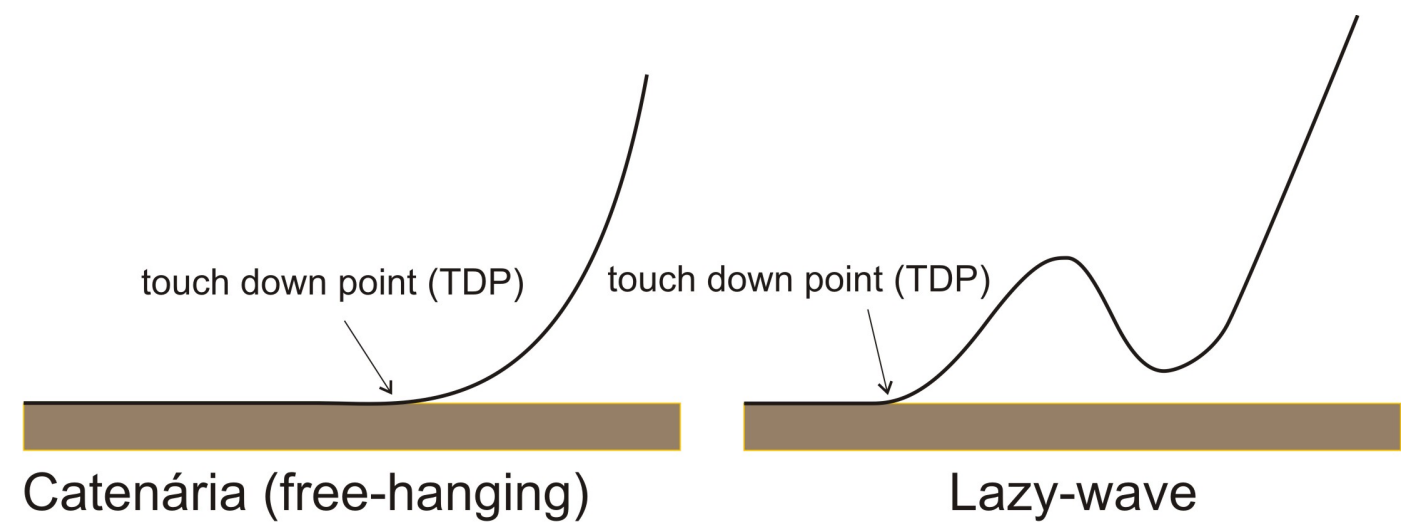

Figura 4.12: Configurações de riser nas formas de catenária e de lazy-wave ilustrando seus TDPs.

Para a análise desses tipos de configuração de riser, a posição do TDP não é conhecida a priori. O campo de velocidades da correnteza marítima, por exemplo, pode afetar sensivelmente a posição do TDP. Devido a essas características, o contato entre o riser e o solo deve ser tratado como uma inequação no problema, impondo que a região do solo não deve ser invadida pela elastica do riser. A forma de realizar essa restrição é um assunto bastante vasto, sendo detalhado em muitos trabalhos. Um exemplo de referência bastante abrangente sobre o assunto "Contato Computacional" é o livro de Wriggers (2002). Essa obra notável aborda detalhadamente os algoritmos para imposição desse tipo de restrição, indicando diversas outras referências sobre o assunto, bem como discussões comparativas entre os métodos apresentados.

\subsubsection{Cinemática do contato}

Para realizar a imposição de uma restrição do tipo "contato", geralmente se definem duas superfícies no espaço, correspondentes às possíveis interfaces de contato: superfície master e superfície slave. A superfície slave é descrita através de diversos pontos. Quanto mais pontos, melhor sua descrição. Já a superfície master geralmente não é tratada com pontos, mas através da composição de um conjunto de regiões curvas ou planas no espaço. Para definir a restrição cinemática de contato, impõe-se que os pontos representativos da superfície slave não possam invadir a região cujo contorno é dado pela superfície master. 


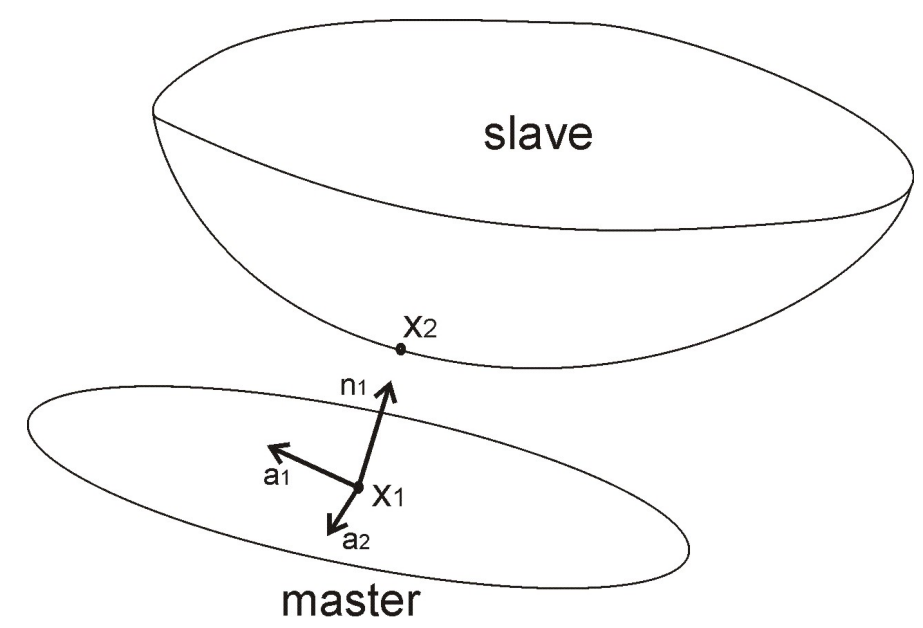

Figura 4.13: Descrição das superfícies master e slave para definir o par de contato

A Figura 4.13 ilustra ambas as regiões. Uma vez definidos os pontos da superfície slave (na figura existe apenas um ponto representado), é possível, para cada ponto cuja posição é dada por um vetor posição $\boldsymbol{x}_{2}$, determinar qual o ponto da superfície master que está mais próximo de $\boldsymbol{x}_{\mathbf{2}}$. A posição desse ponto é dada pelo vetor $\boldsymbol{x}_{\mathbf{1}}$. Sendo $\boldsymbol{n}_{\mathbf{1}}$ a direção da normal à superfície master no ponto $\boldsymbol{x}_{\mathbf{1}}$, é possível definir a seguinte restrição matemática, que deverá ser obedecida para todos os pontos da superfície slave:

$$
\left(x_{2}-x_{1}\right) \cdot n_{1} \geq 0
$$

Se faz conveniente a definição de uma função gap normal $g_{N}$ para verificar a obediência ou não dessa restrição. Dessa forma:

$$
g_{N}=\left(\boldsymbol{x}_{\mathbf{2}}-\boldsymbol{x}_{\mathbf{1}}\right) \cdot \boldsymbol{n}_{\mathbf{1}}
$$

A função $g_{N}$ deve ser necessariamente maior ou igual a zero, para todos os pontos da superfície slave. Se ela se tornar negativa para algum desses pontos, fisicamente significa que houve penetração desse ponto na região master, o que não é permitido e deverá ser tratado posteriormente. A função $g_{N}$ pode ser classificada como gap na direção normal, uma vez que representa uma projeção de um vetor na direção $\boldsymbol{n}_{\mathbf{1}}$. No entanto, o estudo de movimentos tangenciais no contato é também bastante importante, principalmente na caracterização de problemas que envolvam atrito. Quando se deseja estudar a existência ou não do deslizamento em pontos de contato é necessário definir uma nova função gap, 
dessa vez vetorial:

$$
g=x_{2}-x_{1}
$$

A projeção da função $g$ na direção de $\boldsymbol{n}_{\mathbf{1}}$ é a própria função $g_{N}$. Para estudar o comportamento tangencial, pode-se definir dois vetores $\boldsymbol{a}_{\mathbf{1}}$ e $\boldsymbol{a}_{\mathbf{2}}$ ortogonais entre si que são tangenciais à superfície master em cada ponto $\boldsymbol{x}_{\boldsymbol{1}}$ (vide Figura 4.13). As projeções da função $\boldsymbol{g}$ nas direções $\boldsymbol{a}_{\mathbf{1}}$ e $\boldsymbol{a}_{\mathbf{2}}$ representam as componentes de movimento tangencial do ponto da superfície slave sobre a superfície master, da seguinte forma:

$$
\begin{aligned}
& g_{a 1}=\boldsymbol{g} \cdot \boldsymbol{a}_{\mathbf{1}}=\left(\boldsymbol{x}_{\mathbf{2}}-\boldsymbol{x}_{\mathbf{1}}\right) \cdot \boldsymbol{a}_{\mathbf{1}} \\
& g_{a 2}=\boldsymbol{g} \cdot \boldsymbol{a}_{\mathbf{2}}=\left(\boldsymbol{x}_{\mathbf{2}}-\boldsymbol{x}_{\mathbf{1}}\right) \cdot \boldsymbol{a}_{\mathbf{2}}
\end{aligned}
$$

É possível combinar os efeitos em ambas as direções tangenciais, definindo outra forma de função gap cuja norma é dada por $g_{T}=\sqrt{g_{a 1}^{2}+g_{a 2}^{2}}$ e pode ser escrita na forma vetorial por:

$$
\boldsymbol{g}_{\boldsymbol{T}}=g_{a 1} \boldsymbol{a}_{\mathbf{1}}+g_{a 2} \boldsymbol{a}_{\mathbf{2}}
$$

A restrição tangencial de contato deve ser aplicada sob duas condições típicas: deslizamento (sliding) ou não deslizamento (sticking). Não entrando no mérito de modelos de atrito, mas atentando-se apenas à cinemática do contato tangencial, a condição de não deslizamento é descrita através da seguinte restrição: $g_{a 1}=0$ e $g_{a 2}=0$. A condição de deslizamento permite valores não nulos dos gaps tangenciais.

A ocorrência de deslizamento é conceitualmente bem mais complicada de ser tratada do que o não deslizamento, uma vez que a força de atrito nessa condição depende da trajetória realizada pelos pontos slave sobre a superfície master. Assim, as direções das forças de atrito dependem de hipóteses feitas acerca do histórico de movimento realizado. Quase estaticamente, isso pode ser feito através da hipótese acerca dos pontos de contato iniciais entre o riser e o solo no momento do lançamento. 


\subsubsection{Leis constitutivas de contato na direção normal}

O comportamento do contato tanto na direção normal quanto nas direções tangenciais definidas anteriormente obedece algumas leis constitutivas. Essas leis descrevem o comportamento dos deslocamentos nessas direções, em função da força mecanicamente solicitada entre as partes que compõem o par de contato. Em primeiro lugar, para a direção normal, o comportamento "ideal" é dado por uma condição bastante brusca: não se permite um gap negativo (penetração). Um gap nulo representa uma situação de singularidade em que qualquer magnitude solicitada de força normal poderia ser trocada no par de contato. Essa condição idealiza o contato, forçando inter-penetração nula. No entanto, existem outras formas de abordar o problema. Fisicamente, é possível que haja, dependendo do valor da pressão de contato, uma diferente penetração de uma superfície em outra, devida a acomodações das asperezas presentes nas superfícies reais de contato. Esse comportamento pode ser descrito através de uma Compliance law. Exemplos dessas equações podem ser vistos em Wriggers (2002). Para tratamento numérico, utilizando-se o Método das Penalidades, é possível descrever de forma aproximada um comportamento constitutivo do contato na direção normal através de uma aproximação linear, da seguinte forma:

$$
f_{N}=\epsilon_{N} g_{N}
$$

Na expressão 4.202 o valor de $\epsilon_{N}$ escolhido regula a taxa de aumento da força normal, em função da penetração no contato. Quanto maior seu valor, menor será a penetração que ocorrerá na solução do problema. A Figura 4.14 ilustra as três formas descritas para o comportamento constitutivo na direção normal. 


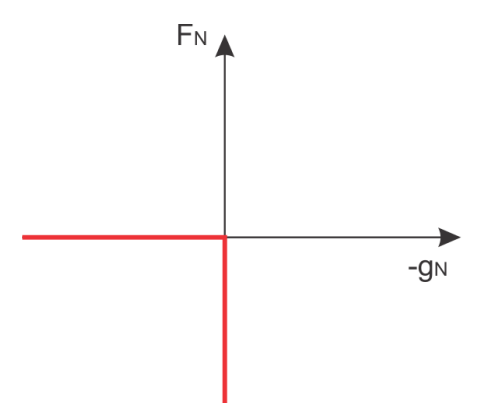

(a)

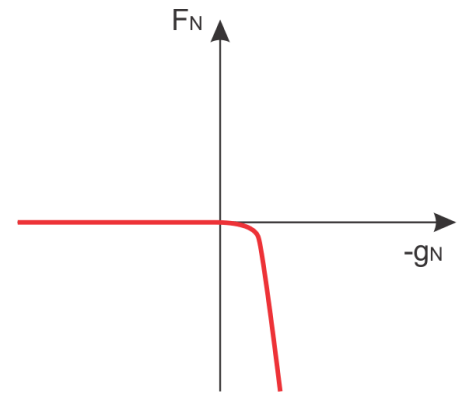

(b)

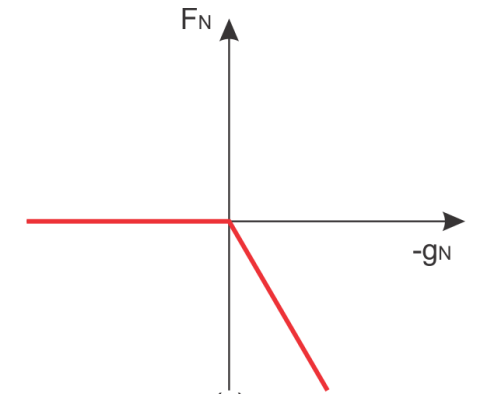

(c)

Figura 4.14: Leis constitutivas para o comportamento do contato na direção normal. (a) Idealização da restrição normal (b) Utilização de uma Compliance law (c) Utilização do Método das Penalidades

O Método das Penalidades aqui utilizado é uma opção bastante interessante para a inclusão de contato em um modelo de elementos finitos, sem grandes alterações na estrutura do código programado, uma vez que não envolve a determinação de equações adicionais, mas somente a contribuição de rigidez e das forças de contato em situações que violem os vínculos impostos. A desvantagem desse método é que sempre existirá alguma inter-penetração no contato, porém essa diminui à medida que se aumenta o valor de $\epsilon_{N}$. O valor escolhido desse parâmetro, denominado "rigidez de contato", pode possuir significado físico quando é buscada uma aproximação de uma Compliance law. Pode, entretanto, ter simplesmente um significado numérico. A rigidez de contato introduz certa relaxação ao problema, a fim de facilitar a convergência para a solução em situações como a mostrada na Figura 4.14 (a).

\subsubsection{Lei constitutiva de contato na direção tangencial (atrito)}

O comportamento na direção tangencial procura reproduzir os fenômenos de atrito existentes em uma interface de contato. Fenômenos de atrito podem ser difíceis de modelar, uma vez que são fisicamente descritos essencialmente através do tratamento das micro asperezas dos dois materiais em contato. O nível de rugosidade, a pressão de contato na interface, bem como a velocidade de deslizamento relativo podem influenciar significativamente no valor da força de atrito. Um modelo bastante utilizado para considerar o atrito em simulações computacionais é o Modelo de Coulomb (WRIGGERS, 2002). A Figura 4.15 ilustra o comportamento da função gap tangencial e as consequentes forças de atrito que surgem. 


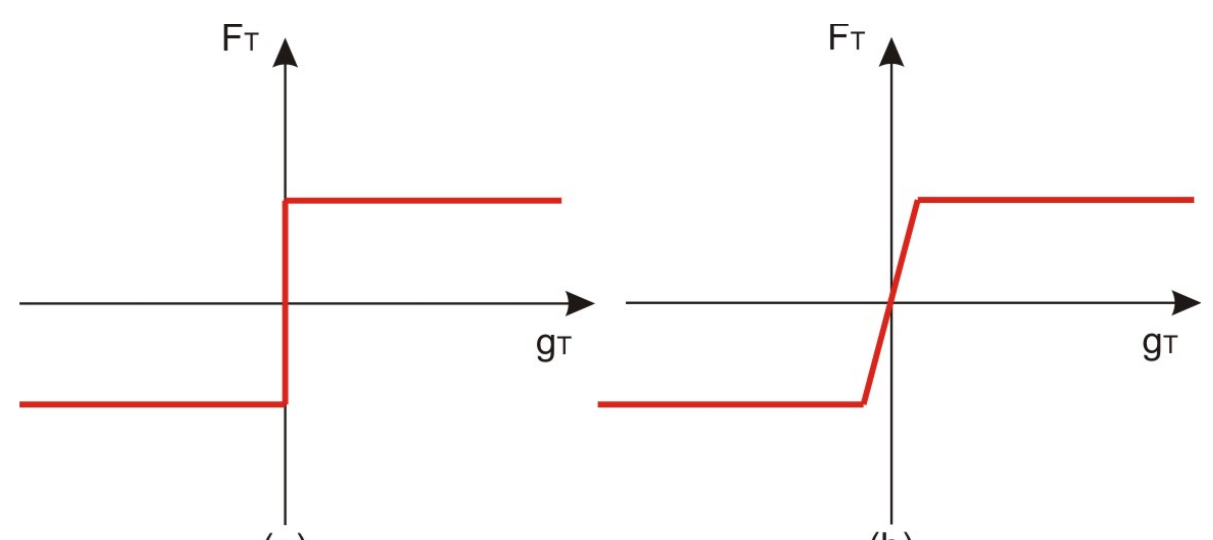

(a)

(b)

Figura 4.15: Leis constitutivas para o comportamento do contato na direção tangencial. (a) Lei de Coulomb (b) Lei de Coulomb modificada por um parâmetro de penalidade tangencial

Note que quando a função gap tangencial for nula, correspondendo a uma situação de não-escorregamento, o valor solicitado da força de atrito possui um limite. Após tal limite ser atingido, a norma da força de atrito se mantém constante, para qualquer variação no gap tangencial. Uma forma de escrever essa condição com uma única expressão matemática, é a seguinte:

$$
f_{T} \leq \mu f_{N}
$$

Em que:

- $f_{T}$ representa a norma da força de atrito;

- $f_{N}$ representa a norma da componente normal da força de contato;

- $\mu$ representa o coeficiente de atrito no contato.

Novamente a utilização do Método das Penalidades pode ser feita, agora para a situação de não-escorregamento, relaxando a condição de Coulomb. A Figura 4.15 (b) ilustra essa relaxação. Assim sendo, para a situação de não-escorregamento pode-se escrever:

$$
\boldsymbol{f}_{\boldsymbol{T}}=\epsilon_{T} \boldsymbol{g}_{\boldsymbol{T}}
$$


Para quando ocorrer escorregamento, é possível escrever o vetor força de atrito como sendo:

$$
\boldsymbol{f}_{\boldsymbol{T}}=\mu\left|f_{N}\right| \frac{\dot{\boldsymbol{g}_{\boldsymbol{T}}}}{\left\|\dot{\boldsymbol{g}_{\boldsymbol{T}}}\right\|}
$$

A expressão 4.205 mostra que a direção da força de atrito, quando há deslizamento, depende da direção instantânea da variação temporal da função gap tangencial. Isso mostra que a distribuição das forças de atrito é dependente do histórico do movimento existente na região de contato. Quando o efeito do atrito é inserido em um modelo dinâmico, no domínio do tempo, é necessário re-calcular a cada passo de tempo a direção da força de atrito, dado o movimento instantâneo de cada ponto afetado por essa força. Já a solução de um modelo estático pode admitir mais de uma solução, dependendo da ordem de imposição de carregamentos inseridos. Uma forma de particularizar a solução é se fazer uma hipótese acerca da trajetória feita pelos pontos contidos na região do domínio afetada pelo atrito.

\subsubsection{Linha de lançamento e atrito entre riser e o solo}

Para tornar única a solução do modelo estático é definida a chamada linha de lançamento do riser, como sendo aquela que contém os pontos iniciais de contato entre o riser e o solo. É admitido que, quando há deslizamento, o riser se desloca através de uma trajetória conhecida, definindo a direção da força de atrito. Uma alternativa à essa hipótese seria calcular a direção do atrito assim como em um modelo dinâmico, através da direção do vetor deslocamento de cada ponto afetado pelo atrito a cada sub-step. Esse procedimento pode se tornar impreciso quando forem aplicados poucos sub-steps, que não consigam descrever bem a história do movimento. Por isso foi adotada a primeira forma aqui explicada para a descrição da direção do atrito na região de deslizamento, mais precisamente através de uma hipótese de trajetória retilínea

Através dessa hipótese, o problema fica bem definido, possibilitando a particularização para uma solução de interesse prático. A Figura 4.16 ilustra essa hipótese e, como é esperada a distribuição qualitativa vetorial do campo de forças de atrito sobre o riser, na porção que sofre deslizamento sobre o solo. 


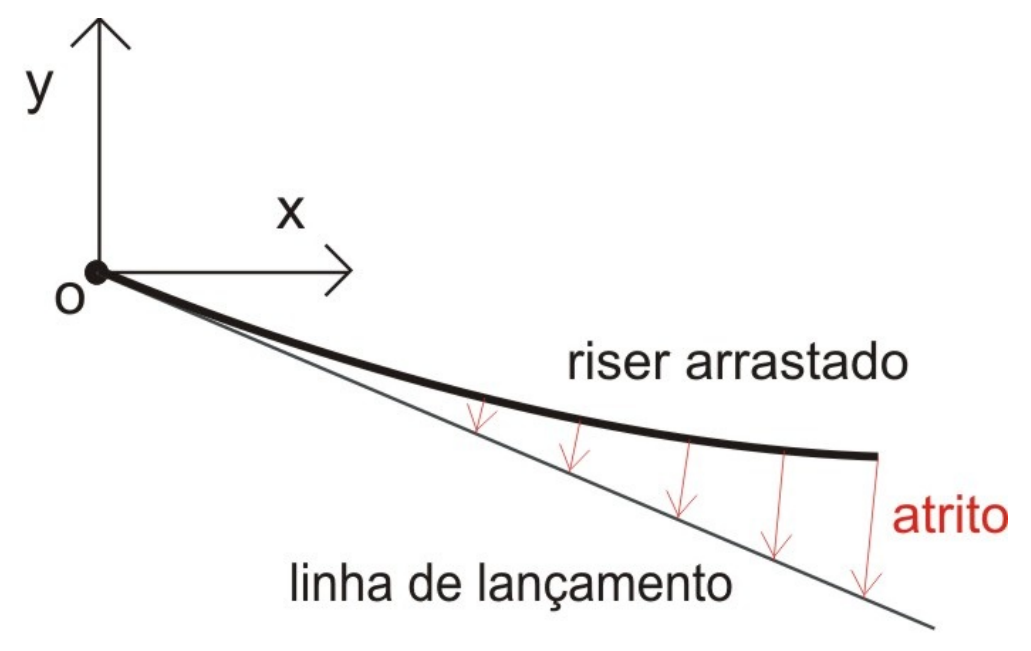

Figura 4.16: Campo de forças de atrito entre o riser e o solo na região de deslizamento para o modelo estático

\subsubsection{Elemento de contato entre o riser e o solo}

Para considerar o contato entre riser e solo, os mesmos nós presentes nos elementos de viga que representam o riser são considerados como pontos slave para detecção de contato. O solo do fundo do mar é tratado como uma superfície plana, horizontal e invariante durante a solução do problema.

Nessa seção é exibida a formulação desenvolvida para um elemento de contato do tipo nó-superfície, sendo a superfície sempre fixa e a posição do nó podendo variar livremente, com pequenos ou grandes deslocamentos. A Figura 4.17 ilustra o elemento de contato formulado. Para representar a equação constitutiva do contato, foram utilizados os comportamentos ilustrados anteriormente e o Método das Penalidades.

\section{slave $x_{2}$}

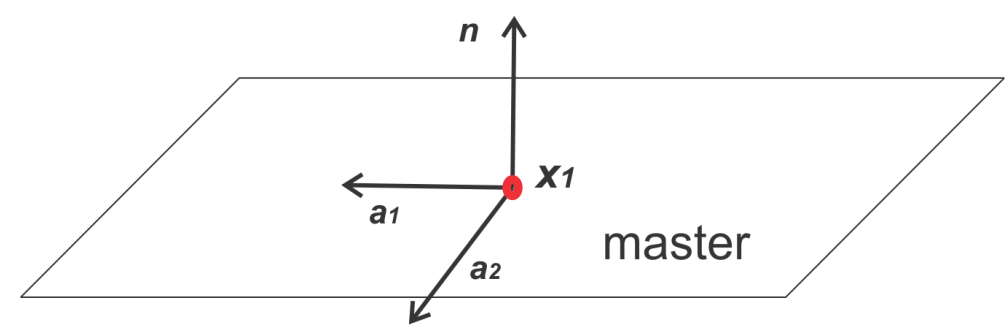

Figura 4.17: Elemento de contato com um nó slave e uma região plana definida como master 
Para saber a contribuição do elemento de contato em termos de esforços e de rigidez é necessário escrever o trabalho virtual referente às forças de contato $\delta W_{C}$ em função do gap existente entre o nó slave, cuja posição é $\boldsymbol{x}_{2}$ e sua projeção no plano que define o solo do fundo do mar, cuja posição é $\boldsymbol{x}_{\mathbf{1}}{ }^{10}$. Supõe-se que a região de contato $\Gamma_{C}$ entre o riser e o solo seja conhecida para uma certa iteração do Método de Newton-Raphson (isso não representa nenhuma perda de generalidade, uma vez que no início de cada iteração do Método de Newton-Raphson é possível realizar uma varredura e identificar quais as regiões em que ocorre contato). Assim sendo, pode-se calcular a função gap nessa situação para cada nó slave, procurando identificar seus esforços e contribuição de rigidez. Sendo $\boldsymbol{t}_{\boldsymbol{T}}$ o vetor que representa a tensão de cisalhamento na interface de contato e $A_{i}$ a área de influência de cada nó slave, pode-se escrever a seguinte expressão para o trabalho virtual das forças envolvidas:

$$
\delta W_{C}=\int_{\Gamma_{C}}\left(\epsilon_{N} g_{N} \delta g_{N}+\boldsymbol{t}_{\boldsymbol{T}} \cdot \delta \boldsymbol{g}_{\boldsymbol{T}}\right) d \Gamma \approx \sum_{i=1}^{N_{\text {slave }}}\left(\epsilon_{N} g_{N} \delta g_{N} A_{i}+\boldsymbol{t}_{\boldsymbol{T}} \cdot \delta \boldsymbol{g}_{\boldsymbol{T}} A_{i}\right)
$$

É possível escrever uma expressão para a variação da função gap em cada direção, utilizando-se da posição do ponto slave $\boldsymbol{x}_{2}$ e de sua projeção na superfície master $\boldsymbol{x}_{\mathbf{1}}$ :

$$
\begin{aligned}
& \delta g_{a 1}=\delta\left(\boldsymbol{x}_{\mathbf{2}}-\boldsymbol{x}_{\mathbf{1}}\right) \cdot \boldsymbol{a}_{\mathbf{1}}+\left(\boldsymbol{x}_{\mathbf{2}}-\boldsymbol{x}_{\mathbf{1}}\right) \cdot \delta \boldsymbol{a}_{\mathbf{1}} \\
& \delta g_{a 2}=\delta\left(\boldsymbol{x}_{\mathbf{2}}-\boldsymbol{x}_{\mathbf{1}}\right) \cdot \boldsymbol{a}_{\mathbf{2}}+\left(\boldsymbol{x}_{\mathbf{2}}-\boldsymbol{x}_{\mathbf{1}}\right) \cdot \delta \boldsymbol{a}_{\mathbf{2}} \\
& \delta g_{n}=\delta\left(\boldsymbol{x}_{\mathbf{2}}-\boldsymbol{x}_{\mathbf{1}}\right) \cdot \boldsymbol{n}+\left(\boldsymbol{x}_{\mathbf{2}}-\boldsymbol{x}_{\mathbf{1}}\right) \cdot \delta \boldsymbol{n}
\end{aligned}
$$

As expressões 4.207 podem ser simplificadas assumindo-se que a direção normal e as direções tangenciais são constantes. Assim, chega-se em expressões importantes utilizadas na dedução dos esforços do contato, bem como para sua contribuição para o operador tangente:

$$
\begin{aligned}
& \delta g_{a 1}=\left(\delta \boldsymbol{x}_{\mathbf{2}}-\delta \boldsymbol{x}_{\mathbf{1}}\right) \cdot \boldsymbol{a}_{\mathbf{1}} \\
& \delta g_{a 2}=\left(\delta \boldsymbol{x}_{\mathbf{2}}-\delta \boldsymbol{x}_{\mathbf{1}}\right) \cdot \boldsymbol{a}_{\mathbf{2}} \\
& \delta g_{n}=\left(\delta \boldsymbol{x}_{\mathbf{2}}-\delta \boldsymbol{x}_{\mathbf{1}}\right) \cdot \boldsymbol{n}
\end{aligned}
$$

\footnotetext{
${ }^{10} \mathrm{O}$ trabalho virtual dos esforços de contato entra como contribuição na definição da função esforço desbalanceado 4.183, bem como sua derivada de Fréchet, contribui com o operador tangente discretizado.
} 
O trabalho virtual dos esforços de contato na direção normal $\delta W_{C i}^{N}$ de um único elemento de contato, ou seja, para um único nó slave, é dado por:

$$
\delta W_{C i}^{N}=\epsilon_{N} g_{N} \delta g_{N}=\epsilon_{N} g_{N} A_{i}\left[\begin{array}{ll}
\delta \boldsymbol{x}_{\mathbf{2}}{ }^{T} & \delta \boldsymbol{x}_{\mathbf{1}}{ }^{T}
\end{array}\right]\left[\begin{array}{r}
\boldsymbol{n} \\
-\boldsymbol{n}
\end{array}\right]
$$

A variação da equação 4.207 leva à contribuição da direção normal das forças de contato ao operador tangente. Assim, tem-se:

$$
\delta\left(\delta W_{C i}^{N}\right)=\epsilon_{N} A_{i}\left[\begin{array}{ll}
\delta \boldsymbol{x}_{\mathbf{2}}^{T} & \delta \boldsymbol{x}_{\mathbf{1}}^{T}
\end{array}\right]\left[\begin{array}{r}
\boldsymbol{n} \\
-\boldsymbol{n}
\end{array}\right]\left[\begin{array}{ll}
\boldsymbol{n}^{T} & -\boldsymbol{n}^{T}
\end{array}\right]\left[\begin{array}{l}
\delta \boldsymbol{x}_{\mathbf{2}} \\
\delta \boldsymbol{x}_{\mathbf{1}}
\end{array}\right]
$$

O operador tangente é dado por:

$$
\boldsymbol{K}_{\boldsymbol{C} \boldsymbol{i}}^{\boldsymbol{N}}=\epsilon_{N} A_{i}\left[\begin{array}{r}
\boldsymbol{n} \\
-\boldsymbol{n}
\end{array}\right]\left[\begin{array}{ll}
\boldsymbol{n}^{T} & -\boldsymbol{n}^{T}
\end{array}\right]
$$

Focando-se agora no comportamento tangencial para a situação de não-deslizamento (sticking), utilizando-se do Método das Penalidades através da relação $\boldsymbol{t}_{\boldsymbol{T}}=\epsilon_{T} \boldsymbol{g}_{\boldsymbol{T}}$ é possível calcular o trabalho virtual dos esforços de contato na direção tangencial para a situação de não deslizamento:

$$
\left(\delta W_{C i}^{T}\right)_{\text {sticking }}=\epsilon_{T} A_{i} \boldsymbol{g}_{\boldsymbol{T}} \cdot \delta \boldsymbol{g}_{\boldsymbol{T}}
$$

Após manipulações algébricas é possível obter:

$$
\left(\delta W_{\text {Cs }}^{T}\right)_{\text {sticking }}=\epsilon_{T} A_{i}\left[\begin{array}{ll}
\delta \boldsymbol{x}_{\mathbf{2}}^{T} & \delta \boldsymbol{x}_{\mathbf{1}}^{T}
\end{array}\right]\left(g_{a 1}\left[\begin{array}{r}
\boldsymbol{a}_{\mathbf{1}} \\
-\boldsymbol{a}_{\mathbf{1}}
\end{array}\right]+g_{a 2}\left[\begin{array}{r}
\boldsymbol{a}_{\mathbf{2}} \\
-\boldsymbol{a}_{\mathbf{2}}
\end{array}\right]\right)
$$

A variação da equação 4.213 leva à contribuição ao operador tangente das forças tangenciais na situação de não deslizamento: 


$$
\begin{aligned}
& \delta\left(\delta W_{C s}^{T}\right)_{\text {sticking }}= \\
& \epsilon_{T} A_{i}\left[\begin{array}{ll}
\delta \boldsymbol{x}_{\mathbf{2}}^{T} & \delta \boldsymbol{x}_{\mathbf{1}}^{T}
\end{array}\right]\left(\left[\begin{array}{r}
\boldsymbol{a}_{\mathbf{1}} \\
-\boldsymbol{a}_{\mathbf{1}}
\end{array}\right]\left[\begin{array}{ll}
\boldsymbol{a}_{\mathbf{1}}^{T} & -\boldsymbol{a}_{\mathbf{1}}^{T}
\end{array}\right]+\left[\begin{array}{r}
\boldsymbol{a}_{\mathbf{2}} \\
-\boldsymbol{a}_{\mathbf{2}}
\end{array}\right]\left[\begin{array}{ll}
\boldsymbol{a}_{\mathbf{2}}^{T} & -\boldsymbol{a}_{\mathbf{2}}^{T}
\end{array}\right]\right)\left[\begin{array}{l}
\delta \boldsymbol{x}_{\mathbf{2}} \\
\delta \boldsymbol{x}_{\mathbf{1}}
\end{array}\right]
\end{aligned}
$$

Logo, o operador tangente é dado por:

$$
\left(\boldsymbol{K}_{\boldsymbol{C i}}^{\boldsymbol{T}}\right)_{\text {sticking }}=\epsilon_{T} A_{i}\left(\left[\begin{array}{r}
\boldsymbol{a}_{\mathbf{1}} \\
-\boldsymbol{a}_{\mathbf{1}}
\end{array}\right]\left[\begin{array}{ll}
\boldsymbol{a}_{\mathbf{1}}^{T} & -\boldsymbol{a}_{\mathbf{1}}^{T}
\end{array}\right]+\left[\begin{array}{r}
\boldsymbol{a}_{\mathbf{2}} \\
-\boldsymbol{a}_{\mathbf{2}}
\end{array}\right]\left[\begin{array}{ll}
\boldsymbol{a}_{\mathbf{2}}{ }^{T} & -\boldsymbol{a}_{\mathbf{2}}{ }^{T}
\end{array}\right]\right)
$$

De maneira análoga é possível definir a força de contato bem como o operador tangente do elemento de contato para o caso em que ocorre deslizamento. No entanto, para essa situação é necessário definir um vetor que represente a direção de deslizamento que ocorre no problema, uma vez que essa será a direção da solicitação do atrito. Esse vetor pode ser obtido por hipótese como o vetor deslocamento do ponto slave de interesse da posição de sua origem na linha de lançamento (tido como o ponto em que se iniciou o contato com o solo) e sua posição atual. Define-se o versor direção de deslizamento $\boldsymbol{n}_{\boldsymbol{T}}$ cujas componentes nas direções tangenciais $\boldsymbol{a}_{\mathbf{1}}$ e $\boldsymbol{a}_{\mathbf{2}}$ são dadas respectivamente por $n_{T 1}$ e $n_{T 2}$.

$$
\boldsymbol{n}_{\boldsymbol{T}}=n_{T 1} \boldsymbol{a}_{\mathbf{1}}+n_{T 2} \boldsymbol{a}_{\mathbf{2}}
$$

Sendo $\mu$ o coeficiente de atrito entre o riser e o solo e $p_{N}$ a pressão de contato em um dado elemento de contato $i$, é possível escrever o vetor tensão de cisalhamento atuante no par de contato por:

$$
\boldsymbol{t}_{\boldsymbol{T}}=\mu p_{N} \boldsymbol{n}_{\boldsymbol{T}}
$$

Utilizando-se da expressão 4.217 é possível escrever a expressão para o cálculo do trabalho virtual do atrito de deslizamento: 


$$
\left(\delta W_{C i}^{T}\right)_{\text {sliding }}=\mu p_{N} A_{i} \cdot \delta \boldsymbol{g}_{\boldsymbol{T}}
$$

Após manipulações algébricas é possível obter:

$$
\left(\delta W_{C s}^{T}\right)_{\text {sliding }}=\mu p_{N} A_{i}\left[\delta \boldsymbol{x}_{\mathbf{2}}^{T} \quad \delta \boldsymbol{x}_{\mathbf{1}}^{T}\right]\left(n_{T 1}\left[\begin{array}{r}
\boldsymbol{a}_{\mathbf{1}} \\
-\boldsymbol{a}_{\mathbf{1}}
\end{array}\right]+n_{T 2}\left[\begin{array}{r}
\boldsymbol{a}_{\mathbf{2}} \\
-\boldsymbol{a}_{\mathbf{2}}
\end{array}\right]\right)
$$

A variação da expressão 4.219 é dada por dois termos:

$$
\delta\left(\delta W_{C s}^{T}\right)_{\text {sliding }}=\boldsymbol{c}_{\mathbf{1}}+\boldsymbol{c}_{\mathbf{2}}
$$

Em que:

$$
\boldsymbol{c}_{\mathbf{1}}=\mu \delta p_{N} A_{i}\left[\delta \boldsymbol{x}_{\mathbf{2}}^{T} \quad \delta \boldsymbol{x}_{\mathbf{1}}^{T}\right]\left(n_{T 1}\left[\begin{array}{r}
\boldsymbol{a}_{\mathbf{1}} \\
-\boldsymbol{a}_{\mathbf{1}}
\end{array}\right]+n_{T 2}\left[\begin{array}{r}
\boldsymbol{a}_{\mathbf{2}} \\
-\boldsymbol{a}_{\mathbf{2}}
\end{array}\right]\right)
$$

e

$$
\boldsymbol{c}_{\mathbf{2}}=\mu p_{N} A_{i}\left[\delta \boldsymbol{x}_{\mathbf{2}}^{T} \quad \delta \boldsymbol{x}_{\mathbf{1}}^{T}\right]\left(\delta n_{T 1}\left[\begin{array}{r}
\boldsymbol{a}_{\mathbf{1}} \\
-\boldsymbol{a}_{\mathbf{1}}
\end{array}\right]+\delta n_{T 2}\left[\begin{array}{r}
\boldsymbol{a}_{\mathbf{2}} \\
-\boldsymbol{a}_{\mathbf{2}}
\end{array}\right]\right)
$$

A pressão de contato pode ser calculada através da função gap normal, de tal forma que: $p_{N}=-\epsilon_{N} g_{N}$. Logo, $\delta p_{N}=-\epsilon_{N} \delta g_{N}$. Assim, o termo $\boldsymbol{c}_{1}$ é dado por:

$$
\boldsymbol{c}_{\mathbf{1}}=-\mu A_{i} \epsilon_{N}\left[\delta \boldsymbol{x}_{\mathbf{2}}^{T} \quad \delta \boldsymbol{x}_{\mathbf{1}}^{T}\right]\left(n_{T 1}\left[\begin{array}{r}
\boldsymbol{a}_{\mathbf{1}} \\
-\boldsymbol{a}_{\mathbf{1}}
\end{array}\right]+n_{T 2}\left[\begin{array}{r}
\boldsymbol{a}_{\mathbf{2}} \\
-\boldsymbol{a}_{\mathbf{2}}
\end{array}\right]\right)\left[\begin{array}{ll}
\boldsymbol{n}^{T} & -\boldsymbol{n}^{T}
\end{array}\right]\left[\begin{array}{l}
\delta \boldsymbol{x}_{\mathbf{2}} \\
\delta \boldsymbol{x}_{\mathbf{1}}
\end{array}\right]
$$

O termo $\boldsymbol{c}_{\mathbf{2}}$ envolve o cálculo de $\delta n_{T 1}$ e $\delta n_{T 2}$. Para tal, é possível escrever: 


$$
\begin{aligned}
& \delta n_{T 1}=\boldsymbol{a}_{\mathbf{1}} \cdot \delta \boldsymbol{n}_{\boldsymbol{T}} \\
& \delta n_{T 2}=\boldsymbol{a}_{\mathbf{2}} \cdot \delta \boldsymbol{n}_{\boldsymbol{T}}
\end{aligned}
$$

Logo, é necessário calcular $\delta \boldsymbol{n}_{\boldsymbol{T}}$. A variação desse versor é dependente da direção instantânea da força de atrito. Pode-se escrever que:

$$
n_{T}=\frac{t_{T}}{\left\|t_{T}\right\|}
$$

Desenvolvendo o diferencial da expressão 4.225, obtém-se:

$$
\delta \boldsymbol{n}_{\boldsymbol{T}}=\frac{\delta \boldsymbol{t}_{\boldsymbol{T}}\left\|\boldsymbol{t}_{\boldsymbol{T}}\right\|-\boldsymbol{t}_{\boldsymbol{T}} \delta\left\|\boldsymbol{t}_{\boldsymbol{T}}\right\|}{\left\|\boldsymbol{t}_{\boldsymbol{T}}\right\|^{2}}=\frac{1}{\left\|\boldsymbol{t}_{\boldsymbol{T}}\right\|}\left(\boldsymbol{I}-\boldsymbol{n}_{\boldsymbol{T}} \boldsymbol{n}_{\boldsymbol{T}}^{T}\right) \delta \boldsymbol{t}_{\boldsymbol{T}}
$$

É necessário fazer uma hipótese acerca da variação da tensão cisalhante $\delta \boldsymbol{t}_{\boldsymbol{T}}$. A Figura 4.15 apresenta relações entre a força de atrito e o valor da função gap. Note que, uma vez ocorrido o deslizamento, a curva de descarregamento será paralela à de carregamento. Isso significa que ao final de uma situação de deslizamento, ocorrerá novamente uma situação de não deslizamento (sticking), quando houver descarregamento. Quando ocorre deslizamento na região de contato, a variação da força de atrito fica indefinida, uma vez que se está exatamente em um ponto não derivável do gráfico representado na Figura 4.15. A contribuição de rigidez do contato deslizante devida à variação da força de atrito pode ser nula, para variação no sentido de continuar realizando o deslizamento, e não nula, no sentido de haver não escorregamento. Assume-se a partir desse ponto que a derivada é tomada com seu valor não nulo, isto é, $\delta \boldsymbol{t}_{\boldsymbol{T}}=\epsilon_{T} \delta \boldsymbol{g}_{\boldsymbol{T}}$. Com base nessa hipótese, o termo $\boldsymbol{c}_{\mathbf{2}}$ pode ser expresso por:

$$
\boldsymbol{c}_{\mathbf{2}}=\epsilon_{T} A_{i}\left[\begin{array}{ll}
\delta \boldsymbol{x}_{\mathbf{2}}^{T} & \delta \boldsymbol{x}_{\mathbf{1}}^{T}
\end{array}\right] \sum_{\alpha=1}^{2} \sum_{\beta=1}^{2}\left(\delta_{\alpha \beta}-n_{T \alpha} n_{T \beta}\right)\left[\begin{array}{r}
\boldsymbol{a}_{\boldsymbol{\alpha}} \\
-\boldsymbol{a}_{\boldsymbol{\alpha}}
\end{array}\right]\left[\begin{array}{ll}
\boldsymbol{a}_{\boldsymbol{\beta}}^{T} & -\boldsymbol{a}_{\boldsymbol{\beta}}^{T}
\end{array}\right]\left[\begin{array}{l}
\delta \boldsymbol{x}_{\mathbf{2}} \\
\delta \boldsymbol{x}_{\mathbf{1}}
\end{array}\right]
$$

Portanto, escrevendo a parcela dos esforços de atrito do operador tangente para o contato com deslizamento, tem-se a seguinte expressão: 


$$
\begin{aligned}
\left(\boldsymbol{K}_{\boldsymbol{C i}}^{\boldsymbol{T}}\right)_{\text {sliding }}= & -\mu A_{i} \epsilon_{N}\left(n_{T 1}\left[\begin{array}{r}
\boldsymbol{a}_{\mathbf{1}} \\
-\boldsymbol{a}_{\mathbf{1}}
\end{array}\right]+n_{T 2}\left[\begin{array}{r}
\boldsymbol{a}_{\mathbf{2}} \\
-\boldsymbol{a}_{\mathbf{2}}
\end{array}\right]\right)\left[\begin{array}{ll}
\boldsymbol{n}^{T} & -\boldsymbol{n}^{T}
\end{array}\right]+(4.228) \\
& +\epsilon_{T} A_{i} \sum_{\alpha=1}^{2} \sum_{\beta=1}^{2}\left(\delta_{\alpha \beta}-n_{T \alpha} n_{T \beta}\right)\left[\begin{array}{r}
\boldsymbol{a}_{\boldsymbol{\alpha}} \\
-\boldsymbol{a}_{\boldsymbol{\alpha}}
\end{array}\right]\left[\begin{array}{ll}
\boldsymbol{a}_{\boldsymbol{\beta}}^{T} & -\boldsymbol{a}_{\boldsymbol{\beta}}^{T}
\end{array}\right]
\end{aligned}
$$

Note que esse operador não é simétrico, pois o atrito apresenta papel dissipativo na situação em que ocorre deslizamento. 


\section{RESULTADOS E ANÁLISES}

Esse capítulo ilustra a aplicação computacional da teoria apresentada nos capítulos anteriores. Para tal, foi desenvolvido um código implementando o MEF não linear para resolução de modelos de vigas. A teoria estrutural vista no Capítulo 4 foi utilizada, bem como os métodos de avaliação de estabilidade, vistos no Capítulo 3. O presente capítulo mostra os resultados de simulações realizadas e suas análises.

\subsection{O código FEMCABLE}

O código gerado durante esse trabalho acabou por se transformar em um solver de elementos finitos que utiliza elementos de vigas, desenvolvido utilizando-se a linguagem $\mathrm{C}++$. Desenvolveram-se rotinas próprias para alocação de matrizes quadrada e de banda, bem como para montagem de matrizes locais e globais presentes no MEF. As rotinas matemáticas utilizadas para resolução de sistemas lineares estão na biblioteca Intel Math Kernel Library $(\mathrm{MKL})^{\mathrm{TM}}$ que é uma compilação de funções da biblioteca LAPACK ${ }^{\mathrm{TM}}$. Para a extração de autovalores, utilizou-se a biblioteca ARPACK ${ }^{\mathrm{TM}}$ que implementa o Método de Arnoldi, podendo ser utilizado tanto para matrizes simétricas e não-simétricas. Isso foi necessário, uma vez que as presentes análises de estabilidade foram feitas tanto para sistemas conservativos como para sistemas não conservativos, que apresentam matrizes não-simétricas.

Em todos os resultados aqui mostrados foi utilizada a aproximação de solução dada por elementos de viga de três nós, com interpolação quadrática e com integração utilizando-se dois pontos de Gauss, conforme foi mostrado no Capítulo 4.

O nome dado ao código desenvolvido é "FEMCABLE". Esse nome será referenciado nos resultados comparativos com outros programas, quando for necessário identificar sua solução em meio à de outro programa. 


\subsection{Análises estáticas de risers - verificação dos mo- delos}

O objetivo dessa seção é mostrar as verificações que foram feitas no código FEMCABLE. Para isso, compararam-se os resultados obtidos com os de pacotes comerciais já existentes no mercado para alguns estudos de caso típicos. Como ferramentas de comparação utilizaram-se os pacotes comerciais de elementos finitos ANSYS $^{\text {TM }}$, ABAQUS ${ }^{\text {TM }}$ e ainda o software ORCAFLEX ${ }^{\mathrm{TM}}$, especializado na solução de análises globais de risers.

\subsubsection{Caso 1}

O caso 1 trata de uma configuração de um riser em catenária fictício, com suas propriedades arbitradas somente para teste do código desenvolvido. É assumindo que a estrutura não se encontra imersa em água do mar. As características do modelo estão descritas a seguir, nas tabelas 5.1 e 5.2 .

Tabela 5.1: Dados do Caso 1 - Riser

\begin{tabular}{|c|c|}
\hline Comprimento $(L)$ & $1.600 \mathrm{~m}$ \\
Rigidez axial $(E A)$ & $700.000 .000 \mathrm{~N}$ \\
Rigidez flexional $(E I)$ & $120.000 \mathrm{Nm}^{2}$ \\
Rigidez à torção $(G J)$ & $80.000 \mathrm{Nm}^{2}$ \\
Rigidez ao cisalhamento $(G A)$ & $233.333 .333 \mathrm{~N}$ \\
Massa por unidade de comprimento $(\rho)$ & $81,9 \mathrm{~kg} / \mathrm{m}$ \\
Diâmetro externo $(D)$ & $0,06 \mathrm{~m}$ \\
\hline
\end{tabular}

Tabela 5.2: Dados do Caso 1 - Riser com o ambiente

\begin{tabular}{|c|c|}
\hline Aceleração da gravidade $(\boldsymbol{g})$ & $-9,81 \boldsymbol{k}\left[\mathrm{m} / \mathrm{s}^{2}\right]$ \\
Cota do solo retilíneo & $z=0 \mathrm{~m}$ \\
Cota de fixação do riser na superfície (posição da plataforma) & $z=1000 \mathrm{~m}$ \\
Projeção horizontal do riser no solo & $800 \mathrm{~m}$ \\
Coeficiente de atrito entre o riser e o solo $(\mu)$ & 0 \\
\hline
\end{tabular}

\subsubsection{Estratégia de solução}

A configuração de referência considerada é um riser retilíneo alinhado com o eixo $X$ global. Para a consideração do contato entre o riser e o solo foi utilizado o parâmetro de 
penalidade $\epsilon_{n}=1.000 .000$ e, como não foi considerado atrito, $\epsilon_{t}=0$. Esse conjunto de parâmetros garantiu uma penetração muito pequena no solo, em relação às dimensões do modelo resolvido.

A solução do problema foi feita através de três passos de carregamento, sequencialmente considerados da seguinte forma:

1. Fixação da origem do riser (âncora) e imposição de deslocamento em $Z$ da outra extremidade para a cota da plataforma, a fim de tracionar a estrutura, fazendo-a adquirir rigidez geométrica.

2. Inserção do carregamento do peso próprio na estrutura, pré tensionada no passo 1.

3. Alívio da tração da estrutura, feito através da imposição de um deslocamento na direção $X$ à extremidade do riser oposta à âncora, até que sua projeção horizontal chegue exatamente no valor imposto para o modelo. Durante esse passo ocorre o contato entre o riser e o solo, apresentando algumas dificuldades para convergência. No entanto, a utilização da técnica de passo auto-adaptativo apresentada no Capítulo 4 auxiliou nessas dificuldades, possibilitando a solução do modelo. Durante as iterações que envolvem a interação de contato entre o riser e o solo ocorre o maior custo computacional da solução desse modelo. Isso foi identificado não somente no código FEMCABLE, mas também no código ANSYS ${ }^{\mathrm{TM}}$, utilizado para comparação dos resultados.

\subsubsection{Resultados}

A Figura 5.1 mostra a perspectiva da configuração final do riser após sua simulação no software ANSYS ${ }^{\mathrm{TM}}$.

Os gráficos seguintes ilustram a comparação feita entre as soluções dos códigos ANSYS $^{\mathrm{TM}}$, ORCAFLEX ${ }^{\mathrm{TM}}$ e FEMCABLE para resultados relevantes para o modelo em questão: 


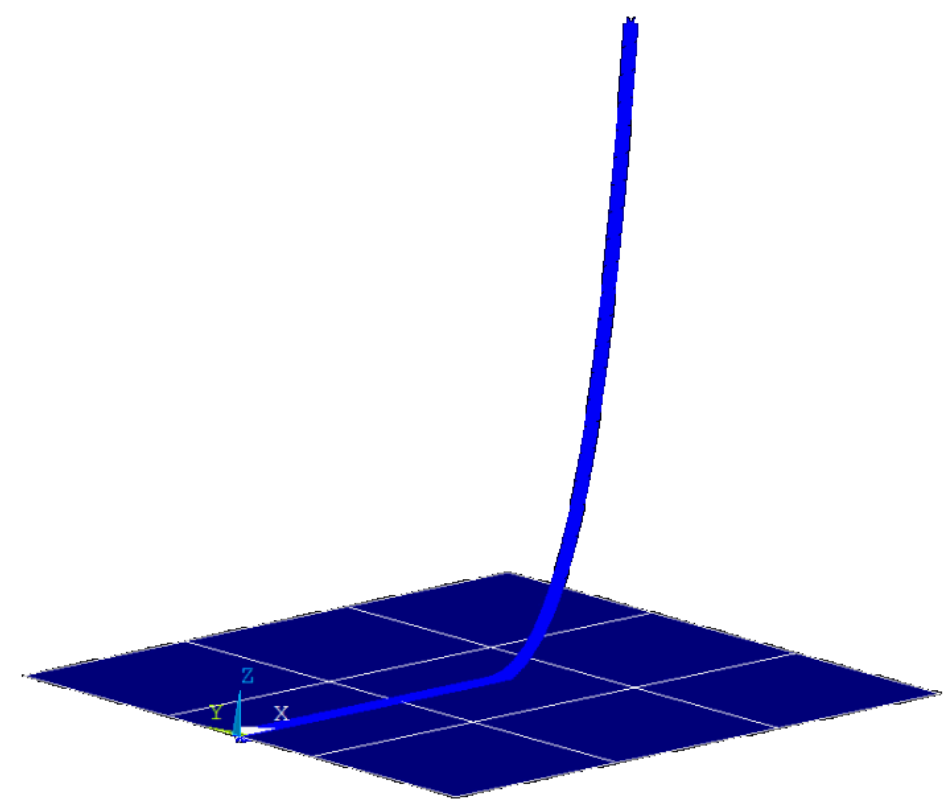

Figura 5.1: Perspectiva do riser em catenária simulado através do software ANSYS

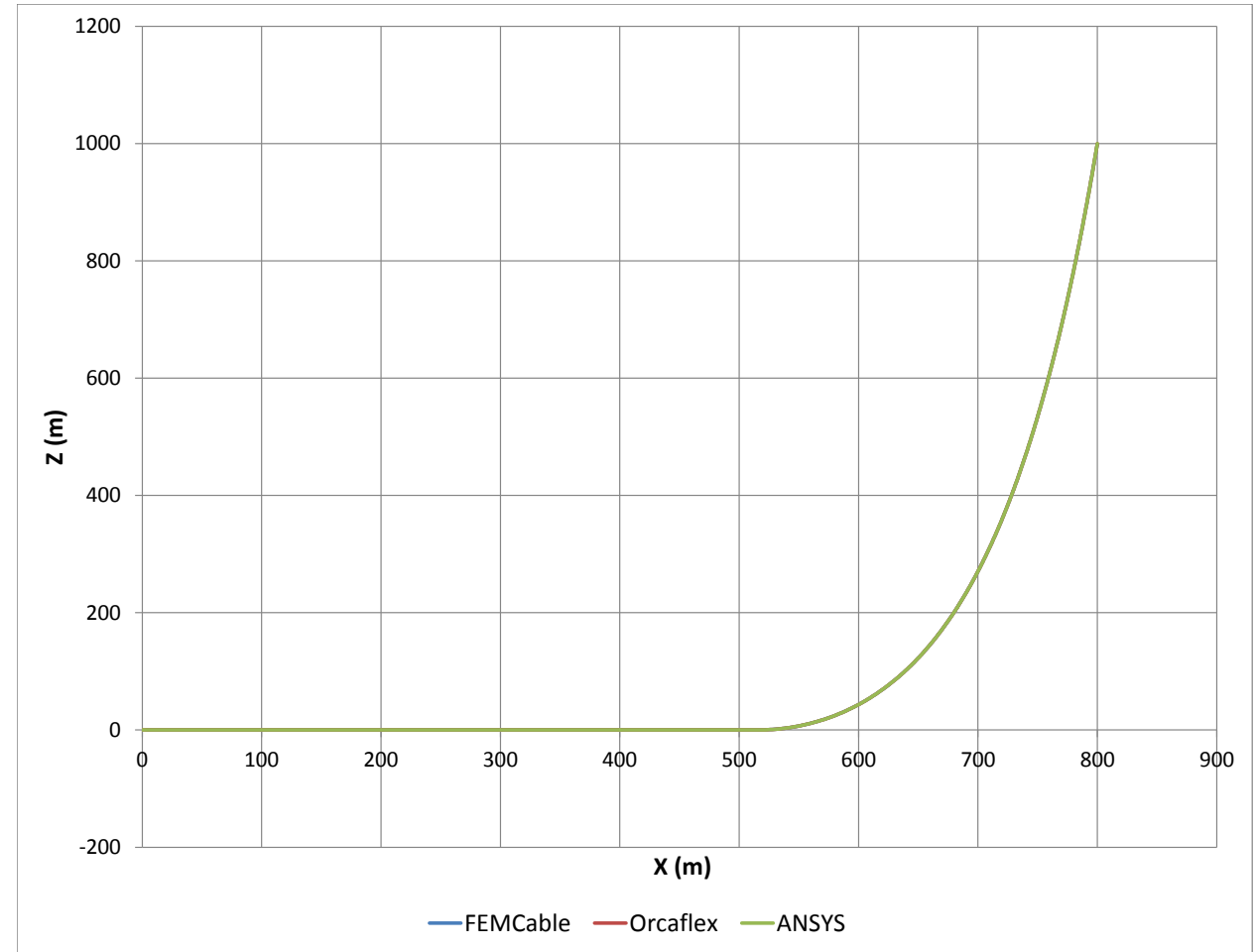

Figura 5.2: Elastica do riser em catenária - vista do plano XZ (Caso 1) 


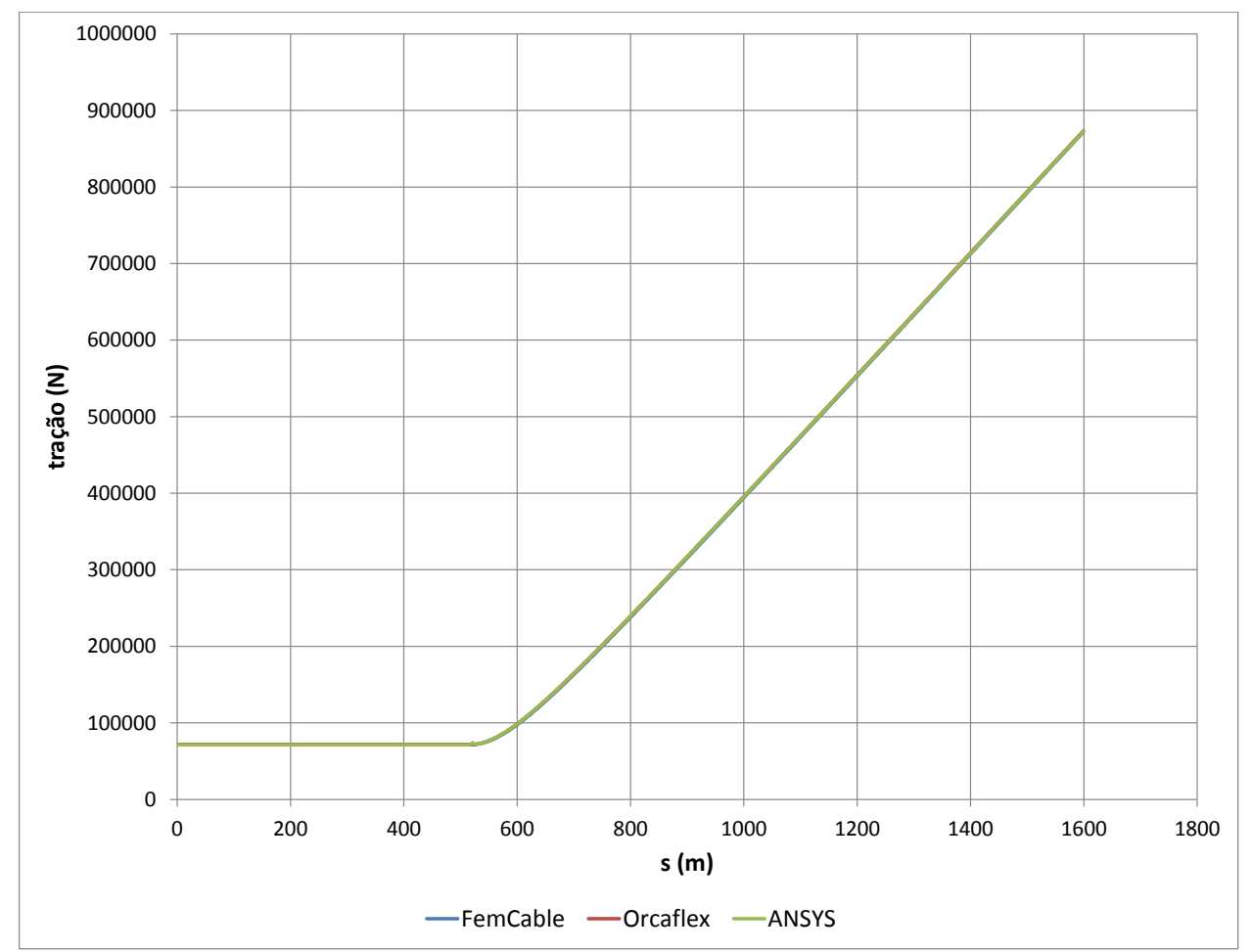

Figura 5.3: Tração no riser em função da abscissa curvilínea indeformada $s$ (Caso 1)

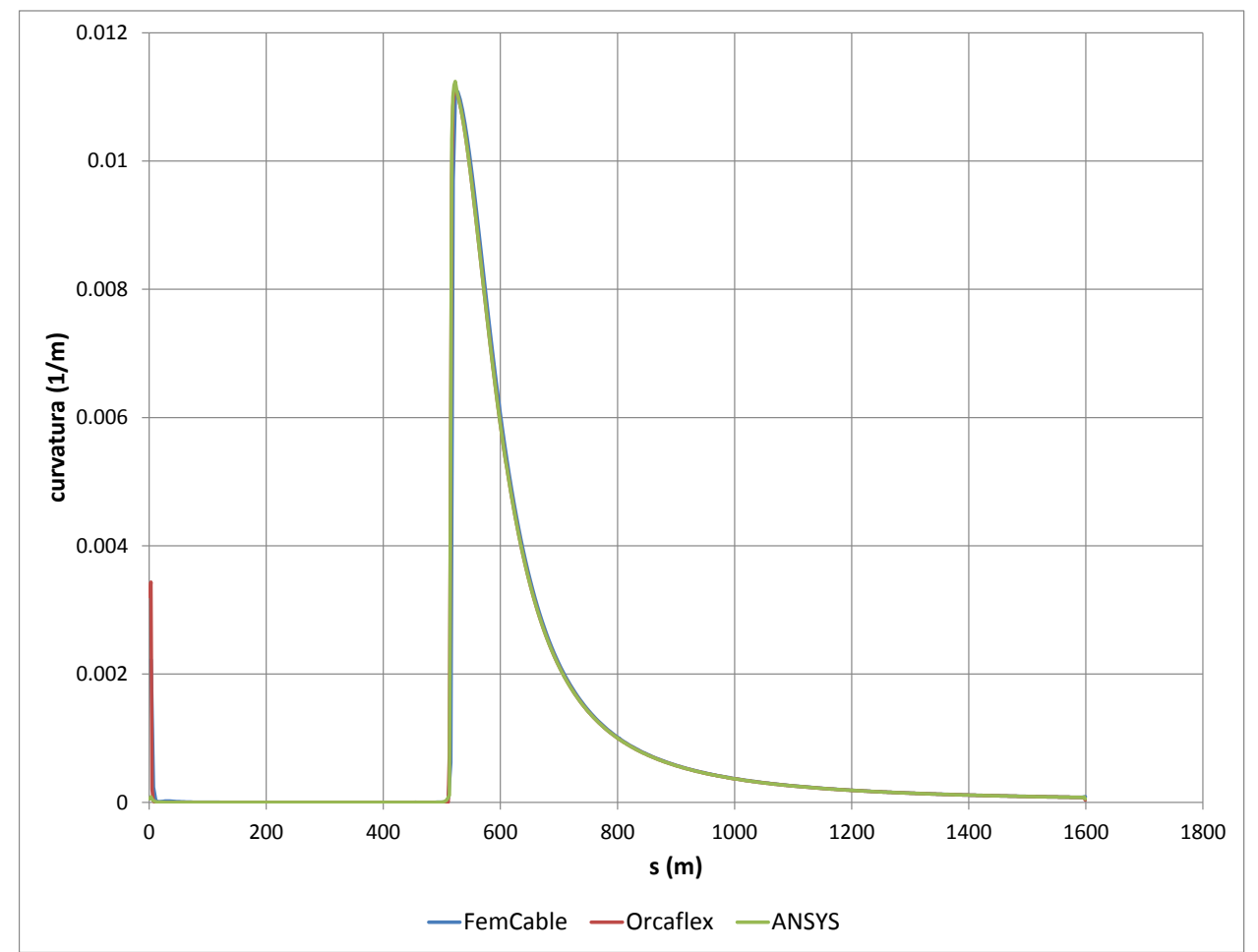

Figura 5.4: Curvatura no riser em função da abscissa curvilínea indeformada $s$ (Caso 1)

Os três gráficos ilustram uma excelente correlação entre os três códigos testados. 
A Figura 5.2 mostra as elasticas obtidas, praticamente superpostas. A tração, na Figura 5.3 também apresenta comportamento semelhante, enquanto alguma diferença muito pequena é identificada entre o três resultados no pico da curvatura (Figura 5.4). Ainda salienta-se que em todos os códigos surge uma singularidade de alta curvatura na origem, em função da condição de engastamento considerada nessa posição. Um pequeno deslocamento vertical devido à flexibilidade do solo causa esse pico de curvatura.

\subsubsection{Caso 2}

O caso 2 trata uma configuração de tubo rígido em catenária não imerso em água. As características condizem com a de um tubo de aço de 16 polegadas de diâmetro externo, com 1 polegada de espessura. As características da análise estão detalhadas nas tabelas 5.3 e 5.4 .

Tabela 5.3: Dados do Caso 2 - Riser

\begin{tabular}{|c|c|}
\hline Comprimento $(L)$ & $1.600 \mathrm{~m}$ \\
Rigidez axial $(E A)$ & $6.080 .489 .749 \mathrm{~N}$ \\
Rigidez flexional $(E I)$ & $110.821 .607,7 \mathrm{Nm}^{2}$ \\
Rigidez à torção $(G J)$ & $85.247 .390,5 \mathrm{Nm}^{2}$ \\
Rigidez ao cisalhamento $(G A)$ & $2.338 .649 .904 \mathrm{~N}$ \\
Massa por unidade de comprimento $(\rho)$ & $237 \mathrm{~kg} / \mathrm{m}$ \\
Diâmetro externo $(D)$ & $0,4 \mathrm{~m}$ \\
Coeficiente de arrasto na direção tangencial $\left(C_{d t}\right)$ & 0,1 \\
Coeficiente de arrasto na direção normal $\left(C_{d n}\right)$ & 1,0 \\
\hline
\end{tabular}

Tabela 5.4: Dados do Caso 2 - Riser com o ambiente

\begin{tabular}{|c|c|}
\hline Aceleração da gravidade $(\boldsymbol{g})$ & $-9,81 \boldsymbol{k}\left[\mathrm{m} / \mathrm{s}^{2}\right]$ \\
Cota do solo retilíneo & $z=0 \mathrm{~m}$ \\
Cota de fixação do riser na superfície (posição da plataforma) & $z=1000 \mathrm{~m}$ \\
Projeção horizontal do riser no solo & $800 \mathrm{~m}$ \\
Coeficiente de atrito entre o riser e o solo $(\mu)$ & 0 \\
\hline
\end{tabular}

\subsubsection{Estratégia de solução}

A estratégia de solução, bem como os passos de carregamento utilizados foram os mesmos do Caso 1. 


\subsubsection{Resultados}

Os gráficos seguintes ilustram uma comparação feita entre as soluções dos códigos ANSYS ${ }^{\mathrm{TM}}$, ORCAFLEX ${ }^{\mathrm{TM}}$ e FEMCABLE.

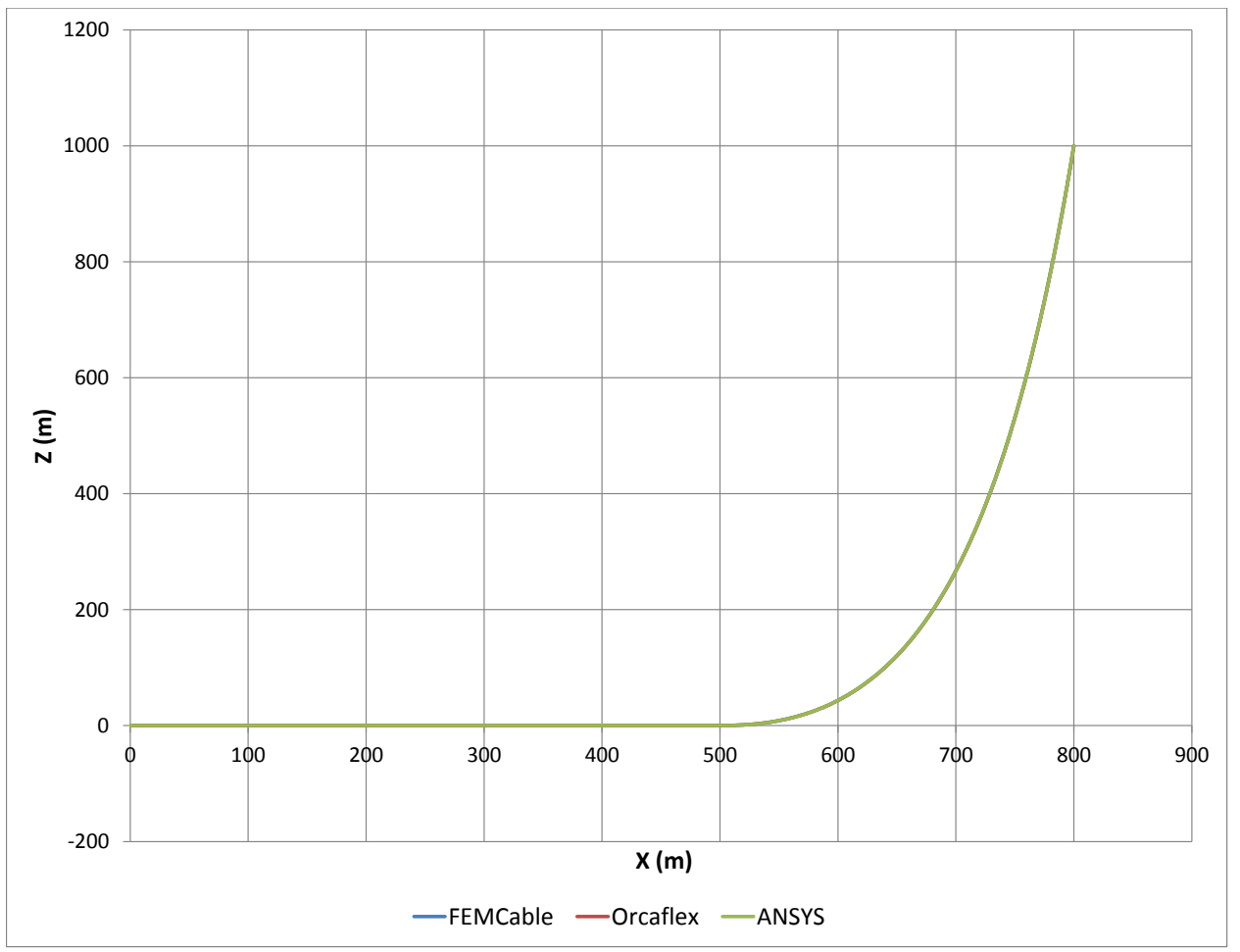

Figura 5.5: Elastica do riser em catenária - vista do plano XZ (Caso 2) 


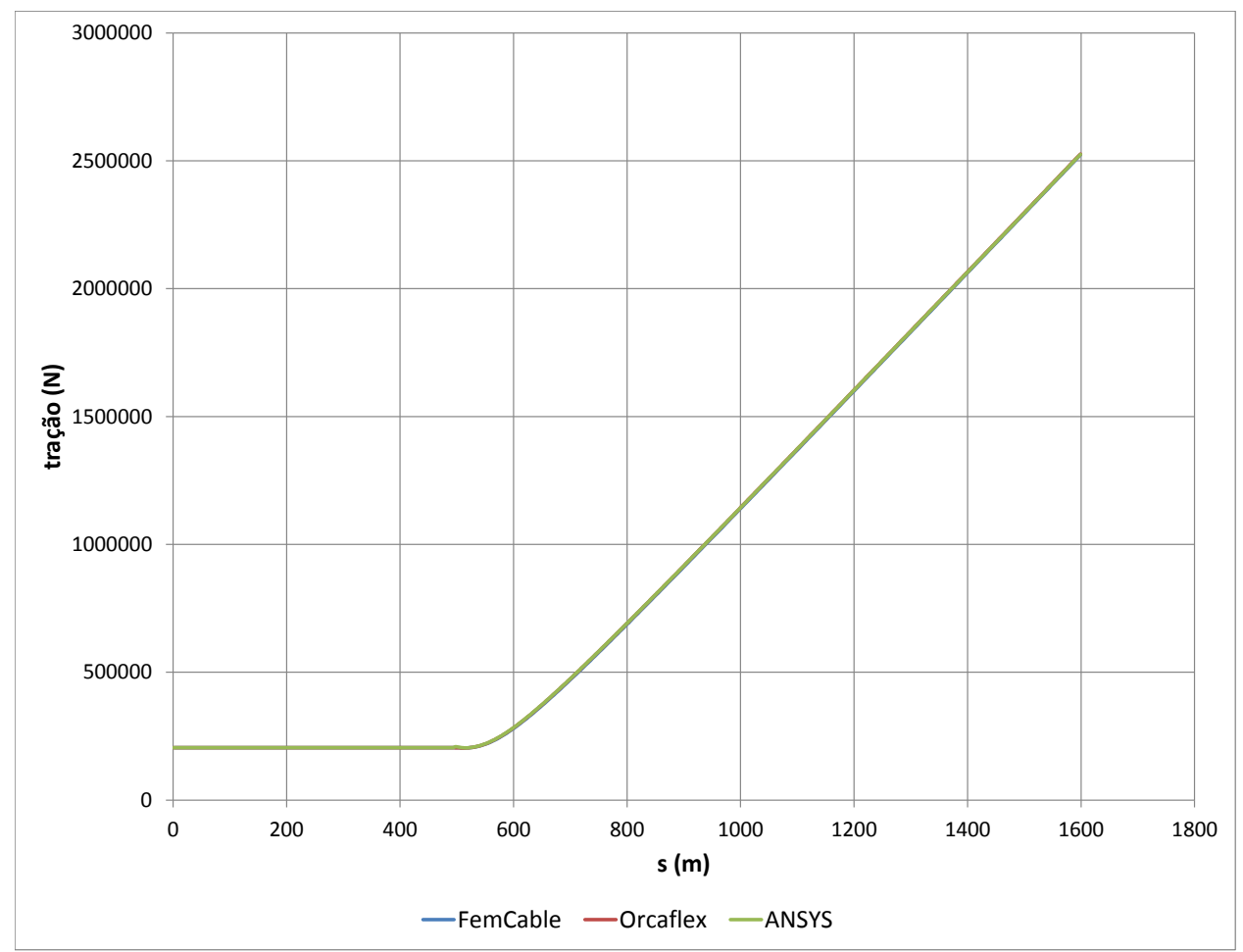

Figura 5.6: Tração efetiva no riser em função da abscissa curvilínea indeformada $s$ (Caso 2)

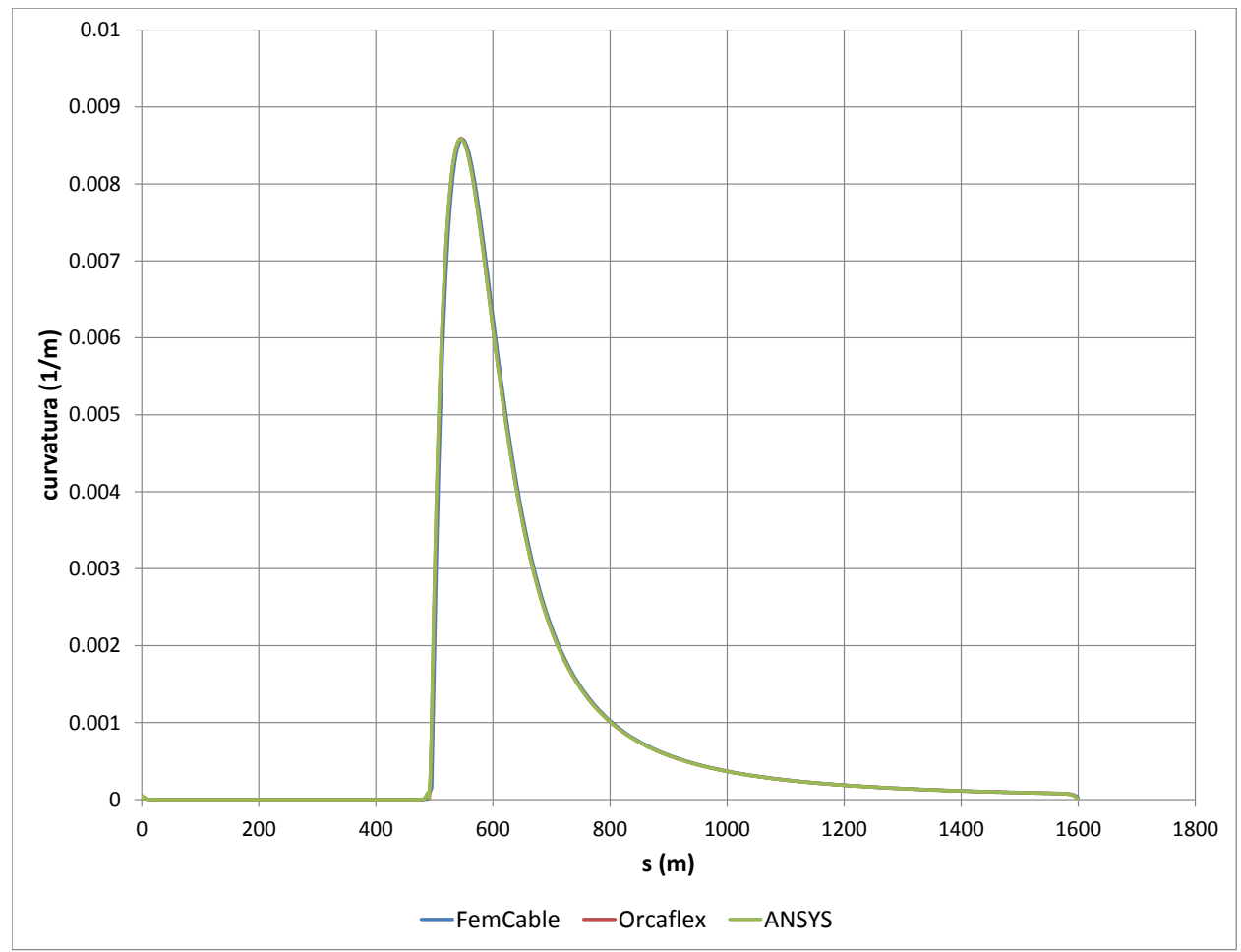

Figura 5.7: Curvatura no riser em função da abscissa curvilínea indeformada $s$ (Caso 2) 
Os três gráficos ilustram uma excelente correlação entre os três resultados. As diferenças essenciais entre os casos 1 e 2 são as propriedades de rigidez do tubo considerado. O primeiro caso apresenta valores de rigidez axial, flexional e à torção muito inferiores em relação ao segundo caso. A diferença de rigidez flexional pode ser identificada pelo gráfico de curvatura, muito mais suave no Caso 2, que apresenta maior EI.

\subsubsection{Caso 3}

O Caso 3 trata de uma configuração de riser em catenária, dessa vez imerso em água. A abordagem para tratar o efeito da pressão externa da coluna de água em cada ponto das paredes externas do riser foi a consideração do peso efetivo (em água), em vez do peso em ar (discutido em detalhes no Apêndice A). As características do riser são as mesmas consideradas no Caso 2 e sua pressão interna foi considerada nula. Adicionalmente, foi levada em consideração uma correnteza atuante sobre o riser.

As características relevantes do ambiente estão descritas na Tabela 5.5.

Tabela 5.5: Dados do Caso 3 - Riser com o ambiente

\begin{tabular}{|c|c|}
\hline Aceleração da gravidade $(\boldsymbol{g})$ & $-9,81 \boldsymbol{k}\left[\mathrm{m} / \mathrm{s}^{2}\right]$ \\
Cota do solo retilíneo & $z=0 \mathrm{~m}$ \\
Cota de fixação do riser na superfície (posição da plataforma) & $z=1000 \mathrm{~m}$ \\
Projeção horizontal do riser no solo & $800 \mathrm{~m}$ \\
Coeficiente de atrito entre o riser e o solo $(\mu)$ & 0 \\
Velocidade da correnteza marítima - constante $(\mathrm{V})$ & $1,0 \mathrm{~m} / \mathrm{s}($ direção Y) \\
Massa específica da água do mar $\left(\rho_{f}\right)$ & $1025 \mathrm{~kg} / \mathrm{m}^{3}$ \\
\hline
\end{tabular}

\subsubsection{Estratégia de solução}

A configuração de referência do riser, bem como os parâmetros de contato considerados condizem com o Caso 1.

A solução do problema foi feita através de quatro passos de carregamento, sequencialmente considerados da seguinte forma:

1. Fixação da origem do riser (âncora) e imposição de deslocamento em $Z$ da outra extremidade para a cota da plataforma, a fim de tracionar a estrutura, fazendo-a adquirir rigidez geométrica.

2. Inserção do carregamento do peso próprio na estrutura, pré tensionada no passo 1. 
3. Alívio da tração da estrutura, feito através da imposição de um deslocamento na direção $X$, até que sua projeção horizontal chegue exatamente no valor imposto para o modelo. Durante esse passo ocorre o contato entre o riser e o solo, apresentando algumas dificuldades para convergência. No entanto, a utilização da técnica de passo auto-adaptativo apresentada no Capítulo 4 auxiliou nessas dificuldades, possibilitando a solução do modelo. Durante as iterações que envolvem a interação de contato entre o riser e o solo ocorre o maior custo computacional da solução desse modelo.

4. Imposição dos esforços de correnteza marítima, sendo re-calculados na medida que surge movimento na estrutura, uma vez que trata-se de um carregamento que varia em função da orientação da estrutura com a direção do escoamento (força seguidora). Nesse caso, a correnteza torna a configuração tridimensional.

\subsubsection{Resultados}

Os gráficos seguintes (de 5.8 a 5.11) ilustram a comparação feita entre as soluções dos códigos ORCAFLEX ${ }^{\mathrm{TM}}$ e FEMCABLE. O software ANSYS ${ }^{\mathrm{TM}}$ não foi utilizado a partir desse ponto pela dificuldade em lidar com carregamentos específicos de correnteza marítima modelados pela Fórmula de Morison (Capítulo 4) e seu caráter seguidor.

Os quatro gráficos ilustram uma excelente correlação entre os dois códigos testados. Mesmo em uma situação em que ocorre tridimensionalização do problema, o FEMCABLE se demonstrou robusto e capturou de forma condizente com o ORCAFLEX os esforços solicitantes distribuídos no riser. A Figura 5.11 mostra a norma da curvatura ao longo da abscissa curvilínea. Por se tratar de um caso em que a elastica é 3D, é necessário compor diferentes direções do vetor curvatura. 


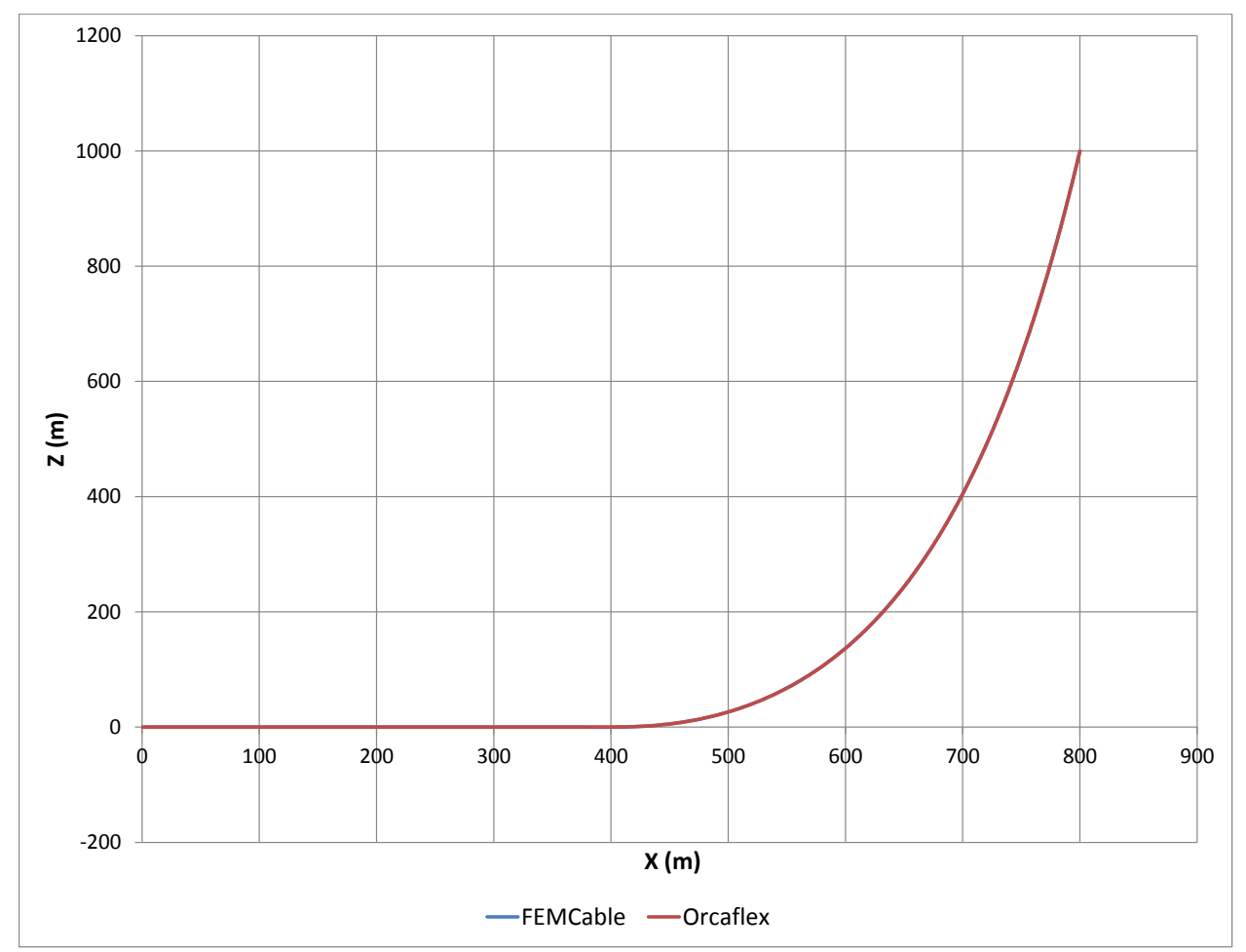

Figura 5.8: Elastica do riser em catenária - vista do plano XZ (Caso 3)

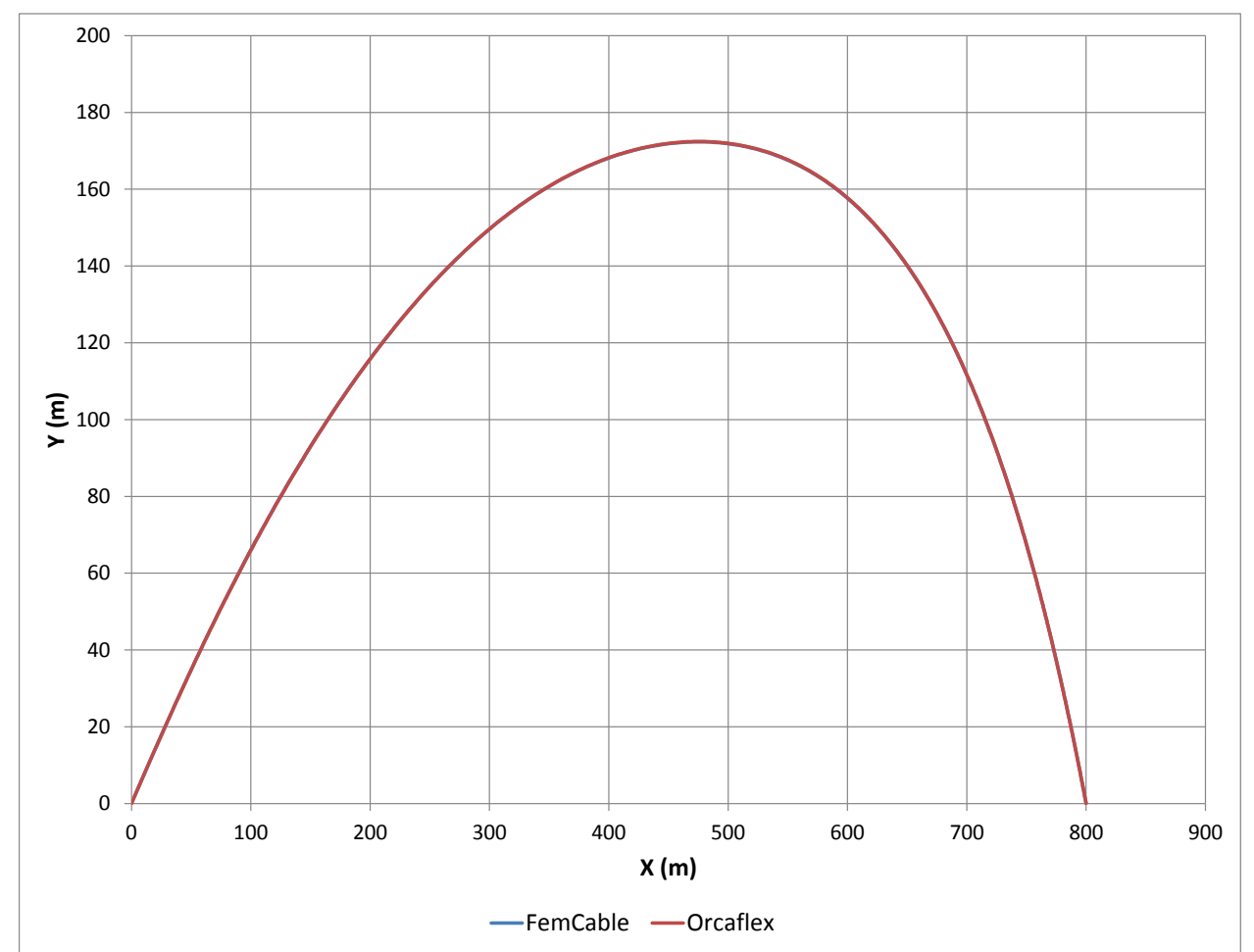

Figura 5.9: Elastica do riser em catenária - vista do plano XY (Caso 3) 


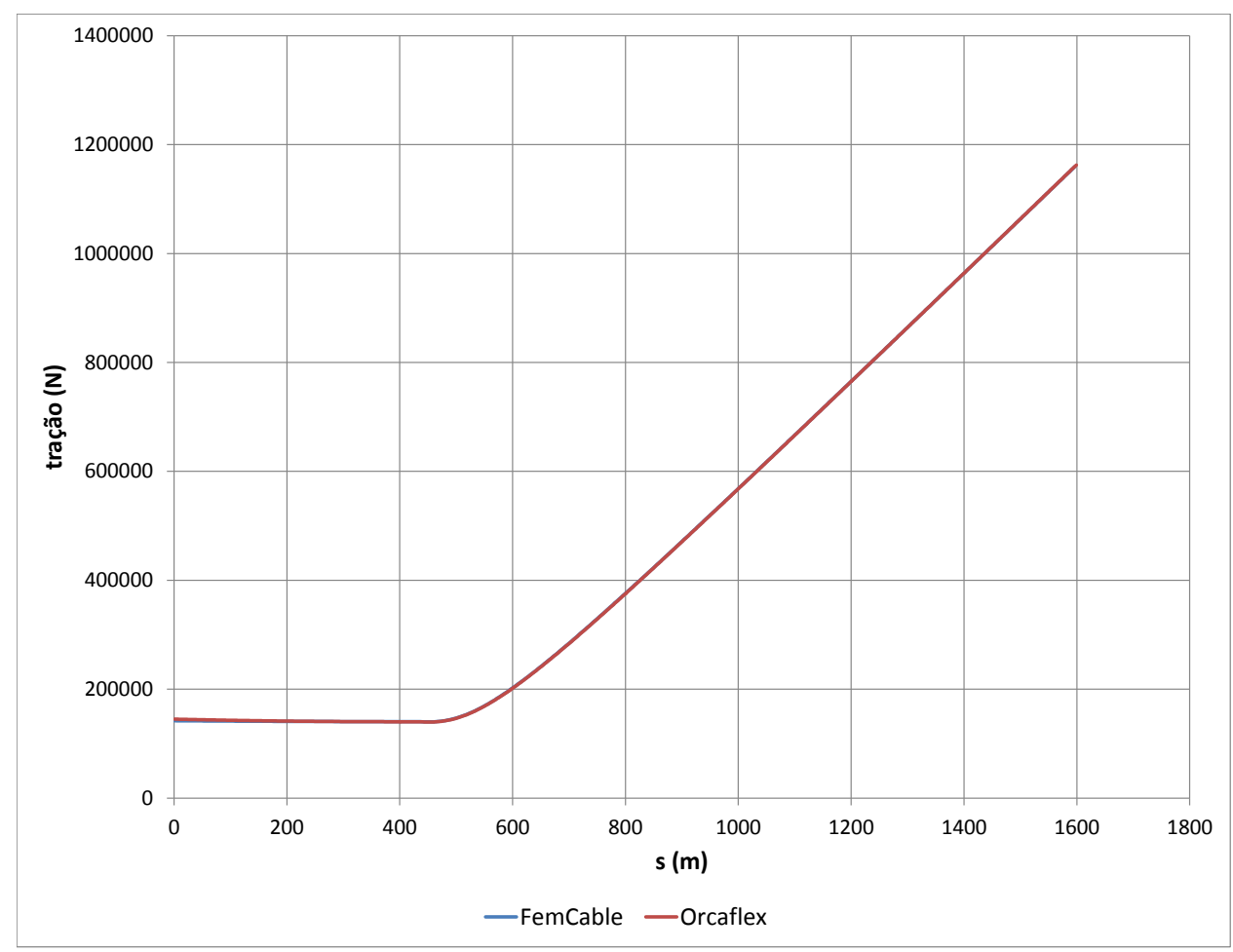

Figura 5.10: Tração efetiva no riser em função da abscissa curvilínea indeformada $s$ (Caso 3)

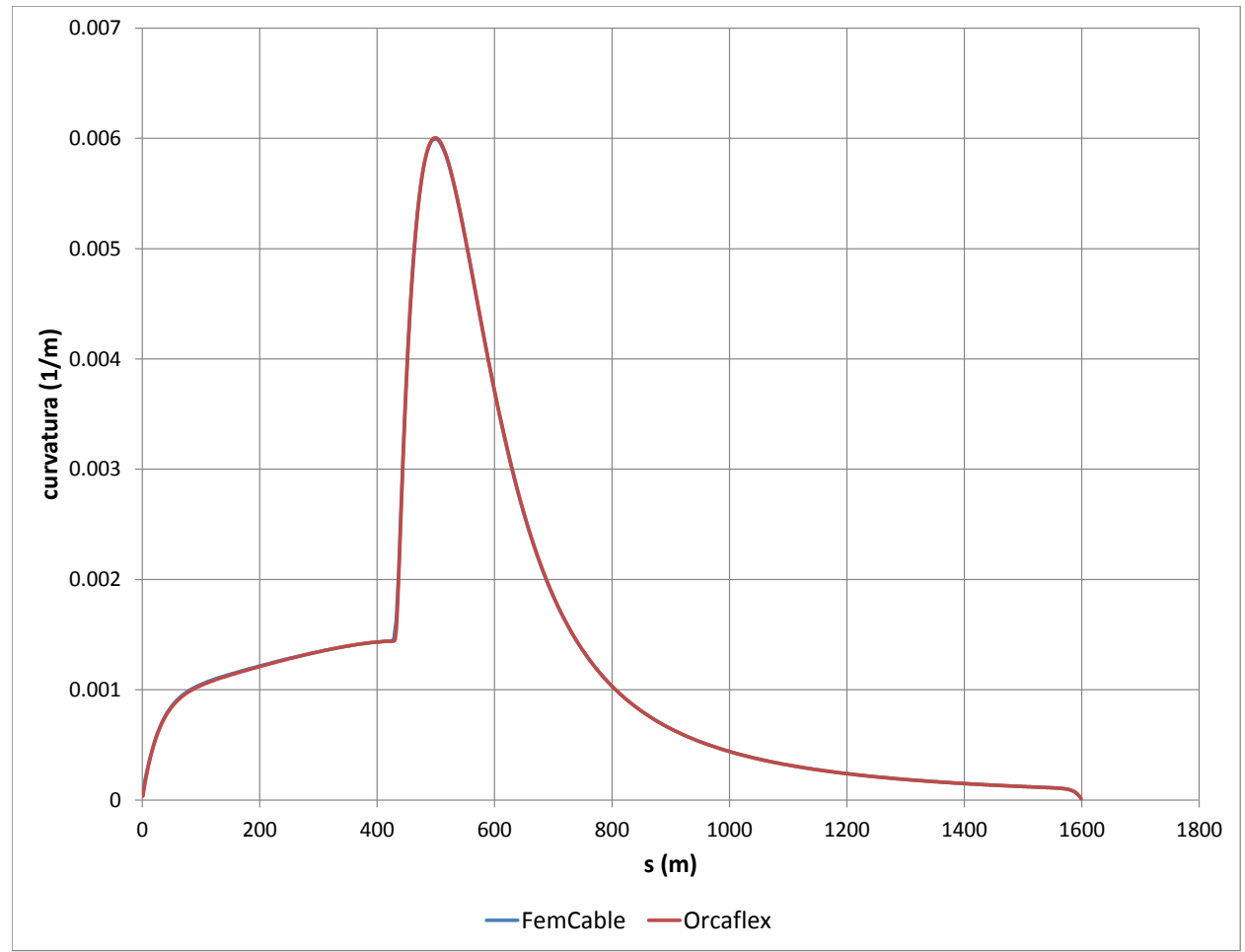

Figura 5.11: Curvatura no riser em função da abscissa curvilínea indeformada $s$ (Caso 3) 


\subsubsection{Caso 4}

O Caso 4 trata a mesma configuração do Caso 3 porém, dessa vez, foi considerado atrito entre o riser e o solo. O valor do coeficiente de atrito considerado é $\mu=0,4$.

\subsubsection{Estratégia de solução}

A configuração de referência do riser condiz com o Caso 1. O parâmetro de penalidade de contato considerado na direção normal é $\epsilon_{n}=1.000 .000$, sendo suficiente para uma descrição com penetração desprezível no solo em relação à ordem de grandeza do modelo. A componente tangencial do esforço de contato surge pelo valor não nulo considerado de coeficiente de atrito. Esse efeito causa dificuldades adicionais de convergência, inerentes à física do problema, uma vez que coexistem duas escalas bastante distintas de magnitude de deslizamento no solo: a direção transversal e a direção axial do riser. A direção transversal apresenta-se com deslocamentos bem mais elevados do que a direção axial. A direção axial é a responsável pela diminuição de tração do riser no solo (ancoragem), conforme detalhado no ítem 4.6.

Sendo o parâmetro $\epsilon_{t}$ e o nível de deslizamentos do riser no solo os responsáveis pelo cálculo da força de atrito (ver Capítulo 4), é de se esperar que diferentes magnitudes de $\epsilon_{t}$ sejam necessárias para uma boa descrição do atrito, dependendo da magnitude dos deslocamentos. Uma vez que no Caso 4 ocorre correnteza transversal ao plano de lançamento do riser (por hipótese o plano XZ), existe parte do deslizamento no solo que terá direção transversal a esse plano, e outra parte que será na direção axial. A dificuldade que existe nessas duas escalas de movimento coexistindo, do ponto de vista numérico, é que o valor de $\epsilon_{t}$ escolhido poderá descrever muito bem a escala de deslizamento em uma delas, mas não a outra. Por exemplo, um valor mais baixo de $\epsilon_{t}$ poderá representar muito bem o comportamento do atrito na direção transversal ao riser, mas não representa corretamente as forças de atrito que surgem na direção axial, não representando corretamente a ancoragem do riser. Já um valor muito elevado desse parâmetro, resolveria bem as duas escalas de movimento, porém, tornaria o modelo muito difícil de convergir.

Essa dificuldade numérica pôde ser contornada através de um algoritmo de adaptação da penalidade tangencial $\epsilon_{t}$, incrementando seu valor, ou diminuindo-o, de acordo com a dificuldade encontrada na convergência do Método de Newton-Raphson. O caso 4 foi resolvido da seguinte forma: primeiramente foi escolhido um valor de $\epsilon_{t}=10.000$. Durante a imposição da correnteza marítima com o riser seu deslocamento transversal 
é quem domina o problema, sendo esse valor de $\epsilon_{t}$ suficiente para uma boa descrição da solução. No entanto, a descrição da ancoragem do riser não é modelada corretamente com esse valor de $\epsilon_{t}$. Por isso, após realizar os mesmos passos de carregamento do Caso 3, foi criado um quinto passo para levar em conta o aumento de $\epsilon_{t}$, a fim de corrigir o erro cometido ao considerá-lo com valor inferior. Esse procedimento foi feito, impondo um valor de $\epsilon_{t}=10.000 .000$ ao final desse último passo de cálculo. Houve convergência pois, nos passos anteriores, as maiores mudanças de configuração do riser já haviam sido registradas. Assim, nesse último passo, foram registradas apenas mudanças nos esforços de tração ao longo da região em que ocorre contato, sem alterações relevantes na elastica. Dessa forma consegue-se uma boa descrição do papel do atrito nas direções transversal e axial ao riser.

\subsubsection{Resultados}

Os gráficos seguintes ilustram uma excelente correlação entre os dois códigos testados (ORCAFLEX $^{\mathrm{TM}}$ e FEMCABLE). Note que nesse caso o valor do coeficiente de atrito considerado não garante a total ancoragem do riser, uma vez que um valor de tração não nula chega na âncora. Novamente, por ser uma configuração tridimensional, a exibição da curvatura se dá na Figura 5.15 através de sua norma composta de diferentes contribuições.

Mesmo em uma situação em que ocorre tridimensionalização do problema e atrito, o código desenvolvido se demonstrou robusto e capturou de forma condizente com o ORCAFLEX ${ }^{\mathrm{TM}}$ os esforços solicitantes distribuídos no riser. Para testar efeitos de coeficientes de atrito mais elevados, foi desenvolvido o Caso 5. 


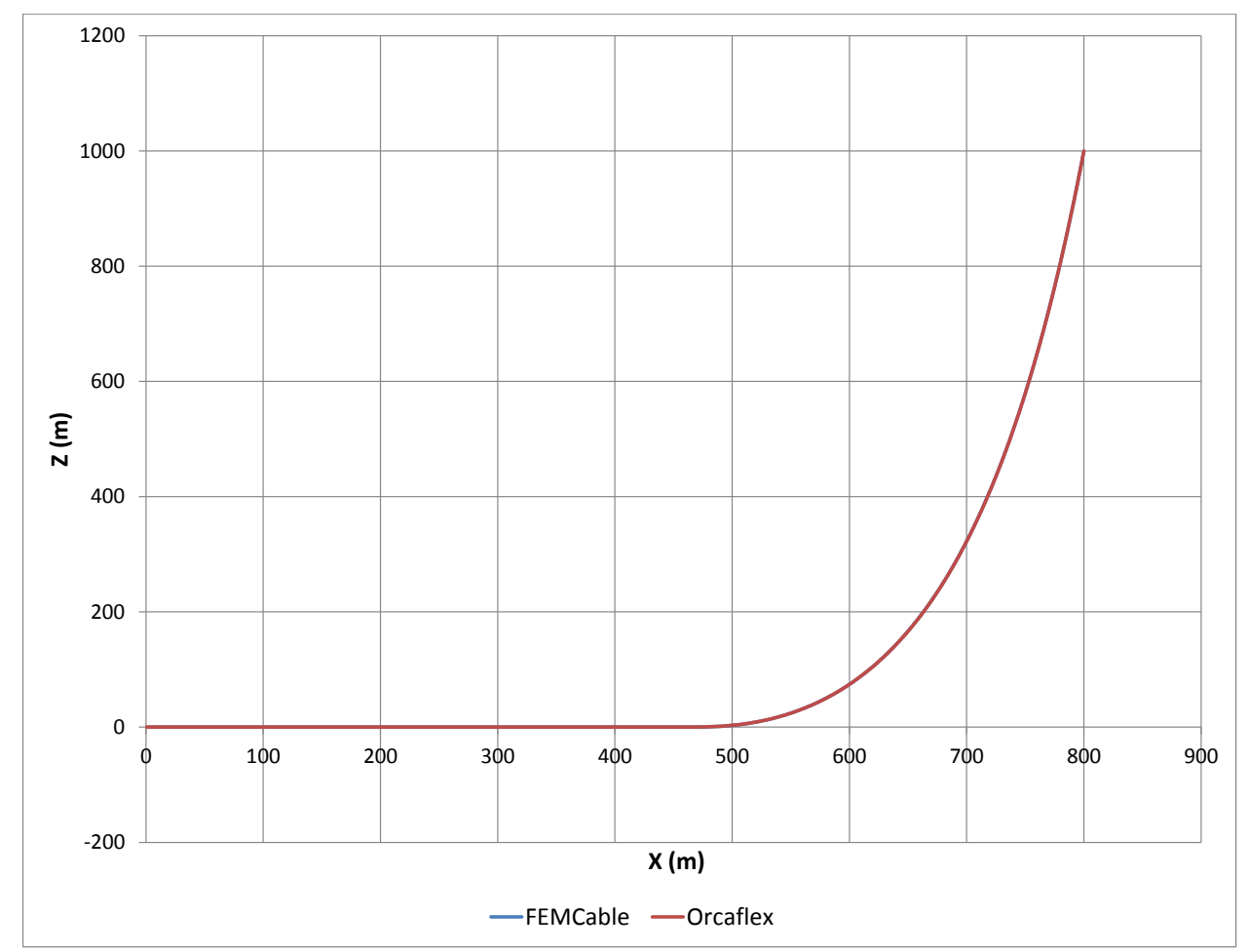

Figura 5.12: Elastica do riser em catenária - vista do plano XZ (Caso 4)

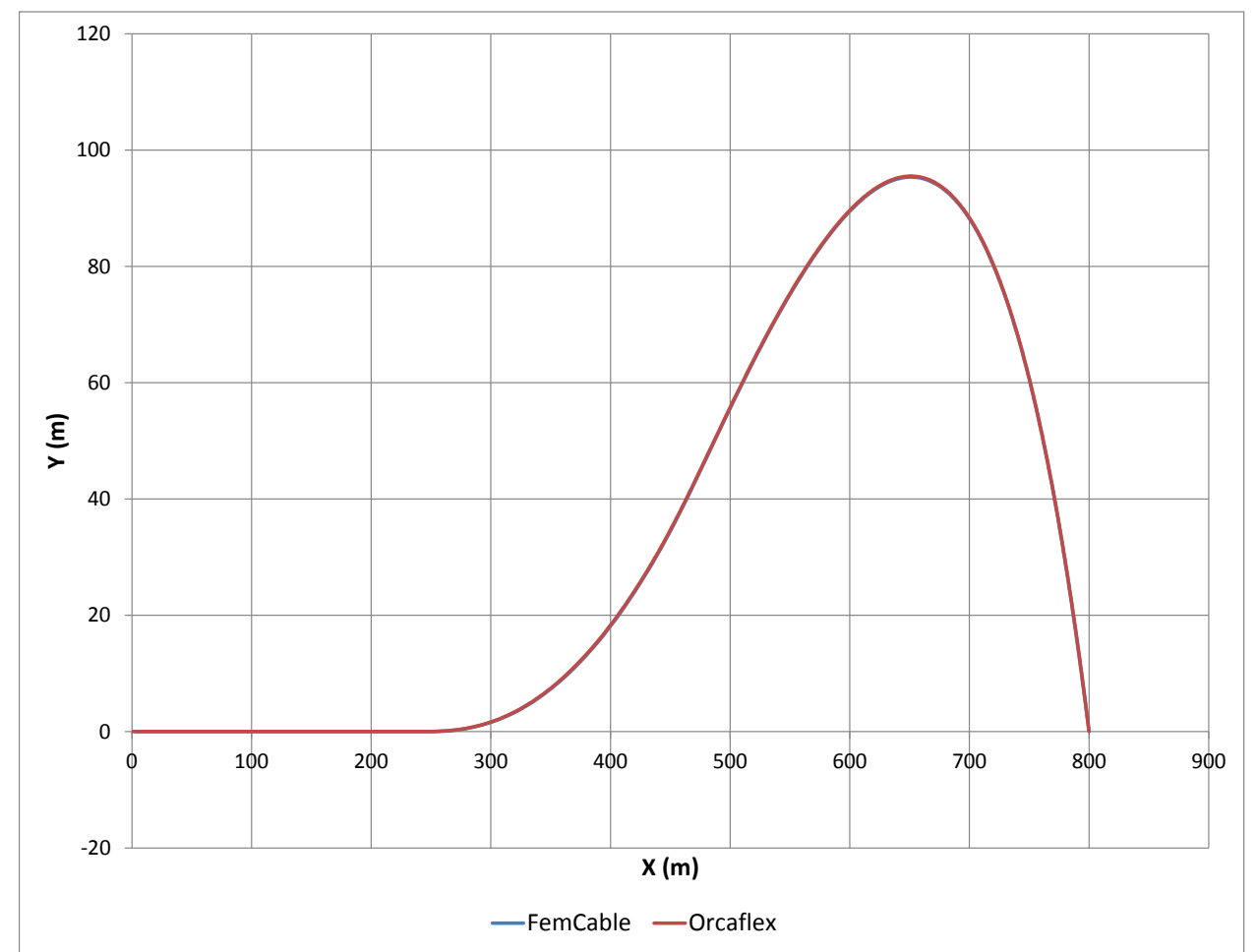

Figura 5.13: Elastica do riser em catenária - vista do plano XY (Caso 4) 


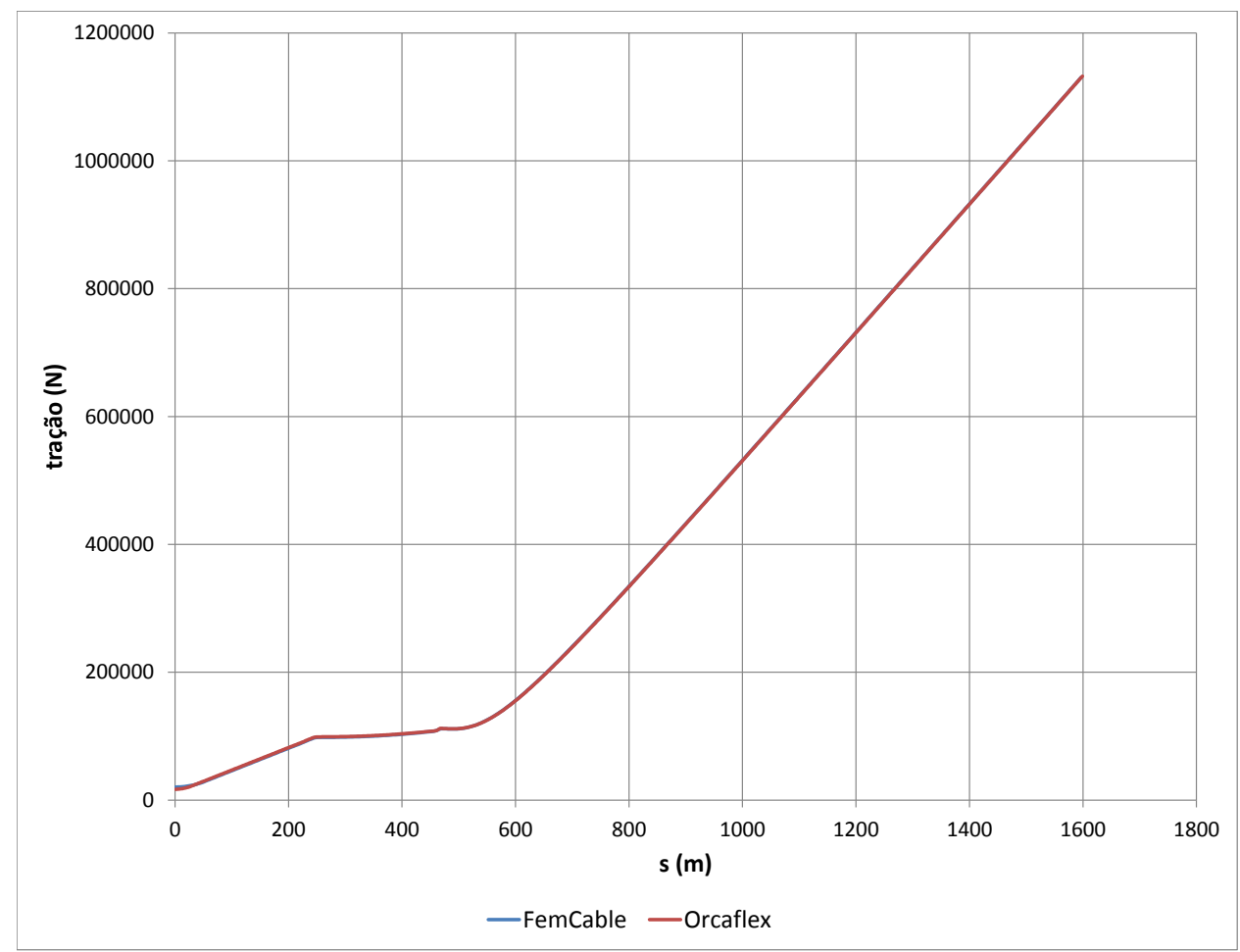

Figura 5.14: Tração efetiva no riser em função da abscissa curvilínea indeformada $s$ (Caso 4)

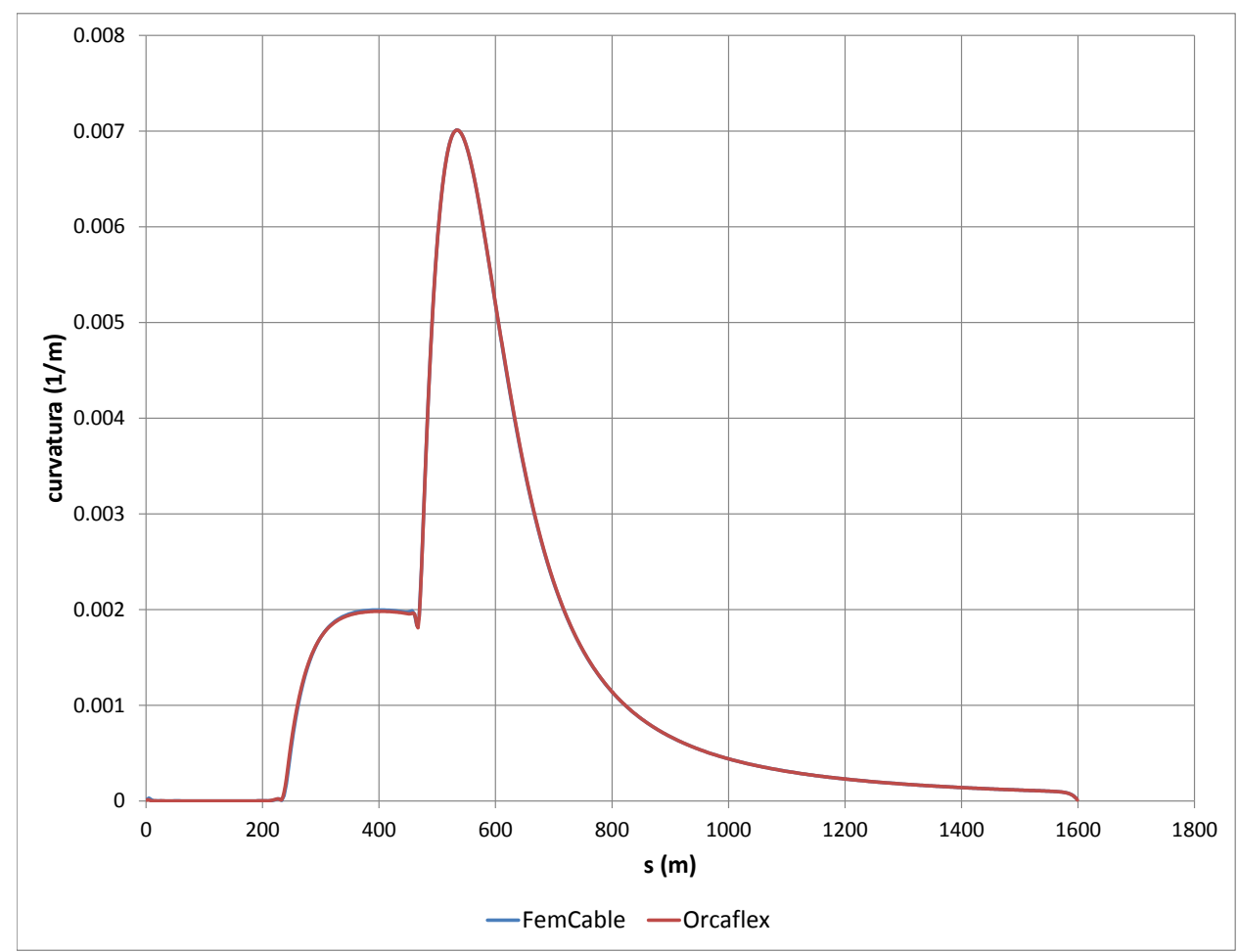

Figura 5.15: Curvatura no riser em função da abscissa curvilínea indeformada $s$ (Caso 4) 


\subsubsection{Caso 5}

O Caso 5 trata a mesma configuração do Caso 4 porém, dessa vez, foi considerado um coeficiente de atrito mais elevado, tal que a tração ficasse nula em parte da região de contato entre o riser e o solo. Considerou-se o coeficiente de atrito $\mu=0,8$.

\subsubsection{Estratégia de solução}

A estratégia de solução, bem como os passos de carregamento considerados foram exatamente os mesmos do Caso 4.

\subsubsection{Resultados}

Os gráficos seguintes (de 5.16 a 5.19) ilustram a comparação feita entre as soluções dos códigos ORCAFLEX ${ }^{\mathrm{TM}}$ e FEMCABLE. Note que dessa vez houve ancoragem total do riser no solo. A tração que chega à âncora é de valor nulo, devido ao atrito que atua na interação riser-solo. 


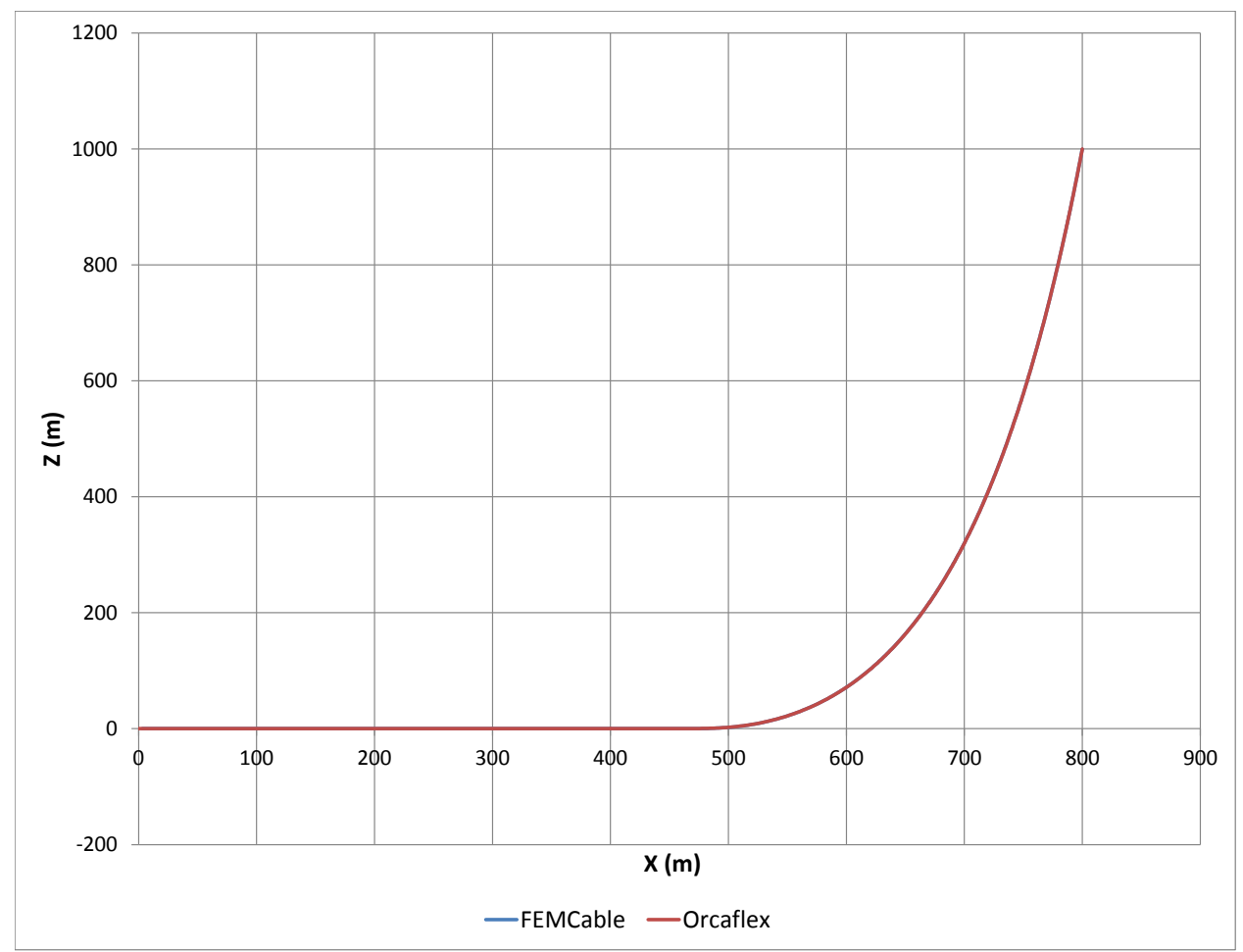

Figura 5.16: Elastica do riser em catenária - vista do plano XZ (Caso 5)

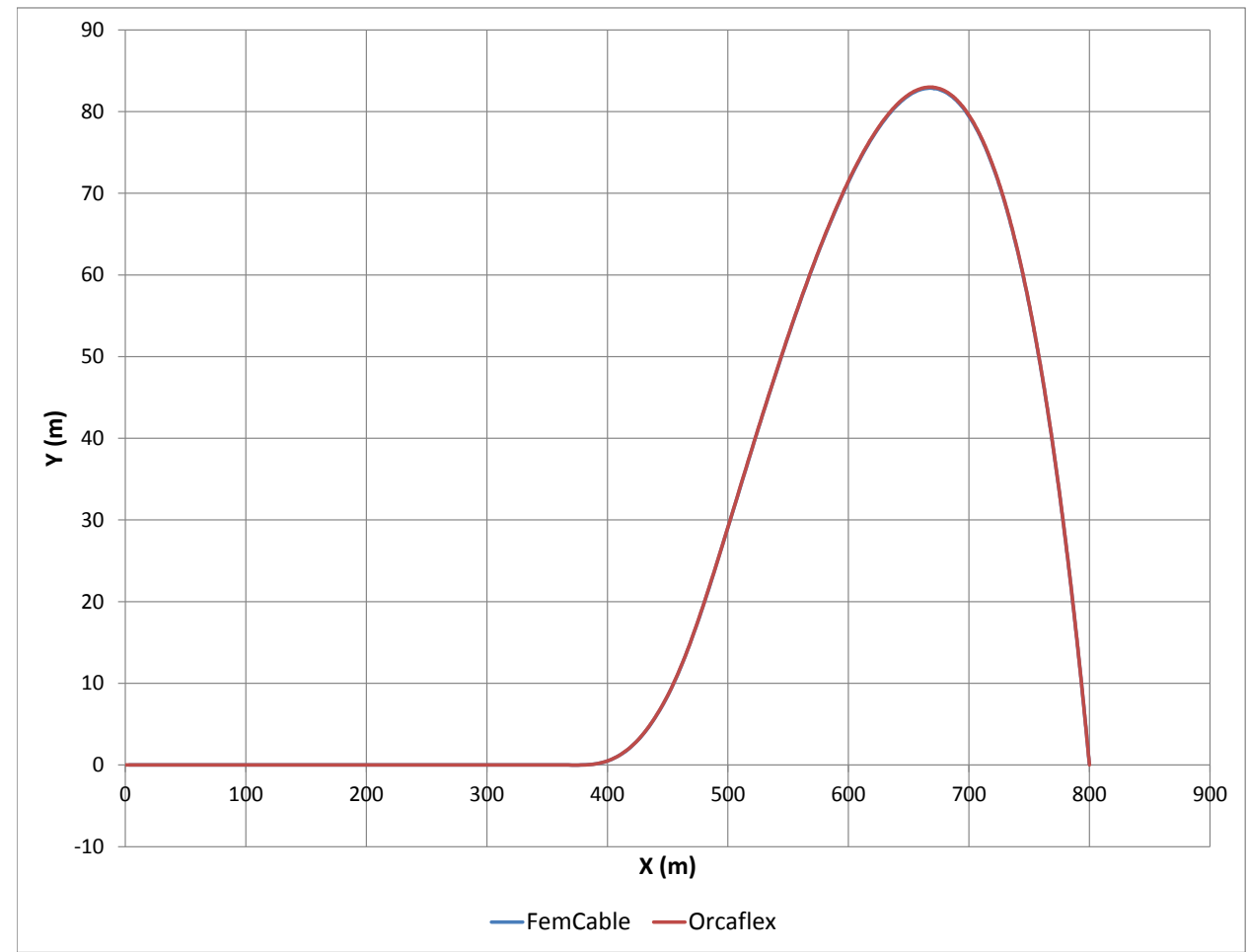

Figura 5.17: Elastica do riser em catenária - vista do plano XY (Caso 5) 


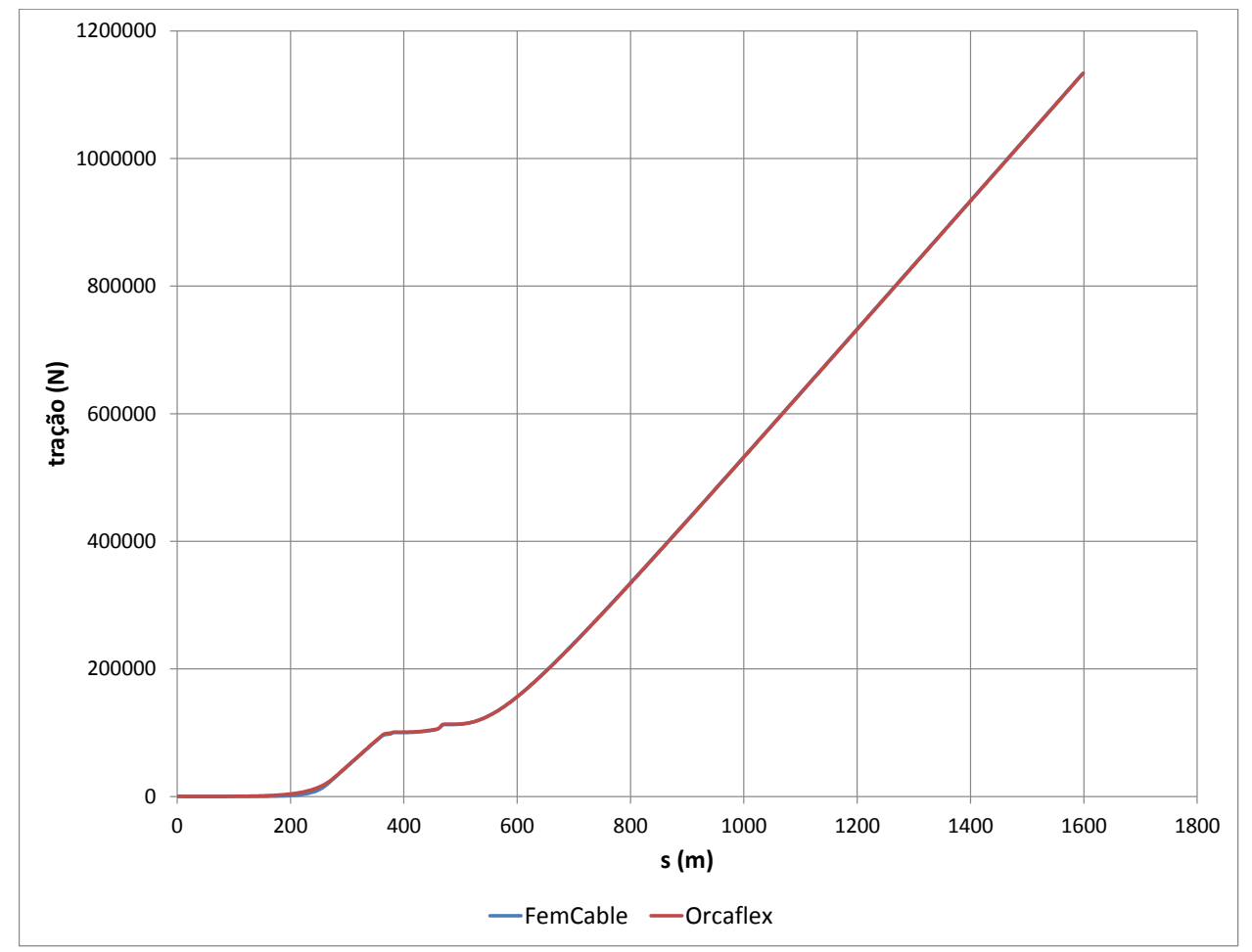

Figura 5.18: Tração efetiva no riser em função da abscissa curvilínea indeformada $s$ (Caso $5)$

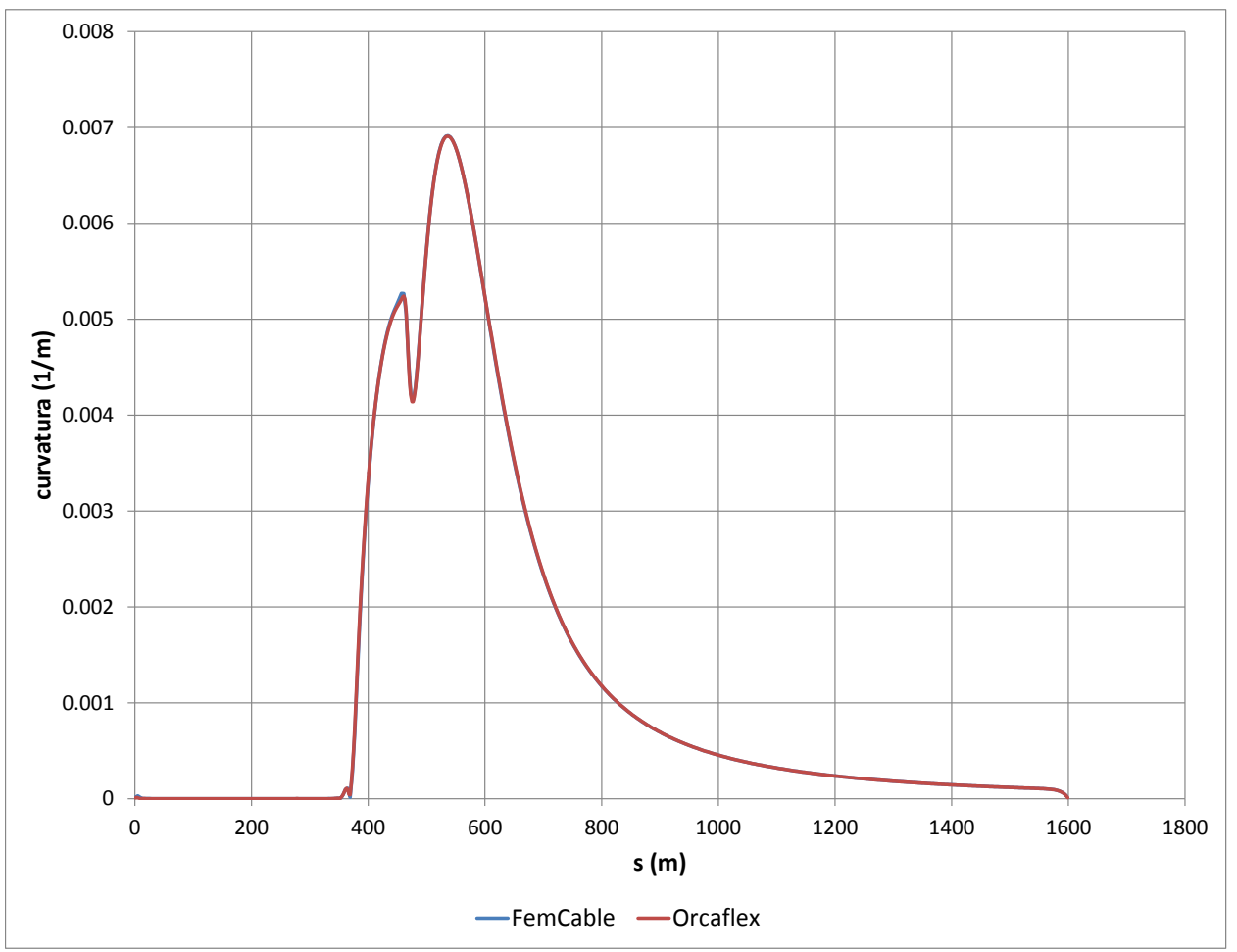

Figura 5.19: Curvatura no riser em função da abscissa curvilínea indeformada $s$ (Caso 5) 


\subsubsection{Caso 6}

Esse caso trata um problema estrutural bastante importante para do presente trabalho: a estabilidade de uma viga sob compressão e torção. Trata-se de um problema clássico que envolve a formação de um laço a partir de uma viga com uma pré-torção elevada, sofrendo flambagem e posteriormente formando um laço, na configuração pós-crítica (veja, por exemplo, Miyazaki e Kondo (1997) para uma abordagem teórica e Goss (2003) para uma abordagem teórica comparada com experimental).

Foram feitas simulações utilizando-se do FEMCABLE e seus resultados foram comparados com o software comercial ABAQUS ${ }^{\mathrm{TM}}$, bastante robusto para lidar com nãolinearidades da natureza encontrada nesse problema.

O modelo consiste basicamente em uma viga bi-engastada, com possibilidade de imposição de deslocamento axial em uma das extremidades, bem como fixação da outra extremidade. As características da viga considerada estão ilustradas na Tabela 5.6.

Tabela 5.6: Dados do Caso 6 - Viga

\begin{tabular}{|c|c|}
\hline Comprimento $(L)$ & $400 \mathrm{~m}$ \\
Rigidez axial $(E A)$ & $7.000 .000 \mathrm{~N}$ \\
Rigidez flexional $(E I)$ & $120.000 \mathrm{Nm}^{2}$ \\
Rigidez à torção $(G J)$ & $100.000 \mathrm{Nm}^{2}$ \\
Rigidez ao cisalhamento $(G A)$ & $2.000 .000 \mathrm{~N}$ \\
Massa por unidade de comprimento $(\rho)$ & $0 \mathrm{~kg} / \mathrm{m}$ \\
Diâmetro externo $(D)$ & $0,4 \mathrm{~m}$ \\
\hline
\end{tabular}

\subsubsection{Estratégia de solução}

Foram considerados dois passos de carregamento para o modelo em questão:

1. Engastamento das extremidades da viga, imposição de uma força transversal à estrutura de $1,0 N$ no meio vão e aplicação de um deslocamento rotacional de $2 \pi$ rad na direção axial da viga, em uma das extremidades, causando uma pré torção de 1.570 N.m. O objetivo da força aplicada é induzir a instabilidade na estrutura. Trata-se de uma imperfeição introduzida ${ }^{1}$.

\footnotetext{
${ }^{1}$ Nesse problema também caberia um estudo da variação da imperfeição, bem como de diferentes tipos de imperfeições. Assim, poder-se-ia concluir muito mais sobre seu comportamento, bem como sua sensibilidade a parâmetros de imperfeição. No entanto, no presente contexto o objetivo é apenas uma comparação com outro software para verificar o modelo do FEMCABLE.
} 
2. Imposição de um deslocamento compressivo, e monitoração das reações vinculares.

\subsubsection{Resultados}

O modelo proposto sofre flambagem primeiramente no plano XZ e, com o aumento da imposição de deslocamento, vai sofrendo tridimensionalização (início da formação do laço). Após essa formação, o problema se torna praticamente bidimensional novamente. A Figura 5.20 ilustra a sequência desses eventos.

É interessante também monitorar algumas forças e momentos aplicados à extremidade da viga, a fim de obter cargas críticas, bem como prever o comportamento do acoplamento entre a torção e a flexão no modelo. A Figura 5.21 ilustra a força compressiva em função do deslocamento imposto na extremidade da viga. Trata-se de uma forma de exibir uma trajetória de equilíbrio. Note que inicialmente um pequeno deslocamento imposto é associado a um significativo aumento na força compressiva. Essa situação é perdida no momento da flambagem da estrutura. Após a flambagem, a estrutura começa a buscar suas novas configurações de equilíbrio no decorrer do curso de deslocamento axial imposto, sofrendo mudanças em seus esforços solicitantes. Isso pode ser observado para os momentos fletores através das trajetórias de equilíbrio mostradas nas Figuras 5.22 e 5.23 e, para o momento de torção, através da Figura 5.24.

A comparação entre as soluções do Caso 6 com o FEMCABLE e ABAQUSTM mostra consistência total entre elas. 

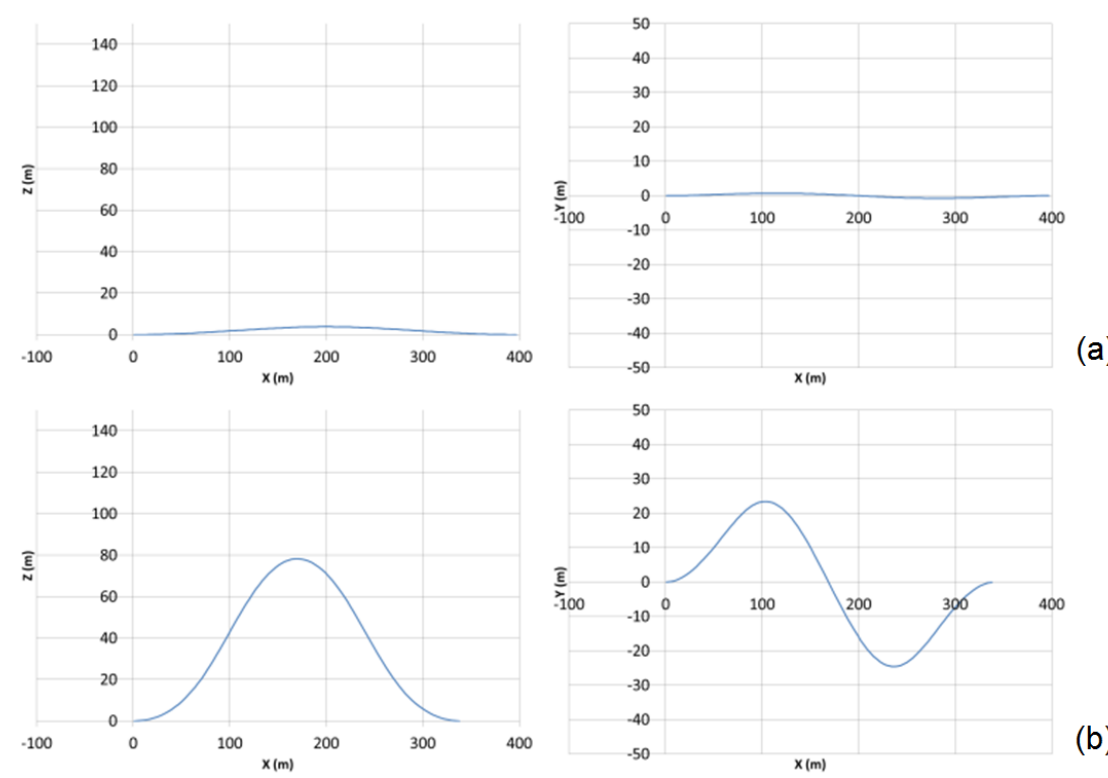

(a)
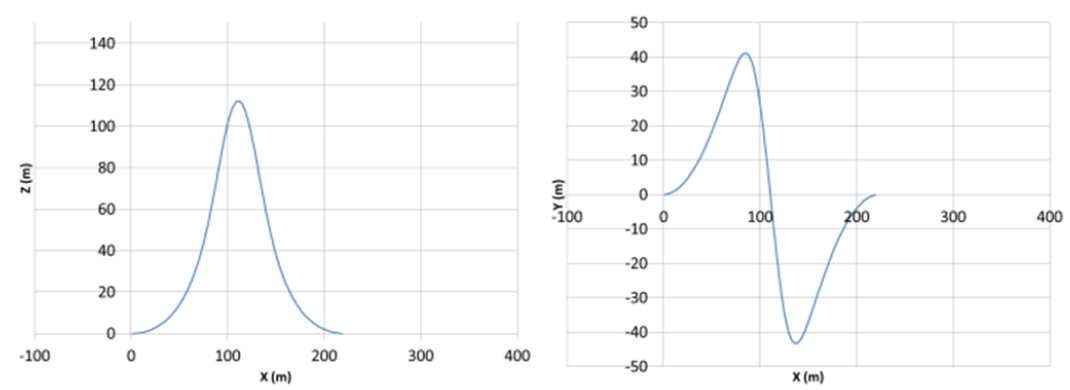

(b)
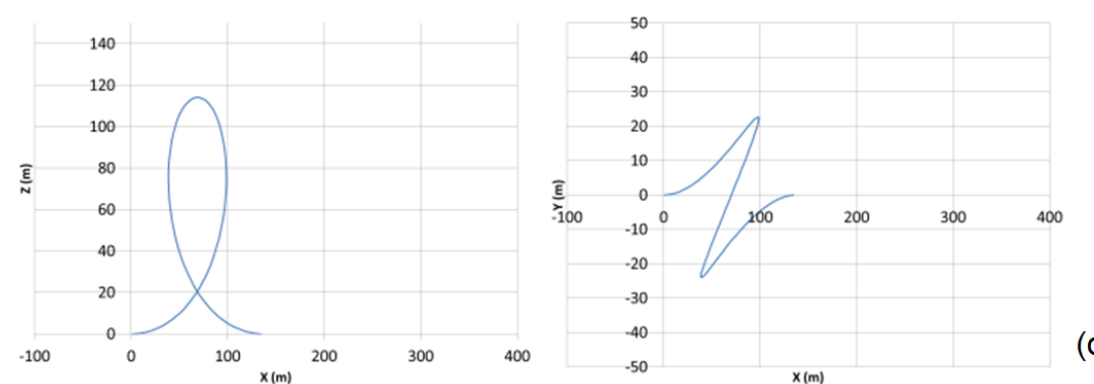

(c)

(d)
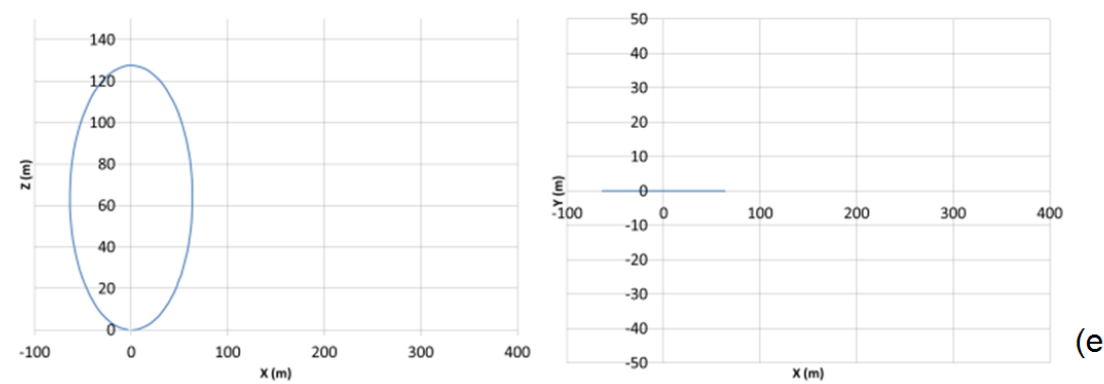

Figura 5.20: Evolução da configuração da viga vista lateralmente (figuras à esquerda) e superiormente (figuras à direita) (a) Logo após o início da compressão (b) Um pouco de tridimensionalização começa a aparecer (c) Antes da formação do laço (d) Logo após a formação do laço (e) Configuração final, quando os pontos extremos da viga atingem a mesma posição 


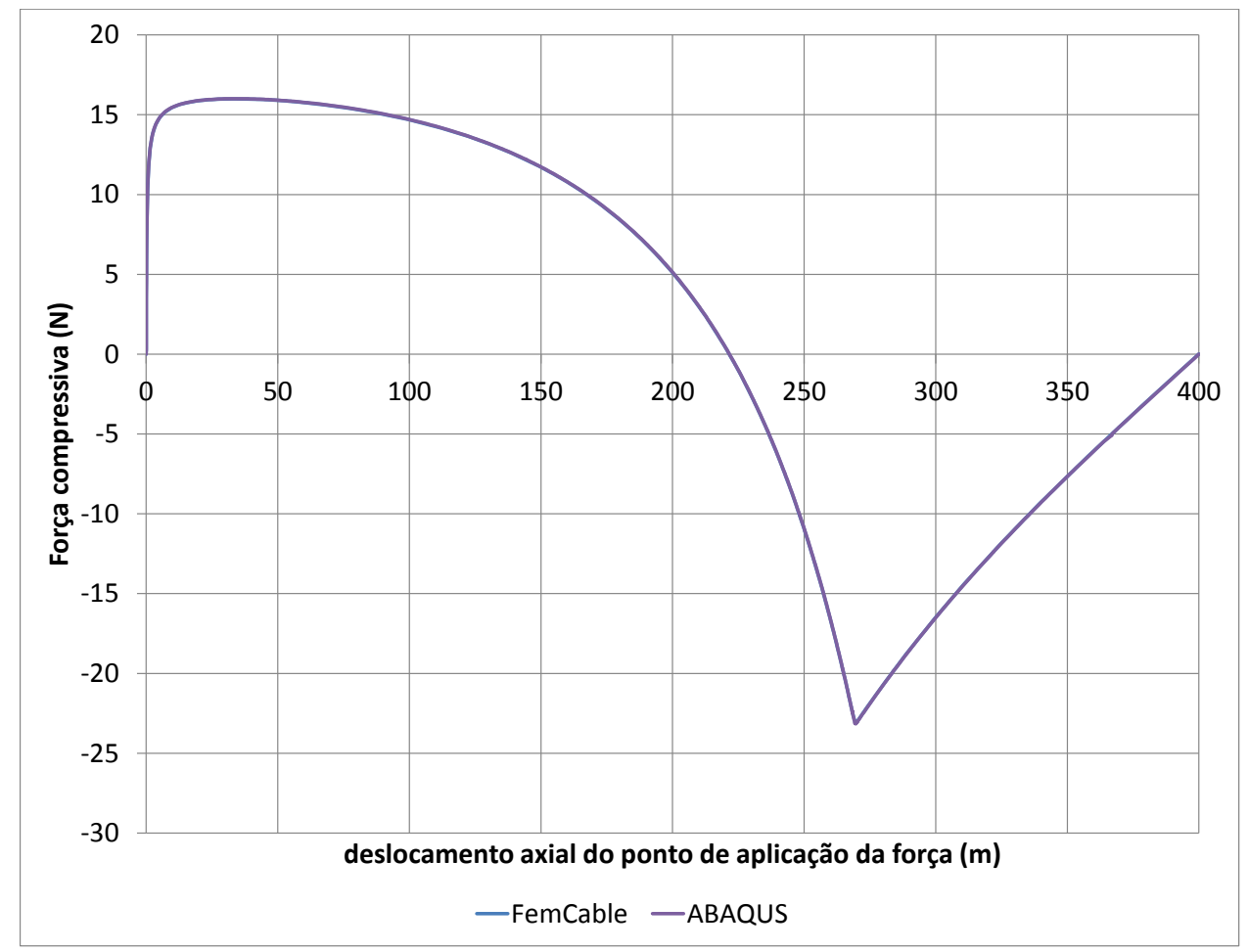

Figura 5.21: Força compressiva aplicada pelo engaste móvel à extremidade da viga, em função do deslocamento axial desse ponto de aplicação

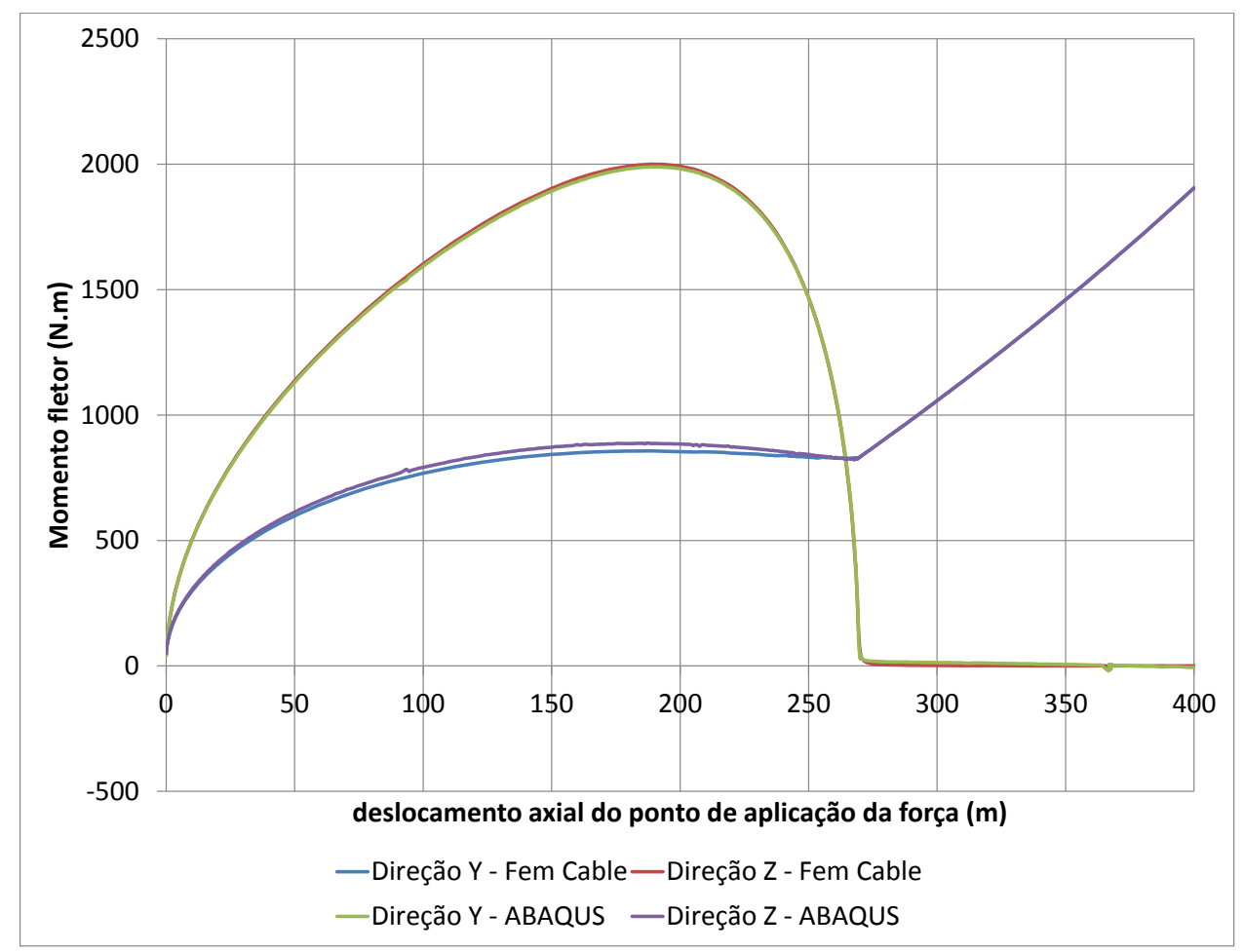

Figura 5.22: Momentos que causam flexão aplicados pelo engaste móvel à extremidade da viga, em função do deslocamento axial desse ponto de aplicação 


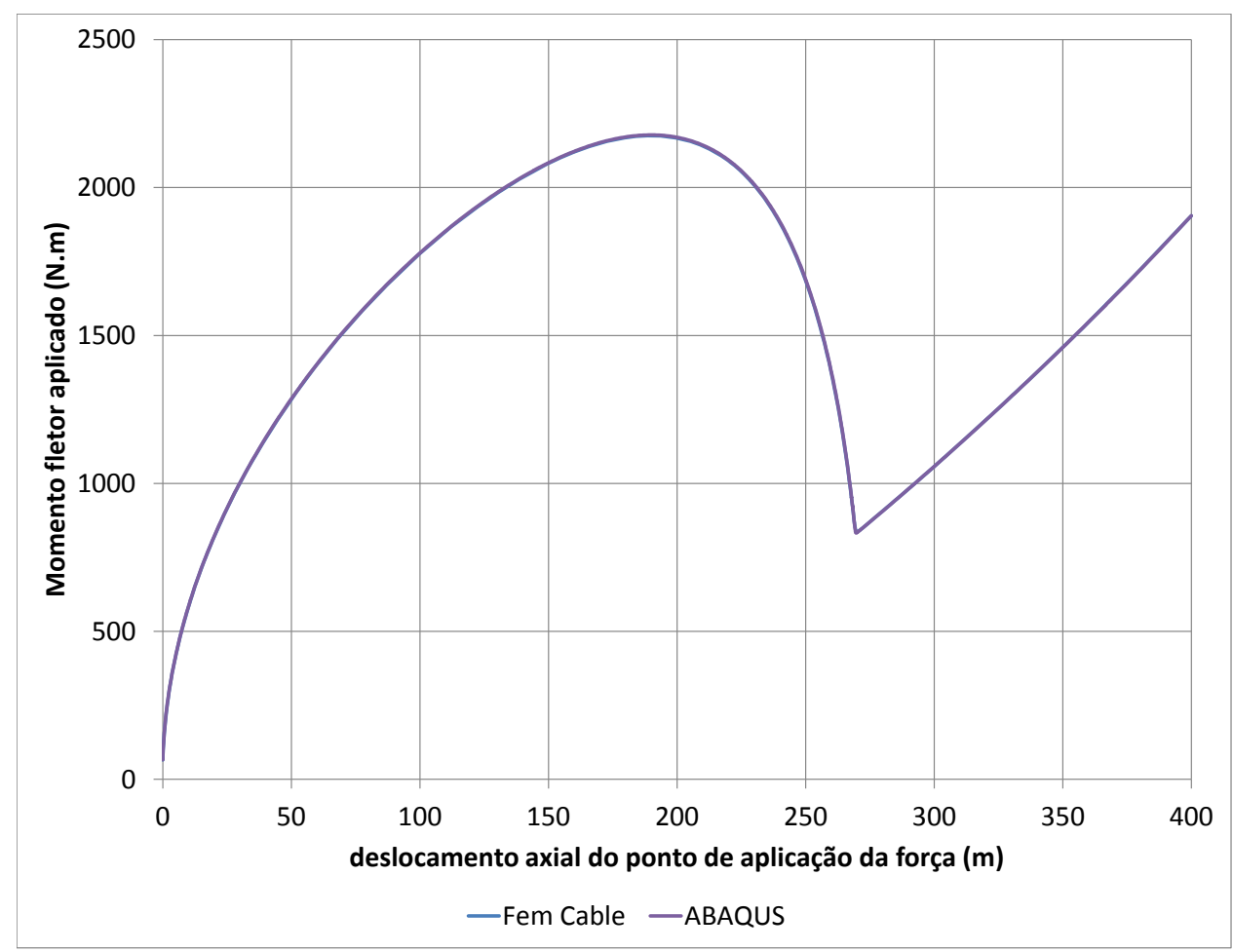

Figura 5.23: Soma vetorial dos momentos que causam flexão aplicados pelo engaste móvel à extremidade da viga, em função do deslocamento axial desse ponto de aplicação

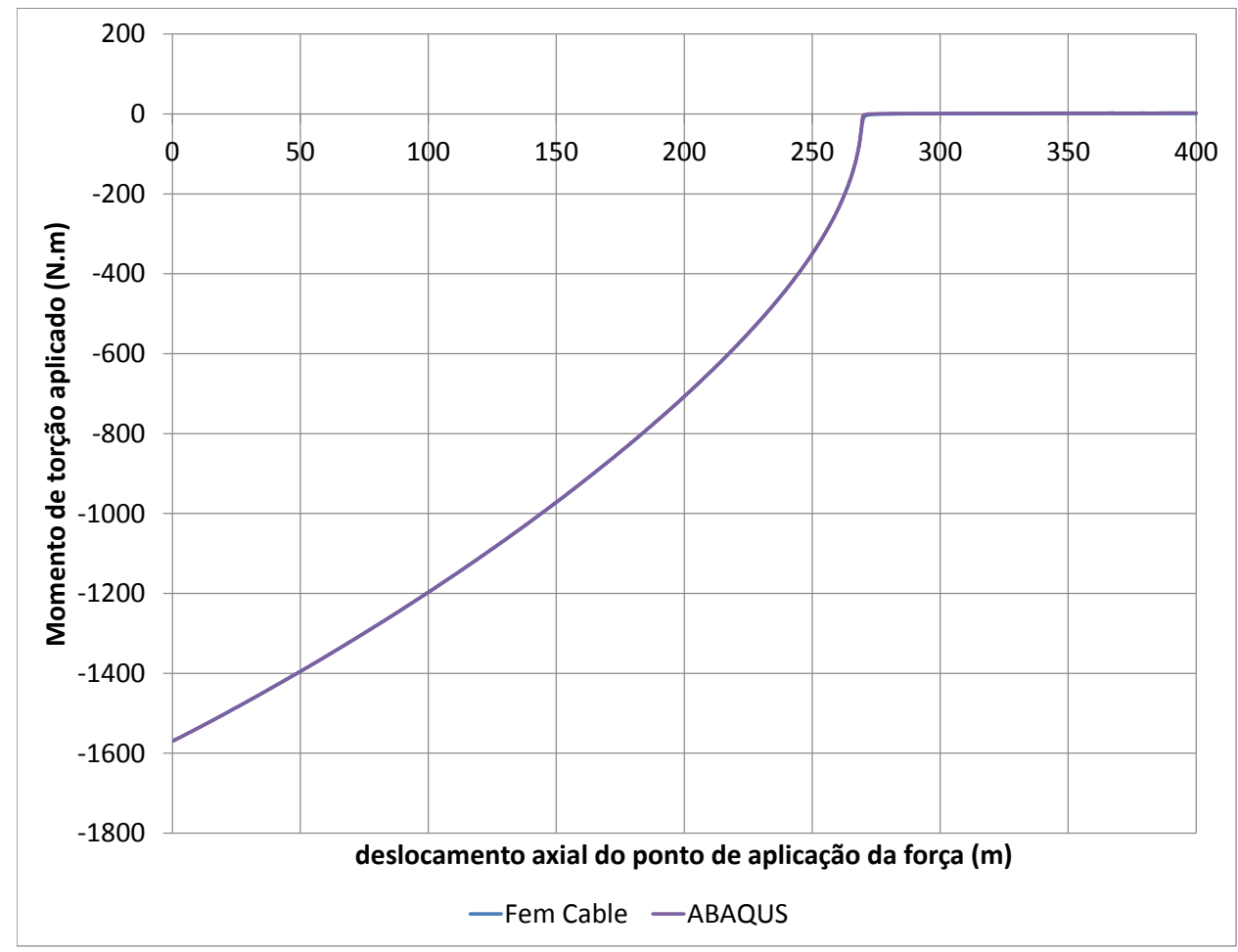

Figura 5.24: Momento que causa torção aplicado pelo engaste móvel à extremidade da viga, em função do deslocamento axial desse ponto de aplicação 


\subsubsection{Análise Modal}

Conforme foi mostrado no Capítulo 3, o estudo da estabilidade de configurações de risers com correnteza marítima pode necessitar de um critério cinético. Foi dito no ítem 3.2.6 que a observação das frequências naturais pode ser utilizada para estudar a estabilidade, segundo o Primeiro Método de Lyapunov. No Capítulo 4 ainda foram mostradas expressões para o cálculo da matriz de rigidez e de massa para o elemento de viga.

A presente seção tem por objetivo mostrar uma comparação das frequências naturais de algumas configurações de risers em catenária obtidas com o FEMCABLE com as obtidas utilizando-se o software ORCAFLEX ${ }^{\mathrm{TM}}$. Para tal, uma configuração de cabo umbilical com as seguintes características foi considerada:

Tabela 5.7: Dados do cabo umbilical

\begin{tabular}{|c|c|}
\hline Rigidez axial $(E A)$ & $409.000 .000 \mathrm{~N}$ \\
Rigidez flexional $(E I)$ & $5.030 \mathrm{Nm}^{2}$ \\
Rigidez à torção $(G J)$ & $1.000 .000 \mathrm{Nm}^{2}$ \\
Rigidez ao cisalhamento $(G A)$ & $40.600 .000 .000 \mathrm{~N}$ \\
Peso fora da água $(\gamma)$ & $253,9 \mathrm{~N} / \mathrm{m}$ \\
Diâmetro externo $(D)$ & $0,12 \mathrm{~m}$ \\
Coeficiente de arrasto na direção tangencial $\left(C_{d t}\right)$ & 0,1 \\
Coeficiente de arrasto na direção normal $\left(C_{d n}\right)$ & 1,0 \\
Coeficiente de massa adicional na direção tangencial $\left(C_{a t}\right)$ & 0 \\
Coeficiente de massa adicional na direção normal $\left(C_{a n}\right)$ & 1,0 \\
\hline
\end{tabular}

Os dados do ambiente considerado são:

Tabela 5.8: Dados do ambiente

\begin{tabular}{|c|c|}
\hline Aceleração da gravidade $(\boldsymbol{g})$ & $-9,81 \boldsymbol{k}\left[\mathrm{m} / \mathrm{s}^{2}\right]$ \\
Cota do solo retilíneo & $z=0 \mathrm{~m}$ \\
Cota de fixação do riser na superfície (posição da plataforma) & $z=1000 \mathrm{~m}$ \\
Massa específica da água do mar $\left(\rho_{f}\right)$ & $1.024 \mathrm{~kg} / \mathrm{m}^{3}$ \\
\hline
\end{tabular}

Consideraram-se diferentes condições de correnteza marítima, bem como de coeficientes de atrito entre o riser e o solo. A referência para orientação da correnteza marítima é o ângulo $\psi$ ilustrado na Figura 5.25. Em todos os casos com correnteza marítima não nula dessa seção foi considerado um valor de velocidade de $0,5 \mathrm{~m} / \mathrm{s}$.

O procedimento para obtenção das frequências naturais envolve, em primeiro lugar, a obtenção da elastica do riser. Uma vez feito o cálculo do problema estático não 
linear, as matrizes de massa e de rigidez associadas à configuração final são utilizadas como ponto de linearização para o cálculo dos modos de vibrar e frequências naturais.

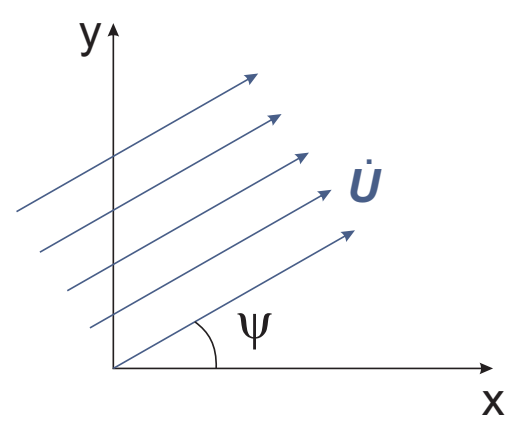

Figura 5.25: Referência para orientação da correnteza marítima (vista superior)

A seguir são mostrados os resultados das trinta menores frequências naturais para diversas condições ambientais. Os resultados estão nas Tabelas 5.9 a 5.13 , em que se pode observar uma boa aderência entre os valores do ORCAFLEX ${ }^{\mathrm{TM}}$ e do FEMCABLE, principalmente nos casos que não envolvem atrito e correnteza. Ao inserir esses efeitos a consistência é mantida mas a aderência entre as frequências naturais é menor. 


\subsubsection{Sem correnteza e sem atrito}

Tabela 5.9: Frequências naturais - sem correnteza e sem atrito

\begin{tabular}{|c|c|c|c|c|}
\hline & \multicolumn{2}{|c|}{ ORCAFLEX $^{\mathrm{TM}}$} & \multicolumn{2}{|c|}{ FEMCABLE } \\
\hline Modo & Período (s) & Frequência $(\mathrm{Hz})$ & Período (s) & Frequência $(\mathrm{Hz})$ \\
\hline 1 & 251,43 & 0,00398 & 250,91 & 0,00399 \\
\hline 2 & 127,47 & 0,00785 & 127,22 & 0,00786 \\
\hline 3 & 90,17 & 0,01109 & 90,03 & 0,01111 \\
\hline 4 & 74,72 & 0,01338 & 74,59 & 0,01341 \\
\hline 5 & 59,81 & 0,01672 & 59,69 & 0,01675 \\
\hline 6 & 57,72 & 0,01733 & 57,98 & 0,01725 \\
\hline 7 & 48,75 & 0,02051 & 48,65 & 0,02055 \\
\hline 8 & 41,30 & 0,02421 & 41,22 & 0,02426 \\
\hline 9 & 36,48 & 0,02741 & 36,41 & 0,02746 \\
\hline 10 & 33,04 & 0,03026 & 32,98 & 0,03032 \\
\hline 11 & 29,71 & 0,03366 & 29,65 & 0,03373 \\
\hline 12 & 28,55 & 0,03502 & 28,65 & 0,03490 \\
\hline 13 & 26,77 & 0,03735 & 26,71 & 0,03743 \\
\hline 14 & 24,42 & 0,04096 & 24,36 & 0,04104 \\
\hline 15 & 22,63 & 0,04418 & 22,59 & 0,04427 \\
\hline 16 & 21,15 & 0,04728 & 21,10 & 0,04739 \\
\hline 17 & 19,70 & 0,05076 & 19,65 & 0,05088 \\
\hline 18 & 19,09 & 0,05238 & 19,14 & 0,05223 \\
\hline 19 & 18,37 & 0,05443 & 18,33 & 0,05456 \\
\hline 20 & 17,25 & 0,05798 & 17,21 & 0,05812 \\
\hline 21 & 16,33 & 0,06125 & 16,29 & 0,06139 \\
\hline 22 & 15,49 & 0,06454 & 15,46 & 0,06470 \\
\hline 23 & 14,68 & 0,06811 & 14,64 & 0,06829 \\
\hline 24 & 14,39 & 0,06951 & 14,42 & 0,06934 \\
\hline 25 & 13,93 & 0,07178 & 13,89 & 0,07198 \\
\hline 26 & 13,28 & 0,07530 & 13,24 & 0,07550 \\
\hline 27 & 12,72 & 0,07864 & 12,68 & 0,07886 \\
\hline 28 & 12,18 & 0,08211 & 12,14 & 0,08235 \\
\hline 29 & 11,66 & 0,08578 & 11,62 & 0,08604 \\
\hline 30 & 11,56 & 0,08652 & 11,58 & 0,08632 \\
\hline
\end{tabular}


5.2.7.2 Sem correnteza e com atrito $\mu=0,4$

Tabela 5.10: Frequências naturais - sem correnteza e com atrito $\mu=0,4$

\begin{tabular}{|c|c|c|c|c|}
\hline & \multicolumn{2}{|c|}{ ORCAFLEX $^{\mathrm{TM}}$} & \multicolumn{2}{|c|}{ FEMCABLE } \\
\hline Modo & Período $(\mathrm{s})$ & Frequência $(\mathrm{Hz})$ & Período (s) & Frequência $(\mathrm{Hz})$ \\
\hline 1 & 66,06 & 0,01514 & 66,28 & 0,01509 \\
\hline 2 & 57,48 & 0,01740 & 57,98 & 0,01725 \\
\hline 3 & 31,65 & 0,03159 & 31,74 & 0,03151 \\
\hline 4 & 28,46 & 0,03513 & 28,65 & 0,03491 \\
\hline 5 & 20,87 & 0,04791 & 20,92 & 0,04779 \\
\hline 6 & 19,04 & 0,05252 & 19,14 & 0,05223 \\
\hline 7 & 15,59 & 0,06415 & 15,63 & 0,06400 \\
\hline 8 & 14,35 & 0,06968 & 14,42 & 0,06934 \\
\hline 9 & 12,45 & 0,08035 & 12,48 & 0,08015 \\
\hline 10 & 11,53 & 0,08671 & 11,58 & 0,08632 \\
\hline 11 & 10,36 & 0,09652 & 10,39 & 0,09629 \\
\hline 12 & 9,65 & 0,10363 & 9,69 & 0,10320 \\
\hline 13 & 8,87 & 0,11268 & 8,90 & 0,11241 \\
\hline 14 & 8,30 & 0,12048 & 8,33 & 0,12002 \\
\hline 15 & 7,76 & 0,12884 & 7,78 & 0,12853 \\
\hline 16 & 7,28 & 0,13727 & 7,31 & 0,13677 \\
\hline 17 & 6,90 & 0,14501 & 6,91 & 0,14467 \\
\hline 18 & 6,49 & 0,15402 & 6,51 & 0,15349 \\
\hline 19 & 6,20 & 0,16119 & 6,22 & 0,16082 \\
\hline 20 & 5,86 & 0,17073 & 5,88 & 0,17018 \\
\hline 21 & 5,64 & 0,17738 & 5,65 & 0,17700 \\
\hline 22 & 5,34 & 0,18742 & 5,35 & 0,18685 \\
\hline 23 & 5,17 & 0,19360 & 5,18 & 0,19320 \\
\hline 24 & 4,90 & 0,20409 & 4,91 & 0,20350 \\
\hline 25 & 4,77 & 0,20984 & 4,77 & 0,20942 \\
\hline 26 & 4,53 & 0,22075 & 4,54 & 0,22015 \\
\hline 27 & 4,42 & 0,22610 & 4,43 & 0,22568 \\
\hline 28 & 4,21 & 0,23739 & 4,22 & 0,23679 \\
\hline 29 & 4,13 & 0,24239 & 4,13 & 0,24197 \\
\hline 30 & 3,94 & 0,25404 & 3,95 & 0,25343 \\
\hline
\end{tabular}




\subsubsection{Com correnteza de orientação $\psi=30^{\circ}$ e sem atrito}

Tabela 5.11: Frequências naturais - com correnteza de orientação $\psi=30^{\circ}$ e sem atrito

\begin{tabular}{|c|c|c|c|c|}
\hline & \multicolumn{2}{|c|}{ ORCAFLEX $^{\mathrm{TM}}$} & \multicolumn{2}{|c|}{ FEMCABLE } \\
\hline Modo & Período (s) & Frequência $(\mathrm{Hz})$ & Período (s) & Frequência $(\mathrm{Hz})$ \\
\hline 1 & 117,00 & 0,00855 & 118,44 & 0,00844 \\
\hline 2 & 71,63 & 0,01396 & 72,37 & 0,01382 \\
\hline 3 & 49,00 & 0,02041 & 50,74 & 0,01971 \\
\hline 4 & 46,72 & 0,02140 & 46,47 & 0,02152 \\
\hline 5 & 35,75 & 0,02797 & 36,93 & 0,02708 \\
\hline 6 & 29,31 & 0,03412 & 30,25 & 0,03306 \\
\hline 7 & 24,68 & 0,04053 & 25,23 & 0,03964 \\
\hline 8 & 24,23 & 0,04127 & 24,48 & 0,04086 \\
\hline 9 & 20,80 & 0,04807 & 21,51 & 0,04648 \\
\hline 10 & 18,30 & 0,05465 & 18,96 & 0,05273 \\
\hline 11 & 16,85 & 0,05933 & 16,83 & 0,05942 \\
\hline 12 & 16,20 & 0,06172 & 16,76 & 0,05967 \\
\hline 13 & 14,62 & 0,06839 & 15,14 & 0,06607 \\
\hline 14 & 13,29 & 0,07524 & 13,79 & 0,07252 \\
\hline 15 & 12,90 & 0,07753 & 12,85 & 0,07782 \\
\hline 16 & 12,17 & 0,08214 & 12,62 & 0,07926 \\
\hline 17 & 11,25 & 0,08886 & 11,66 & 0,08575 \\
\hline 18 & 10,47 & 0,09550 & 10,83 & 0,09235 \\
\hline 19 & 10,44 & 0,09583 & 10,43 & 0,09586 \\
\hline 20 & 9,75 & 0,10257 & 10,10 & 0,09900 \\
\hline 21 & 9,14 & 0,10941 & 9,48 & 0,10552 \\
\hline 22 & 8,83 & 0,11327 & 8,91 & 0,11218 \\
\hline 23 & 8,60 & 0,11629 & 8,80 & 0,11363 \\
\hline 24 & 8,13 & 0,12307 & 8,42 & 0,11877 \\
\hline 25 & 7,69 & 0,12996 & 7,98 & 0,12535 \\
\hline 26 & 7,64 & 0,13093 & 7,61 & 0,13133 \\
\hline 27 & 7,31 & 0,13678 & 7,58 & 0,13200 \\
\hline 28 & 6,96 & 0,14362 & 7,22 & 0,13857 \\
\hline 29 & 6,74 & 0,14842 & 6,89 & 0,14520 \\
\hline 30 & 6,64 & 0,15049 & 6,72 & 0,14886 \\
\hline
\end{tabular}


5.2.7.4 Com correnteza de orientação $\psi=30^{\circ}$ e com atrito $\mu=0,4$

Tabela 5.12: Frequências naturais - com correnteza de orientação $\psi=30^{\circ}$ e com atrito $\mu$ $=0,4$

\begin{tabular}{|c|c|c|c|c|}
\hline & \multicolumn{2}{|c|}{ ORCAFLEX $^{\mathrm{TM}}$} & \multicolumn{2}{|c|}{ FEMCABLE } \\
\hline Modo & Período $(\mathrm{s})$ & Frequência $(\mathrm{Hz})$ & Período (s) & Frequência $(\mathrm{Hz})$ \\
\hline 1 & 60,05 & 0,01665 & 62,78 & 0,01593 \\
\hline 2 & 46,99 & 0,02128 & 47,34 & 0,02112 \\
\hline 3 & 29,33 & 0,03409 & 30,84 & 0,03242 \\
\hline 4 & 24,54 & 0,04075 & 24,80 & 0,04032 \\
\hline 5 & 19,49 & 0,05130 & 20,61 & 0,04851 \\
\hline 6 & 16,78 & 0,05961 & 17,02 & 0,05875 \\
\hline 7 & 14,62 & 0,06840 & 15,51 & 0,06448 \\
\hline 8 & 12,84 & 0,07788 & 13,11 & 0,07630 \\
\hline 9 & 11,70 & 0,08546 & 12,40 & 0,08066 \\
\hline 10 & 10,42 & 0,09597 & 10,74 & 0,09310 \\
\hline 11 & 9,76 & 0,10250 & 10,27 & 0,09740 \\
\hline 12 & 8,79 & 0,11378 & 9,15 & 0,10929 \\
\hline 13 & 8,37 & 0,11954 & 8,73 & 0,11458 \\
\hline 14 & 7,60 & 0,13151 & 7,98 & 0,12533 \\
\hline 15 & 7,32 & 0,13659 & 7,58 & 0,13196 \\
\hline 16 & 6,71 & 0,14907 & 7,07 & 0,14138 \\
\hline 17 & 6,51 & 0,15364 & 6,70 & 0,14932 \\
\hline 18 & 6,00 & 0,16660 & 6,35 & 0,15754 \\
\hline 19 & 5,86 & 0,17069 & 6,00 & 0,16671 \\
\hline 20 & 5,43 & 0,18402 & 5,75 & 0,17379 \\
\hline 21 & 5,33 & 0,18775 & 5,43 & 0,18403 \\
\hline 22 & 4,96 & 0,20142 & 5,26 & 0,19015 \\
\hline 23 & 4,88 & 0,20481 & 4,97 & 0,20135 \\
\hline 24 & 4,57 & 0,21875 & 4,84 & 0,20658 \\
\hline 25 & 4,51 & 0,22187 & 4,57 & 0,21862 \\
\hline 26 & 4,24 & 0,23608 & 4,48 & 0,22308 \\
\hline 27 & 4,19 & 0,23894 & 4,24 & 0,23590 \\
\hline 28 & 3,95 & 0,25335 & 4,17 & 0,23963 \\
\hline 29 & 3,91 & 0,25601 & 3,95 & 0,25314 \\
\hline 30 & 3,70 & 0,27063 & 3,90 & 0,25623 \\
\hline
\end{tabular}




\subsubsection{Com correnteza de orientação $\psi=90^{\circ}$ e sem atrito}

Tabela 5.13: Frequências naturais - com correnteza de orientação $\psi=90^{\circ}$ e sem atrito

\begin{tabular}{|c|c|c|c|c|}
\hline & \multicolumn{2}{|c|}{ ORCAFLEX ${ }^{\mathrm{TM}}$} & \multicolumn{2}{|c|}{ FEMCABLE } \\
\hline Modo & Período (s) & Frequência $(\mathrm{Hz})$ & Período (s) & Frequência $(\mathrm{Hz})$ \\
\hline 1 & 102,70 & 0,00974 & 97,17 & 0,01029 \\
2 & 78,96 & 0,01267 & 77,07 & 0,01297 \\
3 & 52,84 & 0,01892 & 51,28 & 0,01950 \\
4 & 42,43 & 0,02357 & 42,16 & 0,02372 \\
5 & 36,99 & 0,02704 & 36,70 & 0,02725 \\
6 & 30,36 & 0,03294 & 30,15 & 0,03317 \\
7 & 25,12 & 0,03981 & 24,97 & 0,04004 \\
8 & 23,87 & 0,04189 & 23,91 & 0,04183 \\
9 & 21,36 & 0,04682 & 21,31 & 0,04693 \\
10 & 18,79 & 0,05322 & 18,75 & 0,05333 \\
11 & 16,71 & 0,05985 & 16,70 & 0,05987 \\
12 & 16,56 & 0,06039 & 16,56 & 0,06038 \\
13 & 14,97 & 0,06681 & 14,96 & 0,06686 \\
14 & 13,61 & 0,07348 & 13,60 & 0,07351 \\
15 & 12,84 & 0,07791 & 12,85 & 0,07785 \\
16 & 12,45 & 0,08032 & 12,45 & 0,08032 \\
17 & 11,51 & 0,08692 & 11,51 & 0,08691 \\
18 & 10,68 & 0,09367 & 10,68 & 0,09365 \\
19 & 10,45 & 0,09569 & 10,46 & 0,09562 \\
20 & 9,96 & 0,10040 & 9,96 & 0,10036 \\
21 & 9,34 & 0,10707 & 9,34 & 0,10702 \\
22 & 8,84 & 0,11316 & 8,84 & 0,11311 \\
23 & 8,78 & 0,11388 & 8,79 & 0,11381 \\
24 & 8,30 & 0,12051 & 8,30 & 0,12043 \\
25 & 7,86 & 0,12724 & 7,86 & 0,12716 \\
26 & 7,65 & 0,13067 & 7,66 & 0,13062 \\
27 & 7,46 & 0,13396 & 7,47 & 0,13388 \\
28 & 7,11 & 0,14066 & 7,11 & 0,14056 \\
29 & 6,79 & 0,14735 & 6,79 & 0,14728 \\
30 & 6,75 & 0,14804 & 6,76 & 0,14798 \\
\hline & & & & \\
\hline
\end{tabular}

\subsection{Estudo da estabilidade de configurações de risers instalados em catenária}

Configurações de riser em catenária podem sofrer instabilidades estruturais, havendo a possibilidade de formação de laços na linha, conforme discutido no Capítulo 1. Nessa seção 
são apresentadas as análises de estabilidade dessas configurações, procurando prever as condições críticas, isto é, situações em que existe a possibilidade da formação de laços.

Um parâmetro que pode ser utilizado para caracterizar a geometria de uma configuração de catenária é o ângulo de inclinação do riser (ver Figura 5.26). Em particular, o ângulo de inclinação do topo $\left(\theta_{\text {topo }}\right)$ caracteriza bem a geometria de uma catenária, uma vez que a inclinação máxima nessa configuração ocorre sempre nesse ponto (sem considerar a ação de correntezas marítimas que podem eventualmente modificar a forma da catenária). De fato, o ângulo de inclinação do topo da catenária determina a componente horizontal da força de tração presente ao longo da linha.

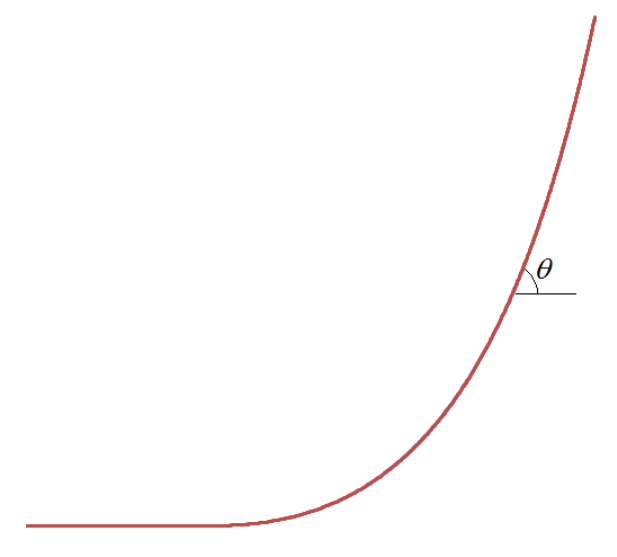

Figura 5.26: Ângulo de inclinação $(\theta)$ de um riser em catenária em relação a um plano horizontal de referência

Durante sua instalação, o riser é sustentado no topo por um conjunto de sapatas localizadas em um navio instalador. As forças envolvidas são provenientes do atrito entre a superfície externa do riser e um conjunto de sapatas localizadas no navio. Dado um coeficiente de atrito entre o o riser e as sapatas, quanto maior a força normal aplicada por essas, maior a força de atrito disponível para sustentar o riser. No entanto, valores elevados de força normal podem causar esmagamentos permanentes na estrutura do riser, aumentando a ovalização inicial de sua seção transversal e tornando-o mais suscetível ao colapso. Desse modo é desejável um nível de tração no topo de menor valor possível durante o lançamento, para que não sejam necessários esforços normais muito elevados para sustentar o riser. Para isso, durante a instalação de risers é comum que se atinjam ângulos de topo próximos de $90^{\circ}$, tornando a componente horizontal da tração quase nula. Esse tipo de configuração proporciona um nível de tração bastante diminuto não só no topo, como também no TDP.

Quando há, além da tração, certo nível de momento de torção aplicado no riser, 
pode ocorrer sua instabilidade estrutural, ocasionando a formação de um laço. Conforme apresentado no Capítulo 2, Liu (1975) apresenta uma teoria relacionando o nível de tração e momento de torção que causariam a instabilidade estrutural de cabos longos, culminando na equação 2.1. Nessa formulação, o autor considera que os esforços solicitantes são constantes ao longo do comprimento do cabo. Essa poderia ser utilizada como uma primeira forma de prever a situação de instabilidade de um riser, desconsiderando sua curvatura inicial e a variação de esforços solicitantes ao longo da linha. A equação 2.1 também pode ser obtida através da Fórmula de Greenhill (ver Apêndice C), para um caso particular de comprimento infinito. Assim, esse modelo analítico será referenciado nesse trabalho simplesmente como "Greenhill".

O surgimento da tração em uma configuração de catenária ocorre devido à ação do peso próprio do riser. O nível mais baixo de tração de toda a configuração é localizado no TDP $\left(T_{t d p}\right)$. Trata-se de um parâmetro que possui grande importância para o estudo da estabilidade estrutural da catenária. Conforme discutido no Capítulo 1, a fonte da ocorrência do momento de torção na linha pode ser o acoplamento entre esforços de tração e rotações axiais de um riser, devido ao desbalanço de torque suportado por suas armaduras de tração. Estando as extremidades opostas da linha impedidas de girar livremente, o momento de torção se acumula quando a linha é submetida a um carregamento de tração. Além disso, o momento de torção pode ser acrescido (ou diminuído) quando ocorrem rotações na unidade flutuante. Em casos de catenárias com ângulo de topo próximo de $90^{\circ}$, rotações do tipo yaw sensibilizam a variação do momento de torção.

Deseja-se responder à seguinte pergunta: dada uma configuração de riser em catenária com seus esforços solicitantes distribuídos ao longo da linha, qual o nível de momento de torção incorporado à linha tal que haja a possibilidade da formação de laços? A resposta a essa pergunta exige uma metodologia para incorporar o momento de torção ao riser e verificar seu nível crítico.

A equação constitutiva de um tubo flexível ou cabo umbilical real pode possuir termos cruzados entre os graus de liberdade de tração e torção, pelos motivos já expostos no Capítulo 1. No entanto, nesse trabalho considerou-se essa equação constitutiva com contribuições cruzadas nulas, conforme apresentado no Capítulo 4. Do ponto de vista de solução numérica do modelo, optou-se por incorporar esse efeito na linha posteriormente à solução estática da catenária (já considerados todos os outros efeitos relevantes para a configuração). Para tal, poder-se-ia impor a rotação na direção axial do riser em uma das extremidades da catenária, ou impor um momento de torção, sendo decorrente a rotação 
em seu ponto de aplicação. Apesar de serem muito semelhantes, ambas as formas podem apresentar diferentes previsões de instabilidade. Conforme discutido para o problema de treliças de von Mises com dois graus de liberdade no Capítulo 3, um estudo comparativo entre a imposição da rotação ou do momento se torna relevante para a presente aplicação e é mostrada no ítem 5.3.1.

Procurando-se tratar o problema prático da ocorrência de possibilidade de formação de laços durante a instalação desse tipo de configuração, procurou-se estudar famílias de catenárias com diferentes valores de ângulo de topo, mas focando-se em valores próximos de $90^{\circ}$. Considerou-se um exemplo de cabo umbilical típico, cujas propriedades se encontram na Tabela 5.7. Os dados referentes ao ambiente se encontram na Tabela 5.8.

Em todas as análises numéricas foi utilizado o software FEMCABLE, e foi seguida a seguinte sequência de passos de carregamento:

1. Fixação da origem do riser (âncora) e imposição de deslocamento em $Z$ da outra extremidade para a cota da plataforma, a fim de tracionar a estrutura, fazendo-a adquirir rigidez geométrica.

2. Inserção do carregamento do peso próprio na estrutura, pré tensionada no primeiro passo.

3. Alívio da tração da estrutura, feito através da imposição de um deslocamento na direção $X$ à extremidade do riser oposta à âncora, até que sua projeção horizontal chegue exatamente no valor imposto para o modelo. Quando há correnteza marítima, a mesma é inserida também nesse passo ou ao final do mesmo, em um passo adicional. Ao fim, tem-se a configuração de catenária cuja estabilidade se deseja investigar.

4. Imposição de rotação ou momento de torção na direção $X$ (alinhada à direção axial ao riser) na extremidade inferior do mesmo ${ }^{2}$. Durante esse passo é que pode ocorrer a formação de um laço, instabilizando a estrutura. A aplicação da torção no ponto inferior do riser permite obter esforços solicitantes de momento de torção essencialmente constantes ao longo de seu comprimento de maneira semelhante à imposição de rotação na extremidade superior, pois o momento de torção reativo no topo possui o mesmo valor do obtido como reação vincular na extremidade inferior

\footnotetext{
${ }^{2}$ Note que durante esse passo de carregamento as rotações transversais ao riser são fixas e nulas no ponto de imposição de rotação de tal forma que, conforme discutido no Capítulo 3 e Apêndice C, o momento aplicado seja conservativo.
} 
(na direção axial do riser). Assim, a escolha da extremidade para aplicação da rotação que sensibiliza a formação do laço é arbitrária.

Foram analisados diversos valores de comprimentos $L$ de riser, que resultaram nos ângulos de topo descritos na Tabela 5.14. A mesma tabela contém o valor da tração inicial do TDP $\left(T_{t d p}\right)$ da configuração de catenária, obtido através do software FEMCABLE, ao final do terceiro passo enumerado anteriormente. Esse valor representa uma ordem de grandeza do nível de tração que irá reger o problema de instabilidade. No entanto, não deve ser tratado como um valor constante, uma vez que tanto a posição do TDP como o valor da tração nesse ponto podem sofrer alterações durante a ação do momento de torção aplicado ao riser no quarto passo.

Fazendo uso da equação 2.1 (Greenhill) para uma primeira estimativa dos valores dos momentos de torção críticos é possível utilizar a tração inicial do TDP para obter os valores mostrados na Tabela 5.14. É possível construir um gráfico relacionando o momento de torção crítico com o ângulo de topo da configuração de catenária. Esse está representado na Figura 5.27.

Tabela 5.14: Configurações analisadas de um cabo umbilical e suas predições analíticas de carga crítica

\begin{tabular}{|l|c|c|c|}
\hline$L(\mathrm{~m})$ & $\theta_{\text {topo }}$ (graus) & $T_{t d p}(\mathrm{~N})$ & Momento de torção crítico $\sqrt{4 T_{t d p} E I}(\mathrm{~N} . \mathrm{m})$ \\
\hline 1.001 & 89,93 & 165,99 & $1.827,48$ \\
1.002 & 89,88 & 293,72 & $2.430,98$ \\
1.003 & 89,82 & 427,05 & $2.931,25$ \\
1.005 & 89,71 & 701,66 & $3.757,30$ \\
1.007 & 89,6 & 980,76 & $4.442,17$ \\
1.010 & 89,43 & $1.402,93$ & $5.312,91$ \\
1.020 & 88,86 & $2.823,58$ & $7.537,26$ \\
1.030 & 88,29 & $4.259,29$ & $9.257,26$ \\
1.040 & 87,74 & $5.709,27$ & $10.717,76$ \\
1.050 & 87,18 & $7.173,30$ & $12.013,61$ \\
1.100 & 84,5 & $14.702,30$ & $17.199,13$ \\
1.150 & 81,95 & $22.579,14$ & $21.314,13$ \\
\hline
\end{tabular}




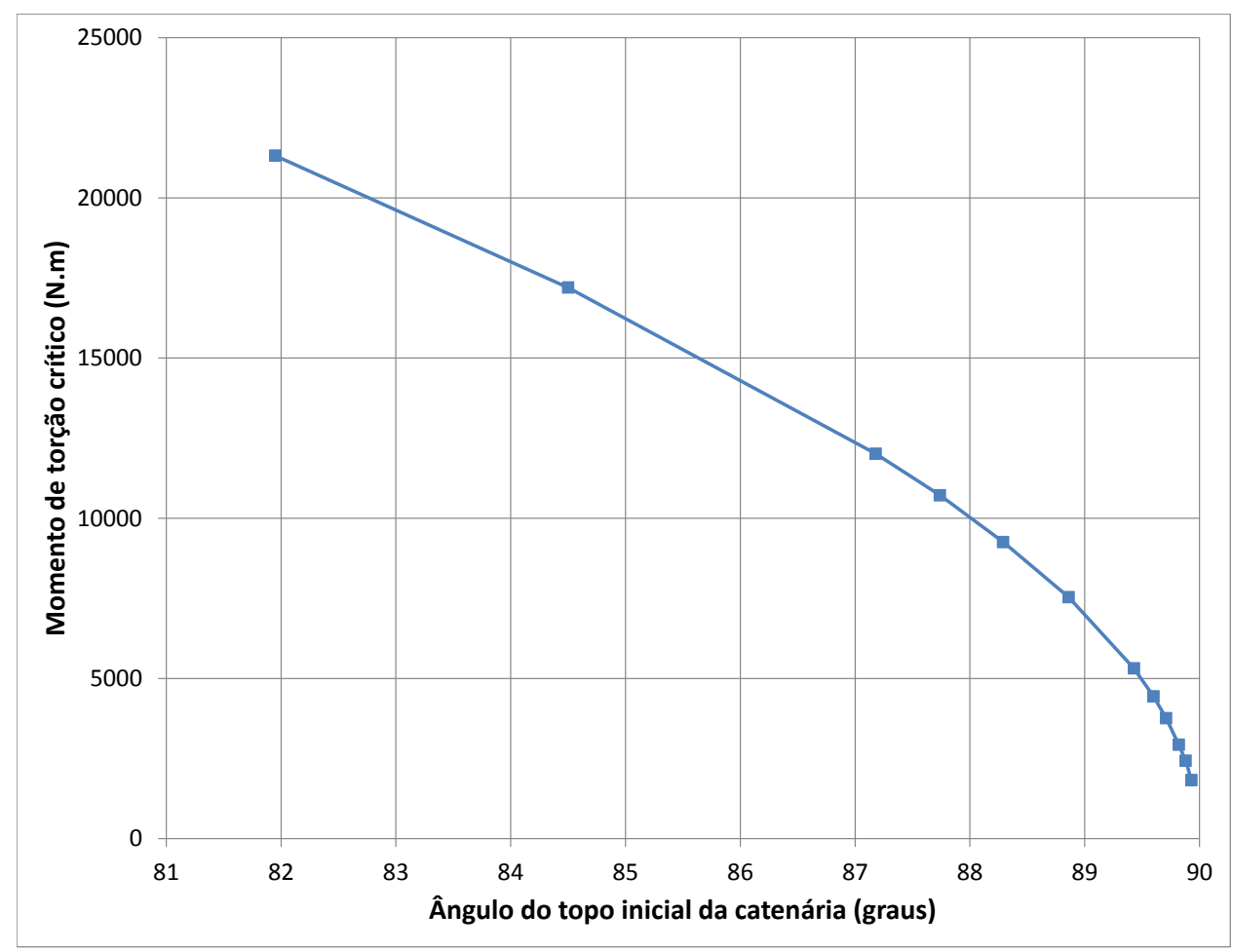

Figura 5.27: Momento de torção crítico versus ângulo do topo da configuração de catenária. Modelo analítico de Greenhill

\subsubsection{Comparação entre a imposição do momento e da rotação}

A presente seção discute as diferenças entre a imposição do momento de torção e a rotação no riser, uma vez que pode haver diferentes interpretações de estabilidade da estrutura dependendo da condição considerada. Em primeiro lugar, a escolha entre imposição de momento ou rotação deve obedecer a um critério físico, acerca de qual a real situação do problema que se está resolvendo. No entanto, no presente trabalho tanto a imposição do momento como da rotação não são a forma exata em que a torção aparece no problema real, mas são artifícios numéricos para reproduzir a situação de torção acumulada no riser. Assim, surge a natural pergunta: quais as diferenças entre essas abordagens para o presente problema e suas implicações na análise de estabilidade?

Para responder à pergunta, foi considerado um caso-exemplo do modelo que considera o cabo umbilical descrito na Tabela 5.7 no cenário descrito na Tabela 5.8, desconsiderando atrito entre o riser e o solo e correntezas marítimas. Nessa situação resolveram-se os três passos iniciais de carregamento descritos no ítem anterior, e no quarto passo foram simuladas duas condições diferentes: imposição de momento $(\mathrm{M})$ e imposição de rota- 
ção (R). As trajetórias de equilíbrio obtidas, bem como as evoluções dos autovalores e frequências naturais mínimas estão mostradas na Figura 5.28.

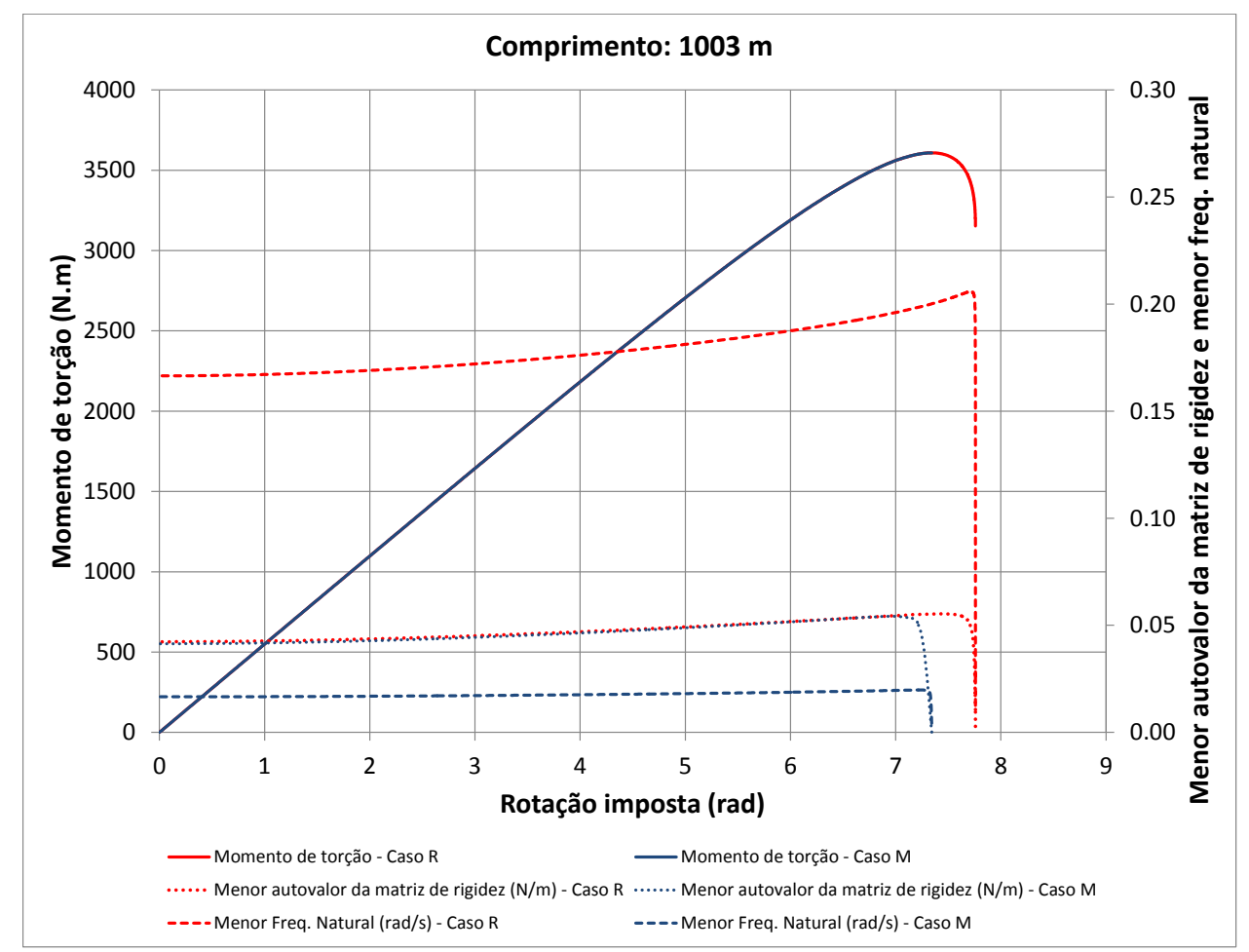

Figura 5.28: Comparação entre a imposição de momento de torção e imposição de rotação axial no estudo de estabilidade.

Note que no caso de imposição de momento a previsão de instabilidade tanto pelos critérios estáticos como cinéticos está relacionada ao ponto limite da trajetória de equilíbrio. Trata-se uma situação em que, no caso de tentar aumentar o valor do momento, resultaria em um salto dinâmico do tipo snap-through. Já quando se impõe a rotação, os critérios de estabilidade estático e cinético mostram que a instabilidade seria não mais associada ao ponto limite, mas ao ponto de snapback. Nesse caso, ao tentar incrementar a rotação ocorreria um salto dinâmico denominado snapdown.

Utilizando-se do FEMCABLE, no qual foi implementado o Método de NewtonRaphson, é possível realizar incrementos parciais de momentos ou rotações impostas e achar soluções intermediárias. Essas soluções parciais é que foram utilizadas para construir as curvas da Figura 5.28. No entanto, o Método de Newton-Raphson não pode realizar decrementos de carregamentos impostos. Para isso, seria necessário utilizar-se de outros métodos, como por exemplo o Arc-length que, justamente, surge com o objetivo de solucionar essa limitação. No entanto, no contexto desse trabalho o objetivo é determinar as condições para ocorrência do laço e, não a configuração pós-formação do mesmo. 
Uma vez que existe melhor observação do ponto limite no caso da imposição da rotação, bem como por sua melhor taxa de convergência em relação à imposição do momento, optou-se no presente estudo por impor a rotação na extremidade do riser, sabendo que o último ponto a ser atingido pelo Método de Newton-Raphson é exatamente o snapback. O ponto limite, no entanto, foi considerado como o ponto de ocorrência da instabilidade, uma vez que está associado a uma grande mudança de rigidez da estrutura, registrada na simulação de imposição do momento.

Após a ocorrência do snapback, o decremento de rotação pode ser observado em uma trajetória de equilíbrio em um problema de instabilidade semelhante ao abordado nesse trabalho. Miyazaki e Kondo (1997) apresentam esse comportamento na trajetória de equilíbrio com decremento de ângulo imposto, a partir do ponto S2, visto na Figura 2.6 .

A fim de confrontar as previsões analíticas com resultados numéricos que consideram a variação da tração ao longo da linha, bem como também contemplam a curvatura do riser, foram feitos diferentes modelos. Em cada um, calculou-se o valor do momento de torção crítico. Em todas as simulações realizadas o critério para estabelecer a perda de estabilidade estrutural está relacionado ao comportamento da trajetória de equilíbrio do momento de torção da linha versus a rotação axial do riser imposta. Ainda foram calculados os critérios associados aos autovalores da matriz de rigidez, bem como das frequências naturais da estrutura, já estabelecidos no Capítulo 3.

\subsubsection{Modelo com o TDP engastado}

Nesse modelo foi considerado como domínio computacional somente a parte suspensa do riser, sem incluir a parte que está sobre o solo. A condição de contorno aplicada ao TDP foi um engastamento, não sendo considerado que sua posição pudesse se modificar devido à ação do momento de torção aplicado. Essa hipótese assume que os efeitos do atrito sejam de promover total ancoragem ao riser no TDP quando o mesmo é submetido a um momento de torção. Esse esforço foi introduzido no problema através da imposição de uma rotação axial no próprio TDP. Assim, o modelo considera não exatamente um engaste no TDP, mas que existe nesse ponto um grau de liberdade de rotação axial $\alpha$ não nula que é imposta durante a simulação (recalque angular).

A rotação $\alpha$ estimada analiticamente para causar a instabilidade da catenária pode atingir valores bastante elevados, suficientes para justificar a utilização da descrição lagrangiana atualizada no modelo de elementos finitos, já explicada no Capítulo 4. 
A seguir são mostrados os gráficos que relacionam o momento de torção (calculado como uma reação vincular no TDP, quando se impõe a rotação $\alpha$ ) versus o próprio ângulo de rotação $\alpha$. Essa curva representa uma forma interessante de analisar a estabilidade do sistema pois, espera-se que a relação entre essas grandezas seja linear até certo ponto quando, por meio de uma transformação de torção própria em tortuosidade (ver Apêndice B), naturalmente parte da energia de deformação do sistema seja migrada para a flexão ${ }^{3}$. Quando essa transição de energia de deformação se tornar relevante é esperada uma não linearidade na relação momento de torção reativo $M_{t}$ versus $\alpha$. Isso ocorre pois parte da rotação imposta não será traduzida em momento de torção (energia de deformação por torção) mas, por momentos fletores (energia de deformação por flexão). Essa transição marca o início da formação do laço, sendo a instabilidade, de fato, vista como um pontolimite na trajetória de equilíbrio $M_{t}$ versus $\alpha$, conforme já discutido na seção 5.3.1.

\footnotetext{
${ }^{3}$ A transição de uma configuração de viga que apresente apenas torção própria para uma configuração que envolva a composição de torção própria e tortuosidade é um fenômeno que necessariamente envolverá o surgimento de flexão pois, para surgir a tortuosidade, necessariamente deve-se criar curvatura. Isso pode ser identificado, além de no problema de estabilidade de uma catenária, no problema de formação de um laço em uma barra inicialmente retilínea (ítem 5.2.6).
} 


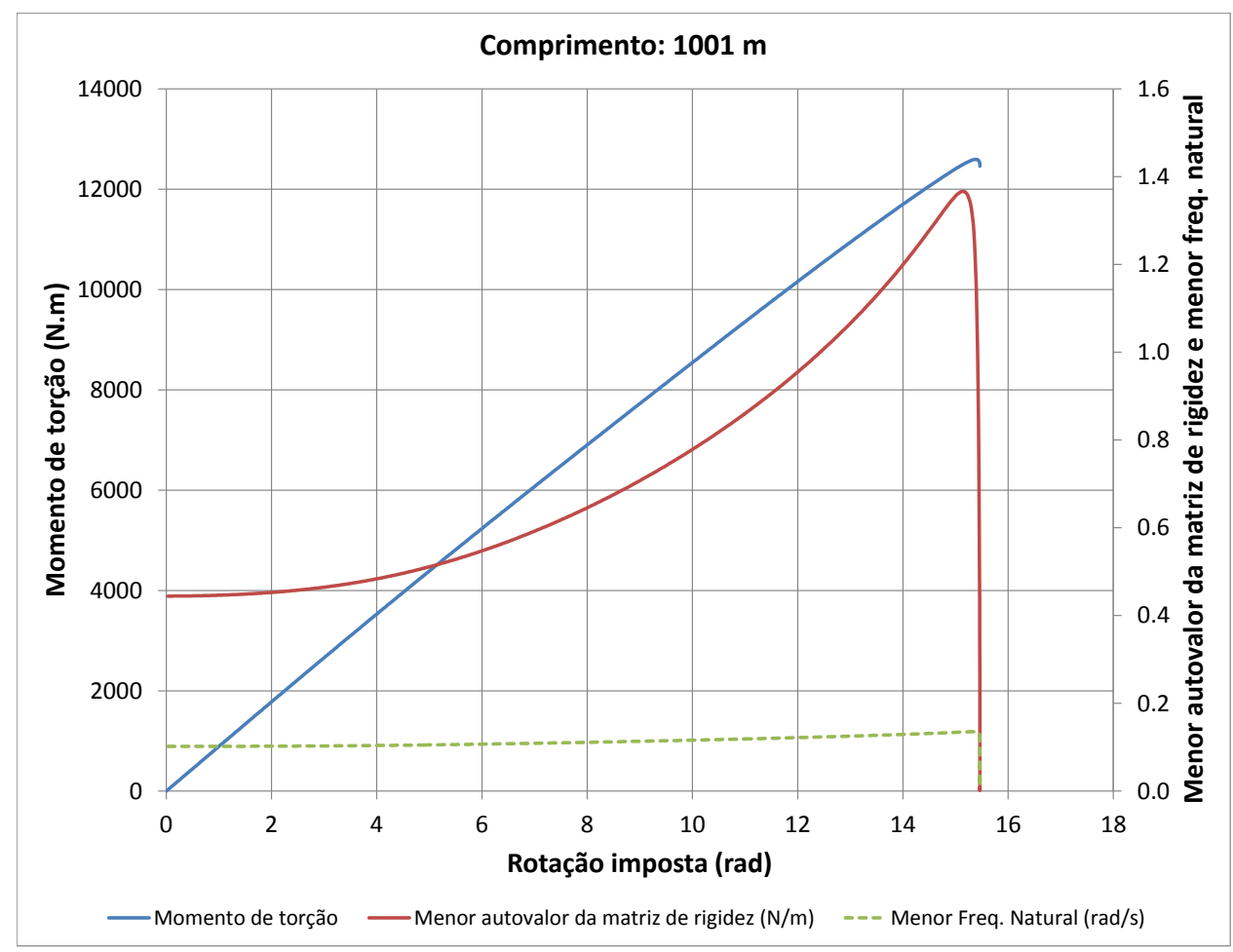

Figura 5.29: Trajetória de equilíbrio $M_{t}$ versus $\alpha$ e evolução do menor autovalor da matriz de rigidez tangente do sistema para o caso $\mathrm{L}=1001 \mathrm{~m}\left(\theta_{\text {topo }}=89,93^{\circ}\right)$. TDP engastado.

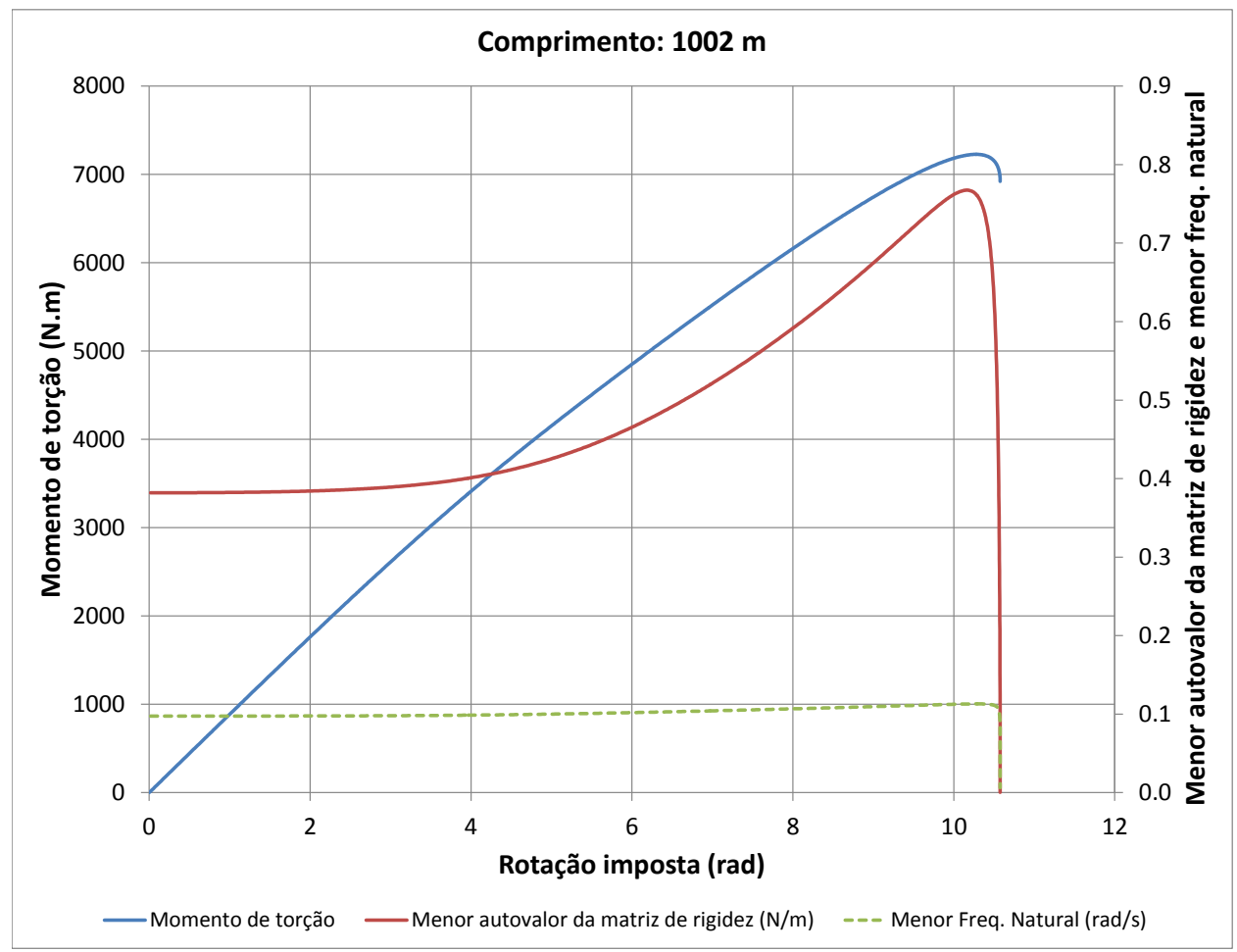

Figura 5.30: Trajetória de equilíbrio $M_{t}$ versus $\alpha$ e evolução do menor autovalor da matriz de rigidez tangente do sistema para o caso $\mathrm{L}=1002 \mathrm{~m}\left(\theta_{\text {topo }}=89,88^{\circ}\right)$. TDP engastado. 


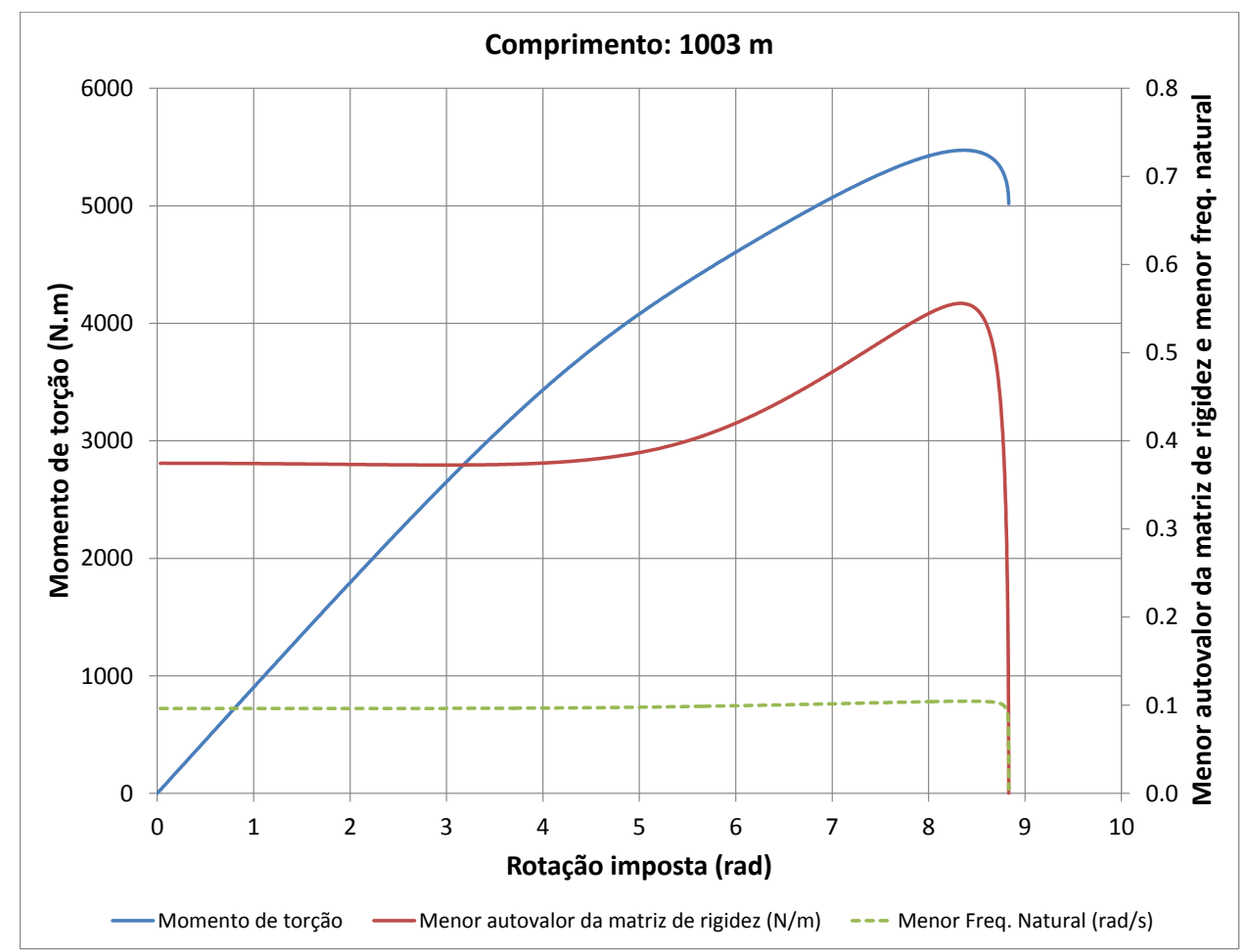

Figura 5.31: Trajetória de equilíbrio $M_{t}$ versus $\alpha$ e evolução do menor autovalor da matriz de rigidez tangente do sistema para o caso $\mathrm{L}=1003 \mathrm{~m}\left(\theta_{\text {topo }}=89,82^{\circ}\right)$. TDP engastado.

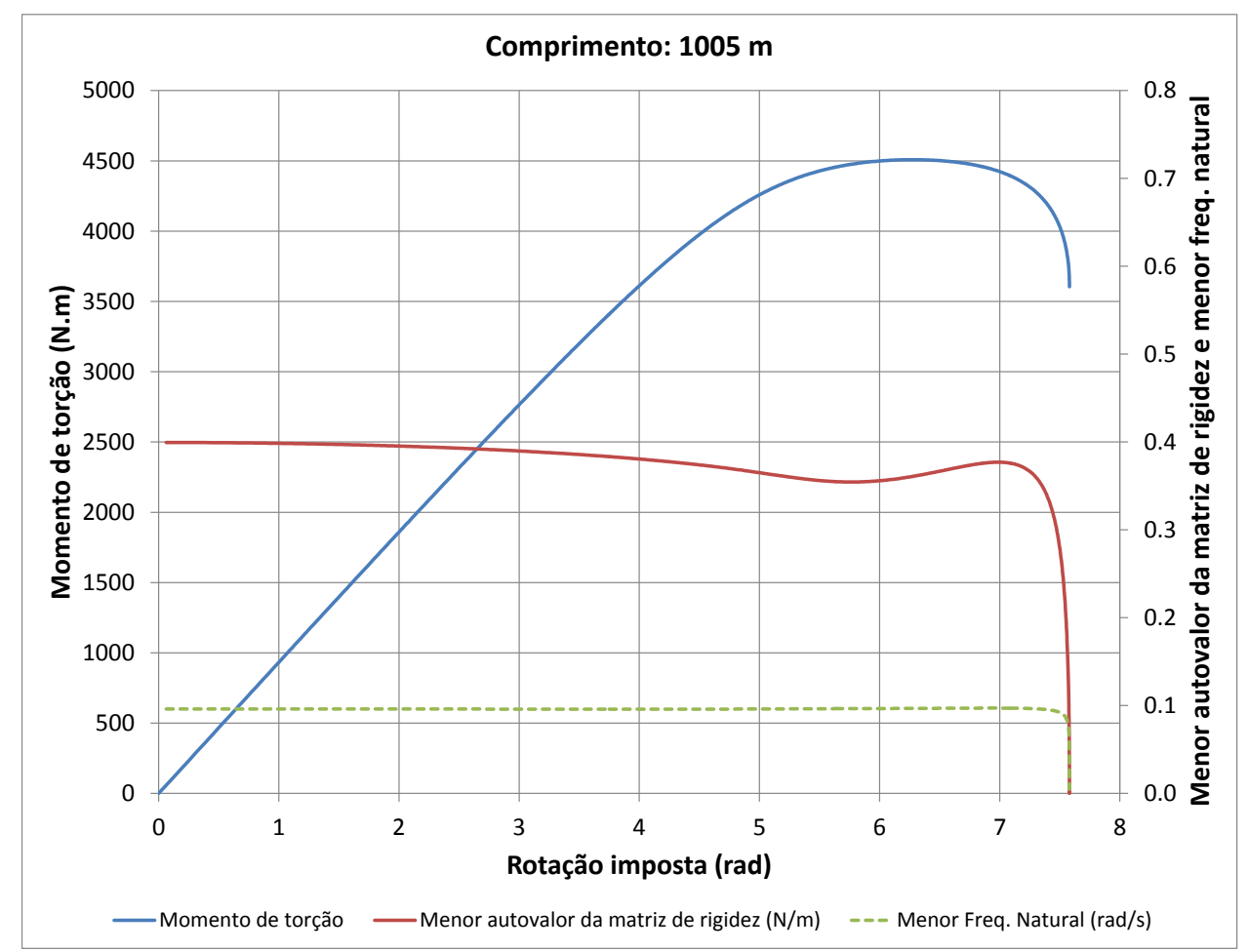

Figura 5.32: Trajetória de equilíbrio $M_{t}$ versus $\alpha$ e evolução do menor autovalor da matriz de rigidez tangente do sistema para o caso $\mathrm{L}=1005 \mathrm{~m}\left(\theta_{\text {topo }}=89,71^{\circ}\right)$. TDP engastado. 


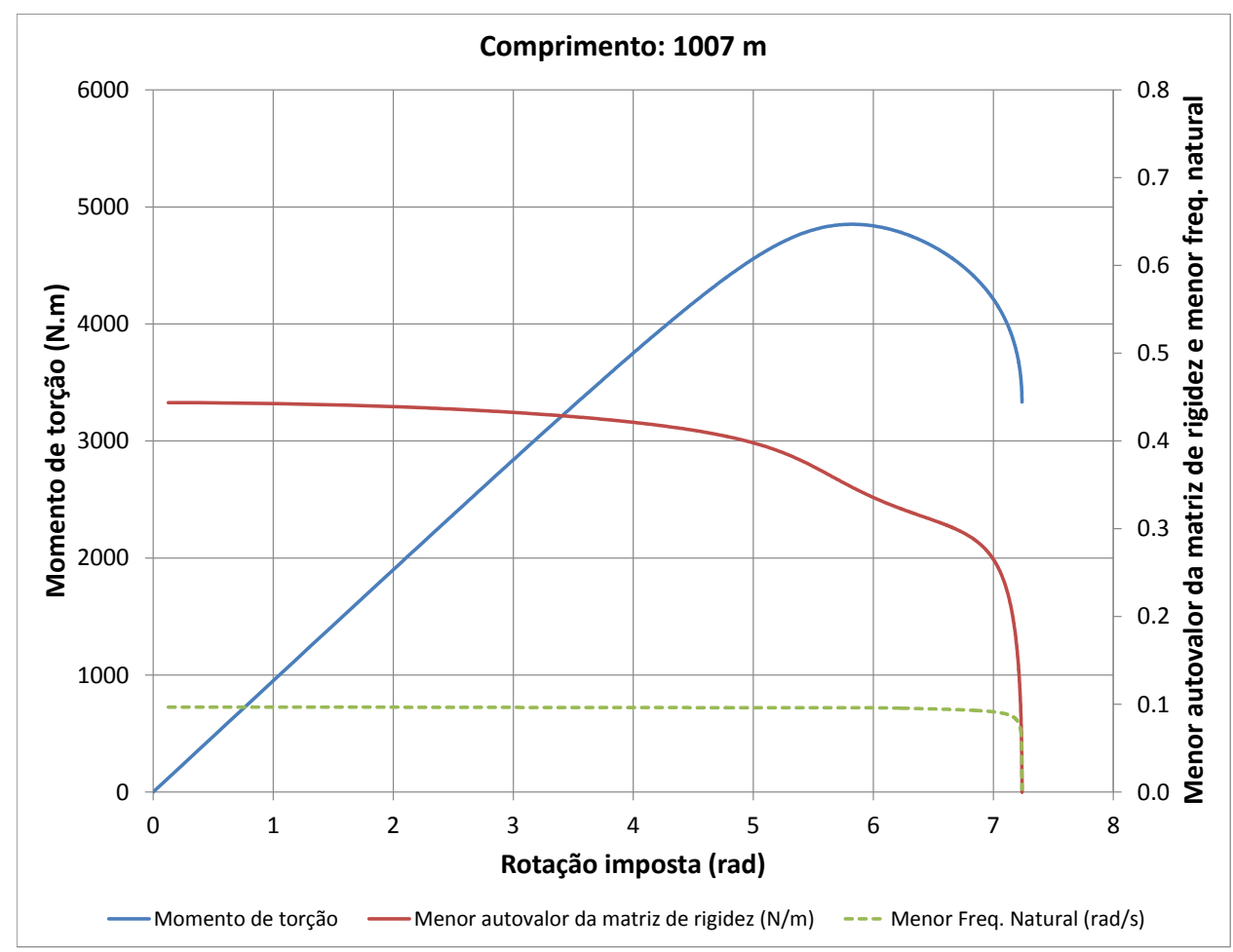

Figura 5.33: Trajetória de equilíbrio $M_{t}$ versus $\alpha$ e evolução do menor autovalor da matriz de rigidez tangente do sistema para o caso $\mathrm{L}=1007 \mathrm{~m}\left(\theta_{\text {topo }}=89,60^{\circ}\right)$. TDP engastado.

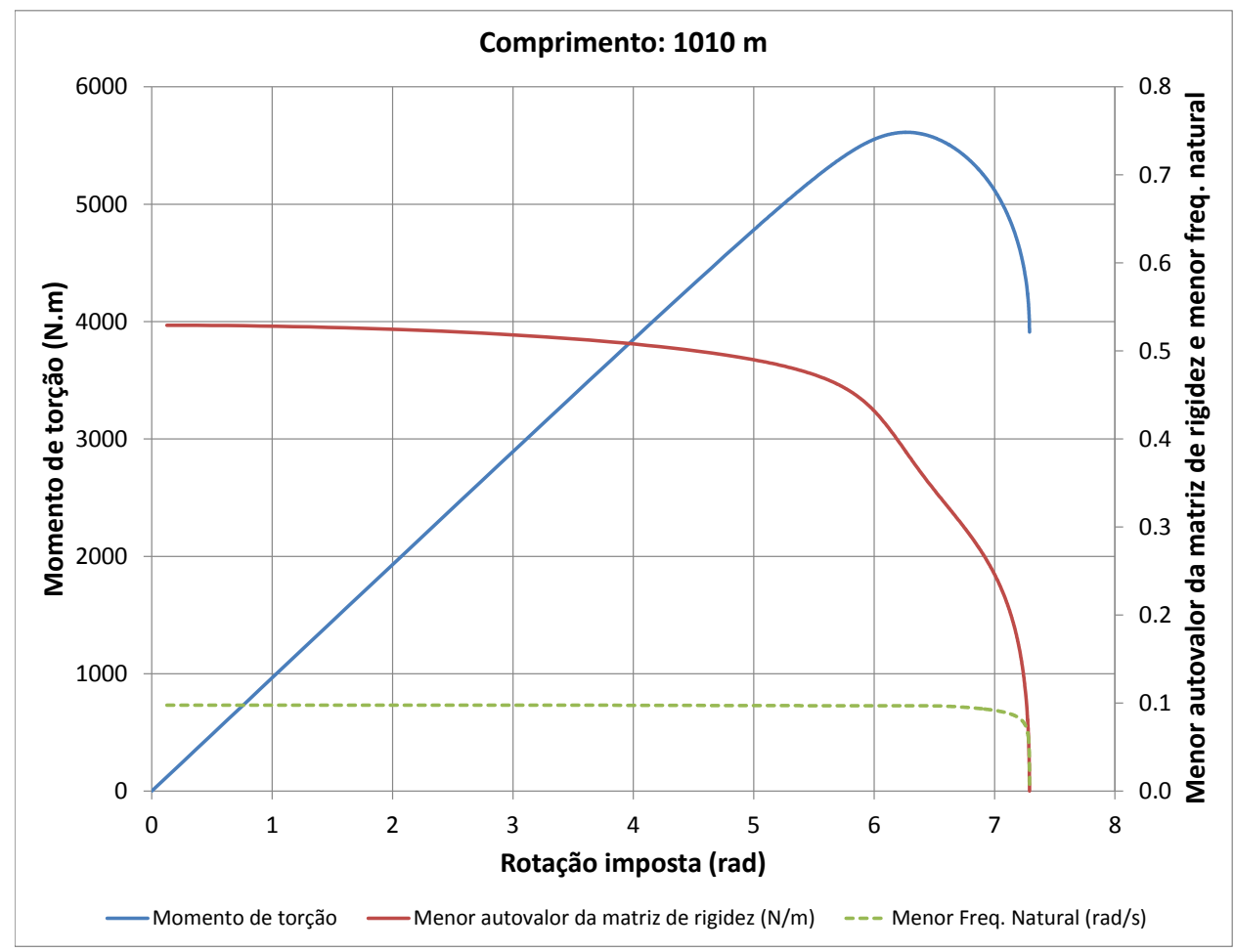

Figura 5.34: Trajetória de equilíbrio $M_{t}$ versus $\alpha$ e evolução do menor autovalor da matriz de rigidez tangente do sistema para o caso $\mathrm{L}=1010 \mathrm{~m}\left(\theta_{\text {topo }}=89,43^{\circ}\right)$. TDP engastado. 


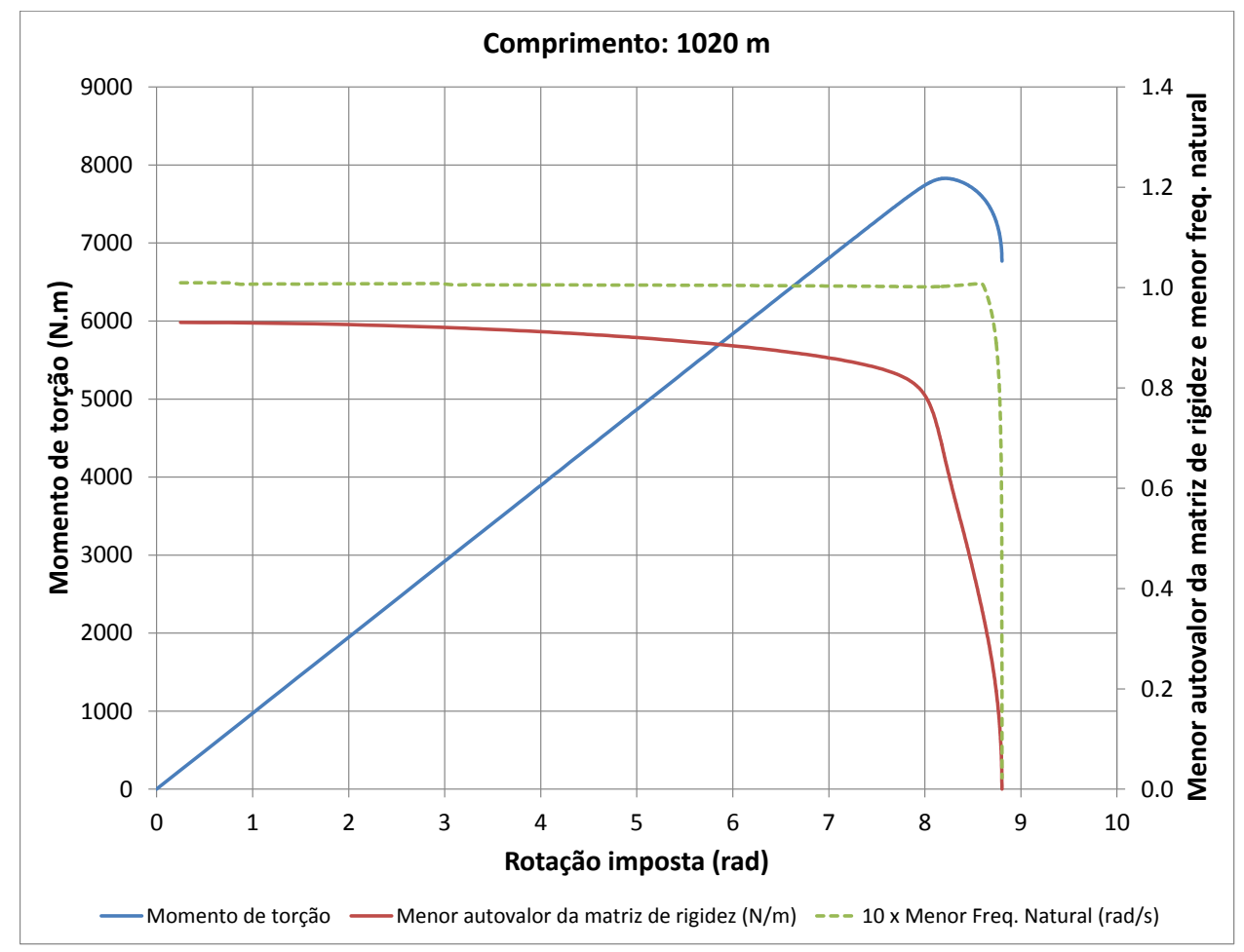

Figura 5.35: Trajetória de equilíbrio $M_{t}$ versus $\alpha$ e evolução do menor autovalor da matriz de rigidez tangente do sistema para o caso $\mathrm{L}=1020 \mathrm{~m}\left(\theta_{\text {topo }}=88,86^{\circ}\right)$. TDP engastado.

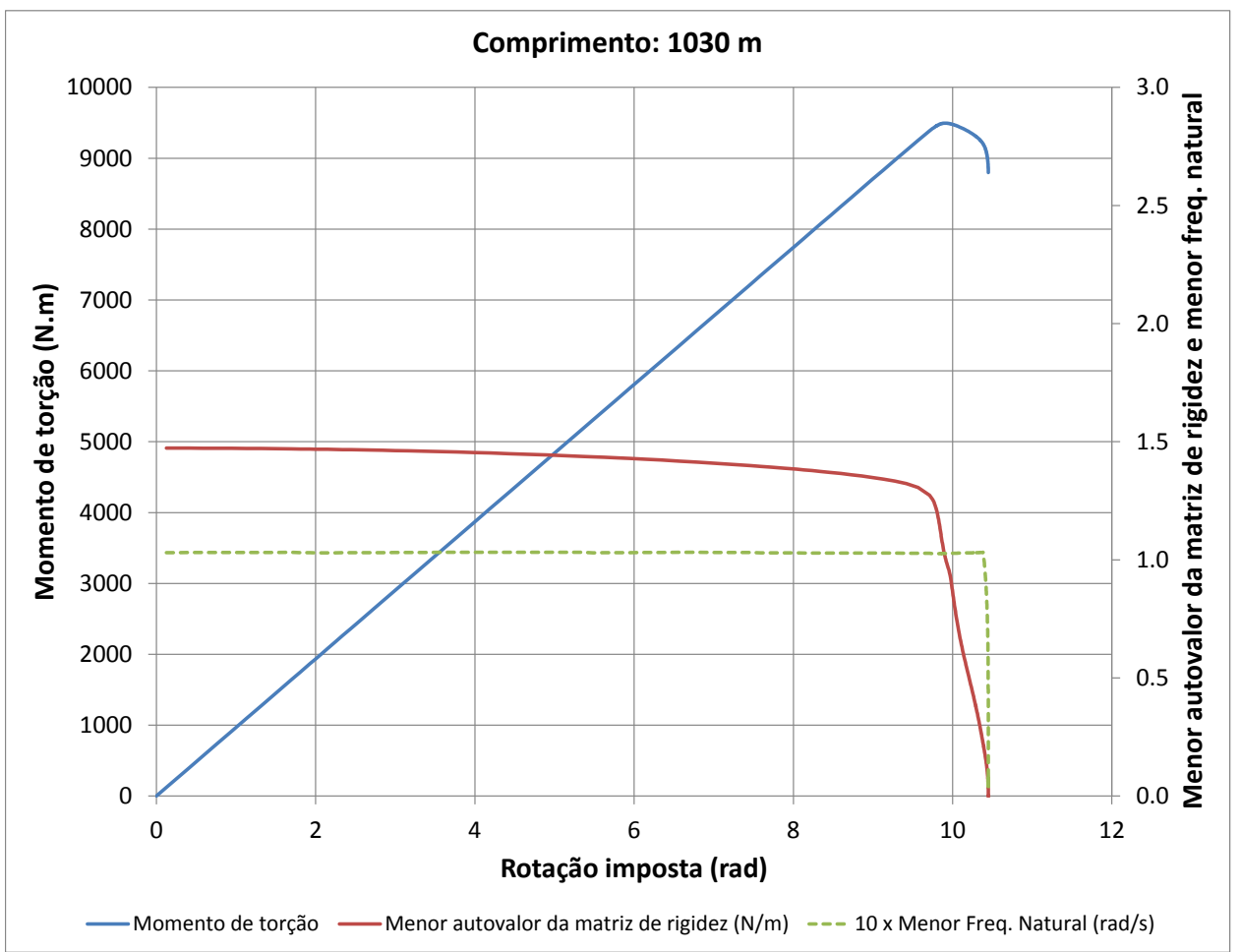

Figura 5.36: Trajetória de equilíbrio $M_{t}$ versus $\alpha$ e evolução do menor autovalor da matriz de rigidez tangente do sistema para o caso $\mathrm{L}=1030 \mathrm{~m}\left(\theta_{\text {topo }}=88,29^{\circ}\right)$. TDP engastado. 


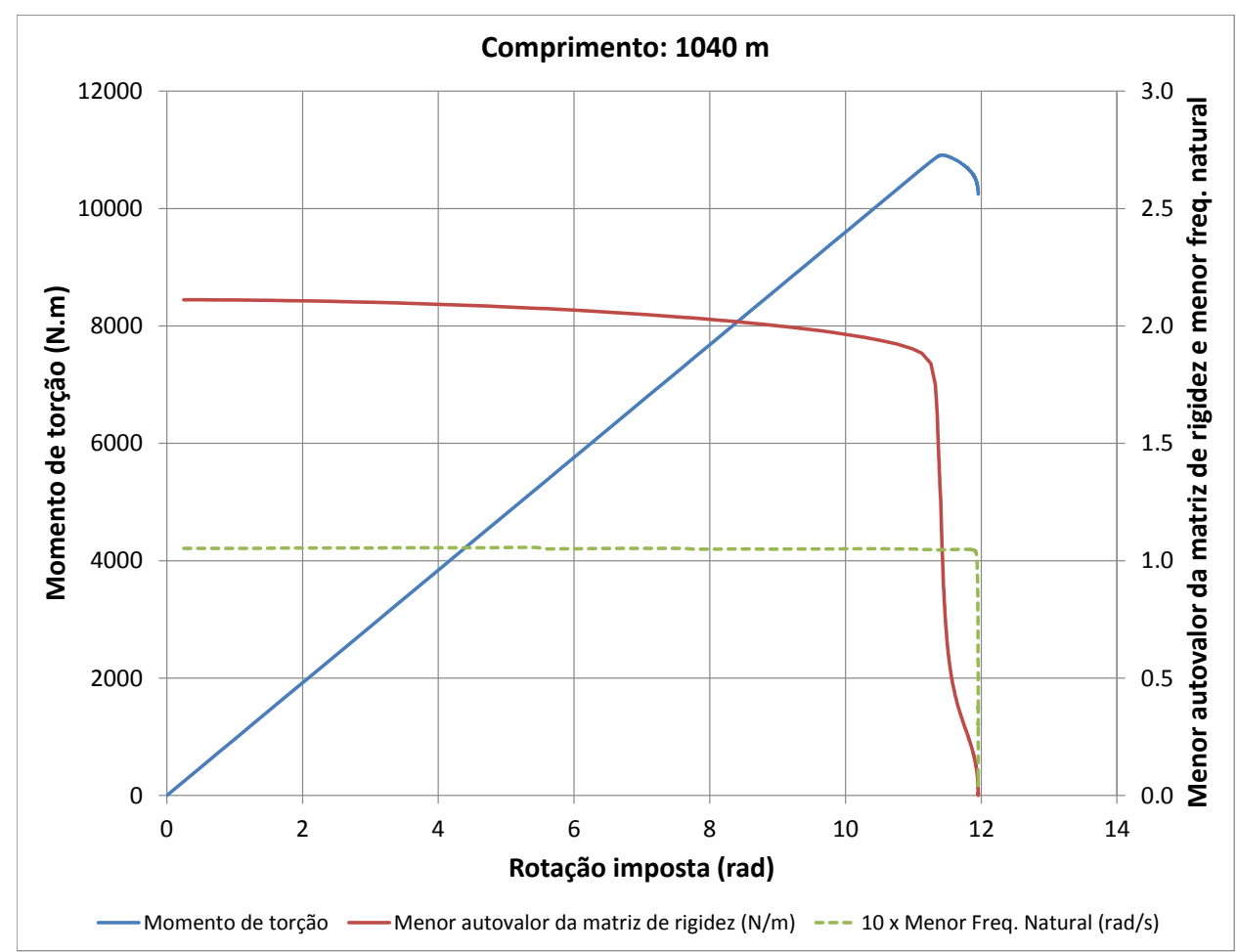

Figura 5.37: Trajetória de equilíbrio $M_{t}$ versus $\alpha$ e evolução do menor autovalor da matriz de rigidez tangente do sistema para o caso $\mathrm{L}=1040 \mathrm{~m}\left(\theta_{\text {topo }}=87,74^{\circ}\right)$. TDP engastado.

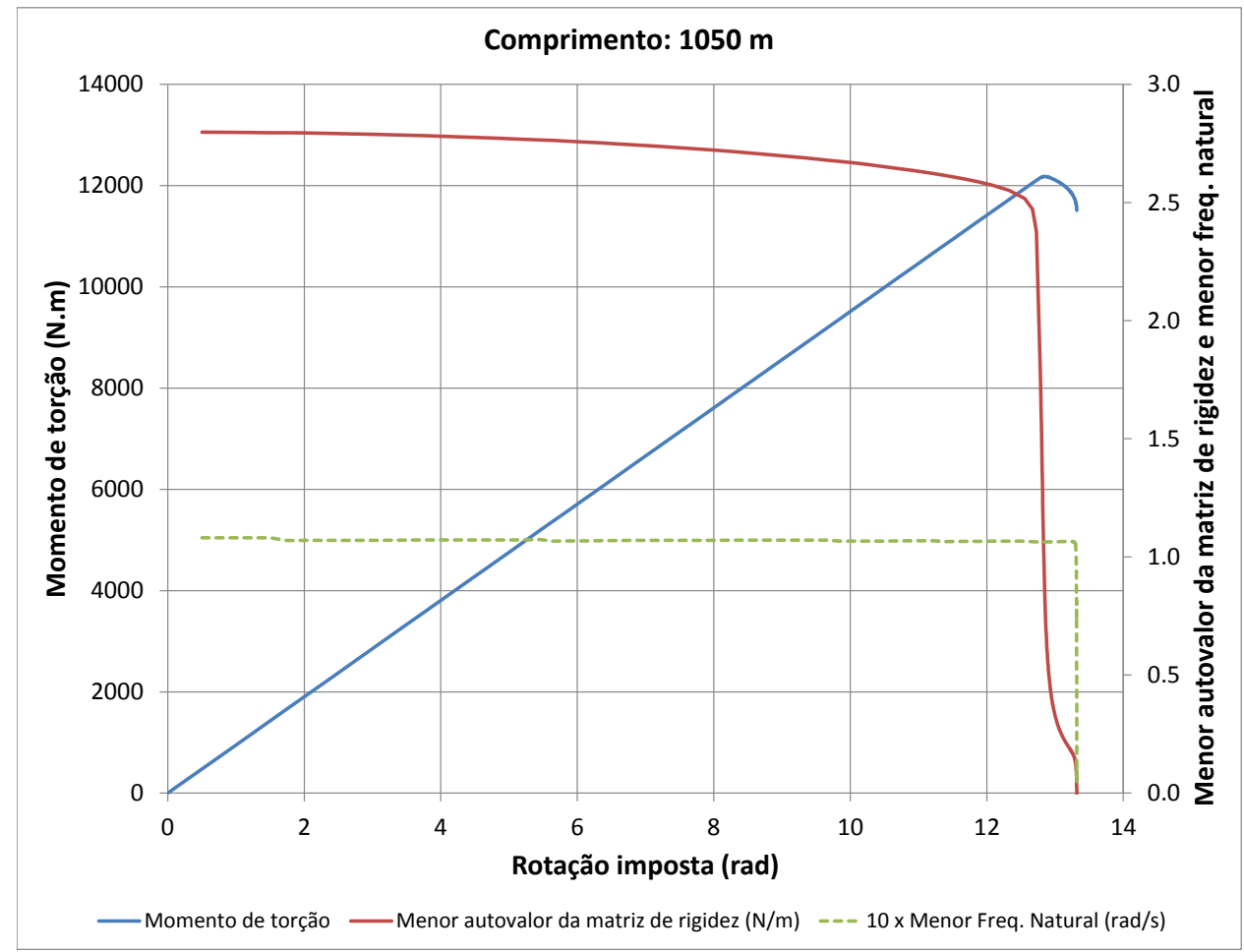

Figura 5.38: Trajetória de equilíbrio $M_{t}$ versus $\alpha$ e evolução do menor autovalor da matriz de rigidez tangente do sistema para o caso $\mathrm{L}=1050 \mathrm{~m}\left(\theta_{\text {topo }}=87,18^{\circ}\right)$. TDP engastado. 


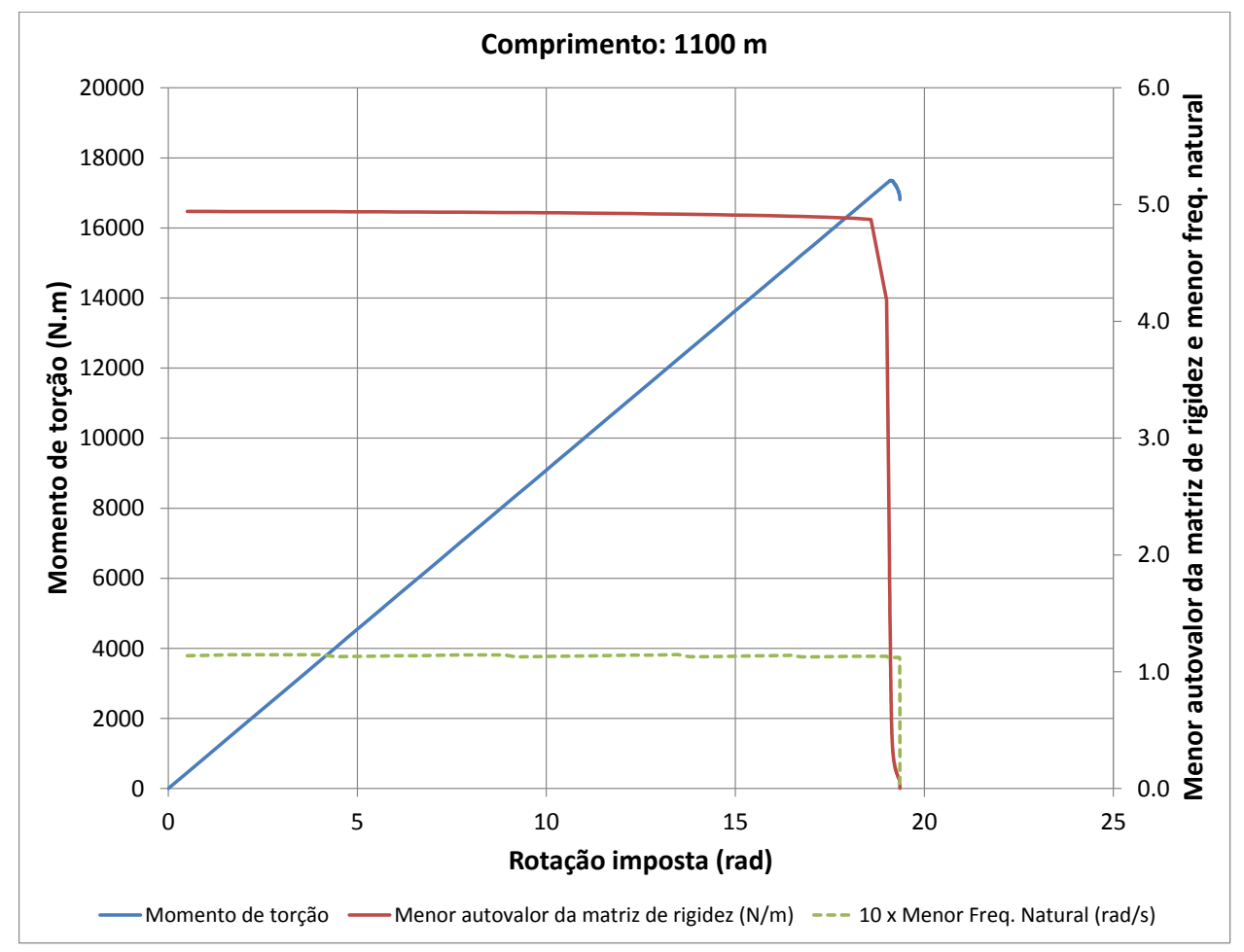

Figura 5.39: Trajetória de equilíbrio $M_{t}$ versus $\alpha$ e evolução do menor autovalor da matriz de rigidez tangente do sistema para o caso $\mathrm{L}=1100 \mathrm{~m}\left(\theta_{\text {topo }}=84,50^{\circ}\right)$. TDP engastado.

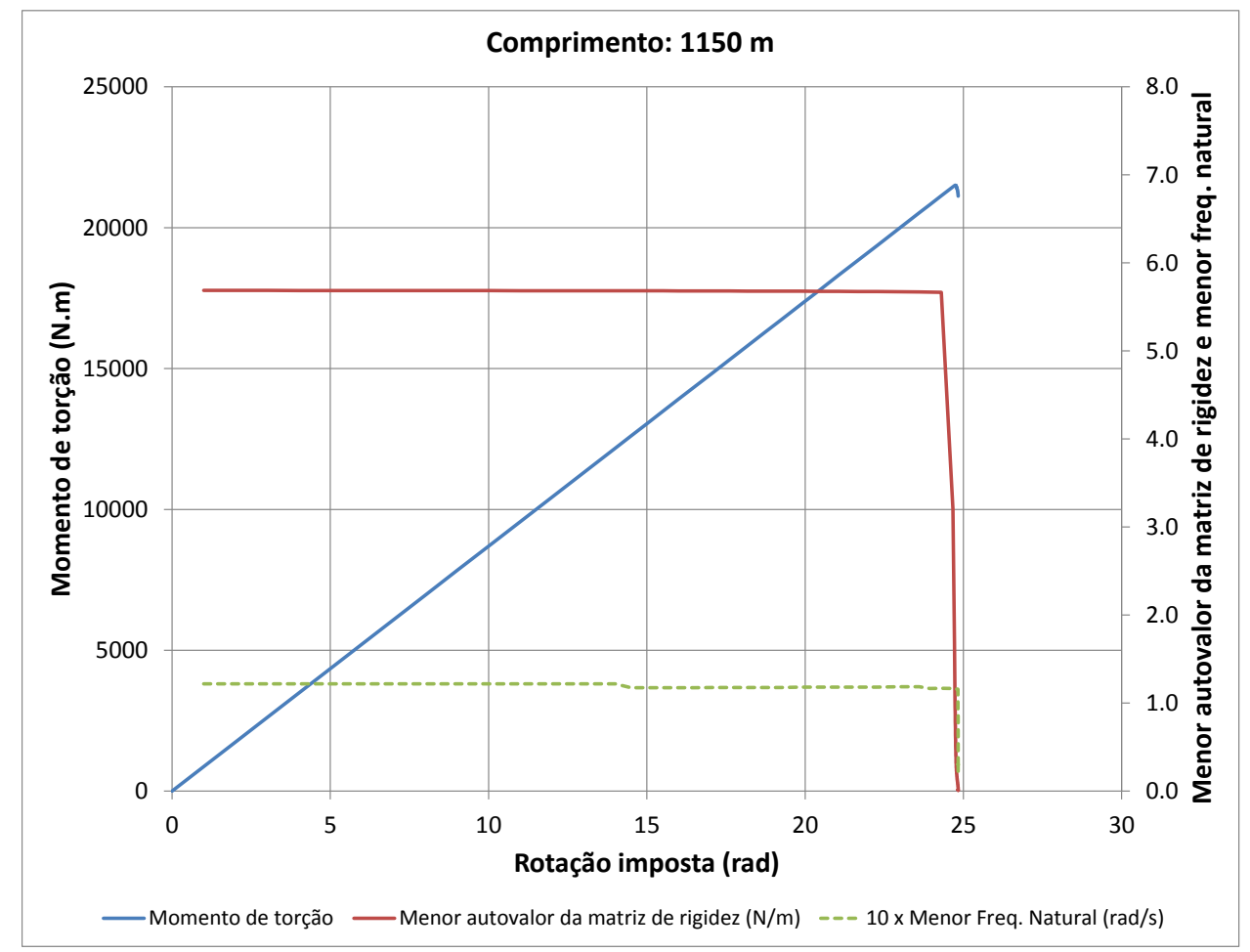

Figura 5.40: Trajetória de equilíbrio $M_{t}$ versus $\alpha$ e evolução do menor autovalor da matriz de rigidez tangente do sistema para o caso $\mathrm{L}=1150 \mathrm{~m}\left(\theta_{\text {topo }}=81,95^{\circ}\right)$. TDP engastado. 
As Figuras 5.29 a 5.40 ilustram as trajetórias de equilíbrio $M_{t}$ versus $\alpha$. Note que a transição para valores negativos do primeiro autovalor da matriz de rigidez, bem como da menor frequência natural ocorrem no ponto de snapback, pois a imposição foi feita na rotação. Antes do snapback, naturalmente a trajetória de equilíbrio passa por um ponto limite. Isso é um resultado esperado segundo o Teorema 9, apresentado no Capítulo 3. Para comparações com o modelo analítico de Greenhill, o valor do momento de torção associado ao ponto limite é considerado como crítico. Quando é difícil identificar o ponto-limite na trajetória de equilíbrio, como pode ser identificado em casos que apresentam maior nível de tração no TDP, a própria queda da rigidez e da menor frequência natural podem ser usadas para identificá-lo, uma vez que nesses sistemas os pontos limite e snapback são tão próximos que coalescem. É possível plotar em uma única curva, conforme foi feito para o modelo analítico de Greenhill, os momentos de torção críticos em função do ângulo de topo da configuração de riser em catenária. Obtém-se a curva da Figura 5.41, na qual também foi plotado o resultado do modelo analítico de Greenhill, para comparação.

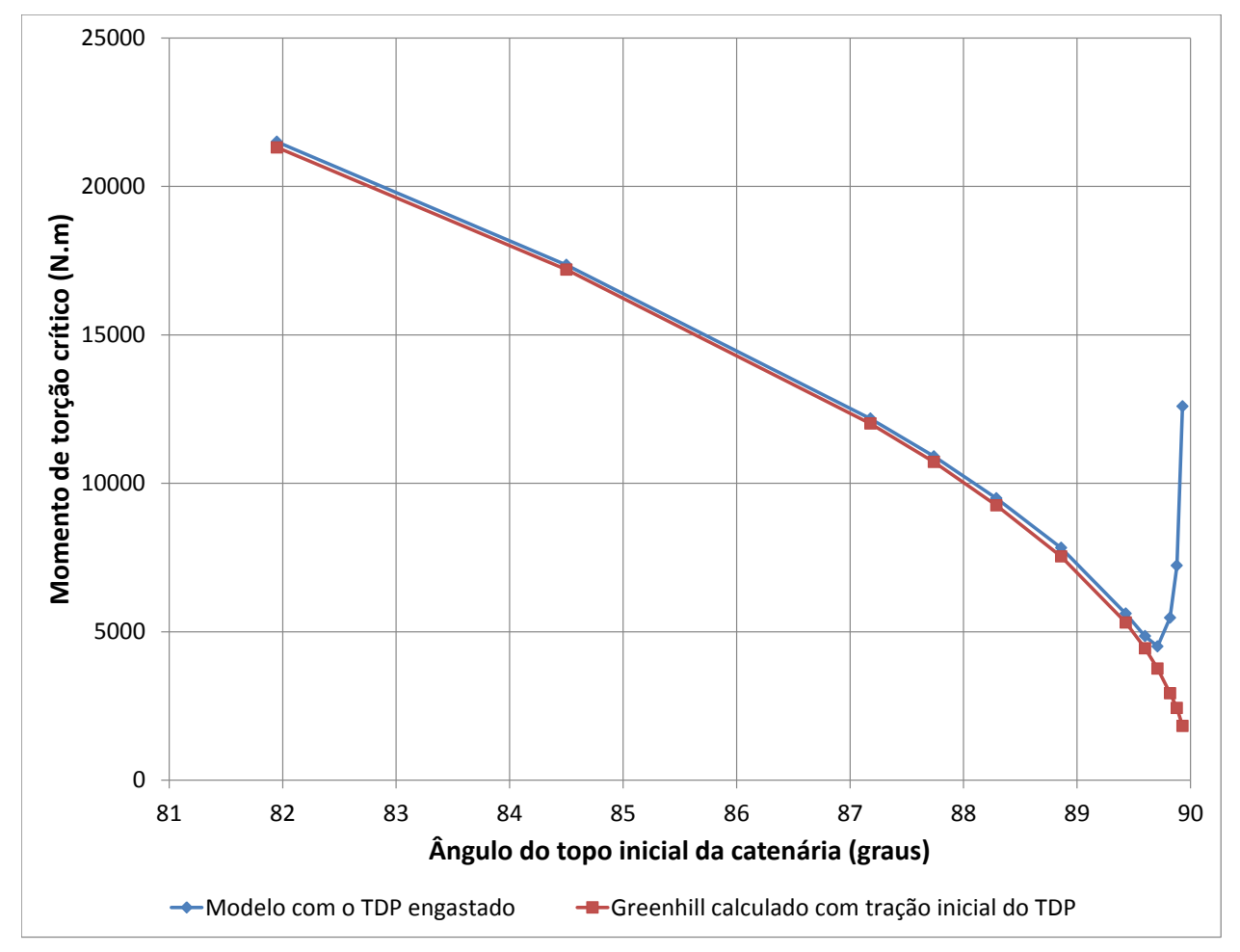

Figura 5.41: Momento de torção crítico versus ângulo do topo da configuração de catenária. Modelo com o TDP engastado comparado com Greenhill.

Note que comparando a solução analítica de Greenhill e os resultados do modelo numérico com o TDP engastado é possível observar um comportamento não concordante 
dos momentos de torção críticos na faixa de ângulos de topo da catenária entre cerca de $89,5^{\circ}$ e $90,0^{\circ}$. Essa diferença de resultados se deve às mudanças registradas na elastica da catenária que ocorrem antes da formação do laço. As Figuras 5.42 e 5.43 mostram a elastica no ponto de snapback para os casos de $1001 \mathrm{~m}$ e $1050 \mathrm{~m}$, respectivamente. O modelo numérico captura grandes mudanças geométricas ocorridas nos casos de baixa tração, como mostrado para o caso de $1001 \mathrm{~m}$. A posição do TDP sendo fixa nesse modelo força uma mudança na elastica, não realista, na condição real de contato unilateral com o solo. Logo, os casos de baixa tração (ângulos de topo muito próximos 90, $0^{\circ}$ ) apresentam resultados não esperados no problema real do riser, quando modelados com TDP engastado.

Para estudar a influência do movimento do TDP e, portanto, da interação entre o riser e o solo, optou-se por fazer um modelo considerando o contato unilateral sem atrito e, posteriormente, com atrito. 

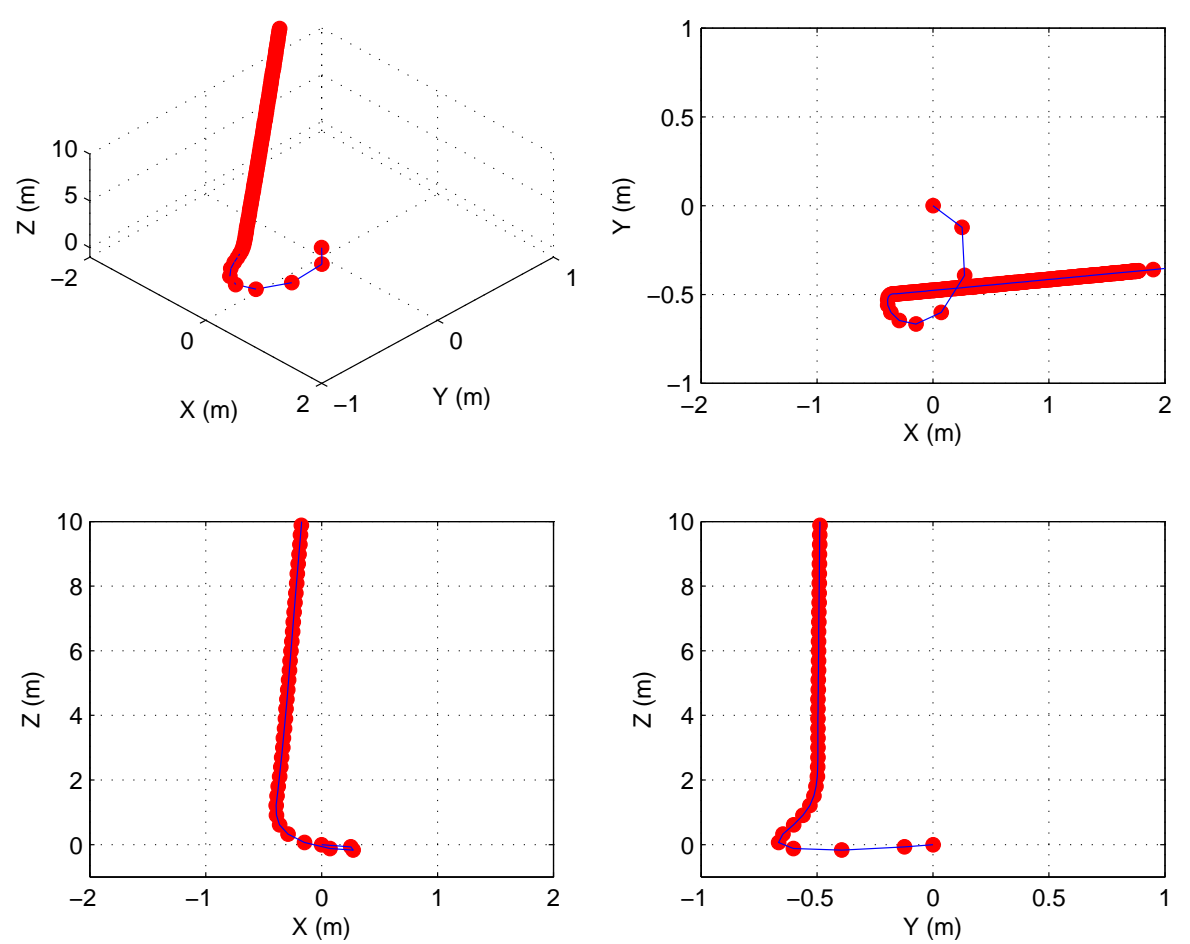

Figura 5.42: Configuração final da simulação realizada utilizando-se as propriedades descritas nas Tabelas 5.7 e 5.8. Visualização da formação do laço para o caso com TDP engastado com $1001 \mathrm{~m}$ de comprimento de umbilical.
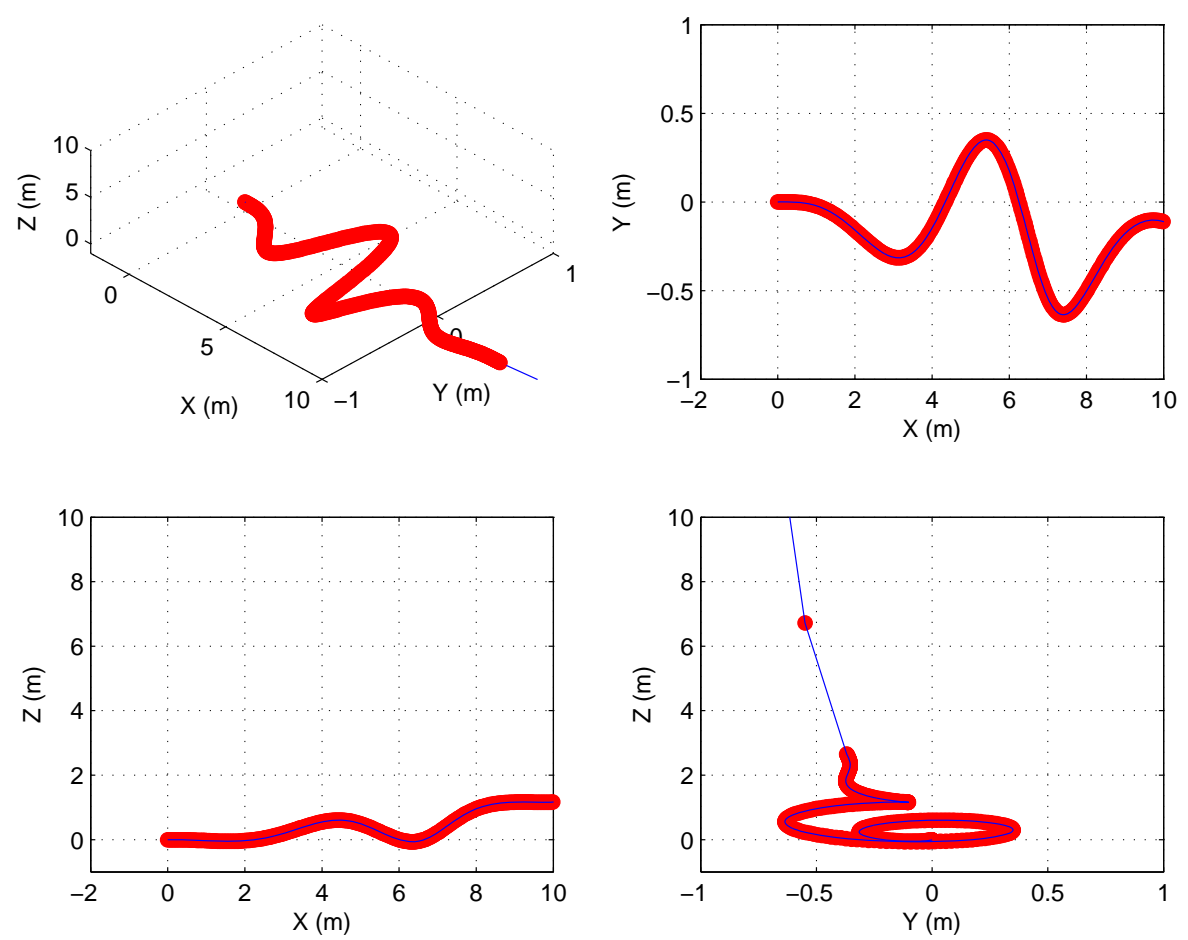

Figura 5.43: Configuração final da simulação realizada utilizando-se as propriedades descritas nas Tabelas 5.7 e 5.8. Visualização da formação do laço para o caso com TDP engastado com $1050 \mathrm{~m}$ de comprimento de umbilical. 


\subsubsection{Modelo considerando o contato unilateral sem atrito}

Nesse modelo considerou-se o contato unilateral entre o riser e o solo. No entanto, para simplificar a modelagem, o atrito foi desprezado e levou-se em conta somente a componente normal da força de contato. Trata-se de uma não linearidade presente no modelo ${ }^{4}$. Com isso se torna possível tratar o movimento do TDP e sua influência no valor do carregamento do momento de torção crítico no problema de estabilidade da configuração de catenária. Para o tratamento do contato nesses modelos adotou-se o parâmetro de penalidade na direção normal no valor de 10.000 .

Foi considerado um trecho de $600 \mathrm{~m}$ de flowline. A imposição da rotação $\alpha$ no quarto passo de carregamento é feita na âncora (ao contrário do modelo com o TDP engastado que não contém um trecho de flowline, no qual a imposição de rotação foi feita no próprio TDP). O comprimento considerado no solo acabou por garantir a não influência da forma que a rotação é imposta no modelo na região do TDP (dessa vez distante desse ponto de aplicação de rotação), que é algo que é duvidoso no modelo com o TDP engastado.

As Figuras 5.44 a 5.55 mostram as trajetórias de equilíbrio $M_{t}$ versus $\alpha$ para o modelo considerando o contato unilateral sem atrito. Note que os casos de comprimentos mais curtos apresentam facilidade na visualização do ponto-limite em sua trajetória de equilíbrio. Já os casos de comprimento maior, que possuem maior tração no TDP, acabam por ter pontos-limite muito próximos dos pontos de snapback. No entanto, a plotagem da queda do autovalor da matriz de rigidez, bem como da menor frequência natural, auxiliam para indicar a ocorrência da instabilidade na configuração, sendo usado como critério nessa situação de dificuldade de visualização do ponto limite.

\footnotetext{
${ }^{4} \mathrm{~A}$ formulação cinematicamente exata apresentada no Capítulo 4 considera a não linearidade geométrica existente com os grandes deslocamentos e as grandes rotações. A presença do contato acaba por dificultar mais a convergência, uma vez que promove grandes variações de rigidez no sistema. Isso ocorre pois a região do riser que está em contato com o solo pode variar de acordo com os carregamentos considerados.
} 


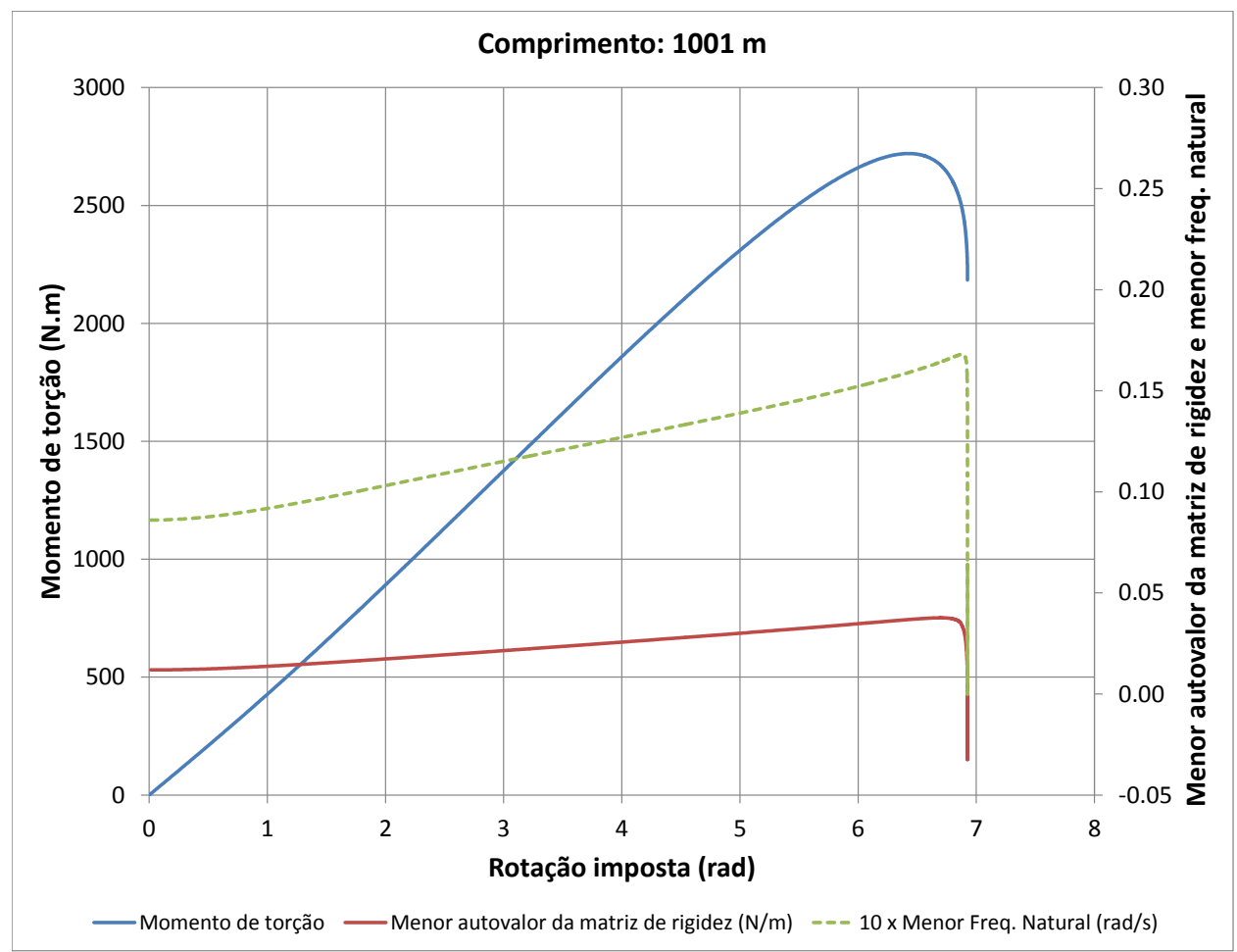

Figura 5.44: Trajetória de equilíbrio $M_{t}$ versus $\alpha$ para o caso $\mathrm{L}=1001 \mathrm{~m}\left(\theta_{\text {topo }}=89,93^{\circ}\right)$. Sem atrito.

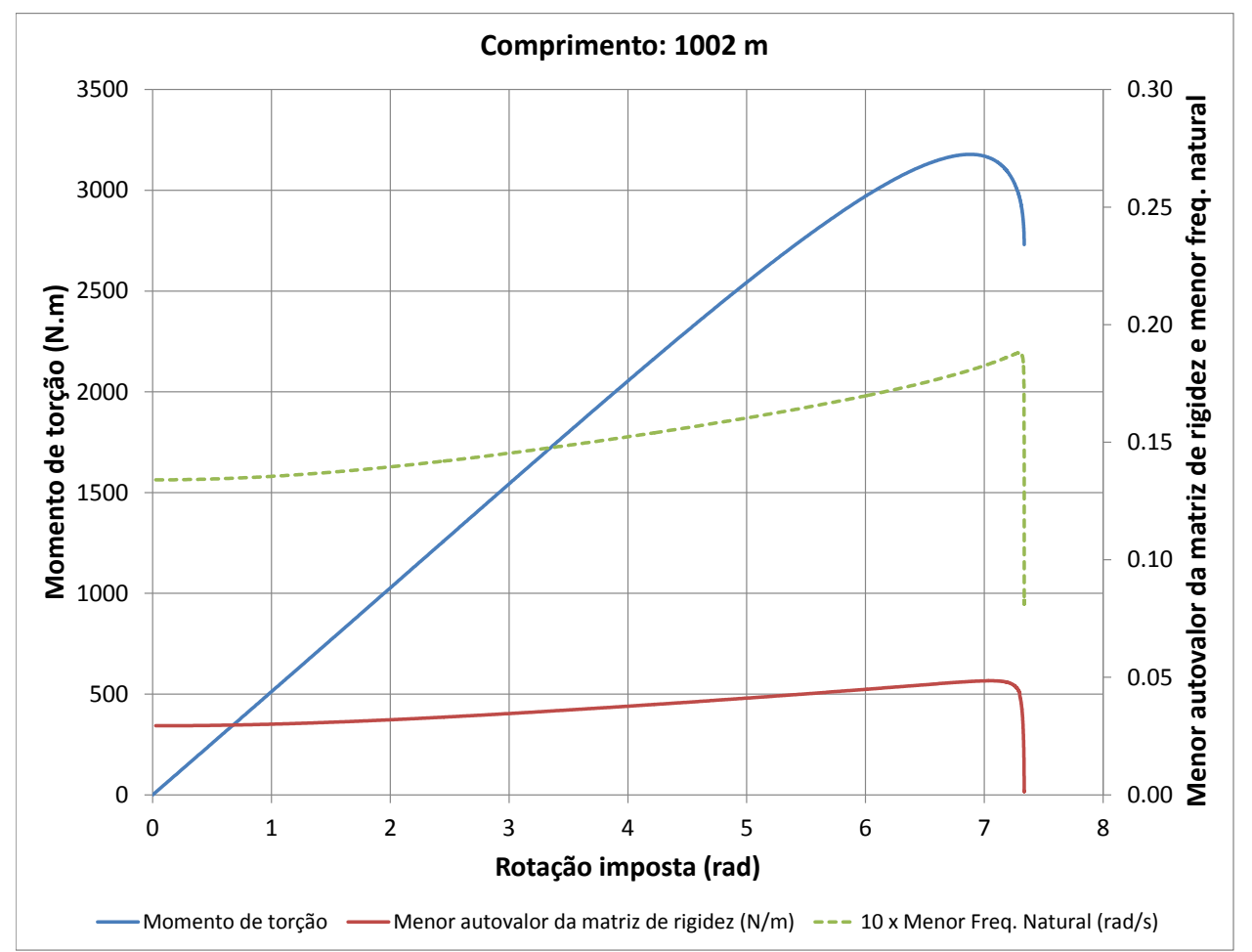

Figura 5.45: Trajetória de equilíbrio $M_{t}$ versus $\alpha$ para o caso $\mathrm{L}=1002 \mathrm{~m}\left(\theta_{\text {topo }}=89,88^{\circ}\right)$. Sem atrito. 


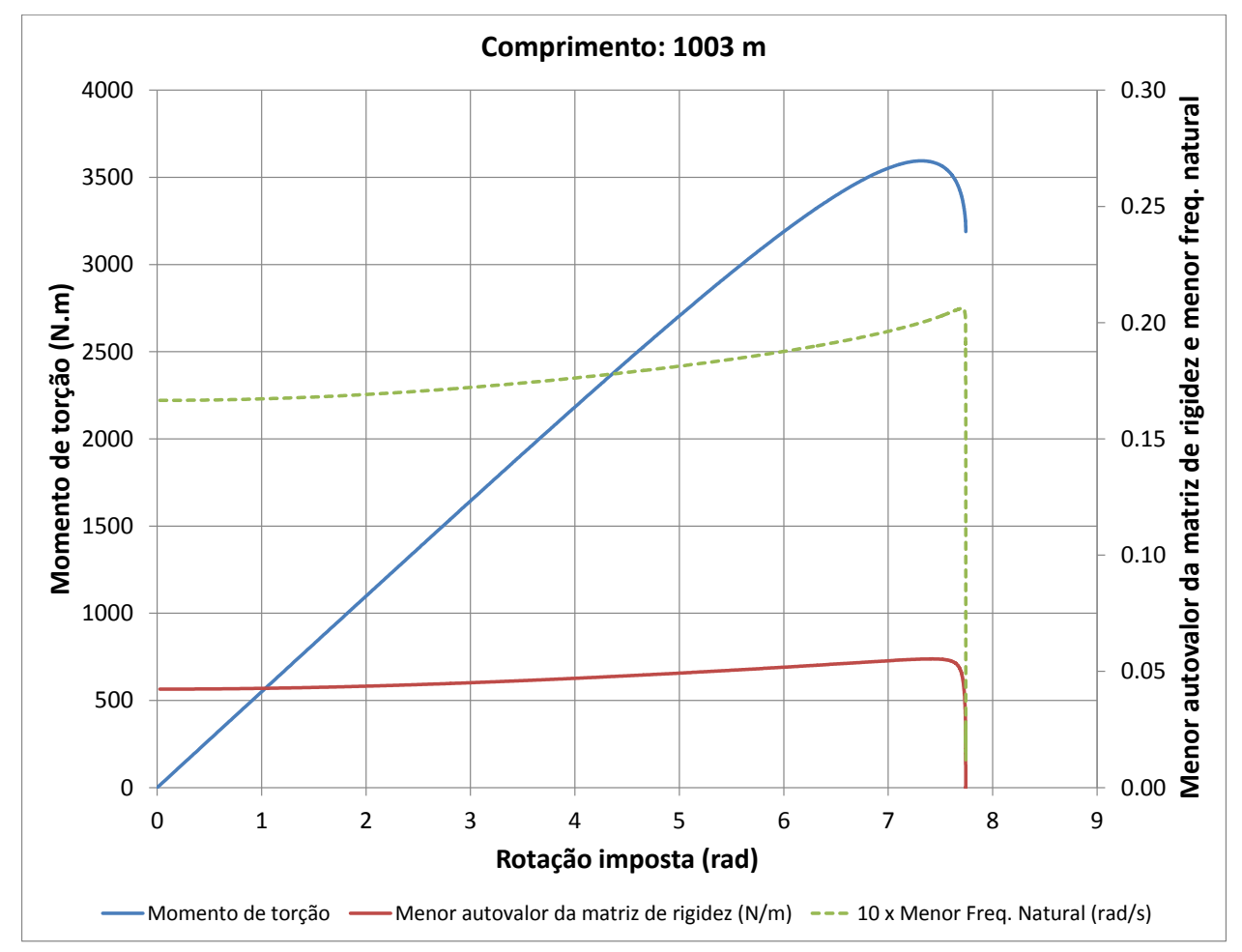

Figura 5.46: Trajetória de equilíbrio $M_{t}$ versus $\alpha$ para o caso $\mathrm{L}=1003 \mathrm{~m}\left(\theta_{\text {topo }}=89,82^{\circ}\right)$. Sem atrito.

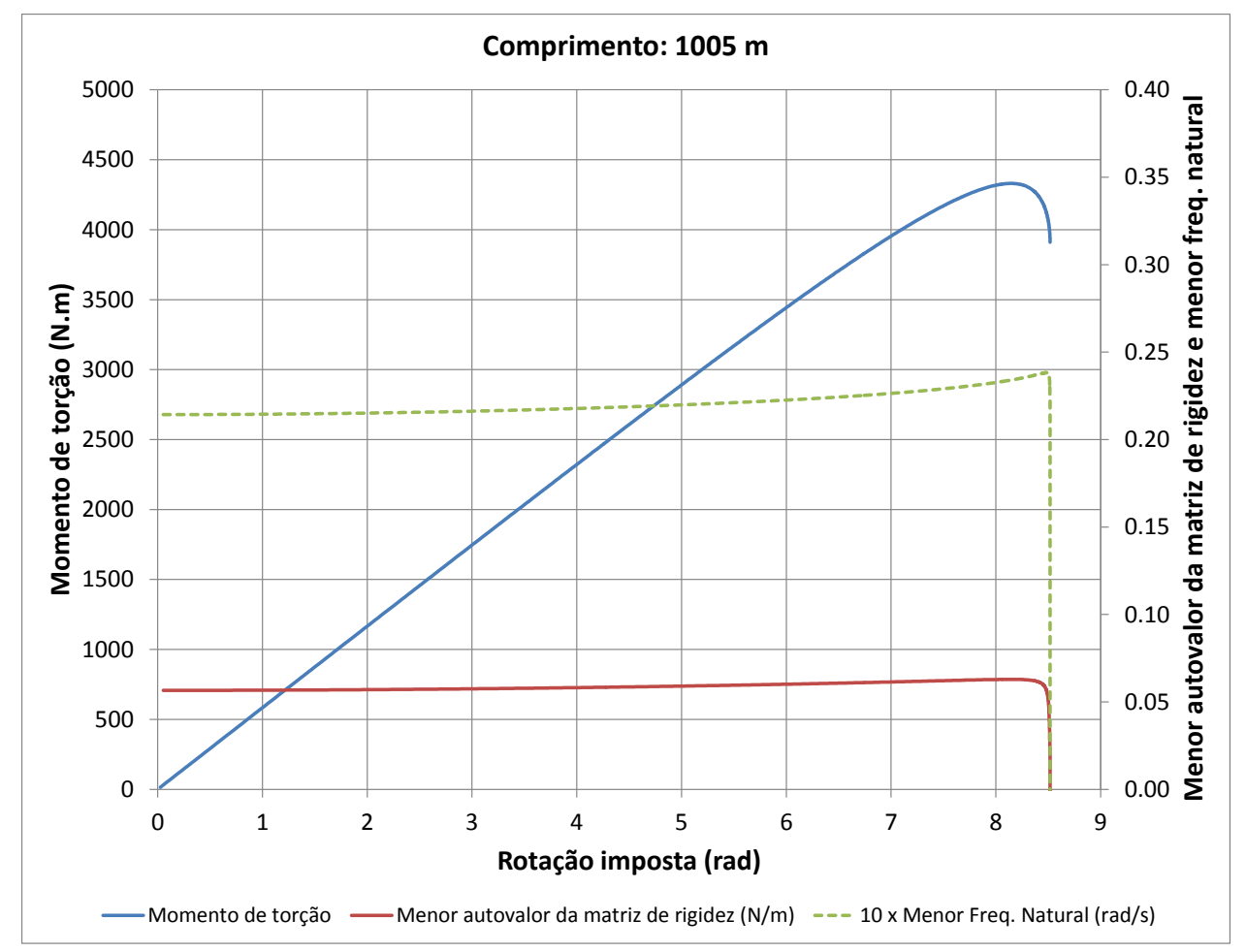

Figura 5.47: Trajetória de equilíbrio $M_{t}$ versus $\alpha$ para o caso $\mathrm{L}=1005 \mathrm{~m}\left(\theta_{\text {topo }}=89,71^{\circ}\right)$. Sem atrito. 


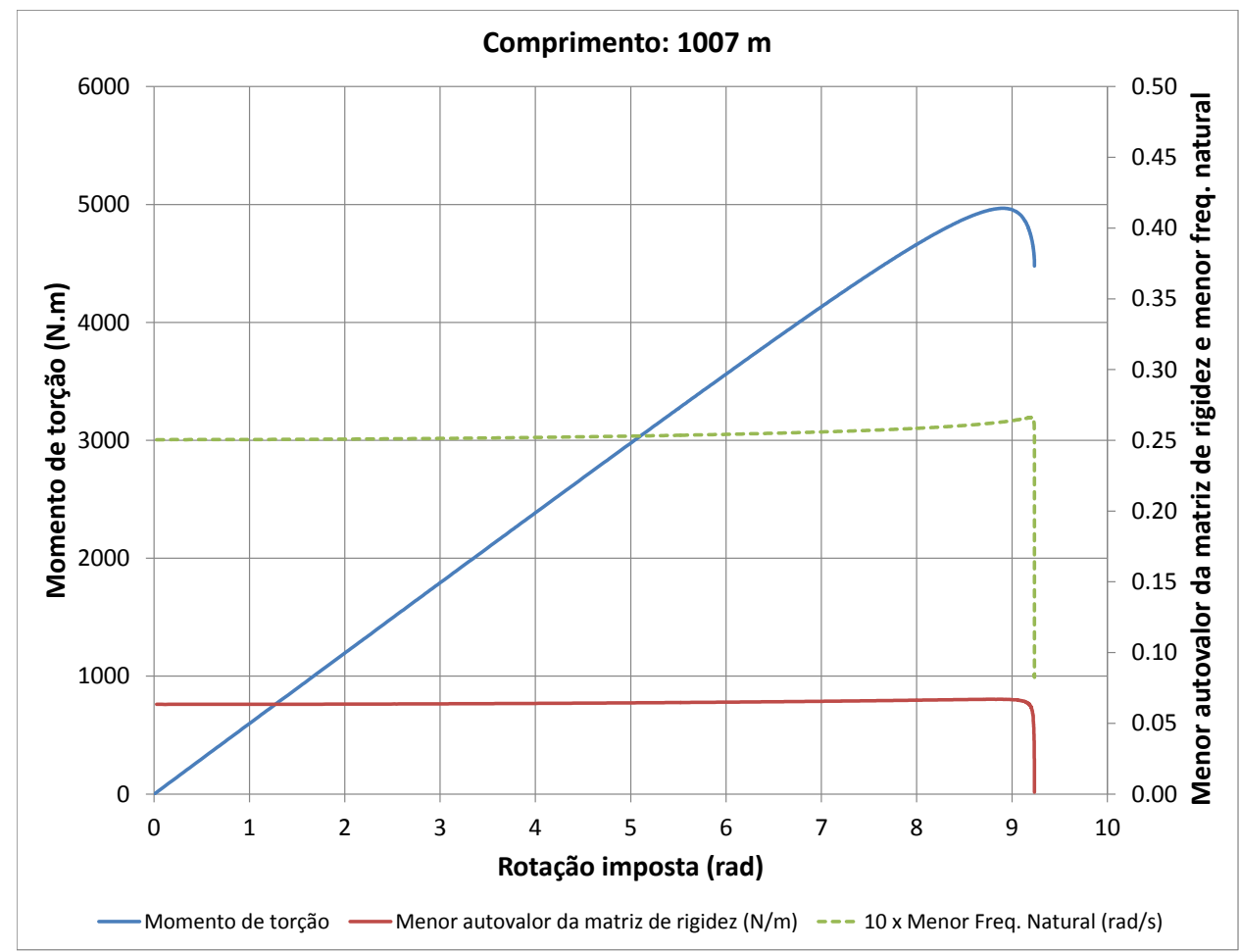

Figura 5.48: Trajetória de equilíbrio $M_{t}$ versus $\alpha$ para o caso $\mathrm{L}=1007 \mathrm{~m}\left(\theta_{\text {topo }}=89,60^{\circ}\right)$. Sem atrito.

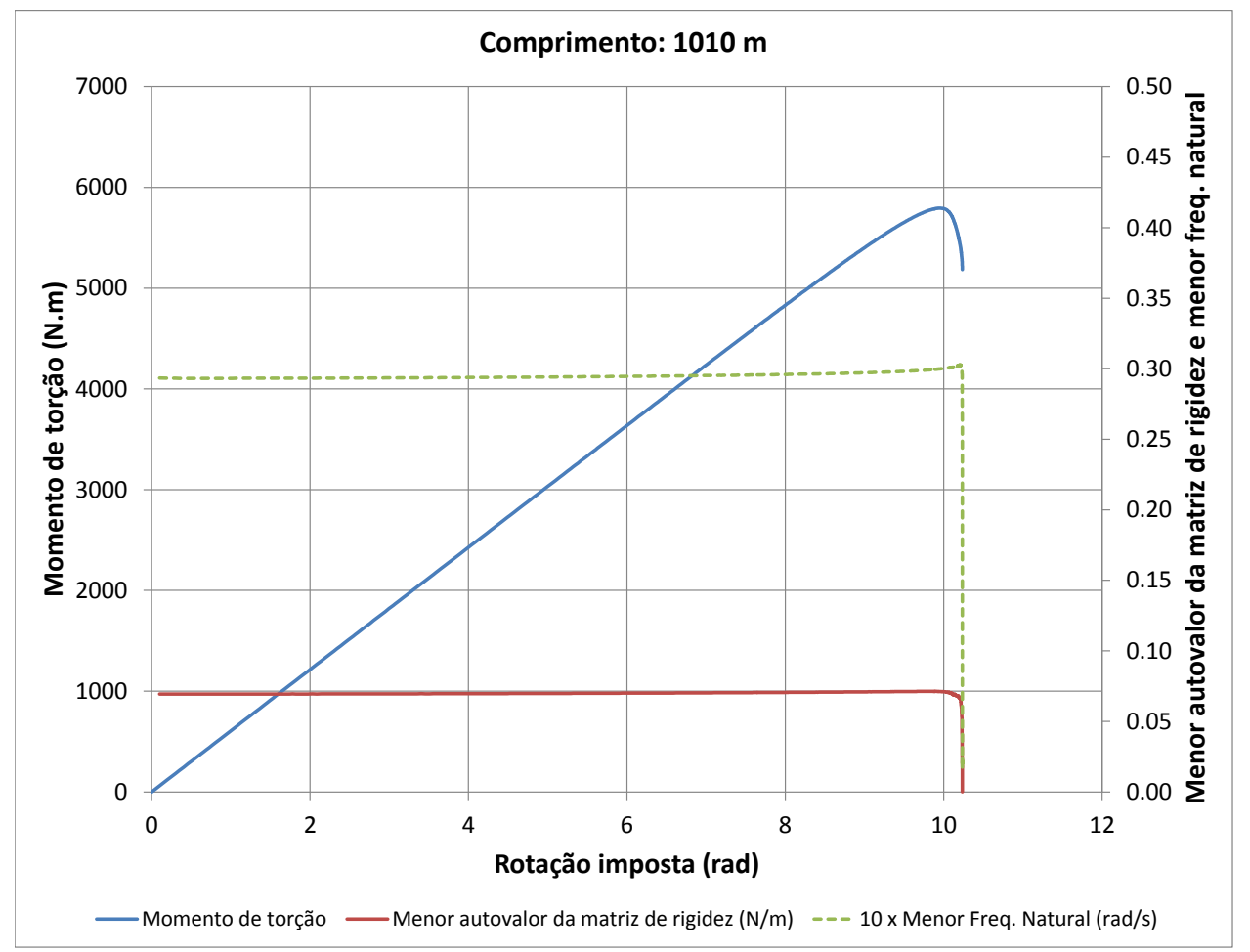

Figura 5.49: Trajetória de equilíbrio $M_{t}$ versus $\alpha$ para o caso $\mathrm{L}=1010 \mathrm{~m}\left(\theta_{\text {topo }}=89,43^{\circ}\right)$. Sem atrito. 


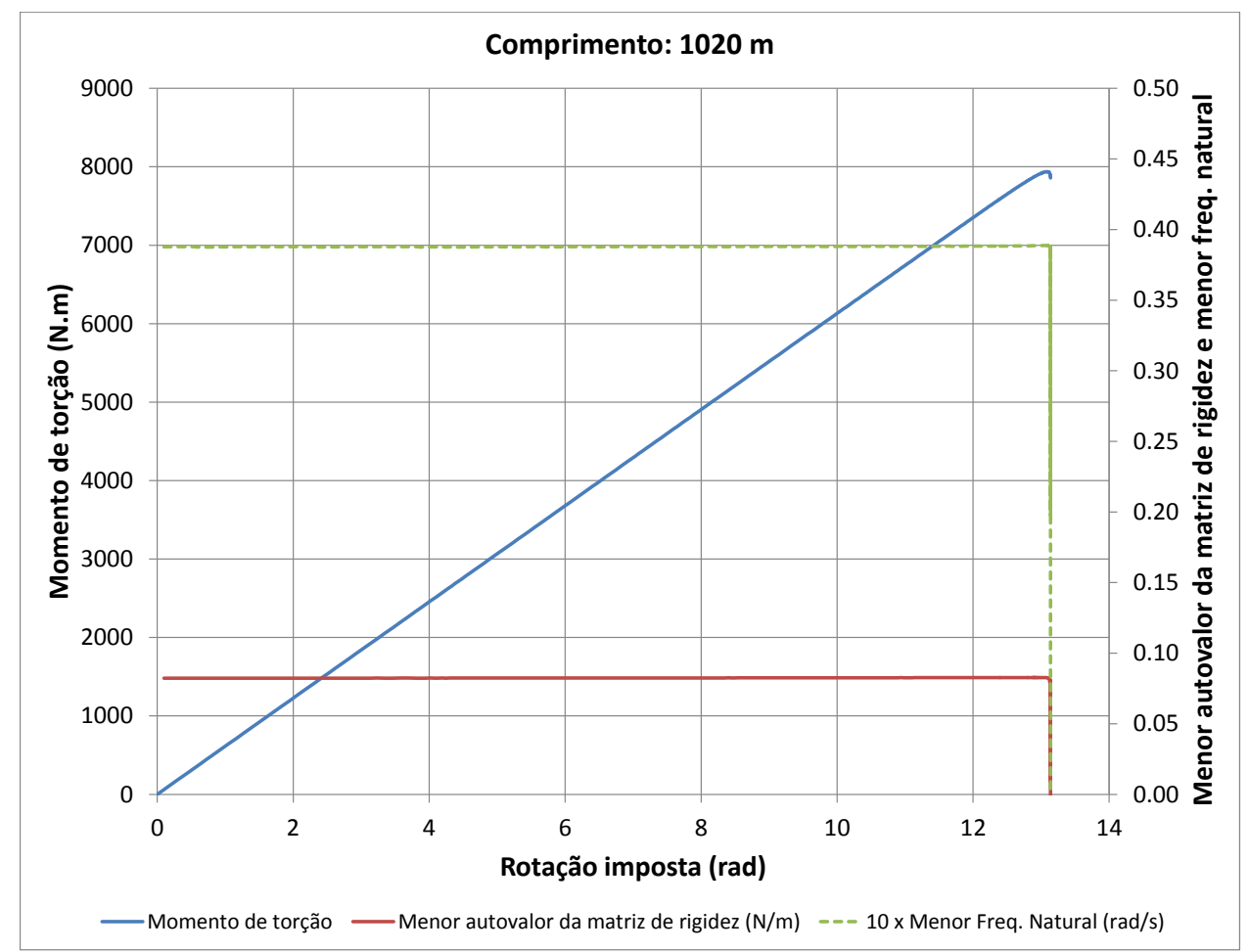

Figura 5.50: Trajetória de equilíbrio $M_{t}$ versus $\alpha$ para o caso $\mathrm{L}=1020 \mathrm{~m}\left(\theta_{\text {topo }}=88,86^{\circ}\right)$. Sem atrito.

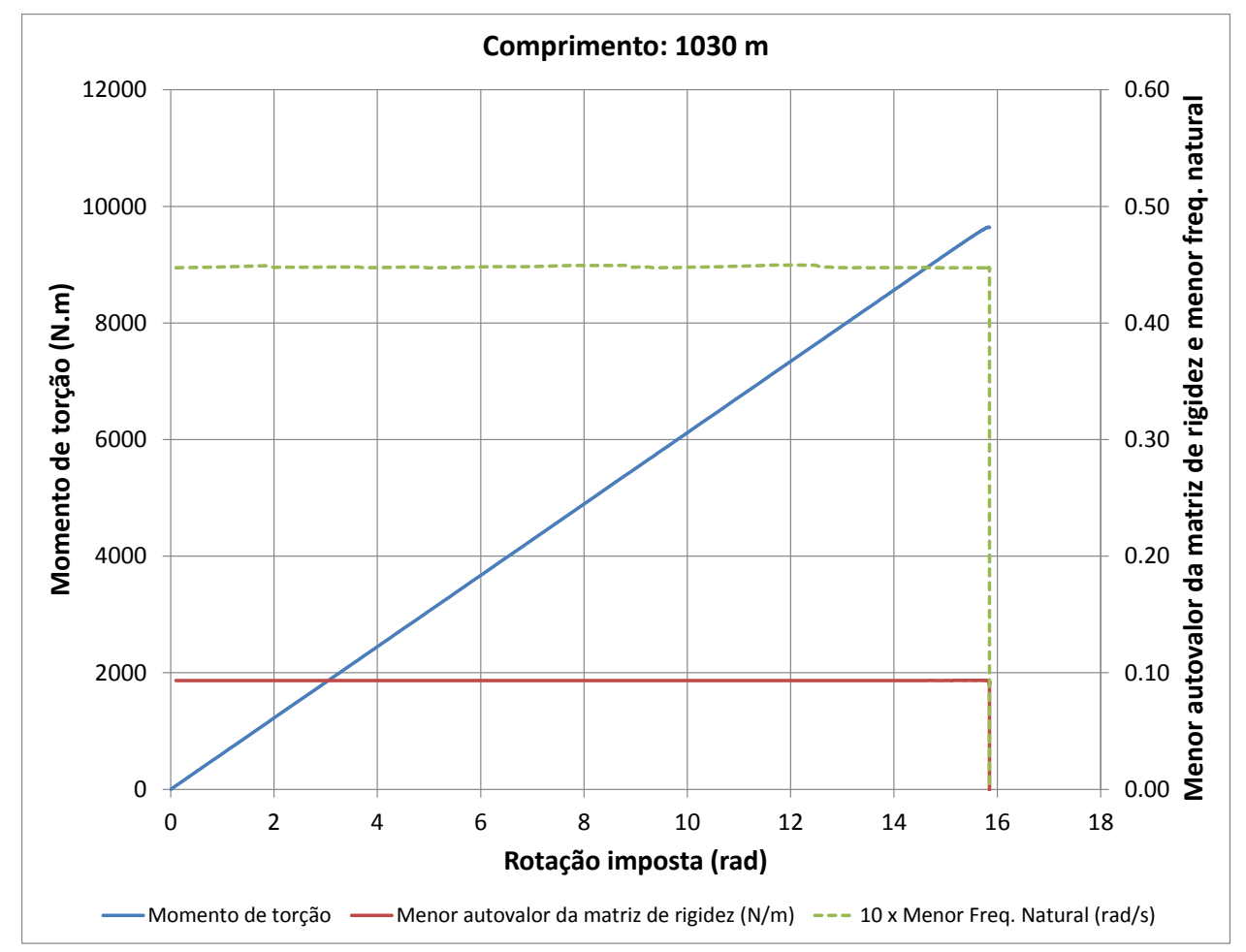

Figura 5.51: Trajetória de equilíbrio $M_{t}$ versus $\alpha$ para o caso $\mathrm{L}=1030 \mathrm{~m}\left(\theta_{\text {topo }}=88,29^{\circ}\right)$. Sem atrito. 


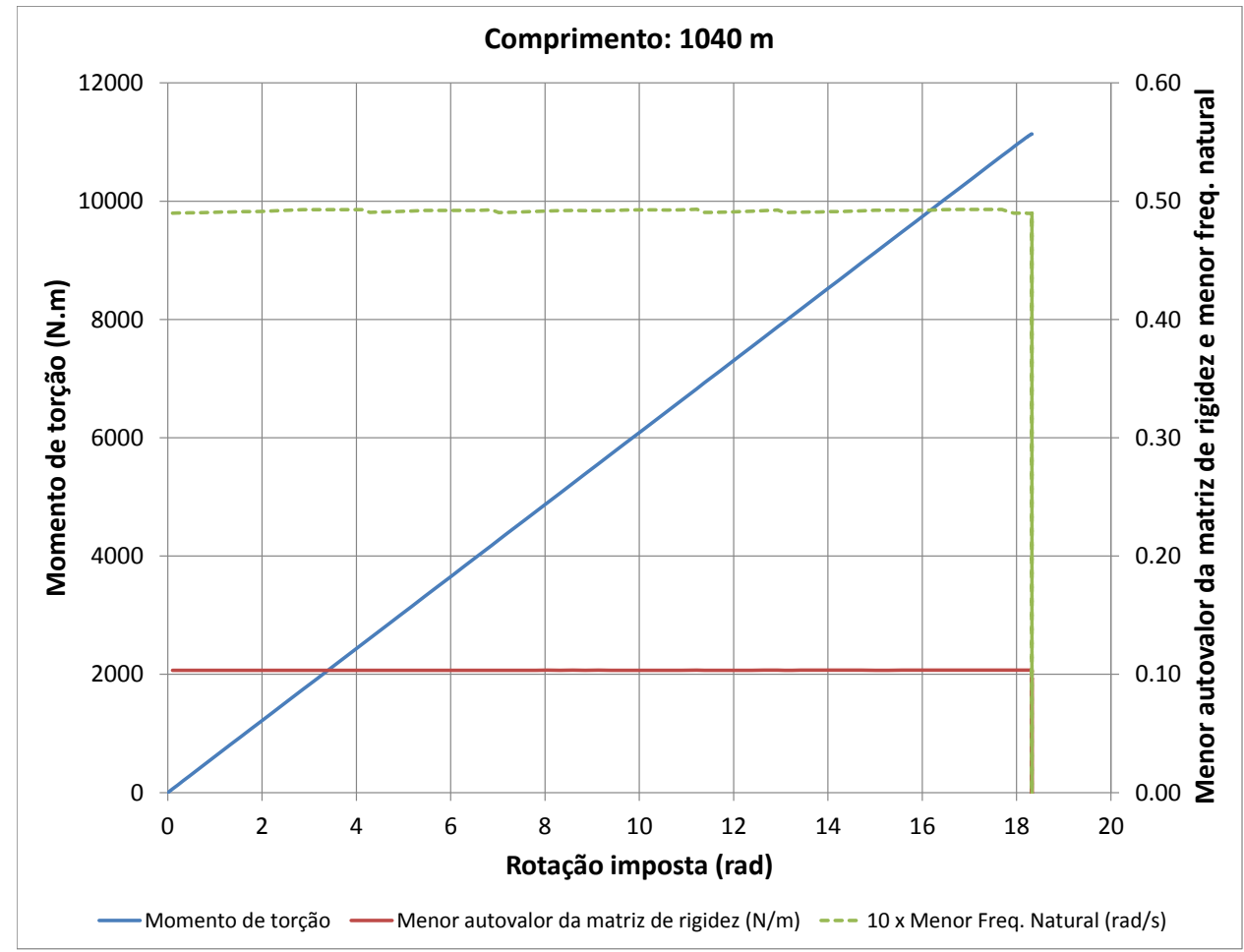

Figura 5.52: Trajetória de equilíbrio $M_{t}$ versus $\alpha$ para o caso L $=1040 \mathrm{~m}\left(\theta_{\text {topo }}=87,74^{\circ}\right)$. Sem atrito.

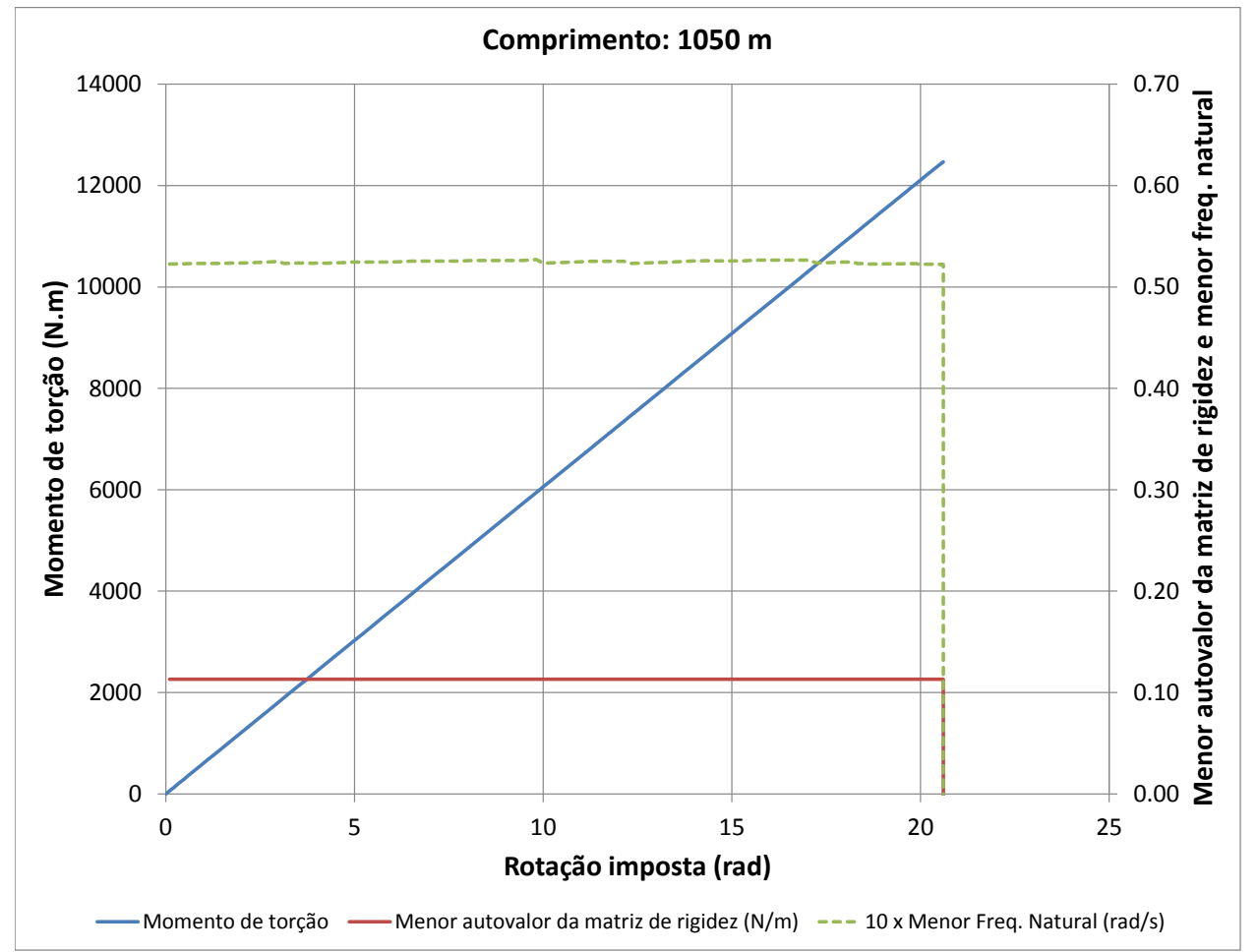

Figura 5.53: Trajetória de equilíbrio $M_{t}$ versus $\alpha$ para o caso $\mathrm{L}=1050 \mathrm{~m}\left(\theta_{\text {topo }}=87,18^{\circ}\right)$. Sem atrito. 


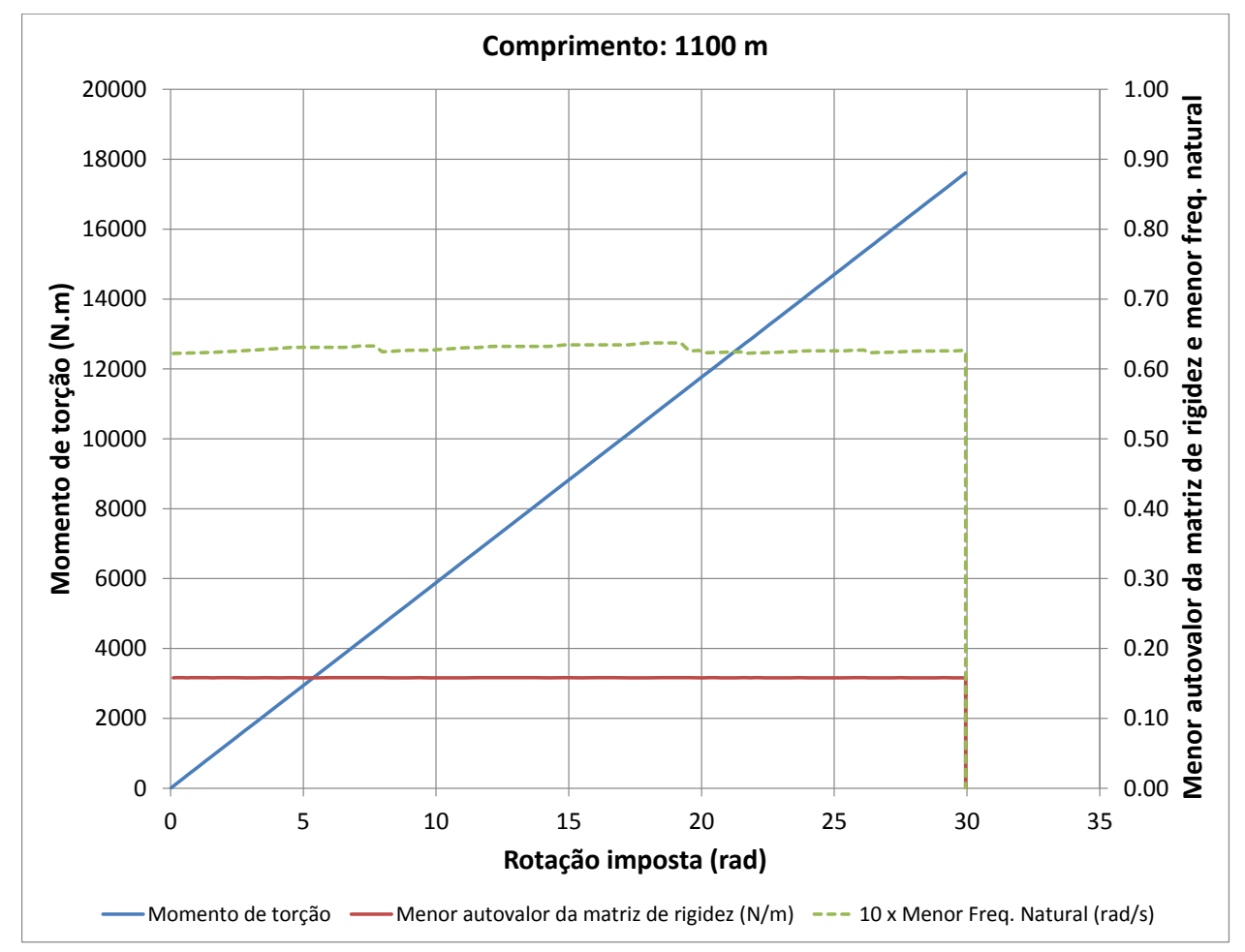

Figura 5.54: Trajetória de equilíbrio $M_{t}$ versus $\alpha$ para o caso $\mathrm{L}=1100 \mathrm{~m}\left(\theta_{\text {topo }}=84,50^{\circ}\right)$. Sem atrito.

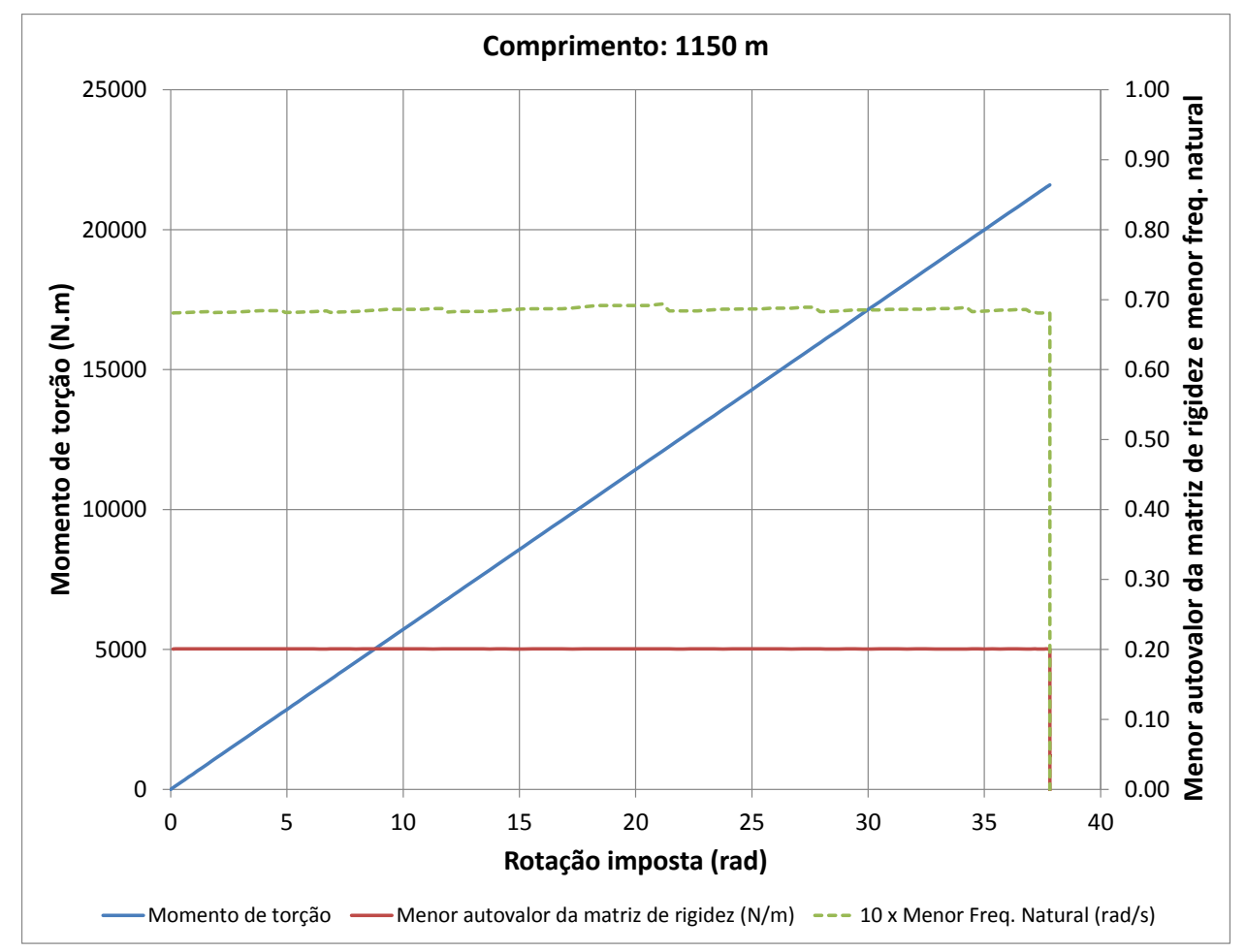

Figura 5.55: Trajetória de equilíbrio $M_{t}$ versus $\alpha$ para o caso $\mathrm{L}=1150 \mathrm{~m}\left(\theta_{\text {topo }}=81,95^{\circ}\right)$. Sem atrito. 
Novamente é possível plotar uma curva relacionando os valores dos momentos de torção críticos em função do ângulo de topo da configuração de riser em catenária. Obtém-se a curva da Figura 5.56.

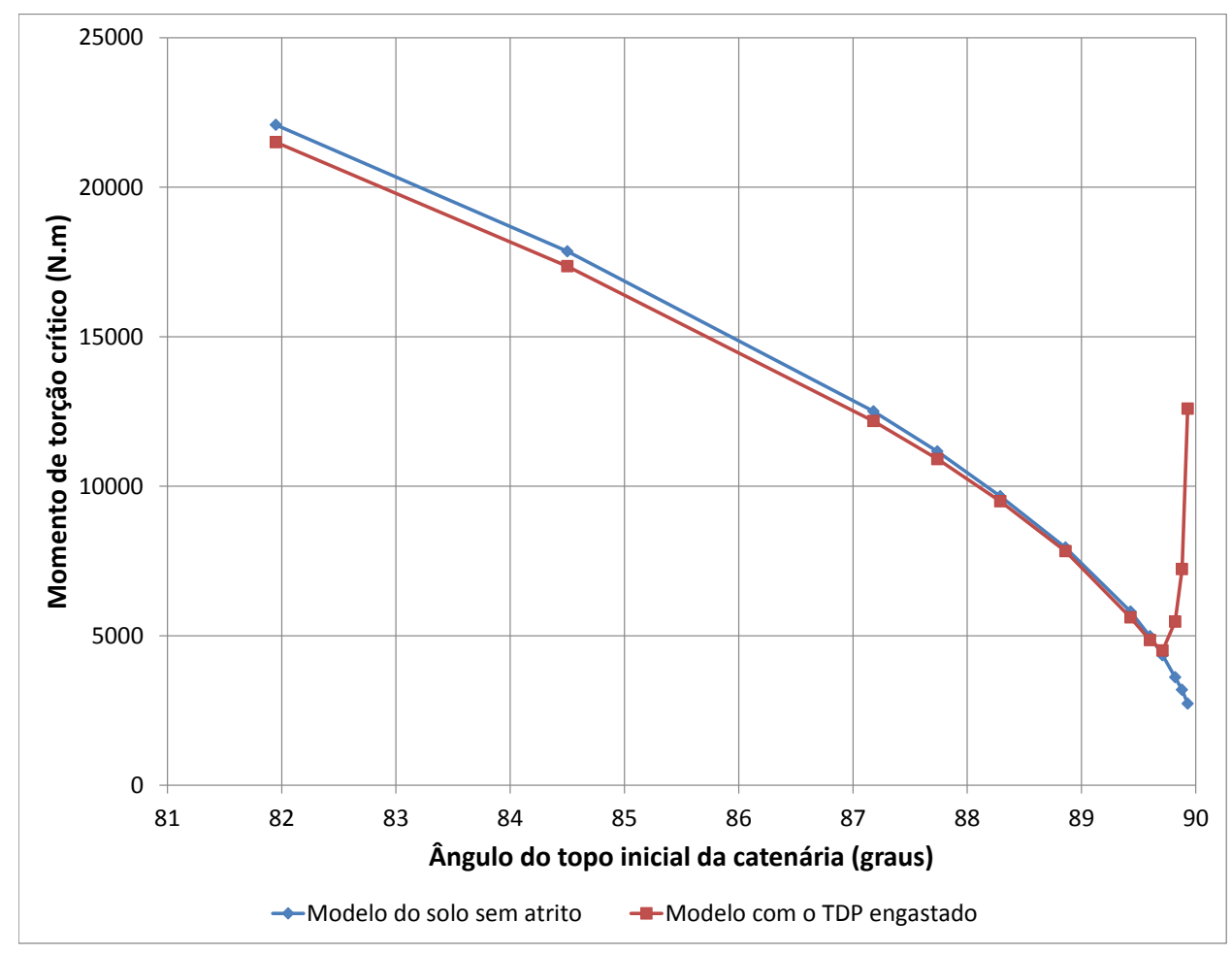

Figura 5.56: Momento de torção crítico versus ângulo do topo da configuração de catenária. Modelo com contato unilateral sem atrito comparado com Modelo com TDP engastado.

Nessa curva é possível visualizar que, de fato, considerar o TDP engastado causa uma errônea interpretação na carga crítica em relação a quando se permite seu movimento durante a aplicação do momento de torção. Isso é bastante evidenciado na faixa de ângulos de topo entre $89,5^{\circ}$ e $90,0^{\circ}$ devido ao baixo de nível de tração que ocorre, que torna a rigidez geométrica pouco elevada.

Outra forma de mostrar a curva de resultados de carga crítica é através do valor da torção total $\tau_{t}$ no riser, que pode ser obtida simplesmente dividindo o momento de torção pelo valor da rigidez à torção $G J$. Nas simulações realizadas observa-se que o riser apresenta uma distribuição de $\tau_{t}$ praticamente constante ao longo de seu comprimento, mesmo em sua configuração associada ao ponto limite. Assim, o valor do momento de torção é também praticamente constante ao longo do comprimento, pois: 


$$
\tau_{t}=\frac{M_{t}}{G J}
$$

O valor de $\tau_{t}$ é fisicamente interpretado como a rotação por unidade de comprimento na direção axial do riser, em suas subsequentes seções transversais. Seu valor é não nulo quando existe torção própria e/ou tortuosidade. Uma comparação interessante que pode ser feita é entre a torção total identificada no ponto de snapback de uma configuração de riser, e a rotação $\alpha$ dividida pelo comprimento do riser $L$ (rotação imposta por unidade de comprimento). Em situações em que há pouca alteração da elastica da catenária antes da formação do laço, há de se esperar que a torção total se confunda com o valor de $\frac{\alpha}{L}$. No entanto, situações que permitem mais movimento da catenária antes da formação do laço (tipicamente configurações com menor tração no TDP) podem apresen$\operatorname{tar} \tau_{t}<\frac{\alpha}{L}$, pois nem toda a rotação imposta é convertida em torção mas, parte dela se apresenta geometricamente em direções transversais do riser, sendo portanto relacionada à flexão. Isso ocorre através do surgimento de uma configuração com maior tortuosidade que, inerentemente, apresenta também flexão além de torção. Isso é observado no gráfico da Figura 5.57.

Ainda utilizando-se da torção total $\tau_{t}$, uma comparação entre o modelo que considera o contato unilateral sem atrito e o modelo analítico de Greenhill está exibida na Figura 5.58. 


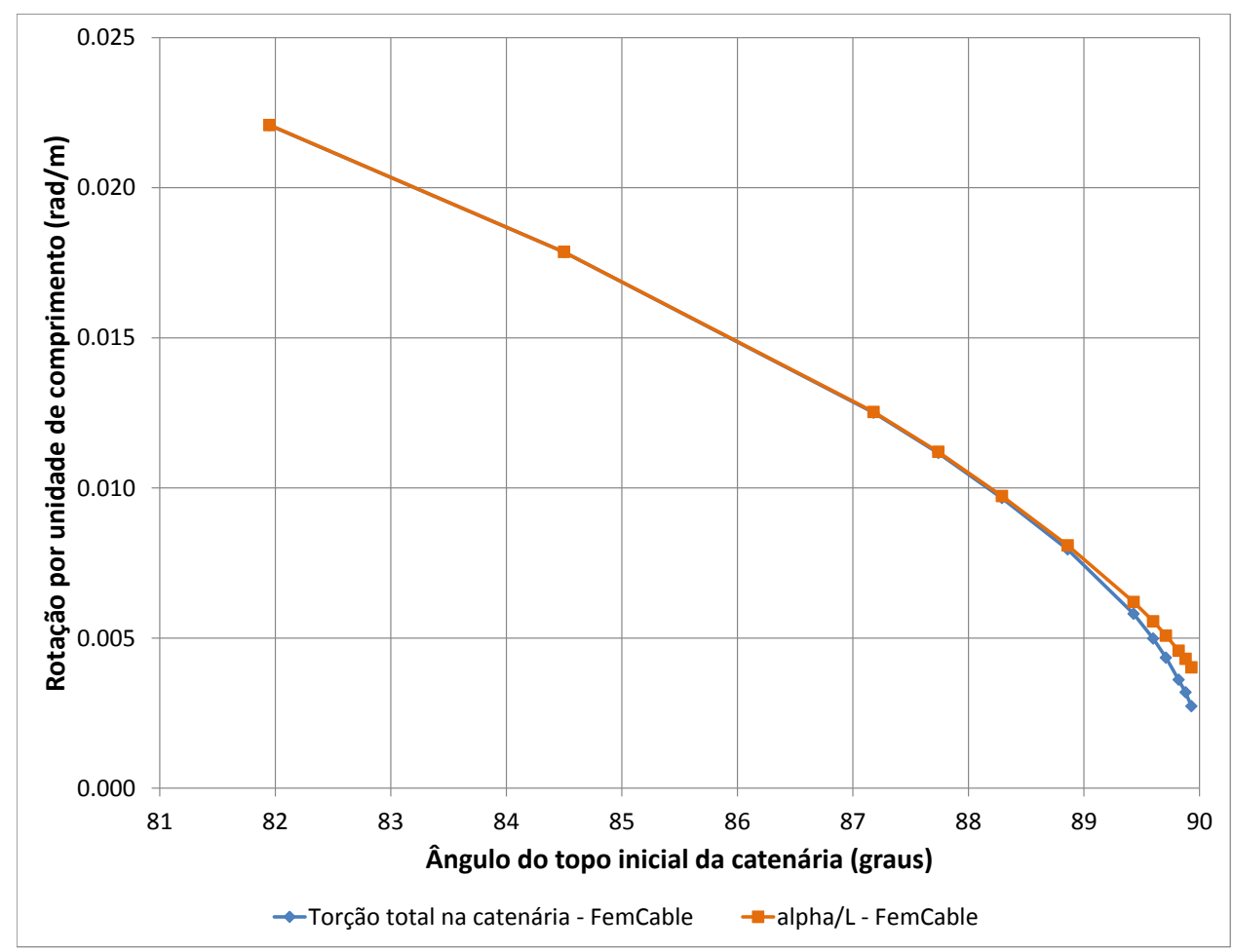

Figura 5.57: Torção total e rotação imposta por unidade de comprimento $\left(\frac{\alpha}{L}\right)$ no pontolimite versus ângulo do topo da configuração de catenária.

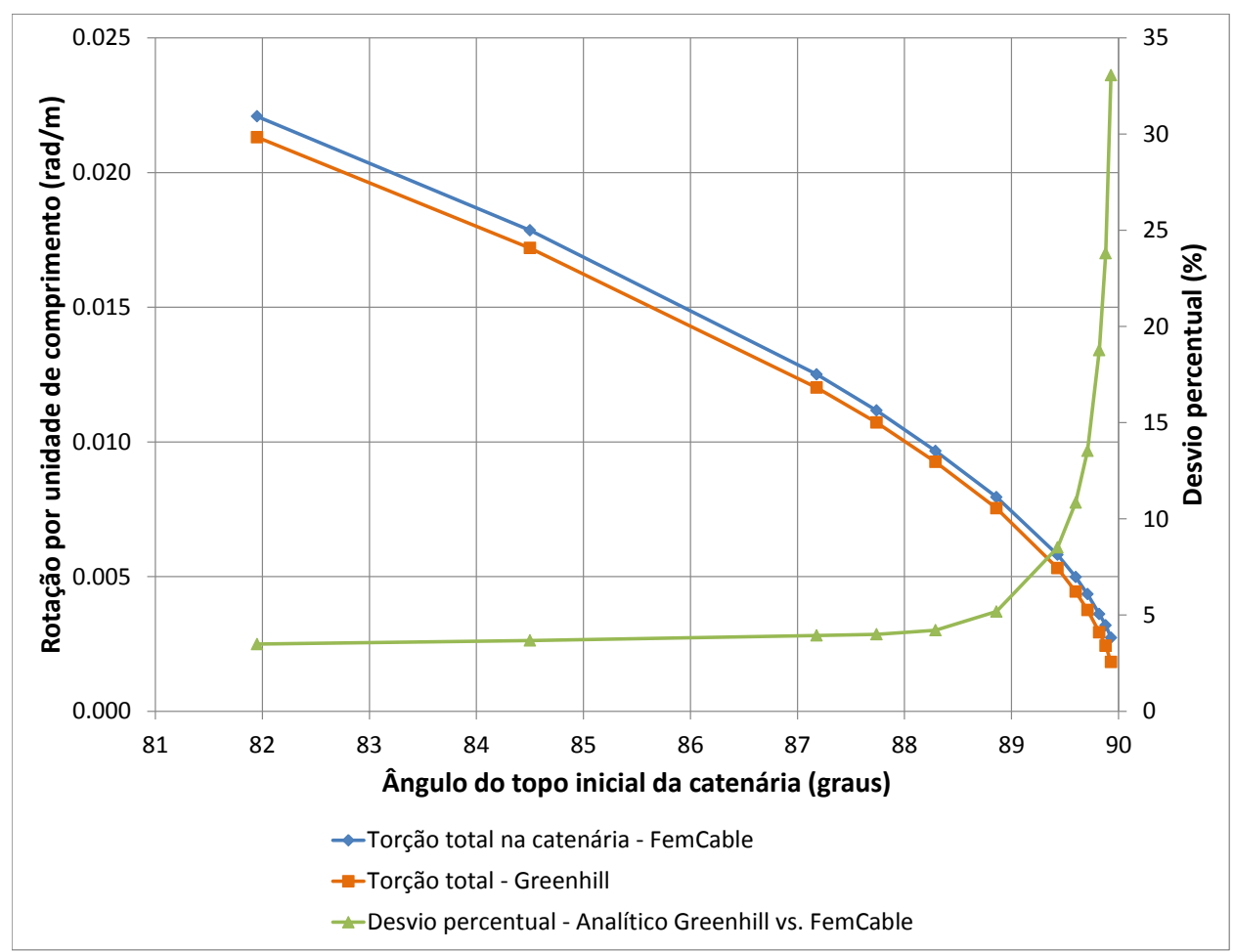

Figura 5.58: Torção total no ponto limite versus ângulo do topo da configuração de catenária. Comparação entre o modelo com contato sem atrito e Greenhill. 
Note que a previsão analítica é percentualmente mais próxima da numérica para valores de ângulo de topo menores e, portanto, para configurações mais tracionadas. Note, ainda, que a previsão analítica em toda a faixa de ângulos de topo estudada se mostrou a favor da segurança, prevendo valores inferiores de carga crítica.

\subsubsection{Modelo considerando o contato unilateral com atrito}

Nesse modelo considerou-se o contato unilateral entre o riser e o solo e, de forma mais completa que o modelo anteriormente apresentado, considerou-se a existência de atrito, além da força normal que já fora considerada. Foram adotados dois valores diferentes de coeficiente de atrito, sendo $\mu=0,4$ e $\mu=1,0$. De forma semelhante ao modelo sem atrito, foi considerado um trecho de $600 \mathrm{~m}$ de comprimento de riser no solo. A imposição da rotação $\alpha$ também no quarto passo de carregamento é feita na âncora. Para o tratamento numérico da direção normal, a presença do atrito dificulta a convergência dos modelos. Para o tratamento do contato nesses modelos adotou-se o parâmetro de penalidade na direção normal no valor de 10.000. Para o tratamento do atrito com o Método das Penalidades adotou-se $\epsilon_{t}=1.000$. Valores mais elevados acabaram por não permitir a convergência do Método de Newton-Raphson até o ponto necessário para analisar a estabilidade.

No problema considerando o atrito, no entanto, surge uma dificuldade adicional para a análise de estabilidade. A matriz de rigidez tangente em problemas com atrito pode apresentar não-simetrias (ver Capítulo 4). Isso dificulta a extração de autovalores, sendo necessário utilizar algoritmos específicos que possam lidar com esse tipo de situação, como o algoritmo de Arnoldi da biblioteca ARPACK ${ }^{\mathrm{TM}}$.

As Figuras 5.59 a 5.70 mostram as trajetórias de equilíbrio $M_{t}$ versus $\alpha$ para o modelo considerando o contato unilateral com atrito $\mu=0,4$, e as figuras 5.71 a 5.82 com atrito $\mu=1,0$. Note que, novamente, os casos de comprimentos mais curtos apresentam facilidade na visualização do ponto-limite em sua trajetória de equilíbrio. Já em alguns casos de comprimento mais longo, novamente ocorre a coalescência entre o ponto limite e o ponto de snapback, em que a evolução do menor autovalor da matriz de rigidez e da menor frequência natural mostram uma predição abrupta de instabilidade. 


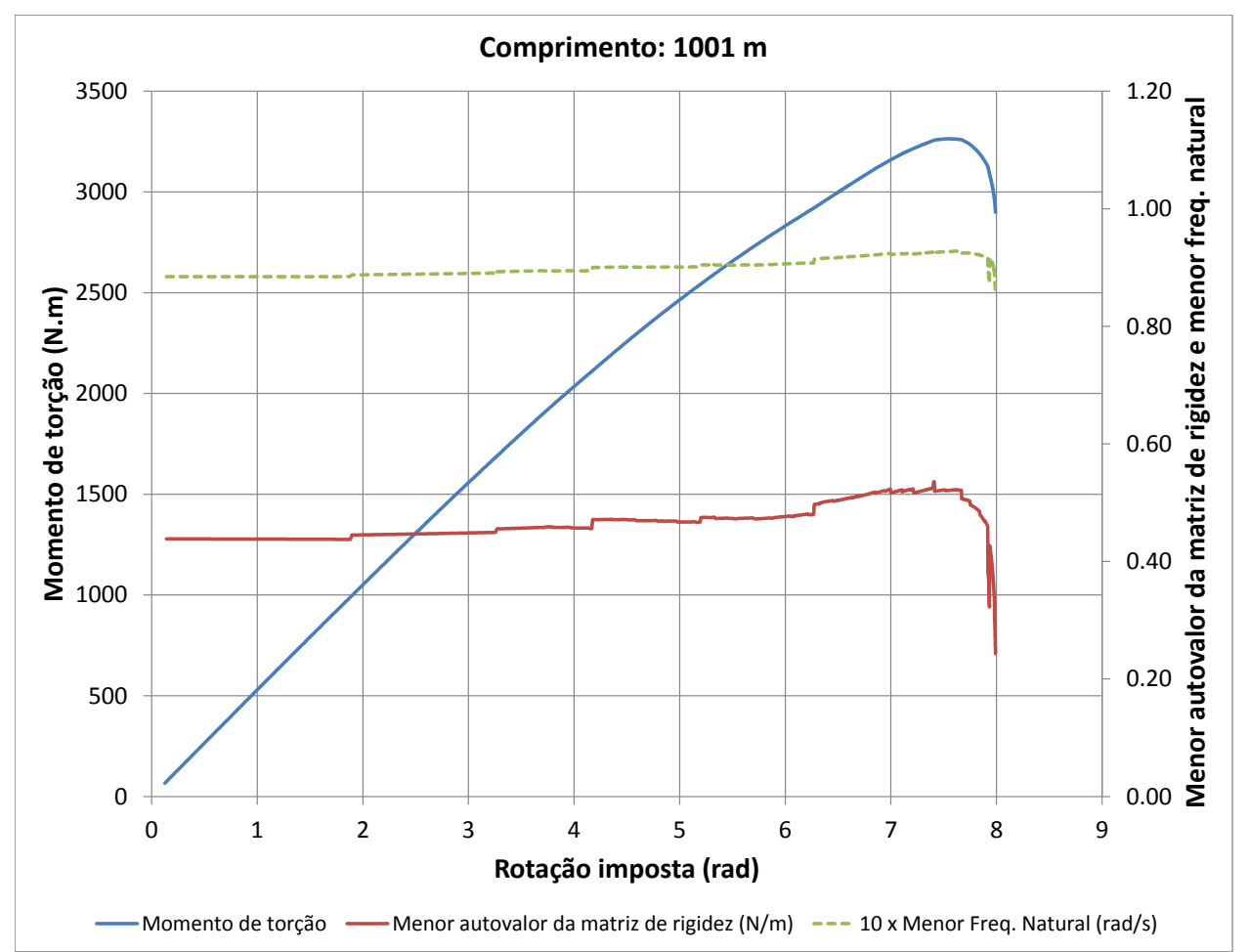

Figura 5.59: Trajetória de equilíbrio $M_{t}$ versus $\alpha$ para o caso $\mathrm{L}=1001 \mathrm{~m}\left(\theta_{\text {topo }}=89,93^{\circ}\right)$. Com atrito $\mu=0,4$

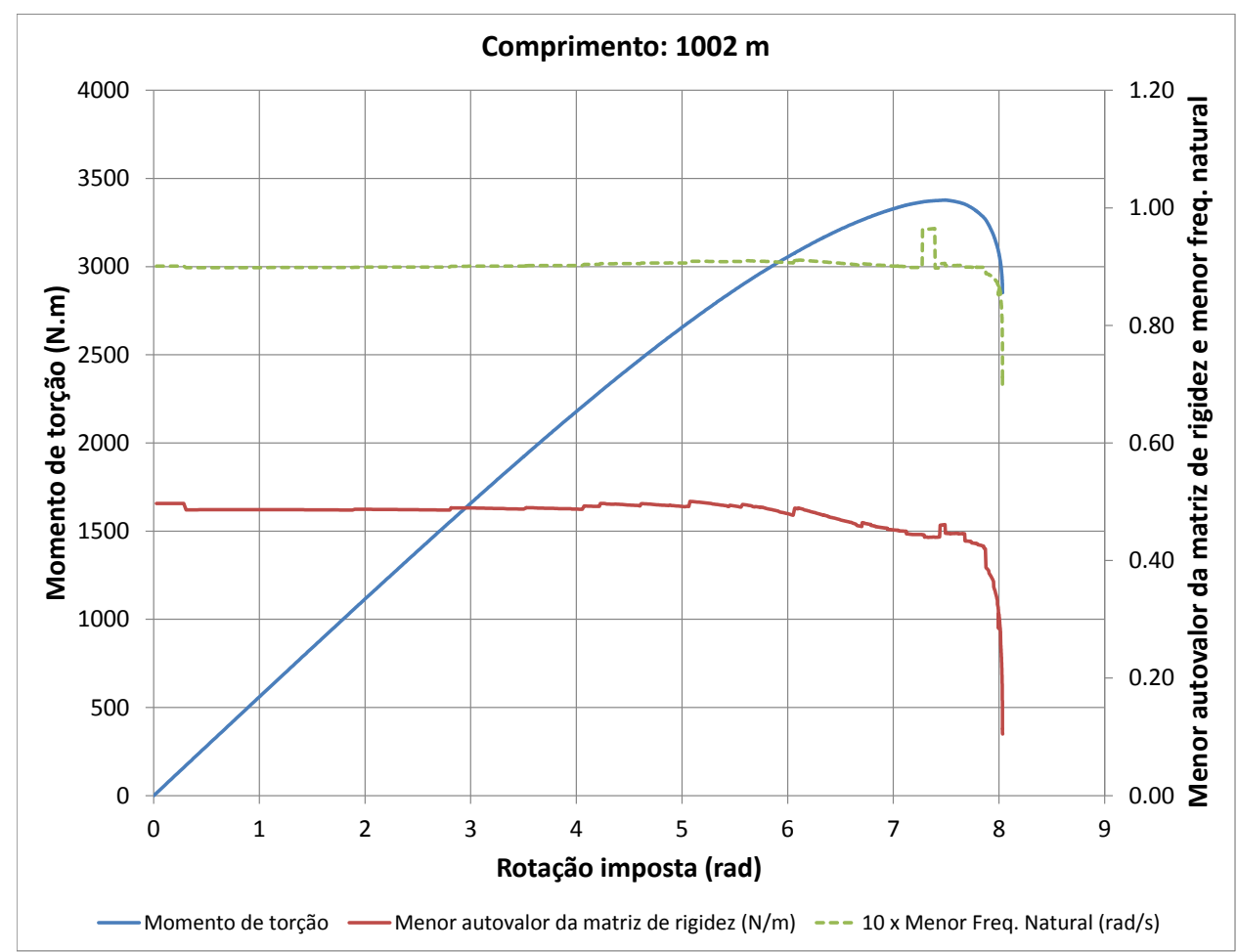

Figura 5.60: Trajetória de equilíbrio $M_{t}$ versus $\alpha$ para o caso $\mathrm{L}=1002 \mathrm{~m}\left(\theta_{\text {topo }}=89,88^{\circ}\right)$. Com atrito $\mu=0,4$ 


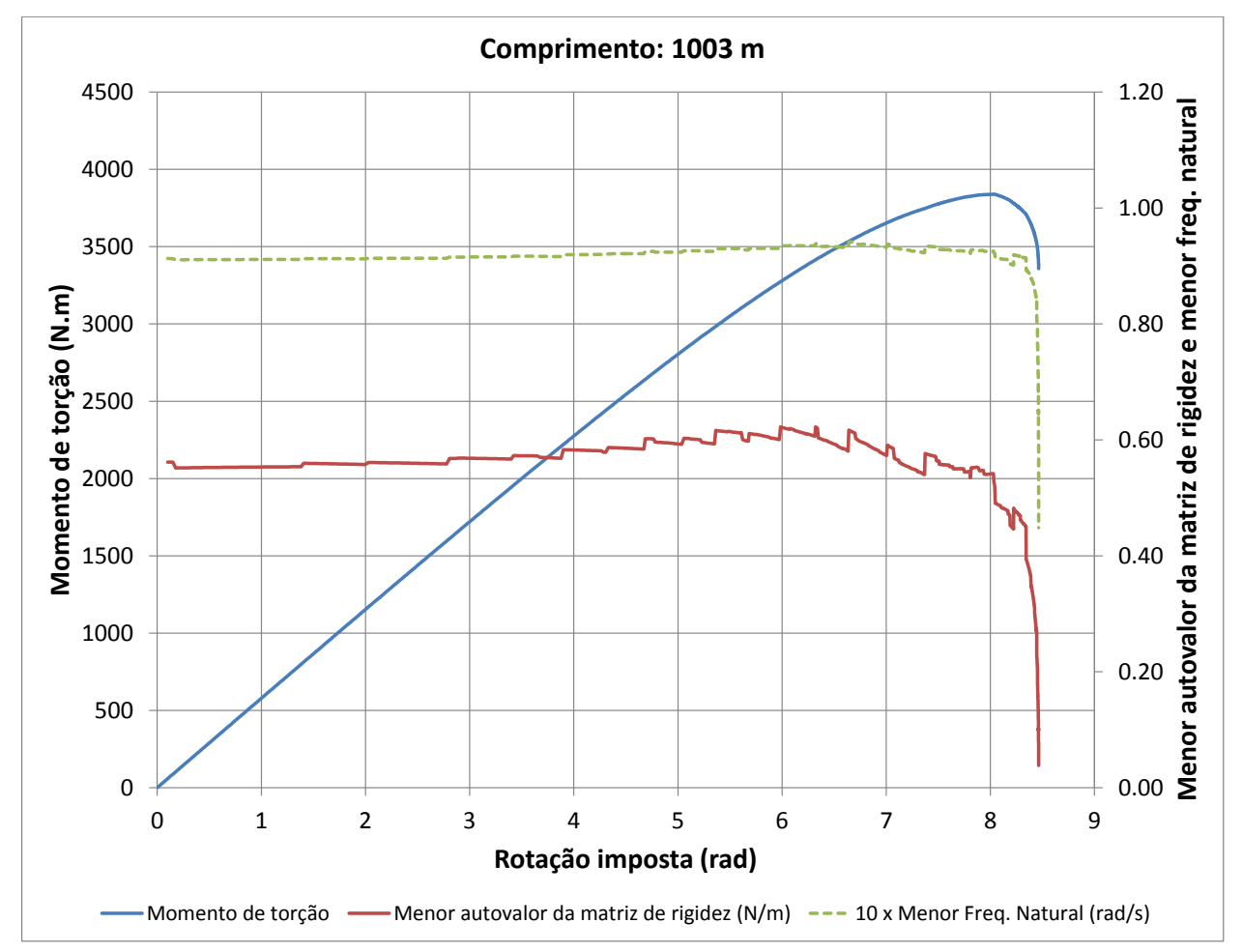

Figura 5.61: Trajetória de equilíbrio $M_{t}$ versus $\alpha$ para o caso $\mathrm{L}=1003 \mathrm{~m}\left(\theta_{\text {topo }}=89,82^{\circ}\right)$. Com atrito $\mu=0,4$

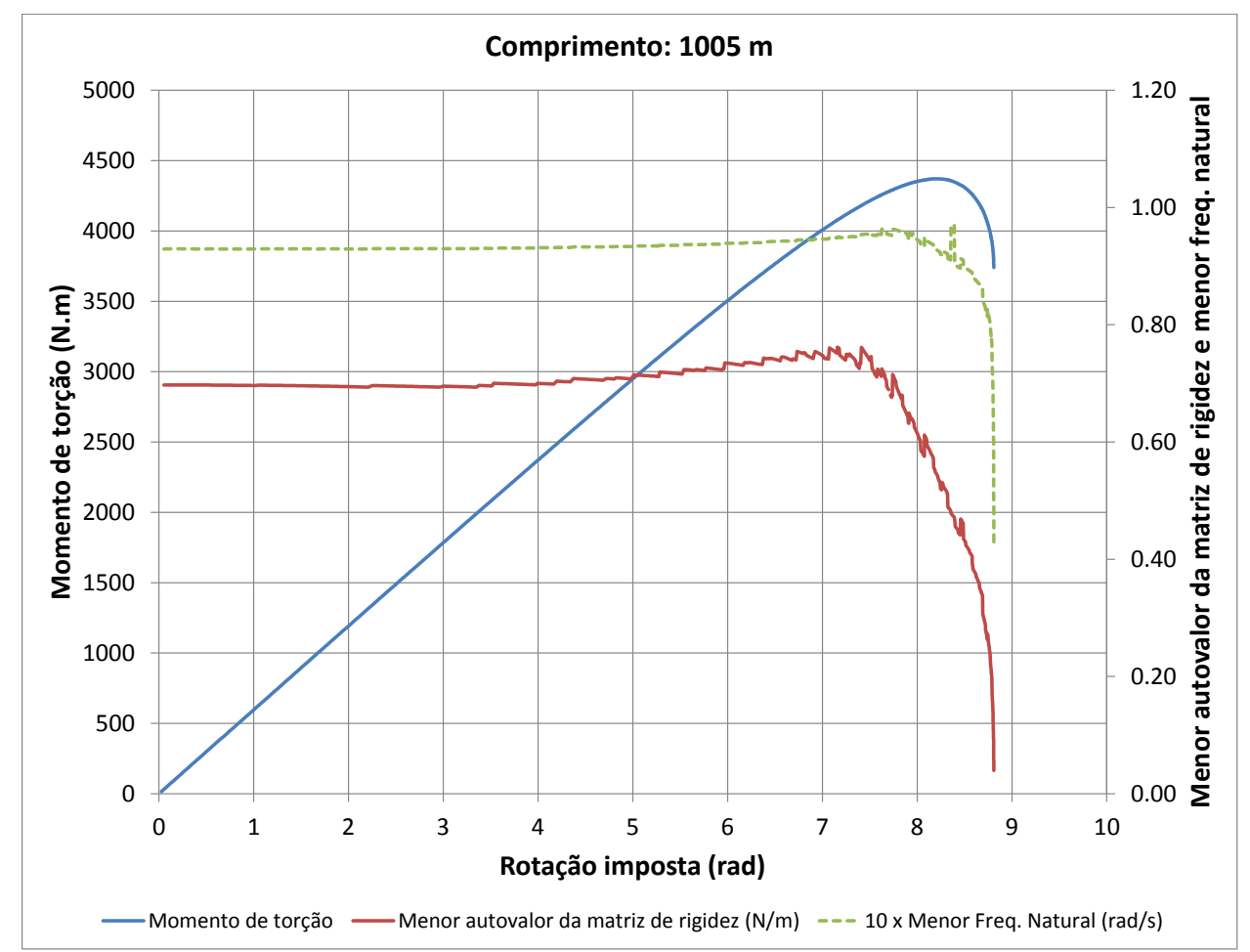

Figura 5.62: Trajetória de equilíbrio $M_{t}$ versus $\alpha$ para o caso $\mathrm{L}=1005 \mathrm{~m}\left(\theta_{\text {topo }}=89,71^{\circ}\right)$. Com atrito $\mu=0,4$ 


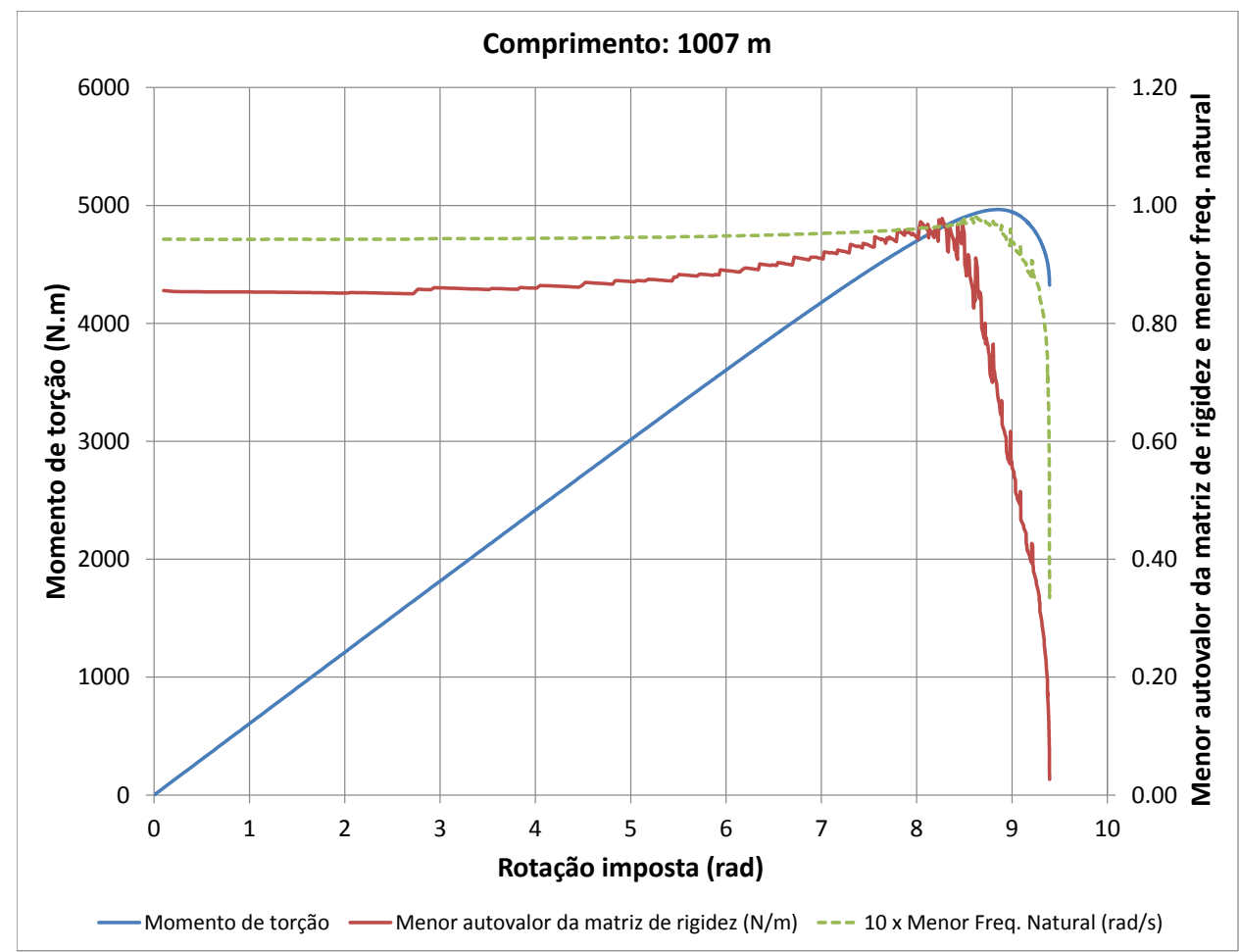

Figura 5.63: Trajetória de equilíbrio $M_{t}$ versus $\alpha$ para o caso $\mathrm{L}=1007 \mathrm{~m}\left(\theta_{\text {topo }}=89,60^{\circ}\right)$. Com atrito $\mu=0,4$

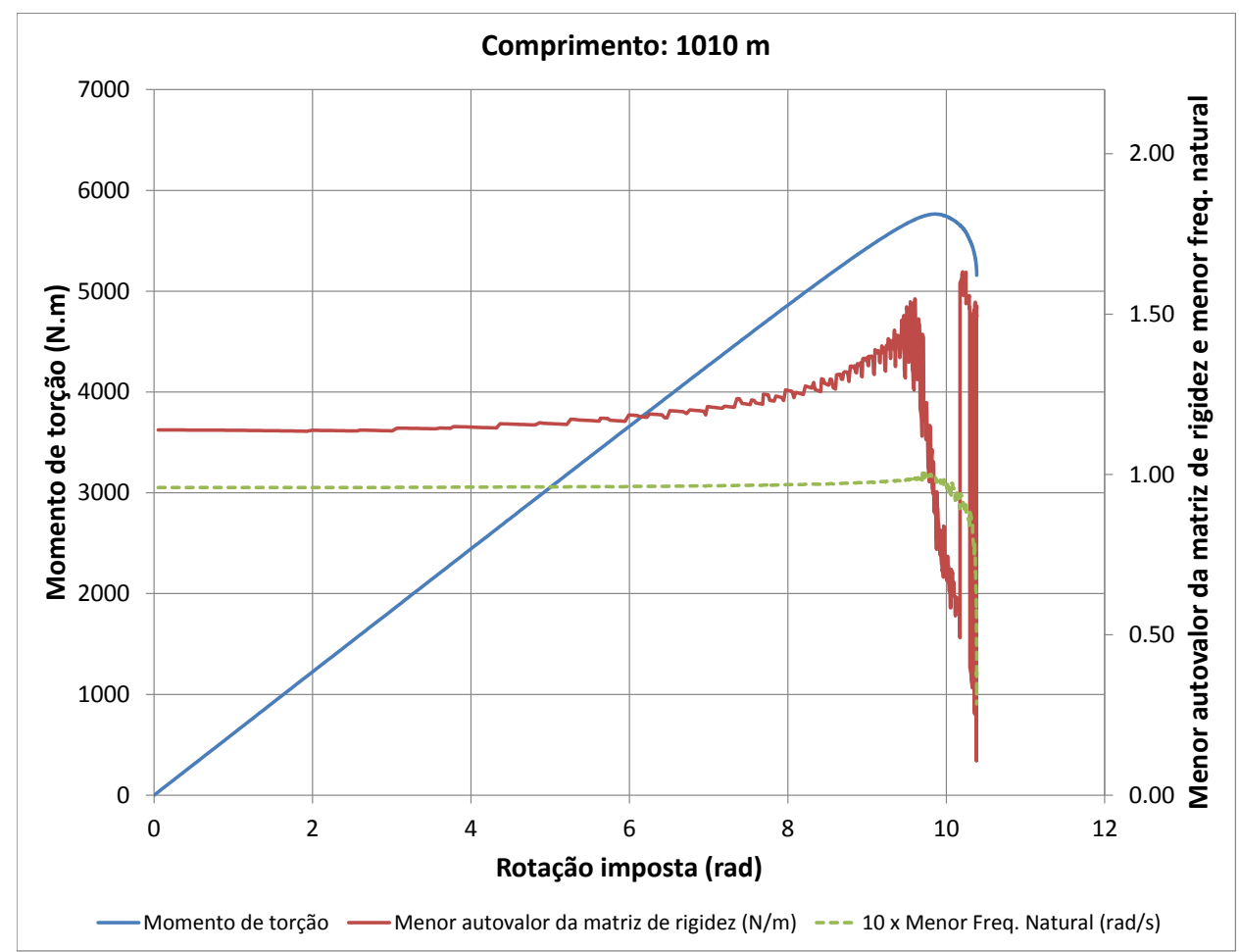

Figura 5.64: Trajetória de equilíbrio $M_{t}$ versus $\alpha$ para o caso $\mathrm{L}=1010 \mathrm{~m}\left(\theta_{\text {topo }}=89,43^{\circ}\right)$. Com atrito $\mu=0,4$ 


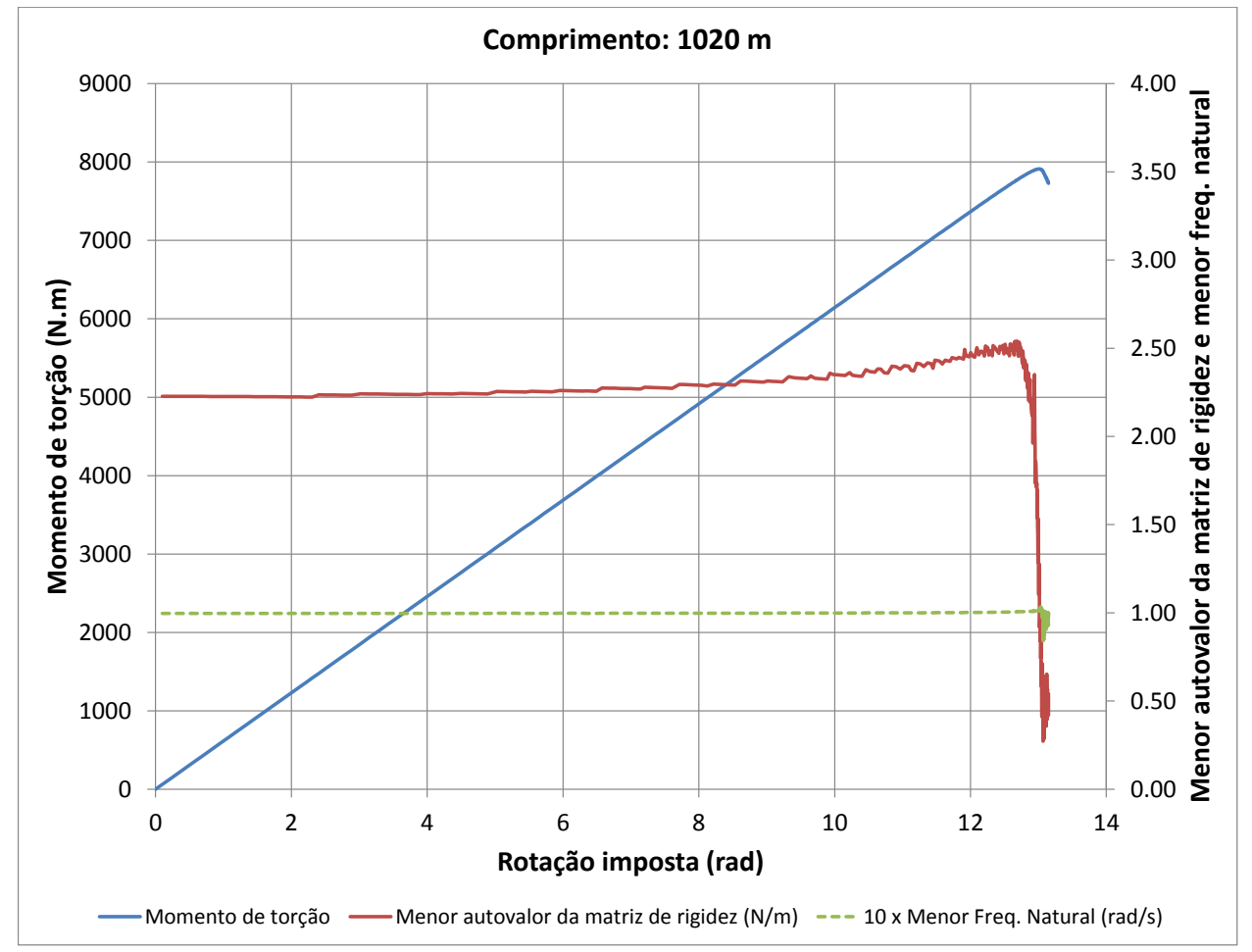

Figura 5.65: Trajetória de equilíbrio $M_{t}$ versus $\alpha$ para o caso $\mathrm{L}=1020 \mathrm{~m}\left(\theta_{\text {topo }}=88,86^{\circ}\right)$. Com atrito $\mu=0,4$

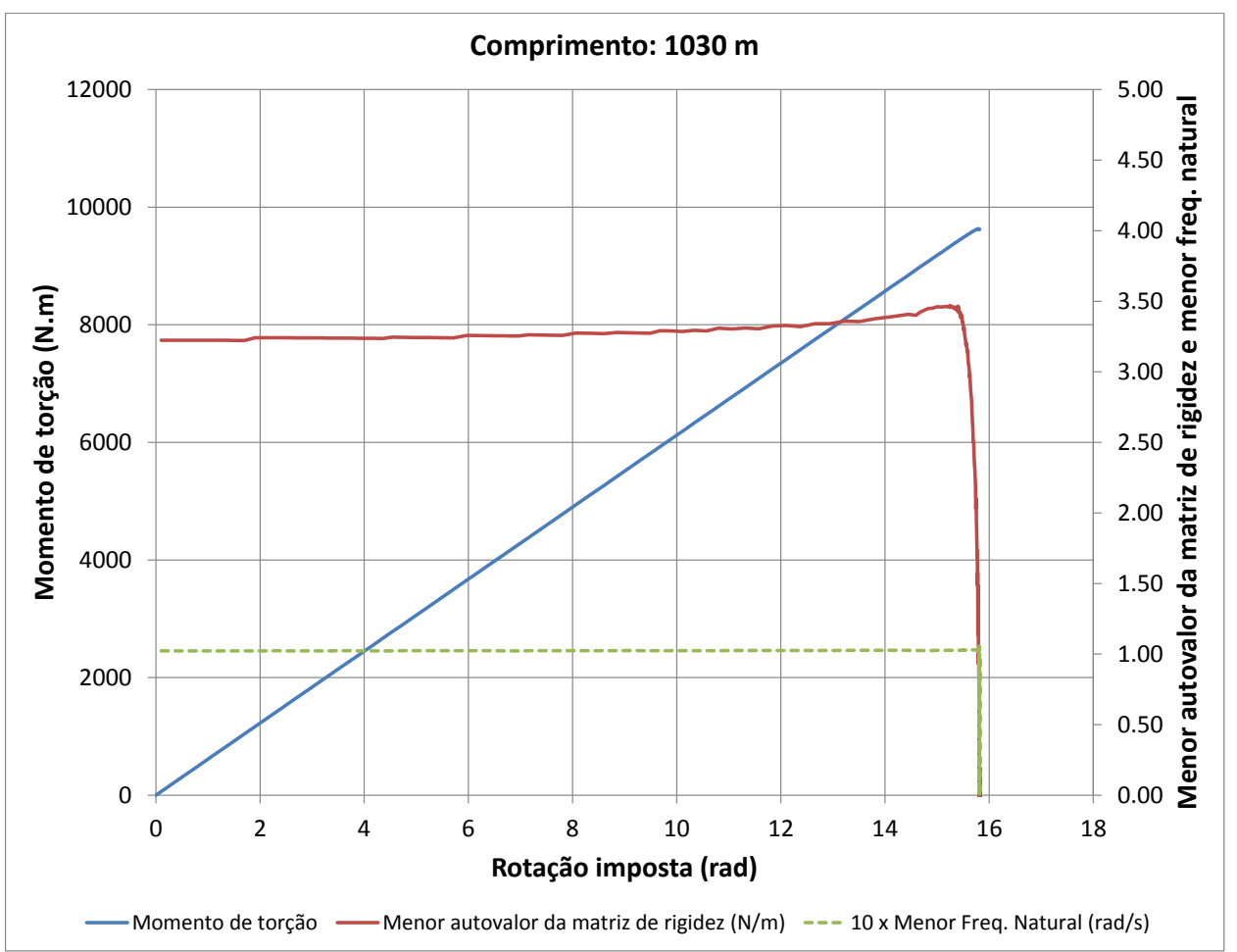

Figura 5.66: Trajetória de equilíbrio $M_{t}$ versus $\alpha$ para o caso $\mathrm{L}=1030 \mathrm{~m}\left(\theta_{\text {topo }}=88,29^{\circ}\right)$. Com atrito $\mu=0,4$ 


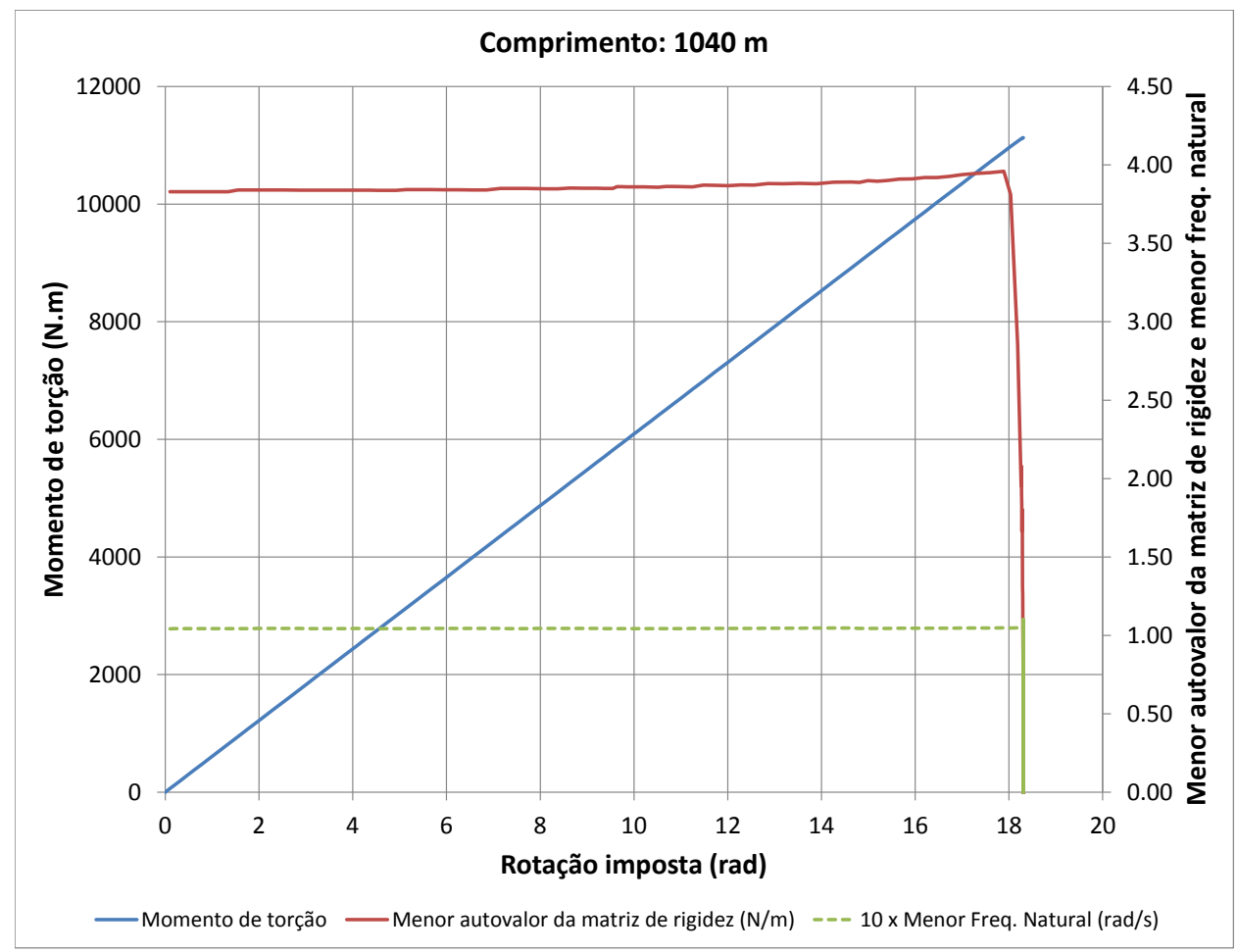

Figura 5.67: Trajetória de equilíbrio $M_{t}$ versus $\alpha$ para o caso $\mathrm{L}=1040 \mathrm{~m}\left(\theta_{\text {topo }}=87,74^{\circ}\right)$. Com atrito $\mu=0,4$

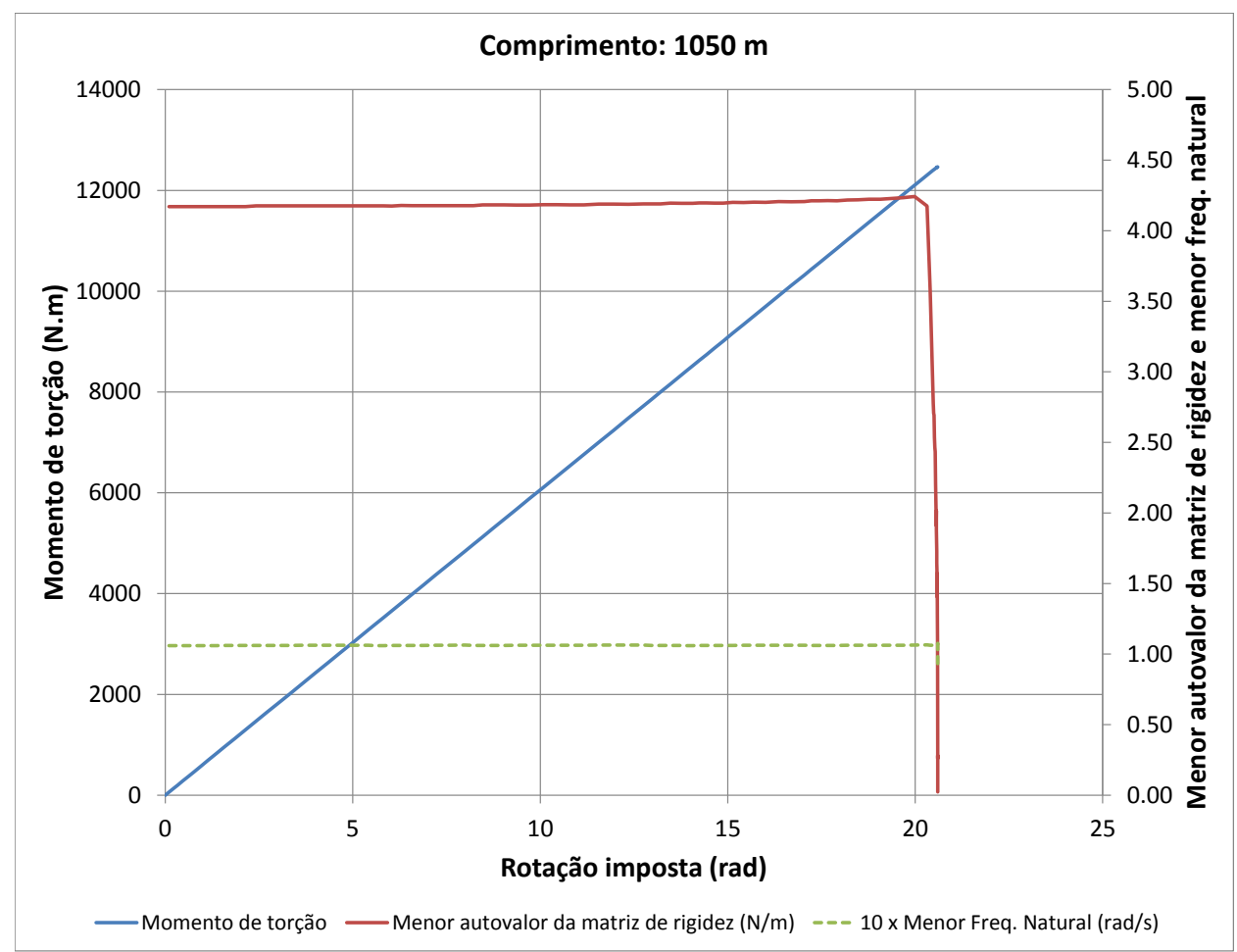

Figura 5.68: Trajetória de equilíbrio $M_{t}$ versus $\alpha$ para o caso $\mathrm{L}=1050 \mathrm{~m}\left(\theta_{\text {topo }}=87,18^{\circ}\right)$.

Com atrito $\mu=0,4$ 


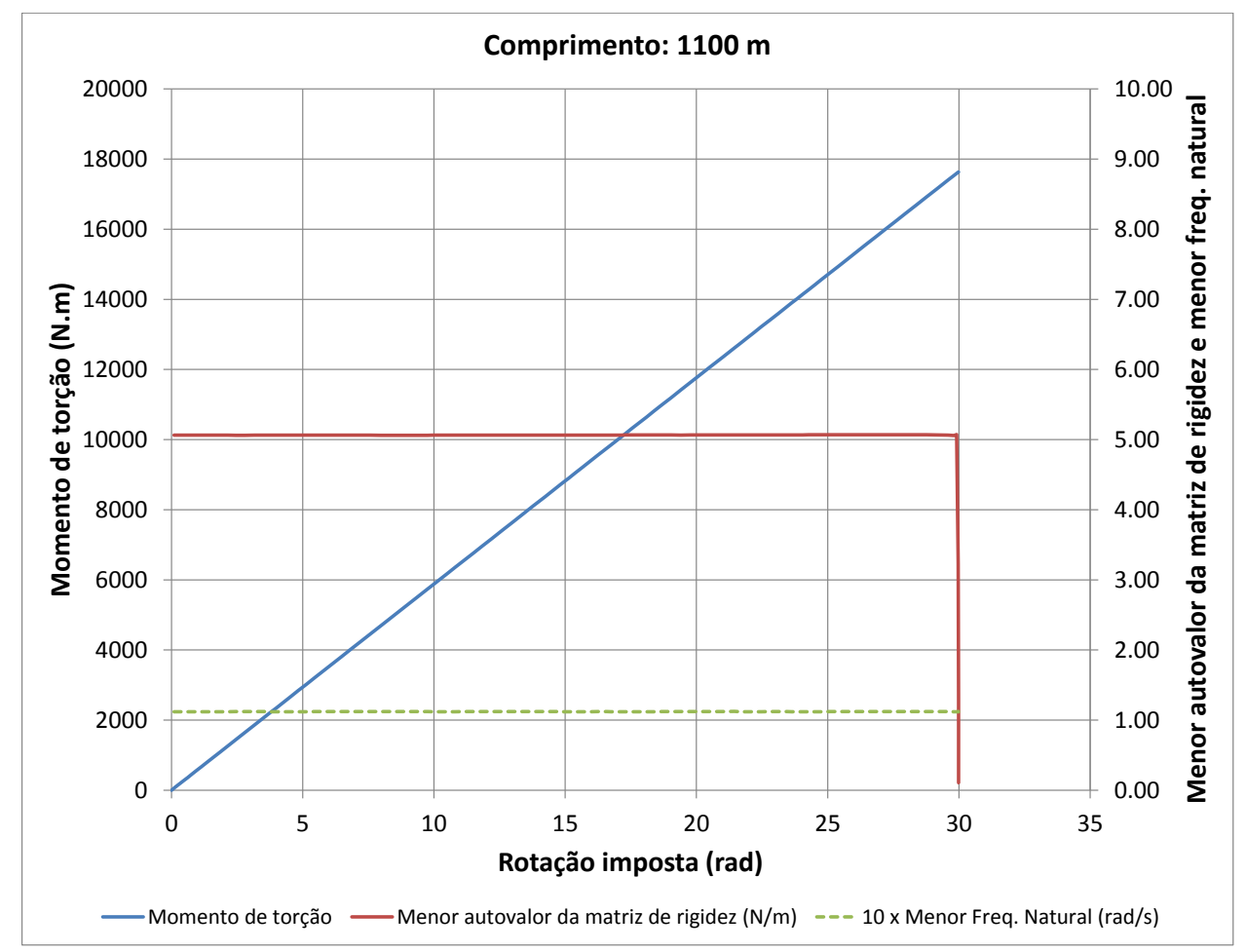

Figura 5.69: Trajetória de equilíbrio $M_{t}$ versus $\alpha$ para o caso $\mathrm{L}=1100 \mathrm{~m}\left(\theta_{\text {topo }}=84,50^{\circ}\right)$. Com atrito $\mu=0,4$

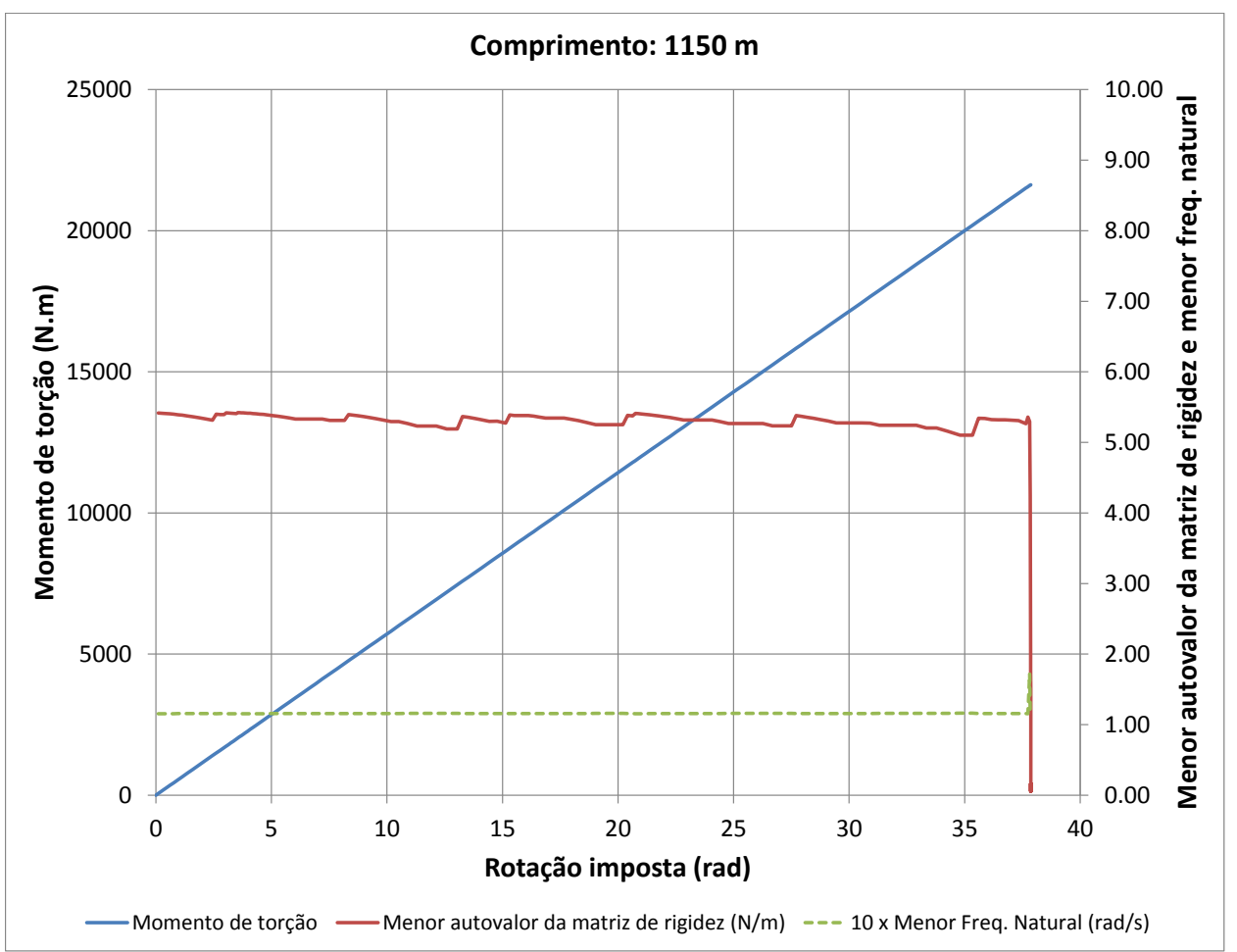

Figura 5.70: Trajetória de equilíbrio $M_{t}$ versus $\alpha$ para o caso $\mathrm{L}=1150 \mathrm{~m}\left(\theta_{\text {topo }}=81,95^{\circ}\right)$. Com atrito $\mu=0,4$ 


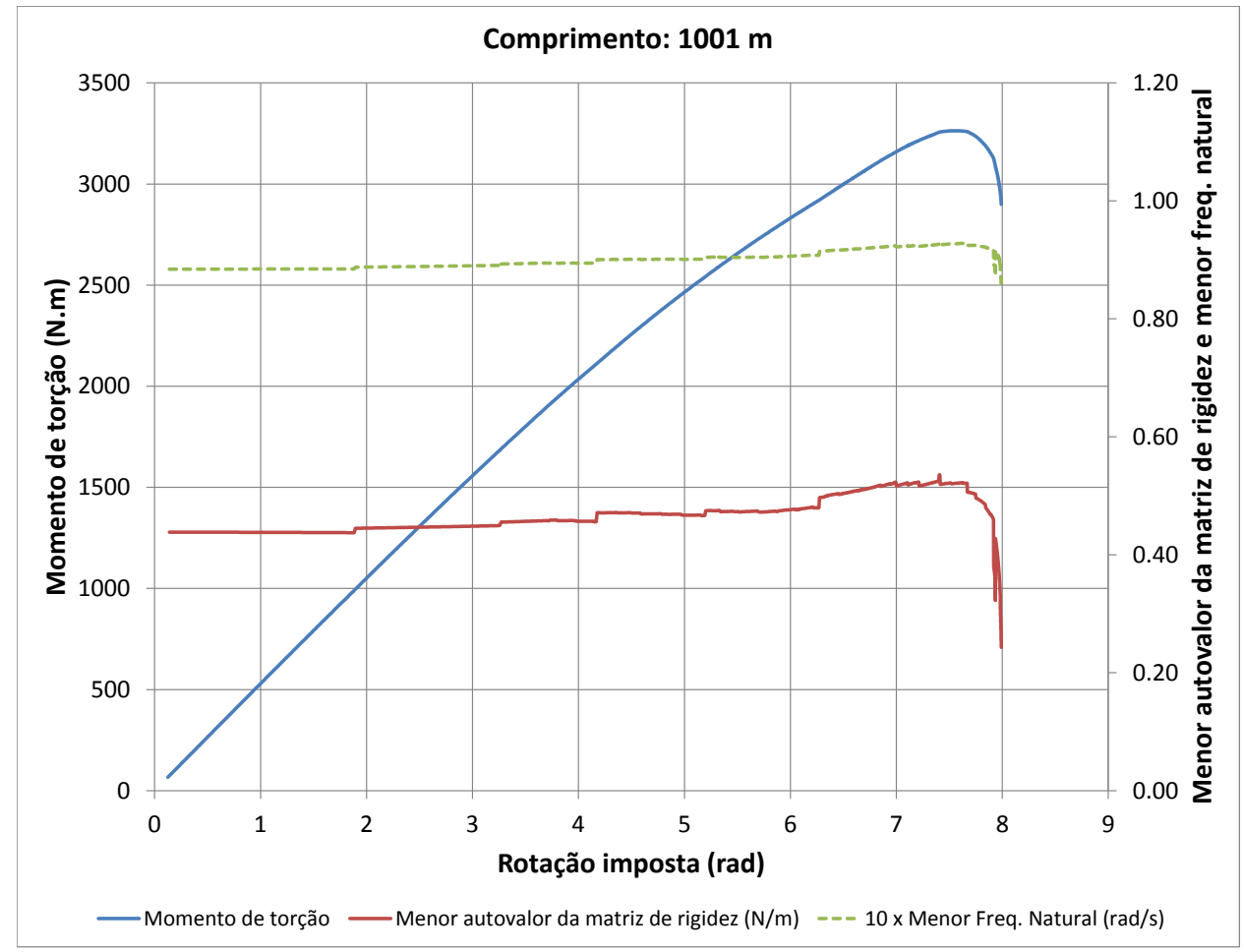

Figura 5.71: Trajetória de equilíbrio $M_{t}$ versus $\alpha$ para o caso $\mathrm{L}=1001 \mathrm{~m}\left(\theta_{\text {topo }}=89,93^{\circ}\right)$. Com atrito $\mu=1,0$

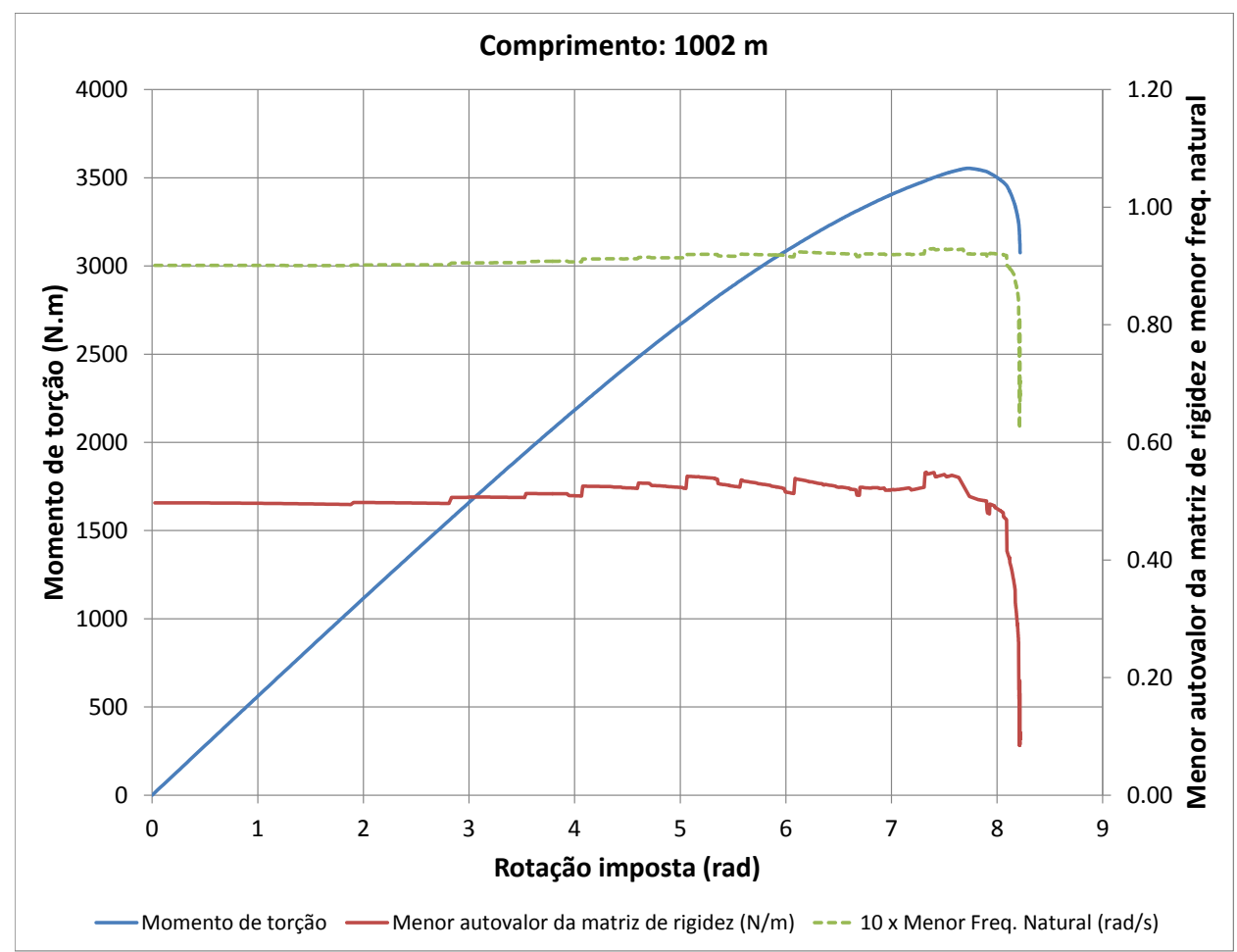

Figura 5.72: Trajetória de equilíbrio $M_{t}$ versus $\alpha$ para o caso $\mathrm{L}=1002 \mathrm{~m}\left(\theta_{\text {topo }}=89,88^{\circ}\right)$. Com atrito $\mu=1,0$ 


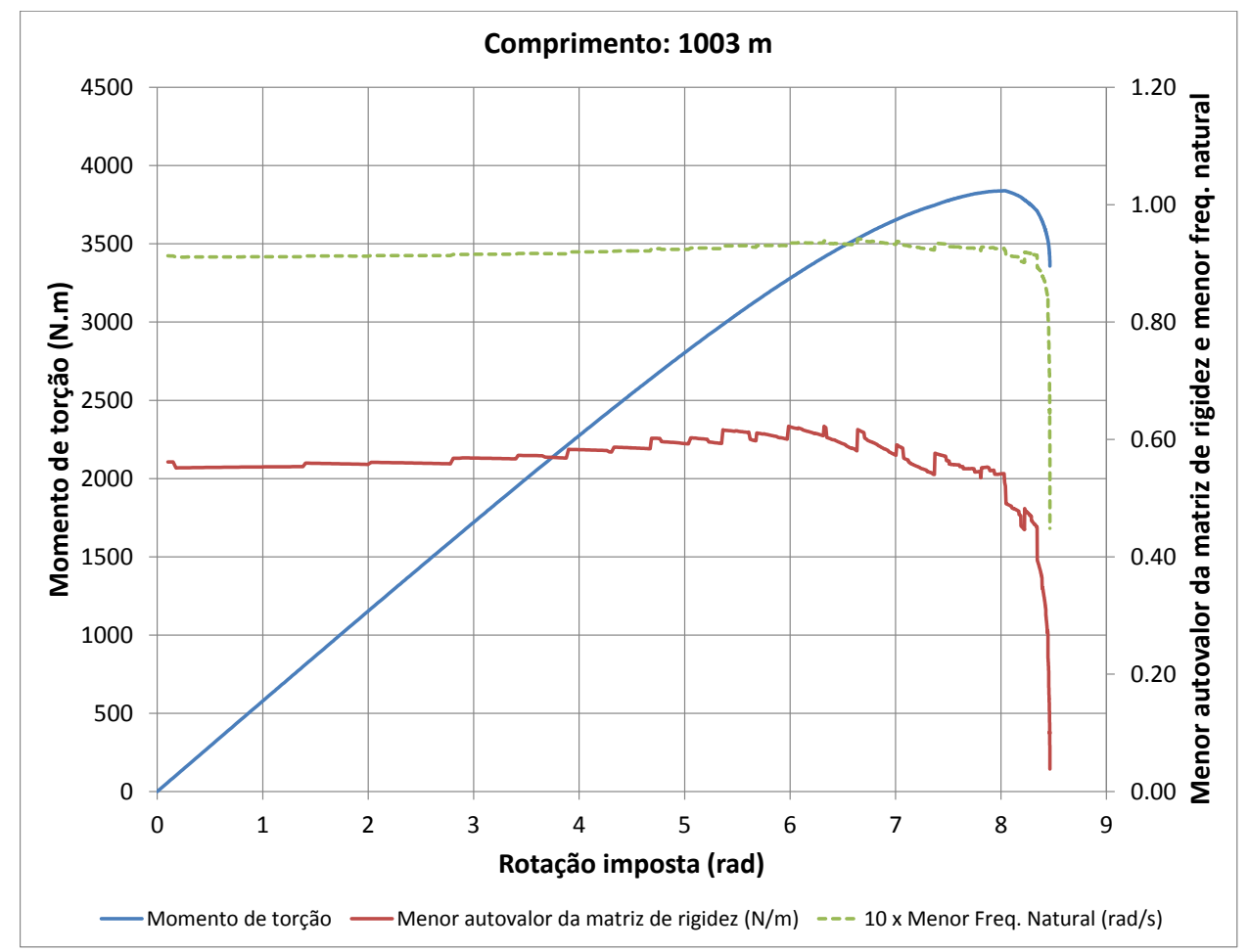

Figura 5.73: Trajetória de equilíbrio $M_{t}$ versus $\alpha$ para o caso $\mathrm{L}=1003 \mathrm{~m}\left(\theta_{\text {topo }}=89,82^{\circ}\right)$. Com atrito $\mu=1,0$

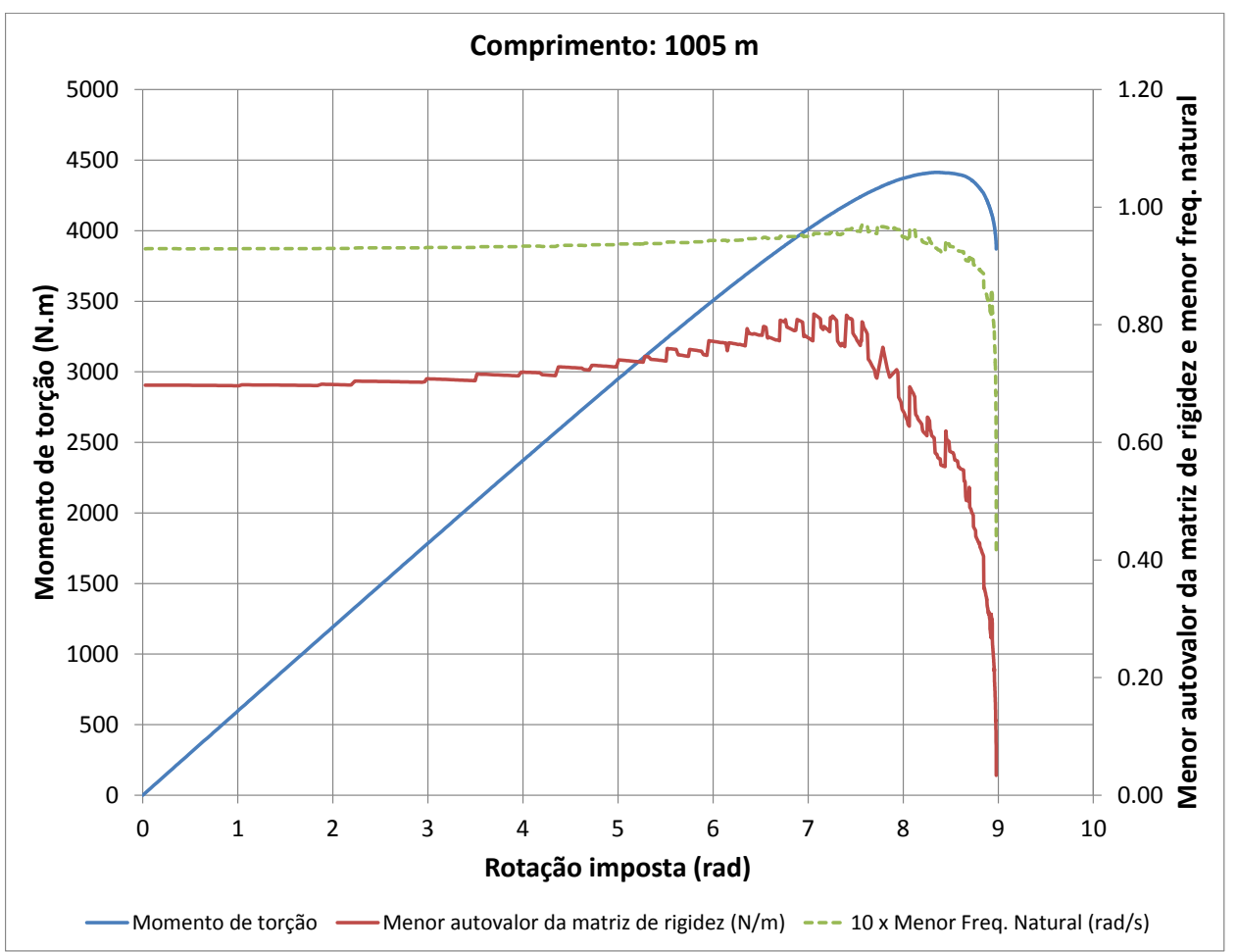

Figura 5.74: Trajetória de equilíbrio $M_{t}$ versus $\alpha$ para o caso $\mathrm{L}=1005 \mathrm{~m}\left(\theta_{\text {topo }}=89,71^{\circ}\right)$. Com atrito $\mu=1,0$ 


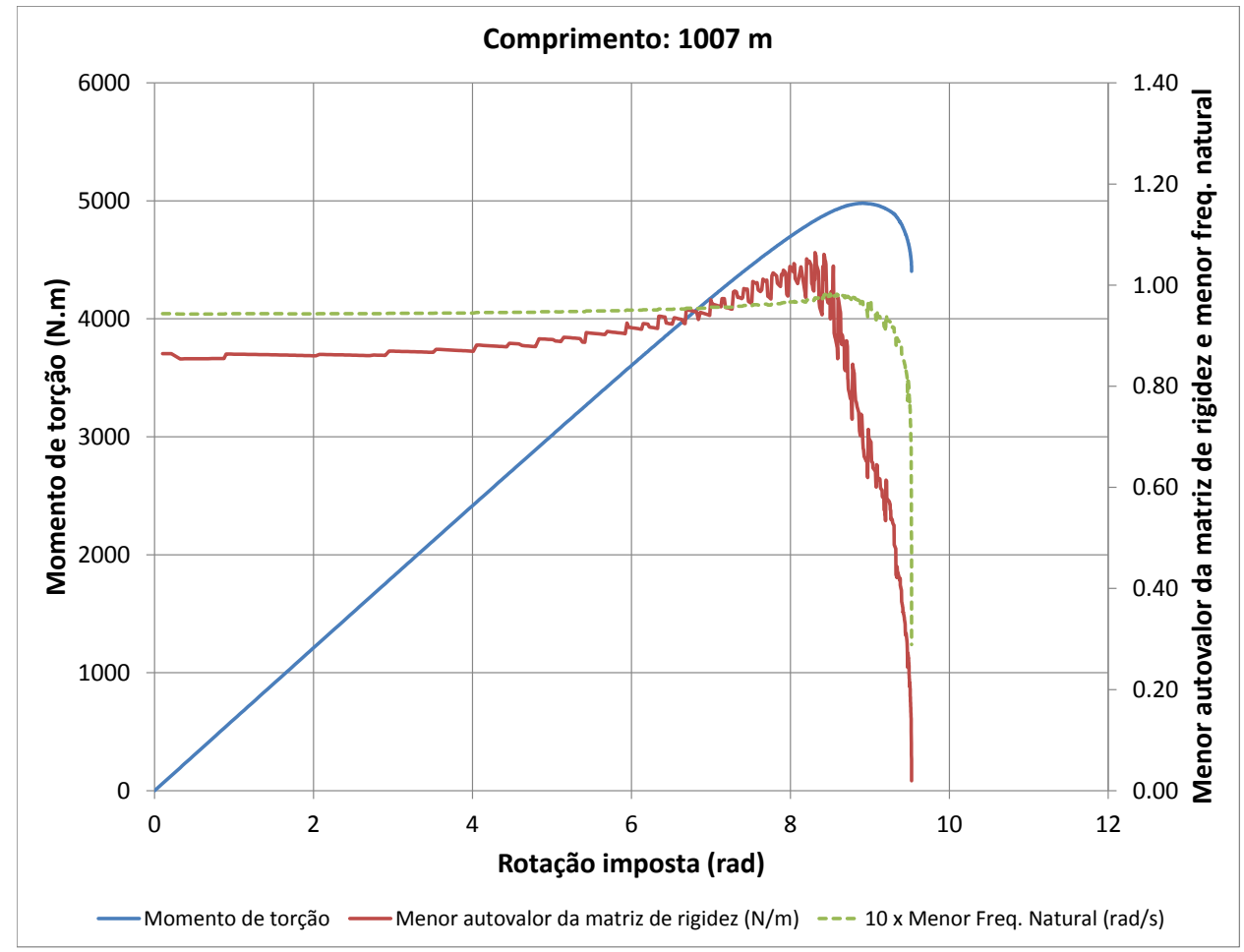

Figura 5.75: Trajetória de equilíbrio $M_{t}$ versus $\alpha$ para o caso $\mathrm{L}=1007 \mathrm{~m}\left(\theta_{\text {topo }}=89,60^{\circ}\right)$. Com atrito $\mu=1,0$

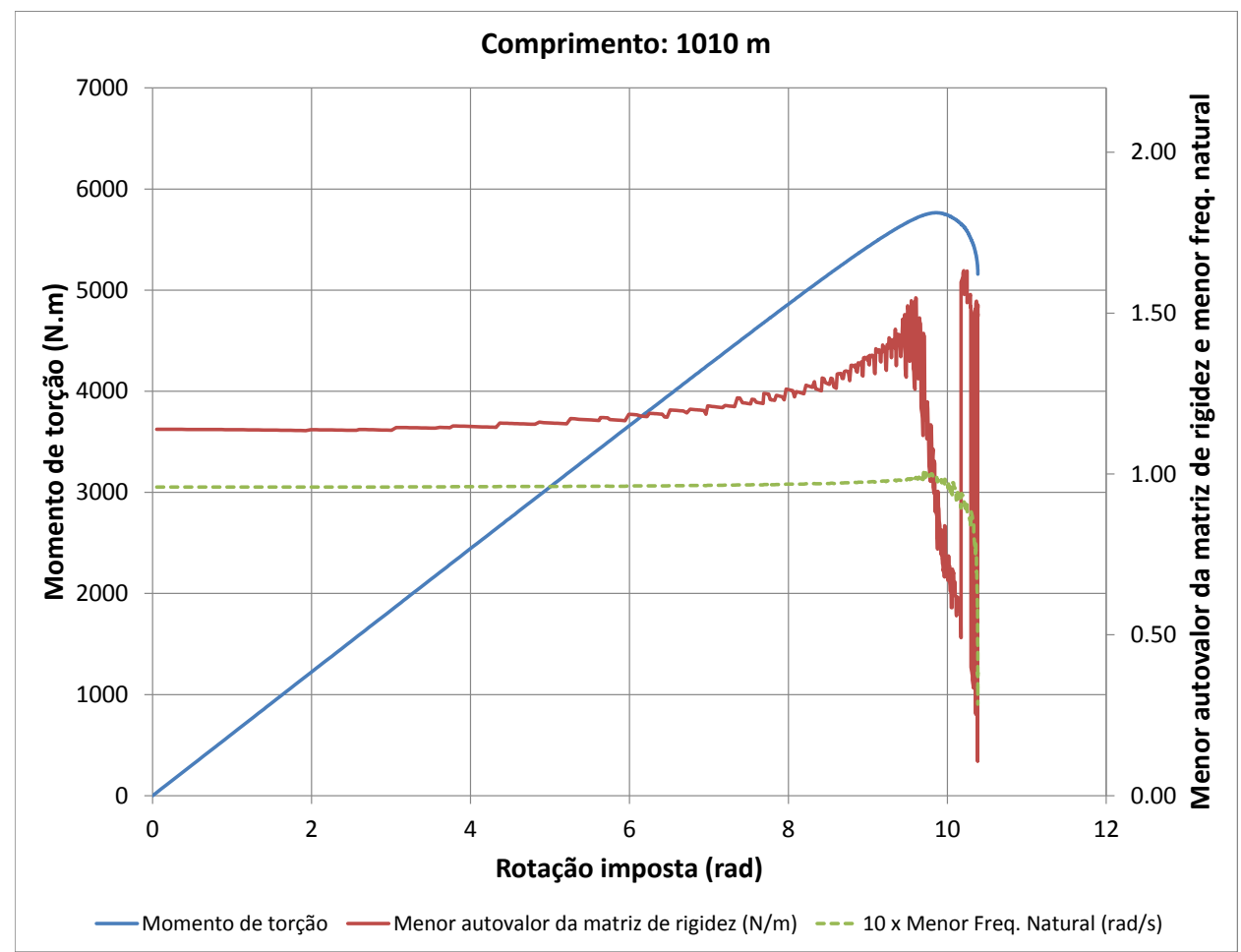

Figura 5.76: Trajetória de equilíbrio $M_{t}$ versus $\alpha$ para o caso $\mathrm{L}=1010 \mathrm{~m}\left(\theta_{\text {topo }}=89,43^{\circ}\right)$. Com atrito $\mu=1,0$ 


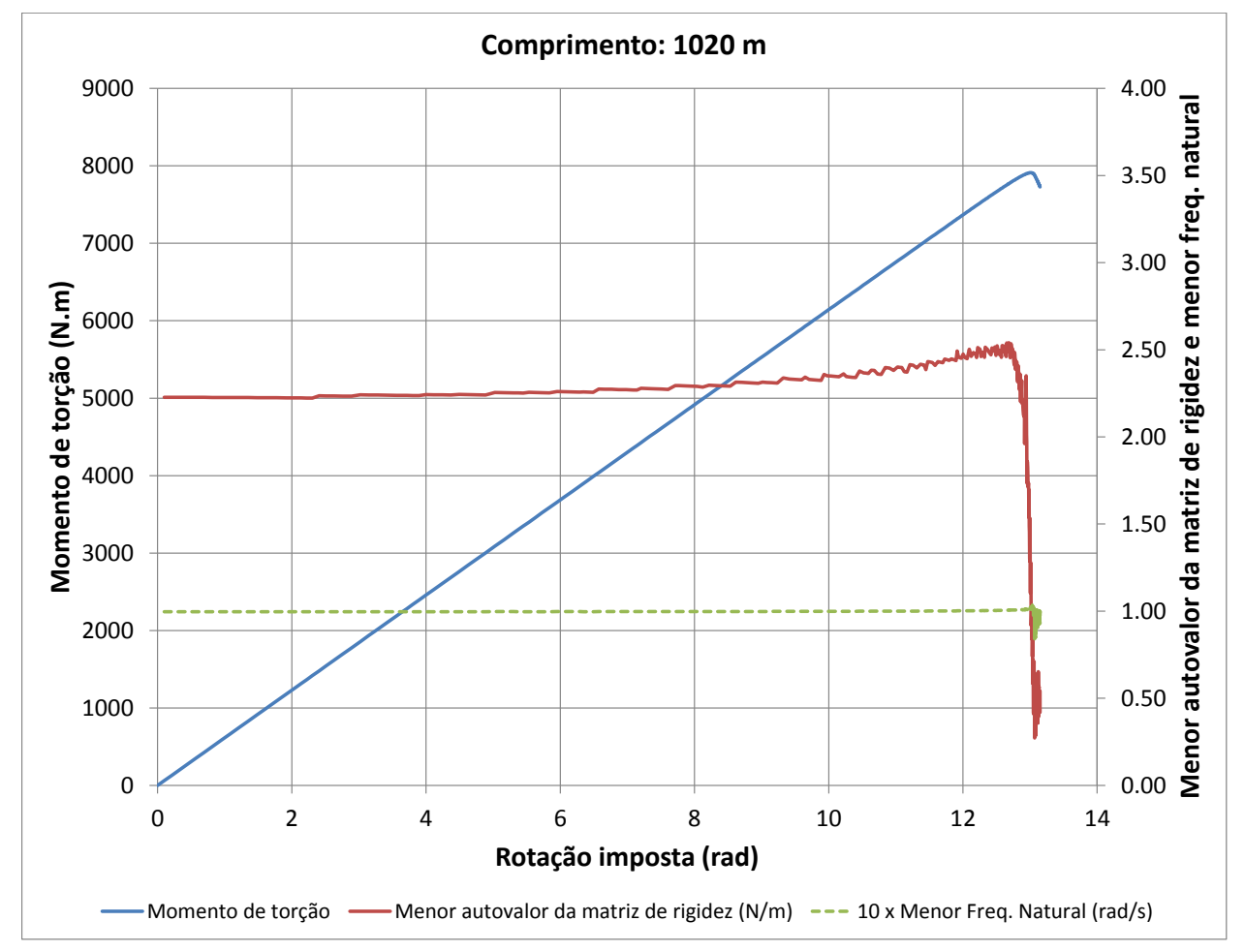

Figura 5.77: Trajetória de equilíbrio $M_{t}$ versus $\alpha$ para o caso $\mathrm{L}=1020 \mathrm{~m}\left(\theta_{\text {topo }}=88,86^{\circ}\right)$. Com atrito $\mu=1,0$

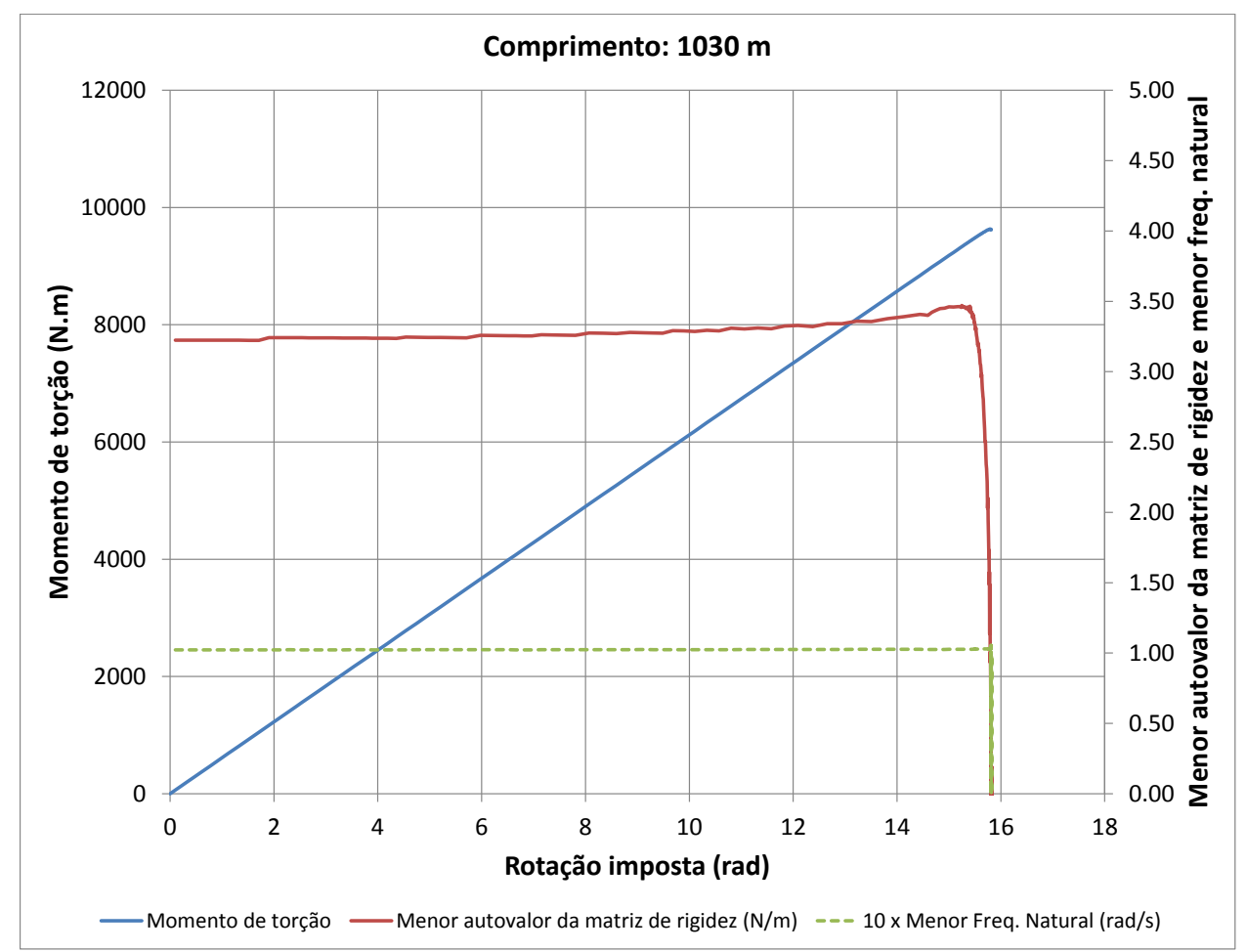

Figura 5.78: Trajetória de equilíbrio $M_{t}$ versus $\alpha$ para o caso $\mathrm{L}=1030 \mathrm{~m}\left(\theta_{\text {topo }}=88,29^{\circ}\right)$. Com atrito $\mu=1,0$ 


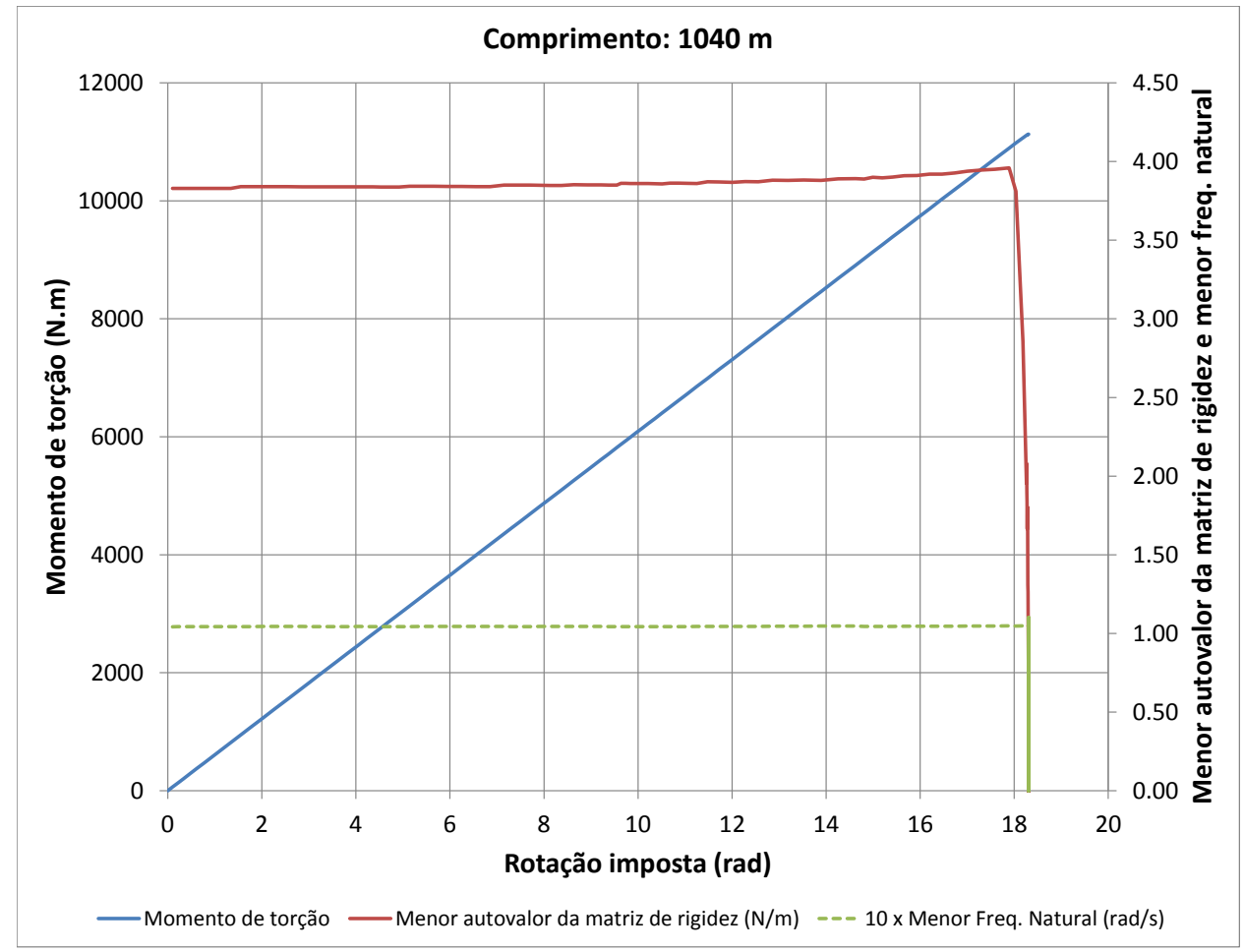

Figura 5.79: Trajetória de equilíbrio $M_{t}$ versus $\alpha$ para o caso $\mathrm{L}=1040 \mathrm{~m}\left(\theta_{\text {topo }}=87,74^{\circ}\right)$. Com atrito $\mu=1,0$

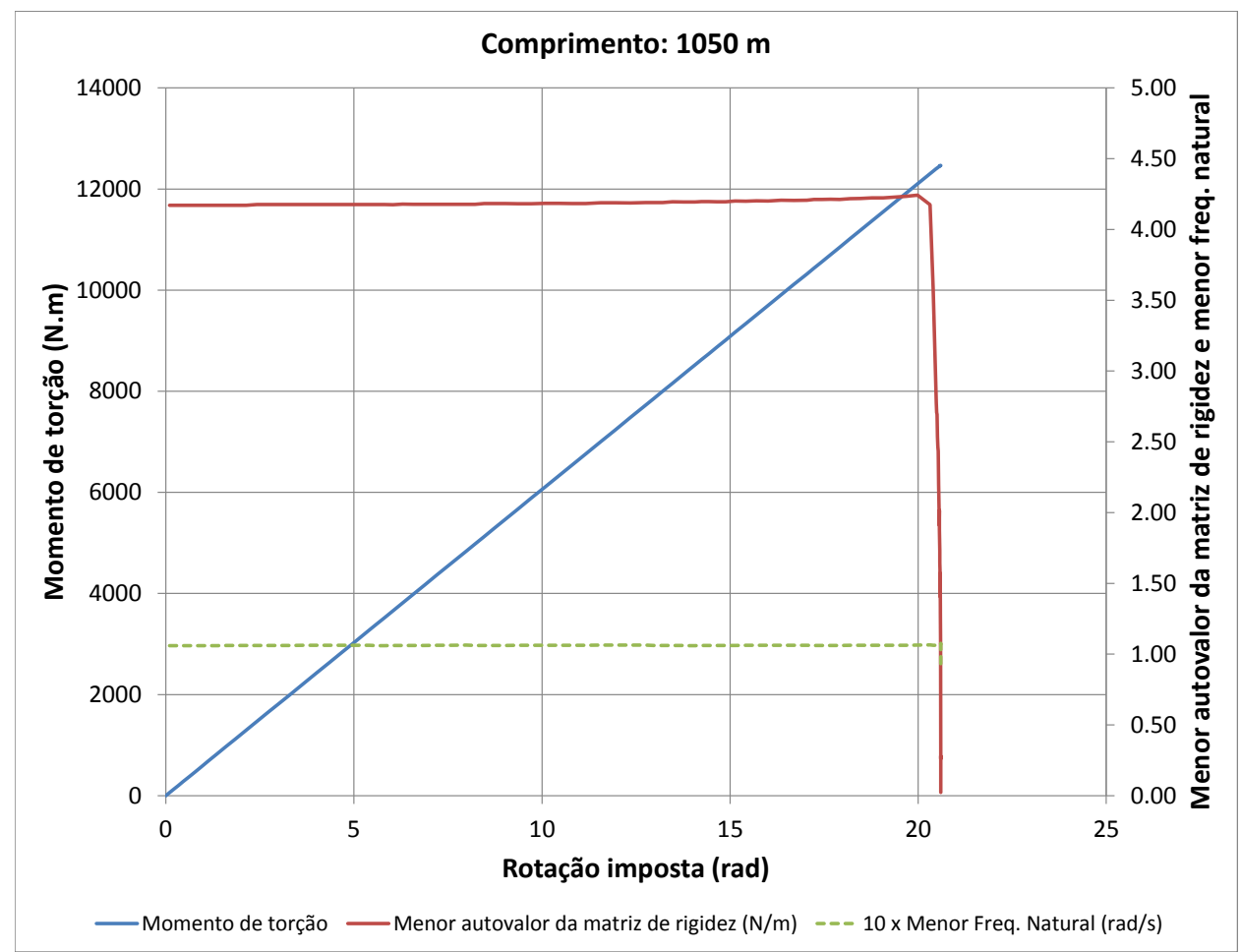

Figura 5.80: Trajetória de equilíbrio $M_{t}$ versus $\alpha$ para o caso $\mathrm{L}=1050 \mathrm{~m}\left(\theta_{\text {topo }}=87,18^{\circ}\right)$. Com atrito $\mu=1,0$ 


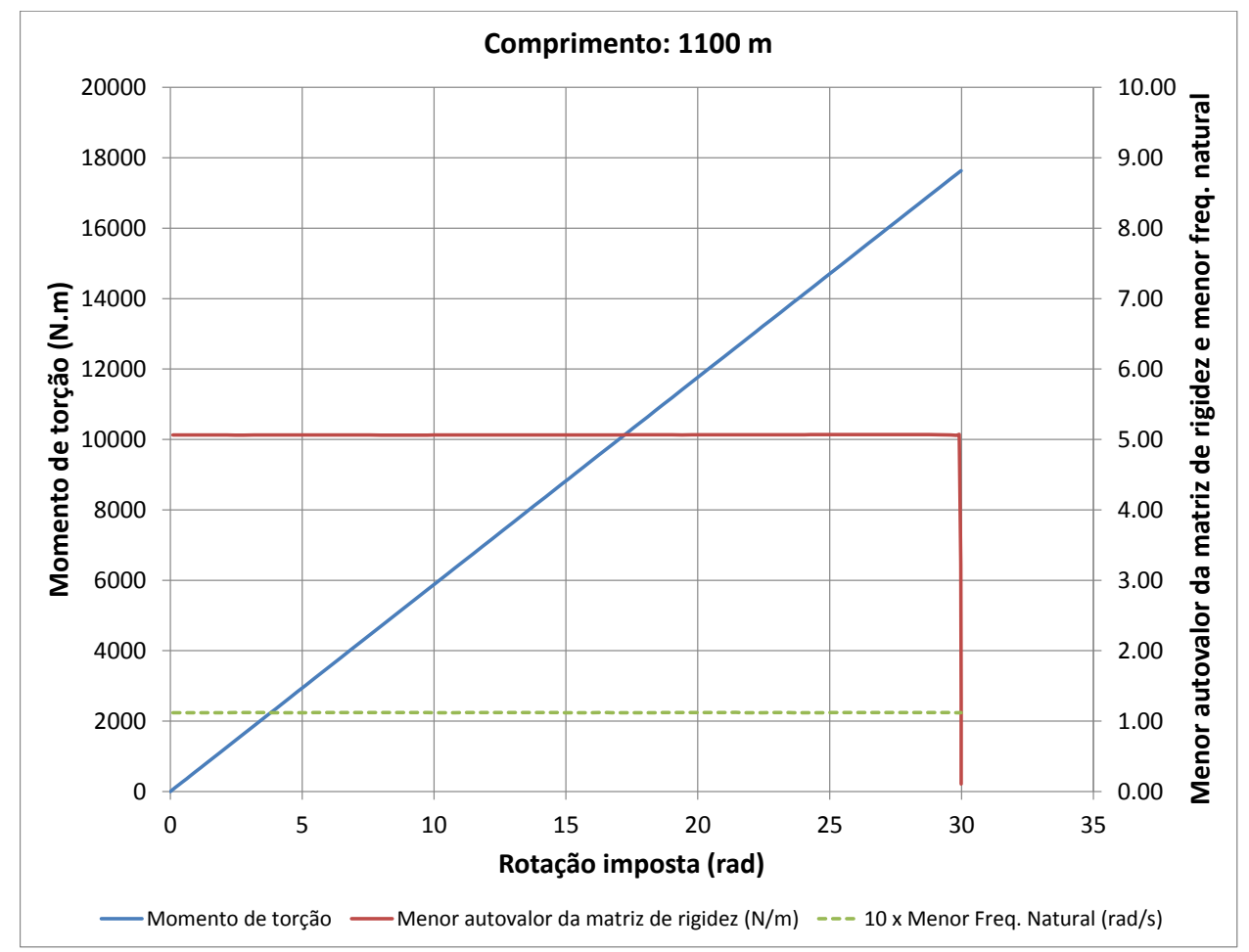

Figura 5.81: Trajetória de equilíbrio $M_{t}$ versus $\alpha$ para o caso $\mathrm{L}=1100 \mathrm{~m}\left(\theta_{\text {topo }}=84,50^{\circ}\right)$. Com atrito $\mu=1,0$

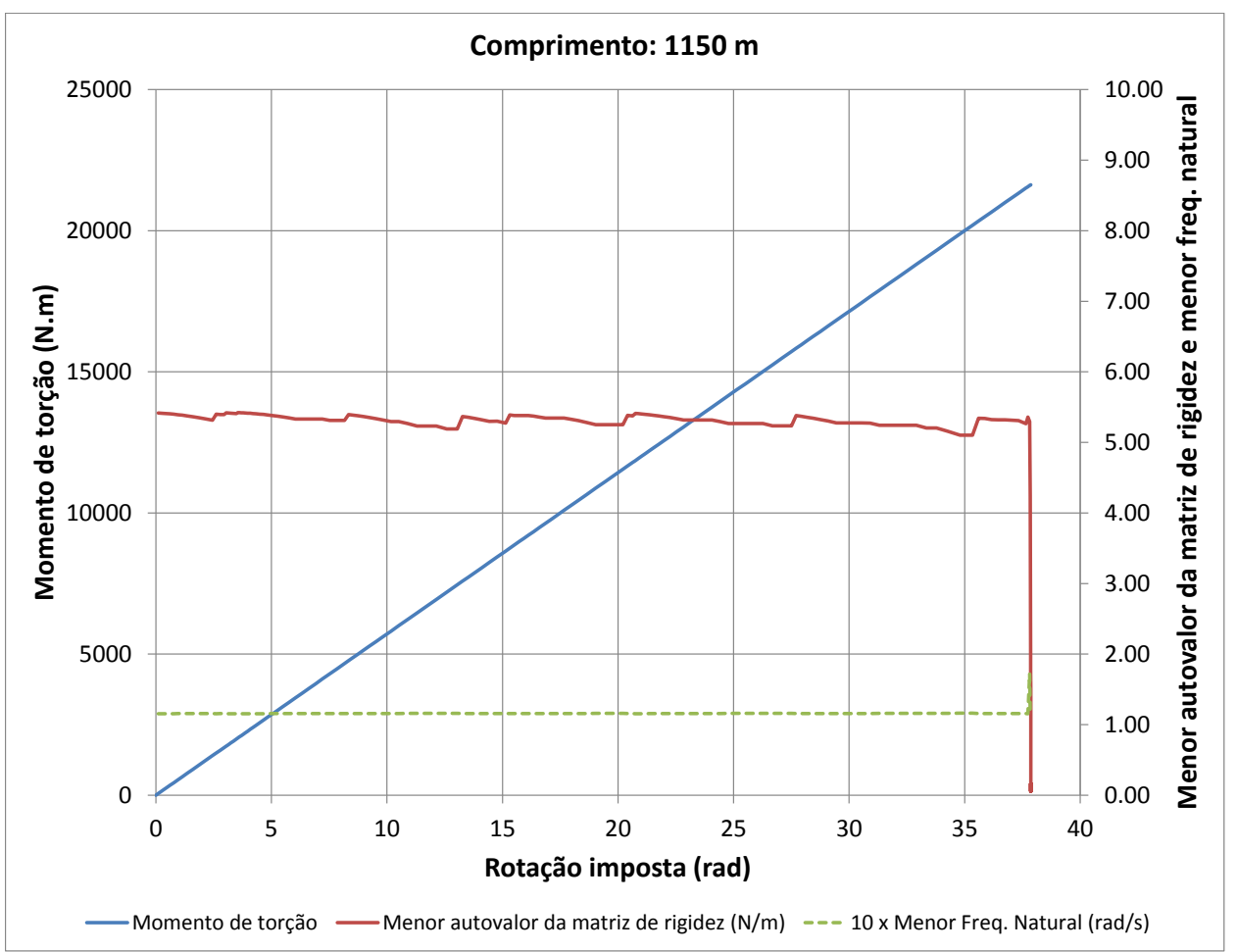

Figura 5.82: Trajetória de equilíbrio $M_{t}$ versus $\alpha$ para o caso $\mathrm{L}=1150 \mathrm{~m}\left(\theta_{\text {topo }}=81,95^{\circ}\right)$. Com atrito $\mu=1,0$ 
O comportamento dos menores autovalores da matriz de rigidez, bem como das menores frequências naturais prevêem o mesmo ponto para ocorrência de instabilidade, como pode ser visto também nos resultados dos casos com TDP engastado e sem atrito. Isso foi previsto com argumentos conceituais no Capítulo 3, uma vez que sistema do riser com atrito com o solo é puramente dissipativo. Todas as trajetórias de equilíbrio apresentaram uma nítida queda do menor autovalor da matriz de rigidez e menor frequência natural associada ao ponto de snapback. No entanto, diferente do modelo sem atrito, o menor autovalor da matriz de rigidez sofre oscilações bastante abruptas, altamente sensíveis ao valor de penalidade normal escolhido. Essas oscilações se dão em função do atrito de deslizamento que ocorre. Assim, a alternância entre situações de deslizamento e não deslizamento durante a imposição da rotação pode causar diferentes espectros na matriz de rigidez tangente em cada ponto de análise, levando às oscilações de pequena amplitude quando comparadas ao valor absoluto dos autovalores. Ainda foram encontradas algumas dificuldades numéricas quanto à extração do menor autovalor da matriz de rigidez ou menor frequência natural. Em alguns casos o algoritmo de Arnoldi acabou por "pular" o menor autovalor do problema, identificando o segundo menor autovalor como sendo o menor. Isso pôde ser corrigido utilizando-se para extração do autovalor nesses casos o pacote MATLAB ${ }^{\mathrm{TM}}$ que também utiliza o ARPACK ${ }^{\mathrm{TM}}$. No entanto, nesse pacote os parâmetros do algoritmo de Arnoldi estão mais otimizados do que no código próprio desenvolvido no presente trabalho.

Outra observação do ponto de vista numérico para os casos com atrito é a ocorrência de autovalores da matriz de rigidez e de frequências naturais com parte imaginária não nula durante a solução do modelo. Uma interpretação direta desse fato, segundo discutido no Capítulo 3, sugeriria a ocorrência de instabilidade dinâmica da estrutura (flutter), uma vez que o surgimento dessas partes imaginárias teria ocorrido sem antes passar por um valor real nulo, que caracterizaria a divergência (buckling). No entanto, o aparecimento desses valores imaginários se mostrou não consistente, uma vez que ponto após ponto da linearização das matrizes de rigidez e de massa, por vezes ocorre seu retorno para valores puramente reais. Portanto, trata-se de erros numéricos decorrentes do mal condicionamento da matriz de rigidez. Observando-se a equação 4.228 é possível notar que a contribuição não simétrica da rigidez do atrito é sensível ao parâmetro de penalidade na direção normal. Assim, alternando-se tal parâmetro pode-se alterar sensivelmente os autovalores. No entanto, em todos os testes realizados variando-se parâmetros de penalidade foi mantida a consistência da queda do menor autovalor da matriz de rigidez e menor frequência natural no ponto de snapback, embora suas oscilações até atingir tal ponto se- 
jam distintas. Notou-se que com parâmetros de penalidade normal mais baixos (da ordem de 10.000) os surgimentos de partes imaginárias espúrias nas frequências naturais diminui substancialmente ou até mesmo desaparece.

Ainda acerca dos resultados, em todos os casos existiu grande dificuldade numérica para observar na simulação a queda dos autovalores e frequências naturais. Isso, pois estando sobre um ponto de snapback, a passagem para autovalores nulos ocorre exatamente no último ponto em que o Método de Newton-Raphson converge. Logo, muitas vezes parâmetros de simulação como taxas de incremento de carregamento e critérios de parada tiveram que ser modificados a fim de obter os resultados aqui mostrados, que enfatizassem o ponto derradeiro da perda de estabilidade.

É possível plotar uma curva relacionando os valores dos momentos de torção críticos em função do ângulo de topo da configuração de riser em catenária para ambos os valores de coeficientes de atrito considerados. Obtém-se a curva da Figura 5.83.

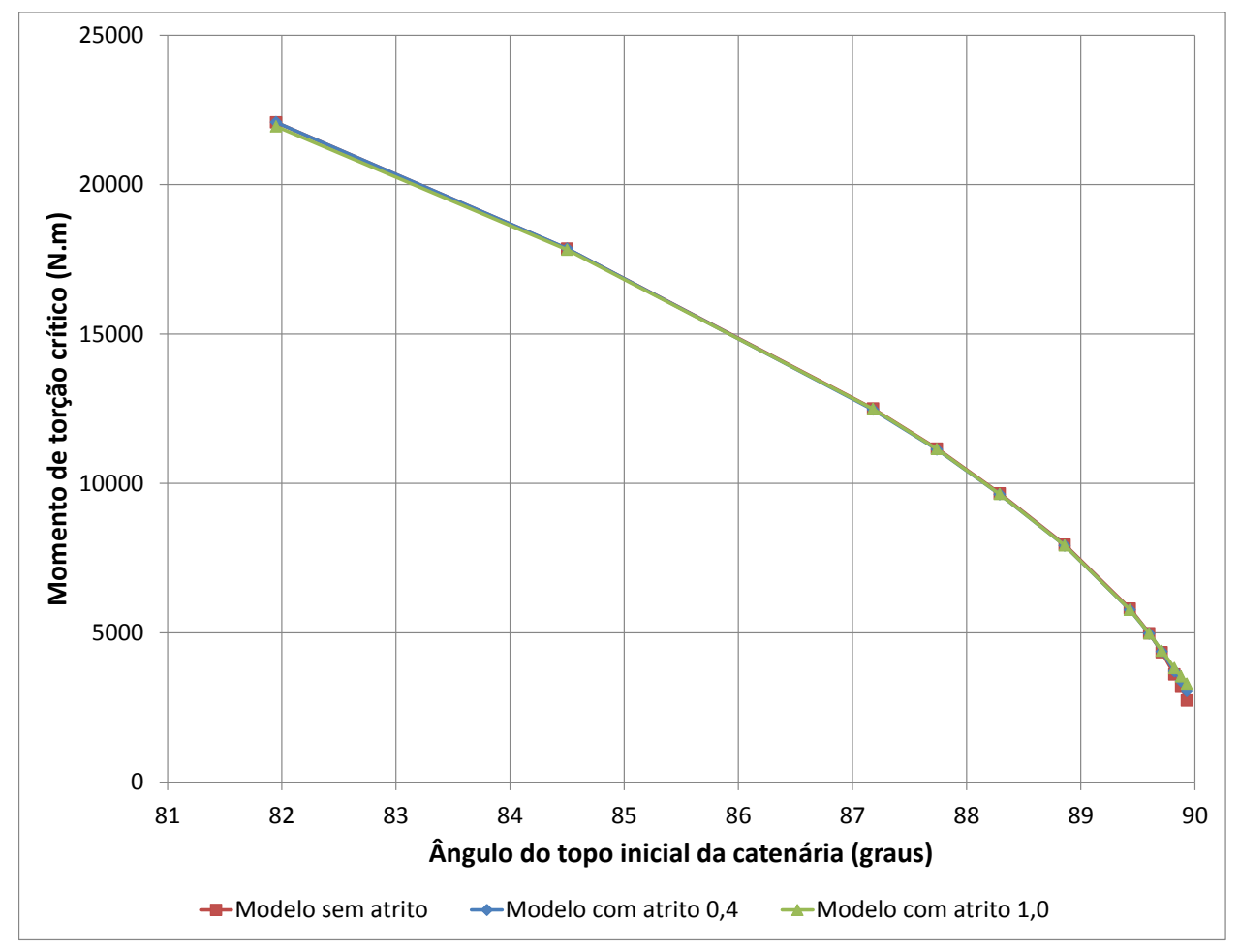

Figura 5.83: Momento de torção crítico versus ângulo do topo da configuração de catenária. Modelo com contato unilateral com atrito. 


\subsubsection{Comparação entre os modelos}

A Figura 5.84 mostra o momento de torção crítico versus o ângulo do topo da configuração de catenária para todos os modelos apresentados.

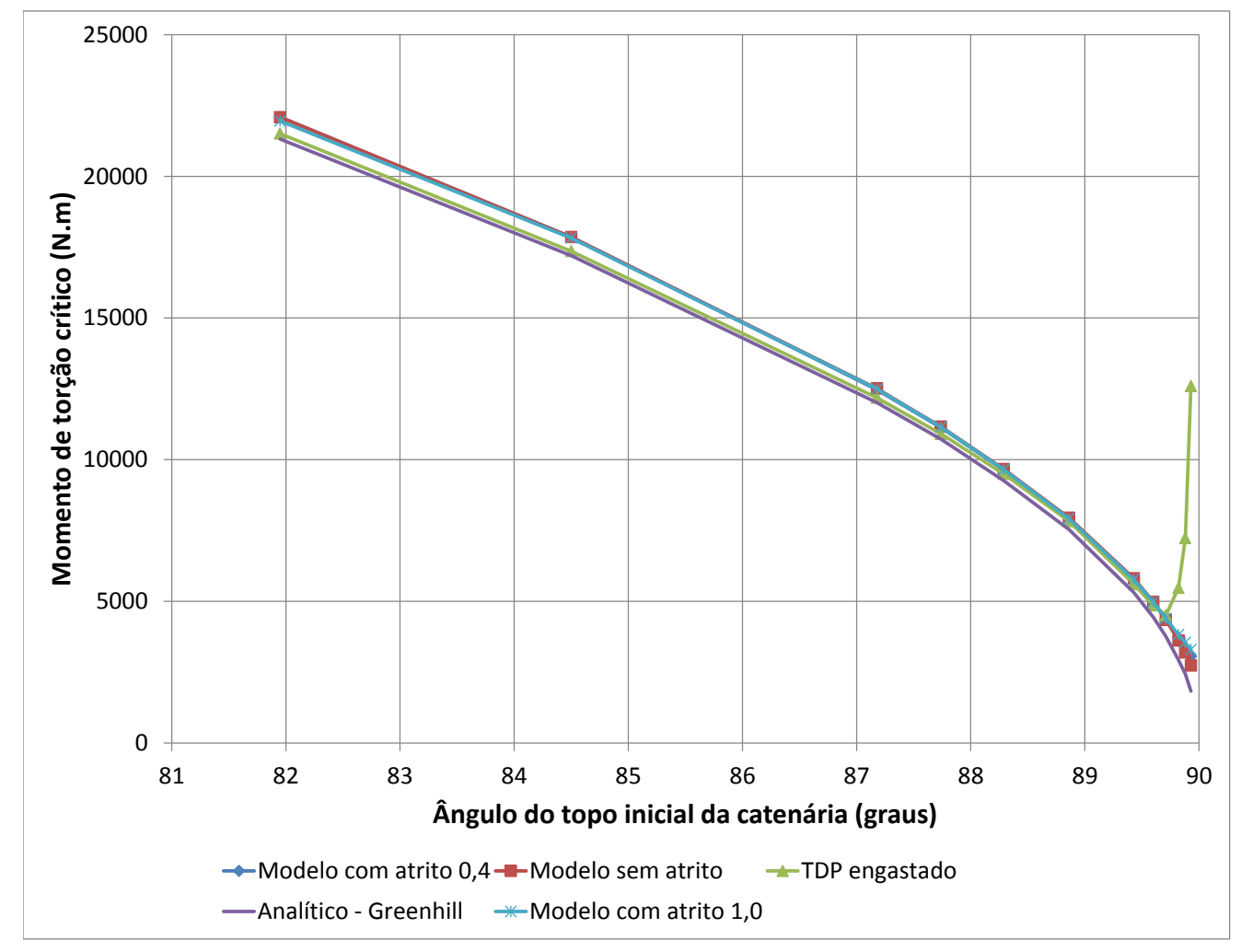

Figura 5.84: Momento de torção crítico versus ângulo do topo da configuração de catenária. Comparação entre os modelos.

Por meio dessa curva é possível visualizar que o comportamento do modelo com o TDP engastado não representa bem o problema físico para os casos de ângulo de topo entre $89,5^{\circ}$ e $90,0^{\circ}$. As acomodações e mudanças de posicionamento do TDP ao considerar o contato unilateral (com ou sem atrito) não são bem representadas, bem como as mudanças não realistas da elastica acabam por tornar a discretização até mesmo grosseira para representar o nível de curvatura a que se chega. Sendo a evolução da elastica não realista, seus resultados não devem ser tomados como referência.

Já a comparação entre os modelos considerando o contato, com e sem atrito, não apresentam grandes diferenças. A presença do atrito realiza a ancoragem a movimentos laterais da configuração que está no solo. No entanto, para os casos analisados, o efeito do atrito não se mostrou relevante na determinação do momento de torção crítico para quase toda a faixa de ângulos de topo. Isso pode ser observado pela grande semelhança entre as curvas referentes aos modelos com e sem atrito na Figura 5.84. A tabela 5.15 mostra 
os valores numéricos dos momentos de torção críticos para os casos com e sem atrito. O modelo sem atrito possui resultados muito próximos àqueles que consideram o atrito na faixa de comprimento suspenso superiores a $1005 \mathrm{~m}$. Nos casos com comprimento suspenso inferior a esse valor, o atrito colabora de forma mais significativa na ancoragem do riser e diminuição dos movimentos laterais. Isso resulta no aumento do momento de torção crítico em relação a uma situação em que não há restrição alguma desse tipo de movimento.

Tabela 5.15: Momentos de torção críticos. Comparação entre os valores numéricos sem atrito e com atrito.

\begin{tabular}{|l|c|c|c|}
\hline$L(\mathrm{~m})$ & Sem atrito (N.m) & Com atrito 0,4 (N.m) & Com atrito 1,0 (N.m) \\
\hline 1001 & $2.720,15$ & $3.078,18$ & $3.263,41$ \\
1002 & $3.178,28$ & $3.377,48$ & $3.554,26$ \\
1003 & $3.594,56$ & $3.710,57$ & $3.838,95$ \\
1005 & $4.330,67$ & $4.371,04$ & $4.413,12$ \\
1007 & $4.967,93$ & $4.965,85$ & $4.979,68$ \\
1010 & $5.794,06$ & $5.777,93$ & $5.765,16$ \\
1020 & $7.937,17$ & $7.925,19$ & $7.911,63$ \\
1030 & $9.645,43$ & $9.654,38$ & $9.632,88$ \\
1040 & $11.135,98$ & $11.158,01$ & $11.130,14$ \\
1050 & $12.464,15$ & $12.503,15$ & $12.466,02$ \\
1100 & $17.608,33$ & $17.858,34$ & $17.632,09$ \\
1150 & $21.599,16$ & $22.087,50$ & $21.627,53$ \\
\hline
\end{tabular}

Adicionalmente, para esses casos simulados, o modelo analítico de Greenhill pode ser utilizado para prever, sempre de forma a favor da segurança, o valor do momento de torção crítico. Para tal, deve-se utilizar a tração do TDP na configuração de catenária inicialmente considerada, antes da formação do laço.

Por fim, realizou-se um estudo da variação do momento fletor presente na configuração da catenária para o caso de $\mathrm{L}=1001 \mathrm{~m}$. Foram analisadas as configurações no ponto limite, para os casos de contato unilateral com atrito com $\mu=0,4$ e sem atrito. A Figura 5.85 mostra a distribuição de momento fletor inicial da catenária para esse caso, antes de ser aplicada a rotação na âncora. Também é exibido o momento fletor associado ao ponto-limite, considerando ou não o atrito. 


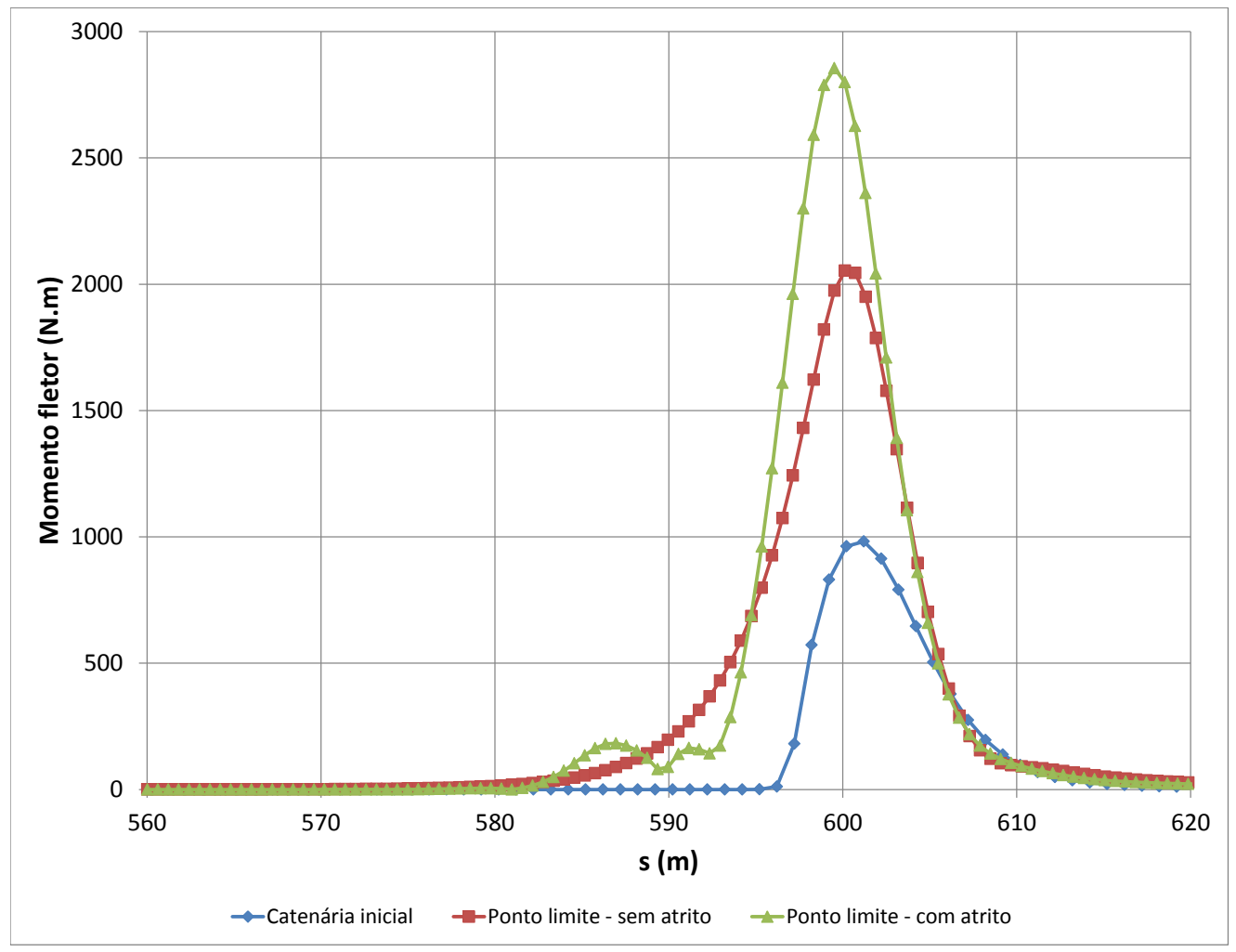

Figura 5.85: Momento fletor na configuração associada ao ponto-limite para o caso L = 1001 m em função da abscissa curvilínea $s$. Comparação entre os modelos com e sem atrito.

É possível identificar uma alteração significativa de momento fletor na configuração associada ao ponto-limite, quando comparada à curvatura inicial. No modelo com atrito, a alteração é ainda maior do que quando o atrito é desprezado. Essa informação é importante na medida que, mesmo que não se chegue ao ponto de formação de um laço, a inserção de um momento de torção na linha pode gerar acréscimos de curvatura estática que podem ter importância em outros tipos de problemas de risers em que o nível de curvatura estática é um parâmetro relevante.

\subsubsection{Casos com correnteza marítima}

A fim de estudar o efeito da correnteza marítima na instabilidade estrutural, tomou-se o caso do cabo umbilical com comprimento suspenso $\mathrm{L}=1030 \mathrm{~m}$. A correnteza considerada foi um perfil uniforme de velocidades ao longo da altura, e com um ângulo $\psi$ constante (ver Figura 5.25).

O procedimento de solução dos casos com correnteza é semelhante aos da seção 
5.3.4. Considerou-se o coeficiente de atrito $\mu=0,4$ entre o riser e o solo. Esse possui um papel fundamental na obtenção da elastica, uma vez que quando a correnteza tende a torná-la tridimensional, o atrito procura manter a posição da parte do riser que se encontra em contato com o solo (flowline). Desprezar o atrito levaria a resultados absolutamente não realistas nesses casos.

Outro fator que apresenta importância no caso com correnteza marítima é o sentido em que a estrutura foi sensibilizada com a imposição da rotação axial $\alpha$. Em todos os casos até então exibidos, sem correnteza marítima, a configuração sendo plana antes da imposição da rotação torna indiferente o sentido desse carregamento na previsão do momento de torção crítico. Para casos que envolvem uma elastica inicialmente plana, a alteração do sentido da imposição da rotação causa somente a formação de laços em direções diferentes, sensibilizados pela tridimensionalização causada pelo momento de torção ao longo da linha. Já análises de configurações estáticas inicialmente tridimensionais não apresentam a mesma peculiaridade, pois não gozam do plano de simetria original. Assim, alguns dos casos mostrados a seguir que possuem correnteza que torna 3D a elastica da configuração foram simulados considerando-se dois sentidos opostos para imposição da rotação.

Seis casos foram considerados, baseados no caso de comprimento suspenso de 1030 m desenvolvido nas seções anteriores, ou seja, considerando-se as mesmas propriedades do umbilical mostradas na Tabela 5.7 e nas condições ambientais da Tabela 5.8. A correnteza e a orientação da imposição da rotação axial foi considerada segundo a Tabela 5.16:

Tabela 5.16: Informações dos casos com correnteza

\begin{tabular}{|c|c|c|c|}
\hline Caso & $\psi$ & Velocidade $(\mathrm{m} / \mathrm{s})$ & Direção da imposição da rotação \\
\hline $1030-2$ & $0^{\circ}$ & 0,3 & $+\boldsymbol{i}$ \\
$1030-3$ & $180^{\circ}$ & 0,3 & $+\boldsymbol{i}$ \\
$1030-4$ & $90^{\circ}$ & 0,3 & $+\boldsymbol{i}$ \\
$1030-5$ & $90^{\circ}$ & 0,3 & $-\boldsymbol{i}$ \\
$1030-6$ & $90^{\circ}$ & 0,5 & $+\boldsymbol{i}$ \\
$1030-7$ & $90^{\circ}$ & 0,5 & $-\boldsymbol{i}$ \\
\hline
\end{tabular}

Os resultados das trajetórias de equilíbrio, bem como evolução do menor autovalor da matriz de rigidez e menor frequência natural estão dispostos a seguir: 


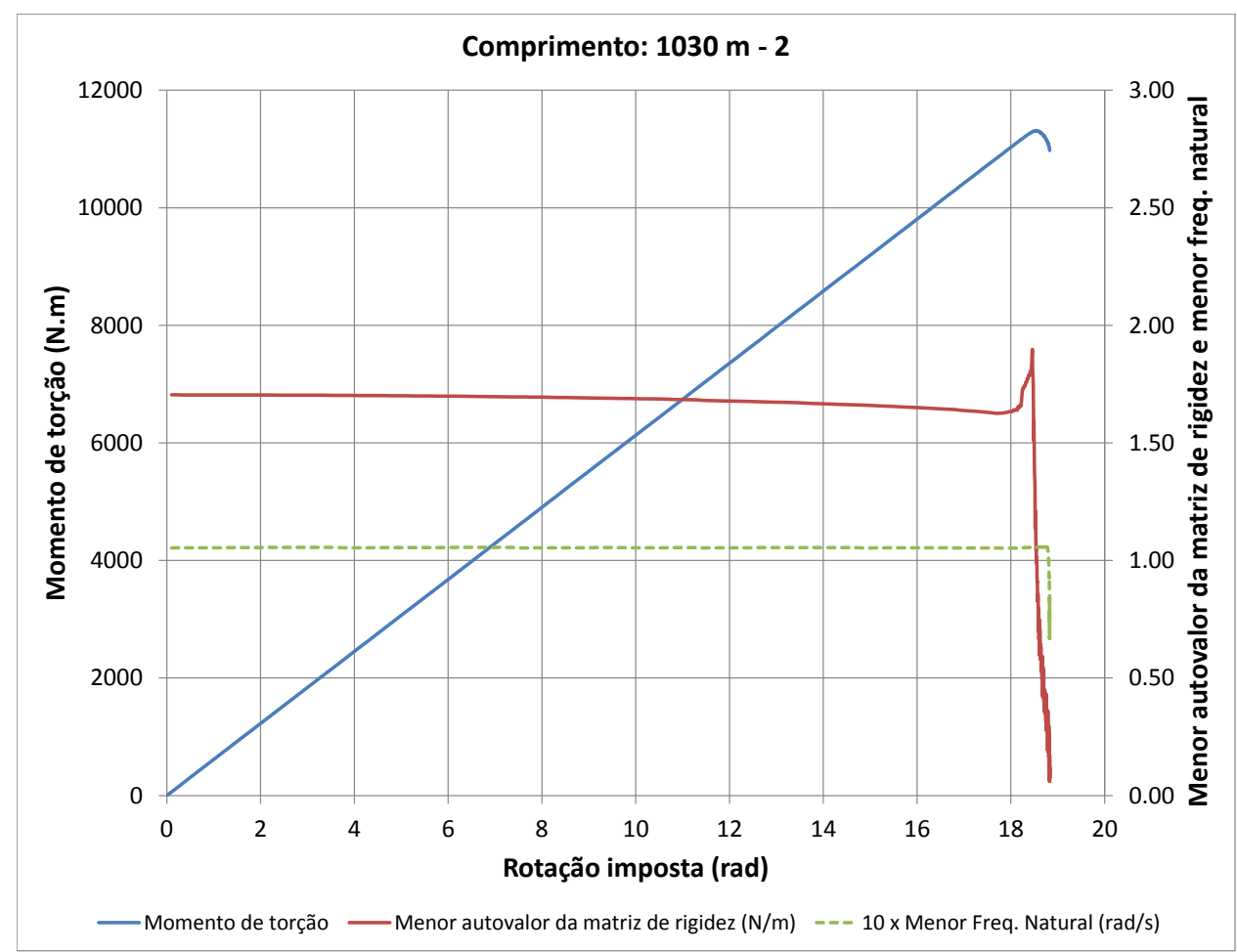

Figura 5.86: Trajetória de equilíbrio $M_{t}$ versus $\alpha$ para o caso $\mathrm{L}=1030 \mathrm{~m}-2$. Com atrito e correnteza marítima.

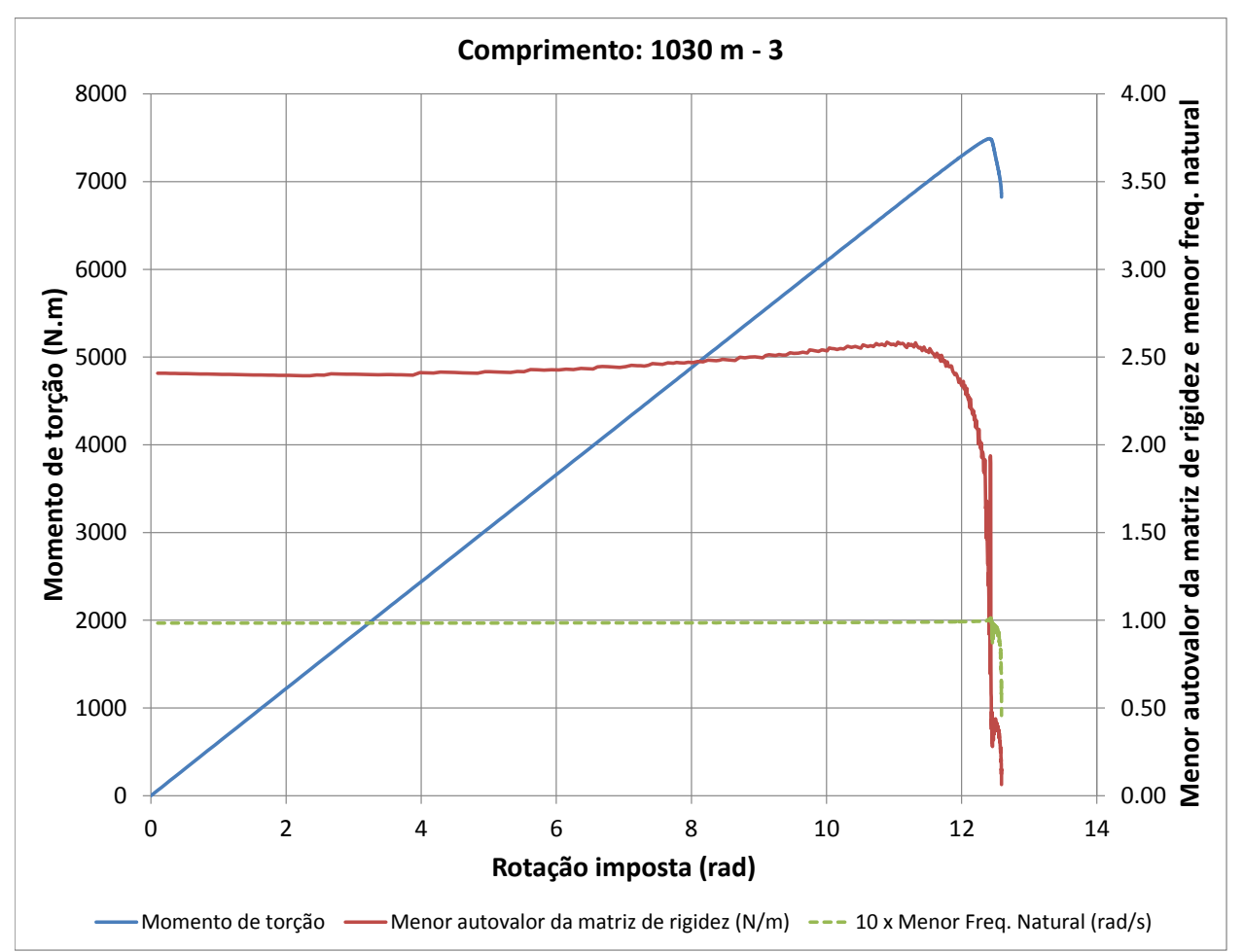

Figura 5.87: Trajetória de equilíbrio $M_{t}$ versus $\alpha$ para o caso $\mathrm{L}=1030 \mathrm{~m}-3$. Com atrito e correnteza marítima. 


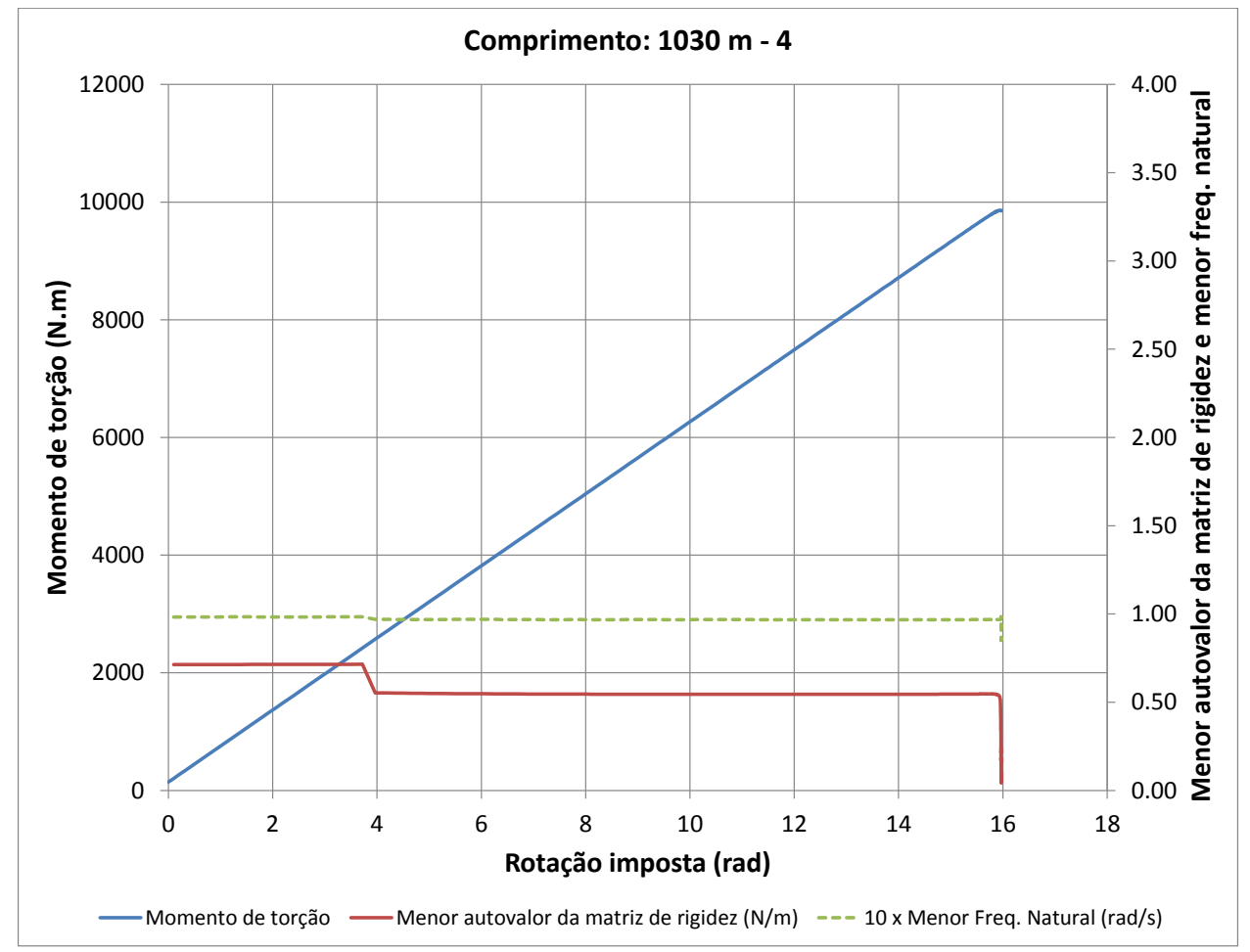

Figura 5.88: Trajetória de equilíbrio $M_{t}$ versus $\alpha$ para o caso $\mathrm{L}=1030 \mathrm{~m}-4$. Com atrito e correnteza marítima.

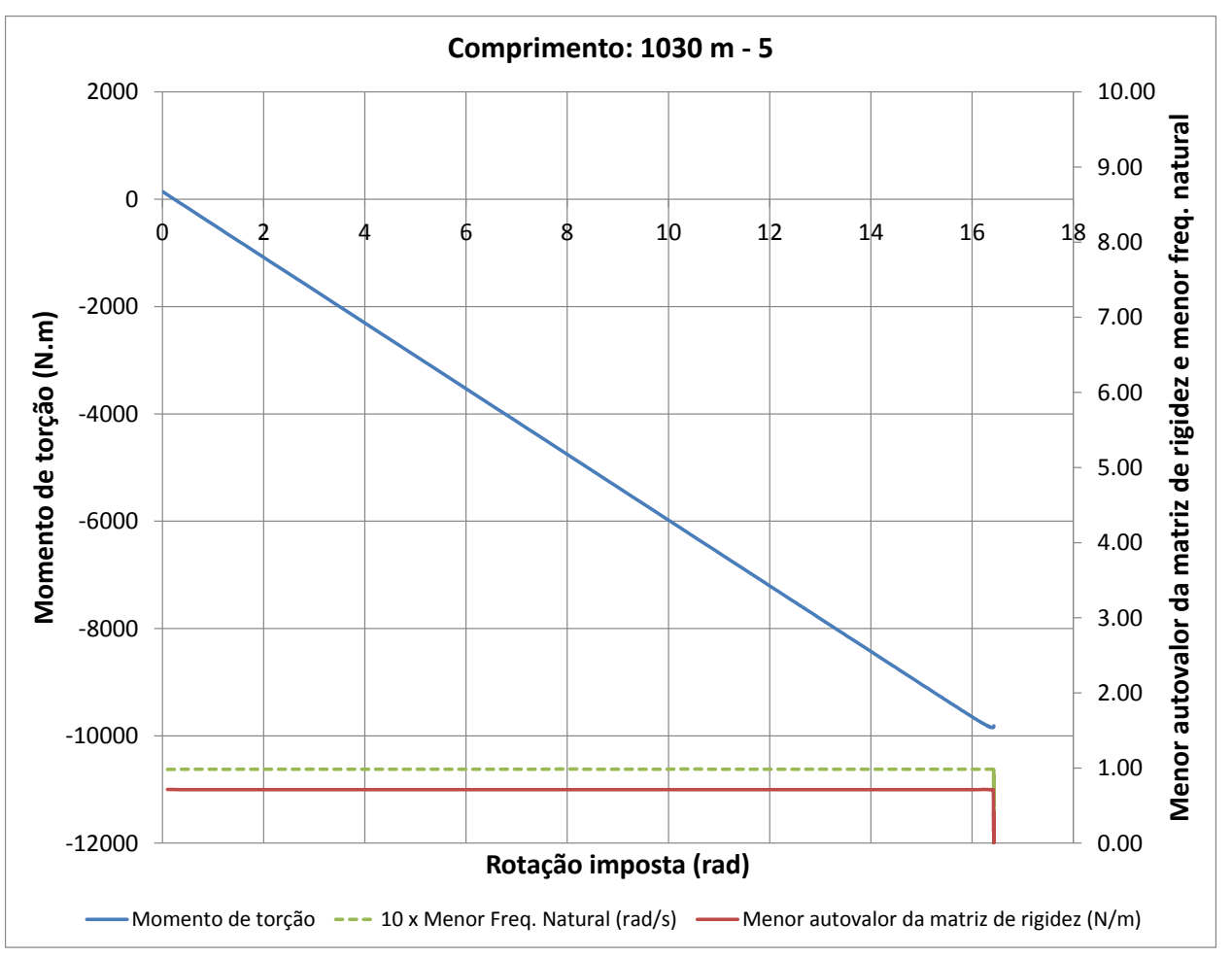

Figura 5.89: Trajetória de equilíbrio $M_{t}$ versus $\alpha$ para o caso $\mathrm{L}=1030 \mathrm{~m}-5$. Com atrito e correnteza marítima. 


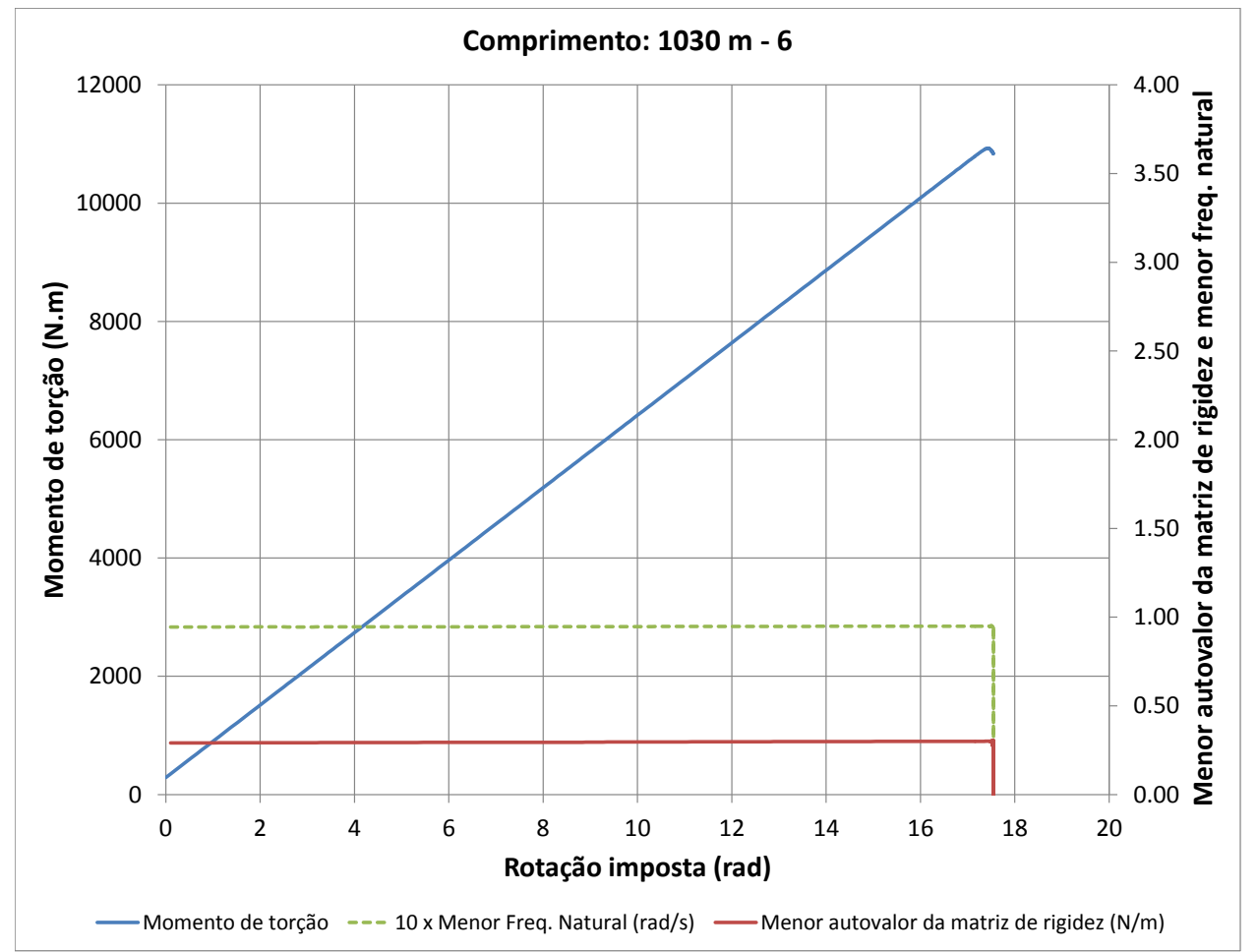

Figura 5.90: Trajetória de equilíbrio $M_{t}$ versus $\alpha$ para o caso $\mathrm{L}=1030 \mathrm{~m}-6$. Com atrito e correnteza marítima.

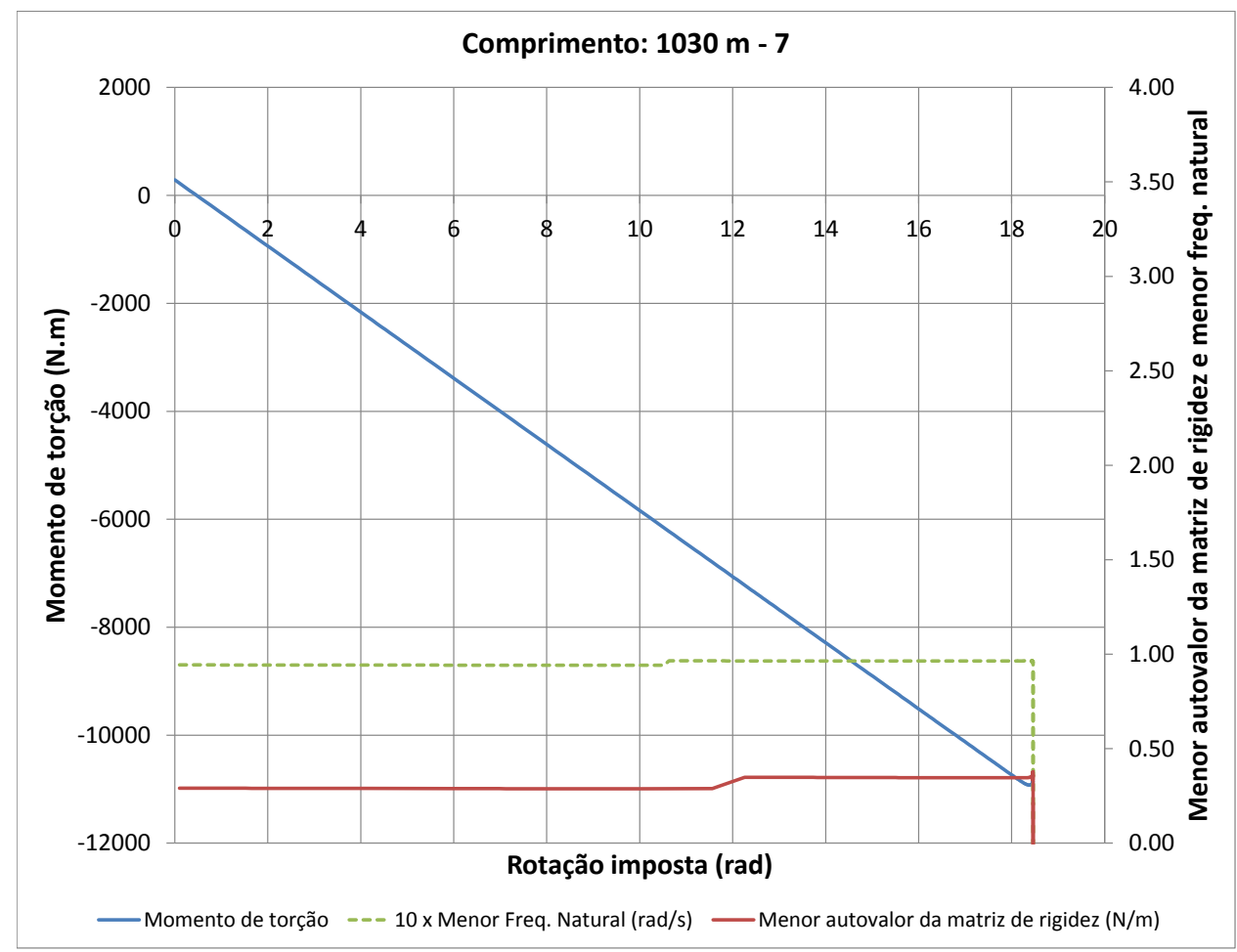

Figura 5.91: Trajetória de equilíbrio $M_{t}$ versus $\alpha$ para o caso $\mathrm{L}=1030 \mathrm{~m}-7$. Com atrito e correnteza marítima. 
Nota-se que nos resultados dos casos 1030-2 e 1030-3 o papel da correnteza é de aumentar ou diminuir a distribuição de tração no riser, mas mantém a configuração estática plana antes da aplicação do momento de torção. Já os casos 1030-4 e 1030-5 apresentam configuração 3D na elastica inicial antes de sensibilizar a estrutura com a torção. Comparando-os é possível verificar que não houve grande diferença na predição do momento crítico, uma vez que a tração do TDP pouco se alterou durante a imposição da rotação. No entanto, o ângulo de giro necessário para atingir o momento de torção crítico foi diferente nos dois casos. Isso pode ser visto claramente nas Figuras 5.88 e 5.89, em que é nítido que a configuração estática antes de impor a rotação $\alpha$ apresenta uma torção residual devido à correnteza. No caso de a rotação ser imposta no mesmo sentido dessa torção residual (Figura 5.88) o momento de torção já inicia de um valor não nulo e positivo. Já no caso de a rotação ser imposta em sentido oposto (Figura 5.89), registra-se inicialmente o alívio da torção residual para o posterior carregamento da torção ao longo do riser. Esse efeito exige um ângulo de giro $\alpha$ maior para sensibilizar a formação do laço. Para os casos 1030-6 e 1030-7 as mesmas observações são válidas. No entanto, o acréscimo de tração do TDP devido ao efeito da correnteza causou um aumento do momento de torção crítico.

Outra diferença a ser comentada entre os casos 1030-4 e 1030-5 é o sentido de formação do laço. No caso 1030-4 o sentido de tridimensionalização causado pelo momento é o mesmo induzido pela correnteza. Assim, o riser não tende a deslizar de volta para a direção da linha de lançamento (eixo X) durante a imposição da rotação. Já no caso 1030-5 a imposição de rotação tenta trazer a estrutura do riser de volta à linha de lançamento, no sentido oposto à tridimensionalização causada pela correnteza. Nesse ponto a modelagem do sentido da força de atrito se torna questionável, uma vez que se assumiu que o deslizamento sempre seria a partir da linha de lançamento, e nesse caso registra-se um deslizamento no sentido oposto durante a aplicação do momento de torção. As mesmas conclusões podem ser tiradas para o par de casos 1030-6 e 1030-7.

É possível observar que tanto o critério estático como o critério cinético de estabilidade mostram a mesma previsão de carga crítica de maneira consistente, o que leva a crer que o papel da correnteza marítima no problema é simplesmente a alteração da elastica e da tração no TDP, alterando a previsão de momento de torção crítico. Pode-se observar na Tabela 5.17 os valores de tração no TDP para cada caso, associados à configuração base, que corresponde ao riser deformado pela correnteza. Ainda na mesma tabela observa-se o momento de torção crítico calculado numericamente, bem como o momento de torção calculado com o modelo de Greenhill, utilizando-se a tração no TDP associada 
à configuração base. Novamente observa-se que o modelo analítico consegue prever com boa precisão a ocorrência da instabilidade, utilizando-se o valor da tração do TDP.

Tabela 5.17: Cargas-limite para casos com correnteza marítima

\begin{tabular}{|c|c|c|c|}
\hline Caso & Tração no TDP (N) & Mom. crít. numérico (N.m) & Mom. crít. Greenhill (N.m) \\
\hline $1030-2$ & 6168 & 11310 & 11140 \\
$1030-3$ & 2444 & 7490 & 7012 \\
$1030-4$ & 4502 & 9862 & 9518 \\
$1030-5$ & 4502 & 9846 & 9518 \\
$1030-6$ & 5696 & 10928 & 10705 \\
$1030-7$ & 5696 & 10924 & 10705 \\
\hline
\end{tabular}

Assim como nos casos da seção 5.3.4, também é possível observar que o comportamento dos autovalores da matriz de rigidez fica bastante afetado pelo atrito nos casos com correnteza. Os casos simulados que apresentam matriz de rigidez não simétrica, tanto pelo efeito não conservativo do atrito de deslizamento, como pela correnteza marítima apresentam maior sensibilidade numérica na extração de autovalores. Novamente foram observados em muitos casos o surgimento de autovalores da matriz de rigidez e frequências naturais com parte imaginária não nula. No entanto, trata-se de casos pontuais que a cada sub-passo de carregamento acabam por se alternar entre puramente reais e com parte imaginária não nula. Novamente esse tipo de efeito se mostrou sensível à alteração de parâmetros de penalidade. Através de testes variando-se a penalidade normal, verificou-se que para parâmetros mais brandos de penalidade esses fenômenos diminuiram, se não desapareceram. Trata-se, portanto, de erros numéricos ocorridos em situações de mal-condicionamento matricial.

Pela consistência entre os critérios de estabilidade estático e cinético é possível concluir para os presentes estudos de caso realizados, que a utilização do critério de estabilidade estática seria suficiente inclusive para situações com atrito e correnteza marítima, pois sua previsão foi a mesma indicada pelo critério cinético.

\subsubsection{Discussão sobre o problema}

Observando a Figura 5.84, nota-se que a previsão analítica de Greenhill consegue recuperar qualitativamente a forma de solução numérica dos modelos com e sem atrito. Ainda a Tabela 5.17 mostra que mesmo em simulações com correnteza marítima o modelo analítico pode ser alimentado com a tração no TDP associada ao ponto limite, resultando em uma 
boa estimativa para o momento de torção crítico.

O único parâmetro que foi variado nessa formulação analítica é a tração do TDP, calculada de forma numérica, como sendo a tração inicial nessa posição do riser antes da imposição da rotação nos modelos numéricos. Portanto, essa abordagem não foi puramente analítica, uma vez que se utilizou do valor de tração, determinado numericamente. Seria possível realizar uma estimativa puramente analítica para casos sem correnteza, supondo que a tração que surge no TDP é aquela de uma solução analítica de um cabo inextensível e com rigidez flexional nula. Nessa situação, tem-se a seguinte equação que representa a elastica da catenária, já considerando que o TDP se encontra na origem do sistema de coordenadas ${ }^{5}$ :

$$
z(x)=\frac{T_{t d p}}{\gamma_{e f}}\left[\cosh \left(\frac{\gamma_{e f}}{T_{t d p}} x\right)-1\right]
$$

A expressão 5.2 mostra que a geometria da catenária, vista como uma curva matemática, é completamente determinada somente com um valor de coeficiente numérico. A forma apresentada em 5.2 associa esse coeficiente, no problema de risers, ao valor dado por: $\frac{T_{t d p}}{\gamma_{e f}}$. Uma vez escolhido tal valor, dada uma profundidade, decorrerá a projeção horizontal da linha. No entanto, nota-se que uma dada geometria de catenária pode ser assumida por infinitas combinações de propriedades físicas da linha, desde que a razão $\frac{T_{t d p}}{\gamma_{e f}}$ seja constante. Dadas a propriedade do peso efetivo da linha por unidade de comprimento, a profundidade e a projeção horizontal ou, a profundidade e o comprimento, é possível determinar o valor de $T_{t d p}$.

De forma alternativa, é possível escrever uma expressão relacionando o ângulo de inclinação de uma catenária em função de sua cota z:

$$
\cos (\theta)=\frac{1}{1+\frac{\gamma_{e f} z}{T_{t d p}}}
$$

Aplicando a expressão 5.3 ao topo da catenária, bem como isolando a tração do TDP, é possível obter uma conveniente expressão para cálculo da tração do TDP em função de parâmetros geométricos da catenária e do peso efetivo da linha por unidade de

\footnotetext{
${ }^{5}$ Deduções de solução analítica de catenária podem ser encontradas em diversas referências clássicas. Uma abordagem voltada à física de linhas de risers pode ser encontrada em Martins (2008)
} 
comprimento:

$$
T_{t d p}=\frac{\cos \left(\theta_{\text {topo }}\right) \gamma_{e f} z_{\text {topo }}}{1-\cos \left(\theta_{\text {topo }}\right)}
$$

A expressão 5.4 pode ser utilizada para uma obtenção aproximada da tração no TDP para uma dada configuração de riser. Por exemplo, aplicando-se para os casos estudados anteriormente, tem-se as aproximações analíticas para o valor da tração no TDP ilustradas na Tabela 5.18. Ainda é possível estimar o momento de torção crítico $M_{c}$ utilizando-se a fórmula de Greenhill combinada com a obtenção analítica da tração no TDP. Essa forma de estimar o momento de torção crítico é denominada no presente trabalho como "Modelo puramente analítico", uma vez que não depende de nenhum parâmetro que venha de resultados numéricos. Tem-se:

$$
M_{c}=\sqrt{4 E I \frac{\cos \left(\theta_{\text {topo }}\right) \gamma_{\text {ef }} z_{\text {topo }}}{1-\cos \left(\theta_{\text {topo }}\right)}}
$$

Tabela 5.18: Tração no TDP e momento de torção crítico calculados pelo Modelo puramente analítico, através da equação 5.5

\begin{tabular}{|l|c|c|c|}
\hline$L(\mathrm{~m})$ & $\theta_{\text {topo }}$ (graus) & $T_{t d p}(\mathrm{~N})$ eq. 5.4 & $M_{c}$ (N.m) eq. 5.5 \\
\hline 1.001 & 89,93 & 171,60 & $1.858,10$ \\
1.002 & 89,88 & 294,42 & $2.433,89$ \\
1.003 & 89,82 & 442,10 & $2.982,46$ \\
1.005 & 89,71 & 713,65 & $3.789,27$ \\
1.007 & 89,60 & 986,24 & $4.454,56$ \\
1.010 & 89,43 & $1.409,59$ & $5.325,50$ \\
1.020 & 88,86 & $2.847,65$ & $7.569,32$ \\
1.030 & 88,29 & $4.314,90$ & $9.317,50$ \\
1.040 & 87,74 & $5.759,05$ & $10.764,39$ \\
1.050 & 87,18 & $7.258,82$ & $12.085,01$ \\
1.100 & 84,50 & $14.870,84$ & $17.297,43$ \\
1.150 & 81,95 & $22.843,83$ & $21.438,70$ \\
\hline
\end{tabular}

A Figura 5.92 mostra os resultados comparativos entre os modelos sem atrito, com atrito e puramente analítico. Note que a equação 5.5 se mostra como uma alternativa bastante prática e simples para determinação do momento de torção crítico, a partir dos parâmetros geométricos (profundidade e ângulo do topo), rigidez flexional $(E I)$ e peso efetivo por unidade de comprimento $\gamma_{e f}$ (ver Apêndice A). 


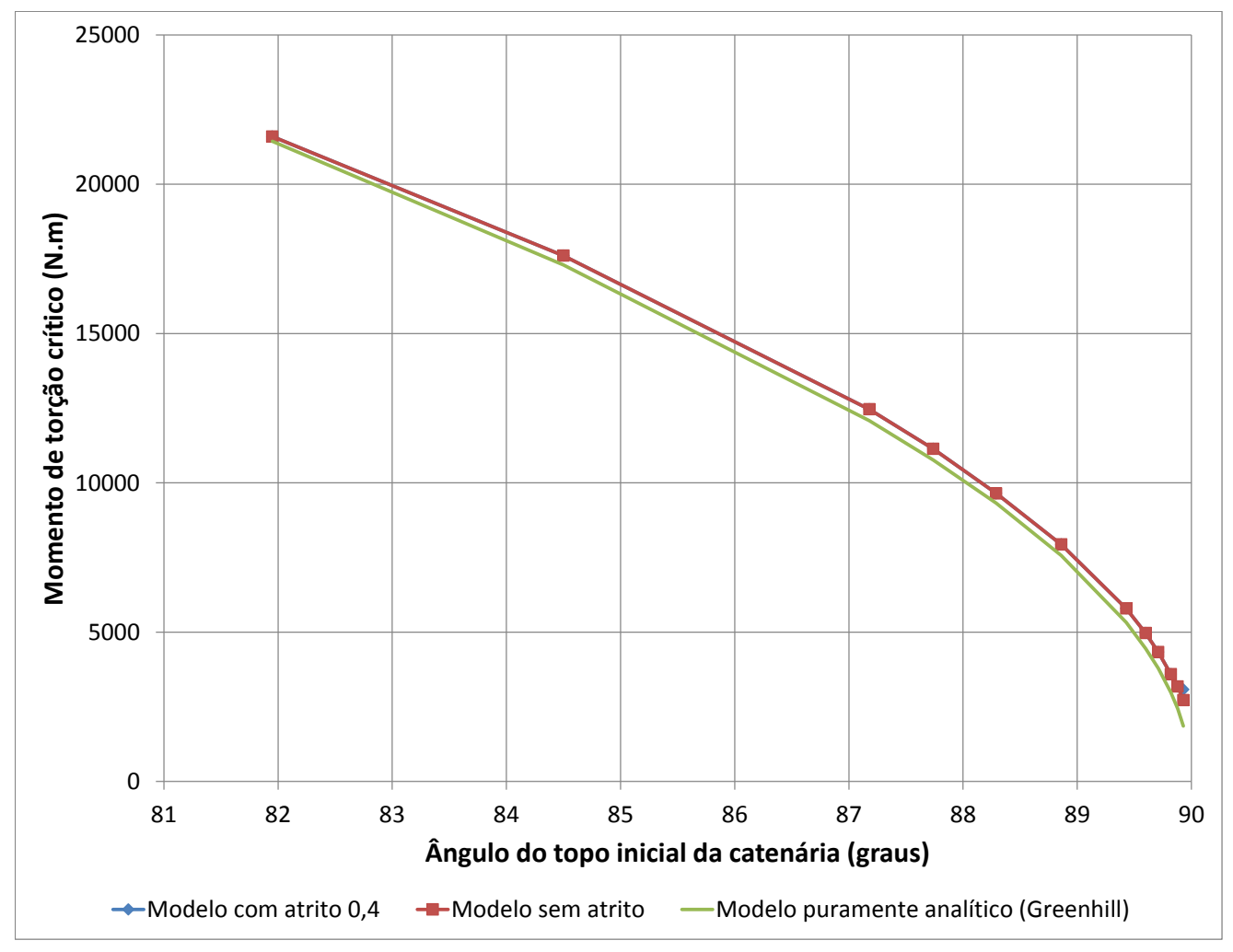

Figura 5.92: Momento de torção crítico versus ângulo do topo da configuração de catenária. Comparação entre os modelos sem atrito, com atrito e puramente analítico

Note que os valores de tração são ligeiramente diferentes dos determinadas numericamente (considerando-se a extensibilidade axial do riser e sua rigidez flexional). No entanto, o comportamento qualitativo e quantitativo descreve bem a forma dos modelos numéricos com e sem atrito para obtenção dos momentos de torção críticos.

A formação do laço é um fenômeno que ocorre em uma escala local, limitada a uma pequena região de influência dentro de uma configuração de riser. Trata-se de uma região próxima ao TDP, pois essa contém baixas magnitudes de tração na linha, atingindo primeiramente a condição de momento de torção crítico, em relação aos outros pontos da linha. Uma pequena zona suspensa e próxima ao TDP é onde se forma o laço, uma vez que essa região não contém restrições físicas de movimentos, por estar suspensa. A escala de comprimento de formação do laço pode ser estimada de forma analítica. Por exemplo, em Thompson e Champneys (1996) essa estimativa é feita para a flambagem de uma barra reta em um modo helicoidal. Chega-se à conclusão de que o passo da hélice é dado por $2 \pi \sqrt{\frac{E I}{T_{c}}}$ (sendo $T_{c}$ a tração na barra). A escala que caracteriza esse problema é a mesma que domina a flexão local em regiões de interesse em risers: trata-se do comprimento de flexão, dado por $\lambda=\sqrt{\frac{E I}{T_{c}}}$. Em Coyne (1990) uma análise da re-abertura de laços já 
formados é feita ilustrando-se suas dimensões características na situação de re-abertura. O parâmetro usado como dimensão característica nesse trabalho é também o comprimento de flexão. Conclui-se que a medida de comprimento $\sqrt{\frac{E I}{T_{t d p}}}$ pode ser utilizada também como dimensão característica para descrever o fenômeno de formação de laços, por se tratar de uma flexão local que ocorre na linha nas proximidades do TDP.

Essa é uma informação de grande importância para a geração de malhas nos modelos uma vez que, tratando-se de um fenômeno dessa escala, é necessário garantir que a discretização de elementos finitos escolhida seja capaz de representar corretamente o problema. Em todos os modelos anteriormente apresentados a malha utilizada foi feita com a seguinte premissa: estimando-se a tração no TDP, calcula-se o comprimento de flexão. Utiliza-se um tamanho de elemento de valor menor ou igual a cerca de $1 / 5$ do comprimento de flexão. Em se tratando de elementos com 3 nós (funções de forma quadráticas), para cada comprimento de flexão tem-se pelo menos 10 nós distribuídos. Essa discretização se mostrou suficiente para todas as simulações realizadas.

Em todos os resultados mostrados nas seções anteriores (analíticos, com TDP engastado, sem atrito e com atrito com o solo) é possível mostrar essa escala de formação de laços. As Figuras 5.93 e 5.94 mostram a configuração final das simulações realizadas, considerando o contato unilateral com o solo, desprezando-se o atrito. Nesse momento da simulação o início da formação do laço já ocorreu. Para o caso de 1001 m de comprimento suspenso do umbilical, a tração no TDP estimada analiticamente indica o valor de 171,60 N. Calculando-se o comprimento de flexão, tem-se $\lambda \approx 5,4 \mathrm{~m}$. Já no caso de $1040 \mathrm{~m}$ de comprimento, a tração estimada é de 5.759, $05 \mathrm{~N}$, levando a uma previsão de $\lambda \approx 0,93 \mathrm{~m}$.

No caso de comprimento suspenso inferior (1001 m) o nível de tração é muito menor, levando a uma rigidez geométrica pequena na região do TDP, possibilitando movimento lateral mais acentuado. Já o caso com maior nível de tração apresenta um movimento lateral menor, uma vez que existe maior rigidez do riser na região de formação do laço. Quanto à importância do atrito nesse tipo de situação, conforme ilustrado na Tabela 5.15, o atrito se apresenta como um restritor de movimentos no solo, colaborando com o aumento do momento de torção crítico. A forma da elastica, se apresenta de forma diferenciada no modelo sem atrito e com atrito. No primeiro observa-se o afastamento lateral do riser como colaborador com a formação do laço. Já no segundo, o atrito não permite esse afastamento e parte do riser se eleva do solo nas proximidades do TDP, havendo uma formação bastante peculiar que pode ser vista na Figura 5.95. 

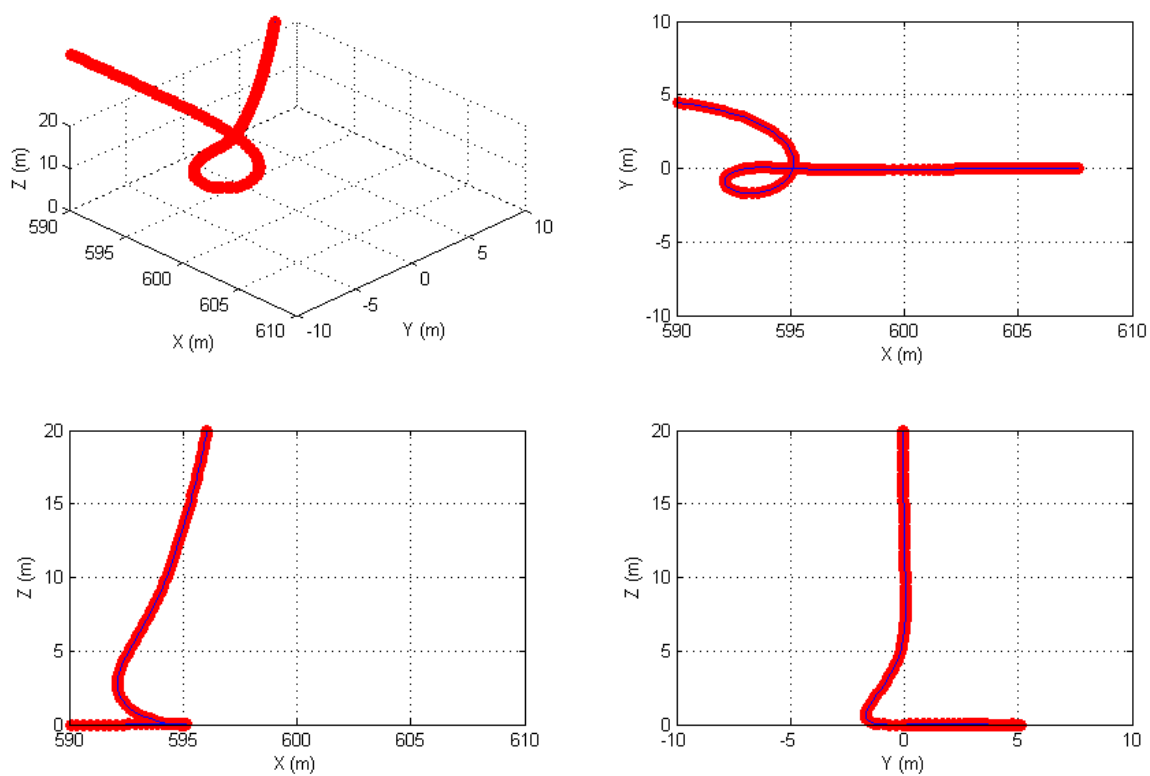

Figura 5.93: Configuração final da simulação realizada utilizando-se as propriedades descritas nas Tabelas 5.7 e 5.8. Visualização da formação do laço para o caso sem atrito com $1001 \mathrm{~m}$ de comprimento de umbilical.
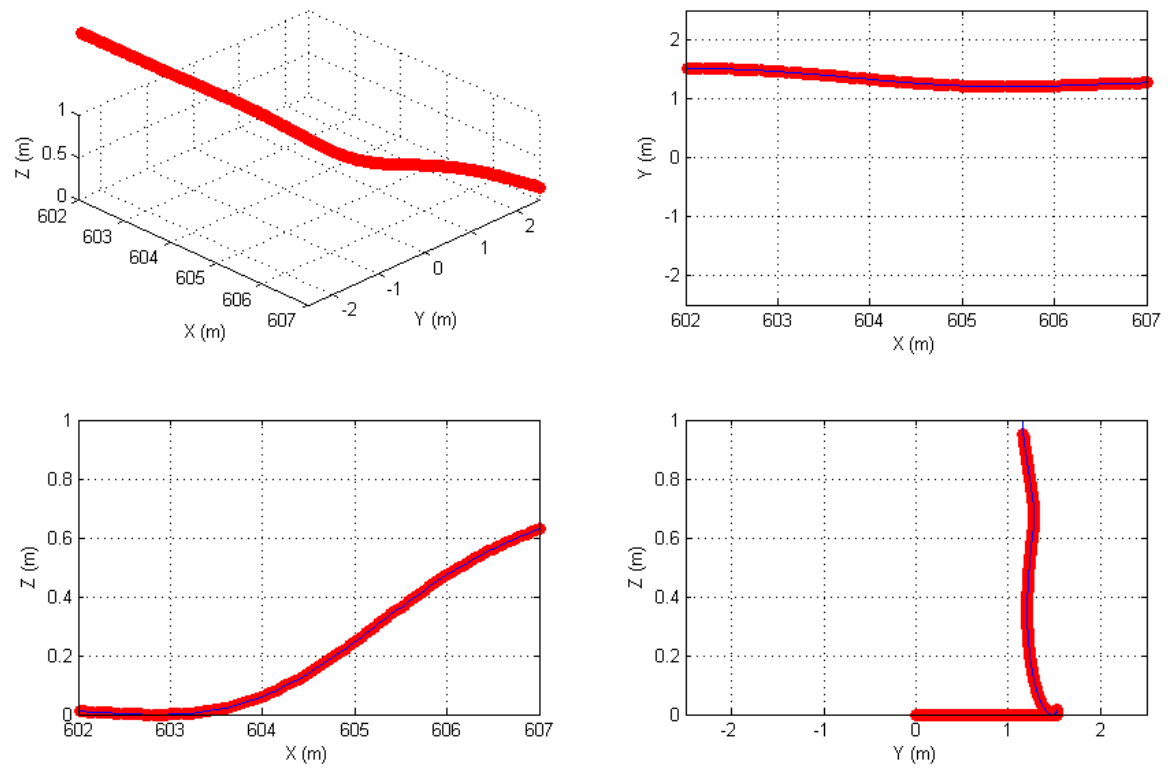

Figura 5.94: Configuração final da simulação realizada utilizando-se as propriedades descritas nas Tabelas 5.7 e 5.8. Visualização da formação do laço para o caso sem atrito com $1040 \mathrm{~m}$ de comprimento de umbilical. 

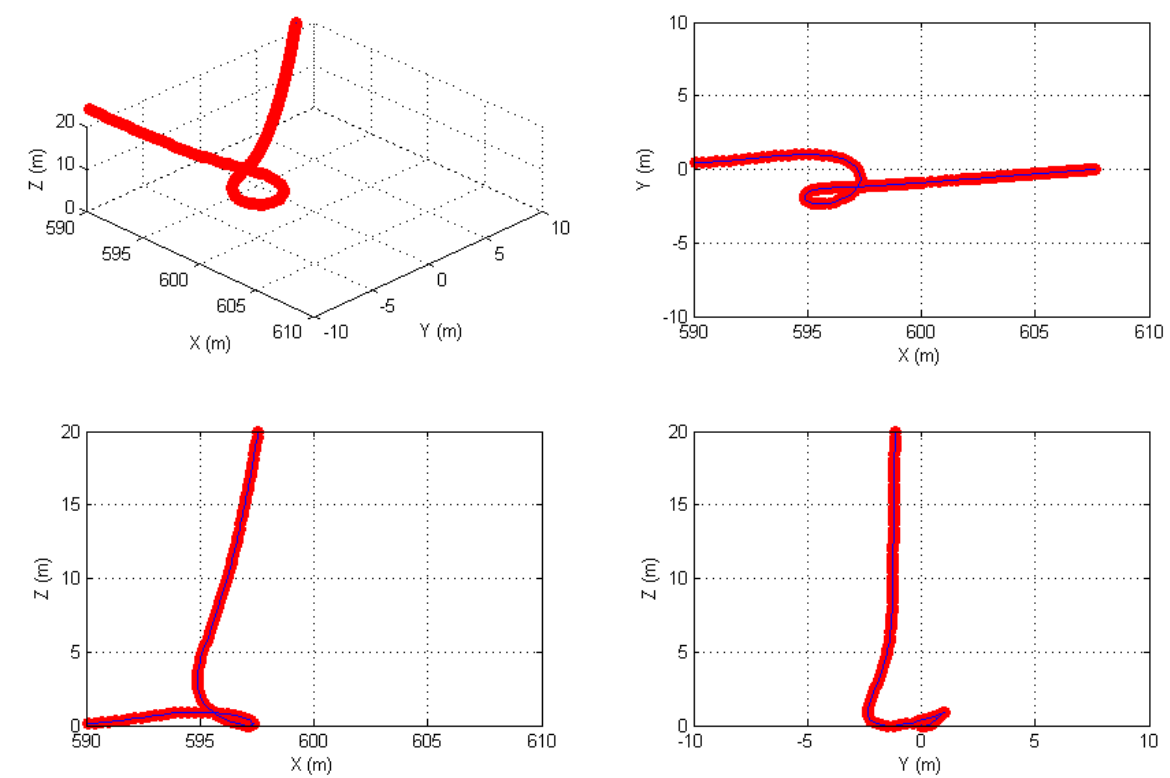

Figura 5.95: Configuração final da simulação realizada utilizando-se as propriedades descritas nas Tabelas 5.7 e 5.8. Visualização da formação do laço para o caso com atrito com $1001 \mathrm{~m}$ de comprimento de umbilical.
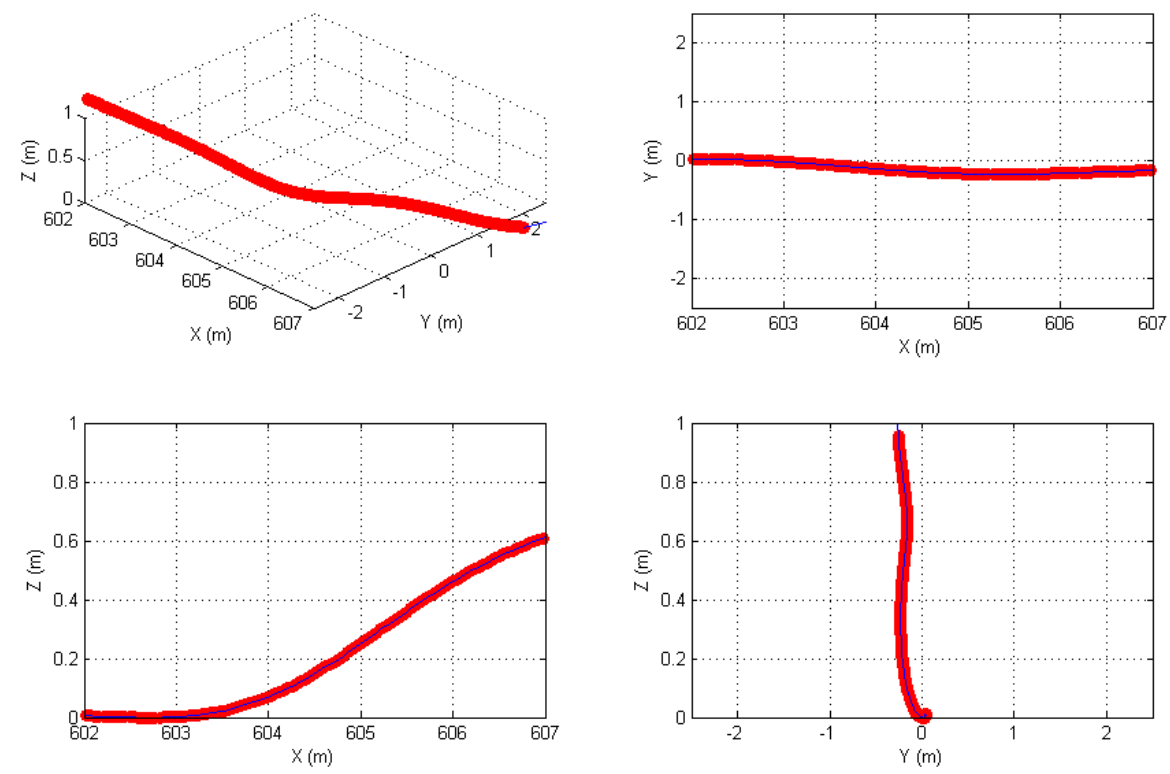

Figura 5.96: Configuração final da simulação realizada utilizando-se as propriedades descritas nas Tabelas 5.7 e 5.8. Visualização da formação do laço para o caso com atrito com $1040 \mathrm{~m}$ de comprimento de umbilical. 
As Figuras 5.93 a 5.96 ilustram que a ocorrência do laço é local, limitada à região do TDP. Assim, desde que mantida a curvatura estática da catenária, a alteração do ângulo do topo (e consequentemente o comprimento da linha) não altera substancialmente a previsão de formação do laço, desde que o comprimento suspenso seja maior do que a escala local de ocorrência do fenômeno. No entanto, o número de rotações necessárias para sensibilizar a estrutura com esse momento de torção crítico obviamente poderá ser significativamente alterado pelo comprimento suspenso considerado e pela rigidez à torção do riser.

Para ilustrar esse efeito, um caso-exemplo tomando o parâmetro geométrico da catenária dado por $\frac{\gamma_{e f}}{T_{t d p}}=0,0995$ foi simulado com três diferentes profundidades de catenária: $1000 \mathrm{~m}\left(\theta_{\text {topo }}=89,43^{\circ}\right), 1.500 \mathrm{~m}\left(\theta_{\text {topo }}=89,62^{\circ}\right)$ e $2.000 \mathrm{~m}\left(\theta_{\text {topo }}=89,72^{\circ}\right)$. Os modelos foram feitos sem o atrito com o solo. A Figura 5.97 ilustra as elasticas dos três casos antes da imposição de rotação que causa torção no riser. Geometricamente, as três curvas são partes da mesma catenária. Modifica-se, somente, a posição do topo.

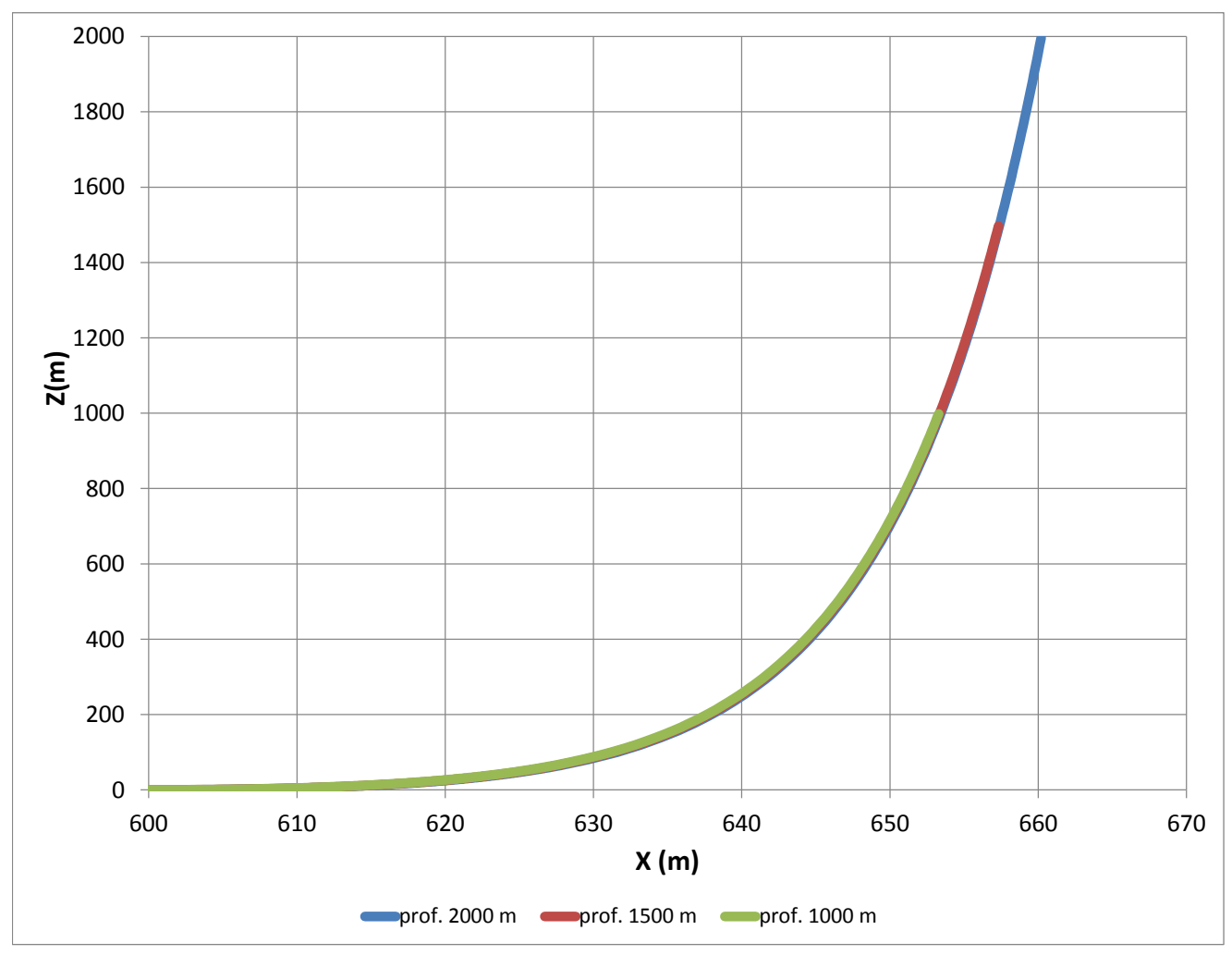

Figura 5.97: Elasticas antes da imposição de rotação que causa torção no riser para os três casos com $\frac{\gamma_{e f}}{T_{t d p}}=0,0995$

Os gráficos que ilustram a evolução dos momentos de torção para o aumento da rotação imposta na âncora para esses três casos estão na Figura 5.98. Note que os valores 
de carga limite são essencialmente os mesmos. A pequena variação que existe no momento de torção crítico entre os casos se deve ao fato de que a extensibilidade axial da catenária provoca pequenas mudanças na posição do TDP nos três casos. Consequentemente, os valores efetivos de $\frac{\gamma_{e f}}{T_{t d p}}$ não são exatamente os desejados (uma vez que a imposição para esses valores foi feita supondo-se a extensibilidade axial desprezível, por meio de um modelo analítico de catenária).

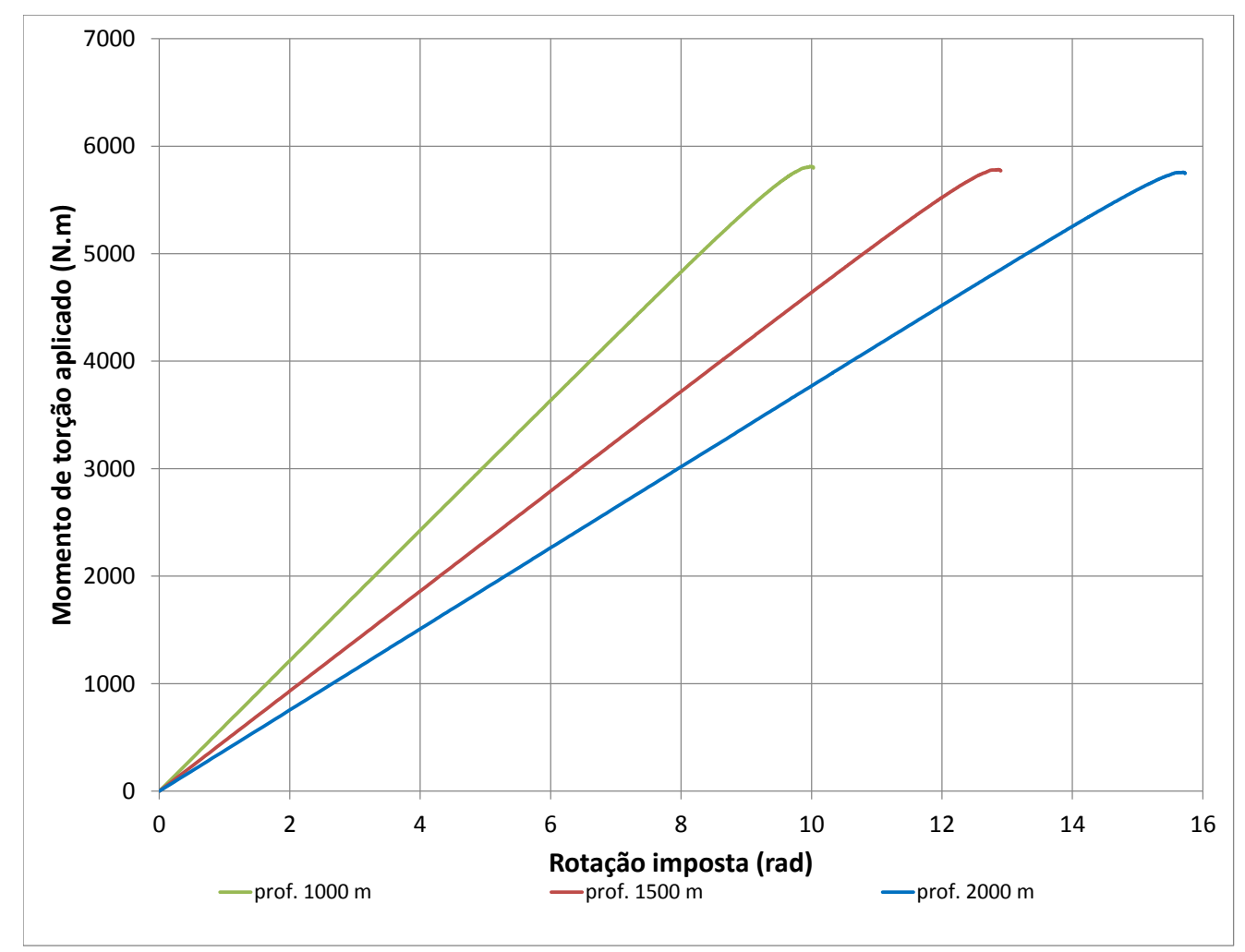

Figura 5.98: Evolução dos momentos de torção para os três casos com $\frac{\gamma_{e f}}{T_{t d p}}=0,0995$ ilustrando essencialmente o mesmo valor de carga crítica

Apesar de o valor de GJ ser exatamente o mesmo para os três casos considerados, o ângulo de rotação imposta associado ao ponto limite é diferente nos três casos. Isso ocorre essencialmente pela diferença de comprimento total entre os casos analisados, resultando em uma rigidez à torção diferente em cada uma das configurações. Isso pode ser observado na Figura 5.98.

\subsubsection{Generalização}

Com base nas discussões realizadas na seção 5.3.7, procurou-se generalizar os resultados obtidos nas simulações do cabo umbilical (cujas propriedades se encontram na Tabela 
5.7). O objetivo de tal estudo é prever qual seria o comportamento obtido para outros modelos de risers com propriedades diferentes, configurados em diferentes geometrias de catenária, com diferentes níveis de tração e de curvatura.

Para tal, realizou-se um estudo paramétrico. Com base nos resultados já mostrados e na formulação analítica de Greenhill é possível identificar que as variáveis que possuem importância para a ocorrência da formação do laço são: o valor da rigidez flexional EI, o peso efetivo por unidade de comprimento do riser $\gamma_{e f}$ e a tração no TDP $T_{t d p}$. O próprio modelo puramente analítico que consegue reproduzir de forma qualitativa o fenômeno estudado possui como dados de entrada o valor de EI e a tração no TDP, sendo esse último diretamente associado ao peso por unidade de comprimento do riser. Note que os dois últimos parâmetros determinam qual é a geometria de catenária em questão (ver equação 5.2).

Algumas propriedades não se mostraram importantes de forma direta para a previsão de formação de laços. A rigidez axial $E A$ acaba por apresentar um efeito de uma pequena mudança na geometria da catenária inicial do problema e, por isso, sua influência na formação de laços é indireta. Tomando como base a catenária já formada e considerando o riser já deformado axialmente, sua influência já terá sido contemplada. Quanto à rigidez à torção $G J$, sua importância no problema está em quantificar o ângulo de giro que promoverá certo valor de momento de torção na linha. Assim, sua importância prática no problema é bastante grande, na medida que em uma situação de rotação na direção yaw da embarcação, o ângulo de rotação crítico é altamente dependente do GJ. No entanto, a variação desse parâmetro acaba por não ter influências relevantes no valor do momento de torção crítico, que é o foco das análises aqui realizadas. A rigidez ao cisalhamento $G A$ também pode ser considerada como não influente no problema, desde que assuma valores fisicamente plausíveis. Assim, para os casos que serão mostrados a seguir, consideraram-se as propriedades $E A, G J$ e $G A$ as mesmas mostradas na Tabela 5.14 .

Para uma dada curvatura estática no TDP, a profundidade da linha considerada também não possui influência alguma no valor do momento de torção crítico, desde que a escala de formação do laço seja suficientemente inferior ao valor considerado. Para a faixa prática de parâmetros considerados, utilizou-se o valor de $1000 \mathrm{~m}$ e esse se mostrou suficiente para descrever um contorno "ao longe" da escala da formação do laço.

Uma variação paramétrica excessiva pode se tornar algo extremamente laborioso e muitas vezes impraticável. Assim, procurou-se determinar adimensionais que regessem o 
problema através de algum tipo de relação entre as grandezas importantes para a formação de laços, de modo a identificar quais variações paramétricas seriam mais interessantes para tentar generalizar a solução.

Um adimensional para reger a carga crítica do problema certamente estaria relacionado à fórmula de Greenhill. De fato, foi mostrado que para um dado valor de $E I$ e de tração no TDP, pode-se calcular uma estimativa do momento de torção crítico. O valor, de fato, do momento de torção determinado numericamente pode ser adimensionalizado utilizando-se essa estimativa analítica. Assim, constrói-se o seguinte adimensional de carregamento:

$$
\alpha_{l}=\frac{M_{c}}{\sqrt{4 E I T_{t d p}}}
$$

Já para descrever geometricamente o problema em questão, a curvatura no TDP é um parâmetro de grande importância. Seu valor (representado por $\kappa_{t d p}$ ), se escrito de forma analítica para um caso de cabo inextensível e sem rigidez flexional, leva à seguinte expressão:

$$
\kappa_{t d p}=\frac{\gamma_{e f}}{T_{t d p}}
$$

Deseja-se construir um adimensional que caracterize a geometria do problema. Assim, a curvatura no TDP é um parâmetro importante, bem como a escala do comprimento de flexão que regerá a formação do laço. O comprimento de flexão pode ser utilizado para adimensionalizar a curvatura do TDP, construindo assim o seguinte adimensional para descrever a geometria característica do problema:

$$
\beta_{l}=\lambda \kappa_{t d p}=\sqrt{\frac{E I}{T_{t d p}}} \frac{\gamma_{e f}}{T_{t d p}}=\frac{\gamma_{e f} \sqrt{E I}}{T_{t d p}^{3 / 2}}
$$

Note que $\alpha_{l}$ e $\beta_{l}$ dependem somente dos parâmetros $E I, \gamma_{e f}, T_{t d p}$ e do momento de torção crítico. No caso do adimensional $\alpha_{l}$, seu valor unitário ocorrerá se for válido o modelo analítico de Greenhill. Caso haja alguma diferença entre essa predição analítica (Greenhill) e a numérica, o percentual dessa diferença será o valor de $\alpha_{l}$. Para o adimensional $\beta_{l}$, valores próximos de zero representam os casos em que a tração no TDP é mais 
elevada. Isso ocorre em situações com curvaturas mais brandas. Já em casos de curvatura elevada, a tração no TDP será inferior e o adimensional $\beta_{l}$ atingirá valores mais elevados. Ou seja, quanto mais próxima de um riser vertical estiver uma catenária, maiores serão os valores de $\beta_{l}$.

A fim de varrer os parâmetros $\alpha_{l}$ e $\beta_{l}$ para fazer uma análise paramétrica, foram escolhidas cinco diferentes geometrias-base de catenária, através dos valores de curvatura no TDP descritos na Tabela 5.19:

Tabela 5.19: Curvaturas no TDP consideradas nos casos de generalização

\begin{tabular}{|c|c|}
\hline Nome do caso & $\kappa_{t d p}(1 / \mathrm{m})$ \\
\hline L1 & 1,3734 \\
L2 & 0,1000 \\
L3 & 0,0500 \\
L4 & 1,0000 \\
L5 & 2,0000 \\
\hline
\end{tabular}

Para cada uma dessas curvaturas no TDP existem infinitas combinações de $\gamma_{e f}$ e $T_{t d p}$ que podem ser adotadas. Foram escolhidas algumas dessas combinações variandose o parâmetro $\gamma_{e f}$, escolhendo-se quatro valores distintos e que procuram representar uma faixa de aplicações práticas para tubos flexíveis e cabos umbilicais. Cada valor de $\gamma_{\text {ef }}$ foi combinado com um valor de rigidez flexional $E I$, que também sofreu uma variação paramétrica, através de cinco valores diferentes, com ordens de grandeza bastante distintas, procurando varrer desde um cabo com baixíssima rigidez flexional até um tubo flexível ou cabo umbilical típico. Para cada configuração de catenária tem-se 20 casos distintos e que resultam em diferentes momentos de torção críticos. Como são cinco diferentes geometrias de catenária, tem-se no total 100 casos.

As tabelas 5.20 a 5.24 mostram os dados de entrada e os principais resultados relevantes para cada uma dessas simulações. As linhas que não estão preenchidas nas referidas tabelas apresentaram algum problema numérico em sua solução, não atingindo o ponto limite e, consequentemente não permitindo a avaliação de qual o momento de torção crítico. Os valores mostrados nas tabelas são: $\gamma_{e f}, E I$, o valor calculado numericamente da tração da catenária-base considerando-se o efeito da rigidez flexional ( $T_{t d p}$ inicial), o valor calculado numericamente da tração no TDP associado ao ponto limite ( $T_{t d p}$ limite), o valor do momento de torção limite $\left(M_{c}\right)$, e os valores dos adimensionais $\alpha_{l}$ e $\beta_{l}$. Para o cálculo desses, sempre utilizou-se o valor da tração no TDP associada ao ponto limite, pois isso se mostrou muito mais coerente do que utilizar a tração inicial do TDP. Em 
todos os casos processados nessa seção, considerou-se o modelo de contato unilateral com o solo, sem atrito.

Note que nos casos que apresentam menor nível de tração no TDP existe grande variação percentual do nível dessa tração entre o valor da configuração inicial da catenária e a associada ao ponto limite. Isso ocorre pois nessas situações existe mais movimento da catenária antes da formação do laço. Esses movimentos causam mudanças na posição do TDP, bem como alterações em sua tração, motivados por uma baixa rigidez geométrica existente inicialmente. Por isso, adotou-se para o cálculo de $\alpha_{l}$ e $\beta_{l}$ a tração associada ao ponto limite pois, essa é que de fato irá determinar o valor do momento de torção crítico, sendo a atuante no instante da formação do laço. Seria incoerente considerar a tração inicial no TDP pois seu valor no momento da formação do laço já não faz nenhum sentido prático para esses casos de tração inicial muito pequena. Esse comportamento pode ser facilmente observado na Figura 5.58, em que o desvio percentual entre o modelo analítico de Greenhill e o resultado predito pelo FEMCABLE sobe abruptamente para as configurações com ângulo de topo próximo de $90^{\circ}$, pois nessa situação a tração do TDP se modifica significativamente durante a imposição da rotação. Já em casos de nível de tração mais elevado, o nível de movimentação da configuração altera muito pouco a tração no TDP, sendo que não faz diferença praticamente alguma considerar para o cálculo dos adimensionais a tração inicial do TDP ou a associada ao ponto limite ${ }^{6}$.

A fim de relacionar os adimensionais $\alpha_{l}$ e $\beta_{l}$ e procurar encontrar um padrão nessa relação, tomando todos os casos apresentados nas tabelas 5.20 a 5.24 exibiu-se um gráfico $\alpha_{l}$ versus $\beta_{l}$ na Figura 5.99. No mesmo gráfico foram referidos como "extras" os pontos referentes aos adimensionais calculados para os resultados da seção 5.3.3, tomando-se os pontos-limite das Figuras 5.44 a 5.55 e considerando-se a tração no TDP relacionada a esses pontos-limite. Ainda foram incluídos pontos referentes ao caso com correnteza marítima exibidos na seção 5.3.6, referidos como "extras 2", calculados com os dados da Tabela 5.17.

A Figura 5.99 atrelada à observação das Tabelas de resultados 5.20 a 5.24 mostra um padrão claro: quando o valor de $\beta_{l}$ tende a zero, o adimensional $\alpha_{l}$ tende a um, o que significa que a previsão analítica utilizando-se a tração inicial no TDP (que é muito próxima à tração atualizada no ponto limite) daria resultados muito bons quando

\footnotetext{
${ }^{6}$ Para efeito prático de previsão da ocorrência de formação do laço é sempre mais conveniente utilizar a tração inicial do TDP, associada à catenária-base. A tração inicial pode ser obtida utilizando-se um modelo analítico ou modelos numéricos simples. O erro cometido, no entanto, seria muito grande nos casos de tração muito baixa, pois a estrutura poderia se re-organizar, aumentando bastante a tração (percentualmente) até atingir o ponto de formação do laço.
} 
Tabela 5.20: Dados e resultados para os casos do conjunto L1

\begin{tabular}{|c|c|c|c|c|c|c|}
\hline$\gamma(\mathrm{N} / \mathrm{m})$ & EI $\left(\mathrm{Nm}^{2}\right)$ & $T_{t d p}$ inicial $(\mathrm{N})$ & $T_{t d p}$ limite $(\mathrm{N})$ & $M_{c}(\mathrm{~N} . \mathrm{m})$ & $\alpha_{l}$ & $\beta_{l}$ \\
\hline 49,05 & 5 & 34,85 & 39,42 & 30,04 & 1,0697 & 0,4431 \\
98,10 & 5 & 69,02 & 74,79 & 41,44 & 1,0715 & 0,3392 \\
490,50 & 5 & 307,94 & 317,64 & 85,22 & 1,0692 & 0,1937 \\
981,00 & 5 & 524,08 & 534,91 & 110,95 & 1,0727 & 0,1773 \\
\hline 49,05 & 100 & 32,32 & 57,09 & 157,75 & 1,0439 & 1,1372 \\
98,10 & 100 & 65,66 & 100,63 & 210,61 & 1,0497 & 0,9718 \\
490,50 & 100 & 301,06 & 377,08 & 412,53 & 1,0622 & 0,6699 \\
981,00 & 100 & 510,87 & 621,14 & 531,85 & 1,0670 & 0,6337 \\
\hline 49,05 & 1000 & 24,40 & 97,05 & 637,67 & 1,0235 & 1,6224 \\
98,10 & 1000 & 54,53 & 161,34 & 826,14 & 1,0284 & 1,5138 \\
490,50 & 1000 & 276,49 & 534,80 & 1519,92 & 1,0392 & 1,2542 \\
981,00 & 1000 & 474,98 & 861,42 & 1930,71 & 1,0401 & 1,2270 \\
\hline 49,05 & 10000 & 0,88 & 194,80 & 2809,76 & 1,0066 & 1,8041 \\
98,10 & 10000 & 20,01 & 310,04 & 3568,43 & 1,0133 & 1,7970 \\
490,50 & 10000 & 194,80 & 934,99 & 6242,97 & 1,0208 & 1,7157 \\
981,00 & 10000 & 352,75 & 1476,12 & 7849,26 & 1,0215 & 1,7298 \\
\hline 49,05 & 20000 & - & - & - & - & - \\
98,10 & 20000 & 0,69 & 388,22 & 5615,41 & 1,0076 & 1,8137 \\
490,50 & 20000 & 146,75 & 1142,59 & 9719,18 & 1,0166 & 1,7961 \\
981,00 & 20000 & 279,61 & 1797,65 & 12183,80 & 1,0160 & 1,8202 \\
\hline
\end{tabular}

comparada ao cálculo utilizando o MEF e considerando o contato unilateral sem atrito. Já nos casos em que existe menos rigidez geométrica da linha (tração no TDP mais baixa), se utilizada a tração atualizada no TDP, ou seja, considerando o seu nível de tração no ponto limite, o cálculo analítico daria bons resultados. No entanto, não é possível determinar esse nível de tração sem realizar a análise de MEF. Assim, para os casos de tração mais baixa, o modelo de MEF se torna bastante importante para a correta predição de momento de torção crítico para a formação do laço. A utilização de um modelo analítico considerando a tração inicial do TDP da catenária-base daria resultados bastante incorretos e prevendo de forma muito conservadora a formação do laço.

Nota-se, por fim, que os casos com correnteza marítima e atrito ("extras 2") também se correlacionam com os demais, apresentando a mesma tendência segundo os adimensionais $\alpha_{l}$ e $\beta_{l}$. 
Tabela 5.21: Dados e resultados para os casos do conjunto L2

\begin{tabular}{|c|c|c|c|c|c|c|}
\hline$\gamma(\mathrm{N} / \mathrm{m})$ & $\mathrm{EI}\left(\mathrm{Nm}^{2}\right)$ & $T_{t d p}$ inicial $(\mathrm{N})$ & $T_{t d p}$ limite $(\mathrm{N})$ & $M_{c}(\mathrm{~N} . \mathrm{m})$ & $\alpha_{l}$ & $\beta_{l}$ \\
\hline 49,05 & 5 & 489,49 & 489,57 & 99,90 & 1,0095 & 0,0101 \\
98,10 & 5 & 977,17 & 977,27 & 140,74 & 1,0067 & 0,0072 \\
490,50 & 5 & 4813,79 & 4813,97 & 315,37 & 1,0164 & 0,0033 \\
981,00 & 5 & 9454,04 & 9455,68 & 435,57 & 1,0016 & 0,0024 \\
\hline 49,05 & 100 & 489,47 & 491,04 & 459,70 & 1,0373 & 0,0451 \\
98,10 & 100 & 977,18 & 978,68 & 643,05 & 1,0278 & 0,0320 \\
490,50 & 100 & 4812,42 & 4814,05 & 1409,43 & 1,0157 & 0,0147 \\
981,00 & 100 & 9443,80 & 9446,39 & 1977,28 & 1,0172 & 0,0107 \\
\hline 49,05 & 1000 & 488,58 & 503,46 & 1512,95 & 1,0661 & 0,1373 \\
98,10 & 1000 & 976,27 & 990,16 & 2110,48 & 1,0605 & 0,0996 \\
490,50 & 1000 & 4812,25 & 4827,73 & 4560,19 & 1,0377 & 0,0462 \\
981,00 & 1000 & 9443,81 & 9459,92 & 6329,56 & 1,0290 & 0,0337 \\
\hline 49,05 & 10000 & 488,58 & 575,40 & 5124,73 & 1,0682 & 0,3554 \\
98,10 & 10000 & 969,08 & 1084,93 & 7043,19 & 1,0691 & 0,2745 \\
490,50 & 10000 & 4803,21 & 4947,85 & 15001,98 & 1,0664 & 0,1409 \\
981,00 & 10000 & 9434,39 & 9597,28 & 20770,53 & 1,0601 & 0,1043 \\
\hline 49,05 & 20000 & 477,16 & 617,66 & 7501,26 & 1,0671 & 0,4519 \\
98,10 & 20000 & 962,80 & 1147,08 & 10238,94 & 1,0688 & 0,3571 \\
490,50 & 20000 & 4794,38 & 5080,75 & 21547,51 & 1,0688 & 0,1915 \\
981,00 & 20000 & 9424,47 & 9733,87 & 29742,92 & 1,0658 & 0,1445 \\
\hline
\end{tabular}


Tabela 5.22: Dados e resultados para os casos do conjunto L3

\begin{tabular}{|c|c|c|c|c|c|c|}
\hline$\gamma(\mathrm{N} / \mathrm{m})$ & $\mathrm{EI}\left(\mathrm{Nm}^{2}\right)$ & $T_{t d p}$ inicial $(\mathrm{N})$ & $T_{t d p}$ limite $(\mathrm{N})$ & $M_{c}(\mathrm{~N} . \mathrm{m})$ & $\alpha_{l}$ & $\beta_{l}$ \\
\hline 49,05 & 5 & 979,81 & 979,84 & 140,55 & 1,0040 & 0,0036 \\
98,10 & 5 & 1957,24 & 1957,27 & 198,60 & 1,0038 & 0,0025 \\
490,50 & 5 & 9690,98 & 9691,29 & 442,52 & 1,0051 & 0,0011 \\
981,00 & 5 & 19155,61 & 19157,00 & 617,69 & 0,9979 & 0,0008 \\
\hline 49,05 & 100 & 979,76 & 980,26 & 635,30 & 1,0146 & 0,0160 \\
98,10 & 100 & 1957,16 & 1957,68 & 894,31 & 1,0106 & 0,0113 \\
490,50 & 100 & 9690,89 & 9691,48 & 1984,15 & 1,0077 & 0,0051 \\
981,00 & 100 & 19145,81 & 19149,40 & 2800,69 & 1,0119 & 0,0037 \\
\hline 49,05 & 1000 & 979,46 & 983,99 & 2064,56 & 1,0406 & 0,0503 \\
98,10 & 1000 & 1956,86 & 1961,75 & 2886,54 & 1,0304 & 0,0357 \\
490,50 & 1000 & 9690,39 & 9695,27 & 6319,47 & 1,0148 & 0,0162 \\
981,00 & 1000 & 19144,96 & 19149,98 & 8847,29 & 1,0109 & 0,0117 \\
\hline 49,05 & 10000 & 976,75 & 1018,64 & 6825,01 & 1,0692 & 0,1509 \\
98,10 & 10000 & - & - & - & - & - \\
490,50 & 10000 & 9687,33 & 9735,39 & 20539,76 & 1,0409 & 0,0511 \\
981,00 & 10000 & 19141,79 & 19192,25 & 28570,98 & 1,0312 & 0,0369 \\
\hline 49,05 & 20000 & 974,15 & 1045,22 & 9840,43 & 1,0761 & 0,2053 \\
98,10 & 20000 & - & - & - & - & - \\
490,50 & 20000 & - & - & - & - & - \\
981,00 & 20000 & - & - & - & - & - \\
\hline
\end{tabular}


Tabela 5.23: Dados e resultados para os casos do conjunto L4

\begin{tabular}{|c|c|c|c|c|c|c|}
\hline$\gamma(\mathrm{N} / \mathrm{m})$ & $\mathrm{EI}\left(\mathrm{Nm}^{2}\right)$ & $T_{t d p}$ inicial $(\mathrm{N})$ & $T_{t d p}$ limite $(\mathrm{N})$ & $M_{c}(\mathrm{~N} . \mathrm{m})$ & $\alpha_{l}$ & $\beta_{l}$ \\
\hline 49,05 & 5 & 48,28 & 51,82 & 34,46 & 1,0704 & 0,2940 \\
98,10 & 5 & 95,74 & 99,69 & 47,84 & 1,0714 & 0,2204 \\
490,50 & 5 & 439,10 & 444,61 & 100,18 & 1,0624 & 0,1170 \\
981,00 & 5 & 781,44 & 788,30 & 133,22 & 1,0610 & 0,0991 \\
\hline 49,05 & 100 & 46,24 & 68,09 & 173,80 & 1,0531 & 0,8731 \\
98,10 & 100 & 93,11 & 123,35 & 235,03 & 1,0581 & 0,7160 \\
490,50 & 100 & 433,65 & 492,93 & 475,29 & 1,0704 & 0,4482 \\
981,00 & 100 & 769,01 & 851,41 & 627,67 & 1,0756 & 0,3949 \\
\hline 49,05 & 1000 & 39,23 & 107,42 & 675,93 & 1,0312 & 1,3932 \\
98,10 & 1000 & 83,42 & 182,46 & 885,15 & 1,0361 & 1,2587 \\
490,50 & 1000 & 413,71 & 641,59 & 1681,14 & 1,0494 & 0,9544 \\
981,00 & 1000 & 740,92 & 1073,01 & 2177,55 & 1,0511 & 0,8826 \\
\hline 49,05 & 10000 & 16,84 & 204,48 & 2904,03 & 1,0154 & 1,6775 \\
98,10 & 10000 & 51,68 & 330,61 & 3707,06 & 1,0194 & 1,6319 \\
490,50 & 10000 & 340,36 & 1037,45 & 6621,35 & 1,0279 & 1,4679 \\
981,00 & 10000 & 634,81 & 1675,75 & 8432,93 & 1,0300 & 1,4301 \\
\hline 49,05 & 20000 & 3,77 & 254,88 & 4566,34 & 1,0112 & 1,7047 \\
98,10 & 20000 & 32,41 & 407,91 & 5801,95 & 1,0157 & 1,6840 \\
490,50 & 20000 & 295,49 & 1245,09 & 10210,21 & 1,0230 & 1,5789 \\
981,00 & 20000 & 568,69 & 1991,79 & 12946,82 & 1,0256 & 1,5607 \\
\hline
\end{tabular}


Tabela 5.24: Dados e resultados para os casos do conjunto L5

\begin{tabular}{|c|c|c|c|c|c|c|}
\hline$\gamma(\mathrm{N} / \mathrm{m})$ & $\mathrm{EI}\left(\mathrm{Nm}^{2}\right)$ & $T_{t d p}$ inicial $(\mathrm{N})$ & $T_{t d p}$ limite $(\mathrm{N})$ & $M_{c}(\mathrm{~N} . \mathrm{m})$ & $\alpha_{l}$ & $\beta_{l}$ \\
\hline 49,05 & 5 & 23,51 & 29,41 & 25,76 & 1,0620 & 0,6877 \\
98,10 & 5 & 46,51 & 54,36 & 35,16 & 1,0665 & 0,5473 \\
490,50 & 5 & 198,32 & 214,17 & 70,04 & 1,0702 & 0,3499 \\
981,00 & 5 & 309,83 & 334,38 & 87,63 & 1,0715 & 0,3588 \\
\hline 49,05 & 100 & - & - & - & - & - \\
98,10 & 100 & 42,27 & 82,31 & 188,60 & 1,0394 & 1,3136 \\
490,50 & 100 & 189,09 & 283,31 & 353,66 & 1,0506 & 1,0286 \\
981,00 & 100 & 294,46 & 438,03 & 440,78 & 1,0530 & 1,0701 \\
\hline 49,05 & 1000 & - & - & - & - & - \\
98,10 & 1000 & 29,77 & 143,98 & 774,33 & 1,0204 & 1,7957 \\
490,50 & 1000 & 159,32 & 448,32 & 1376,82 & 1,0281 & 1,6340 \\
981,00 & 1000 & 248,78 & 694,89 & 1710,37 & 1,0259 & 1,6935 \\
\hline 49,05 & 10000 & - & - & - & - & - \\
98,10 & 10000 & - & - & - & - & - \\
490,50 & 10000 & 68,28 & 851,12 & 5912,13 & 1,0133 & 1,9754 \\
981,00 & 10000 & 110,41 & 1311,61 & 7340,30 & 1,0134 & 2,0652 \\
\hline 49,05 & 20000 & - & - & - & - & - \\
98,10 & 20000 & - & - & - & - & - \\
490,50 & 20000 & 15,84 & 1057,68 & 9293,21 & 1,0103 & 2,0166 \\
981,00 & 20000 & 29,89 & 1633,49 & 11533,16 & 1,0089 & 2,1014 \\
\hline
\end{tabular}




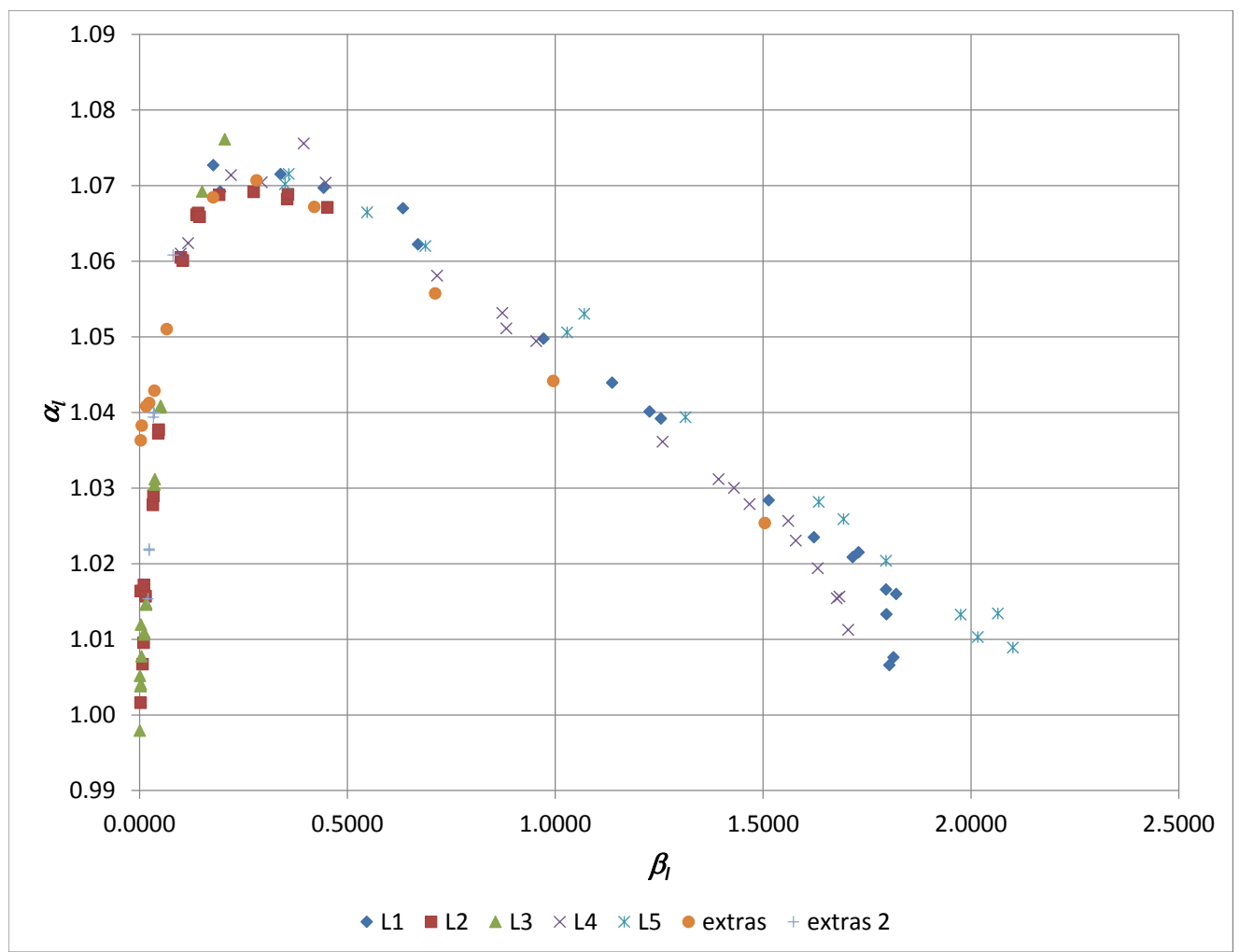

Figura 5.99: Relação entre os adimensionais $\alpha_{l}$ e $\beta_{l}$ para os casos das Tabelas 5.20 a 5.24 e para os casos das seções 5.3 .3 (extras) e 5.3.6 (extras 2) 


\section{CONCLUSÕES}

Nesse trabalho realizou-se o estudo de estabilidade de configurações de risers em catenária, especificamente focando no problema da formação de laços durante condições típicas de lançamento. Nessas situações, um nível de tração bastante baixo pode ocorrer na região do TDP. Ao solicitar um esforço de tração em tubos flexíveis ou cabos umbilicais é possível que surjam momentos de torção, decorrentes do desbalanceamento de suas armaduras de tração. Além disso, movimentos de rotação da unidade flutuante podem levar a variações no momento de torção já acumulado na linha. A combinação de momentos de torção com baixos níveis de tração pode levar à instabilidade estrutural e formação de laços no riser.

A análise de estabilidade de uma viga reta submetida à torção e tração (ou compressão) pode ser feita de forma analítica, com base na fórmula clássica de Greenhill. No entanto, sua utilização não é imediata para uma viga com tração variável e com curvatura, como a configuração de catenária de um riser.

A determinação da elastica e dos esforços solicitantes de uma configuração de catenária durante o lançamento do riser envolve alguns tipos de carregamentos, como o peso próprio, pressão hidrostática externa, correntezas marítimas, contato entre o riser e o solo, bem como eventuais rotações impostas devidas a movimentos da unidade flutuante. Assim, para realizar a análise de estabilidade dessa estrutura foi necessário verificar a influência de cada um desses esforços no problema, bem como estabelecer qual a metodologia correta para o estudo de estabilidade por conta da combinação desses efeitos. Para o caso sem correnteza marítima, concluiu-se que um critério estático de estabilidade pode ser utilizado. Já para situações em que existe correnteza, essa conclusão não é imediata, sendo conveniente a utilização de um critério cinético.

Apresentou-se adicionalmente no Apêndice A uma discussão sobre a pressão interna e externa em um riser, as diferentes abordagens para seu tratamento, por meio da integração da pressão nas paredes externa e interna de um tubo e, a abordagem clássica de peso efetivo e tração efetiva. Concluiu-se que a tração efetiva é a dominante do ponto 
de vista de estabilidade estrutural. Com o objetivo de estudar condições típicas de lançamento de risers, adotou-se a utilização do peso efetivo, implicando na obtenção da tração efetiva. Essa abordagem foi utilizada em todas as análises de estabilidade feitas nesse trabalho.

Após apresentar a dedução de um modelo estrutural estático no Capítulo 4, aplicaram-se os critérios de estabilidade estático e cinético para examinar o comportamento de estruturas de risers em catenária. O problema em particular da formação de laços é caracterizado pela instabilidade na forma de um ponto limite na trajetória de equilíbrio, quando se impõe o momento de torção. Já quando se impõe um ângulo de rotação (utilizando-se de um recalque angular) para torcer a estrutura e decorre o momento de torção, a instabilidade se dá em ponto de snapback. Pela maior conveniência numérica e maior facilidade de visualização da trajetória de equilíbrio, nesse trabalho optou-se por realizar as simulações impondo-se a rotação, mas tomando o ponto limite como limiar de instabilidade. Nessa situação é aplicável o Teorema topológico de Thompson que garante que necessariamente a estrutura apresentará um ponto limite antes de se tornar instável.

Além disso, foram utilizados os critérios estático e cinético para analisar a estabilidade, por meio da extração de autovalores das matrizes envolvidas nas soluções parciais utilizadas para construir a trajetória de equilíbrio. O critério estático consiste em extrair o menor autovalor da matriz de rigidez. Sendo positivo, indica que a estrutura é estável. Sua inversão para valores negativos indica a perda de estabilidade. O critério cinético se baseia no Primeiro Método de Lyapunov e consiste em calcular a menor frequência natural do sistema e analisar sua evolução. Se a mesma se tornar negativa ou possuir componente imaginária, indicará a perda de estabilidade.

As análises de estabilidade das configurações de catenária seguiram sempre a seguinte metodologia: primeiro é determinada a configuração-base, com todos os esforços atuantes (com exceção do momento de torção no riser). Em segundo lugar, as extremidades são engastadas e é aplicada uma rotação axial em uma das extremidades, surgindo um momento de torção distribuído ao longo da linha. Essa rotação é incrementada até a ocorrência de instabilidade. Durante esse processo, a matriz de rigidez tangente é analisada, bem como é calculada em cada incremento a menor frequência natural. Por se tratar de um problema que pode envolver grandes magnitudes de rotações no espaço, escolheu-se trabalhar com uma teoria estrutural cinematicamente exata, considerando a não linearidade geométrica. Além disso, foi necessário desenvolver um algoritmo para o tratamento do contato entre o riser e o solo, sendo uma não linearidade adicional pre- 
sente no problema e tendo contribuição na matriz de rigidez, inclusive com partes não simétricas devidas ao atrito. O carregamento da correnteza marítima também possui contribuição não nula na matriz de rigidez, por seu papel "seguidor". Esse efeito também foi considerado. Foi necessário utilizar uma descrição lagrangiana atualizada para poder lidar com as grandes magnitudes de rotação envolvidas no problema.

Foram feitas diversas simulações para estudar a estabilidade de famílias de configurações de risers em catenária. Foram desenvolvidos os seguintes modelos:

1. Modelo analítico (com base na fórmula de Greenhill) alimentado com a tração no TDP, obtida numericamente na catenária considerada;

2. Modelo numérico considerando o TDP engastado;

3. Modelo numérico considerando o contato unilateral entre o riser e o solo sem atrito;

4. Modelo numérico considerando o contato unilateral entre o riser e o solo com atrito;

5. Modelo puramente analítico (com base na fórmula de Greenhill) considerando a tração no TDP obtida com modelos analíticos de catenária.

Os resultados comparativos entre os modelos indicaram que o TDP engastado pode não representar bem a condição física do problema para alguns ângulos de topo bastante elevados (próximos de $90^{\circ}$ ), que é melhor predita pelo modelo de contato unilateral (com ou sem atrito). Ambos os modelos analíticos se mostraram bastante práticos e coerentes para uma estimativa do momento de torção crítico de uma dada configuração de riser em catenária.

Procurou-se, ainda, generalizar as conclusões para famílias de diferentes configurações de catenária. Nesse estudo foi concluído que a formação do laço é um fenômeno local, dominado por uma escala dada pelo comprimento de flexão do riser. Ainda foram construídos dois adimensionais para caracterizar o problema: um valor que representa o carregamento e outro que representa a geometria e caracteriza a catenária a ser analisada. Um gráfico relacionando esses adimensionais foi construído através de uma extensa variação paramétrica e determinação de diversas condições de instabilidade, utilizando-se do modelo sem atrito, determinando um padrão de comportamento para todas as simulações realizadas.

O efeito da correnteza marítima tem papel fundamental no problema, uma vez que altera a configuração-base de catenária. Para os estudos de caso realizados a correnteza se mostrou influente de maneira indireta, por meio da alteração da tração no TDP. 
Assim, o momento de torção crítico também é alterado. Ainda nesses casos, o modelo analítico de Greenhill alimentado com a tração no TDP no limiar de instabilidade apresenta resultados muito bons, com desvio em relação aos numéricos inferior a $10 \%$. No entanto, sua utilização se torna mais difícil do ponto de vista prático em configurações com tração muito pequena no TDP, uma vez que durante a imposição da rotação que causa a torção, a estrutura pode apresentar sensível variação de tração do TDP, alterando seu momento de torção crítico. Em configurações com tração mais elevada a direta utilização da Fórmula de Greenhill leva a resultados muito bons, mesmo utilizando-se da tração do TDP antes de sensibilizar a estrutura à formação do laço.

Casos com correnteza marítima e com atrito de deslizamento entre o riser e o solo no fundo do mar apresentam matriz de rigidez não-simétrica. Nesses casos a extração dos frequências naturais não deveria dar origem a valores com parte imaginária não nula, a não ser em situações de instabilidade dinâmica. No entanto, o tratamento do vínculo do contato nos modelos simulados se fez utilizando-se o Método das Penalidades, existindo certa arbitrariedade quanto aos parâmetros de penalidade utilizados. Dependendo da magnitude do parâmetro adotado surgem frequências naturais espúrias e sem evolução consistente ao longo da imposição da rotação que causa torção na estrutura, devido ao mal condicionamento matricial induzido pelos parâmetros de penalidade. Alterando-se tais parâmetros, verificou-se que possuem grande influência nos autovalores da matriz de rigidez, levando essas partes imaginárias a desaparecerem ou se enfatizarem. No entanto, mesmo com valores diferentes de penalidades, houve consistência na predição da queda da parte real do menor autovalor da matriz de rigidez, bem como da menor frequência natural da estrutura, conseguindo prever a perda de estabilidade. Mesmo sendo a correnteza marítima um carregamento não conservativo, para os estudos de caso simulados a predição de instabilidade foi idêntica tanto para os critérios estático e cinético.

O presente trabalho representa uma contribuição tanto para a indústria de petróleo no que tange à predição de um modo de falha de risers, mostrando que a possibilidade de ocorrência de um laço em uma configuração de catenária pode ser feita com uma fórmula simples (Greenhill), fornecendo resultados a favor da segurança, sendo prévia somente uma análise estática para prever a tração no TDP. Em situações sem correnteza, essa estimativa pode inclusive ser feita com modelos analíticos de catenária com boa precisão. Do ponto de vista acadêmico, a aplicação simultânea de modelos de viga cinematicamente exata com efeitos de correnteza marítima e algoritmos de contato representa uma contribuição. Além disso, o estudo realizado para concluir questões conceituais de estabilidade para o problema da configuração de risers em catenária com inclusão de 
efeitos de contato unilateral, atrito e correnteza marítima e sua aplicação com um modelo numérico não linear é, na opinião do autor, sua maior contribuição. 


\section{REFERÊNCIAS}

ALFUTOV, N. A. Stability of Elastic Structures. Berlin: Springer, 2000.

ALTMANN, S. L. Rotations, Quaternions, and Double Groups. New York: Dover Books on Mathematics, 2005.

API. API RECOMMENDED PRACTICE 17B. Third edition. Washington, D.C., March 2002.

ARANHA, J. A. P.; MARTINS, C. A.; PESCE, C. P. Analytical approximation for the dynamic bending moment at the touchdown point of a catenary riser. International Journal of Offshore and Polar Engineering, v. 7, p. 293-300, December 1997.

BATHE, K. J. Finite Element Procedures. New Jersey: Prentice-Hall Inc, 1996.

BATTINI, J. M.; PACOSTE, C. Co-rotational beam elements with warping effects in instability problems. Computer Methods in Applied Mechanics and Engineering, v. 191, p. $1755-1789,2002$.

BAZANT, Z. P.; CEDOLIN, L. Stability of Structures. New York: Dover, 2003.

BLEVINS, R. D. Flow-induced Vibration. Malabar Florida: Krieger Publishing Company, 2001.

BOLOTIN, V. V. Nonconservative Problems of the Theory of Elastic Stability. Northwestern University, Evanston, Illinois: Pergamon Press, 1963.

BROGLIATO, B. Absolute stability and the lagrange-dirichlet theorem with monotone multivalued mappings. Systems and control letters, 2004.

CAMPELlO, E. M. B. Análise não-linear de perfis metálicos conformados a frio. São Paulo: Universidade de São Paulo, 2000. (Dissertação de Mestrado).

CAMPELLO, E. M. B. Modelos não-lineares de casca em elasticidade e elastoplasticidade com grandes deformações: teoria e implementação em elementos finitos. São Paulo: Universidade de São Paulo, 2005. (Tese de Doutorado).

CHAMPNEYS, A. R.; HEIJDEN, G. H. M. Van der; THOMPSON, J. M. T. Spatially complex localization after one-twist-per-wave equilibria in twisted circular rods with initial curvature. Proc. R. Soc. Lond. A, Royal Society Publishing, v. 355, p. 2151-2174, 1997.

CHAMPNEYS, A. R.; THOMPSON, J. M. T. A multiplicity of localized buckling modes for twisted rod equations. Proc. R. Soc. Lond. A, Royal Society Publishing, 1996.

CHAREYRON, S.; WIEBER, P. B. Stability and regulation of nonsmooth dynamical systems. Insitut National de Recherche en Informatique et en Automatique, 2004. 
COHEN, G. A. Conservativeness of a normal pressure field acting on a shell. AIAA, v. 4, p. $1886,1966$.

COOK, R. D. Finite Element Modeling for Stress Analysis. United States of America: John Wiley and Sons, Inc., 1995.

COYNE, J. Analysis of the formation and elimination of loops in twisted cable. IEEE Journal of Oceanic Engineering, v. 15, p. 72-83, 1990.

CRISFIELD, M. A. A consistent co-rotational formulation for non-linear, threedimensional, beam-elements. Computer Methods in Applied Mechanics and Engineering, v. 81, p. $131-150,1990$.

CRISFIELD, M. A.; MOITA, G. F. A co-rotational formulation for 2-d continua including incompatible modes. International journal for numerical methods in engineering, v. 39, p. 2619-2633, 1996.

DASAMBIAGIO, E. R. Um modelo geometricamente exato de barras com grandes deformações, que considera a distorção e o empenamento da seção transversal, e sua discretização pelo Método dos Elementos Finitos. São Paulo: Universidade de São Paulo, 2008. (Dissertação de Mestrado).

EL FATMI, R. Non-uniform warping including the effects of torsion and shear forces. part 1: A general beam theory. International Journal of Solids and Structures, 2007.

ELISHAKOFF, I. Controversy associated with the so-called follower forces: Critical overview. Applied Mechanics Reviews, 2005.

ERMOLAEVA, N. S.; REGELINK, J.; KRUTZEN, M. P. M. Hockling behavior of single- and multiple-rope systems. Engineering Failure Analysis, Elsevier, v. 15, p. 142-153, 2008.

FALTISEN, O. M. Sea loads on ships and offshore structures. United Kingdom: The press syndicate of the university of Cambridge, 1990.

FRANÇA, L. N. F.; MATSUMURA, A. Z. Mecânica Geral. São Paulo: Editora Edgard Blucher LTDA, 2004.

FYRILEIV, O.; COLLBERG, L. Influence of pressure in pipeline design - effective axial force. Proceedings of 24th International Conference on Offshore Mechanics and Arctic Engineering, June 2005.

GAY NETO, A.; CORREIA, R. P. Ambiente de Análise de Risers em águas ultraprofundas: análise estática, pré e pós-processadores. São Paulo: Universidade de São Paulo, 2006. (Trabalho de Formatura).

GAY NETO, A.; MARTINS, C. A. A comparative buckling study for the carcass layer of flexible pipes. Proceedings of the 28th International Conference on Offshore Mechanics and Arctic Engineering, 2009.

GAY NETO, A.; MARTINS, C. A. Flexible pipes: Influence of the pressure layer in the wet collapse resistance. Proceedings of the 30th International Conference on Offshore Mechanics and Arctic Engineering, 2011. 
GAY NETO, A.; MARTINS, C. A. A comparative wet collapse buckling study for the carcass layer of flexible pipes. Journal of Offshore Mechanics and Arctic Engineering, v. 134, August 2012.

GAY NETO, A.; MARTINS, C. A.; PESCE, C. P.; MEIRELlES, C. O. C.; MALTA, E. R.; BARBOSA NETO, T. F.; GODINHO, C. A. F. Burst prediction of flexible pipes. Proceedings of the 29th International Conference on Offshore Mechanics and Arctic Engineering, 2010.

GLOBAL SECURITY. Spar Platform. jul 2010. Disponível em: < http://www.globalsecurity.org/military/systems/ship/images/spars-image2.jpg >.

GLOBAL SECURITY. TLP Platform. jul 2010. Disponível em: <http://www.globalsecurity.org/military/systems/ship/images/platform-tension-leg3.jpg $>$.

GOLDSTEIN, H. Classical Mechanics. United States of America: Addison-Wesley Publishing Company, 1980.

GOSS, V. G. A. Snap buckling, writhing and loop formation in twisted rods. London: University of London, 2003. (PhD Thesis).

GOSS, V. G. A.; VAN DER HEIJDEN, G. H. M.; THOMPSON, J. M. T.; NEUKIRCH, S. Experiments on snap buckling, hysteresis and loop formation in twisted rods. Exeprimental Mechanics, p. 101-111, 2005.

GOYAL, S.; PERKINS, N. C.; LEE, C. L. Non-linear dynamic intertwining of rods with self-contact. International Journal of Non-linear Mechanics, v. 43, p. 65-73, 2008.

GUARIZE, R.; MATOS, N. A. F.; SAGRILO, L. V. S.; LIMA, E. C. P. Neural networks in the dynamic response analysis of slender marine structures. Applied Ocean Research, v. 29, p. 191-198, 2008.

KORDKHEILI, S. A. H.; BAHAI, H. Non-linear finite element analsysis of flexible risers in presence of buoyancy force and seabed interaction boundary condition. Springer-Verlag, October 2007.

KUZNETSOV, Y. A. Elements of Applied Bifurcation Theory. New York: SpringerVerlag, 2004.

LEINE, R. I.; VAN DE WOUW, N. Stability and Convergence of Mechanical Systems with Unilateral Constraints. German: Springer-Verlag Berlin Heidelberg, 2008.

LEIPHOLZ, H. Six Lectures on Stability of Elastic Systems. Waterloo, Ontario, Canada: University of Waterloo, 1975.

LEIPHOLZ, H. Stability Theory An Introduction to the Stability of Dynamic Systems and Rigid Bodies. Great Britain: Wiley, 1987.

LIU, F. C. Kink formation and rotational response of single and multi-strand electromechanical cables. Tech. Note N-1403, Civil Engineering Lab, Naval Construction Batallion Center, 1975. 
LOVE, A. E. H. A Treatise on the Mathematical Theory of Elasticity. New York: Dover pulications, 1944.

LOW, Y. M.; LANGLEY, R. S. Dynamic analysis of a flexible hanging riser in the time and frequency domain. Proceedings of OMAE2006, 2006.

MARINE LOG. Marine Log Magazine. jul 2010. Disponível em: <http://www.marinelog.com/IMAGESMMII/caldive49.jpg>.

MARTINS, C. A. Uma Ferramenta Expedita para Estudo de Viabilidade de Risers Rígidos em Catenária. São Paulo: Universidade de São Paulo, 2000. (Tese de Livre Docência).

MARTINS, C. A. Cabos flexíveis inextensíveis. Sistemas Hidrodinâmicos. Notas de aula., 2008.

MAZZILLI, C. E. N. Sobre a instabilidade de estruturas elásticas sensiveis a imperfeicões. São Paulo: Universidade de São Paulo, 1979. (Dissertação de Mestrado).

MAZZILLI, C. E. N. A class of non-linear vibrations and their stability. London: University College London, 1982. (PhD Thesis).

MAZZILli, C. E. N. Conceito e Definicões de estabilidade. São Paulo: Universidade de São Paulo, 2009. (Notas de Aula da Discliplina PEF 5735).

MIYAZAKI, Y.; KONDO, K. Analytical solution of spatial elastica and its application to kinking problem. International Journal of Solid and Structures, v. 27, p. 3619-3636, 1997.

MOREIRA, M. L. T. Parametrizacão das rotacões em teorias de barras e cascas. São Paulo: Universidade de São Paulo, 2009. (Tese de Doutorado).

MORISON, J. R.; OB́RIEN, M. P.; JOHNSON, J. W.; SCHAAF, S. A. The force exerted by surface waves on piles. Transactions of the American Institute of Mining and Metallurgical Engineers, 1950.

MOURELlE, M. M. Análise Dinâmica de Sistemas Estruturais constituídos por linhas marítimas. Rio de Janeiro: COPPE/UFRJ, 1993. (Tese de Doutorado).

NOWINSKI, J. L. Note on applications of the fréchet derivative. Internation Journal of Non-linear Mechanics, 1983.

O'BRIEN, P. J.; MCNAMARA, J. F. Significant characteristics of three-dimensional flexible riser analysis. Engineering Structures, v. 11, p. 223-233, October 1989.

ORCINA. OrcaFlex 9.3a. Ulverston: Orcina Ltd., 2009.

PATEL, M. H.; SAROHIA, S.; NG, K. F. Finite-element analysis of the marine riser. Engineering Structures, v. 6, p. 175-184, July 1984.

PATEL, M. H.; SEYED, F. B. Review of flexible riser modelling and analysis techniques. Engineering Structures, v. 17, p. 293-304, 1995. 
PESCE, C. P. Mecânica de cabos e tubos submersos lançados em catenária. São Paulo: Universidade de São Paulo, 1997. (Tese de Livre Docência).

PESCE, C. P.; ARANHA, J. A. P.; MARTINS, C. A. Dynamic Curvature in Catenary Risers at the touchdown point region: an experimental study and the analytical boundary-layer solution. São Paulo, 1997.

PETROBRAS. Blog Petrobras. jul 2010. Disponível em: <http://www.blogspetrobras.com.br/fatosedados/wp-content/uploads/2009/12/p53.JPG >.

PIMENTA, P. de M. Rotações finitas. Boletim Técnico do Departamento de Estruturas e Fundações (PEF) da Escola Politécnica - USP, Fevereiro 1987.

PIMENTA, P. M.; CAMPELLO, E. M. B.; WRIGGERS, P. An exact conserving algorithm for nonlinear dynamics with rotational dof's and general hyperelasticity. part 1: Rods. Computational Mechanics, 2008.

PRYSMIAN CABLES AND SYSTEMS. Umbilicals. jul 2010. Disponível em: <http://www.prysmian.com.br/energy/industrial_applications/umbilicals.html>.

RAMOS JR, R. Modelos analíticos no estudo do comportamento estrutural de tubos flexíveis e cabos umbilicais. São Paulo: Universidade de São Paulo, 2001. (Tese de Doutorado).

RAMOS JR, R.; PESCE, C. P. A stability analysis of risers subjected to dynamic compression coupled with twisting. Journal of Offshore Mechanics and Arctic Engineering, v. 125, p. 183-189, August 2003.

RAND, O. On the importance of cross-sectional warping in solid composite beams. Composite Structures, 2000.

ROMANO, G. Potential operators and conservative systems. Meccanica, p. 7:141-146, 1972.

ROSENTHAL, F. The application of greenhill's formula to cable hockling. Journal of Applied Mechanics, v. 43, p. 681-683, 1976.

ROSS, A. L. Cable kinking analysis and prevention. Journal of Engineering for Industry, p. $112-115,1977$.

SANTOS, M. F. Mecânica Global Tridimensional de Linhas Submersas. São Paulo: Universidade de São Paulo, 2003. (Tese de Doutorado).

SCHWEIZERHOF, K.; RAMM, E. Displacement dependent pressure loads in nonlinear finite element analyses. Computer and Structures, v. 18, p. 1099-1114, 1984.

SEYED, F. B.; PATEL, M. H. Mathematics of flexible risers including pressure and internal flow effects. Marine Structures, 1992.

SILVEIRA, L. M. Y.; MARTINS, C. A. A numerical method to solve the static problem of a catenary riser. Proceeding of the 23rd International Conference on Offshore Mechanics and Arctic Engineering, 2004. 
SIMO, J. C. A finite strain beam formulation. three-dimensional dynamic problem. part i. Computer Methods in Applied Mechanics and Engineering, v. 49, p. 55-70, 1985.

SIMO, J. C. A three-dimensional finite strain rod model. part ii: Computational aspects. Computer Methods in Applied Mechanics and Engineering, v. 58, p. 79-116, 1986.

SIMO, J. C. A geometrically exact rod model incorporating shear and torsion-warping deformation. Computer Methods in Applied Mechanics and Engineering, v. 27, p. 371-393, 1991.

SPARKS, C. P. The influence of tension, pressure and weight on pipe and riser deformations and stresses. Journal of Energy Resources Technology, 1984.

SPARKS, C. P. Fundamentals of Marine Riser Mechanics. Tulsa, Oklahoma USA: PennWell Corporation, 2007.

SPRING, K. W. Euler parameters and the use of quaternion algebra in the manipulations of finite rotations: a review. Mechanism and Machine Theory, v. 21, p. 365-373, 1986.

STUMP, D. M. The hockling of cables: a problem in shearable and extensible rods. International Journal of Solids and Structures, v. 37, p. 515-533, 2000.

TAKAFUJI, F. C. M. Dinâmica Tridimensional de Risers. São Paulo: Universidade de São Paulo, 2010. (Tese de Doutorado).

TAKAFUJI, F. C. M.; MARTINS, C. A. Damping linearization for frequency domain lazy-wave riser analysis. Proceedings of the Seventh International Offshore and Polar Engineering Conference, p. 834-841, July 2007.

THOMAS, J. H. Fundamentos da Engenharia de Petróleo. Rio de Janeiro: Editora Interciência Ltda, 2001. 271 p.

THOMPSON, J. M. T.; CHAMPNEYS, A. R. From helix to localized writhing in the torsional post-buckling of elastic rods. Proc. R. Soc. Lond. A, Royal Society Publishing, v. 452 , p. $117-138,1996$.

THOMPSOn, J. M. T.; HUNT, G. W. A General Theory of Elastic Stability. London: John Wiley and Sons, 1973. (A Wiley-Interscience Publication).

TOPOGOnOV, V. A. Differential Geometry of Curves and Surfaces - A Concise Guide. Boston: Birkhauser, 2006.

TWI TECHNOLOGY AND ENGINEERING. Oil, Gas and Chemicals - Exploration and production facilities. jul 2011. Disponível em: <http://www.twi.co.uk>.

VAN DER HEIJDEN, G. H. M.; THOMPSON, J. M. T. Helical and localised buckling in twisted rods: A unified analysis of the symmetric case. Nonlinear Dynamics, v. 21, p. 71-99, 2000.

VAZ, M. A.; PATEL, M. H. Three-dimensional behaviour of elastic marine cables in sheared currents. Applied Ocean Research, v. 22, p. 45-53, 2000.

WITZ, J. A.; TAN, Z. On the flexural structural behaviour of flexible pipes, umbilicals and marine cables. Marine Structures, 1992. 
WRIGGERS, P. Computational Contact Mechanics. England: John Wiley and sons Ltd, The Atrium, Southern Gate, Chichester, West Sussex, 2002. 440 p.

YABUTA, T. Submarine cable kink analysis. Bulletin of JSME, v. 27, p. 1821-1828, 1984.

YOUNG, W. C.; BUDYNAS, R. G. Roark's Formulas for Stress and Strain. United States of America: McGraw-Hill, 2002.

ZIEGLER, H. Principles of Structural Stability. Federal Institute of Technology Zurich, Switzerland: Blaisdell Publishing Company, 1968. 


\section{APÊNDICE A - EFEITO DAS PRESSÕES INTERNA E EXTERNA NA ESTABILIDADE ESTRUTURAL DE UM RISER}

\section{A.1 Introdução}

Neste apêndice são equacionados e discutidos os carregamentos de pressão externa e interna que atuam sobre um riser. A pressão externa surge do posicionamento físico da estrutura, submersa e submetida a um campo de pressão hidrostática. Já a pressão interna se refere à ação do fluido interno ao tubo, quando se trata de tubos flexíveis ou rígidos. Nesse caso também existe a pressão hidrostática do fluido interno, mas também pode haver um nível de pressurização adicional. Cabos umbilicais também podem apresentar mangueiras com pressurização interna, mas esse efeito não será aqui discutido.

Os carregamentos de pressão interna e externa são bastante relevantes para a determinação dos esforços solicitantes de tração ao longo de um riser. Ainda podem ter grande influência sobre a estabilidade estrutural, tanto em termos globais como locais. A Figura A.1 ilustra a ocorrência da ovalização da carcaça intertravada de um tubo flexível quando o mesmo é submetido ao carregamento de pressão externa. O fenômeno em questão é denominado "colapso molhado". Trata-se de um modo de falha de tubos flexíveis que assume danos na capa plástica externa do tubo, tal que o carregamento da pressão recai sobre a carcaça intertravada. Não sendo desejável a ovalização excessiva da mesma, é possível através de uma análise local do tubo flexível verificar o máximo valor de pressão admissível para que não ocorra o colapso. Tal tema foi abordado pelo autor em Gay Neto e Martins (2009), Gay Neto e Martins (2011) e Gay Neto e Martins (2012). 
Outro efeito local relevante em tubos flexíveis ou risers rígidos é a influência da pressão interna em seu comportamento, uma vez que ao pressurizar um tubo, o mesmo passa a funcionar como um vaso de pressão, podendo atingir tensões de membrana muito elevadas. Tal assunto foi tratado pelo autor em Gay Neto et al. (2010) no estudo de tubos flexíveis através de uma análise elastoplástica da armadura de pressão.

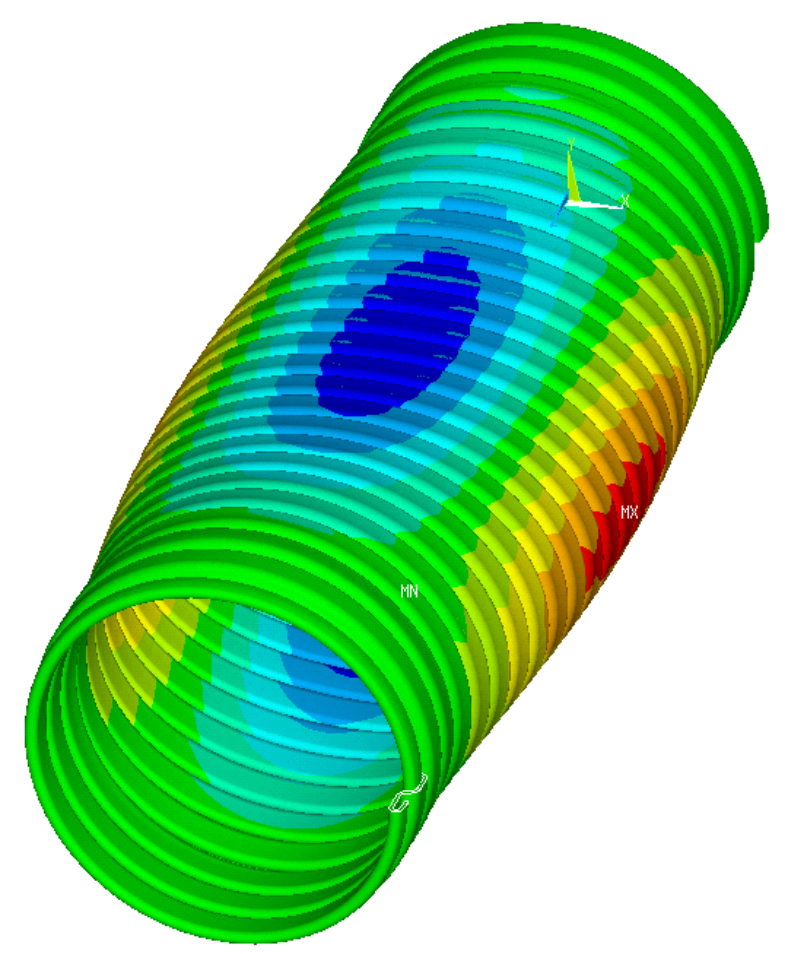

Figura A.1: Exemplo de ovalização da carcaça intertravada de um tubo flexível.

Esses exemplos de influência das pressões externa e interna na mecânica de risers se referem a modos de falha locais. O objetivo desse apêndice é analisar a influência das pressões externa e interna nos esforços globais de uma configuração de riser. Uma abordagem comum para análise global de risers é a utilização de um conceito denominado peso efetivo e tração efetiva (ver por exemplo Martins (2000), Sparks (1984) e Pesce (1997)). Aqui tal tema será detalhado, juntamente de uma segunda abordagem em que é feita a integração da pressão hidrostática nas paredes de um tubo retilíneo ou curvilíneo. Embora muito trabalhosa, a integração da pressão pode ajudar a compreender algumas questões conceituais e pode ser comparada com a abordagem da utilização do peso e tração efetivos, tirando-se conclusões interessantes. 


\section{A.2 Riser retilíneo e vertical}

Para iniciar a discussão pode-se imaginar um riser retilíneo e vertical (Figura A.2) imerso nas águas do mar e contendo um fluido interno pressurizado. Os carregamentos da pressão externa e interna atuam na direção radial em cada seção transversal do riser sendo, portanto, carregamentos axi-simétricos. A Figura A.3 mostra uma seção transversal com esses carregamentos aplicados.

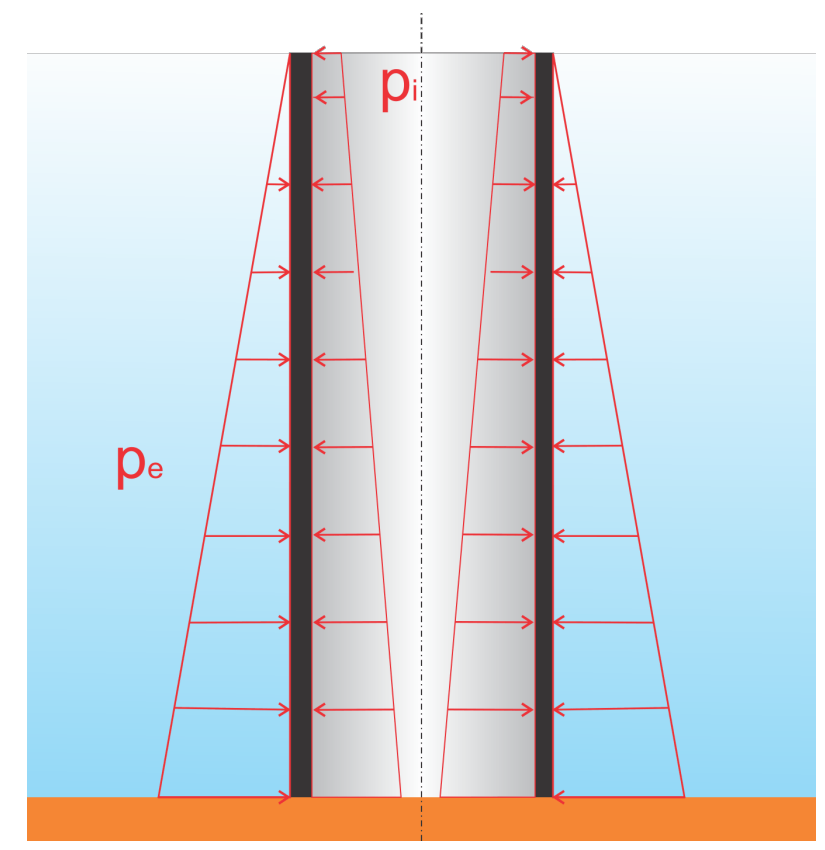

Figura A.2: Riser vertical perfeitamente retilíneo com pressurização interna e imerso nas águas do mar

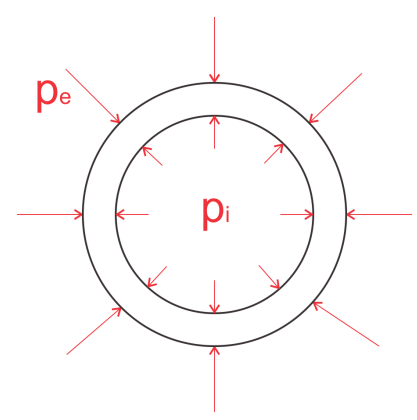

Figura A.3: Carregamentos axi-simétricos das pressões interna e externa aplicadas a uma seção transversal de um riser retilíneo

Idealizando uma situação de inexistência de correntezas marítimas ou de qualquer carregamento transversal sobre o riser, sua configuração deformada continuaria sendo retilínea. No entanto, se for considerada uma situação mais realista, levando-se em conta 
alguma imperfeição geométrica na estrutura ou ação de um carregamento lateral, o riser apresentaria certo nível de curvatura, ainda que muito pequeno. Dessa forma, os carregamentos de pressão deixariam de ser axi-simétricos e passariam a ter resultante transversal não nula, podendo alterar a configuração do riser. Essa discussão é feita com relação ao efeito da pressão interna em Bazant e Cedolin (2003) e com relação à pressão externa e interna em Sparks (2007).

A Figura A.4 mostra um elemento infinitesimal de um tubo com curvatura e com pressurização interna. Como o tubo é curvo, a integral da pressão possuirá resultante não nula no plano osculador e tal resultante será na direção normal à elastica. Assim, o efeito da pressão interna em um tubo curvo é, além das tensões de membrana que estarão na seção transversal (efeito de um vaso de pressão), promover um carregamento transversal ao riser, atuante no plano osculador, na direção normal e tendendo a aumentar a curvatura ainda mais. Por conta disso, seu efeito é instabilizador do ponto de vista de alteração da configuração global.

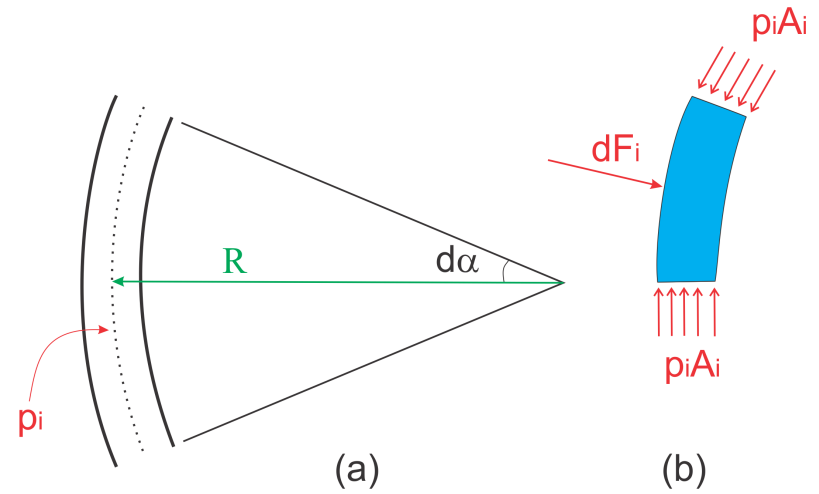

Figura A.4: Influência da pressão interna como um carregamento lateral quando ocorre flexão no tubo. (a) Tubo com pressão interna (b) Forças atuantes em um corte do fluido interno ao tubo

Sejam $d F_{i}$ a resultante das forças atuantes no elemento infinitesimal de comprimento $d s=R d \alpha$ e $A_{i}$ a área da seção transversal interna do tubo. Para determinar $d F_{i}$ pode-se equacionar o equilíbrio de um trecho infinitesimal de fluido interno ao tubo, considerando no fluido a reação da pressão aplicada nas paredes do tubo. Considerando que o tubo não possui carregamento axial, pode-se escrever com base na Figura A.4:

$$
d F_{i}-p_{i} A_{i} d \alpha=0
$$




$$
d F_{i}=\frac{p_{i} A_{i}}{R} d s
$$

Por outro lado, se for considerado o papel da pressão externa, sua resultante no tubo curvo também será não nula, atuante no plano osculador e na direção normal. No entanto, o sentido será oposto ao da pressão interna. Assim, seu efeito é estabilizador, uma vez que a curvatura inicial do tubo tende a se anular por conta do carregamento da pressão externa.

Dentro da ótica de estudo da integração das pressões externa e interna sobre as paredes de um tubo, o triedro de Frenet é o sistema de coordenadas que surge naturalmente para facilitar a decomposição de forças, uma vez que sempre está alinhado ao plano osculador e a direção normal indica a direção da curvatura. Assim, para o cálculo da resultante transversal das pressões interna e externa foi utilizado esse sistema de coordenadas. A ideia é elaborar mais as equações dadas em A.2, tornando-as mais genéricas para qualquer tubo, com curvatura não constante em magnitude e direção e, além disso, considerando não um campo de pressão uniforme, mas uma distribuição hidrostática. A seguir são ilustradas as bases teóricas para esse procedimento.

\section{A.3 Pressão hidrostática}

A pressão hidrostática $p_{h}$ exercida por uma coluna de fluido em um certo ponto $P$ (Figura A.5), é uma função da altura $\left(z_{\text {surf }}-z_{p}\right)$ da coluna de fluido acima do ponto $P$, da massa específica do fluido $\rho_{e}$ e da aceleração da gravidade local $\boldsymbol{g}$. Seu cálculo é feito através da seguinte expressão:

$$
p_{h}=\rho_{e}\|\boldsymbol{g}\|\left(z_{\text {surf }}-z_{p}\right)
$$

Um riser instalado possui um carregamento de pressão hidrostática em suas paredes externas. Esse carregamento deve ser levado em consideração quando se faz a sua análise estrutural, uma vez que possui importante influência sobre os níveis de tração preditos na análise. Supondo que um riser se encontre totalmente submerso, incluindo suas seções transversais das extremidades, ou seja, o carregamento da pressão hidrostática atuaria sobre todas as suas superfícies externas. Pelo princípio de Arquimedes o sistema 


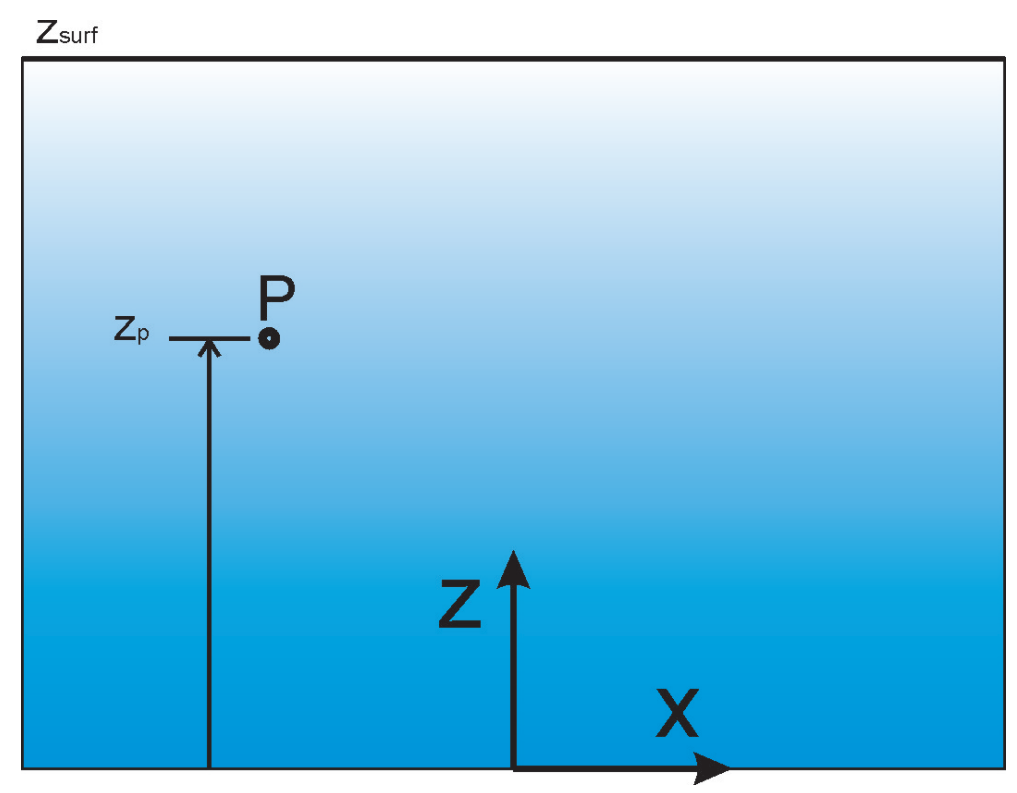

Figura A.5: Ponto $P$ localizado em uma coluna de fluido

de forças equivalente à pressão hidrostática distribuída nas paredes desse riser equivale a um sistema de forças paralelas denominado "empuxo" $\boldsymbol{E}$, atuante na direção da aceleração da gravidade, mas no sentido oposto à mesma. A magnitude do empuxo é igual a:

$$
\|\boldsymbol{E}\|=\rho_{e} V\|\boldsymbol{g}\|
$$

No cálculo do empuxo, $V$ é o volume total do riser que está imerso no fluido. Uma discussão relevante acerca do sistema de forças equivalente à pressão hidrostática atuante sobre um corpo imerso é feita em Sparks (1984). É discutida a questão da equivalência mecânica entre a pressão hidrostática e um sistema de forças paralelas na mesma direção de $\boldsymbol{g}$, mas no sentido oposto ao mesmo, para representação do empuxo. O autor utiliza argumentos físicos de equilíbrio para demonstrar essa equivalência.

Porém, de modo geral, o cenário de carregamentos de um riser em condições reais não corresponde à total imersão no fluido. A fim de se estudar o equilíbrio de forças que ocorre em cada trecho do riser mas não o considerando como um corpo totalmente imerso, pode-se realizar cortes transversais em sua estrutura e focar-se apenas nas forças atuantes no trecho de riser delimitado por esses cortes. Note que a ação do campo de pressão hidrostática ocorre apenas em sua área lateral. Nessa situação, a resultante desse campo de pressão não é igual ao empuxo $\boldsymbol{E}$, pois não há pressão atuante nas seções transversais de corte desse trecho de riser. A Figura A.6 mostra o sistema de forças original que atua sobre o trecho estudado: 


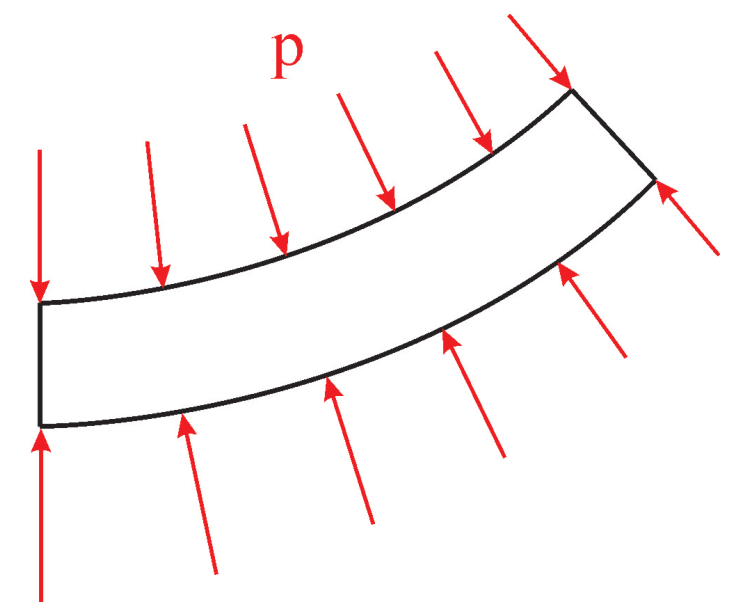

Figura A.6: Pressão externa distribuída em um corte de riser submerso

O sistema de forças formado pela pressão hidrostática aplicada às paredes externas de um riser resulta em carregamentos transversais aplicados à estrutura.

\section{A.4 Carregamento da pressão externa sobre um riser}

A pressão hidrostática atuante na parede externa de um riser pode ser integrada de forma a se obter uma expressão para o cálculo de um esforço externo equivalente. Esse procedimento possibilita a obtenção de expressões para uso direto em modelos de vigas aplicando-se o Método dos Elementos Finitos. A mesma ideia aqui desenvolvida pode ser verificada no artigo de Seyed e Patel (1992). Os autores desenvolveram expressões para o carregamento em elementos finitos (elementos de tubo), considerando em primeiro lugar um tubo reto, posteriormente um tubo curvo, de forma aproximada, e por fim um tubo curvo com elastica na forma de um trecho de circunferência. Em todas as formulações, os autores apresentam a dedução das forças nos elementos, expandindo a pressão a partir do centro do elemento considerado. As expressões obtidas são um tanto quanto complexas, pois se utilizam de coordenadas cartesianas, apresentando muitas funções trigonométricas que dificultam a interpretação dos termos obtidos em cada expressão.

Motivando-se assim como Seyed e Patel (1992), apresenta-se nessa seção a dedução de expressões para o cálculo de esforços devidos à pressão hidrostática externa em risers. Motivou-se, adicionalmente, pelo interesse em verificar o que se diz no artigo de Sparks (1984), que a abordagem de tração efetiva (explicada posteriormente) pode ser utilizada diretamente em problemas de risers, inclusive para fins de estudo de flambagem. 


\section{A.4.1 Riser com elastica retilínea}

Considerando-se um riser cuja elastica é retilínea, a integração da pressão sobre a parede externa se torna bastante simplificada em relação ao caso mais geral. Um riser retilíneo pode se encontrar inclinado em relação ao plano horizontal. Dependendo da inclinação, a resultante da pressão distribuída nas paredes laterais externas possui uma magnitude diferente. Seja a representação da superfície externa do corte de um riser dada pela Figura A.7.

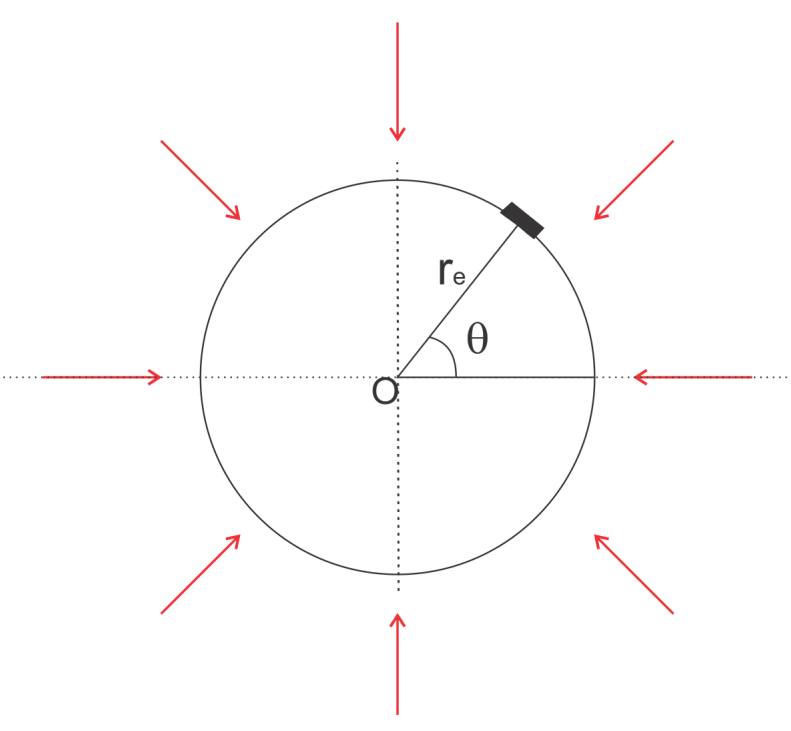

Figura A.7: Representação da parede externa de um riser reto

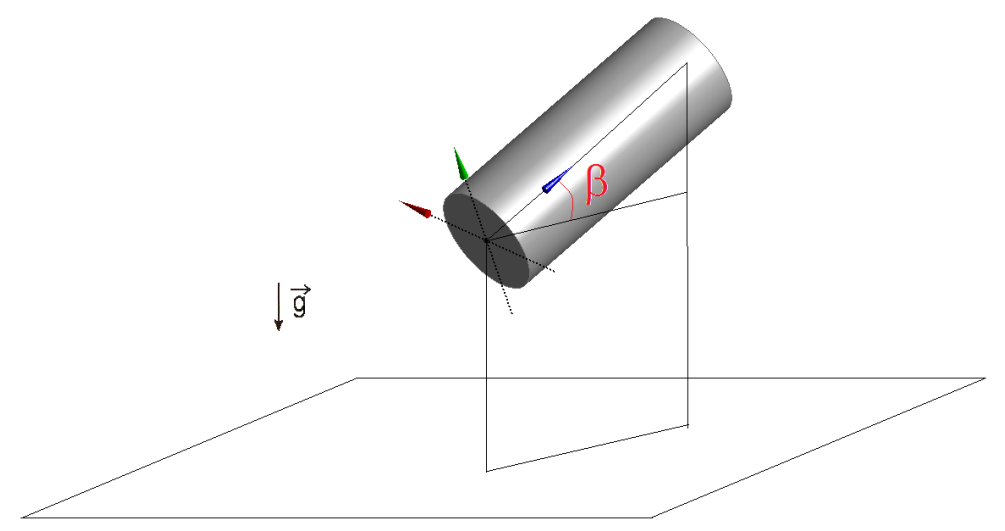

Figura A.8: Ângulo de inclinação de um riser reto

Estando o riser inclinado, segundo um ângulo de inclinação $\beta$ (ver Figura A.8), é possível escrever uma expressão para a coluna de água presente sobre cada ponto da superfície externa do riser, associado a um ângulo $\theta$. A expressão A.5 mostra a função que relaciona a altura da coluna de água sobre cada ponto, em função da posição angular 
$\theta$ desse ponto na superfície do riser. A variável $h_{o}$ indica a coluna de água atuante sobre o ponto do centro da seção transversal analisada.

$$
h(\theta)=h_{o}-r_{e} \operatorname{sen} \theta \cos \beta
$$

Por simetria, é possível realizar a integração da pressão no intervalo $[-\pi / 2, \pi / 2]$, projetando cada força normal infinitesimal na direção do plano de simetria. Assim sendo, a resultante da pressão hidrostática por unidade de comprimento do riser retilíneo $\frac{d f}{d s}$ vale:

$$
\frac{d f}{d s}=2 \int_{-\frac{\pi}{2}}^{\frac{\pi}{2}} \rho_{e}\|\boldsymbol{g}\| h(\theta) r_{e}(-\operatorname{sen} \theta) d \theta
$$

Utilizando-se a expressão A.5 em A.6 e realizando algum trabalho algébrico chegase em:

$$
\frac{d f}{d s}=\rho_{e}\|\boldsymbol{g}\| \pi r_{e}^{2} \cos \beta
$$

A direção do carregamento $\frac{d f}{d s}$ é a direção normal à seção transversal de corte, passando pelo plano de simetria considerado na integração, e mostrado na Figura A.7. O sentido é o oposto ao da projeção do vetor aceleração da gravidade no plano transversal de corte do riser.

Note que a expressão A.7 apresenta a inclinação do riser como sendo importante para a resultante da integração da pressão nas paredes externas. Apesar de a expressão A.7 ser deduzida como um carregamento a ser integrado ao longo do comprimento do riser, a fim de obter a força transversal correta, ela só deve ser integrada a risers retos. Se aplicada a elasticas genéricas tridimensionais levará a resultados incorretos. Para aplicações mais gerais, é necessário utilizar-se das expressões desenvolvidas a seguir.

\section{A.4.2 Riser com elastica curvilínea}

Para a descrição de forma mais genérica possível do carregamento de pressão hidrostática em qualquer ponto de um riser, a seguinte hipótese foi feita: um elemento infinitesimal de riser pode ser imaginado como sendo pertencente a um torus, com raio de curvatura 
$R(s)$, em que $s$ é a abscissa curvilínea do riser. Cada seção transversal do riser possui uma curvatura diferente, e pertence a um torus imaginário diferente, podendo esse sólido apresentar-se em qualquer posição e variar seu raio de curvatura de acordo com o raio de curvatura no decorrer da abscissa curvilínea s. A Figura A.9 mostra um exemplo de torus para uma certa seção de um riser.

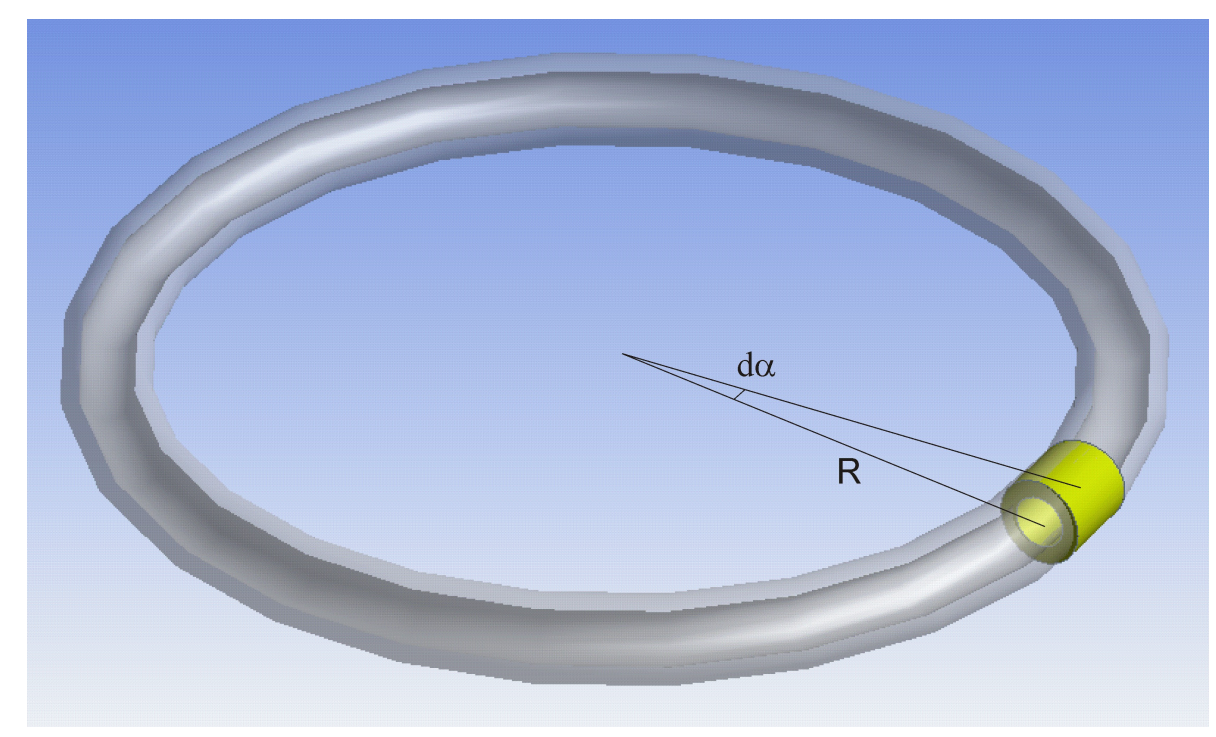

Figura A.9: Exemplo de um torus utilizado como base para a determinação do elemento infinitesimal no comprimento de um riser curvo

A Figura A.10 ilustra com mais detalhes o elemento de área infinitesimal utilizado para representar a superfície externa de um riser. Note que o raio de curvatura na abscissa curvilínea $s$, vale $R$. A descrição de um elemento de área infinitesimal na superfície externa do torus pode ser feita utilizado-se o sistema de coordenadas toroidais. Um ângulo $\theta$ é utilizado para descrever a posição de um elemento infinitesimal de área na superfície do torus, conforme a Figura A.10. O raio da seção do torus vale $r_{e}$. É possível escrever uma expressão para a área de um elemento infinitesimal na superfície externa do torus da seguinte forma:

$$
d A=r_{e}\left(R+r_{e} \cos \theta\right) d \theta d \alpha
$$

A fim de facilitar a notação vetorial empregada nas equações que serão deduzidas a seguir, utilizar-se-á um sistema de coordenadas conveniente para a descrição da orientação da elastica do riser ao longo da abscissa curvilínea $s$ : o triedro de Frenet. A Figura A.11 ilustra esse sistema de coordenadas.

Tem-se que, para cada valor de abscissa curvilínea, estão associados três vetores 


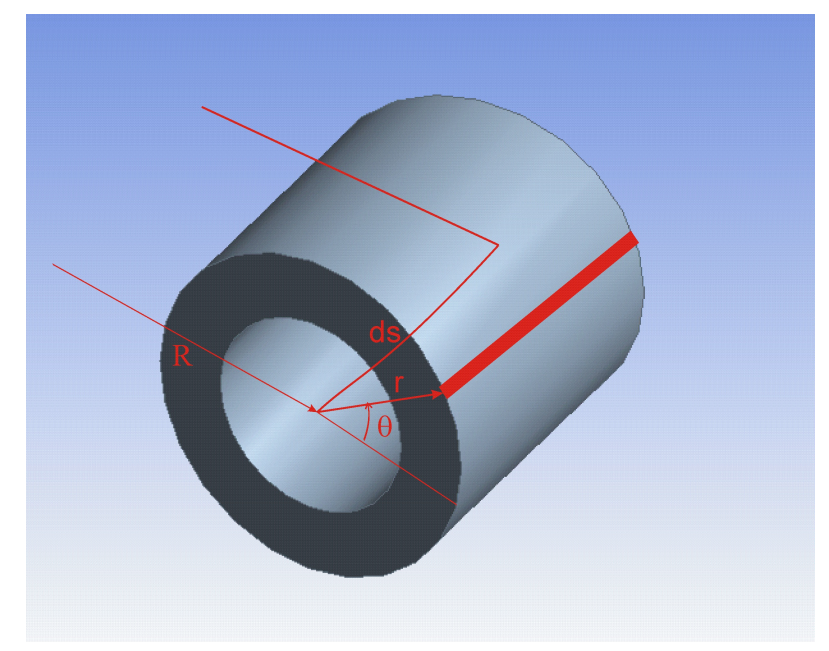

Figura A.10: Corte na direção da abscissa curvilínea (s) de um riser curvo com raio de curvatura $R$

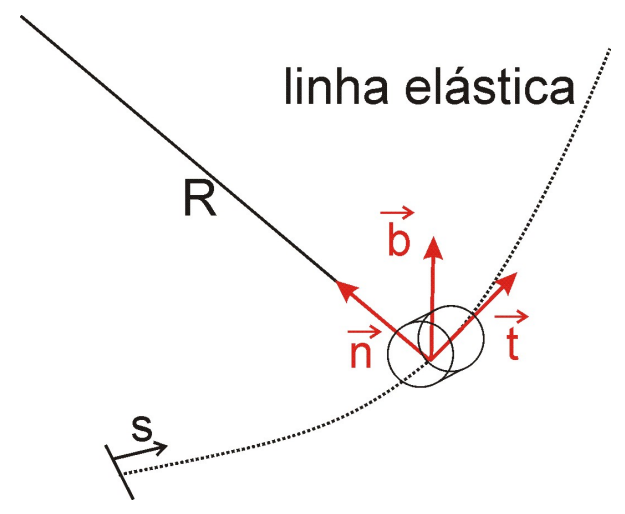

Figura A.11: Triedro de Frenet utilizado na descrição vetorial dos esforços em um elemento infinitesimal de riser

para orientar a curva no espaço que representa a elastica: $\boldsymbol{t}(s), \boldsymbol{n}(s)$ e $\boldsymbol{b}(s)$. Por simplicidade de notação, a partir desse ponto as direções de Frenet serão representadas apenas por $\boldsymbol{t}, \boldsymbol{n}$ e $\boldsymbol{b}$, ficando implícita sua dependência em relação à abscissa $s$. A fim de descrever os esforços de pressão que atuam na superfície externa do torus, é necessário escrever uma expressão para a direção normal à superfície. A direção normal principal em um ponto $P$ é designada por $\boldsymbol{n}_{\boldsymbol{p}}$.

$$
\boldsymbol{n}_{\boldsymbol{p}}=-\cos \theta \boldsymbol{n}+\operatorname{sen} \theta \boldsymbol{b}
$$

Uma vez que a pressão atua somente na direção normal à superfície externa do riser, seu carregamento atuará somente na direção normal principal e binormal da elastica. A resultante da pressão hidrostática, portanto, é um carregamento transversal atuante sobre o riser. A aceleração da gravidade pode ser decomposta de forma conveniente nas 


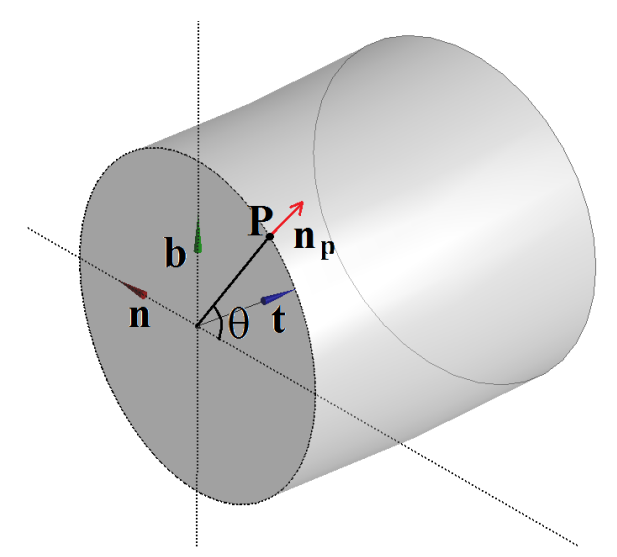

Figura A.12: Vetor normal à superfície do torus

direções do triedro de Frenet, tal que:

$$
\boldsymbol{g}=g_{t} \boldsymbol{t}+g_{n} \boldsymbol{n}+g_{b} \boldsymbol{b}
$$

Seja o ponto $O$ o centro do elemento infinitesimal de riser (ponto que pertence à elastica) e $P$, um ponto qualquer sobre a superfície do torus, de tal forma que:

$$
(P-O)=-r_{e} \cos \theta \boldsymbol{n}+r_{e} \operatorname{sen} \theta \boldsymbol{b}
$$

Denominando a altura da coluna de água do ponto $O$ por $h_{o}$, a altura da coluna de água em um ponto genérico $P$ é dada por:

$$
h(P)=h_{o}+(P-O) \cdot\left(\frac{\boldsymbol{g}}{\|\boldsymbol{g}\|}\right)
$$

Utilizando-se da cota de um ponto $P$ é possível calcular a pressão hidrostática, bem como a força proveniente da ação dessa pressão em um elemento de área infinitesimal na superfície do torus. A pressão $p$ é dada por:

$$
p=\rho_{e}\|\boldsymbol{g}\| h(P)
$$

A força infinitesimal sobre o elemento de área $d A$ é dada por: 


$$
d \boldsymbol{f}=-p d A \boldsymbol{n}=-\rho_{e}\|\boldsymbol{g}\|\left[h_{o}+(P-O) \cdot\left(\frac{\boldsymbol{g}}{\|\boldsymbol{g}\|}\right)\right] \boldsymbol{n}_{\boldsymbol{p}} d A
$$

A expressão A.14 se simplifica para:

$$
d \boldsymbol{f}=-\rho_{e}\left(h_{o}\|\boldsymbol{g}\|+(P-O) \cdot \boldsymbol{g}\right) \boldsymbol{n}_{\boldsymbol{p}} d A
$$

Sendo $g_{n}$ e $g_{b}$ as componentes da aceleração da gravidade nas direções normal principal e binormal, respectivamente, tem-se que:

$$
(P-O) \cdot \boldsymbol{g}=-r_{e} \cos \theta g_{n}+r_{e} \operatorname{sen} \theta g_{b}
$$

A partir da expressão vetorial para as forças elementares em um elemento de área $d A$, é possível obter três expressões escalares para o cálculo do esforço devido à pressão externa em um ponto $P$ :

$$
\begin{aligned}
& d f_{t}=0 \\
& d f_{n}=\rho_{e} r_{e}\left(h_{o} g+r_{e} \operatorname{sen} \theta g_{b}-r_{e} \cos \theta g_{n}\right)\left(R+r_{e} \cos \theta\right) \cos \theta d \theta d \alpha \\
& d f_{b}=-\rho_{e} r_{e}\left(h_{o} g+r_{e} \operatorname{sen} \theta g_{b}-r_{e} \cos \theta g_{n}\right)\left(R+r_{e} \cos \theta\right) \operatorname{sen} \theta d \theta d \alpha
\end{aligned}
$$

Desenvolvendo os termos das equações A.17, obtém-se as seguintes expressões:

$$
\begin{aligned}
& d f_{t}=0 \\
& d f_{n}=\rho_{e} r_{e}\left[h_{o} g R \cos \theta+h_{o} g r_{e} \cos ^{2} \theta+r_{e} R \operatorname{sen} \theta \cos \theta g_{b}+\right. \\
& \left.+r_{e}^{2} g_{b} \operatorname{sen} \theta \cos ^{2} \theta-r_{e} R g_{n} \cos ^{2} \theta-r_{e}^{2} g_{n} \cos ^{3} \theta\right] d \theta d \alpha \\
& d f_{b}=-\rho_{e} r_{e}\left[h_{o} g R \operatorname{sen} \theta+h_{o} g r_{e} \operatorname{sen} \theta \cos \theta+r_{e} R \operatorname{sen}^{2} \theta g_{b}+\right. \\
& \left.+r_{e}^{2} g_{b} \operatorname{sen}^{2} \theta \cos \theta-r_{e} R g_{n} \operatorname{sen} \theta \cos \theta-r_{e}^{2} g_{n} \operatorname{sen} \theta \cos ^{2} \theta\right] d \theta d \alpha
\end{aligned}
$$

Integrando-se as expressões A.18 na variável $\theta$, no intervalo $[0,2 \pi]$, obtém-se: 


$$
\begin{aligned}
& \int_{\theta} d f_{t}=0 \\
& \int_{\theta} d f_{n}=\rho_{e} \pi r_{e}^{2}\left(h_{o} g-R g_{n}\right) d \alpha \\
& \int_{\theta} d f_{b}=\rho_{e} \pi r_{e}^{2} R g_{b} d \alpha
\end{aligned}
$$

Realizando a mudança de variável: $d s=R d \alpha$, é possível chegar em expressões para o cálculo das forças, dessa vez em função do elemento infinitesimal $d s$, e não $d \alpha$ :

$$
\begin{aligned}
& d f_{t}=0 \\
& d f_{n}=\rho_{e} \pi r_{e}^{2}\left(\frac{h_{o} g}{R}-g_{n}\right) d s \\
& d f_{b}=-\rho_{e} \pi r_{e}^{2} g_{b} d s
\end{aligned}
$$

As equações representadas em A.20 são bastante úteis para o cálculo do esforço da pressão externa sobre risers. Trata-se de um carregamento sempre ortogonal à elastica. Pode-se integrar essas expressões em relação à abscissa curvilínea $s$, sendo esse procedimento bastante conveniente para a implementação em elementos finitos, sendo que a integração em $s$ pode ser facilmente feita utilizando-se a quadratura gaussiana. As expressões A.20 mostram que a contribuição de força transversal devida à pressão hidrostática externa sobre um riser possui duas componentes: normal principal e binormal. Na direção normal principal aparece um efeito que é proporcional à curvatura, adicionado a um efeito que é proporcional à componente da aceleração da gravidade na direção normal à seção do riser. Na direção binormal surge apenas o efeito que é proporcional à componente da aceleração da gravidade na direção binormal. A decomposição da aceleração da gravidade nas equações A.20 mostra que a integração da pressão sobre um riser com as paredes externas submersas possui dois tipos de contribuição:

1.Devido à inclinação do riser: efeito que surge pelas componentes do $\boldsymbol{g}$ nas direções normal principal e binormal. Se o alinhamento do riser for tal que a aceleração da gravidade for totalmente em sua direção tangencial, esse efeito se torna nulo. Essa situação ocorre quanto o riser se encontra na vertical. Essa conclusão é bastante intuitiva, uma vez em tal situação todo o carregamento se torna axi-simétrico, com resultante transversal nula. 
2.Devido à curvatura do riser: efeito que surge devido à resultante não nula da integração da pressão na parede externa de um riser curvo. Nitidamente surge uma resultante em cada ponto, na direção normal. Nesse termo aparece a contribuição da altura $h_{o}$ do ponto central da seção considerada na integração e da aceleração da gravidade. No fundo esse resultado pode ser generalizado inclusive para uma pressão constante na parte externa de um riser, não se limitando a quando há variações da pressão com a profundidade. O efeito da variação de profundidade promove variações adicionais nesse carregamento ao longo de diferentes seções transversais do riser mas, a razão de sua ocorrência é pelo efeito da curvatura existente em cada seção.

As expressões A.20 são muito simples do ponto de vista algébrico, no entanto no contexto de implementação em termos de carregamento em um problema resolvido através do Método dos Elementos Finitos essas expressões representam não-linearidades do carregamento, uma vez que dependem do raio de curvatura de cada ponto do riser. Esse valor não é conhecido a priori para uma análise estática global de uma linha de riser. Em cada posição do riser a curvatura pode ser diferente. Essas expressões devem ser re-calculadas durante as iterações de uma rotina não linear até que haja convergência.

Em termos computacionais, expressões escritas em um sistema de coordenadas global para a integração das equações A.20 em $s$ podem ser muito úteis, assumindo-se que se saiba a priori (ou ao menos no início de cada iteração) as direções de Frenet. Assume-se que se possa escrever as direções normal e binormal da seguinte forma:

$$
\begin{aligned}
& \boldsymbol{n}(s)=\left(n_{x}, n_{y}, n_{z}\right) \\
& \boldsymbol{b}(s)=\left(b_{x}, b_{y}, b_{z}\right)
\end{aligned}
$$

Assim sendo o carregamento proveniente da integração da pressão sobre a parede externa de um riser é dado, em coordenadas cartesianas globais, pelo vetor $\boldsymbol{f}=$ $\left(f_{x}, f_{y}, f_{z}\right)$, tal que: 


$$
\begin{aligned}
& f_{x}=\rho_{e} \pi r_{e}^{2} \int_{s}\left[\left(\frac{h_{o}(s) g}{R(s)}-g_{n}(s)\right) n_{x}(s)-g_{b}(s) b_{x}(s)\right] d s \\
& f_{y}=\rho_{e} \pi r_{e}^{2} \int_{s}\left[\left(\frac{h_{o}(s) g}{R(s)}-g_{n}(s)\right) n_{y}(s)-g_{b}(s) b_{y}(s)\right] d s \\
& f_{z}=\rho_{e} \pi r_{e}^{2} \int_{s}\left[\left(\frac{h_{o}(s) g}{R(s)}-g_{n}(s)\right) n_{z}(s)-g_{b}(s) b_{z}(s)\right] d s
\end{aligned}
$$

\section{A.5 Carregamento da pressão interna sobre um riser}

No desenvolvimento da seção anterior, deduziram-se expressões para o cálculo de forças devido ao efeito da pressão hidrostática externa. Agora, na consideração da pressão do fluido interno, o equacionamento é bastante semelhante, com apenas algumas modificações. Em primeiro lugar, por hipótese será considerado que a pressão aplicada a um certo ponto $P$ localizado sobre a parede interna de um riser é dada pela seguinte expressão:

$$
p=\rho_{i}\|\boldsymbol{g}\| h(P)+p_{p}
$$

$\mathrm{Na}$ equação A.23 $\rho_{i}$ é a massa específica do fluido que se encontra na parte interna do riser, $h(P)$ é o valor da coluna de fluido interno que se localiza acima da cota do ponto $P$, e $p_{p}$ representa o valor da pressurização do fluido além da pressão hidrostática existente. $\mathrm{O}$ valor de $p_{p}$ deve variar ao longo da linha do riser e da posição dentro da seção transversal de análise. No entanto, uma possível aproximação para seu comportamento é assumir que é constante em cada seção transversal, podendo ser escrito apenas como uma função de $s$. Assim sendo, $p_{p}$ não mais será utilizado a partir de agora, mas será adotada a hipótese da função $p_{o}(s)$ para representar essa grandeza (para simplificar a notação, será por hora representada apenas por $p_{o}$ ). Se a equação A.14 for modificada incluindo esse efeito, invertendo-se o sinal da força (que agora é devida à pressão interna) e substituindo o raio externo $r_{e}$ do riser, pelo raio interno $r_{i}$, ela poderá ser escrita da seguinte forma:

$$
d \boldsymbol{f}=\left\{\rho_{i}\|\boldsymbol{g}\|\left[h_{o}+(P-O) \cdot\left(\frac{\boldsymbol{g}}{\|\boldsymbol{g}\|}\right)\right]+p_{o}\right\} \boldsymbol{n}_{\boldsymbol{p}} d A
$$

A partir da expressão A.24, o procedimento apresentado nas equações do efeito da pressão externa pode ser feito de forma totalmente análoga, resultando nas seguintes 
equações para as forças devidas à pressão interna:

$$
\begin{aligned}
& d f_{t}=0 \\
& d f_{n}=-\frac{\pi r_{i}^{2}}{R}\left(\rho_{i} g h_{o}+p_{o}\right) d s+\rho_{i} \pi r_{i}^{2} g_{n} d s \\
& d f_{b}=\rho_{i} \pi r_{i}^{2} g_{b} d s
\end{aligned}
$$

A pressurização adicional à pressão hidrostática da linha $\left(p_{o}\right)$ pode ser constante ou variável em função de $s$. Considerando-se a extração de petróleo do fundo do mar para a superfície, para promover o escoamento é necessário que a linha possua um valor de pressurização. No entanto, podem ocorrer fenômenos do tipo "golfada severa" que promoveriam transientes na pressurização ao longo da abscissa $s$, tornando o valor de $p_{o}$ variável. O equacionamento apresentado em A.25 pode tratar tanto valores de pressurização constante como variável.

\section{A.6 Expressões para carregamentos de pressão interna e externa combinadas}

Juntado-se os efeitos das expressões desenvolvidas para cálculo dos esforços em risers devidos às pressões externa e interna, chega-se às seguintes equações combinadas:

$$
\begin{aligned}
& d f_{t}=0 \\
& d f_{n}=\left[\frac{\pi}{R(s)}\left(g h_{o}(s) \rho_{e} r_{e}^{2}-g h_{o}(s) \rho_{i} r_{i}^{2}-p_{o} r_{i}^{2}\right) d s+\pi g_{n}\left(-\rho_{e} r_{e}^{2}+\rho_{i} r_{i}^{2}\right)\right] d s \\
& d f_{b}=\pi g_{b}\left(-\rho_{e} r_{e}^{2}+\rho_{i} r_{i}^{2}\right) d s
\end{aligned}
$$

Realizando a projeção das forças em um sistema de coordenadas global cartesiano, assim como feito nas equações A.22 para as contribuições da pressão externa, para a contribuição combinada da pressão interna e externa as expressões ficam da seguinte forma: 


$$
\begin{aligned}
f_{x}= & \int_{s}\left\{\left[\frac{\pi}{R(s)}\left(g h_{o}(s) \rho_{e} r_{e}^{2}-g h_{o}(s) \rho_{i} r_{i}^{2}-p_{o} r_{i}^{2}\right)+\right.\right. \\
& \left.\left.+\pi g_{n}\left(-\rho_{e} r_{e}^{2}+\rho_{i} r_{i}^{2}\right)\right] n_{x}(s)+\pi g_{b}\left(-\rho_{e} r_{e}^{2}+\rho_{i} r_{i}^{2}\right) b_{x}(s)\right\} d s \\
f_{y}= & \int_{s}\left\{\left[\frac{\pi}{R(s)}\left(g h_{o}(s) \rho_{e} r_{e}^{2}-g h_{o}(s) \rho_{i} r_{i}^{2}-p_{o} r_{i}^{2}\right)+\right.\right. \\
& \left.\left.+\pi g_{n}\left(-\rho_{e} r_{e}^{2}+\rho_{i} r_{i}^{2}\right)\right] n_{y}(s)+\pi g_{b}\left(-\rho_{e} r_{e}^{2}+\rho_{i} r_{i}^{2}\right) b_{y}(s)\right\} d s \\
f_{z}= & \int_{s}\left\{\left[\frac{\pi}{R(s)}\left(g h_{o}(s) \rho_{e} r_{e}^{2}-g h_{o}(s) \rho_{i} r_{i}^{2}-p_{o} r_{i}^{2}\right)+\right.\right. \\
& \left.\left.+\pi g_{n}\left(-\rho_{e} r_{e}^{2}+\rho_{i} r_{i}^{2}\right)\right] n_{z}(s)+\pi g_{b}\left(-\rho_{w} r_{w}^{2}+\rho_{i} r_{i}^{2}\right) b_{z}(s)\right\} d s
\end{aligned}
$$

As equações A.27 são para implementação direta em um programa de elementos finitos, uma vez que de modo geral para uma rotina desse tipo adota-se um sistema de coordenadas global para todas as forças a serem incluídas no cálculo.

\section{A.7 O conceito de tração efetiva}

As expressões desenvolvidas anteriormente tratam os carregamentos das pressões externa e interna da forma que, de fato, são aplicadas no problema físico. Permitem considerar os efeitos de pressões em uma análise global de um riser, sendo que o esforço de tração que resulta após a solução do problema é naturalmente a tração solicitante em cada seção transversal analisada.

Existe uma outra forma de abordar o carregamento da pressão nas paredes do riser sem utilizar as fórmulas A.27: através da construção de sistemas de forças equivalentes, é possível tratar o problema através da abordagem de peso efetivo e tração efetiva.

A Figura A.13 ilustra três sistemas de forças, sendo que o primeiro é dado pela pressão lateral do fluido no trecho do riser e pelo peso próprio do mesmo. Trata-se do sistema atuante no problema físico.

É possível construir dois sistemas de forças cuja soma seja equivalente ao original. A Figura A.13 mostra esses dois sistemas sendo:

1.Pressão externa equivalente ao riser totalmente imerso no fluido (empuxo sobre o corpo submerso) + peso próprio do trecho considerado. Esse sistema corresponde 

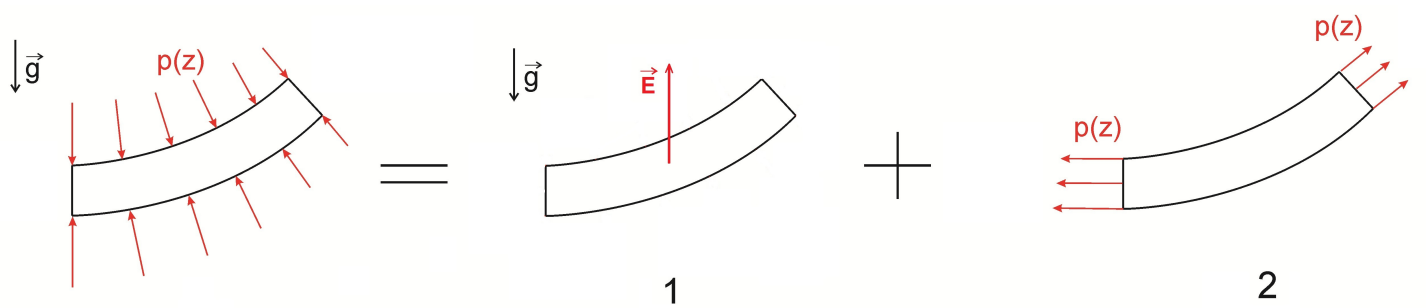

Figura A.13: Pressão hidrostática externa e peso próprio da estrutura do riser

ao chamado peso imerso, ou peso efetivo do riser;

2.Trações adicionais aplicadas nas seções transversais de corte, equivalentes à pressão externa mas com sentido oposto. Esse sistema redefine a tração do problema, doravante chamada de tração efetiva, sendo a soma da tração solicitante e do efeito adicional devido à pressão hidrostática, a fim de manter a equivalência mecânica de sistemas de força.

Essa estratégia permite descrever o problema considerando o empuxo como se o riser estivesse totalmente imerso, incluindo suas seções extremas, porém aplicando uma correção no valor da tração obtida nessa solução, a fim de obter a tração solicitante correta. Seja $\pi r_{e}^{2}$ a área da seção transversal externa em um corte do riser, cuja tração solicitante é dada por $T(s)$. A tração atuante no riser, proveniente de uma solução estática considerando-se o peso efetivo (ou seja, considerando como se todo o riser estivesse mergulhado nas águas do mar, inclusive as "tampas" das seções transversais de corte), denominada "tração efetiva" $T_{e f}$ é dada por:

$$
T_{e f}(s)=T(s)+p(z) \pi r_{e}^{2}
$$

A pressão $p(z)$ corresponde à pressão hidrostática na cota $z$ em que se encontra a seção transversal analisada.

A equivalência mecânica explorada na Figura A.13 pode ser obtida analiticamente com algumas manipulações algébricas aplicadas às expressões A.20. De fato, tomando-as e escrevendo-as em uma única equação vetorial obtém-se:

$$
\frac{d \boldsymbol{f}}{d s}=\rho_{e} \pi r_{e}^{2} g h(s) \frac{1}{R(s)} \boldsymbol{n}-\rho_{e} \pi r_{e}^{2}\left(g_{n} \boldsymbol{n}+g_{b} \boldsymbol{b}\right)
$$


Com o objetivo de determinar a resultante da pressão externa $\boldsymbol{f}_{d s}$ aplicada em um elemento infinitesimal de comprimento $d s$, pode-se integrar a equação A.29 ao longo do comprimento $s$ obtendo:

$$
\boldsymbol{f}_{d s}=\int_{s}^{s+d s} \frac{d \boldsymbol{f}}{d s}=\int_{s}^{s+d s} \rho_{e} \pi r_{e}^{2} g h(s) \frac{1}{R(s)} \boldsymbol{n} d s-\int_{s}^{s+d s} \rho_{e} \pi r_{e}^{2}\left(g_{n} \boldsymbol{n}+g_{b} \boldsymbol{b}\right) d s
$$

O primeiro termo pode ser desenvolvido utilizando-se de uma relação de Frenét (ver Apêndice B), tal que:

$$
\int_{s}^{s+d s} \rho_{e} \pi r_{e}^{2} g h(s) \frac{1}{R(s)} \boldsymbol{n} d s=\int_{s}^{s+d s} \rho_{e} \pi r_{e}^{2} g h(s) \frac{d \boldsymbol{t}}{d s} d s=\rho_{e} \pi r_{e}^{2} g \int_{s}^{s+d s} h(s) \frac{d \boldsymbol{t}}{d s} d s
$$

Utilizando integração por partes obtém-se:

$$
\rho_{e} \pi r_{e}^{2} g \int_{s}^{s+d s} h(s) \frac{d \boldsymbol{t}}{d s} d s=\rho_{e} \pi r_{e}^{2} g\left\{[h(s) \boldsymbol{t}]_{s}^{s+d s}-\int_{s}^{s+d s} \frac{d h(s)}{d s} \boldsymbol{t} d s\right\}
$$

Por sua vez, $\frac{d h(s)}{d s}=\frac{\boldsymbol{g} \cdot \boldsymbol{t}}{g}=\frac{g_{t}}{g}$. Assim, tem-se:

$$
\begin{aligned}
& \rho_{e} \pi r_{e}^{2} g \int_{s}^{s+d s} h(s) \frac{d \boldsymbol{t}}{d s} d s= \\
& =\rho_{e} \pi r_{e}^{2} g h(s+d s) \boldsymbol{t}(s+d s)-\rho_{e} \pi r_{e}^{2} g h(s) \boldsymbol{t}(s)-\rho_{e} \pi r_{e}^{2} \int_{s}^{s+d s} g_{t} \boldsymbol{t} d s
\end{aligned}
$$

O segundo termo da equação A.30 pode ser desenvolvido por:

$$
-\int_{s}^{s+d s} \rho_{e} \pi r_{e}^{2}\left(g_{n} \boldsymbol{n}+g_{b} \boldsymbol{b}\right) d s=-\int_{s}^{s+d s} \rho_{e} \pi r_{e}^{2} \boldsymbol{g}+\rho_{e} \pi r_{e}^{2} \int_{s}^{s+d s} g_{t} \boldsymbol{t} d s
$$

Em A.34 o resultado da integral $-\int_{s}^{s+d s} \rho_{e} \pi r_{e}^{2} \boldsymbol{g}=-\rho_{e} \pi r_{e}^{2} \boldsymbol{g} d s$ é o empuxo que o corpo sofreria se estivesse com o campo de pressão em toda a sua superfície externa, incluindo as "tampas" de fechamento axial.

Por fim, conclui-se a equivalência mecânica que foi utilizada para definir a tração efetiva: 


$$
\boldsymbol{f}_{d s}=\rho_{e} \pi r_{e}^{2} g h(s+d s) \boldsymbol{t}(s+d s)-\rho_{e} \pi r_{e}^{2} g h(s) \boldsymbol{t}(s)-\rho_{e} \pi r_{e}^{2} \boldsymbol{g} d s
$$

O conceito de tração efetiva pode ser generalizado para incluir além do efeito da pressão externa, também a pressão interna, não considerada originalmente na expressão A.28. Sparks (1984) desenvolve o conceito de tração efetiva incluindo o efeito da pressão interna, através de uma figura semelhante à A.13. O efeito da pressão interna surge tanto na correção da tração efetiva (modificando a equação A.28), quanto no valor do peso efetivo a ser considerado, que deve incluir o peso do fluido interno ao riser como um adendo ao peso efetivo anteriormente definido. Dessa forma, redefinimos de maneira mais geral o conceito de peso efetivo como sendo: peso de um riser dentro da água, completamente imerso, somado ao peso de seu fluido interior. A equação A.36 mostra como incluir o efeito da pressão interna no cálculo da tração efetiva, dada a área da seção interna do riser por $\pi r_{i}^{2}$.

$$
T_{e f}(s)=T(s)+p(z) \pi r_{e}^{2}-p_{i}(z) \pi r_{i}^{2}
$$

A definição de peso efetivo por unidade de comprimento do riser $\gamma_{e f}$ é feita com posse do peso do riser vazio em ar $\gamma_{a r}$, massa específica do fluido externo $\rho_{e}$ e do fluido interno $\rho_{i}$ :

$$
\gamma_{e f}=\gamma_{a r}+\rho_{i} g \pi r_{i}^{2}-\rho_{e} g \pi r_{e}^{2}
$$

O valor do peso efetivo é afetado pelas massas específicas dos fluidos interno e externo ao riser, no entanto não se modifica com a magnitude da pressão hidrostática exercida, mas somente é sensibilizado pelo seu gradiente. Isso é facilmente verificado para o cenário de um objeto de volume constante imerso em um fluido. O empuxo exercido sobre o objeto é exatamente o mesmo, seja qual for a profundidade de sua imersão. No entanto, como pode ser observado na equação A.36, a tração efetiva é afetada pela magnitude da pressão externa e interna, além da tração solicitante. O desenvolvimento feito nas expressões A.29 a A.35 para ilustrar de maneira algébrica a definição de tração efetiva para o caso com pressão externa pode ser facilmente generalizado utilizando-se da integração da expressão A.26 em um elemento infinitesimal de comprimento $d s$, auxiliando 
a interpretação das expressões A.36 e A.37.

Como exemplo de aplicação do conceito de tração efetiva, um procedimento muito utilizado é, ao analisar um riser submerso, considerar seu peso efetivo para o cálculo dos esforços presentes no problema (determinando, portanto, a tração efetiva) e determinar posteriormente, através da equação A.36, a tração solicitante. Surgiria naturalmente a seguinte pergunta: a utilização do peso efetivo para o cálculo estrutural altera os esforços solicitantes, como os momentos e forças cortantes presentes, ou somente a tração? Sparks (1984) afirma que para todos os casos mais complicados do que um cilindro uniforme, é mais simples utilizar o peso aparente (ou peso efetivo) do tubo ou riser, somado ao peso de seu conteúdo interno, e a correspondente tração efetiva para o cálculo da curvatura e deflexões de um tubo ou riser. O autor ainda afirma que esse procedimento é válido para todo fenômeno que envolva a flexão, incluindo a flambagem do riser. Sparks (1984) afirma que os outros esforços solicitantes (a menos da tração) não são alterados por essa abordagem, nem a curvatura no riser analisado. Assim, a utilização do peso efetivo e posterior correção da tração através da fórmula A.36 para a determinação da tração solicitante se mostra como uma alternativa bastante interessante e simples para o cálculo dos esforços em um riser, quando comparada à integração da pressão nas paredes externas do mesmo.

No entanto, alguns cuidados devem ser tomados quando se considera o peso efetivo no cálculo da elastica de um riser. Conforme dito anteriormente, a magnitude da pressão não afeta o cálculo do peso efetivo, mas pode alterar o valor da tração efetiva. Como garantir que a utilização do peso efetivo implicará na tração efetiva correta? Para melhor explicar tal pergunta, seja o seguinte exemplo:

Um cilindro vertical com área de seção $A$ se encontra fixo no fundo do mar como ilustrado na Figura A.14. Nesse problema a pressão desempenha um papel que não causa mudanças na tração solicitante, uma vez que é um carregamento axi-simétrico. É possível deduzir, assumindo o problema como estático, a equação diferencial que relaciona a tensão normal que surge devido à tração no cilindro, com um carregamento distribuído $f$ aplicado ao longo de sua direção axial $x$ :

$$
A \frac{d \sigma}{d x}+f=0
$$

A integração dessa equação diferencial leva à seguinte expressão para a distribui- 


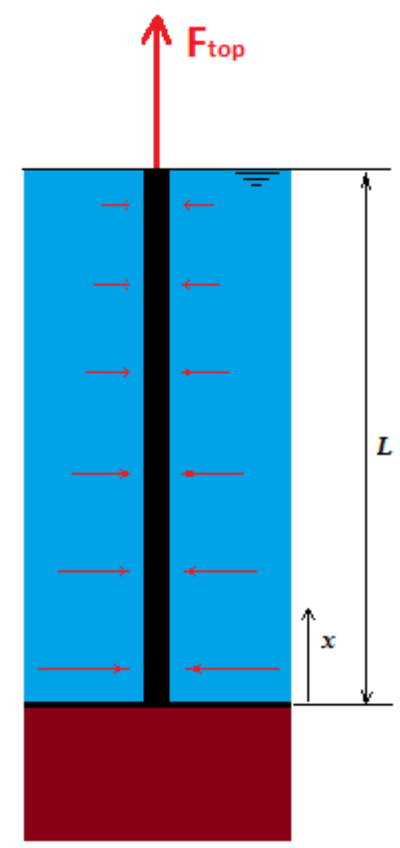

Figura A.14: Exemplo de um cilindro vertical para discussão sobre o conceito de tração efetiva

ção de tensão normal ao longo do cilindro:

$$
\sigma(x)=-\frac{f}{A} x+C_{0}
$$

$C_{0}$ uma constante de integração determinável a partir das condições de contorno. Multiplicando a expressão por A.39 por $A$, obtém-se a seguinte expressão para a distribuição de tração ao longo do cilindro:

$$
T(x)=-f x+T_{0}
$$

A equação A.40 possui um termo $T_{0}$, que deve ser determinado a partir das condições de contorno do problema. A partir desse ponto, é possível seguir com duas diferentes abordagens: utilizar o peso efetivo e a tração efetiva como condição de contorno ou, utilizar o peso real e a tração real como condição de contorno. Denominando $\gamma$ o peso por unidade de comprimento do cilindro, medido fora da água e, $\gamma_{e f}$ o peso efetivo, também por unidade de comprimento. Vale a relação: 


$$
\gamma=\rho A g+\gamma_{e f}
$$

Pode-se escrever as seguintes expressões para a tração real e efetiva:

$$
\begin{gathered}
T(x)=F_{\text {top }}+\gamma(x-L) \\
T_{e f}(x)=F_{t o p}+\gamma_{e f}(x-L)
\end{gathered}
$$

De fato se, em vez de escrever diretamente a expressão A.43, fosse utilizada a expressão A.42 e a correção aplicada pela equação A.28 para a determinação da tração efetiva, seria verificado o mesmo resultado.

Propõe-se agora uma alteração no problema: em vez de o cilindro estar com sua extremidade superior na superfície do líquido como considerado até então, o mesmo está imerso e possui uma bóia que realiza em sua extremidade superior um esforço de empuxo que vale exatamente $F_{\text {top }}$. A Figura A.15 mostra o cenário proposto.

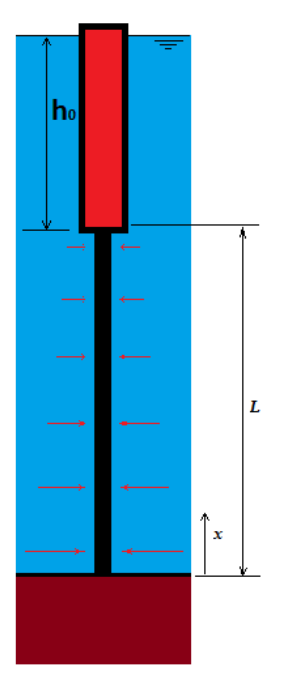

Figura A.15: Exemplo de um cilindro vertical para discussão sobre o conceito de tração efetiva. Inclusão de uma bóia no problema anterior.

Nessa situação, espera-se que os esforços solicitantes de tração no problema sejam exatamente iguais ao do primeiro exemplo, sendo portanto dados pela equação A.42. No 
entanto, devido à imersão adicional do cilindro de uma cota $h_{0}$ em relação à superfície de líquido, é esperada uma mudança na tração efetiva do problema, uma vez que os valores de pressão externa atuantes no segundo exemplo são maiores do que no primeiro. A mesma passará a ser acrescida do valor da pressão hidrostática do topo do cilindro (base da bóia) multiplicada pela área da seção do cilindro $A$. Esse efeito vem justamente do acréscimo de pressão em todo o domínio em relação ao cenário anterior, em que o topo estaria na superfície do líquido:

$$
T_{e f}(x)=F_{t o p}+\gamma_{e f}(x-L)+\rho g h_{0} A
$$

Enfatiza-se que nesse segundo exemplo se está considerando que a pressão no topo do cilindro (base da bóia) não é aplicada ao fechamento superior do cilindro (end cap). Se assim fosse, seu papel alteraria os esforços solicitantes de tal modo que a tração efetiva seria exatamente a mesma do primeiro exemplo.

Note que os exemplos anteriores mostram que a simples utilização do peso efetivo não implica na obtenção do campo de trações efetivas na solução de certo modelo. É necessário ter cuidado com os efeitos de fechamentos (end cap) pois, se os mesmos existem, poderão alterar a tração solicitante. Em problemas de risers é bastante comum que uma das extremidades do domínio esteja localizada em um ponto cuja pressão é nula (acima da lâmina d'água). Nessa situação a utilização do peso efetivo implicará na obtenção da tração efetiva.

O efeito da pressão interna possui, de forma análoga, uma conclusão semelhante: ao considerar o peso efetivo em uma análise de um riser com fluido interno pressurizado, a tração que resultará somente será, de fato, a tração efetiva, se houver fechamentos (end caps) no riser. Caso não haja, ocorrerá o mesmo que foi mostrado para a pressão externa nos exemplos anteriores: o valor da tração calculada não será a efetiva. Em situações em que não há fechamentos (end caps), na expressão A.36 a contribuição de um aumento de pressão interna será na diminuição da tração efetiva. Se houver interesse em determinar o campo de tração efetiva em um riser com pressurização interna além da pressão hidrostática do fluido interno, certamente essa distribuição de tração possuirá valores inferiores aos obtidos considerando-se somente o peso efetivo. Isso pode ser importante no caso de análises de estabilidade estrutural que envolvam pressurização interna em tubulações. Esse assunto será discutido a seguir. 


\section{A.8 Tração efetiva e estabilidade estrutural}

A influência da pressão interna e externa na estabilidade da configuração de um tubo pode ser verificada na equação A.26. Essa influência surge pelo fato de haver termos dependentes da curvatura do riser. Note que a pressão interna promove um esforço transversal instabilizador, portanto causando um aumento da curvatura. Deve-se imaginar que exista um valor de pressão interna crítica a partir da qual um tubo reto se torna instável.

No Apêndice C discute-se a flambagem de Euler de uma viga bi-apoiada através da equação C.6. Na dedução, considera-se apenas o efeito de uma força compressiva ao longo da viga. Se desejarmos incluir o efeito da pressão externa e interna, ao realizar um corte em uma seção transversal da viga, as contribuições recairiam no mesmo termo em que aparece a força compressiva na equação diferencial. Portanto, a solução da equação possui dependência não somente em relação à tração solicitante, mas também às pressões externa e interna. Ao incluir o efeito da pressão externa e interna de um riser vertical na equação diferencial do problema da flambagem de Euler, com as devidas correções de sinais, a mesma toma a seguinte forma:

$$
\frac{d^{2}}{d x^{2}}\left(E I(x) \frac{d^{2} w(x)}{d x^{2}}\right)+\frac{d}{d x}\left[\left(-T(s)-p(z) \pi r^{2}+p_{i}(z) \pi r_{i}^{2}\right) \frac{d w(x)}{d x}\right]=v(x)
$$

O termo da força compressiva da equação A.45 determina a topologia da solução da equação diferencial. A forma dessa solução possui implicação direta na interpretação da análise de estabilidade da estrutura. O termo da força compressiva é dado pela tração efetiva com seu sinal invertido. Infere-se, analogamente, que para uma geometria mais genérica como um riser em catenária, o termo que domina a estabilidade, com relação à tração ou compressão, é dado também pela tração efetiva (ver Sparks (2007), onde se apresenta uma discussão mais detalhada sobre o assunto).

Um trabalho que fala sobre o assunto é o de Fyrileiv e Collberg (2005), que trata especificamente sobre a tração efetiva em risers, suas dificuldades conceituais no contexto da indústria offshore e sua aplicação em normas. Os autores destacam a importância de tratar a tração efetiva em problemas de risers, uma vez que essa governa a resposta estrutural. A resposta estrutural compreende a distribuição de rigidez da estrutura, estabilidade estática da mesma e propriedades dinâmicas como frequências naturais e modos de vibrar. 
Portanto, para realizar uma análise estrutural de estabilidade da configuração global de um riser, deve-se avaliar a estrutura através de sua tração efetiva e, dessa forma, os efeitos das pressões externa e interna já estarão contabilizados do ponto de vista de esforços globais na estrutura. No entanto, a observação feita no ítem anterior acerca de problemas que apresentem pressurização interior ao riser sem end cap deve ser tratada com particular cuidado. Para analisar um riser com pressurização interna e sem efeito de end cap seria possível seguir duas diferentes abordagens:

-Utilizar o peso efetivo: calcular a elastica considerando-se o peso efetivo e, posteriormente, subtrair do campo de tração obtido o valor da pressurização interna ao riser multiplicada pela área interna $p_{o} \pi r_{i}^{2}$, prevendo dessa forma a tração efetiva ao longo do riser. Através dessa distribuição de tração seria possível estimar o local de ocorrência de tração efetiva mínima, mas haveria dificuldade em calcular qual o nível crítico de tração efetiva, misturado aos outros carregamentos e à geometria do problema.

-Utilizar o peso real: calcular a elastica considerando-se o peso real e, para tratar o efeito da pressão, considerar as expressões desenvolvidas no ítem A.6 no cálculo estrutural. Através dessa abordagem, a tração determinada na estrutura será a solicitante. No entanto, os carregamentos de pressão externa e interna atuarão de forma a induzir a flambagem da estrutura se o nível de pressurização for crítico, permitindo não somente a obtenção da carga crítica, mas também a configuração pós-crítica, incluindo as não linearidades geométricas presentes no problema, de acordo com a teoria estrutural considerada. Após a solução, pode-se calcular a tração efetiva a partir da solicitante que resulta dessa metodologia e verificar qual o nível de tração efetiva que induziu a flambagem.

Ao final desse capítulo será exibido um estudo de caso que mostra como obter a carga crítica de flambagem para o problema de uma viga com pressurização interna.

A fim de compreender os efeitos das pressões externa e interna em um riser é necessário considerar a estrutura em seu estado triplo de tensões. Assim, é possível utilizar-se de equações para vasos de pressão cilíndricos (de parede espessa) para mostrar que ao utilizar o peso efetivo e a tração efetiva em um modelo de riser, como o desenvolvido nesse trabalho, se está fazendo uma aproximação quanto ao coeficiente de Poisson. Utilizando-se as fórmulas presentes em Young e Budynas (2002), é possível equacionar as tensões presentes em uma seção transversal submetida à tração solicitante $T_{s}$ em um tubo 
pressurizado externa $\left(p_{e}\right)$ e internamente $\left(p_{i}\right)$ :

$$
\begin{array}{r}
\sigma_{r}=\frac{\left(p_{e}-p_{i}\right) r_{e}^{2} r_{i}^{2}+r^{2}\left(p_{i} r_{i}^{2}-p_{e} r_{e}^{2}\right)}{r^{2}\left(r_{e}^{2}-r_{i}^{2}\right)} \\
\sigma_{\theta}=\frac{\left(p_{i}-p_{e}\right) r_{e}^{2} r_{i}^{2}+r^{2}\left(p_{i} r_{i}^{2}-p_{e} r_{e}^{2}\right)}{r^{2}\left(r_{e}^{2}-r_{i}^{2}\right)} \\
\sigma_{z}=\frac{T_{s}}{\pi\left(r_{e}^{2}-r_{i}^{2}\right)}
\end{array}
$$

em que a coordenada $r$ representa a direção radial, ao longo da espessura do riser.

Supondo-se que o material seja isotrópico com Módulo de Young E e Coeficiente de Poisson $\nu$, seria possível utilizar-se da Lei de Hooke para calcular a deformação axial $\epsilon_{z}$, que se torna um valor constante para todos os pontos da seção transversal (considerando apenas o carregamento de tração e sem incluir no equacionamento os momentos fletores e forças cortantes):

$$
\epsilon_{z}=\frac{\sigma_{z}}{E}-\frac{\nu}{E}\left(\sigma_{r}+\sigma_{\theta}\right)=\frac{T_{s}}{E \pi\left(r_{e}^{2}-r_{i}^{2}\right)}-\frac{2 \nu}{E} \frac{\left(p_{i} r_{i}^{2}-p_{e} r_{e}^{2}\right)}{\left(r_{e}^{2}-r_{i}^{2}\right)}
$$

Ao utilizar em um modelo a abordagem de peso e tração efetivos, calculando-se a deformação axial do tubo por meio dessa tração, obtém-se a seguinte aproximação $\epsilon_{z}^{\prime}$ :

$$
\epsilon_{z}^{\prime}=\frac{T_{e f}}{E \pi\left(r_{e}^{2}-r_{i}^{2}\right)}=\frac{T_{s}+p_{e} \pi r_{e}^{2}-p_{i} \pi r_{i}^{2}}{E \pi\left(r_{e}^{2}-r_{i}^{2}\right)}
$$

Igualando-se as equações A.49 e A.50, conclui-se que, ao utilizar a tração efetiva para calcular a deformação axial de um riser, implicitamente se está assumindo que o coeficiente de Poisson é assumido com o valor $\nu=0,5$. Esse valor corresponderia a um material incompressível.

Dentro da complexidade presente em um cabo umbilical ou riser flexível, essa aproximação é bastante aceitável pois, a própria determinação do coeficiente de Poisson é complexa. No caso real, ainda, a estrutura é anisotrópica, não valendo a hipótese da Lei de Hooke aqui utilizada.

A próxima seção comentará os efeitos de fechamento do tubo, que só podem ser bem compreendidos desde que se imagine sempre o estado triplo de tensões. 


\section{A.9 Condições de contorno e efeitos de fechamento do tubo (end cap)}

As condições de contorno em que se encontram as extremidades de um tubo internamente pressurizado são de grande importância na questão de instabilidade estrutural, pois podem ocasionar estados de tensões completamente diferentes nas paredes do tubo, atenuando ou agravando o efeito instabilizador da pressão interna. Em Bazant e Cedolin (2003) esse tema é abordado através de dois exemplos, que serão a seguir descritos.

A Figura A.16 mostra um exemplo de configuração hiperestática de um tubo. Os vínculos em ambos os lados não permitem deslocamentos axiais do tubo. Assim, ao aplicar pressão interna, espera-se que o único tipo de esforço na direção axial do tubo seja proveniente da tendência de encurtamento do mesmo devido ao deslocamento radial (efeito de Poisson). Em outras condições de contorno o comportamento pode ser diferente. Por exemplo, a Figura A.17 mostra outra condição de contorno: a vinculação axial aplicada apenas de um dos lados. Dessa vez o vínculo não é solicitado com o carregamento da pressão interna e o tubo se encontra sob efeito de uma tensão de tração, cuja integral é exatamente $p_{i} A_{i}$, devido ao efeito do fechamento do tubo (end cap).

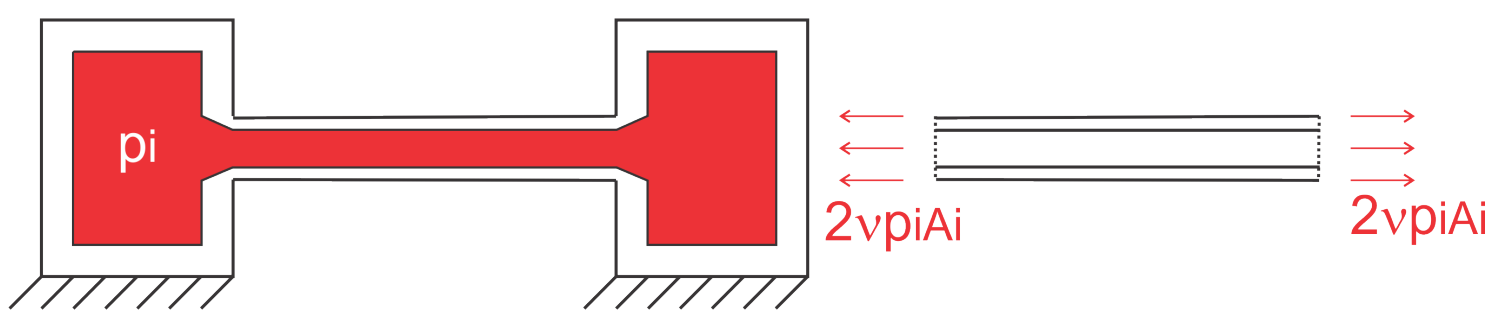

Figura A.16: Tubo sob pressão interna $p_{i}$ e fixo dos dois lados, de forma a surgirem tensões axiais devidas ao efeito de Poisson

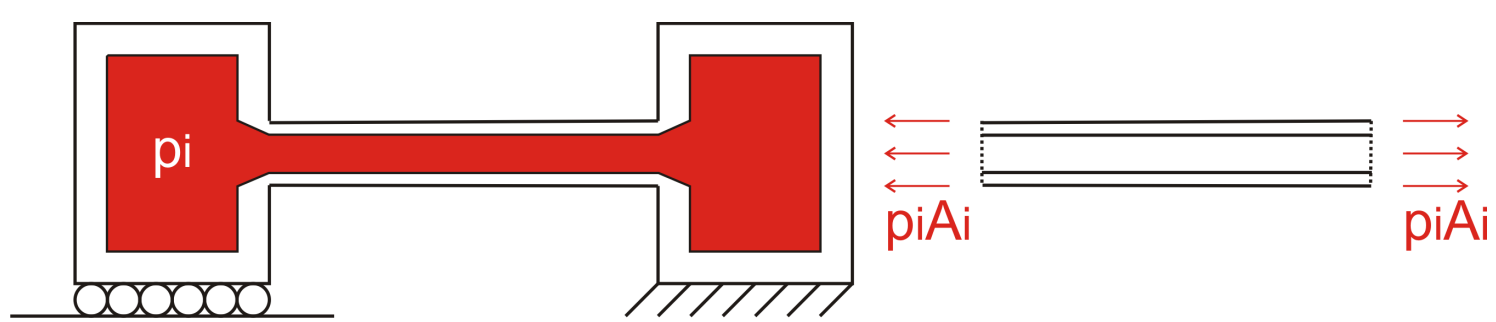

Figura A.17: Tubo sob pressão interna $p_{i}$ e fixo apenas de um lado de forma a surgirem tensões de axiais de tração

O problema referente à Figura A.16 apresenta uma possibilidade de instabilidade, porém o efeito de Poisson colabora estabilizando o problema, pois surgem esforços de tração no tubo. Sendo $L$ o comprimento e $E I$ sua rigidez flexional, a carga crítica de 
Euler é dada por: $P_{c r i t}=\frac{4 \pi^{2} E I}{L^{2}}$. A equação para a pressão interna crítica para esse problema, considerando o efeito de Poisson (surgimento de um esforço de tração) e a pressão interna, é dada por:

$$
p_{c r} A_{i}(1-2 \nu)=\frac{4 \pi^{2} E I}{L^{2}}
$$

Já para o problema da Figura A.17, não há risco algum de instabilidade. Qualquer que seja a pressão interna aplicada, uma vez que surge um esforço axial no tubo exatamente no valor $p_{i} A_{i}$ e a contribuição da pressão interna na tração efetiva é dada pelo mesmo valor, a tração efetiva sempre será nula. Portanto, o efeito do fechamento da tubulação (end cap) nesse exemplo tende a estabilizar o problema.

O end cap de modo geral tende a atenuar o efeito instabilizador da pressão interna, pois colabora com o aumento da tração solicitante. Em uma configuração de riser em catenária a situação mais provável seria a não ocorrência desse efeito, uma vez que pode-se idealizar o problema da seguinte forma: o riser é fixado no fundo do mar, em um conjunto de válvulas, supostas abertas. No topo idealiza-se um reservatório submetido à pressão atmosférica, no qual o fluido extraído é armazenado até que seja transportado para outro local. A figura A.18 ilustra a idealização da situação de um riser em operação. Dessa forma, o problema real poderia nessa situação estar submetido aos efeitos de instabilidade devidos à pressão interna existente, sem que o end cap possua influências no esforço solicitante de tração ao longo da linha.

Efeitos de Poisson semelhantes ao do problema da Figura A.17 em que o tubo se encontra confinado não devem ser importantes no caso de uma configuração de riser em catenária semelhante à da Figura A.18, uma vez que a unidade flutuante se encontra livre para ajustar sua posição dentro de uma faixa considerável de movimento e não confina o riser.

Quanto ao real objetivo do presente trabalho, que é o estudo de risers em condições típicas de instalação a fim de identificar a formação de laços, considera-se que tipicamente não há pressurização da linha. Esse possível efeito instabilizador, portanto, não foi considerado nos resultados mostrados no Capítulo 5. Foi considerado o peso efetivo em todos os cálculos, pela sua simplicidade em relação à utilização das equações provenientes da integração da pressão, apresentadas anteriormente. 


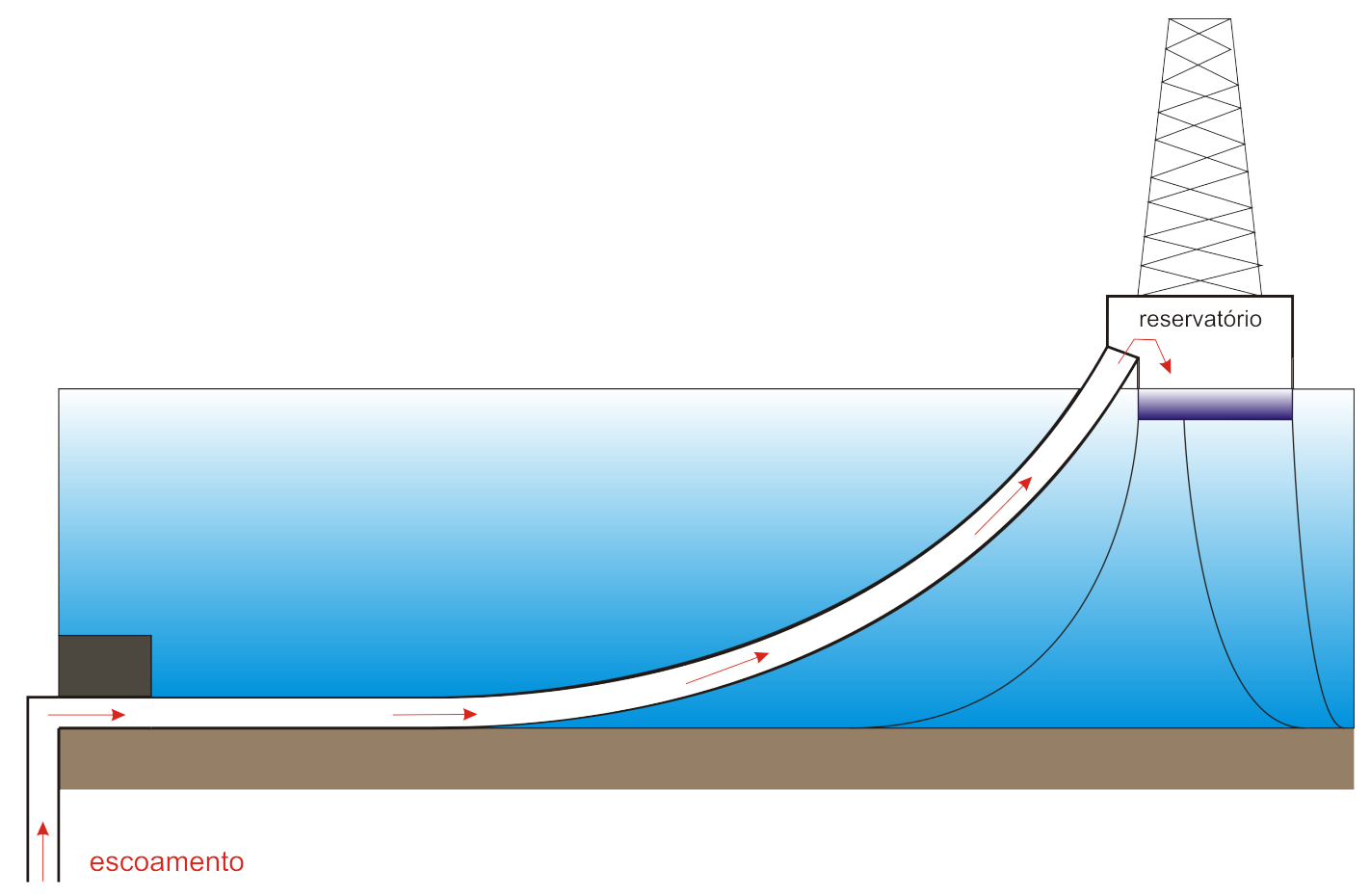

Figura A.18: Esquema de um tubo em catenária com sua ancoragem no solo e unidade flutuante (tubo fora de escala)

\section{A.10 Exemplos de aplicações}

Essa seção aborda, em primeiro lugar, duas aplicações de cálculo de empuxo em um torus, posicionado de duas formas diferentes dentro da água. Esse exemplo visa mostrar a utilização das equações A.20 em uma aplicação bastante simples. Posteriormente será feita a análise de estabilidade de um problema de um tubo vertical com pressão interna, ilustrando a obtenção da carga crítica do tubo. Por fim, será mostrada uma simulação de um cabo umbilical na forma de catenária, imerso em água do mar. Será comparada a abordagem utilizando-se a tração efetiva e a integração da pressão externa.

\section{A.10.1 Exemplo 1 - semi-torus submerso}

A Figura A.19 ilustra um semi-torus submerso, submetido à pressão hidrostática. Foi definido um sistema de coordenadas, cuja direção $z$ corresponde à direção do empuxo. O semi-torus encontra-se totalmente submerso, a menos de suas duas seções de corte, que se encontram, por hipótese, exatamente sobre a superfície do líquido.

Serão utilizadas para o cálculo do empuxo as expressões A.20. No entanto, para facilitar para esse problema, a variável utilizada não será a abscissa curvilínea $s$, mas o ângulo central do semi-torus $\alpha$. Realizando a mudança de variável, as expressões tomam 


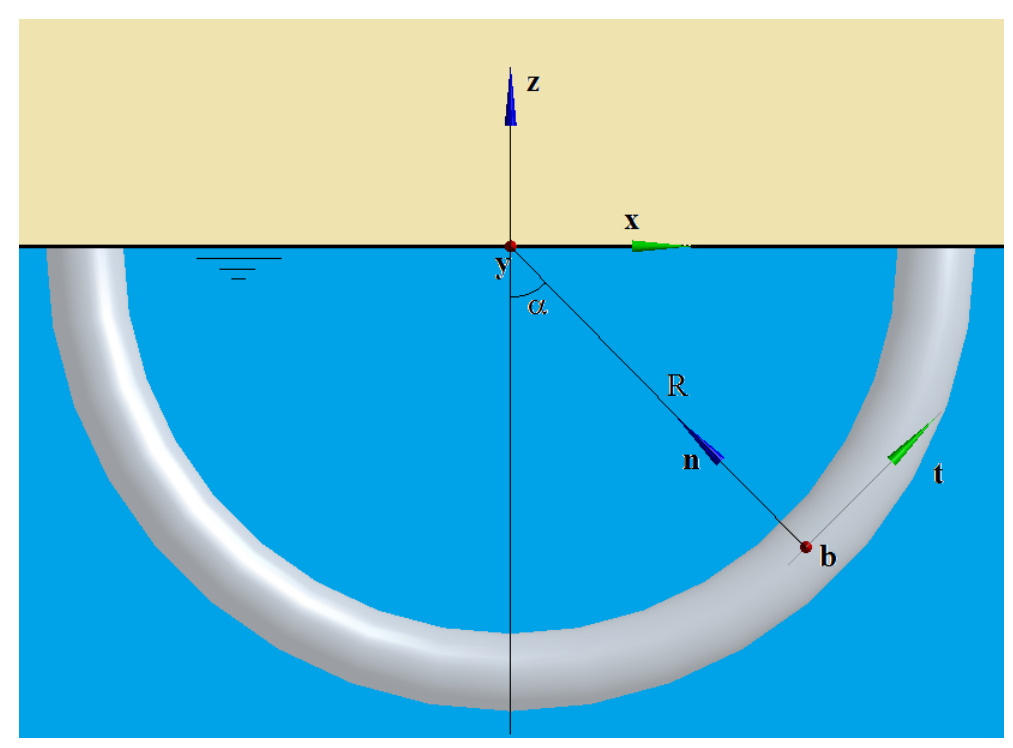

Figura A.19: Exemplo 1 - semi-torus submerso em uma posição

a forma:

$$
\begin{aligned}
& d f_{t}=0 \\
& d f_{n}=\rho \pi r^{2}\left(h_{o} g-g_{n} R\right) d \alpha \\
& d f_{b}=-\rho \pi r^{2} g_{b} R d \alpha
\end{aligned}
$$

A cota do centróide de uma seção transversal genérica pode ser escrita como $h_{o}(\alpha)=R \cos \alpha$. A resultante da integração da pressão na direção $x$ é nula (por simetria) e, o empuxo, ocorre na direção z. Assim, na integração será tomada somente a componente $z$ da força normal. Para tal, a força normal infinitesimal deve ser, no integrando, multiplicada por $\cos \alpha$. O norma do empuxo $\|\boldsymbol{E}\|$ é dada por:

$$
\begin{gathered}
\|\boldsymbol{E}\|=\int_{\alpha} \cos \alpha d f_{n}=\rho \pi r^{2} g R \int_{-\pi / 2}^{\pi / 2} \cos \alpha(R \cos \alpha g+g \cos \alpha R) d \alpha \\
\|\boldsymbol{E}\|=2 \rho \pi r^{2} g R \int_{-\pi / 2}^{\pi / 2} \cos ^{2} \alpha d \alpha=(\rho g)\left(\pi r^{2}\right)(\pi R)
\end{gathered}
$$

O resultado condiz com o obviamente esperado, que é dado pelo volume do semitorus multiplicado pelo peso específico do fluido. 
O mesmo semi-torus pode ser localizado em outra posição, segundo a Figura A.20.

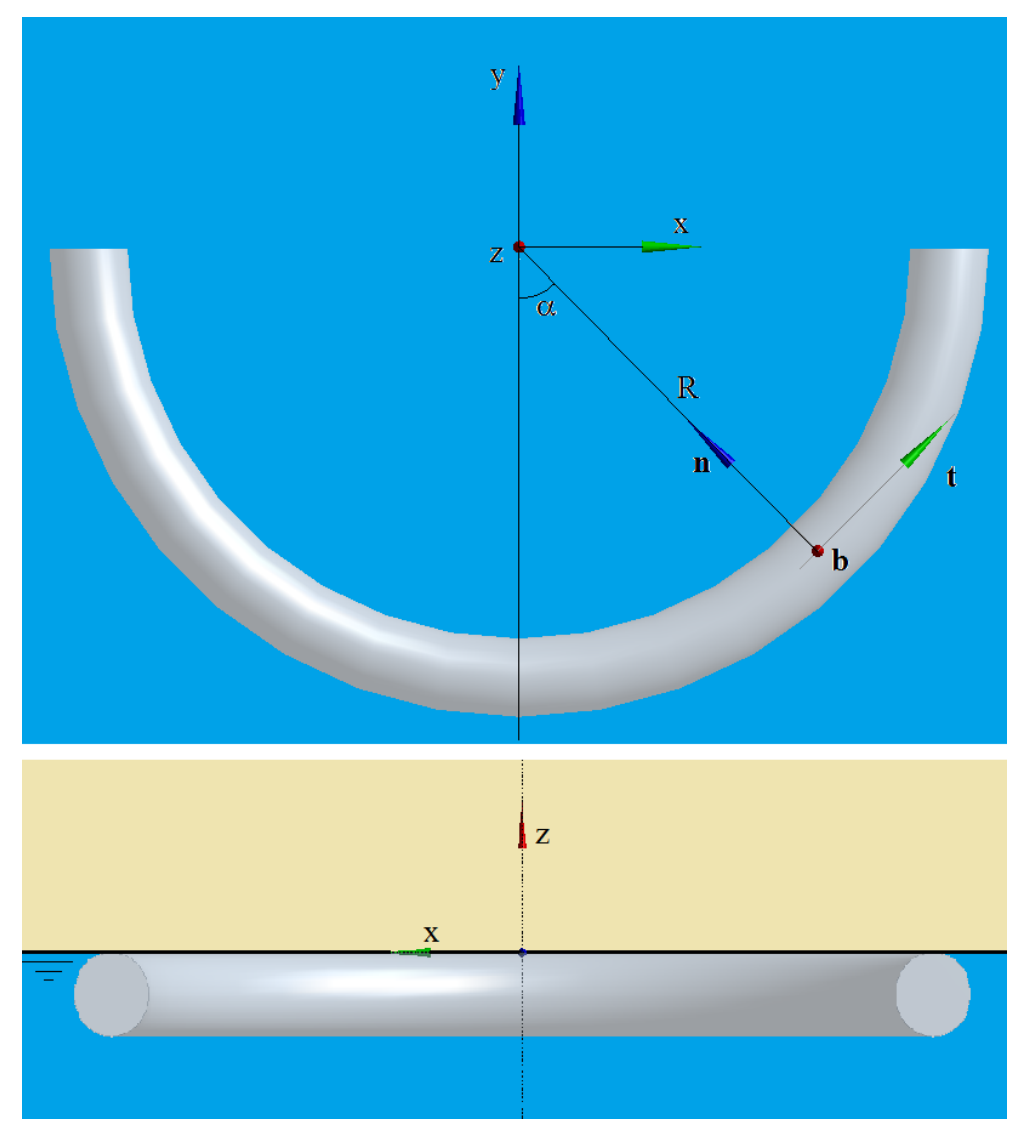

Figura A.20: Exemplo 1 - semi-torus submerso em uma segunda posição

Dessa vez o empuxo ocorrerá na direção e sentido da direção binormal do semitorus. Utilizando-se da expressão na direção binormal de A.52, substituindo $g_{b}=-g$

$$
\|\boldsymbol{E}\|=-\int_{\alpha} \rho \pi r^{2}(-g) R d \alpha=(\rho g)\left(\pi r^{2}\right)(\pi R)
$$

Conforme o esperado, o resultado do empuxo é o mesmo que fora calculado anteriormente para o corpo orientado de outra forma.

Assim, mostrou-se com esse exemplo uma simples aplicação da formulação desenvolvida, para problemas com pressão externa. Para problemas com pressão interna, a ideia é absolutamente análoga. 


\section{A.10.2 Exemplo 2 - flambagem de Euler para uma viga com pres- surização interna}

Seja uma viga tubular de comprimento $L=20 \mathrm{~m}$ com peso desprezível e rigidez flexional dada por $E I=5.030 \mathrm{Nm}^{2}$, área interna da seção circular do tubo dada por $A_{i}=2.827,4 \mathrm{~mm}^{2}$. Sendo a viga apoiada em uma extremidade e a outra conectada a uma junta de expansão. Considera-se que essa extremidade se comporte também como uma articulação. A junta permite movimentos axiais do tubo para acomodar tensões que poderiam surgir devido à pressurização interna. Além disso existe uma força compressiva $P$ aplicada praticamente na extremidade da viga, conforme a Figura A.21.

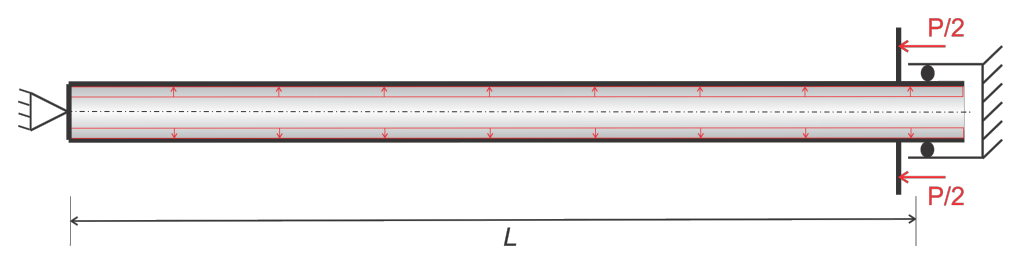

Figura A.21: Exemplo 2 - Tubo com pressurização interna e com junta que permite expansão axial

A análise de estabilidade estrutural desse problema pode ser feita através de um modelo de viga bi-apoiada, supondo que a força $P$ está aplicada exatamente na extremidade da viga. A carga crítica de flambagem de Euler sem considerar pressurização interna é dada por:

$$
P_{\text {crit }}=\pi^{2} \frac{E I}{L^{2}}=124,11 N
$$

O efeito da pressurização interna não solicita o tubo como se houvesse um fechamento. Assim, a tração efetiva será afetada diretamente pela pressão interna pelo valor $p_{i} A_{i}$. Logo, considerando efeitos da pressurização interna, o valor da carga crítica irá decrescer, de acordo com o nível de pressão considerada. A estrutura, inclusive, pode chegar à flambagem sem forças compressivas $P$, mas somente com a pressão interna. Como discutido anteriormente, o esforço que governa a estabilidade estrutural é a tração efetiva. A mesma, na ausência de pressões externas, será dada por:

$$
T_{e f}=-P-p_{i} A_{i}
$$


Para um cenário de pressurização interna dada por: $p_{i}=30 k P a$, a contribuição de tração efetiva negativa (ou compressão efetiva) é de: $p_{i} A_{i}=84,82 N$. Assim, nessa situação a carga compressiva crítica irá baixar para $P_{\text {crit }}=39,29 \mathrm{~N}$.

A fim de exemplificar a utilização das fórmulas desenvolvidas nesse capítulo para os esforços causados pela pressão em um tubo, uma simulação desse problema foi feita utilizando-se do MEF aplicado à Formulação Cinematicamente Exata de vigas, já apresentada no Capítulo 4. O modelo foi montado com uma malha de 35 elementos ao longo do domínio e foi resolvido em dois passos de carregamento. Em primeiro lugar, introduziu-se o esforço dado pela pressurização interna (através das expressões A.27). Sendo o tubo inicialmente retilíneo, segundo as expressões A.27 (particularizadas para aplicar somente o termo de pressão interna constante) não haverá força transversal com resultante não nula. Por isso, foi introduzida uma imperfeição de um esforço lateral, aplicado próximo ao centro geométrico da viga, a fim de induzir um modo de flambagem. No entanto, como é previsível pelo resultado analítico, somente a pressão não é capaz de causar a flambagem nesse problema, mas também é necessário uma parcela de força compressiva. O segundo passo de carregamento é uma imposição de deslocamento axial compressivo em uma das articulações da viga, a fim de causar sua flambagem. A reação vincular devida à prescrição desse deslocamento foi monitorada, e seu papel é o do carregamento compressivo. A fim de comparar o resultados numéricos com analíticos, foi feita a mesma simulação, também sem considerar a pressão interna. Ambos os resultados estão mostrados na Figura A.22, que ilustra as trajetórias de equilíbrio para esse problema.

O gráfico mostra a carga compressiva aplicada, em função do deslocamento axial do ponto de aplicação do carregamento. Note que, quando atingido certo nível crítico de carga, a estrutura perde abruptamente sua rigidez. O ponto dessa perda de rigidez está associado à carga crítica de flambagem predita analiticamente.

É possível notar uma aderência muito boa entre as previsões analíticas e os resultados numéricos, para ambos os casos, com e sem pressão interna. Esse exemplo ilustra o potencial da formulação desenvolvida, que pode ser utilizada, adicionalmente, para outras geometrias de tubos, como um riser na forma de catenária, ou outras formas genéricas. Basta aplicar o esforço da pressão e, conforme a curvatura surge na análise de MEF, utilizando-se da formulação apresentada nesse apêndice. Os esforços são re-calculados, de acordo com os novos níveis de curvatura e, dessa forma, através de um procedimento iterativo chega-se inclusive à configuração pós-crítica. No entanto, é necessário lembrar-se sempre de verificar as condições de fechamento do tubo pois, nesse exemplo, não há fe- 


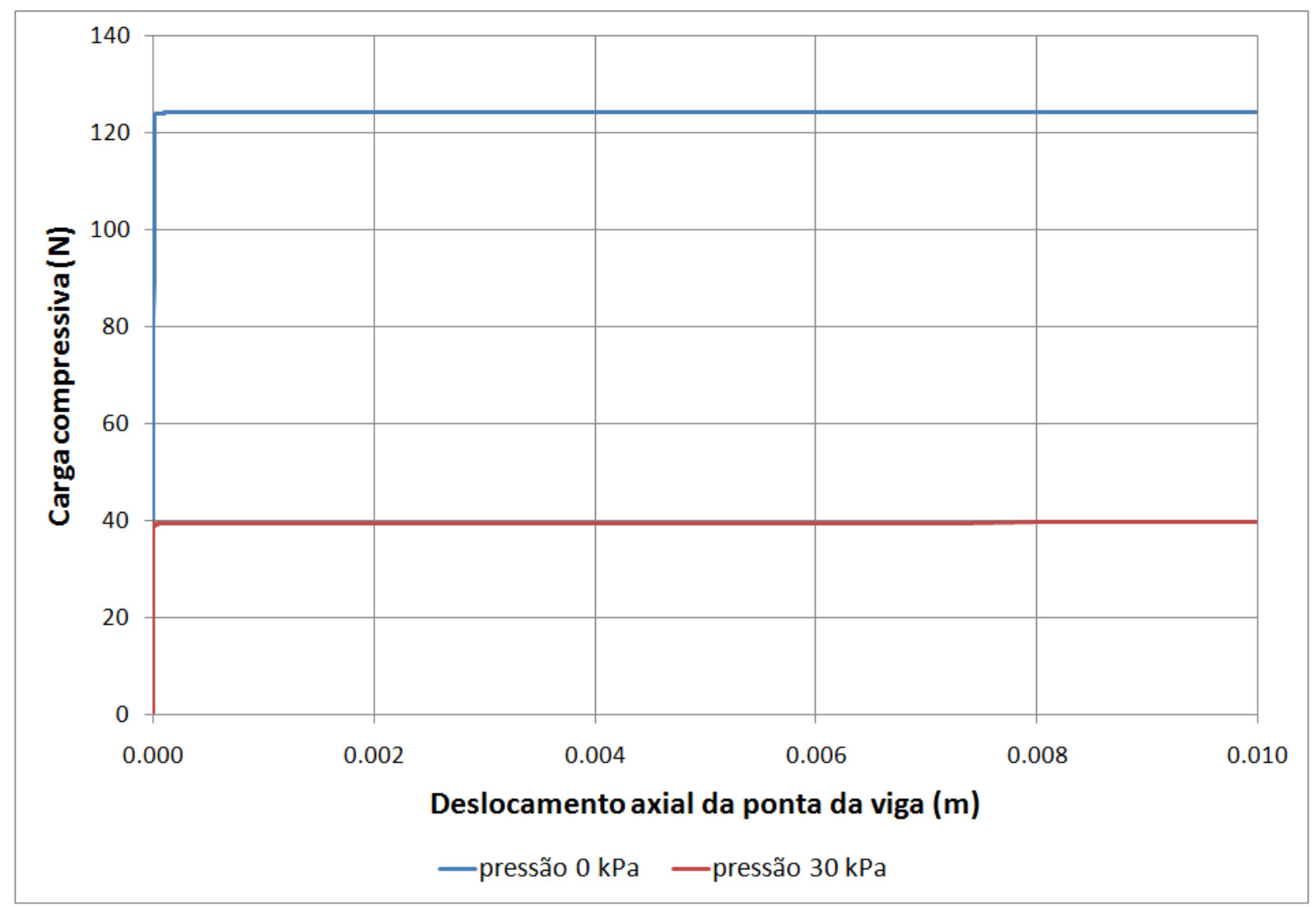

Figura A.22: Resultado das simulações para o exemplo 2 - flambagem de Euler para uma viga com pressurização interna

chamento e por isso a pressurização interna sensibiliza a tração efetiva. No caso de haver fechamento, a tração efetiva não será alterada mas, somente, a tração solicitante.

Note que nesse exemplo o peso da estrutura e do fluido interno foram desprezados. Assim, somente a pressurização interna da viga foi utilizada nas expressões A.27.

\section{A.10.3 Exemplo 3 - cabo umbilical imerso em água do mar}

O estudo da configuração estática de um cabo umbilical imerso em água do mar é tratado nesse exemplo. O objetivo da presente análise é a determinação da configuração do cabo, bem como a distribuição de tração que surge ao longo de sua abscissa curvilínea. As características do cabo umbilical estudado estão descritas na Tabela A.1:

As características relevantes do ambiente em que o cabo umbilical se encontra se encontram na Tabela A.2:

Não é considerada nenhuma contribuição de pressão interna do umbilical em termos de configuração global e esforços, mas somente o efeito de sua pressão externa. 
Tabela A.1: Dados do Exemplo 3 - Cabo umbilical

\begin{tabular}{|c|c|}
\hline Comprimento $(L)$ & $2.000 \mathrm{~m}$ \\
Rigidez axial $(E A)$ & $409.000 .000 \mathrm{~N}$ \\
Rigidez flexional $(E I)$ & $5.030 \mathrm{Nm}^{2}$ \\
Rigidez à torção $(G J)$ & $1.000 .000 \mathrm{Nm}^{2}$ \\
Rigidez ao cisalhamento $(G A)$ & $40.600 .000 .000 \mathrm{~N}$ \\
Massa por unidade de comprimento $(\rho)$ & $25,4 \mathrm{~kg} / \mathrm{m}$ \\
Diâmetro externo $(D)$ & $0,08 \mathrm{~m}$ \\
\hline
\end{tabular}

Tabela A.2: Dados do Exemplo 3 - Cabo umbilical com o ambiente

\begin{tabular}{|c|c|}
\hline Aceleração da gravidade $(\boldsymbol{g})$ & $-9,81 \boldsymbol{k}\left[\mathrm{m} / \mathrm{s}^{2}\right]$ \\
Cota do solo retilíneo & $z=0 \mathrm{~m}$ \\
Cota de fixação do cabo umbilical na superfície (posição da plataforma) & $z=1000 \mathrm{~m}$ \\
Projeção horizontal do cabo umbilical no solo & $1.603,1 \mathrm{~m}$ \\
Coeficiente de atrito entre o cabo umbilical e o solo $(\mu)$ & 0 \\
Massa específica da água do mar $\left(\rho_{e}\right)$ & $1025 \mathrm{~kg} / \mathrm{m}^{3}$ \\
\hline
\end{tabular}

Conforme discutido anteriormente, é possível seguir duas possíveis linhas para a análise:

- Considerar o peso em ar do cabo umbilical e integrar a pressão diretamente nas suas paredes externas. Essa abordagem determina uma distribuição de tração solicitante no umbilical, podendo ser utilizada para a determinação da tração efetiva posteriormente.

- Considerar o peso efetivo do cabo umbilical e não integrar a pressão diretamente em suas paredes externas. A configuração do cabo umbilical proposta apresenta sua extremidade superior na cota da lâmina d'água. Por isso, ao considerar o peso efetivo na análise resultará uma distribuição de tração que é exatamente a tração efetiva. Isso ocorre pois, conforme discutido no exemplo da Figura A.14, quando o cabo umbilical se encontra com sua extremidade superior na superfície do líquido não existe efeito de pressurização externa além da pressão hidrostática já levada em conta no cálculo do peso efetivo. Posteriormente, é possível determinar a tração solicitante através da aplicação da equação A.28.

Ambas as metodologias são equivalentes e devem resultar no mesmo campo de tração efetiva e solicitante ao longo do cabo umbilical. Para mostrar tal fato, foram 
feitas duas simulações utilizando-se do modelo apresentado no Capítulo 4. A estratégia de solução utilizada para a resolução da catenária é a seguinte:

A configuração de referência do cabo umbilical é uma viga retilínea alinhada com o eixo $x$ global. Para a consideração do contato entre a estrutura e o solo, foi utilizado o parâmetro $\epsilon_{n}=1.000 .000$ no Método das Penalidades, e como não foi considerado atrito, $\epsilon_{t}=0$. Esse conjunto de parâmetros garantiu uma penetração muito pequena no solo, em relação às dimensões do modelo resolvido.

A solução do modelo foi feita através de uma sequência de passos de carregamento da seguinte forma:

1.Fixação da origem do umbilical, sendo essa considerada a âncora do mesmo, e imposição de deslocamento em $z$ da outra extremidade para a cota da superfície do mar, a fim de tracionar a estrutura, fazendo-a adquirir rigidez geométrica.

2.Inserção do carregamento do peso próprio na estrutura pré tensionada no primeiro passo (peso real ou peso efetivo, dependendo da abordagem escolhida para a análise).

3.Alívio da tração da estrutura, feito através da imposição de um deslocamento no topo, na direção $x$, até que a projeção horizontal do umbilical atinja exatamente o valor desejado. Durante esse passo ocorre o contato entre o cabo umbilical e o solo, apresentando-se algumas dificuldades numéricas para convergência. É necessário trabalhar com um passo pequeno para a imposição do deslocamento do topo.

No caso da primeira abordagem, com a utilização do peso real, é realizado um último passo para aplicação da pressão externa nas paredes do umbilical. No caso da abordagem do peso efetivo, não é aplicada pressão alguma, uma vez que o efeito da pressão já foi considerado no peso efetivo. Nesse último caso, finaliza-se a simulação após o terceiro passo de carregamento.

Em ambas as simulações as elasticas do cabo umbilical determinadas são praticamente iguais, conforme esperado. A Figura A.23 mostra a elastica da configuração do cabo umbilical.

A distribuição de tração ao longo da abscissa curvilínea $s$ para ambas as abordagens é ilustrada na Figura A.24. Note que existem três curvas plotadas. A curva proveniente da simulação utilizando-se o peso real do cabo e integração da pressão nas suas paredes mostra a tração solicitante. A curva proveniente da simulação se utilizandose o peso efetivo do cabo mostra a tração efetiva. Utilizando-se da equação A.28, e 


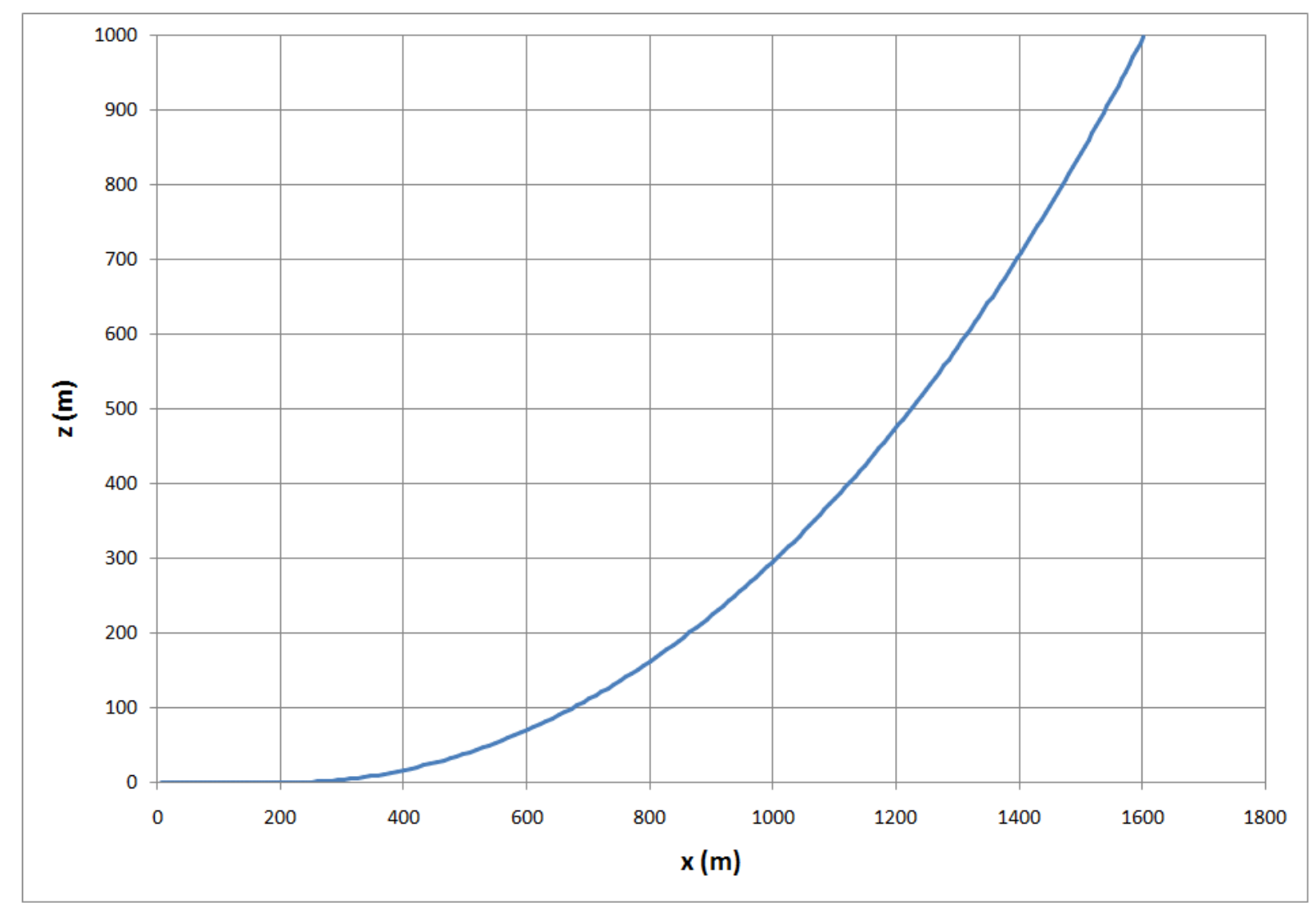

Figura A.23: Exemplo 3. Configuração do cabo umbilical

adaptando-a para pressão externa dada por $\rho_{e} g(h-z)$, foi realizado o cálculo da tração solicitante a partir da tração efetiva. Conforme o esperado, o resultado é muito próximo da tração solicitante determinada na outra simulação.

A abordagem de utilizar o peso efetivo e a tração efetiva é mais prática e rápida para simular do que a utilização do peso real e a integração da pressão nas paredes do cabo umbilical. Para efeito de determinação da elastica, curvaturas, e esforços solicitantes ao longo do riser ambas as abordagens são absolutamente equivalentes. A tração efetiva, inclusive para problemas de estabilidade, conforme discutido, é quem domina o problema. Por isso é possível analisar uma catenária quanto à estabilidade utilizando-se, simplesmente seu peso efetivo para uma situação semelhante à abordada nesse estudo de caso. 


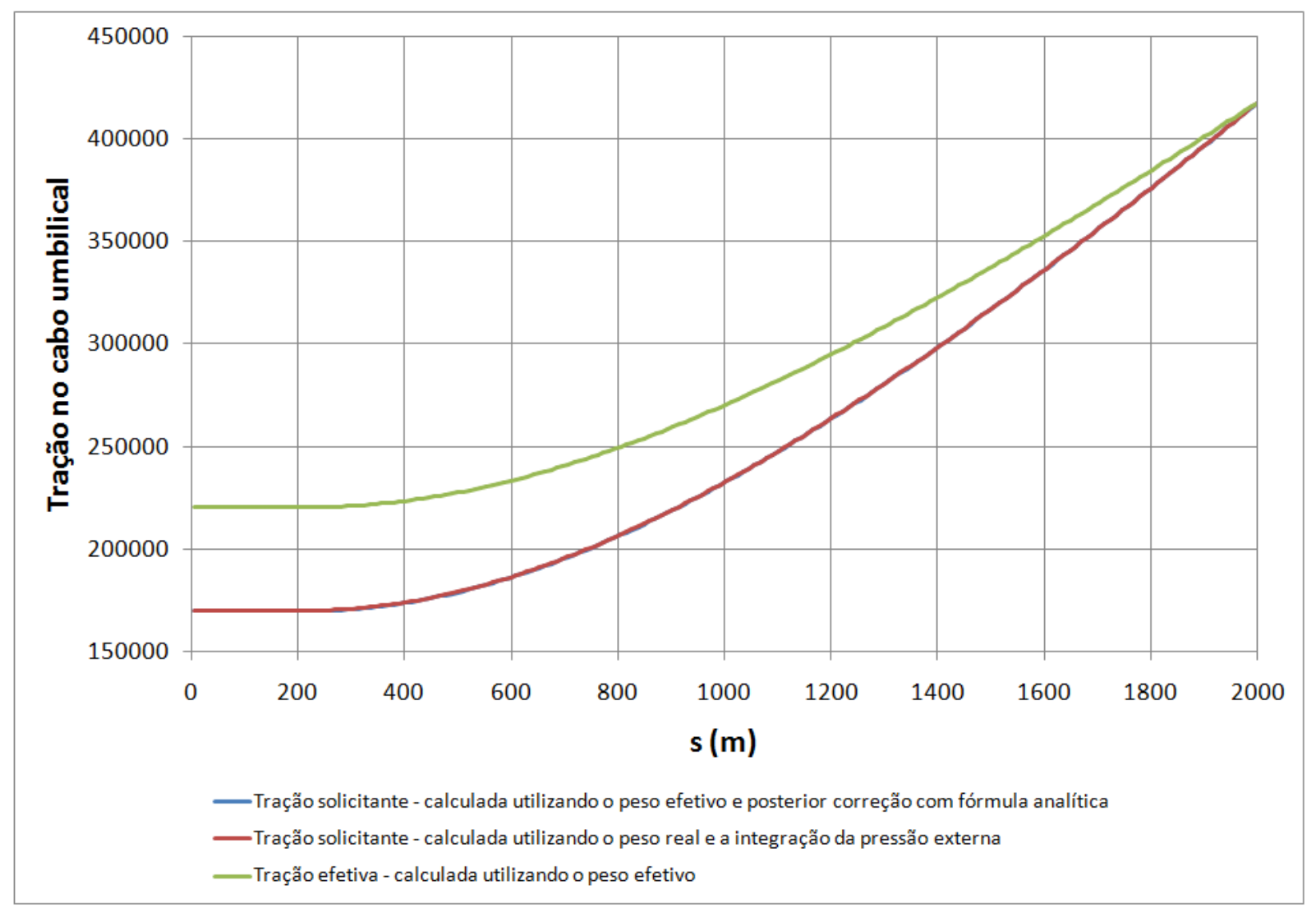

Figura A.24: Exemplo 3. Distribuição de tração ao longo do cabo umbilical 


\section{APÊNDICE B - TEORIA DE VIGAS CURVAS DE LOVE}

Na obra de Love (1944) e com uma notação mais atual em Ramos Jr (2001) são deduzidas equações diferenciais de equilíbrio para vigas curvas tridimensionais. Para o estudo da elastica de risers, incluindo a correta interpretação dos conceitos de torção e flexão, é necessária compreensão de alguns conceitos apresentados nesse apêndice.

Define-se na elastica de uma viga, a abscissa curvilínea $s$ como sendo uma coordenada que mede o comprimento de arco, estando a origem em certa posição escolhida arbitrariamente. Em uma dada seção transversal de uma viga não deformada, uma vez definido um eixo passando pelo seu centróide e com direção ortogonal à seção transversal, pode-se imaginar duas fibras ortogonais a esse eixo, no plano da seção transversal. Das infinitas possibilidades, escolhe-se de maneira conveniente aquelas que estão alinhadas com as direções principais de inércia da seção. Quando a viga é torcida essas fibras sofrem uma rotação de um ângulo $\alpha$ em torno da direção normal à seção transversal. Pode-se definir a torção própria $\tau_{p}$ de uma viga como:

$$
\tau_{p}=\lim _{\delta s \rightarrow 0} \frac{\delta \alpha}{\delta s}
$$

As fibras ortogonais escolhidas definem um sistema de coordenadas denominado "eixos principais de flexo-torção". Esse sistema é composto da seguinte forma:

-O sistema possui origem no centróide da seção transversal

-O eixo Z está na direção tangente à elastica na configuração de equilíbrio

-O eixo X possui a mesma direção de uma fibra que se encontrava alinhada com uma das direções principais de inércia da seção transversal antes da rotação. Após a rotação da seção, essa fibra e também o eixo X sofrem uma rotação de um ângulo $\alpha$, 
de modo que esse eixo continue alinhado com a mesma direção principal de inércia, porém dessa vez na configuração deformada

-O eixo Y é escolhido para que o sistema XYZ seja positivo em uma orientação dextrógira.

\section{B.1 Triedro de Frenet}

Atentando-se temporariamente somente à elastica da viga, será agora mostrada uma definição mais formal de abscissa curvilínea $s$, a fim de introduzir o estudo de uma curva no espaço segundo o triedro de Frenet. Seja uma curva, dada pela parametrização em $t$, escrita da seguinte forma:

$$
\Gamma(t)=(x(t), y(t), z(t))
$$

Pode-se definir a abscissa curvilínea $s$, como sendo:

$$
s=\int_{t_{o}}^{t}\left\|\frac{d \boldsymbol{\Gamma}(\xi)}{d \xi}\right\| d \xi
$$

Pode-se escolher a origem de $s$ como sendo o valor correspondente a $t_{o}$. A parametrização de curvas espaciais pode ser feita utilizando como parâmetro o próprio $s$ em vez de um parâmetro genérico $t$.

A geometria diferencial através das fórmulas de Frenet-Serret define três vetores para cada valor de abscissa curvilínea s. O primeiro a ser definido é o vetor tangente, dado por $\frac{d \Gamma}{d s}$. Esse vetor, como seu próprio nome diz, é aquele que possui direção da reta tangente em cada ponto $s$ da curva. No caso de uma parametrização em função de $t$, e não do abscissa $s$, o cálculo do vetor tangente pode ser feito da forma:

$$
\boldsymbol{t}=\frac{\frac{d \boldsymbol{\Gamma}}{d t}}{\left\|\frac{d \boldsymbol{\Gamma}}{d t}\right\|}
$$

Em uma curva genérica o vetor $\boldsymbol{t}$ não é constante, apresentando variações no 
decorrer da abscissa $s$. Note que a natureza da variação do vetor tangente é apenas em direção e sentido, mas não em norma, uma vez que, da forma que fora definido, apresenta sempre norma unitária. Pode-se demonstrar facilmente que $\frac{d \boldsymbol{t}}{d s}$ é ortogonal a $\boldsymbol{t}$. O vetor $\frac{d \boldsymbol{t}}{d s}$ não possui necessariamente norma unitária. A norma da variação do vetor tangente é denominada curvatura $\chi$ da curva. A direção e o sentido dessa variação são dados pelo vetor normal, simbolizado por $\boldsymbol{n}$. Portanto, $\frac{d \boldsymbol{t}}{d s}=\chi \boldsymbol{n}$.

Para definir completamente um sistema de coordenadas em cada ponto da curva no espaço, é necessário definir um terceiro vetor. Será definido como sendo aquele que é ortogonal ao vetor tangente e ao vetor normal, formando com esses uma base positiva em orientação dextrógira. Esse vetor é denominado bi-normal, será simbolizado por $\boldsymbol{b}$ e pode ser calculado da seguinte forma:

$$
b=t \times n
$$

Note que o vetor tangente pode variar sua direção em $s$ somente através da direção normal à curva, ou seja, para cada $s$ escolhido, é possível construir um plano, no qual ocorre a variação do vetor tangente. Esse plano é formado pelos vetores $\boldsymbol{t}$ e $\boldsymbol{n}$, e é chamado de plano osculador. A variação em $s$ da direção do vetor tangente resultará em uma variação em $s$ na direção do vetor normal, para manter a ortogonalidade do sistema de coordenadas montado. A variação em $s$ do vetor normal pode se dar através de duas direções distintas: direção tangente e direção bi-normal. Para definir a variação em $s$ do vetor normal através da direção bi-normal, define-se a chamada tortuosidade da curva $\tau_{c}$.

$$
\tau_{c}=\boldsymbol{b} \cdot \frac{d \boldsymbol{n}}{d s}
$$

A tortuosidade também pode ser entendida como a taxa de rotação em $s$ sofrida pelo plano osculador. A tortuosidade $\tau_{c}$ é diferente da grandeza denominada torção própria $\tau_{p}$. A tortuosidade é uma propriedade da curva no espaço, estando associada, portanto à forma da elastica de uma viga curva 3D. Já a torção própria, diz respeito à rotação do sistema das direções principais de flexo-torção, não coincidente com o triedro de Frenet de modo geral.

Em Topogonov (2006) são deduzidas de maneira bastante formal as chamadas relações de Frenet-Serret, a seguir escritas nas equações B.7 a B.9. 


$$
\begin{gathered}
\frac{d \boldsymbol{t}}{d s}=\chi \boldsymbol{n} \\
\frac{d \boldsymbol{n}}{d s}=-\chi \boldsymbol{t}+\tau_{c} \boldsymbol{b} \\
\frac{d \boldsymbol{b}}{d s}=-\tau_{c} \boldsymbol{n}
\end{gathered}
$$

Essas três relações exprimem em que direções podem variar, segundo a abscissa $s$, os vetores tangente, normal e bi-normal. Em Topogonov (2006) são deduzidas expressões para o cálculo da tortuosidade e da curvatura a partir da parametrização da curva considerada.

Como dito anteriormente, os dois sistemas de coordenadas definidos (direções principais de flexo-torção e triedro de Frenet) não coincidem de modo geral. A seguir será feita uma relação entre os dois sistemas.

A Figura B.1 mostra duas seções de uma viga curva tridimensional, bem como suas direções principais de flexo-torção e, como ficam as rotações de suas seções transversais segundo uma variação em $s$. Na mesma figura, em vermelho, podem ser visualizados a curva espacial que representa a elastica da viga, e os triedros de Frenet para as duas seções de destaque.

Os eixos Z e Z' coincidem com as direções tangentes da elastica para as duas seções transversais consideradas. O ângulo $\alpha$ indicado é medido entre os eixos normal (do Triedro de Frenet) e Y (das direções principais de flexo-torção). Variações de $\alpha$ indicam que ocorre torção própria (calculada através da equação B.1), além da tortuosidade da curva, medida através da variação da direção do vetor normal.

Definir a torção total $\tau_{t}$ de uma viga retilínea é algo bastante simples e a definição da equação B.1 é totalmente suficiente para descrever de maneira única esse movimento de rotação das seções transversais consideradas, uma vez que não há tortuosidade. Já quando se trata de vigas curvas o conceito de torção total deve ser generalizado, de forma que inclua também a tortuosidade da curva no espaço. Basicamente a mudança que ocorre em relação ao problema da viga reta é que, no caso da viga curva, aparecem dois efeitos 


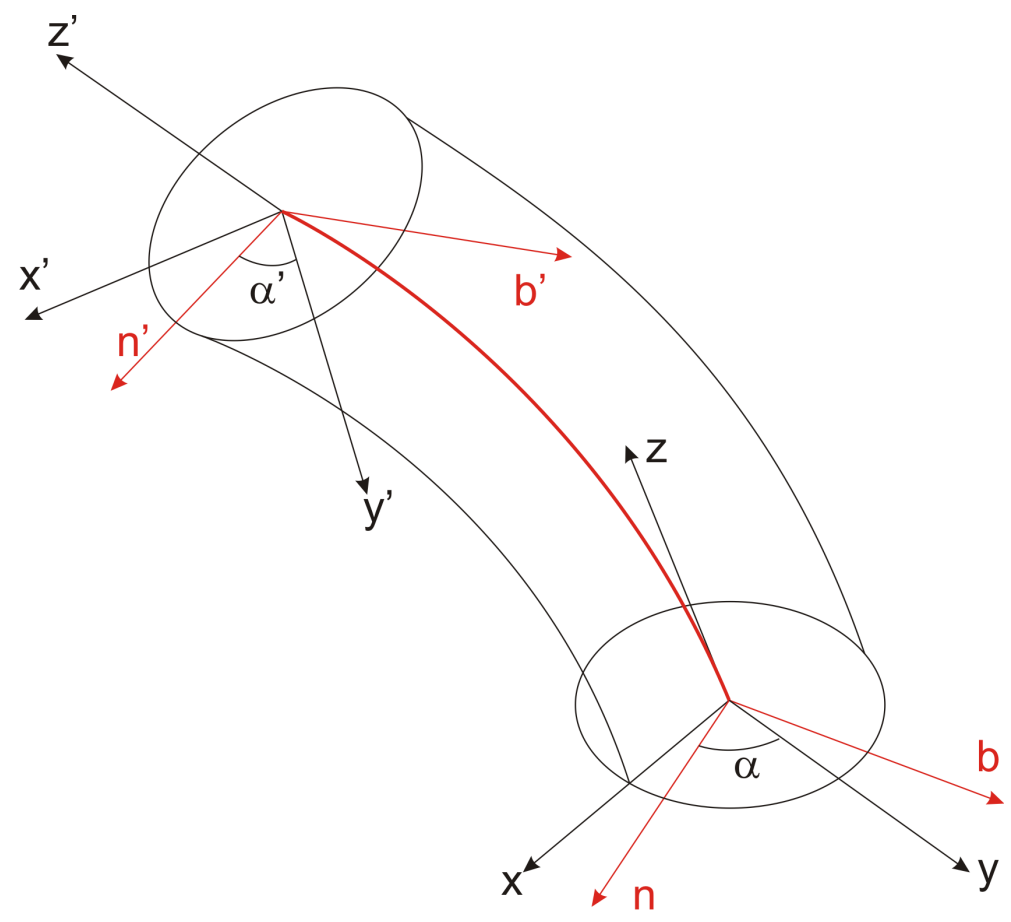

Figura B.1: Elastica e rotações das seções transversais de uma viga curva tridimensional, sendo visualizados dois sistemas de coordenadas em cada seção transversal: o formado pelas direções do triedro de Frenet e o formado pelas direções principais de flexo-torção

combinados de torção:

-Torção própria da viga, que ocorreria sem alteração de sua elastica $\left(\tau_{p}\right)$

-Tortuosidade da elastica, que ocorre dependendo da rotação que ocorre no plano osculador $\left(\tau_{c}\right)$

A torção total de uma viga curva, portanto, pode ser calculada através da seguinte equação:

$$
\tau_{t}=\tau_{p}+\tau_{c}
$$

São definidas também as componentes da curvatura da elastica na configuração deformada. Apesar de a curva no espaço apresentar o vetor curvatura em uma direção não necessariamente coincidente com alguma das direções principais de flexo-torção, é bastante comum definir as variáveis $\kappa$ e $\kappa^{\prime}$ como componentes do vetor curvatura $\chi \boldsymbol{n}$ nessas direções.

Ramos Jr (2001) apresenta a dedução para as derivadas em relação à coordenada 
$s$ dos versores $(\boldsymbol{i}, \boldsymbol{j}, \boldsymbol{k})$ do sistema de coordenadas formado, em cada seção transversal da viga, pelas direções principais de flexo-torção. Através das relações de Frenet-Serret e da construção de matrizes de rotação entre os sistemas de coordenadas formados pelas direções do triedro de Frenet e as direções principais de flexo-torção é deduzida a seguinte relação:

$$
\left[\begin{array}{c}
\frac{d \boldsymbol{i}}{d s} \\
\frac{d \boldsymbol{j}}{d s} \\
\frac{d \boldsymbol{k}}{d s}
\end{array}\right]=\left[\begin{array}{ccc}
0 & \tau_{t} & -\kappa \\
-\tau_{t} & 0 & \kappa^{\prime} \\
\kappa & -\kappa^{\prime} & 0
\end{array}\right]\left[\begin{array}{l}
\boldsymbol{i} \\
\boldsymbol{j} \\
\boldsymbol{k}
\end{array}\right]
$$

A equação B.11 fica completamente definida com três parâmetros: a curvatura nas duas direções principais de flexão $\kappa$ e $\kappa^{\prime}$ e a torção total $\tau_{t}$, que se refere tanto à parcela de torção própria da viga, como à tortuosidade da curva que define a elastica no espaço.

\section{B.2 Equações diferenciais de equilíbrio}

A relação mostrada na equação B.11 é bastante útil para a obtenção das equações diferenciais de equilíbrio de uma viga no espaço, uma vez que relaciona como variam as direções principais de flexo-torção com relação à abscissa curvilínea $s$.

Para obter as equações, basta impor o equilíbrio de forças e de momentos em uma barra 3D infinitesimal. Será adotada a seguinte nomenclatura:

- $N$ se refere ao esforço normal em uma seção transversal, na direção do versor $\boldsymbol{k}$

- $Q_{x}$ se refere ao esforço cortante na direção do versor $\boldsymbol{i}$

- $Q_{y}$ se refere ao esforço cortante na direção do versor $\boldsymbol{j}$

- $M_{x}$ se refere ao momento fletor na direção do versor $\boldsymbol{i}$

- $M_{y}$ se refere ao momento fletor na direção do versor $\boldsymbol{j}$

- $M_{z}$ se refere ao momento de torção, na direção do versor $\boldsymbol{k}$ 
O sistema formado pelos esforços solicitantes é estaticamente equivalente aos esforços distribuídos na seção transversal, na forma de tensões normal e de cisalhamento. Admite-se, por simplificação, que as únicas tensões que agem no problema são as designadas por $\sigma_{z}$ (tensão normal na direção $z$ ), $\tau_{z x}$ e $\tau_{z y}$. Essa hipótese é clássica em teoria de vigas. As relações entre o campo de tensões na seção transversal de área $A$ de uma viga e os esforços solicitantes podem ser calculadas através de expressões integrais, da seguinte forma:

$$
\begin{aligned}
N & =\int_{A} \sigma_{z} d A \\
Q_{x} & =\int_{A} \tau_{z x} d A \\
Q_{y} & =\int_{A} \tau_{z y} d A \\
M_{x} & =\int_{A} y \sigma_{z} d A \\
M_{y} & =\int_{A}-x \sigma_{z} d A \\
M_{z} & =\int_{A} x \tau_{z y}-y \tau_{z x} d A
\end{aligned}
$$

Admite-se que o sistema de forças externo aplicado em cada uma das seções da viga possa ser representado por uma força distribuída $\boldsymbol{f}=\left(f_{x}, f_{y}, f_{z}\right)$ (por unidade de comprimento da viga) e por um momento distribuído $\boldsymbol{m}=\left(m_{x}, m_{y}, m_{z}\right)$ (por unidade de comprimento da viga). Utilizando esses sistemas de esforços é possível desenvolver um equacionamento para relacionar os esforços internos e externos atuantes em cada seção transversal.

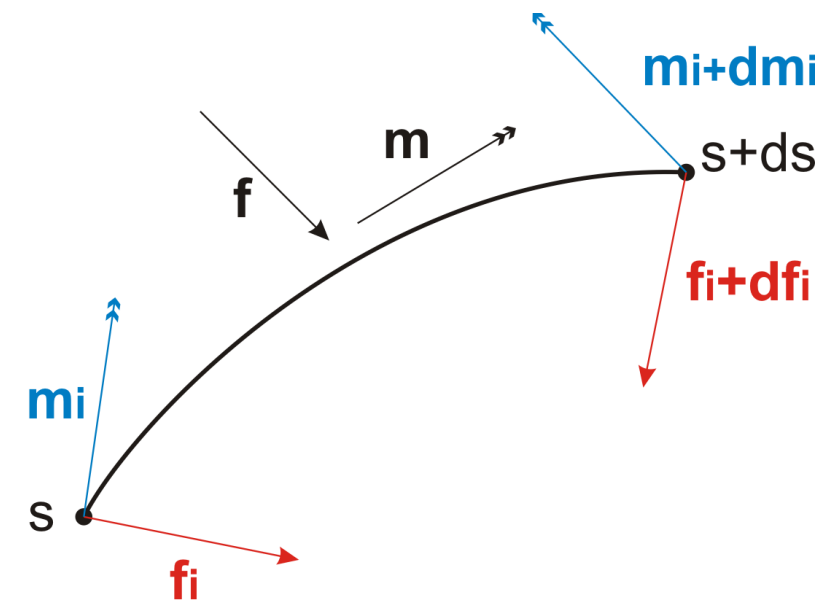

Figura B.2: Elemento infinitesimal de viga curva no espaço 
Escreve-se para o elemento infinitesimal de viga da Figura B.2 o vetor de forças internas em cada seção transversal $\boldsymbol{f}_{i}=\left(Q_{x}, Q_{y}, N\right)$ e o vetor de momentos internos $\mathbf{m}_{i}=$ $\left(M_{x}, M_{y}, M_{z}\right)$. Considerando as forças da Figura B.2 atuantes no elemento infinitesimal de viga, tem-se o seguinte equilíbrio de forças para um problema estático ou quase-estático:

$$
\frac{d \boldsymbol{f}_{i}}{d s}+\boldsymbol{f}=\mathbf{0}
$$

Inserindo as componentes dos vetores $\boldsymbol{f}_{i}$ e $\boldsymbol{f}$, tem-se:

$$
\frac{d Q_{x}}{d s} \boldsymbol{i}+\frac{d Q_{y}}{d s} \boldsymbol{j}+\frac{d N}{d s} \boldsymbol{k}+Q_{x} \frac{d \boldsymbol{i}}{d s}+Q_{y} \frac{d \boldsymbol{j}}{d s}+N \frac{d \boldsymbol{k}}{d s}+f_{x} \boldsymbol{i}+f_{y} \boldsymbol{j}+f_{z} \boldsymbol{k}=\mathbf{0}
$$

Utilizando as relações dadas matricialmente em B.11 e separando-se a equação vetorial em três equações escalares, obtém-se:

$$
\begin{aligned}
& \frac{d Q_{x}}{d s}-Q_{y} \tau_{t}+N \kappa+f_{x}=0 \\
& \frac{d Q_{y}}{d s}-N \kappa^{\prime}+Q_{y} \tau_{t}+f_{y}=0 \\
& \frac{d N}{d s}-Q_{x} \kappa+Q_{y} \kappa^{\prime}+f_{z}=0
\end{aligned}
$$

Escrevendo de maneira análoga a equação de equilíbrio de momentos, de forma vetorial obtém-se:

$$
\frac{d \boldsymbol{m}_{i}}{d s}+\boldsymbol{m}+\boldsymbol{k} \times \boldsymbol{f}_{i}=\mathbf{0}
$$

Desenvolvendo-se também algebricamente de maneira análoga às equações de equilíbrio de forças, obtém-se as três componentes da equação vetorial de equilíbrio de momentos: 


$$
\begin{aligned}
& \frac{d M_{x}}{d s}-M_{y} \tau_{t}+M_{z} \kappa-Q_{y}+m_{x}=0 \\
& \frac{d M_{y}}{d s}-M_{z} \kappa^{\prime}+M_{x} \tau_{t}+Q_{x}+m_{y}=0 \\
& \frac{d M_{z}}{d s}-M_{x} \kappa+M_{y} \kappa^{\prime}+m_{z}=0
\end{aligned}
$$

As seis equações escalares mostradas em B.15 e B.17 são denominadas equações de Love e são muito importantes em abordagens analíticas para análise de vigas no espaço. Como exemplos de aplicação, Ramos Jr (2001), Ramos Jr e Pesce (2003) e Pesce (1997) as utilizam para determinação de esforços e estudo de estabilidade estrutural em risers, além de Goss (2003) que as utiliza para modelos de flambagem de viga sob compressão e torção. 


\section{APÊNDICE C - FLAMBAGEM DE EULER E FÓRMULA DE GREENHILL}

Nesse apêndice serão apresentados dois problemas clássicos de estabilidade estrutural bastante importantes para a base teórica do presente trabalho. Primeiramente se apresentará o problema da flambagem de Euler e, posteriormente, através da inclusão de momentos de torção além da força compressiva, será desenvolvida a Fórmula de Greenhill.

\section{C.1 Flambagem de Euler}

A Figura C.1 ilustra uma viga bi-apoiada, bem como um elemento diferencial da viga, utilizado para a obtenção da equação diferencial do problema:

Impondo o equilíbrio estático em um elemento infinitesimal na configuração deformada, tem-se as seguintes equações diferencias de equilíbrio de forças e de momentos:

$$
V(x)+d V(x)-V(x)+v(x) d x=0
$$

$$
M(x)+d M(x)-M(x)+P \frac{d w(x)}{d x} d x+V(x) d x+v(x) d x\left(\frac{d x}{2}\right)=0
$$

Simplificando ambas as equações, é possível obter equações diferenciais de equilíbrio para a configuração deformada da viga com a hipótese de pequenos deslocamentos.

$$
\frac{d V(x)}{d x}=-v(x)
$$




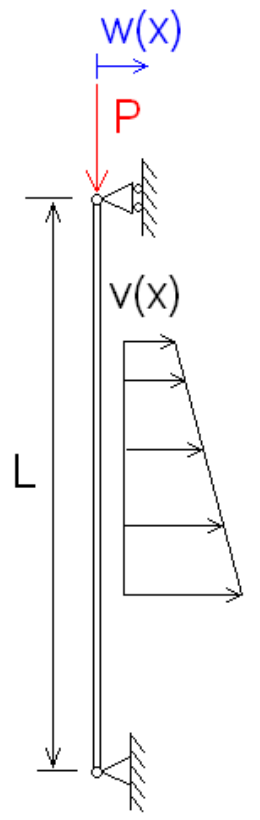

(a)

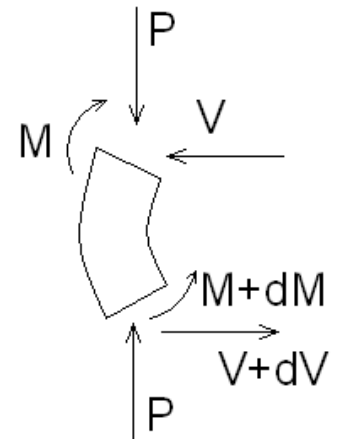

(b)

Figura C.1: (a)Problema de uma viga bi-apoiada (b)Elemento diferencial

$$
\frac{d M(x)}{d x}+P \frac{d w(x)}{d x}+V(x)=0
$$

Considerando a hipótese de Euler-Bernoulli (seções planas da viga permanecem planas e ortogonais ao eixo da elastica) e ainda que as rotações específicas ocorridas no problema sejam pequenas, de tal forma que possam ser aproximadas pela segunda derivada da elastica, pode-se escrever a equação constitutiva:

$$
M=E I(x) \frac{d^{2} w}{d x^{2}}
$$

Juntando as duas equações C.3 e C.4 em uma única expressão, obtém-se a expressão C.6.

$$
\frac{d^{2}}{d x^{2}}\left(E I(x) \frac{d^{2} w(x)}{d x^{2}}\right)+\frac{d}{d x}\left(P \frac{d w(x)}{d x}\right)=v(x)
$$

Note que as equações apresentadas são diferentes da clássica teoria de vigas, uma vez que apresentam o termo da força compressiva normal $P$ acoplado com o desloca- 
mento transversal da viga, o que representa a contribuição do momento da força normal, na configuração deformada. Essas equações representam uma teoria de segunda ordem linearizada para o equilíbrio de vigas e devem ser utilizadas nos problemas de estabilidade.

A solução $w(x)$ da equação C.6 representa a configuração deformada de uma viga, quando sujeita a um carregamento compressivo $P$ e a um carregamento lateral $v(x)$. A solução geral de C.6, para cargas compressivas, é dada por:

$$
w(x)=A \operatorname{sen} q x+B \cos q x+C x+D+w_{v}(x)
$$

em que $A, B, C$ e $D$ são constantes a serem determinadas pelas condições de contorno e, $w_{v}(x)$ é uma solução particular devida ao carregamento distribuído $v(x)$.

Para o problema da Figura C.1 (a), considerando carregamento lateral nulo $v(x)=0, E I$ constante, e denominando $q^{2}=\frac{P}{E I}$, e utilizando-se das condições de contorno naturais dadas por $\left[\frac{d^{2} w(x)}{d x^{2}}\right]_{0}=0$ e $\left[\frac{d^{2} w(x)}{d x^{2}}\right]_{L}=0$ particulariza-se a equação C.7 para:

$$
w(x)=A \operatorname{sen} q x+B \cos q x
$$

Inserindo as condições de contorno essenciais $w(0)=0$ e $w(L)=0$, chega-se em:

$$
A \operatorname{sen}(q L)=0
$$

Para haver solução não trivial, necessariamente deve-se ter $q L=\pi, 2 \pi, \ldots$. Dessa forma, existem alguns valores de $q$, para os quais a solução do problema pode ser, além da trivial, a solução não trivial. Esses valores de $q$ estão relacionados a valores da força compressiva $P$, que pode ser relacionada a cada possível valor de $q$ pela notação $P_{n}$, através da seguinte expressão:

$$
P_{n}=\frac{n^{2} \pi^{2}}{L^{2}} E I
$$

A solução não trivial do problema é: 


$$
w(x)=q_{n} \operatorname{sen} \frac{n \pi x}{L}
$$

Nessa equação $q_{n}$ são constante arbitrárias de acordo com o valor de $n$ considerado. Note que a arbitrariedade do valor dessas constantes não permite avaliar o valor dos deslocamentos da viga de forma exata, mas somente em termos qualitativos.

A carga $P_{n}$ para $n=1$ é denominada carga de Euler e representa a carga compressiva relacionada à primeira forma possível de solução não trivial para o problema apresentado. Subsequentes formas ocorrem para $n=2,3, \ldots$. As formas não triviais representam configurações nas quais ocorreu o fenômeno de flambagem.

Diagramas exibindo as trajetórias de equilíbrio são utilizadas para representar as diferentes soluções de equilíbrio. Para o problema apresentado o diagrama está representado na Figura C.2. É possível observar os diferentes valores de carga crítica. Note que nos valores das cargas $P_{n}$ ocorrem bifurcações.

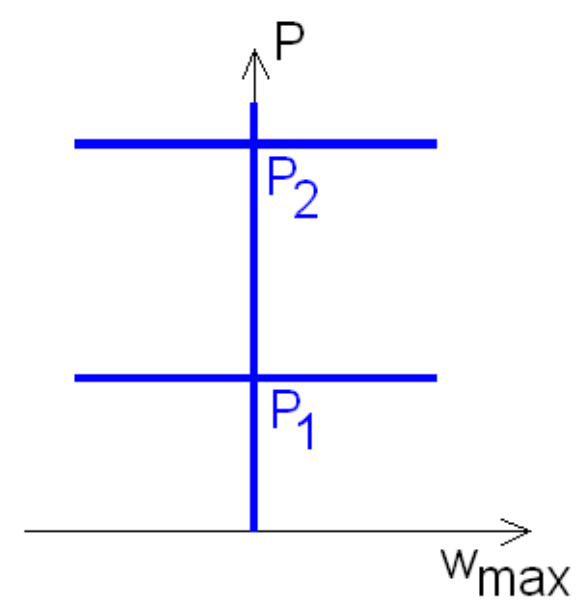

Figura C.2: Trajetórias de equilíbrio para o problema da viga de Euler sob compressão (problema linear)

As cargas $P_{n}$ são denominadas cargas críticas. Elas representam geralmente uma situação não desejada na prática, uma vez que, quando atingidas, a estrutura pode experimentar grandes deslocamentos não desejados.

Para estruturas que apresentam imperfeições, desvios no ponto de aplicação dos carregamentos, induzindo momentos fletores não considerados no equacionamento ou, perturbações laterais, o diagrama apresenta forma diferente da apresentada na Figura C.2. A bifurcação deixa de existir, e a estrutura apresenta um comportamento já definido, sem passar por pontos de bifurcação no decorrer da aplicação da carga $P$. Porém, pode-se dizer 
que nesses casos há grande mudança de rigidez para quando o problema se aproxima dos pontos de bifurcação, agora não mais definidos. As estruturas reais sempre apresentam algum grau de imperfeição. Assim sendo, a predição da carga crítica é apenas teórica e nunca é prática, mas representa uma ótima idéia da ordem de grandeza do esforço próximo ao qual uma estrutura real irá mudar seu comportamento. Na prática, a ocorrência de flambagem estará associada a grandes variações de rigidez a da estrutura, segundo a variação de algum parâmetro, por exemplo, para a viga de Euler, a carga compressiva $P$.

Se a condição de contorno da viga for diferente, o valor da carga crítica é modificado. É possível definir um coeficiente $k$ para modificar o valor da carga de Euler do caso estudado (bi-apoiado) tal que, estudando outras condições de contorno, o valor da carga crítica seja dado por:

$$
P_{\text {crit }}=k \frac{\pi^{2} E I}{L^{2}}
$$

Ziegler (1968) mostra em uma tabela esses coeficientes para diversas condições de contorno:

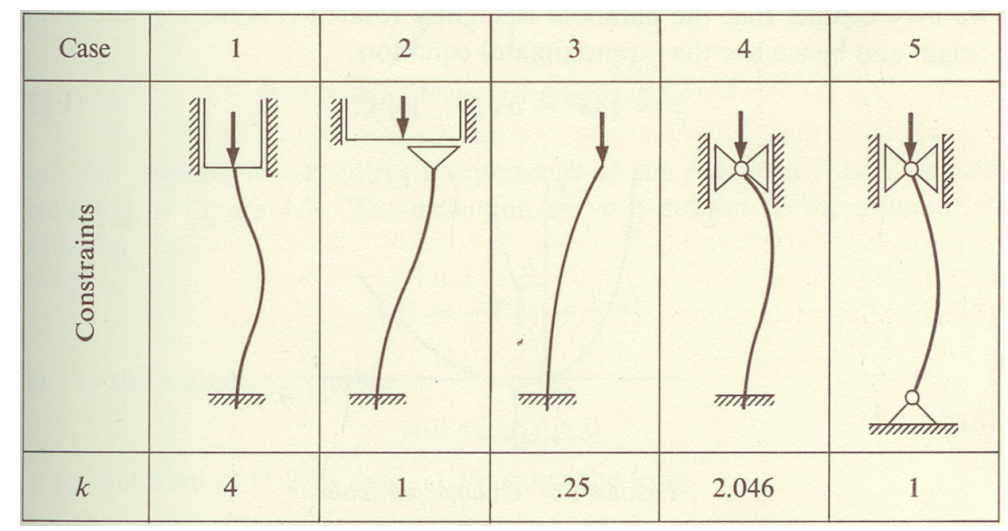

Figura C.3: Fatores de flambagem de Euler para diferentes condições de contorno. Extraído de Ziegler (1968)

\section{C.2 Viga sob compressão e torção}

Para o estudo de flambagem tridimensional em vigas inicialmente retilíneas surge uma extensão da teoria da flambagem de Euler vista anteriormente. Quando se considera um momento de torção aplicado à viga, surgem efeitos até então não contemplados nas equações diferenciais construídas para o fenômeno plano. Em casos bi-dimensionais a 
flexão é o único efeito relevante em termos de carregamentos de momentos, a não ser um caso específico no qual ocorra torção pura de uma viga, sem alteração de sua elastica.

Em casos gerais de carregamentos de torção, em que existe uma curvatura não nula na viga ou mesmo uma perturbação de curvatura, a transmissão do momento que é puramente de torção em uma extremidade acaba se transformando em efeitos de flexão, nas duas direções ortogonais à elastica. Assim sendo, a elastica pode ser alterada por efeitos combinados de flexão e torção na configuração deformada da estrutura. Portanto, o momento de torção pode tornar o fenômeno de flexão inicialmente plano, em um problema 3D. É de se esperar, portanto, uma alteração na carga crítica de Euler, quando ocorre torção na viga em estudo. Essa influência foi estudada por Greenhill que desenvolveu uma fórmula que altera o valor da carga de Euler para tais situações.

É possível escrever, considerando a configuração deformada de uma viga biapoiada (Figura C.4), equações de equilíbrio de momentos de um trecho da viga que varia entre 0 e $x$ (sendo o domínio do problema $0 \leq x \leq L$, sendo $L$ o comprimento da viga.

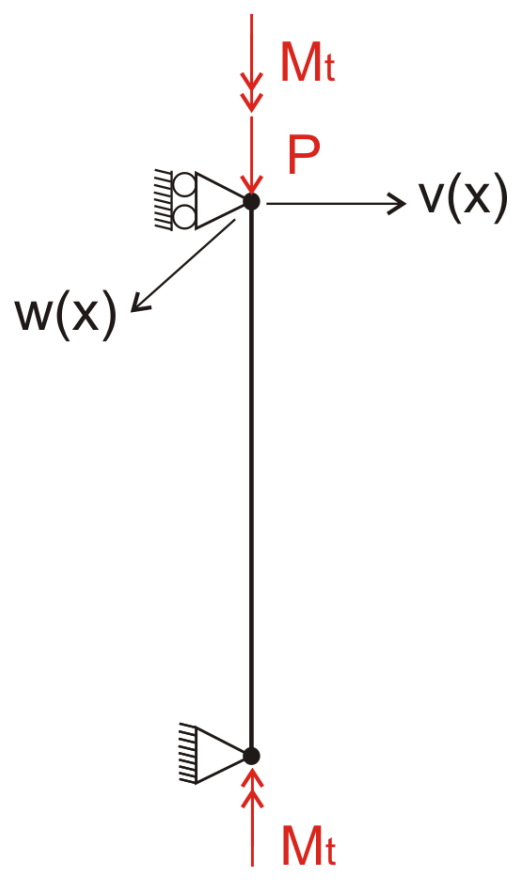

Figura C.4: Viga bi-apoiada sob compressão e sob torção

$$
E I \frac{d^{2}}{d x^{2}} w-M_{t} \frac{d}{d x} v+P w=0
$$




$$
E I \frac{d^{2}}{d x^{2}} v+M_{t} \frac{d}{d x} w+P v=0
$$

Para esse equacionamento é admitido que a direção do momento de torção aplicado na viga não muda durante a deflexão e torção da mesma. Ainda é assumido que a rigidez flexional possui o mesmo valor EI nas duas direções caracterizadas por $v(x)$ e $w(x)$. As equações C.13 e C.14 formam um sistema de equações diferenciais, cuja solução geral pode ser escrita da forma $v(x)=A e^{i \omega x}$ e $w(x)=B e^{i \omega x}$. Substituindo essas formas de solução nas equações que formam o sistema, é possível obter o seguinte sistema linear a ser solucionado:

$$
\left[\begin{array}{cc}
P-E I \omega^{2} & i M_{t} \omega \\
-i M_{t} \omega & P-E I \omega^{2}
\end{array}\right]\left[\begin{array}{l}
A \\
B
\end{array}\right]=\left[\begin{array}{l}
0 \\
0
\end{array}\right]
$$

Trata-se de um sistema homogêneo nas incógnitas $A$ e $B$ e, portanto, para que haja solução não trivial, deve-se impor que o determinante da matriz dos coeficientes seja nulo. Calculando o determinate, chega-se na seguinte equação característica:

$$
\left(P-E I \omega^{2}\right)^{2}-M_{t}^{2} \omega^{2}=0 \Rightarrow\left(P-E I \omega^{2}\right) \pm M_{t} \omega=0
$$

Particularizando a equação para o sinal positivo do termo do torque (sem perda de generalidade, pois as mesmas conclusões seriam obtidas se escolhido o sinal negativo), obtém-se:

$$
E I \omega^{2}+M_{t} \omega-P=0
$$

Encontrando os valores dos coeficientes $\omega$ que satisfazem tal equação, tem-se dois possíveis valores para $\omega$ :

$$
\omega_{1,2}=\frac{1}{2 E I}\left(-M_{t} \pm \sqrt{M_{t}^{2}+4 E I P}\right)
$$

Com isso a solução geral para os deslocamentos nas direções $v(x)$ e $w(x)$ se torna: 


$$
\begin{gathered}
v(x)=A_{1} e^{i w_{1} x}+A_{2} e^{i w_{2} x} \\
w(x)=B_{1} e^{i w_{1} x}+B_{2} e^{i w_{2} x}
\end{gathered}
$$

Os valores de $A_{1}, A_{2}, B_{1}$ e $B_{2}$ são determináveis a partir das condições de contorno do problema. Para as condições de contorno do problema exibido na Figura C.4, tem-se que $v(0)=v(L)=w(0)=w(L)=0$. Essas condições são satisfeitas se forem verdadeiras as seguintes equações:

$$
\begin{gathered}
A_{1}+A_{2}=0 \\
A_{1} e^{i w_{1} L}+A_{2} e^{i w_{2} L}=0
\end{gathered}
$$

Para os valores de $B_{1}$ e $B_{2}$ as equações são idênticas. As condições de contorno, portanto, implicam que:

$$
\left[\begin{array}{cc}
1 & 1 \\
e^{i w_{1} L} & e^{i w_{2} L}
\end{array}\right]\left[\begin{array}{l}
A_{1} \\
A_{2}
\end{array}\right]=\left[\begin{array}{l}
0 \\
0
\end{array}\right]
$$

Procurando-se determinar solução não triviais, impõe-se que o determinante seja nulo. Assim, tem-se a igualdade $e^{i \omega_{1} L}=e^{i \omega_{2} L}$, ou seja, a condição exige que se tenha arcos iguais no expoente, inferindo que: $\omega_{2} L=\omega_{1} L+2 n \pi$, sendo $n$ um número inteiro. Tomando $n$ nulo, tem-se que $\omega_{1}=\omega_{2}$. Nessas condições, tem-se:

$$
\begin{gathered}
\omega_{1}=\omega_{2} \Rightarrow \frac{1}{2 E I}\left(-M_{t}+\sqrt{M_{t}^{2}+4 E I P}\right)=\frac{1}{2 E I}\left(-M_{t}-\sqrt{M_{t}^{2}+4 E I P}\right) \Rightarrow \\
\Rightarrow 2 \sqrt{M_{t}^{2}+4 E I P}=0 \Rightarrow M_{t}^{2}=-4 E I P
\end{gathered}
$$


o que é uma condição impossível para valores não nulos de $M_{t}$ e $P>0$.

Já considerando o valor de $n=1$ e relacionando os valores de $\omega_{1}$ e $\omega_{2}$ obtidos através da equação C.18 obtém-se um importante resultado, denominado de Fórmula de Greenhill:

$$
\frac{P}{P_{c r}^{0}}+\left(\frac{M_{t}}{M_{c r}^{0}}\right)^{2}=1
$$

Sendo a carga crítica quando $M_{t}$ é nulo, dada por:

$$
P_{c r}^{0}=\frac{\pi^{2}}{L^{2}} E I
$$

e o momento de torção crítico, quando a carga de compressão $P$ é nula, dado por:

$$
M_{c r}^{0}=k \frac{\pi}{L} E I
$$

Sendo que para as condições de contorno consideradas o valor de $k=2$. Uma discussão acerca de outras condições de contorno não é tão trivial quanto modificar as constantes presentes nas equações C.19 e C.20. Há aspectos conceituais que também devem ser vistos.

Em Love (1944), Ziegler (1968) e em Bazant e Cedolin (2003) existem mais discussões sobre esse problema. A Fórmula de Greenhill representa uma condição de carga crítica, envolvendo dois esforços: a compressão axial e o momento de torção. O acoplamento entre os esforços é considerado nas equações diferenciais do problema e, os resultados dos modos de flambagem obtidos são essencialmente tridimensionais quando o momento de torção $M_{t}$ é diferente de zero.

Questionamentos acerca da validade da metodologia apresentada para essa abordagem são feitas em Bazant e Cedolin (2003) e Ziegler (1968), uma vez que o momento de torção pode ser não conservativo dependendo das condições de contorno às quais a viga estiver submetida. Esse tipo de situação poderia levar à necessidade da utilização de um critério cinético para análise de estabilidade (ver o Capítulo 3).

Com base nos teoremas e observações sobre estabilidade estrutural apresentados no Capítulo 3, pode-se discutir em mais detalhes o problema da flambagem com compressão e torção para mais condições de contorno. 
O critério para verificação de estabilidade denominado "Método do Equilíbrio", aplicado para a obtenção da Fórmula de Greenhill, assume por hipótese que o momento de torção é um carregamento não circulatório. Caso não fosse assim, a abordagem do Equilíbrio poderia estar incorreta, segundo o Teorema 7 (ver Capítulo 3). No entanto, as condições de contorno utilizadas para a viga considerada foram articulações que, portanto, permitem as rotações dos pontos de aplicação dos momentos de torção. Essa situação pode tornar o momento de torção um carregamento circulatório. Assim sendo, cabe uma discussão mais ampla acerca da validade da Fórmula de Greenhill com sua aplicação para a condição de contorno considerada para a obtenção da equação C.25.

As situações em que todas as rotações são livres no ponto de aplicação do momento de torção, na extremidade da viga, podem permitir diferentes histórias de movimento rotativo com as mesmas posições final e inicial, sendo que em algumas dessas histórias o momento realiza trabalho, e em outras não realiza. Daí o fato de o momento ser circulatório na condição em que existe uma rótula em seu ponto de aplicação.

Para condições de contorno que permitam apenas a rotação em um eixo fixo na extremidades da viga, o momento de torção será um esforço não circulatório. Assim, pelo Teorema 3, é possível utilizar-se do Método do Equilíbrio para avaliação da estabilidade. Essa situação poderá ser observada, por exemplo, em eixos com mancais longos, que permitem apenas a rotação na própria direção do eixo, vinculando outras rotações. Já para o problema analisado por Greenhill, que corresponde a uma viga bi-apoiada com momentos com direção constante aplicados nas extremidades da viga, pelo Teorema 7 não seria possível realizar a análise de estabilidade utilizando-se o Método do Equilíbrio. No entanto, é possível demonstrar que, para esse problema em particular, a utilização de um critério cinético resulta no mesmo que foi obtido através do Método do Equilíbrio (ver Ziegler (1968)).

Em situações particulares como o problema de uma viga engastada com a aplicação de um momento em sua extremidade livre, alguns resultados aparentemente implausíveis são obtidos. Pelo Teorema 7 esse problema exige um tratamento através do Método Cinético, uma vez que é circulatório. No entanto, ao realizar tal tratamento, obtém-se a conclusão de que haveria uma instabilidade para torques extremamente baixos, ou simplesmente perturbações de torque, uma vez que se conclui que com momento nulo ocorreria flambagem. Ziegler (1968) explica tal resultado aparentemente inconsistente argumentando que, na realidade, a aplicação do torque pode se dar de diferentes formas, tal que na realidade sua direção não se mantém constante, o que é assumido, por 
hipótese na obtenção desses estranhos resultados. Se forem consideradas outras formas de aplicação de torque, através de binários, chega-se a conclusões diferentes acerca da instabilidade estrutural. Por exemplo, Ziegler (1968) apresenta duas formas de aplicar um torque: quasitangencial, e semitangencial. Essa duas formas estão associadas a diferentes sistemas de forças que possuem o mesmo valor de momento de torção aplicado à viga. No entanto, a direção do momento não se mantém fixa em nenhum deles e, devido a esse detalhe, resultam diferentes conclusões acerca da instabilidade do sistema. Assim sendo, quando o momento de torção for circulatório, o estudo de estabilidade é muito mais complexo e depende do detalhamento da aplicação do esforço.

A Figura C.5 mostra diversos valores de fator $k$ a serem utilizados para obtenção do momento de torção crítico segundo a equação C.27. Esses fatores mostram que nos problemas 3,4 e 5 que são circulatórios, a forma de aplicar o momento muda o valor de $k$, uma vez que a rotação do ponto de aplicação é permitida. Já nos casos 1 e 2, não circulatórios, não é identificada essa mudança.

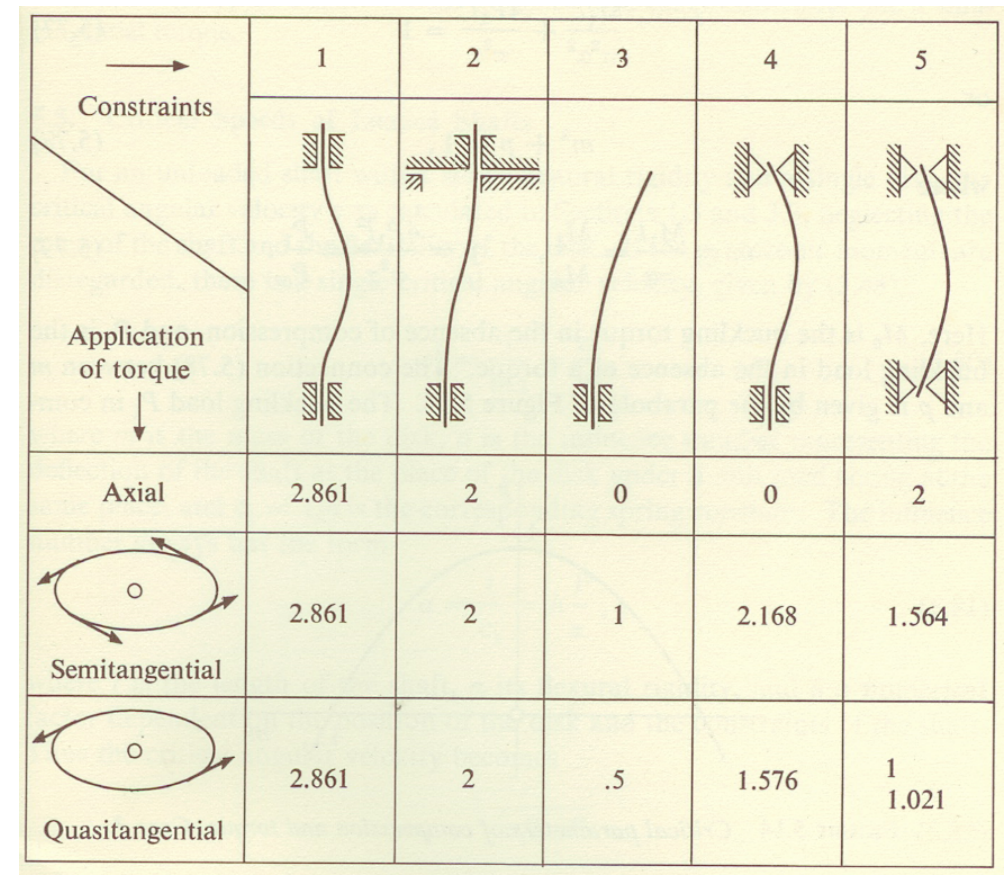

Figura C.5: Fatores de flambagem para serem utilizados para obtenção do momento de torção crítico através da equação C.27. Extraído de Ziegler (1968) 